4

(1)

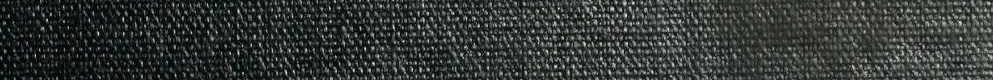
(2) (1)

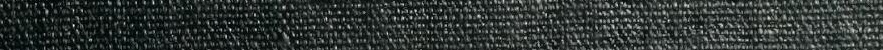
1.4. (1)

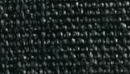

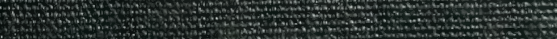
(2)

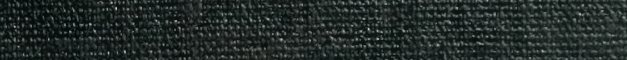

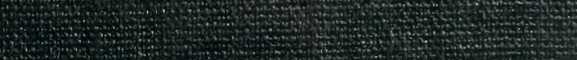
(2) 2. 
(n)

$\frac{1}{m}$

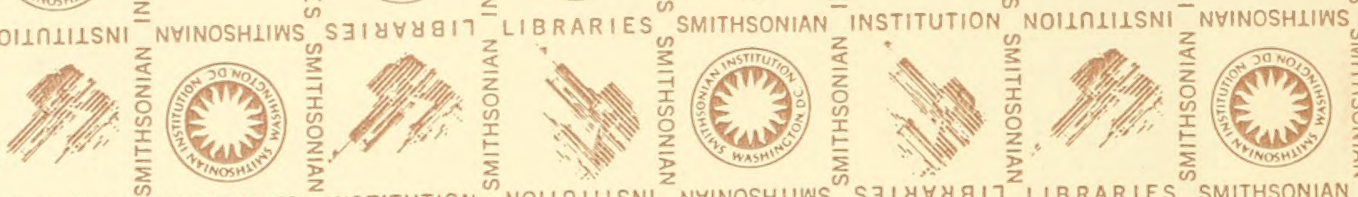

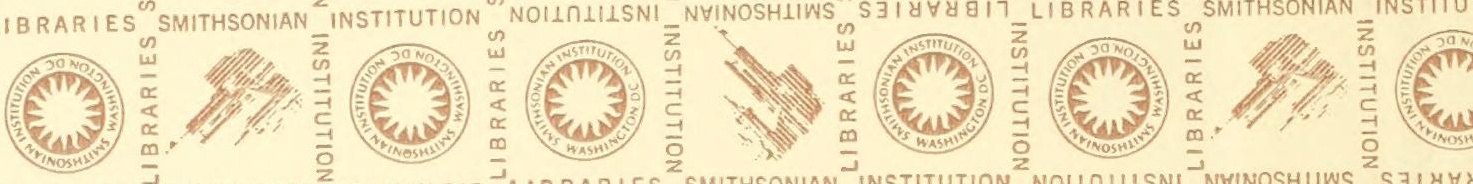
(n) Sils

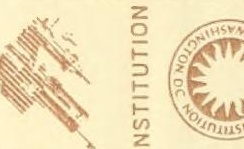
bey

(1)

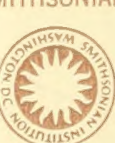
(n) (t) ) ( 列 (1) (3) (i)

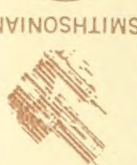

(2) IBRARIES

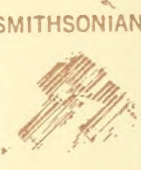
NSTITL
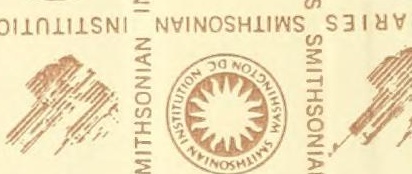
.<smiles>c1ccc(C23CC4CC(CC(C4)C2)C3)cc1</smiles>

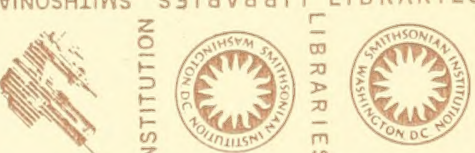

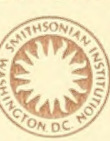

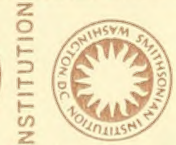

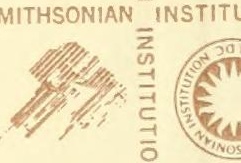
IBRARIES SMITHSONIAN INSTITUTION NOILOIIISNI NYINOSHLIWS (1)

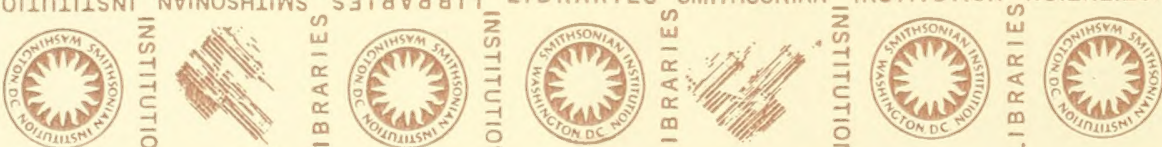
(3) (1) W 4

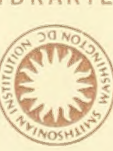





DIE

OPISTHOBRANCHIATA DER SIBOGA-EXPEDITION 



\section{DIE OPISTHOBRANCHIATA DER SIBOGA- EXPEDITION}

VON

Derision of Molloglks

\section{DR. RUD. BERGH}

Mit 20 Tafeln

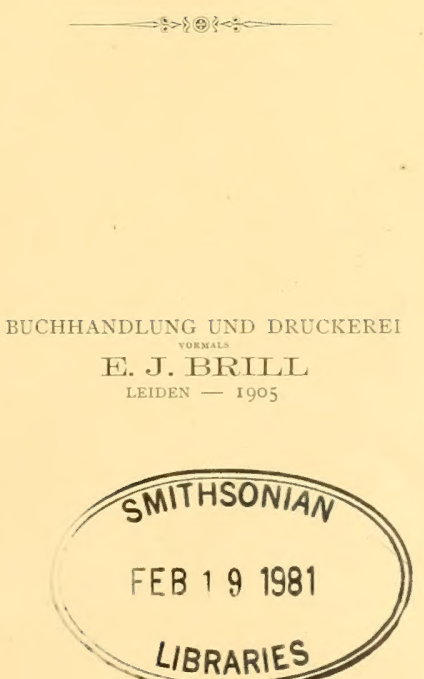





\title{
DIE OPISTHOBRANCHIATA DER SIBOGA-EXPEDITION
}

\author{
VON \\ Dr. RUD. BERGH
}

Mit 20 Tafeln.

Die Untersuchungen der Siboga-Expedition erstreckten sich über fast ein Jahr. Während dieses nicht langen Zeitraums hat sie eine grosse Anzahl von verschiedenen Formen von Opisthobranchier, in Allem gegen I60 Arten, zusammengebracht, eine viel grössere Anzahl als jemals durch andere ähnliche Reisen erworben wurden.

Unter der persönlichen Aufsicht von Prof. WEBER ist eine Anzahl dieser Thiere lebend und mit ihren Farben von dem vorzüglichen Zeichner der Expedition, Herrn J. WV. Huysuass, abgebildet; in Allem lagen 93 (88) Abbildungen vor. Dieselben sind im lithographischen Institut von P. IV. M. TRAP in Leyden schön und getreu chromolithographisch wiedergeben worden.

Die Thiere waren nach Ablauf der Expedition ausgezeichnet verpackt und kamen nach Copenhagen in 8 grossen Blechbüchsen an, die 377 Glascylinder und 9 Packetchen mit grösseren Thieren enthielten. Nur wenig Gläser waren zerbrochen oder hatten die Conservirungsfluissigkeit entleert, so dass die Thiere verloren gegangen oder eingetrocknet waren. Leider war die Conservirung nicht günstig für die Untersuchung. Nian liess an Bord die kleineren Arten in möglichst wenig Seewasser sich ausstrecken und übergoss sie dann, nach Lo Branco's Methode mit einer reichlichen Menge $55 \%$ Eisessig; darauf wurden sie sofort in Alcohol von $70 \%$ oder in Formol 4\% gebracht. Die grösseren Exemplare wurden in reichlichem Seewasser belassen, dem allmählich kleine Mengen Magnesiumsulphat in steigender Dosis zugefugt wurden bis die Thiere betäubt und in Alcohol oder Formol gebracht werden konnten. Letzteres hatte, fast immer ohne Schonung der Farbe, oft die Objecte in der Art erhärtet, dass die Untersuchung dadurch beschränkt wurde oder erst nach Erweichung des Objects ermöglicht wurde. Eine 
Anzahl von Formen, noch dazu mitunter durch ein einzelnes Exemplar repräsentirt, zeigte sich in dem Grade erhärtet, zusammengezogen und verdreht, dass eine Untersuchung von vorne herein aufgegeben werden musste oder ganz misslang.

Eine geringe Anzahl von Nicht-Opisthobranchier (mit starker Mantel- oder EpipodienEntwicklung) hatte sich, von farbigen Figuren begleitet, in die mir geschickte Sammlung eingeschlichen und wurde mit den Opisthobranchiern zusammen untersucht. Die Untersuchungen wurden später mit den dazu gehörenden anatomischen Figuren dem Herrn M. M. SchepmaN in Rhoon, der die Prosobranchier behandelt - was mir damals unbekannt war — geschickt, der aber fur die lebenden Thiere auf die schon lang fertig liegenden chromolithographischen Tafeln der Opisthobranchier (Taf. III, V) hinweisen muss. 


\title{
TECTIBRANCHIATA.
}

\author{
ANASPIDEA.
}

Aplysidie.

Aplysidae propriae.

R. BERGir. Malacolog. Untersuchungen. V, 1902, p. 339.

Epipodia ut plurimum libera alaeformia apertura branchiali longa sejuncta.

Ganglia visceralia postica, a pleuralibus remota.

Mit Ausnahme der kleinen Gruppe der Dolabella haben die ächten Aplysiiden die Fussflügel ihrer ganzen Länge nach von einander geschieden und somit ist die Kiemenspalte weit.

Die visceralen Ganglien liegen weit nach hinten, weit von den pleuralen ab.

Diese Subfamilie umfasst die Gattungen Aplysia und Dolabclla.

\section{Aplysia Linné.}

LiNNÉ. Systema nat. ed. XII, I767, p. IO72.

Cuvier. Tableau élém. (1798), an. VI, p. 386 , pl. IX, fig. 3 .

LAMARCK. Syst. des anim. s. V, I80I, p. 62.

Corpus laeve, limaciforme, antice et postice nonnihil angustius; parapodiis magnis, elongatis, liberis, apertura branchiali longa et larga. Testa pallio inclusa, sat debilis, ovalis vel rotundata, postice margine dextro emarginata, parte nucleali parva.

Systema nervosum gangliis pleuralibus anticis, visceralibus posticis. Radula (linguae) dentibus medianis sat latis, dentibus lateralibus denticulatis non paucis. - Glandula hermaphrodisiaca hepati connata.

Die Gattung Aplysia wurde von LnNné aufgestellt, von Cuvier adoptirt und ist seitdem von den Verff. hauptsächlich für die typischen Formen angewendet.

Diese Formen zeigen einen glatten, hinten und besonders vorne verschmälerten Körper mit grossen langen und freien Fussflugeln und einer langen und breiten Kiemenspalte. Am Boden der letzteren liegt die in den Mantel eingeschlossene Schale; dieselbe ist ziemlich wenig verkalkt, oval oder rundlich, mit Ausrandung des hinteren rechten Randes, mit wenig ausgeprägter 
Nuclealpartie. - Das Nervensystem zeigt die pleuralen Ganglien vorne liegend, die visceralen aber weit nach hinten verschoben. Die Raspel der Zunge trägı́ neben der breiten medianen Platte eine nicht recht lange Reihe von denticulirten Zahnplatten. - Die Zwitterdrüse bekleidet den hintersten Theil der Leber.

Von den ächten Aplysien ist, wie es scheint, eine Reihe von sogenannten Arten beschrieben oder erwähnt, von denen eine Anzahl wohl nie erkannt werden wird. Die Gattung ist in allen Mleeresgegenden repräsentirt.

I. Aplysia scripta Bgh. n. sp. Taf. VI, Fig. I-16.

Von dieser schönen, in ihrer Farbenzeichnung sehr ausgeprägten Art, wurden auf dem Riffe von Ambon (St. I S I) zwei einander in (äusseren) Verhältnissen fast ganz ähnliche, ziemlich schlaffe Individuen gefischt, die alle beide anatomisch untersucht wurden.

Die Länge derselben beträgt $5,5 \mathrm{~cm}$. bei einer Breite von 3 und Höhe von $2,5 \mathrm{~cm}$.; die Länge des Vorderrickens von den Rhinophorien ab I4 mm., die Länge der stärkeren Tentakel 7, der Rhinophorien $5 \mathrm{~mm}$; die Länge der Fusslügel $4 \mathrm{~cm}$., ihre Höhe 1,5 ; die Länge des Mantelschildes $25 \mathrm{~mm}$. bei einer Breite von 16, die Länge des (freien) Sipho's I1; die Länge der Kieme 15 bei einer Höhe ron $\delta$ und Dicke von $5 \mathrm{~mm}$; die Breite der Fusssohle $3 \mathrm{~cm}$., die Länge des Schwanzes $9 \mathrm{~mm}$. - Die Bodenfarbe der ganzen Rückenseite war weisslich, aber durch dicht liegende graue oder schwarzgraue Linien fast verdrängt (Fig. I); diese Linien waren seltener mehr gerade, meistens gebogen, oft schlangenartig oder ringbildend; oft kurzzweigig oder in Punkten aufgelöst. An den Tentakeln und den Rhinophorien scheinen sie nur am Grund vorzukommen, waren an der Innenseite der Fussflügeln fast ebenso stark wie an der Aussenseite; am Mantelschilde eradiirten sie vom Centrum (wo keine Öfnung vorzukommen schien) gegen den Rand und ziemlich regelmässig (Fig. 2). Die Kieme war bräunlichgelb. Die Fusssohle schmutzig röthlichgrau.

Die Formverhältnisse die gewöhnlichen. Die Fussflügel stark, lang. Der Mantelschild ziemlich convex (Fig. 2), hinten in den starken am Ende schräg abgestutzten Sipho (Fig. 2a) verlängert. Die Schale $22 \mathrm{~mm}$. lang bei einer Breite von I 5 und einer Convexität von fast $4 \mathrm{~mm}$., kalkweiss, dünn, aber ziemlich fest, mit kleiner Nuclealpartie, ziemlich starken Anwachsstreifen und schmalem cuticularem Gebräme (Fig. 3, 4). Die Kieme stark gebogen, von 12-15 Hauptblättern gebildet. Der Fuss gross; vorne gerundet, ausgerandet in der Mitte, mit langer Randfurche; hinten ein wenig verschmälert, der gerundete Schwanz kurz.

Das Centralnervensystem rothgelb; seine Breite $5,5 \mathrm{~mm}$., die Länge der visceralen Connective $12 \mathrm{~mm}$; die Ganglien aus ihrer Capsel schwer auszulösen. Die Grenze zwischen den cerebralen sehr deutlich, und dieselben grobknotig; die pleuralen Ganglien kaum oder nur halb so gross wie die pedalen, die Commissur der letzteren doppelt so breit wie das Ganglion selbst, beide Ganglien grobknotig. Die am Ende der langen Connective sitzende grobknotige viscerale Ganglienmasse aus zwei Ganglien zusammengesetzt und vor jedem ein kleineres kugelrundes (Fig. I 5). 
Die an der Hinterseite des Fussknotens liegende Otocyste von 0,25 mm. Durchmesser, mit rundem Otolithen von $0,12 \mathrm{~mm}$. Diam.

Die weissliche Mundröhre $3,5 \mathrm{~mm}$. lang. - Der Schlundk opf bei beiden Individuen $8 \mathrm{~mm}$. lang bei einer Höhe und Breite von $6-6,5$; weisslich, nur die Decke der Mundhöhle aussen schwarz; die Mundhöhle (mitsammt der lingula der Raspelscheide) mit ganz schwarzen gegen die Mandibelplatten und die Raspel stark contrastirenden Wänden. Die schmutzigbraunen Mandibelplatten 4-4,5 mm. hoch bei einer Breite von 2, nicht sehr hart; von dünnen geraden Stäbchen gebildet, die schmutziggelb, fein schräg- und längsstreifig sind und eine Höhe bis wenigstens $0,16 \mathrm{~mm}$. bei einem Durchmesser von 0,007 erreichend (Fig. 5). Die Gaumenplatten nicht breit, ihre schmutziggelblichen Elemente ziemlich dünn und schwach, bis wenigstens O, I $6 \mathrm{~mm}$. hoch. Die schillernd gelbe Raspel der Zunge mit 25-28 Zahnplattenreihen, in der Scheide kamen deren noch I4-13 vor, von denen die 3 hintersten unreif; die Gesammtzahl der Plattenreihen somit 39-4r. Zu jeder Seite der medianen kamen bis 25-26 laterale vor. Die Zahnplatten gelb; die Breite der medianen betrug 0,28 mm.; die Länge der Grundplatte der lateralen bis 0,35 bei einer Höhe des Hakens bis 0,25; die Länge der 5 äussersten war 0,06-0,08-0, 12-0,20 0,25 bei einer Höhe des Hakens der letzteren von $0,14 \mathrm{~mm}$. Die medianen Platten (Fig. 6, 7 ) von gewöhnlicher Grundform, nicht recht breit, mit kurzem starkem Haken mit einem kurzen Dentikel jederseits oder mit zwei bis drei kleineren. Alle die folgenden Platten (Fig. S-I I) mit starkem, an den Seitenrändern meistens einige Dentikel tragendem Haken, weiter nach unten kamen am Innenrande ein Paar kleinere, am Aussenrande ein Paar gröbere Dentikel vor; die Denticulation etwas unregelmässig an den verschiedenen Platten. Die 4 äussersten Platten (Fig. I I $a$ ) ganz klein und ohne Haken, an den folgenden kam ein kleiner Haken vor.

Die langen dünnen Speicheldrüsen hell röthlichgelb, sonst wie gewöhnlich.

Die graue, ganz vorne schwarze Speis eröhre (Fig. I $2 a$ ) $7 \mathrm{~mm}$. lang bei einem Durchmesser von 3. Der graue Vormagen kurz schlauchförmig, gebogen, beiläufig 20-25 mm. lang bei einem Durchmesser von Io (Fig. 12b). Der gelbliche Ka u magen (Fig. 12c) 7 -9 mm. lang bei einem Durchmesser von IO; bei dem einem Individuum fanden sich 8 grosse und 4 kleinere Magenzähne, bei den anderen 8 und 6 , noch dazu eine Reihe von ganz kleinen $(0,3-0,8 \mathrm{~mm}$. hohen) vor (Fig. 13). Die grösseren Platten waren alle schmutzig bräunlicholivenfarbig; die Grundfläche aber von ganz eigenthümlicher doch sehr variabler Farbe, die gewöhnliche olivenartige trat hier und da am Rande besonders stark aber an der Mittelpartie hervor, sonst war die Fläche milchweiss (Fig. I4). Die kleineren Platten waren hell gelb, die kleinsten gelbbraun. Die Formverhältnisse waren wie bei anderen Aplysien, die Höhe betrug bis 4,5 bei einem Durchmesser der Grundfläche von $5 \mathrm{~mm}$. - Der diunnwandige Hintermagen (Fig. I $2 d$ ) grau, $5 \mathrm{~mm}$. lang; ganz vorne in demselben eine (theilweise doppelte) Reihe von niedrigen weichen Kegeln. - Der Inhalt der Verdauungshöhle war in beiden Individuen ein grünlicher vegetabilischer Chymus, in welchem einige bräunliche und gelbliche Fäden ähnlicher Art von einer Länge bis $15 \mathrm{~mm}$. - Der Darm wie gewöhnlich.

Die Leber schwarzgrau, I $_{5}-17 \mathrm{~mm}$. lang bei einer Breite von $\mathrm{I}_{3}$ und einer Höhe von $10-\mathrm{I} 2 \mathrm{~mm}$.

Die an die Leber genau angeheftete, röthlichgelbe $\mathrm{Z}$ witterdrüse 9- $10 \mathrm{~mm}$. breit bei 
einer Höhe von 5-9 und einer Dicke von $5-7$, mit fast glatter Oberfläche, in den Läppchen reife Geschlechtselemente. - Die vordere Genitalmasse I4-I5 mm. lang; die abgestutzte kurz-kegelförmige Schleim-Eiweissdrüse an der linken (Leber-)Seite gräulich, sonst wie die übrige Masse röthlichgelb, von 9-10 mm. Höhe; die kugelförmige Spermatotheke von $4 \mathrm{~mm}$. Durchmesser, die birnförmige Spermatocyste ein wenig kleiner. - Der etwas gebogene, oben dicke Penissack (Fig. I6) ro- I $1 \mathrm{~mm}$. lang, röthlichgelb mit stark durchschimmernden schwarzblauen Längsfalten; die dünne, zusammengedrückte, der Länge nach von einer breiten Furche clurchzogene Glans weiss, fast so lang wie die Vorhaut.

2. Aplysia Benedicti Eliot. Taf. VI, Fig. $17-26$.

ELrot. Notes on Tectibranchs and naked mollusks from Samoa. Proc. of the Ac. of nat. sc. of Philadelphia. 1899, p. 5I3-515, Pl. XIX, Fig. 2a, $2 b$.

Diese Form wurde von Eliot in Apia-Harbor gefischt und sehr kenntlich abgebildet; die Länge des von ihm gezeichneten Alkohol-Exemplars soll $7,5 \mathrm{~cm}$. betragen haben.

Das von mir untersuchte Individuum von der Siboga-Expedition war am Riffe von Haingsisi gefischt (St. 60).

Seine Länge betrug volle $5 \mathrm{~cm}$. bei einer Breite bis 2,5 und einer Höhe bis $3 \mathrm{~cm}$; die Breite des Fusses war durchgehends $20 \mathrm{~mm}$, die Länge der Fussfligel 3,2 cm. bei einer Höhe bis 1,2 , der Durchmesser der Augenflecken bis $4 \mathrm{~mm}$. Der Rückenschild $22 \mathrm{~mm}$. lang, bei einer Breite von 14 ; die Mantelröhre $7 \mathrm{~mm}$. lang. Die Rhinophorien von $6 \mathrm{~mm}$. Länge. Die Bodenfarbe der Rückenseite ist ganz hell gräulichgriin, von einem diunnfadigen, oft unterbrochenen schwarzen und schwärzlichen, weitmaschigen Netze durchzogen; überall, am sparsamsten am Kopfe, kamen schwarz gerandete Augenflecken vor, meistens ziemlich gross und mit dem Netze verbunden; die Aussenseite der Fussflügel war übrigens blau, ihre Innenseite schwarz mit grossen hellen (weisslichen) Flecken, wodurch gleichsam ein grobes Netzwerk gebildet wird. Der Mantel zeigte nur das gewöhnliche schwarze Netzwerk. Die Fusssohle mit schwärzlichen Fleckchen und Streifen.

Die Form war ziemlich kurz, die Formverhältnisse sonst wie bei den typischen Aplysien, der Rücken mit sammt den Fussflügeln ganz eben; der Rand der letzteren etwas wellenartig gebogen. Der Mantel oval, hinten in einen (rechts offenen) Halbkanal verlängert, der etwas zugespitzt ist; der breite (rechte) Rand überragt stark die Kieme; im Mantelrande die grosse Gland. pallealis. Die grosse gelbliche Kieme ${ }_{15} \mathrm{~mm}$. lang bei einer Höhe von 4 und einer Dicke von $3,5 \mathrm{~mm}$., sonst wie gewöhnlich.

In der engen Mantelhöhle die ganz dünne, farblose Schale (Fig. I 7 ) mit Andeutung von Kalk-Ablagerung an der Untenseite; sie hatte eine Länge von I 8 bei einer Breite von $14 \mathrm{~mm}$, ist von der bei den typischen Aplysien gewöhnlichen Form.

Die Mundröhre $4 \mathrm{~mm}$. lang, mit starken Längsfalten der Innenseite. Der Schlundkopf $6,5 \mathrm{~mm}$. lang bei einer Höhe und Breite von 5. Die Mandibelplatten oben fast zusammenstossend, unten geschieden, sehr stark, 4,5 mm. hoch bei einer Breite nach unten von 1,5; ihr vorderes Drittel ist dunkel braungelb, der Uberrest gelb; sie sind aus dichtstehenden, dünnen, 
schmutzig gelben Stäbchen (Fig. 19) von einem Durchmesser von 0,007 mm. bei ciner Höhe bis 0,20 zusammengesetzt. $\mathrm{Zu}$ jeder Seite des quergefalteten medianen Theils des Gaumens eine gelbliche Strecke, die mit Dornen dicht besetzt ist; diese Gaumendornen sind schwach gelblich, wenigstens bis $0,25 \mathrm{~mm}$. hoch, in Form und Grösse sehr variabel, meistens aufrecht und wenig gebogen, etwas zusammengedrückt (Fig. I S). In der schillernd braungelben Raspel der Z unge etwa 3 I Zahnplattenreihen, in der Scheide noch 30, die Gesammtzahl der Reihen somit etwa 60. In den Reihen bis etwa 28 Platten jederseits. Die Zahnplatten gelb, die äussersten fast farblos; die Breite der medianen betrug $0,28 \mathrm{~mm}$; die Länge der lateralen stieg zu der von 0,25 bei einer Höhe bis 0,16 mm. die Länge der äussersten 5 (6) mm. (0,05) 0,060,08-0,09-0,13-0, I6 mm. Die medianen Platten (Fig. 20) mit ziemlich spitzem Haken mit einem Dentikel am Grunde jederseits; die erste Seitenplatte hatte am Grunde des Hakens an der Innenseite einen kleinen, aussen einen stärkeren Dentikel (Fig. 21); die folgenden Seitenplatten hatten nur den äusseren Dentikel (Fig. 22), mitunter aber noch $I-2$ (Fig. 23); die äusseren 3 Platten hatten keinen Haken (Fig. 24), mitunter kam am Aussenrande cler Raspel noch eine ganz winzige Platte vor (Fig. 24a).

Die weisslichen Speicheldrisen lang und diinn (Diam. 0,5 mm.), ihr Hinterende an dem Kaumagen befestigt.

Die Speiseröhre $6 \mathrm{~mm}$. lang, plötzlich in den Vormagen übergehend, der eine Länge von Io bei einer Breite von $8 \mathrm{~mm}$. hatte. Der stark muskulöse, etwas sehnenglänzende Kaumagen $5 \mathrm{~mm}$. lang bei einem Durchmesser von 8 . Am Vorderende des letzteren fanden sich, mehr oder weniger unter einander verschoben, in $\mathrm{I}-2$ Reihen kleinere, in Form sehr variable, meistens etwas zusammengedrückte, bis etwa $0,7 \mathrm{~mm}$. hohe, hell gelbe Nagenplatten (Fig. 25); hinter denselben fanden sich in 2 undeutlich geschiedenen (Quincunx-) Reihen I 2 grössere, aber ungleich grosse, mehr dunkelgelbe Platten, deren drei- oder viereckig-rundliche Grundplatte einen Durchmesser bis I, $5 \mathrm{~mm}$. hatte, sie waren meistens etwas hornartig gebogen, bis $1,25 \mathrm{~mm}$. hoch (Fig. 26); hinter diesen fanden sich an dem Pylorus keine andere. Der Hintermagen war $6 \mathrm{~mm}$. lang so wie breit; hinten war er von der Leber umschlossen, die sich durch zwei runde Öffnungen in den Magen öffnete. Der sich in seiner grössten Länge an der Oberfläche der Leber schlängelnde Darm Io $\mathrm{cm}$. lang bei einem Durchmesser von $\mathrm{I}-\mathrm{I}, 5 \mathrm{~mm}$. Der sparsame Inhalt der Verdauungshöhle bestand aus verschiedenen kleinen Algen.

Die hell graubraune Leber $17 \mathrm{~mm}$. lang bei einer Breite und Höhe von I2.

In den Läppchen der weisslichen Zwitterdrüse reife Geschlechtselemente. Die vordere Genitalmasse etwa $9 \mathrm{~mm}$. lang. Der Penissack $6 \mathrm{~mm}$. lang, an seinem Hinterende ein starker Retractor.

Diese Form scheint specifisch verschieden von den anderen von Eliot (1.c. p. 5I5) erwähnten, im Äusseren verwandten Arten.

Taf. VI, Fig. $27-29$.

Am Riffe von Sanana-Bai an der Ostküste von der Insel Sula Besi (St. I93) wurden ferner + Exx. gefischt, die wahrscheinlich auch dieser Art angehören (sie waren schlecht conservirt). 
Sie hatten eine Länge von $4,3-5-6$ und $7 \mathrm{~cm}$; die Höhe des grössten Individuums betrug 4 und seine Breite $3,3 \mathrm{~cm}$; ; die Augenflecken waren meistens etwas kleiner, bis $3 \mathrm{~mm}$. in Durchmesser haltend. Die Farbe war schmutzig braungelb; das Blaue der Aussenseite der Fussflugel fehlte oder war ziemlich schwarz, die Innenseite derselben wie oben. - Der Schlundkopf von zwei Individuen wurde untersucht. Derselbe hatte eine Länge von $10-1 \mathrm{~mm}$. bei einer Höhe von 8- Io und einer Breite von 9-II. Die Mandibelplatten hatten eine Länge von 6 bei einer Breite von 1,5-2,5 mm., waren dunkel kastanienbraun, im Aussenrande fast schwarz: ihre Elemente von einer Höhe von $0,28 \mathrm{~mm}$. bei einer Breite von 0,005 (Fig. 29). Die Gaumendornen (Fig. 28) wie oben, bis $0,20 \mathrm{~mm}$. hoch. Die $\mathrm{Zunge}$ mit röthlich kastanienbrauner, am Rande dunkler Raspel, die 30 und 36 Zahnplattenreihen enthielt; in der gelblichen starken Scheide 28 und 30 Reihen; die Gesammtzahl der Reihen somit 58 und 66 . In den Reihen kamen 33 und 4 I Platten vor. Die Platten wie oben, die Breite der medianen bis 0,30 (Fig. 27), die Höhe der drei äussersten betrug 0,04-0,06-0, $12 \mathrm{~mm}$.

3. Aplysia atromarginata Bgh. 11. sp. Taf. VI, Fig. 30-35.

Am 26 Oct. wurden bei Pulu-Pasi-Tannette (St. 213) zwei Individuen gefangen.

Die Länge des kleineren war nur $9 \mathrm{~mm}$. - Das grössere, das genauer untersucht wurde, war ziemlich zusammengezogen, r $6 \mathrm{~mm}$. lang bei einer Höhe und Breite von 9; die Höhe der Rhinophorien $3 \mathrm{~mm}$, und die der Tentakel fast ebenso gross; die Länge der Fussflügel (in gerader Linie) I I $\mathrm{mm}$. bei einer Höhe von 4; der Mantel ro mm. lang bei einer Breite von 8, die Öfnung über der Schale 5,5 mm. lang bei einer Breite von 4,5; die Länge des Mantel-Sipho's 4 mm., die der Kieme 6; der Penis ragte mit einer Länge von 4 mm. frei hervor; die Fusssohle $4 \mathrm{~mm}$. breit. - Die Farbe des Thieres war gelblich; die Fussflügel zeigten in ihrer ganzen Länge einen schmalen schwarzen Rand, und eine ähnliche Linie zierte den Rand des Loches des Mantels, gegen die kalkweisse Schale contrastirend, der rechte die Kiemenhöhle überragende Mantelrand in einer Breite von $1,5 \mathrm{~mm}$. dunkel blaugrau; der Fussrand schwarz.

Die aussen und innen kalkweisse, stark erhärtete Schale (Fig. 3O, 3I) mit ziemlich starker, gelber Cuticula, die sich leicht in continuo von der Schale ablöst; sie hat eine Länge von 9 bei einer Breite von 7,5 und einer Höhe von $3 \mathrm{~mm}$; die Nuclealpartie ziemlich stark nach vorne und unten gebogen (Fig. 3I); die Anwuchstreifen ziemlich stark.

Unterhalb der Kieme, am Grunde des Fussflügels ein starkes weisses Druisenlager.

Das Centralnervensystem schien mit dem anderer ächter Aplysien zu stimmen.

Der Schlundkopf $3,5 \mathrm{~mm}$. lang bei einer Breite und Höhe von 3, gelblich. Die Mandibelplatten von gewöhnlicher Form und Grösse, bräunlichgelb; aus den gewöhnlichen stabförmigen Elementen (Fig. 32) von einer Länge bis wenigstens $0,16 \mathrm{~mm}$. bei einem Durchmesser von O,OI3 zusammengesetzt. Die Gaumendornen von Form und Grösse wie bei der vorigen Art. In der braungelben Raspel der Zunge 20 Zahnplattenreihen, in der Scheide noch I4 Reihen, die Gesammtzahl desselben somit 34. In den Reihen fanden sich bis 17 Platten zu jeder Seite der medianen. Die Zahnplatten waren gelb; die Breite der medianen betrug o,20 mm., die Länge der ersten lateralen 0,14 bei einer Höhe von 0,10 ; die Länge des $3-4$ äussersten 
war 0,04 , der folgenden drei $0,05-0,06-0,075$, die der drei nächstfolgenden $0,12-0,13$ $0,14 \mathrm{~mm}$. Die medianen Platten von gewöhnlicher Form, der ziemlich starke Haken jederseits mit mehreren $(5,6)$ Dentikeln, an jeder Seite des Hakens 3 stärkere Dentikeln (Fig. 33). Die innersten lațeralen Platten zeigten auch den Haken an den Rändern denticulirt, und an jeder Seite desselben 2 Dentikel (Fig. 33); mehr nach aussen war der Haken ohne Dentikel, aber an jeder Seite desselben kamen $1-2$ solcher vor (Fig. 34); die 6-7 äussersten hatten keinen Haken (Fig. $34 a$ ).

Die weissen Speicheldrüsen wie bei anderen Aplysiiden.

Der Vormagen 1,5 mm. lang. Der Kaumagen auch $1,5 \mathrm{~mm}$. lang; die Platten in gewöhnlicher Art gestellt, hell gelb, bis 0,75 mm. hoch. Der Hintermagen $4 \mathrm{~mm}$. lang. Die graue Leber $5 \mathrm{~mm}$. lang:

Die vordere Genitalmasse etwas zusammengedrückt, von ovalem Umriss, $4 \mathrm{~mm}$. lang, gelblichgrau und kalkweiss. - Der starke Penis (Fig. 35) mit ausgeprägter, bis an die Spitze reichender Furche.

4. Aplysia Sibogae Bgh. n. sp. Taf. VI, Fig. 36-42. Taf. VII, Fig. 1-6.

Am Riffe von Haingsisi, Insel Samau, Timor (St.60) wurde ein Paar Exx. dieser Form gefischt; das grösste und zugleich am besten erhaltene wurde genauer untersucht.

Die Länge derselben betrug $5,2 \mathrm{~cm}$. bei einer Breite bis 2,6 und Höhe von 2,2; die Länge der Fussflügel war $3,5 \mathrm{~cm}$; die Länge des Mantelschildes 2,2 bei einer Breite von I,4 cm., das centrale rundliche Loch von $3 \mathrm{~mm}$. Durchmesser; die gebogene Kieme $12 \mathrm{~mm}$. lang bei einer Höhe von 6 und einer Dicke von 5, ihr hinteres etwa Drittel frei hervorragend; die Breite der Fusssohle bis $2,2 \mathrm{~cm}$. - Die Farbe der Fussflügel aussen braun mit kleineren und grösseren (bis etwa $2 \mathrm{~mm}$. weiten) unregelmässigen weisslichen Flecken; so war auch der Vorderkörper gefärbt, die Flecken aber kleiner und sparsamer; der Mantelschild bräunlichgrau, weissscheckig; die Innenseite der Fussflügel weisslich, nur die Randpartie wie die Aussenseite gefärbt; die Kieme dunkelbraun; die Fusssohle einfärbig braun.

Die Formverhältnisse die gewöhnlichen, die Haut uberall ganz eben; der Mantelschild gross, etwas gewölbt, hinten rechts seicht ausgeschnitten, das centrale Loch sehr ausgeprägt, kein deutlicher Sipho. Der Fuss vorne gerundet, der kurze Schwanz etwas zugespitzt-gerundet. Die Schale gräulichweiss, 2 I mm. lang bei einer Breite von 12 und einer Convexität von $2 \mathrm{~mm}$, hinten ein wenig ausgerandet abgestutzt, verkalkt, aber diinn, mit kleiner Nuclealpartie (Fig. 36, 37), schwachen Anwuchslinien und einem schmalen cuticularen Gebräm.

Das Centralnervensystem wie sonst bei ächten Aplysien. Das kleine Osphradium an Mantelrande vor der Gegend der Kiemenwurzel mit zwei vortretenden Lippen.

Die Mundröhre I,5 mm. lang, mit bräunlichgrauen Längsfalten der Innenseite. - Der gräuliche Schlundkopf $8 \mathrm{~mm}$. lang bei einer Höhe und Breite von 6; die braungelben Mandibelplatten (Fig. 38) $3 \mathrm{~mm}$. hoch bei einer Breite von I, wenigstens 0,12 mm. hohen Stäbchen (Fig. 39) gebildet; die gräulichen Gaumenplatten mit den gewöhnlichen bis wenigstens $0,10 \mathrm{~mm}$. hohen Dornen. Die Zunge mit gelber Raspel, welche beiläufig 25 Zahnplattenreihen enthielt, während die Scheide noch 23 barg, von welchen die 3 
hintersten unreif; die Gesammtzahl der Reihen sonst 48. In den Reihen schienen bis etwa 25 laterale Platten an jeder Seite der medianen vorzukommen. Die Zahnplatten waren gelb; die Breite der medianen betrug $0,20 \mathrm{~mm}$, die Höhe des Hakens der lateralen bis o, I 4. Die medianen Platten (Fig. 4O, 4I) waren breit, mit kurzem breitem ein wenig zugespitztem Haken, welcher ganz fein denticulirt war, die Zähnelung aber an den meisten der Zunge abgerieben (Fig. 40). Die Seitenzahnplatten hatten alle einen starken Haken mit einem kleinen Dentikel an dem Innenrande, bei den 3-5 innersten war der Haken plumper mit $3-4$ Dentikeln des Aussenrandes (Fig. 41), bei allen folgenden war der Haken spitz mit einem spitzen Dentikel des Aussenrandes (Fig. 42); an den äussersten, besonders den drei äussersten war der Haken kürzer, und die äusserste klein, vielleicht ohne Dentikel (Fig. 2a).

Die Speiseröhre $5 \mathrm{~mm}$. lang. Der Vormagen $22 \mathrm{~mm}$. lang bei einem Durchmesser an der Mitte von 9, dünnwandig, vor der Mitte durch die circuläre Falte gleichsam in zwei Räume getheilt. Der Ka umagen $5 \mathrm{~mm}$. breit bei einer Länge von 4,5; an der Wand kamen in gewöhnlicher Weise 2 Reihen von Pyramiden vor, 9 grosse, 4 kleinere; dieselben waren durchscheinend bläulich, mit einer Grundfläche von bis $2 \mathrm{~mm}$. Durchmesser. Der dünnwandige Hintermagen von $6 \mathrm{~mm}$. Länge bei einem Durchmesser vorne von 4 ; an demselben kamen zwei Reihen von ovalen Facetten von einem Durchmesser bis $0,4 \mathrm{~mm}$. und mit vortretendem Rande vor; Dornen wurden absolut nicht gefunden. Der Darm wie gewöhnlich. - Der sehr sparsame Inhalt der Verdauungshöhle vegetabilischer und unbestimmbarer animalischer Art; im Kaumagen lag eine unbeschädigte weisse Scalaria-ähnliche Schale von $2 \mathrm{~mm}$. Länge.

Die gelbbraune Leber $17 \mathrm{~mm}$. lang bei einer Breite von 12 und Höhe von $1 \mathrm{I} \mathrm{mm}$., durch tief eindringende Furchen in eine Menge von grösseren und kleineren Lappen getheilt.

Die weissliche, zum grössten Theil an die Leber fest angeheftete $Z$ witterdrüse $13 \mathrm{~mm}$. breit bei einer Höhe und Dicke von 6. Die vordere Genitalmasse (Fig. 4) gelblich und weisslich, I5 mm. lang; die fast eiförmige (Fig. 4 b) Schleim-Eiweissảrüse von $6,5 \mathrm{~mm}$. Durchmesser, der Spermoviduct nicht sehr lang.(Fig. 4c), die Spermatotheke kugelförmig, von $5 \mathrm{~mm}$. Durchmesser (Fig. $4 d$ ). - Der gebogene Penissack ausgestreckt I $5 \mathrm{~mm}$. lang (Fig. 5), aussen grau; seine Innenseite stark rothbraun pigmentirt, mit starken Längsfalten, unter welchen eine stärkere; ganz oben waren die Falten circulär; am Scheitel des Sackes verbreitete sich der starke M. retractor (Fig. $5 a$ ). Die Glans sich vom Scheitel durch die ganze Länge des Sackes erstreckend, (Fig. 6) etwas zusammengedriickt, glatt, mit breiter Furche der einen Seite, gelblich, nur an der Spitze röthlich.

Die Art, die vielleicht mit einer der schon angegebenen pacifischen Arten identisch ist, wird durch die eigenthïmliche Form der medianen Platten der Raspel wahrscheinlich zu erkennen sein.

5. Aplysia vexans Bgh. n. sp. Taf. VII, Fig. 7-I3.

Bei Ambon wurde ein Ex. gefangen, das in Formol bewahrt verdreht und ziemlich abgerieben war.

Die Länge betrug $5 \mathrm{~cm}$. bei einer Höhe von 3,5 und einer Breite von 2,3 cm.; die Länge der Fussflügel war 2, 8 bei einer Höhe von I cm.; die Breite der Fusses I, $\delta$ cm.; die 
Länge des Schwanzes $6 \mathrm{~mm}$. Die F arbe der Rückenseite (wenigstens der Fussfiugel und des Schwanzes) scheint schwarz gewesen zu sein; sonst ist sie gelblichweiss.

Die F ormverhältnisse die gewöhlichen; der Rand der Fussflügel fein rundzackig; durch den dünnen Mantel (mit rundem, I,5 mm. weitem Loch) schimmert stark hellweiss die Schale, am Hinterrand Andeutung eines aufrechten Sipho's. Die dünne, etwas gewölbte, ziemlich stark verkalkte und nicht sehr zerbrechliche $\mathrm{Schale}$ I $7 \mathrm{~mm}$. lang bei einer Breite bis 14,5 und dic Höhe etwa 2,75 mm. betragend (Fig. 7), die Nuclealpartie ganz klein. Die stark gebogene Kieme mit etwa ${ }_{3} 3$ Hauptblättern.

Die Hauptganglien des Centralnervensystems hell gelb; das grosse hintere aus zwei Längshälften bestehend, die eine deutlich aus 3 (Ganglion palliale, G. subintestinale, G. viscerale), die andere aus zwei Ganglien zusammengesetzt (Ganglion palliale, G. supraintestinale).

Die Mundröhre $3 \mathrm{~mm}$. lang. Der weissliche $\mathrm{Schlundkopf} 8 \mathrm{~mm}$. lang bei einer Höhe und Breite von 6,5; die gelbbraunen Mandibelplatten (Fig. 8) 3,5 mm. hoch bei einer Breite von 2,25; ihre Elemente bis $0,25 \mathrm{~mm}$. hoch bei einer Dicke von 0,005 , gegen ihr oberes Ende ein wenig gebogen, das Ende abgestutzt, mit feinen Einkerbungen (Fig. 9). Die braungelbe Raspel der Zunge mit 35 Zahnplattenreihen, von denen die 15 vordersten in den Seitentheilen sehr unvollständig; in der Scheide kamen noch 22 vor, von denen die 3 hintersten unreif; die Gesammtzahl der Reihen somit 57. Zu jeder Seite der medianen kamen bis 32 laterale Platten vor. Die Platten waren gelb; die Breite der medianen betrug $0,28 \mathrm{~mm}$; die Länge der 5 äussersten lateralen war $0,04-0,06-0,10-0,12 \mathrm{~mm}$, die der danach folgenden $0,18 \mathrm{~mm}$. Die medianen Platten (Fig. IO) ziemlich breit, mit starkem, fein gezähneltem Haken und einem Dentikel am Grunde. Die folgenden Platten (Fig. I I) mit starkem, fein gezähneltem Haken, die am Grunde aussen zwei starke und innen einen schwächeren Dentikel trugen. Die 5 äussersten Platten ohne Haken und die zunächst anstossenden mit schwächerem solchem (Fig. 12).

Die langen, dünnen, ganz feinknotigen Speicheldrüsen wie gewöhnlich.

Die graue Speiseröhre, 1,5 mm. lang. Der Vormagen war ein zusammengebogener, ausgestreckt, bei einem Durchmesser von 7, fast $20 \mathrm{~mm}$. langer Sack. Der Ka umagen 6,5 mm. lang bei einer Breite von 9; ringsum die Cardia eine Reihe von niedrigen harten Kegeln, dann in zwei Reihen die starken, bis $3 \mathrm{~mm}$. hohen, gelben Pyramiden mit weisslicher Axe. Der Hintermagen $6 \mathrm{~mm}$. lang.

Die grünlichgraue Leber $13 \mathrm{~mm}$. lang bei einer Höhe und Breite von I I. Die weissliche gebogene Gallenblase (Fig. 13) liegt in einer Länge von 5,5 mm. an der oberen Seite der Leber entblösst.

Die gelblichweisse, durch ihre Farbe gegen die Leber, mit welcher sie verwachsen ist, contrastirende grosse $\mathrm{Z}$ witterdrüse ro $\mathrm{mm}$. lang bei einer Breite von I und einer Dicke von 8. Die vordere Genitalmasse gelblichweiss, Io $\mathrm{mm}$. lang bei einer Höhe von 6 und einer Dicke von 5; der Bau wie sonst bei typischen Aplysien. - Der oben umgebogene Penissack $10 \mathrm{~mm}$. lang, oben weisslich, sonst violetgrau aussen und innen; die schmale, platte, lanzetförmige Glans weiss, $5 \mathrm{~mm}$. lang.

Diese Form ist von den anderen hier erwähnten Arten jedenfalls verschieden. 
6. Aplysia velifer Bgh. n. sp. Taf. V, Fig. 2. Taf. VII, Fig. I4-2I.

Aus einer Tiefe von 40 M. wurde in der Bucht von Badjo an der Westküste von Flores (St. 50) ein Individuum gefischt und lebend abgebildet (Fig. 2).

Das lebende Thier hatte eine Länge von $3 \mathrm{~cm}$. gehabt, bei ausgeschlagenen Fussflügeln betrug die Breite bis fast $2,5 \mathrm{~cm}$. Die Farbe des Rückens scheint bräunlich-violet gewesen zu sein, die obere (innere) Seite der Fussflügel von Querbändern ähnlicher Farbe durchzogen, die Seitenäste abgaben.

Das a ufbewahrte Individuum hatte eine Länge von $2,5 \mathrm{~cm}$. bei einer Höhe bei emporgeschlagenen Flügeln von I, 3; die Höhe zum Rücken in der Gegend der Schale 8 mm., vor den Flügeln 5; die Breite der Fusssohle $3 \mathrm{~mm}$. Die Farbe war gelblich; die obere Seite des Körpers überall fein grau und schwarz areolirt (Fig. I4), so war auch die Aussenseite der Fussflügel; die Innenseite derselben dagegen zeigte unregelmässige graue, etwas verzweigte und anastomosirende Querbänder; an der Innenseite der Fussflügel so wie am Mantel kamen sparsam zerstreute schwarze Punkte vor, die in grösserer Menge an der Aussenseite der Fussflügel auftraten. Vor den Rhinophorien schimmerten die Augen stark durch.

Die Formverhältnisse die gewöhlichen, nur waren die Fussflïgel sẹr, und der $(7 \mathrm{~mm}$.) lange Mantel (Fig. 15) stark vortretend, mit fast centraler runder Öffnung und hinten in einen kleinen Sipho verlängert; die braune, in fast ihrer ganzen Länge angeheftete Kieme $3 \mathrm{~mm}$. lang bei einer Breite von I,75; die Fusssohle schmal, der Schwanz ziemlich kurz.

Die ganz dünne, ganz hornartige, fast farblose, ziemlich stark abgeplattete Schale $7 \mathrm{~mm}$. lang (Fig. I6).

Das gelbliche, stark knotige Centralnervensystem wie bei anderen ächten Aplysien, scin Durchmesser durch die pleuro-pedalen Ganglien 1,75 mm., die Länge der visceralen Connective 4,5 mm; die pedalen Ganglien mehr als doppelt so gross wie die pleuralen.

Der gelbliche $\mathrm{Schlundk}$ opf 2,5 mm. lang. Die braunen Mandibelplatten stark, von I mm. Breite; ihre (Fig. I 7) Elemente bis etwa $0,10 \mathrm{~mm}$. hoch, die abgestutzte Spitze etwas gebogen. Die Gaumendornen (Fig. I8) gelb, aufrecht, bis o, IO mm. hoch. Die kastanienbraune Raspel enthielt 24 Zahnplattenreihen, in der Scheide kamen deren noch Io vor, die Gesanmtzahl der Reihen somit 34. Die Zahnplatten braungelb und gelb; die Breite der medianen betrug o,20 mm., die der 6 äussersten lateralen $0,05-0,06-0,06-0,10-0,14-0,16 \mathrm{~mm}$. Die medianen Platten (Fig. 19, 20) mit spitzem fein gezähneltem Haken und einem ziemlich starken Dentikel am Grunde derselben; die lateralen (Fig. 20) mit gezähneltem spitzem Haken und stärkeren Dentikeln an ihrem Grunde, die 3 äussersten ohne Haken, und die folgende mit kleinem glattrandigem Haken (Fig. 2I).

Die Speiseröhre $2 \mathrm{~mm}$. lang. Der von seinem Inhalt etwas ausgedehnte Vormagen $4 \mathrm{~mm}$. lang; der Inhalt war vegetabilischer Art, in demselben ein Paar zerbrochene losgerissene Zahnplatten des Thieres. Der Kaumagen von $2 \mathrm{~mm}$. Länge; seine $\delta$ ziemlich grosse, gelben, unregelmässig kegelförmigen oder abgestutzt pyramidalen Zahnplatten in gewöhnlicher Art gestellt; kleine wurden nicht gesehen. Der Hintermagen 2,5 $\mathrm{mm}$. lang. Die gelblichgraue Leber von ovalem Umriss, 4,5 mm. lang.

Die kleine, an der Spitze hornartig gebogene $Z$ witterdrüse weiss, ohne reife Geschlechtselemente. Der Penis wie gewöhnlich. 


\section{Dolabella Lamarck.}

LAMARCK. Syst. des anim. s. v., ISOr, p. 62.

Cuvier. Mém. sur la Dolabella etc. Ann. du mus. V, r804, p. 435.

Corpus postice latius, oblique truncatum; parapodiis brevioribus, apertura branchiali breviori, angustiori. Testa pro maxima parte nuda, fortior, nonnihil securiformis, margine sinistro crassiori, postice angustior, dextrorsum emarginata et parte nucleali deorsum incurvata carina postica prominenti instructa.

Systema nervosum ut in Aplysiis propriis. Radula (linguae) dentibus medianis elongatis, dentibus lateralibus numerosis non denticulatis. - Glandula hermaphrodisiaca hepati non connata.

Dieses durch sein Äusseres sehr auffallendes Thier wurde als generische Form von LAMARCK $^{1}$ ) aufgestellt, von Cuvier adoptirt und findet sich danach bei den späteren Malacologen.

Die Form ist eigenthiimlich, hinten breiter, mit einer rundlichen, schrägen, grossen Scheibe endigend, bis gegen deren Mitte sich die nicht lange schmale Kiemenspalte erstreckt. Die gleichsam axtartige Schale ist stark verkalkt, mit verdicktem linken Rande, hinten im rechten eine Auskerbung; das schmalere Hinterende (Nuclealpartie) dicker, nach rechts und unten gebogen, hinten mit einem vortretenden scharfen Kiel versehen.

Das Centralnervensystem ist dem der ächten Aplysien ähnlich. Die Raspel zeigt die mediane Platte länglich und eine lange Reihe von nicht denticulirten Seitenplatten. Die Zwitterdrüse ist von der Leber gelöst.

Die Gattung ist auf das Rothe, Indische und Stille Meere beschränkt.

Die Form, welche Cuvier Dolabella Rumphii benannte, ist jetzt nicht bestimmbar, als Type dieser muss die von RANG abgebildete gelten. RANG hat noch eine kleine Reihe von Arten (D. Hasseltii, Teremidi, ccaudata ${ }^{2}$ ) (truncata)) angegeben, und noch einige sind von EHrexberG, Quoy und Gaimard, Sowerby, Stearns (D. Hemprichii, Tongana, elongata, califomica) erwähnt ${ }^{3}$ ). Einige sind nur nach der Form-variablen Schale aufgestellt, und die anderen sind vielleicht nur Varietäten einer weit verbreiteten Art.

I. Dolabella Rumphii Cuv., Rang. Taf. VII, Fig. 22-40. Taf. VIII, Fig. I-7 (9).

(Cuvier. Ann. du Mus. V, ISO4, p. 437, Pl. XXIX, Fig. 1).

RANG. 1. c. I 828 , p. 46, Pl. I.

Auf Riffe von Atjatuning an der Westküste von Neu-Guinea wurde ein Individuum gefischt (St. 169), ferner 2 am Riffe in der Bai von Bima (St. 47) und drei am Riffe von Haingsisi $(6,9$ und $13,5 \mathrm{~cm}$. lang), ferner drei am Riffe der Pepela-Bai an der Ostküste von der Insel Rotti (St. 30r). Das erste war das nächst grösste und wurde genauer untersucht, so wie eins der anderen die etwas kleiner waren.

I) LAMARck schuf die Gattung nach der Figur der Schale von Ruspu geliefert und benannte die . Art Dol. callosct.

2) V. D. DEcken. Reisen in Ostafrika, JII, r\$69. v. MARTevs, Mollusken, p. 65: Dolabilliz ecaudiz Kang (Zanzibar)

3) Trion and Pilsbry. Man, of Conchology, XVI, IS95-I896, p. 15I-I60. 
Die Länge des nächst grössten, betrug 9,5 cm. bei einer Breite bis 5 und einer Höhe bis $4 \mathrm{~cm}$; die Länge der Hinterscheibe war 5,5 bei einer Breite von $4,7 \mathrm{~cm}$.; die Länge der Kiemenspalte $4 \mathrm{~cm}$; die Länge der Rhinophorien $6 \mathrm{~mm}$; die Länge der (stark gekrümmten) Kieme, wenn ausgestreckt, 2,7 cm. bei einer Breite von 1,6 und einer Dicke von $0,9 \mathrm{~cm}$. Die Farbe war durchgehends grünlichgrau, so auch die der Kieme; die Kegelchen der Rückenseite mitunter gelblich.

Die Schale von typischer Form, 3,2 cm. lang bei einer Breite bis 2,3; die obere Seite wegen der gelben (nicht abschuppenden) Cuticula glänzend gelblich, der Kamm hinten an der Nuclealpartie so wie die Unterseite der Schale rein weiss.

Die Formverhältnisse die gewöhnlichen der Dolabellen. Die vorne und etwas weniger hinten kliffende Kiemenspalte bis fast an die Nitte der grossen Hinterscheibe reichend. Der Rand der Fussflügel zeigt eine der Länge nach laufende feine Furche. Die ganze Ruickenseite ist überall äusserst fein granulirt, noch dazu aber mit zahlreich zerstreuten kleinen (bis $3 \mathrm{~mm}$. hohen) Kegeln versehen, die zum Theil in Grubchen retractil sind, zum Theil auch zusammengesetzt d. h. wieder fein knotig sind oder mit kleinen Spitzen versehen. Der etwas vortretende Rand der Hinterscheibe ist fein zackig und trägt ähnliche Knoten. Die Rhinophorien und die Tentakel eben. Die nur an ihrem Anfange von dem (rechten) Fussfluigel bedeckte Samenfurche verläuft in einem Bogen frei über den Vorderkörper hinter dem rechten Tentakel zu der männlichen Genitalöffnung oberhalb der rechten Fussecke. Der breite Fuss vom Oberkörper nicht scharf begrenzt, ganz eben, vorne schmaler und mehr gerade endigend, hinten gerundet, ein Schwanz ist kaum angedeutet. Die Dicke des Fusses zeigt sich hinten fast doppelt so stark wie vorne. - Wenn die Kiemenspalte stark erweitert wird (oder besser die Fussflügel weggenommen werden), erscheint die gelbliche Schale, am Rande von einem rechts und vorne 3 , links 2,5 mm. breitem (bläulich-)grauem Gebräm eingefasst; dieser Mantel (Fig. I) setzte sich in den hohen, schieff abgestutzen, kegelförmigen, nach oben $(7-8 \mathrm{~mm}$.) und etwas rechts hervorragenden Sipho fort; die lintere etwas eingerollte Lippe desselben ist stärker als die vordere; der offene Kanal zwischen denselben setzt sich unter der Kiemenspitze in die Kiemenhöhle fort. Die Lage des Sipho entspricht dem Ausschnitte der Schale, und der Grund der Athemröhre sitzt breit auf dem gebogenen, tief eindringenden Hinterende der Schale. Am Grunde des Sipho's, an der hinteren Lippe desselben die kaum vortretende Analöffnung (Fig. I). Der Mantelrand ragt, mehr grau und dicker geworden, hinten gerundet (Fig. I), noch etwa $3 \mathrm{~mm}$. ïber den Innenrand der Spitze der Kieme hervor; sein Vorderende ist links an die Körperwand angeheftet, sonst frei, mit freiem Eingang rechts in die Kiemenhöhle. Die palliale Drise ist nur hinten an der (weissen) Siphonalpartie stark entwickelt. Dicht unter dem Anus fängt eine feine Falte an, die hinuntersteigt, nach vorne schwingt, längs des Bodens der von dem rechten Fussflügel gebildeten Höhle verläuft und sich in die Samenfurche fortsetzt; ganz vorne unterhalb dieser Falte findet sich die grosse, bis $4-5 \mathrm{~mm}$. breite, weisse mit Wasser stark aufquellende subbranchiale Drüse. Die grosse gebogene Kieme mit beiläufig ro Hauptblättern, fast ihre hintere Hälfte ragt frei hervor, vor dem Grunde ihres Bandes die feine Nieren pore. Dicht am Vorderende der Rhachis der Kieme das etwas vortretende fein quergefurchte Osphradium. Der von den Fussflügeln eingefasste Raum hoch, nur vorne und besonders hinten niedriger. 
Das Centralnervensystem (Fig. 2) stimmt mit dem der ächten Aplysien und nicht, wie man den verschiedenen Beziehungen zu den Notarchen nach vielleicht hätte vermuthen können, mit dem der letzteren. Es ist von einer genau anhängenden Kapsel umgeben, welche sich eine Strecke auf die Hauptnerven hinaus fortsetzt; und diese Kapsel ist reichlichst mit ziemlich dunkelen, kurz-wurstförmigen (meistens etwa $\mathrm{O}, \mathrm{r} 2 \mathrm{~mm}$. langen), bei Essigsäure stark brausenden, stark erhärteten Spikeln versehen (Fig. 22), an den visceralen Ganglien kommen sie in geringerer Menge vor. Die Ganglien schimmern undeutlich und gräulich durch die Käpsel ${ }^{1}$ ). Die fast verschmolzenen cerebralen Ganglien (Fig. 2a) bilden eine kurz-nierenförmige Masse von $2,5 \mathrm{~mm}$. Breite, sind durch ein starkes, $6 \mathrm{~mm}$. langes Connectiv mit der unteren pleuropedalen Ganglienmasse verbunden (Fig. 2bb). Diese letztere hatte eine Breite von 5 mm.; die pedalen Ganglien waren durch eine kurze Commissur verbunden; ausserhalb (und vor) derselben die kleineren pleuralen. An der $(20 \mathrm{~mm}$.) langen pleuralen Commissur ist hinten (vor der Aussenseite der Spermatotheke) ein birnförmiges $(2 \mathrm{~mm}$. langes) Ganglien viscerale (Fig. $2 d$ ) entwickelt, das sich innerhalb der Kapsel aus zwei länglichen Nervenknoten gebildet zeigt. Am Knotenpunkte der buccalen Commissur die durch eine kurze Commissur verbundenen abgeplatteten buccalen Ganglien (Fig. 2c).

In der Haut mit sammt ihren Prominenzen eine Menge von gelben und dunkleren, grösseren, mit Säuren (Essigsäure) nicht aufbrausenden Körpern.

Die Länge der Mundröhre betrug $10 \mathrm{~mm}$. - Der Schlundkopf war I $6 \mathrm{~mm}$. lang bei einer Höhe und Breite von 10, seine Formverhältnisse wie gewöhnlich. Die 3-4 sehr starken, langen unteren Retractoren der Mundröhre und des Schlundkopfs hauptsächlich von der Gegend des Randes der Hinterscheibe entspringend; ein Paar kleine Mm. protractores supp. entspringen hinter der Gegend der Rhinophorien, ein breiter M. protractor lateralis ausserhalb derselben. Die matt dunkel kastanienbraunen, mit ihrem helleren hinteren Drittel in eine Falz eintretenden Mandibel $7 \mathrm{~mm}$. lang bei einer Breite bis 4 und einer Dicke von $0,6 \mathrm{~mm}$., mit vorderem mehr geradem und hinterem mehr convexem Rande (Fig. 23, 24); ihre stabförmigen geraden, quergestrichelten Elemente von einer Höhe bis 0,6 bei einer Breite bis $0,035 \mathrm{~mm}$ (Fig. 25). Am Gaumen jederseits neben der medianen Rinne eine diinne, leicht abzulösende, schmutzig rothgelbe, I $2 \mathrm{~mm}$. lange, bis $3 \mathrm{~mm}$. breite, gleichsam fein punktirte Platte (Fig. 26). Hinten waren sie breiter, nach vorne verschmälert, und fast zusammenstossend; die dicht gedrängten schmutziggelben Gaumendornen zusammengedrückt, etwas gebogen, schräg gestrichelt, von einer Länge bis 0,4 bei einer Breite am Grunde von 0,08 mm. (Fig. 27). Die Zunge stark; die Länge der rothgelben Raspel 7,5 mm. bei einer Breite bis 9 betragend, die in der Kluft liegende Partie mehr schmutziggelb; die Raspelscheide $6 \mathrm{~mm}$. lang, ihre schräge Endfacette 3,5 mm. breit. In der Raspel wurden 3 I-30 Zahnplattenreihen gezählt, in der Scheide kamen deren noch 27-30 vor, die Gesammtzahl der Reihen somit 58 -60. In den Reihen wurden bis etwa 200 Zahnplatten jederseits gezählt. Die Zahnplatten waren gelb; die Länge der medianen betrug 0,16 mm.; die Höhe des Hakens der ersten Seitemplatte 0,08, und

I) Der Erhärtungszustand der Siboga-Exx. gestattene keine Eruirung des Centralnervensystems. Dieselbe ist hier an einem $8 \mathrm{~cm}$. langen Individuum derselben Art gemacht, mir vor Jahren in Alkohol bewahrt von den Herrn SARASIæ geschenkt und aus der Nähe von Ceylon stammend. 
die Höhe der Platten steig bis $0,28 \mathrm{~mm}$., die der äussersten war nur 0, I $2 \mathrm{~mm}$. Die medianen Platten (Fig. 3, 4) in Form von der der ächten Aplysien sehr abweichend, länglich, vorne schmäler mit einem wenig umgebogenen, ganz fein denticulirten Ende (Haken), hinten etwas breiter. Die ersten Seitenplatten (Fig. 3) mit niedrigem plumpem Haken; wie die folgenden glattrandig von gewöhnlicher, etwas plumper Hakenform (Fig. 28), nach aussen wurde der Haken schlanker und höher (Fig. 29); die äussersten kleiner, plumper, mit verkúrztem Körper (Fig. 5).

Die weissen Speicheldrüsen so lang wie die Speiseröhre, mit ihrem Ende an die Gegend der Cardia befestigt, fast cylindrisch, dünn; ihr Durchmesser durch das vordere ungefähre Drittel I,5 $\mathrm{mm}$. betragend, in der ibrigen Strecke 0,5-0,25.

Die Länge der gräulichen $\mathrm{S}_{\mathrm{p}}$ eiseröhre und des Vormagens $(2,5-)+\mathrm{cm}$. betragend bei einem Durchmesser bis $7 \mathrm{~mm}$., in der Mitte und an der Cardia am weitesten; die Innenseite mit niedrigen Zotten (Fig. 3I) dicht bedeckt. - Der Ka umagen von mehr oder weniger regelmässiger Kugelform, gräulich, gelblich- oder grïnlichgrau; seine Länge (I6-) I $8 \mathrm{~mm}$. betragend bei einem Durchmesser von ( $\mathrm{I}_{4}$ ) $2 \mathrm{O}$; die Dicke seiner Wand in der Mitte $3-4 \mathrm{~mm}$. betragend; über den Magen verliefen von der Cardia an den Pylorus die 4 Nerven, die anastomosirend um den Pylorus auch einen Ring bildeten und sich dann verzweigend über den folgenden Magen hin fortsetzen. In etwas vertieften Facetten von viereckiger (rhomboider) oder etwas eiförmiger Gestalt mit vortretendem Rande, und Quincunx-artig in 3 Reihen geordnet, die sehr starken Magenzähne, die vordersten die kleinsten, die hintersten die grössten. Diese Magenzähne waren bei dem einem Individuum von grünlicher, bei dem anderen von schmutziggelblicher Farbe, durchscheinend, die Axe immer dunkler, was besonders an der Spitze der grösseren auffiel; die Höhe der grössten betrug bis $6,5 \mathrm{~mm}$. bei einer Breite der Grundfläche bis 8, die kleineren hatten nur eine Höhe von $3,5-4 \mathrm{~mm}$. bei einer Basis von $2 \mathrm{~mm}$. Durchmesser. Das eine Individuum schien alle diese Platten zu haben, 6 grosse, 6 mittelgrosse und 6 kleine; bei dem anderen schienen einige der kleineren (während der Verdauung?) ausgerissen, es fanden sich 8 grosse, 2 mittelgrosse und 3 kleine. Die grossen und mittelgrossen Magenzähne waren von gewöhnlicher 4-, seltener 3 -seitiger Pyramidenformen mit abgestutzter Spitze; die kleineren waren zugespitzt, zusammengedrückt, von sehr variabler Form (Fig. 32), zum grössen Theil oben getheilt (bicuspides). Alle Magenzähne zeigten feine dichstehende Querlinien. - Der Hintermagen war I3-16 mm. lang bei einem Durchmesser vorne von Io, hinten von $8 \mathrm{~mm}$.; seine Wand war viel dünner, an der Innenseite mit Reihen von dichtstehenden, rundlichen Knötchen von einem Durchmesser von etwa $0,5 \mathrm{~mm}$. besetzt (Fig. 33), aber ohne Spur von Entwicklung von Dornen; die Wand zeigte starke Aufbrausung mit Essigsäure. Die folgende zum Theil schon von der Leber umfasste Strecke der Verdauungshöhle ist sehr dünnwandig und zeigt durchschimmernde Längsfalten (Fig. 6) und neben der Leberöffnung eine sehr starke Falte. Am Eingange in den Darm zwei starke Falten. Der dünwandige Darm von $3-5 \mathrm{~mm}$. Durchmesser, oberflächlich (Fig. 7c) in Furchen über die Leber verlaufend, an dieselbe fast angelöthet, erst in einen grossen Bogen rechts nach unten gehend, an der Unterseite nach vorne kehrend, eine grosse Schlinge bildend, wieder sich nach hinten wendend und durch eine grosse Schlinge an den Anus aufsteigend. - Der rothbraune Inhalt der Verdauungshöhle war hauptsächlich 
vegetabilisch (meistens Algen und Diatomeen), mit feinen Sandkörnern vermischt; bei dem cinen Individuum war der Hintermagen mit feinen und groben Sandkörnern ganz voll gestopft.

Die grosse, schmutzig dunkelbraune oder schwarzbraune Leber $3 \mathrm{~cm}$. lang bei einer Höhe von 2 und Breite von $1,8 \mathrm{~cm}$, durch die Darmschlingen äusserlich gleichsam in 3 grosse Lappen getheilt; kleine, gleichsam isolirte Lappen kamen hier und da längs des Darmes vor. Von den in der vorderen Leberhälfte vorkommenden rundlichen mit einander communicirenden Höhlen war eine grösser und öffnete sich am Anfang des Darmes in die Verdauungshöhle (Fig. 6), in diese Höhle mündet die Gallenblase ein. Diese letztere ist stark zusammengebogen (Fig. 6c,7), weisslich, von einem Durchmesser von $3 \mathrm{~mm}$. und maass ausgestreckt an Länge $2 \mathrm{~cm}$; sie ragte mit ihrer Hälfte (Fig. 7) frei an der Unterseite der Leber hervor; ihre Innenseite zeigte starke Längsfalten, eine besonders starke theilte die Höhle in zwei ungleichgrosse mit einander communicirende Räume.

Der (Figur I) Mantel (Kiemenschild) ist von Form und Grösse wie die Schale, von derselben Farbe an der oberen wie an der unteren Seite, schwarzbraun oder dunkel bläulichgrau, auf Schnitten schwarz, $3 \mathrm{~mm}$. dick. - Vor demselben am Grunde der Kieme das querliegende grosse ( $8 \mathrm{~mm}$. lange) Pericardium; die zusammengezogene Herzkammer $8 \mathrm{~mm}$. lang. Die hinten an der inneren (linken) Wand der Herzkammer liegende gräuliche Pericardialdrüse I $3 \mathrm{~mm}$. lang bei einer Höhe von 4 und einer Dicke von 2. - Die in der ganzen Länge des linken Schalenrandes liegende gräulichweisse Niere halb so breit wie lang, von $5 \mathrm{~mm}$. Dicke.

Die ganz hinten in der Eingeweidehöhle liegende gräulichweissliche $Z_{w i t t e r d r u ̈ s e}$ (Fig. 34a) gross, $23 \mathrm{~mm}$. hoch bei einer Breite von 13 und einer Dicke von 9, nierenförmigMeniscusartig, mit gewölbter Hinterseite, fast eben an beiden Seiten. In den Läppchen der Drüse reife Geschlechtselemente, einige derselben schienen nur männlicher Art. Der Zwitterdruisengang aus einer Nabel der Vorderseite (Fig. 34b) frei vortretend, in kurzen groben Korkzieherwindungen an die vordere Genitalmasse sich hinaberstreckend, an der Hinterseite derselben dünner werdend, theilt sich dann; der Samengang sich um den Rand schlagend und an der vorderen (rechten) Seite eine weisse Schlinge (Fig. 34) über die centrale braune Partie legend, sich dann wahrscheinlich in den Spermovidukt fortsetzend. Die vordere Genitalmasse in situ im Ganzen an Länge $3,7 \mathrm{~cm}$. messend; den grössten Theil derselben bildet die gelbliche Schleim-Eiweissdrise. Diese letztere (Fig. 34c) ist zusammengedrückt, I 9 mm. hoch bei einer Breite von 15 und einer Dicke von 6; an der rechten (Fig. 34c) Seite zeigt sie eine centrale braune Partie, die sich in einen ziemlich langen geschlungenen Blindsack (Fig. $34^{*}, 35^{*}$ ) fortzusetzen scheint; übrigens zeigt diese Seite alternirende gelbliche und weisse Bogen; die linke Seite (Fig. 35) ist viel einfacher, eine grosse gelbliche Schlinge darbietend. Der starke, gebogene Spermovidukt (Fig. $34 d, 35 d$ ) ausgestreckt 2,5 cm. lang bei einem Durchmesser von $4-5 \mathrm{~mm}$., auf Durchschnitten schien derselbe zwei durch eine incomplete gebogene Scheidewand geschiedene Röhren (Fig. 36, 37) zu enthalten; unweit vom Ende des Ganges die (unmittelbar vor dem Pericardium liegende) gräuliche, in Durchmesser I I mm. haltende Spermatotheke (Fig. 34e). - Der zusammengebogene, gräuliche, ausgestreckt bei einem Durchmesser von 4-5 mm., 3,5-4 cm. lange Penissack (Fig. 38) mit einem starken Retractor (Fig. $38 a$ ) und einem längeren Protractor (Fig. 386). Die Innenseite rothbraun oder schwarzbraun wegen 
zahlreich zerstreuter Gruppen von rothbraunen Zellen; in der Wand kam eine Menge von Spikeln gewöhnlicher Art vor; die Innenseite zeigt sonst viele feine Längsfalten und eine stärkere, von einer Furche begleitete. Der obere Theil des Penis ist etwas dicker und birgt die vom Scheitel der Höhle hinabragende starke weissliche, zusammengedrückte Glans; dieselbe ist (ausgestreckt) IO-I 2 mm. lang bei einer Breite von 3, von ziemlich variabler Form (Fig. 39, 40), mit Furche zwischen 2 Falten ${ }^{1}$ ).

Dolabella Rumphii, C. var. maculosa (Hasseltii). Taf. III, Fig. I. Taf. VIII, Fig. 8-9.

Dolabella Hasseltii Fér. Eliot, Notes on Tectibr. and naked moll. from Samoa. Proc. Ac. of Philadelphia, 1899 , p. 515 , Pl. XIX, Fig. 3.

?Dolabella Hasseltii Fér. Ravg, 1. c., I828, p. 49, Pl. XXIV, Fig. I.

?Dolabella Teremidi Rang. 1. c., p. 48, Pl. III, Fig. I-3.

Von dieser Form wurde am Riffe von Sailus ketjil, Paternoster-Inseln (St. 37) ein grosses $(15,5 \mathrm{~cm}$. langes) Individuum gefangen, cocainisirt und dem Leben nach abgebildet (dasselbe fand sich leider später vollständig eingetrocknet); ferner 2 Individuen am Riffe der Sanana-Bai an der Ostküiste von Sula Besi (St. I93), eins am Riffe der Cyrus-Bai an der südlichen Küste der Insel Rotti (St. 299); und noch eins am Ankerplatz von Tual, Kei-Inseln (St. 259) (I 3,5 cm. lang bei einer Breite bis 9).

Die Bodenfarbe des lebenden Thieres scheint scheckig braungrau und weisslich gewesen zu sein mit zerstreuten grossen unregelmässigen braunen Flecken. - Die in Formol a ufbewahrten Individuen waren von ähnlichen Farbenverhältnissen. Das genauer untersuchte hatte eine Länge von $7,5 \mathrm{~cm}$. bei einer Breite von 3,8 und einer Höhe von $3 \mathrm{~cm}$; die Länge des Hinterschildes war 3 bei einer Breite von $3,6 \mathrm{~cm}$., die Länge der Kiemenspalte $3 \mathrm{~cm}$., von welchen die vordere flache Eingangöfnung $9 \mathrm{~mm}$. betrug, der Durchmesser der hinteren Öfnung $3,5 \mathrm{~mm}$; die Länge der stark gebogene Kieme 25 nur bei einer Höhe von 6, ihre Dicke 7 mm., die Anzahl der Hauptblätter 15, die Höhe der Rhinophorien 6 mm. - Die Formverhältnisse waren die gewöhnlichen; die Hautkegeln aber kleiner, mehr einfach und weniger zahlreich, der Rand der Hinterscheibe weniger vortretend und weniger zackig. Die Schale ganz wie bei der typischen Form; sie hatte eine Länge von 3,2 bei eine Breite von $2,5 \mathrm{~cm}$.

Das Centralnervensystem ganz wie oben; an Schnitten des visceralen Doppeltganglions konnte seine respective Zusammensetzung aus 2 Ganglien nicht nachgewiesen werden.

Der Schlundkopf I $2 \mathrm{~mm}$. lang bei einer Höhe und Breite von 8; die gelbbraunen Nandibel (Fig. 8) 5,5 mm. lang, ganz wie oben; ebenso die hell schmutziggelben Gaumenplatten mit sammt ihren Dornen. Die hell schmutziggelbe Raspel mit sammt ihrer Fortsetzung in die Scheide enthielt etwa 60 Zahnplattenreihen und in den Reihen schienen auch gegen 200 Platten vorzukommen; die Zahnplatten ganz wie oben, nur schien die feine Zähnelung der medianen (Fig. 9) ein wenig stärker.

Die Speicheldruisen wie oben. Die Speiseröhre $5 \mathrm{~mm}$. lang; der Vormagen $23 \mathrm{~mm}$. 
lang bei einem Durchmesser von $\bar{\gamma}$, dünnwandig (ohne Zotten der Innenseite). Der Ka umagen $9 \mathrm{~mm}$. lang bei einer Breite von I4; seine Innenseite trug vorne 4 kleinere und sonst 9 grosse, gelbliche Kauplatten von einer Höhe bis $4,5 \mathrm{~mm}$. und sonst ganz wie oben. Der Hintermagen I I mm. lang bei einem Durchmesser von I2, dünnwandig, seine Innenseite mit : ahnlichen Knötchen wie oben. Der Darm wie oben. Der Verdauungshöhle von der Speiseröhre $\mathrm{ab}$ mit hauptsächlich rothbraunem In halt vollgestopft; derselbe war zum allegrösstem Theile vegetabilischer Art, mit zahlreichen bandartigen gelben Stücken von einer Länge bis 7 mm.; Steinchen kamen Masseweise vor und von einem Durchmesser bis $5 \mathrm{~mm}$. - Die schwarze Leber $3 \mathrm{~cm}$. lang bei einer Höhe von 7 und Breite von $5 \mathrm{~mm}$.

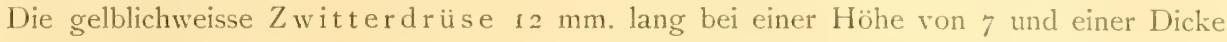
von 5, sonst wie oben. Die vordere Genitalmasse $22 \mathrm{~mm}$. lang, davon betrug die Schleim-Eiweissdrüse an Länge I I bei einer Höhe auch von I I und einer Dicke von $4 \mathrm{~mm}$. Sowohl die rechte wie die linke Seite der letzteren stimmten auffallend mit der oben gegebenen Darstellung, nur war die centrale Partie etwas kleiner, und zeigte sich auch mit einer kleinen (aber schwarzen) Partie an der linken Seite. Der Spermovidukt war kaum kürzer; die gräulichweisse kugelförmige Spermatotheke von $8 \mathrm{~mm}$. Durchmesser. - Der stark zusammengebogene Penissack ausgestreckt $25 \mathrm{~mm}$. lang bei einer Durchmesser von 2-4, in der oberen fast Hälfte gelblich, uibrigens blaugrau; die Innenseite in der unteren Strecke fast schwarz; oben liegt die gelbliche, gebogene und gedrehte, ausgestreckt 9,5 mm. lange Glans, von ziemlich einfacher Form, doch mit Andeutung vom Kräuselung des einen Randes.

Die hier untersuchte Form hat andere Farbenzeichnung als die von Rang benannte D. Rumphii, hat auch kleinere und sparsamere Rückenanhängen; im inneren Bau stimmt sie aber ganz mit der oben untersuchten Form und ist wohl nur eine Varietät derselben.

$$
\text { Taf. IX, Fig. I-3. }
$$

Bei Sanguisiapo (St. 93) wurden noch 4 Individuen einer ähnlichen Varietät gefischt.

Dieselben hatten eine Länge von 7,8,9 und $10,5 \mathrm{~cm}$. Das eine wurde genauer untersucht; bei einer Länge von $9 \mathrm{~cm}$. betrug die Breite durch das Hinterschild 5,3 und die Körperhöhe dort 4 (die Länge des Schildes war $5 \mathrm{~cm}$.). Die Länge der Kiemenspalte 3,6 cm.; die Länge der Schale war $3,2 \mathrm{~cm}$., die grösste Breite 2,5, von welchen die $15 \mathrm{~mm}$. in der Mitte vom Mantel entblösst lagen. Die stark zusammengebogene Kieme ausgestreckt 3,5 cm. lang bei einer Breite von 8 und Höhe bis $9 \mathrm{~mm}$; die Anzahl der Hauptblätter etwa 1 1. - Die Farbe war hell gräulichgelb, an der Riickenseite kamen, besonders stark am Hinterschilde entwickelt, grosse, heller- oder dunklerfarbige olivengraue, unregelmässige Flecken von einem Durchmesser bis I $5 \mathrm{~mm}$. vor.

Der Schlundkopf I $3 \mathrm{~mm}$. lang bei einer Höhe und Breite von IO; die rothgelben Nandibel $6 \mathrm{~mm}$. breit, ihre Dicke 0,25 ; ihre Elemente wie oben, von einer Breite bis 0,02 mm. In der gelben Raspel kamen 3 I Zahnplattenreihen vor, in der Scheide deren noch 30, die Gesammtzahl der Reihen somit 6r. Die medianen Platten von 0,20 mm. Länge: die Höhe der mehr inneren lateralen 0,25 , die Höhe bis 0,30 steigend, die Höhe der acht äussersten $0,10-$ 
$0,14-0,18-0,22-0,26-0,28-0,30 \mathrm{~mm}$. Die Formverhältnisse der medianen Platten, der mehr inneren, der grössten (Fig. I) und der äusseren (Fig. 2, 3) etwa wie oben.

Die Speiseröhre $3 \mathrm{~cm}$. lang bei einem Durchmesser, in der vorderen Hälfte von 7 , in der hinteren von $3 \mathrm{~mm}$. Diese letztere ohne Grenze in den Vormagen übergehend, welcher bei einer Länge von 6 fast $10 \mathrm{~mm}$. breit war, und hinten am Übergange in den Kaumagen die Längsfalten sehr stark entwickelt zeigte. Der $\mathrm{K}$ a umagen $10 \mathrm{~mm}$. lang bei einer Breite von 14; wie bei einem der obigen Individuen fanden sich ganz sicher 18 Magenplatten, vorne 6 kleinere und 4 mittelgrosse, alle meistens bicuspides, und 8 grössere von einer Höhe bis 6 mm.; die Platten waren schmutziggelb und sonst ganz wie oben. Der Hintermagen $15 \mathrm{~mm}$. lang bei einem Durchmesser von $\mathrm{I} 4$; in der ganzen vorderen Strecke die gewöhnlichen dichtstehenden rundlichen Knötchen.

Die schwarzbraune Leber 3,5 cm. lang bei einer Breite von 2,2 und Höhe von 2; durch die Darmschlingen war sie auch hier gleichsam in drei Lappen getheilt. Die Gallenblase ganz wie oben, aber von ähnlicher dunkler Farbe wie die Leber.

Die gelblichweisse $Z$ witterdrüse I $3 \mathrm{~mm}$. lang bei einer Höhe von 8 und Dicke von 4 . Die vordere Genitalmasse auch klein, $10 \mathrm{~mm}$. lang bei einer Höhe von 8 und Dicke von 3; die centrale Partie schmutzig gelb. Der Spermoviduct $2 \mathrm{~cm}$. lang bei einer Dicke von 1,5-3 mm.; die Samenblase von 5,5 mm. Durchmesser. - Der vorne gräuliche, hinten gelbliche, zusammengebogene Penissack ausgestreckt $2 \mathrm{~cm}$. lang bei einen Durchmesser von $2-3 \mathrm{~mm}$.

\section{Notarchidae.}

R. BERGH, Malacolog. Unters. V, I902, p. 343 .

Epipodia (brevia) fissura branchiali brevi sejuncta.

Ganglia visceralia antica, inter ganglia pleuralia sita.

Von den ächten Aplysiiden unterscheiden sich die Notarchiden durch die (kurzen) durch eine kurze und schmale Kiemenspalte geschiedenen Fussflügel.

Die visceralen Ganglien liegen nicht wie bei jenen weit nach hinten, sondern vorne zwischen den pleuralen Ganglien.

Augenblicklich umfasst die Gruppe die Gattungen Notarchus (Cuv.) ${ }^{2}$ ), Aclesia (Rang), Aplysiella (P. Fischer) und Phyllaplyysia (P. Fischer) ${ }^{2}$ ), welche nur durch die erwähnten, äusseren und inneren Charactere zusammengehalten werden, sonst von einander sehr differiren.

\section{Aclesia Rang.}

RANG, Hist. nat. des Aplysiens. I828, (p. 68), P1. XX, XXI, XXII.

R. BERGH, Gasteropoda opisthobranchiata. The Danish expedition to Siam I899-I900. I902, p. I68-174, Pl. I, Fig. 3I-38; Pl. II, Fig. I-II.

R. BERGH, Malacolog. Unters. V, 1902, p. 352-36I.

1) Vgl. 1.c. V, 1902, p. 344-35r.

2) Vgl. 1.c. V, 1902, p. $368-370$. 
Notaeum sicut rhinophoria et tentacula villis majoribus simplicibus et compositis ut plurimum instructa; podarium non angustum in caudam elongatum (ut plurimum) continuatum. Fissura branchialis brevis; scutum palliale sicut testa desunt, branchia et ren et pericardium in cavitate branchiali denudata (scuto non tecta).

Glans ut plurimum seriebus conulorum armata.

Die Gattung wurde von RANG aufgestellt, und die Tafeln XX-XXII tragen den Namen Aclesia; im Text hat er (p. 68) wieder den Namen zurückgezogen, und die in den Tafeln genannten Arten in das Genus Notarchus von Cuvier einverleibt, wohin sie nicht gehören. Die Gattung Aclesia ist später von den Malacologen und Conchyliologen meistens für ähnliche Formen, wie die ursprünglich von RANG dargestellten, angewendet worden.

Die Aclesien zeigen meistens einfache oder zusammengesetzte Villositäten oder Anhänge am Riicken so wie an den Rhinophorien und Tentakeln. Die Kiemenspalte ist kurz; im Gegensatz zu dem Verhältnisse bei den anderen Notarchiden fehlen Mantel und Schale ganz und die sonst bei den Aplysiiden unterliegenden Eingeweide zeigen sich entblösst. Der Fuss ist nicht schmal, meistens in einen nicht kurzen Schwanz verlängert. - Das Centralnervensystem wie bei anderen Notarchiden. Die glans penis ist meistens mit (weichen oder) Dornentragenden Kegelchen versehen.

Die Aclesien scheinen nur den wärmeren und besonders den tropischen Meeresgegenden an zu gehören. Als etwas mehr sichere Arten scheinen die folgenden aufgeführt wurden zu können:

I. Aclesia Pleii Rang. M. atl. occ. (Rio Janeiro).

2. Aclesia striata (Quoy et Gaim.). M. pacific.

3. Aclesia cirrhifera (Q. et $\mathrm{G}$.). M. africano-indic.

4. Aclesia impexa Bgh. M. philipp.

5. Aclesia ocelligera Bgh. M. Siamense.

6. Aclesia varicolor Bgh. n. sp. M. indic.

7. Aclesia pusilla Bgh. n. sp. M. indic.

ferner vielleicht:

8. Aclesia Savignana (Fér.).

Notarchus laciniatus Rüppell.? M. mediterr.

9. Aclesia citrina Rang. M. pacific.?

IO. Aclesia mudata Rang. M. pacific.

I 1. Aclesia limacina (Blainv.). M. mediterr.

I 2. Aclesia longicauda (Q. et G.). M. pacific.

I3. Aclesia? ocellata (Fér. (van Hass.)). MI. indic.

I. Aclesia varicolor Bgh. n. sp. Taf. III, Fig. 2. Taf. VIII, Fig. Io-I5.

Am Riffe von Kilsuin an der Westküste der Insel Kur (St. 250) wurde ein Individuum gefangen und lebend abgebildet. 
Lebend hatte das Thier eine Länge ron $3,8 \mathrm{~cm}$. bei einer Breite hinten von 2. Die Farbe war scheckig gräulich und rothbraun mit weissen Punkten.

Das a ufbewahrte Individuum war $38 \mathrm{~mm}$. lang bei einer Breite bis 17 und Höhe bis 9, die Länge der Kiemenspalte war $8 \mathrm{~mm}$. Die Farbe war durchgehends gräulich, am Rücken kamen einige schwärzliche Ringe und schwarze Punkte vor; die Fusssohle ein wenig gelblich.

Die Form war etwas abgeplattet, hinten breiter; das Hinterende gerundet, der dünne Rückenrand rundzackig; die Tentakel wie die Rhinophorien ziemlich klein; die etwas S-förmige Kiemenspalte weit nach hinten liegend, eng, mit überklappender linker Lippe, die lange Samenrille stark ausgeprägt; der Rücken ganz glatt; die breite Fusssohle mit ihrem gerundeten Hinterende den Rücken unbedeutend überragend.

Vor den Rhinophorien schimmerten die Augen stark durch, sonst nirgends die Eingeweide.

Das weisse Centralnervensystem wesentlich wie bei anderen Notarchiden.

Die Mundröhre I,5 mm. lang. - Der weisse Schlundkopf von $3 \mathrm{~mm}$. Länge. Der Gaumen wie gewöhnlich, mit den gewöhnlichen lateralen Dornentragenden Strecken; die Dornen etwa wie gewöhnlich (Fig. Io), bis O, I $2 \mathrm{~mm}$. lang. Die Lippenplatten fast farblos, schmal; ihre Elemente gewöhnlicher Art, von einen Durchmesser von 0,0055 mm. Die Raspel der Zunge gelb, mit 20 Zahnplattenreihen, ebenso viele kamen in der Scheide vor. In den Reihen wurden bis etwa 90 Platten gezählt. Die Platten gelb, die Breite der medianen 0,12 mm., die Länge des Körpers der ersten Seitenplatte war 0,09, die Höhe der (dünnen) Seitenplatten erhob sich zu O, I 2, die der äussersten betrug $0,035 \mathrm{~mm}$. Die medianen Platten (Fig. I I, I 2) von gewöhnlicher Form, mit 2 Dentikeln an jeder Seite des Hakens; die meisten Seitenplatten (Fig. I3) auch von gewöhnlicher Form, mit gabeliger Spitze und mit Dentikeln; die äusseren höher, dünner mit kleiner Gabel an der Spitze und einem Dentikel (Fig. I 4).

Die Speiseröhre weiss, $6 \mathrm{~mm}$. lang, hinten in einen kleinen Vormagen entwickelt, der gegen den Kaumagen ein starke Längsfalte zeigte. Der Ka umagen von $3 \mathrm{~mm}$. querem Durchmesser, mit $\&$ grösseren gelben Platten mit starker irisirender Axe und 7 kleineren. Der cylindrische Hintermagen 4,5 mm. lang, vorne fand sich eine Reihe von weichen Kegeln von einem Durchmesser von $0,16 \mathrm{~mm}$; in der Höhle ein Paar von der Zunge abgerissene Seitenplatten, - Die kegelförmige, grüngraue Leber $8 \mathrm{~mm}$. lang bei einer Höhe und Breite von 4.

Die gelblichweisse Zwitterdruise 2,5 mm. breit bei einer Dicke von 2; die vordere Genitalmasse bis an die Vulva $5 \mathrm{~mm}$. lang, weiss; die weisse Samenblase von 0,75 mm. Durchmesser. Der Penis etwas gebogen; die kegelförmige Glans mit Reihen von dornartigen Kegeln (Fig. 15) von einer Höhe bis O, I 4 mm., deren Spitze gleichsam aus einer dünnen Scheide hervorragte.

Diese Form scheint eher eine Aclesia zu sein als dem Notarchus an zu gehören.

2. Aclesia pusilla Bgh. n. sp. Taf. VIII, Fig. I $6-27$.

An der Meeresoberfläche, in der Nähe der Paternoster-Inseln" wurden am 28 März mehr als zwanzig Individuen dieser kleinen Form gefischt.

Sie waren von (schwach röthlich-)weisslicher Farbe; ihre Länge betrug $4-7 \mathrm{~mm}$., wovon der Schwanz, wenn nicht zusammengezogen, fast die Hälfte betrug. 
Der Kopf mit den Tentakeln und Rhinophorien wie gewöhnlich, am Grunde der letzteren schimmerten die Augen undeutlich durch. Der Körper fast kugelförmig; die Oberfläche ganz eben, ganz ohne Papillen; die Kiemenspalte ziemlich kurz, eng. Der Fuss nicht schmal, aber rom Körper mit seinen Rändern fast gar nicht vorspringend; der Schwanz lang, zugespitzt, flach (Fig. I6).

Die Individuen waren im Ganzen einander ganz ähnlich, die Eingeweide schimmerten nicht durch. Drei grössere Individuen wurden anatomisch untersucht.

Das Centralnervensystem wie bei den Notarchen und Aplysiellen, mit den visceralen Ganglien vorne zwischen den pleuralen liegend (Fig. I 7). - Die Augen von 0,06 mm. Durchmesser.

Der Schlundkopf von I,2 mm. Länge, von gewöhnlicher Form, gräulichweisser Farbe; die Raspelscheide hinten an der Unterseite vorspringend. Die Mundhöhle gräulichweiss, die Gaumendornen von gewöhnlichen variablen Formverhältnissen (Fig. I9), bis 0,05 mm. lang und von einer Höhe bis 0,0I6. Die schwach-gelblichen Mandibelplatten etwa $0,20 \mathrm{~mm}$. lang bei einer Breite bis 0,30 , von etwa I 7 Reihen von ziemlich niedrigen, zusammengedrückten Säulen (Fig. I8) von einer Höhe bis $0,04 \mathrm{~mm}$. gebildet. In der fast farblosen Raspel mit sammt ihrer Fortsetzung schienen 25 Zahnplattenreihen vorzukommen, und in den Reihen zu jeder Seite der medianen 25 laterale Platten. Die medianen Platten (Fig. 20, $2 \mathrm{I}$ ) etwa 0,09 mm. breit bei einer Höhe (bis an die Hakenspitze) von 0,04 ; die lateralen Platten erreichten eine Höhe bis 0,09 mm., die drei äussersten maassen $0,05-0,04-0,02 \mathrm{~mm}$. Die ziemlich langbeinigen medianen Platten zeigten an jeder Seite des spitzen Hakens zwei spitze Dentikeln. Die innersten Seitenplatten mit plumpem gegabeltem Haken und einem spitzen Dentikel am Grunde derselben (Fig. 2 I), die folgenden zeigten die Spitze des Hakens kurzgabelig und unterhalb derselben $2-4$ Dentikel (Fig. 22-24), die Platten des äusseren ungefähren Drittels der Reihen waren alle ganz fein denticulirt (Fig. 25, 26).

Die langen, weissen Speicheldrüsen wie gewöhnlich.

Der Kaumagen von gewöhnlicher Form, von I mm. Durchmesser, mit dem gewöhnlichen Gürtel von hellgelblichen Platten, die einen Durchmesser bis etwa $0,4 \mathrm{~mm}$. erreichten bei einer Höhe bis 0,25. Seine Höhle war mit Algen gefüllt. - Die Leber gelblichgrau.

In den Läppchen der Zwitterdrüse reife Geschlechtselemente. - Der (zurückgezogene) Penis (Fig. 27) etwas zusammengebogen, mit langer, kegelförmiger Glans von einem Durchmesser von $0,18 \mathrm{~mm}$., deren Oberfläche ganz glatt (ohne Höcker) war.

\section{Aplysiella P. Fischer.}

Aply'siclla P. Fischer. Descr. d'une espèce nouvelle du genre Phy'llaply'sia. Journ. de conchyl. I872, p. 295-296.

Aplysiella. R. BerGH, Malacolog. Unters. V, I902, p. 362-367.

Aplysiella. R. BERGH, Gasteropoda opisthobranchiata. The Danish expedition to Siam I S9g-rgoo. 1902, p. 164-168.

Dolabrifera Gray? A list of Moll. Proc. zool. soc. I847, p. I6z.

Forma corporis in universum quasi ut in Aplysiis propriis attamen nonnihil elongata, postice nonnihil latior, antice (capite et collo) angustior. Scutum palliale cum testa non deest. 
Die Aplysiellen, die vielleicht (vgl. 1. c. V, p. 362) mit den Dolabriferen von Gray identisch sind, gleichen im Äusseren so ziemlich den ächten Aplysien. Von den verwandten Aclesien unterscheiden sie sich durch das Vorhandensein eines Mantelschildes mit Schale.

Eine kleine Reihe von zum Theil zweifelhaften Arten ist vom Mittelmeere und dem Indischen Ocean angegeben.

I. Aplysiclla Pasirana Bgh. n. sp. Taf. V, Fig. I. Taf. VIII, Fig. 38-47.

Taf. XII, Fig. I 5 .

Am Riffe von Pasir Pandjang an der Westküste von Binongka (St. 220) wurde ein Individuum gefangen und lebend abgebildet.

Das lebende Thier hatte eine Länge von $4,5 \mathrm{~cm}$. bei einer Breite (nach hinten) von I, 8 ; die Farbe der Rückenseite war braun, in der Mitte weiss und dazu kamen noch zerstreute weisse Flecken vor; der Grund der Rhinophorien war weiss und ebenso der Körperrand.

Das a ufbewahrte Individuum hatte eine Länge von 2,8 bei einer Breite bis I, 6 und Höhe von $0,7 \mathrm{~cm}$; die Kiemenspalte von $5 \mathrm{~mm}$. Länge. - Die Farbe durchgehends hell gelblichweiss; median am Ruicken fanden sich abei 4 hell graubraune rundliche Fleckchen von einem Durchmesser bis I,5 mm., das vorderste zwischen den Rhinophorien liegend; neben dieser Reihe kam jederseits eine laterale von kleineren und mehr verwischten Fleckchen vor, und gegen den Rückenrand hin einige zerstreute. - Vor den Rhinophorien schimmerten die Augen stark durch, vor der Schale ein gräuliches Eingeweide.

Die Form länglich-eiförmig, ziemlich niedergedrückt, nach vorne ziemlich verschmälert, hinten gerundet, mit breiter Fusssohle (von dünnen, gräulichen, stark zerstückelten Längslinien durchzogen). Die rechte Lippe der kleinen Kiemenspalte dick, die linke dünn, die Schale fast deckend. Der Rücken ganz glatt.

Die kalkweisse Schale $5,5 \mathrm{~mm}$. lang bei einer Breite bis 3 ; ziemlich abgeplattet, vorne breiter und etwas ausgerandet; die nach unten umgebogene Nuclealpartie ziemlich stark, mit einem kleinen knotenartigen Vorsprung (Fig. 38, 39).

Das Centralnervensystem (Fig. 40) war wie bei anderen Notarchiden. Die Otocysten von einem Durchmesser von $0,08 \mathrm{~mm}$, mit Otokonien gewöhnlicher Art prall gefullt. Die graubraunen Flecken der Haut zeigten meistens eine centrale Vertiefung mit einer kleinen Öffnung.

Die Mundröhre halb so lang wie der Schlundkopf. Dieser letztere $3,5 \mathrm{~mm}$. lang, schmutzig hell gelblich; die bräunlichen Mandibelplatten ziemlich schmal, von einer Breite von 0, I $4 \mathrm{~mm}$., ihre stabförmigen Elemente von einem Durchmesser (Fig. 42) von 0,007 mm. Die Dornen der zwei Gaumenbänder von gewöhnlichen Formverhältnissen (Fig. 4I), von einer Länge bis $0,10 \mathrm{~mm}$. In der gelblichen, nach vorne sehr zugespitzten Raspel 30 Zahnplattenreihen; von welchen die vordersten I 6 sehr incomplet, in der ziemlich starken Scheide deren noch I 3 . In den Reihen kamen bis etwa I I Zahnplatten vor. Diese letzteren fast farblos; die Breite der medianen betrug $0,12 \mathrm{~mm}$; die Höhe der innersten lateralen etwa 0,08 , durch die Reihe erhob sich die Höhe dieser Platten bis zu 0,14 , um nach aussen bis zu o,o8 zu sinken. Die medianen Platten (Fig. 43) mit 2 Dentikeln zu jeder Seite des nicht ganz schmalen Hakens; 
die lateralen (Fig. $44-46$ ) mit zerklifteter Spitze und einem Dentikel am Aussenrande, die inneren (Fig. 44) plumper, sie werden allmählig schmächtiger (Fig. 45), mit kurzerer Klüft, die äussersten nur mit Andeutung von solcher und ohne Dentikel (Fig. 46).

Die langen weissen Speicheldrusen wie gewöhnlich, an der Einschnirung hinter dem Vorderende des Kaumagens geheftet.

Die weissliche Speiseröhre $8 \mathrm{~mm}$. lang, in der Mitte etwas erweitert. Der grauc $\mathrm{K}$ a umagen $3 \mathrm{~mm}$. lang bei einem Durchmesser von 3 ; derselbe zeigte in gewöhnlicher Weise die gelben schillernden Kauplatten, I o grosse und + kleinere; dieselben erreichten eine Höhe bis I,5 mm., zeigten die feinen Querlinien ungewöhnlich stark entwickelt (Fig. I5) Der Hintermagen $4 \mathrm{~mm}$. lang bei einem Durchmesser von 2.5; vorne kamen 2 Reihen von in Allem 25 rundlichen Facetten vor von einem Durchmesser bis etwa 0,25 mm. Der (wegen seines Inhalts) weissliche Darm sich in gewöhnlicher Weise durch und um die dunkelgrine Leber windend. Diese letztere $8 \mathrm{~mm}$. lang bei einem Durchmesser von 5 und 5 , clunkel grin, auf Schnitten schwärzlich dunkler.

Der Pen is 4,5 mm, lang; die in Reihen stehenden Kegel (Fig. 47) desselben am Grunde von einem Durchmesser von $0,05 \mathrm{~mm}$, ihre Höhe bis $0,06 \mathrm{~mm}$. betragrend.

\section{Aplysiella viridis Bgh. n. sp. Taf. III, Fig. 3. Taf. VIII, Fig. 28-37.}

Am Ankerplatz östlich von Sailus Besar, Paternoster-Inseln (St. 315) wurde ein Ex, gefischt und lebend abgebildet.

Im Leben war dasselbe $30 \mathrm{~mm}$. lang bei einer Breite bis 7. Die Farbe der Rückenseite war hell grün mit deutlich umgrenzten Knötchen, am Vorderrücken ein submedianer gelblicher Längsstreifen (die Genitalfurche), die Mantelplatte weisslich; die Rhinophorien gelb.

Das a ufbewahrte Individuum war $20 \mathrm{~mm}$. lang bei einer Breite bis 7 und Höhe bis $5.5 \mathrm{~mm}$., die Höhe der Rhinophorien war 3, die Länge der Kiemenspalte $5 \mathrm{~mm}$. - Die Farbe durchgehends grau; die feinen Bäumchen des Rückens (Fig. 28) farblos; aussen am Grunde der Rhinophorien schimmerten die schwarzen Augen stark durch.

Die ziemlich gewölbte Rückenseite war überall mit kleinen und kleinsten Knötchen bedeckt, noch dazu kamen jederseits neben dem oberen Rand der Fussflugel 2 ( $2 \mathrm{~mm}$. hohe) feine Bäumchen vor und (median) am Hinterrücken mehrere. Die Rhinophorien doppelt so hoch wie die Tentakel; die Genitalfurche sehr ausgeprägt. Die Kiemenspalte rundlich, die rechts etwas dreieckig über die Kieme vorspringende Mantelplatte etwas weisslich; aussen unter dem Hinterrande derselben die Analpapille; die Kieme $4 \mathrm{~mm}$. lang bei einer Breite von 2 und Höhe von I,5, mit etwa Io Blättern. Der Fuss ziemlich breit, vom Rückengebräm nur wenigg geschieden und iberragt; vorne gerundet und etwas mehr geschieden.

Im Mantelschilde war keine deutliche (hornige) Schale nachzuweisen, und Essigsäure gab kein Aufbrausen.

Das Centralnervensystem wie bei anderen Aplysiellen.

Der Schlundkopf von gewöhnlicher Form, von bräunlichgrauer Farbe, 2 mm, lang; die hell schmutziggelben Mandibelplatten von vielen Reihen von Säulchen gebildet, die eine 
Höhe bis 0,06 mm. erreichten (Fig. 29); die kleineren schienen (mitunter) an einem Rand ganz fein denticulirt. Die Gaumendornen wie gewöhnlich. Die schmutzig bräungelbliche Raspel enthielt I3 Zahnplattenreihen, in der Scheide fanden sich deren noch I3, die Gesammtzahl der Reihen somit 26; zu jeder Seite der medianen Platten schienen bis 40 laterale vorzukommen. Die Zahnplatten hell gelblich; die medianen bis $0,12 \mathrm{~mm}$. breit, die lateralen bis $0,2 \mathrm{~mm}$. hoch; die drei äussersten von 0,05-O, I I-O, I $4 \mathrm{~mm}$. Höhe. Die medianen Platten (Fig. 30) mit zwei spitzen Dentikeln an jeder Seite des ziemlich plumpen Hakens; die innerste Seitenplatte (Fig. 30) mit 2-3 Dentikeln an jeder Seite des abgestutzten oder. schwach geklüfteten Hakens (Fig. 31), nach aussen wurden die Platten schmächtigè, mit geklüfteter Spitze, mit einem spitzen Dentikel des einen und mehreren mehr gerundeten des anderen Randes (Fig. 32, 33); die äussersten waren duinn, ohne Dentikel (Fig. 34, 35). Abnorme Zahnplatten fehlten nicht (Fig. 36, 37).

Die dünnen, weisslichen Speicheldrüsen wie gewöhnlich. - Die Speiseröhre und der Vormagen $3 \mathrm{~mm}$. lang. Der Kaumagen 2,5 mm. lang bei einer Breite von 3, mit 7 grossen und 8 kleinen Platten; die Platten gelb, mit grosser, stark irisirender Axe, bis I mm. hoch. Der Hintermagen $3 \mathrm{~mm}$. lang. - Die hintere Eingeweidemasse (Leber) kurz kegelförmig, $4,5 \mathrm{~mm}$. lang; die graue Leber zum grössten Theil von dem dünnen Lager der gelblichen Zwitterdrüse eingehüllt.

Trotz des (zweifelhaften) Fehlens einer Schale im deutlichen Mantelschilde gehört diese Form doch ziemlich sicher den Aplysiellen an.

\section{Phyllaplysia P. Fischer.}

P. FISCher, Descr. d'une espèce nouv. du genre Phyllaplysia. Journ. de conchyl. XX, I872, p. 295-30I, PI. XV, Fig. I-3.

R. IERGH, Malacol. Unters. IV, I 900 , p. ISI-IS5, 368-370.

Corpus magnopere depressum, fissura branchialis sat brevis.

Testa ut in Aplysiis propriis.

Durch ihre Form, die grosse Abplattung, unterscheiden sich die Phyllaplysien von allen anderen Aplysiiden. Sonst stimmt die Gattung in Bezug auf Schale und den Bau des Schlundkopfes mit den anderen Gattungen der Familie. Die:

I. Phyllaply'sia depressa (Cantr.), und

Phyllaplysia ornata (Desh.) des Mittelmeeres, und die

Phyllaplysia Lafonti Fischer, so wie

Phyllaplysia Paullini Mazzarelli des östlichen atlant. Oceans

gehören wohl einer einzigen Art an; von derselben scheinen verschieden:

2. Phyllaplysia pacifica Bgh. M. pacific.

3. Plyyllaplysia Taylori Dall. M. pacific.

4. Phyllaplysia inornata Bgh. M. indic. 
1. Phyllaplysia inornata Bgh. n. sp. Taf. XII, Fig. 7-14.

Das mit der Archidoris Kurana zusammen bei der Insel Kur gefangene Individum war $8 \mathrm{~mm}$. lang bei einer Breite von 4 und Höhe von $\mathrm{r}, 5$; weisslich, ganz durchsichtig, mit durchschimmernden Eingeweiden.

Die Rhinophorien und Tentakel wie gewöhnlich (Fig. 7); an Grunde jener die deutlichen schwarzen Augen. Der ganz glatte Rücken allmählig in den Fuss übergehend, der Rand scharf: die Samenfurche sehr ausgeprägt. Die Kiemenspalte $3 \mathrm{~mm}$. lang; am Vorderende die gelbliche Genitalpapille; fast durch die hintere Hälfte erstreckte sich die feine weissliche Kieme, oberhalb derselben hinten die Analpapille. Es fand sich eine kleine, äusserst dünne, membranartige, schwach gelbliche Schale ron etwas kurzer, sonst gewöhnlicher Form (Fig. S), mit wenig vorspringender Nuclealpartie.

Die Augen von o, I2 mm. Durchmesser. Die Haut ohne Spur von Papillen.

Der Schlundkopf. I,25 mm. lang; die etwas länglichen bräunlichen Mandibelplatten von einer Länge bis $0,16 \mathrm{~mm}$., ihre hakenartigen Elemente (Fig. 9) von einer Höhe bis o,or mm. In der schwach gelblichen Raspel kamen is Zahnplattenreihen vor, in der Scheicle noch I5, von welchen 3 unreif, die Gesammtzahl der Reihen somit 33. Zu jeder Seite der medianen wenigstens 40 laterale Platten. Die Zahnplatten fast farblos, die Breite der medianen 0,06 mm. Die Platten (Fig. IO-I2) von gewöhnlicher Form; die medianen mit einem (selten 2) Dentikel jederseits am Grunde des Hakens (Fig. IO); die lateralen (Fig. I I, I 2) auch wesentlich von gewöhnlicher Form, die äussersten meistens von einfacher Hakenform.

Der kugelförmige $\mathrm{Kaumagen}$ zeigte vorne und hinten die bis wenigstens $0,10 \mathrm{~mm}$ hohen kegelförmigen Stachel (Fig. I 3) und sonst die zwei Reihen von grossen bis 0,37 mm. hohen, gelben, durchsichtigen Pyramiden (Fig. I4). - Die oben und unten stark durchschimmernde Leber bräunlich (Fig. 7).

Hinter der Leber die weissliche Zwitterdrüse; in ihren Läppchen reife Geschlechtselemente. Die vordere Genitalmasse weisslich, die Glans penis schien glatt.

Rechts am Boden der Kiemenhöhle ein starkes Drüsenlager wie bei der Ph. pacifica.

Vielleicht is diese Form wirklich von der des Mittelmeeres und des Atlantischen Meeres so wie von der P/2. pacifica verschieden, viel näher als diesen steht sie noch der P/2. Taylori. 


\section{CEPHALASPIDEA.}

\section{Piiminidina.}

\section{Philine Ascan.}

Philine Ascanius. Vetensk Ak. Handl. 1772, p. 329.

Lobaria O. Fr. Müller. Zool. Dan. prodr. I776, p. XXIX, 226.

Lobaria O. Fr. Muiller. Zool. Dan. III, 1788, p. 30-31, Tab. C, Fig. I-5.

Bullaca Lam. Syst. des anim. s. v. 1801, p. 63.

Philine Asc. R. Bergir, Malacol. Unters. V, 1901, p. 274(-2\$5).

Eine Reihe von "Arten" ist auch aus dem Indo-Chinesischen und dem Australischen Meere (vgl. 1. c. p. 285 Note) angegeben, die zum Theil wohl identisch sind, zum grossen Theils sich ganz unbestimmbar zeigen werden.

\section{Philine quadripartita Asc.}

R. Bergil, 1. c. V, I90I, p. 276-285, Taf. XXIII, Fig. 15-35; Taf. XXIV, Fig. 2-5; Taf. XXVI, Fig. I-g.

Ein bei Elat an der Westkiiste der Insel Hoch-Kei (St. 262) gefangenes Individuum war durchgehends von weisslicher Farbe, nur die Kieme bräunlichgrau. Die Länge betrug $3,8 \mathrm{~cm}$. bei einer Breite bis 1,7 und einer Höhe (durch den Hinterschild) bis 1,1 ; die Länge des Vorderschilcles war 2, die des Hinterschildes $1,8 \mathrm{~cm}$; die Länge des Fusses war I,5 cm., die Höhe der Fussflügel $5 \mathrm{~mm}$., die Länge der Fläche hinter dem Fuss $12 \mathrm{~mm}$; die Kieme $6 \mathrm{~mm}$. lang bei einer Breite von 4,5. - Auf dem Riff bei Banda wurden ferner 3 ganz schlecht conservirte und beschädigte Exx. erbeutet.

Die Formverhältnisse die gewöhnlichen; der Hinterrand des Fusses wie gewöhnlich schrïge. - Die dïnne kalkweisse $\mathrm{Schale}$ war in viele Stuicke zerbrochen, schien aber von typischen Verhältnissen.

Der schwach gelblich-weisse Schlundkopf $5 \mathrm{~mm}$. lang bei einer Breite von 3,5 und Höhe von 3, mit vortretender Raspelscheide. Die dunkel braungelbe Raspel enthielt i 6 Zahnplattenreihen, in der Scheide deren noch 12, von welchen die hintersten zwei unreif; die Gesammtzahl der Reihen somit 28. Die gelben Zahnplatten bis o,8 mm. lang, von typischer Form. - Die weissen Speicheldriisen wie gewölnnlich.

Der Kaumagen von gewöhnlichen Lage- und Formverhältnissen, I $4 \mathrm{~mm}$. lang bei 
einer Breite von 7,5 und Höhe von $\delta \mathrm{mm}$. Dic Magenplatten an der Aussenseite gelb, an der inneren wie gewöhnlich; die grossen $14 \mathrm{~mm}$. lang bei einer Breite von 6 und ciner Dicke von 2, die kleine $10 \mathrm{~mm}$. lang bei einer Breite von 3,5; die zwei Gruben der Aussenseite tief, bis 2,25-2,5 mm. lang, die entsprechenden Öfnungen der Innenscite klein. - Der Inhalt dieses Mages und des Darmes war unbestimmbare thicrische Masse mit Schalentrimmern und Sandkörnern vermischt.

Die braungraue Leber von $9 \mathrm{~mm}$. Länge.

Die gelblichweisse Zwitterdrüse $8 \mathrm{~mm}$. lang. Die gelblichweisse vordere Genitalmasse von typischer Form, $12 \mathrm{~mm}$. lang, die kugelformige Spermatotheke von $4 \mathrm{~mm}$. Durchmesser. Der etwas gelbliche Penissack 3,5 mm. lang, sein innerer Bau konnte wegen des Erhärtungszustandes nicht eruirt werden; der Knäuel der gelben Prostata-Windungen sehr gross; die kugelförmige Drüse kurzgestielt.

Im Meere von Siam hat Dr. Mortensen mehrere Exemplare einer Philine gefischt, die sicherlich mit der typischen nordischen identisch ist ${ }^{1}$ ) und mit der hier untersuchten ubereinstimmt. Die verschiedenen anderen aus dem Indo-Chinesischen Meere beschriebenen "Arten" von Plitine ${ }^{1}$ ) scheinen nur durch die Schale bekannt, welche ja wie innere Schalen überhaupt ziemlich Form-variabel ist ${ }^{5}$ ).

Philine quadripartita Ascan. var. Taf. IX, Fig. 5 .

Am Ankerplatz an der Nord-Ostseite der Insel Daram, östlich von Misool (St. r66) wurden zwei Individuen gefischt.

Dieselben stimmten in Grösse-, Form- und Farben-Verhältnissen vollständig mit einander überein; sie waren Io mm. lang bei einer Breite von 8 und Höhe von $4 \mathrm{~mm}$; sie waren weiss, aber ungewöhnlich durchscheinend, so dass Schlundkopf und besonders der Kaumagen sehr deutlich waren. Die Formverhältnisse waren die gewöhnlichen; die Schale aber ungewöhnlich flach, ganz dünn und sehr zerbrechlich.

Der Schlundkopf I,5 mm. lang; an der Raspel der Zunge 8-9 und in cler Scheide 10-I I Zahnplatten gewöhnlicher Art, die Gesammtzahl der Platten somit 18-20. Der Kaumagen $4 \mathrm{~mm}$. lang bei einem Durchmesser von 2,5; die Kauplatten kastanienbraun, kaum halb so dick (Fig. 5) wie gewöhnlich und biegsam, schmaler und mit mehr ausgezogenen Enden, das Verhältniss war bei beiden Individuen ganz dasselbe.

2. Philine mbra Bgh. n. sp. Taf. IX, Fig. 6-8.

An der Westseite der Insel Taam (St. 253) wurde am Io Dec. ein Individuum gefangen; ferner an der St. 69 eins und an Stat. $25 \mathrm{l}$ zwei.

1) The Danish expedition to Siam, I. R. Hergi, Gastcropoda opisthobranchiata. 1902, p. 20-21 (178-179).

2) Vgl. meine Malacolog. Unters. VI, 1902, p. 285 . 
Das erste hatte, in Formol bewahrt, eine Länge von $2,4 \mathrm{~cm}$. bei ciner Breite von 1,5 und einer Höhe ron $0,7 \mathrm{~cm}$; die Länge des Stirn-oder Vorderschildes war $13 \mathrm{~mm}$. bei einer Breite hinter dem Vorderende von I I, hinten von 7 ; der Hinter-oder Mantelschild hatte eine Länge von $10 \mathrm{~mm}$. bei einer Breite vorne von 7 , hinten von $9 \mathrm{~mm}$; die Fusssohle war I5 mm. lang bei einer Breite von 14, die Höhe der Epipodien an ihrer Mitte $5 \mathrm{~mm}$. - Die weisse, dünne, aber harte und sehr zerbrechliche Schale schien eine Länge von 7,5 bei einer Breite ron $7 \mathrm{~mm}$. gehabt zu haben. - Die Farbe des Thieres war oben wie unten durchgehends rothbraun, die niedrigen Körperseiten ein wenig heller.

Die Formverhältnisse waren wie bei der typischen Art, der Hinterschild schien nur etwas kürzer zu sein. Am Vorderschilde eine schwach mediane Längsfurche. Am Hinterschilde konnte eine Öffnung nicht nachgewiesen werden; sein Hinterrand ragt hinten, in der Mitte etwas ausgekerbt, über das Hinterende der Schale hervor und schlägt sich in die gerundete drei- oder viereckige Fläche über, die hinter dem Fusse die Unterseite des Körpers bildet, ron jenem durch einen kleinen Zwischenraum geschieden. Aus der kleinen Kiemenhöhle ragt die kleine, bei einer Dicke von fast $2 \mathrm{~mm}$., $5 \mathrm{~mm}$. lange, rothbraune Kieme hervor. Die Analpapille, die Vulva, und die Samenrille wie gewöhnlich. Das Rhinophor etwa r,5 mm. lang, mit den gewöhnlichen senkrechten Falten. Der Hinterrand des Fusses schräge, von rechts nach links und nach hinten abgeschrägt.

Die Mundröhre rothbraun, I mm. lang. Der fast $2 \mathrm{~mm}$. lange Schlundkopf rothbraun, mit stark vorspringender Raspelscheide. Die starke Zunge mit dunkelbrauner Raspel, die I I Zahnplaitenreihen enthielt, in der Scheide kamen i 2 vor, von welchen die zwei hintersten unfertig, die Gesammtzahl der Reihen somit 23. Die Rhachis nicht schmal. Die Zahnplatten wie gewöhnlich sichelförmig (Fig. 6), deren der typischen Art ziemlich ähnlich, unten gelbbraun, oben fast farblos, eine Höhe bis 0,5 mm. erreichend, mit einer langen Reihe von starken und spitzen Dentikeln.

Die röthlichgelben Speicheldrüsen ein wenig länger als bei der typischen Art, I,25 mm. lang.

Die kurze Speiseröhre in den kleinen Vormagen von einem Durchmesser von $3 \mathrm{~mm}$. iibergehend. Der starke $\mathrm{K}$ a umagen $5,5 \mathrm{~mm}$. lang bei einem Durchmesser in der Mitte von 3,25, gräulich, auf der unteren medianen Kauplatte in situ ruhend. Die 3 Kauplatten (Fig. 7 ) hatten eine Länge von $4,5 \mathrm{~mm}$., stimmten in Form- und Farbenverhältnissen fast mit denen der typischen Art, nur waren sie plumper, ihre Innenseite rothbraun und die Löcher, die die Platten durchbohren, im Ganzen wie bei jener, erreichten bei den lateralen eine Länge von $0,75 \mathrm{~mm}$. Der fast kugelförmige Hintermagen hatte einen Durchmesser von 2,5 $\mathrm{mm}$. Der Inhalt der Magen war aus kleinen Bivalven, meistens mehr oder weniger zerbrochenen Bruchstuicken von kleinen Gasteropoden-Schalen, mit Sandkörnchen, Diatomeen. Polythalamien und animalischer unbestimmbarer Masse vermischt, gebildet. Der Darm wie bei der typischen Art. mit ähnlicher Masse wie der Magen gefullt. - Die Leber braungrau.

Der rothbraune Penissack $2 \mathrm{~mm}$. lang, an seinem Hinterende heftet sich ein starker Retractor; in denselben mindet die lange, rohrförmige, aufgerollte Prostata (Fig. $8 b$ ), die doch kiurzer als bei der typischen Art war, und die langstielige kleine kugelförmige Drüse (Fig. $\delta c$ ). 
3. Philine clegans Bgh. n. sp. Taf. IX, Fig. 9-i3.

Am I6 Febr. wurde an dem Ankerplatz östlich von Dangar Besar, Salch-Bai (St. 31 . . ein Individuum aus einer Tiefe von $36 \mathrm{M}$. gefischt.

Aufbewahrt hatte dasselbe eine Länge von 15 bei einer Breite von 6 und einer Höhe von 4,5 mm.; die Länge des Vorderschildes war 7 bei einer Breite von 5, die Länge des Hinterschildes mit der Schale fast $\&$ bei einer Breite von $6 \mathrm{~mm}$; die Länge des Fusses I I bei einer Breite von 6, die Höhe der Fussflügel 2,5 mm. - Die Farbe war gelblichweiss, die Schale kalkweiss. Hinten am Vorderriicken, in der Furche zwischen den Schildern, hinten an den Körperseiten und in der Mitte der Fusssohle schimmerte ein Eingeweide (der Kaumagen) schwarzblau durch, an der letzteren noch dazu rechts ein gebogenes weissliches (die Muskelmasse zwischen zwei Magenplatten), median noch ein langer weisser Faden (Penismuskel).

Die Formverhältnisse die gewöhnlichen. Vorne, oberhalb des Aussenmundes jederseits eine feine Pore, unter dem Rande des Vorderschilds die Rhinophorien; median verläuft eine feine Furche durch die Länge des Schildes. Das Hinterende des Hinterschildes wie gewöhnlich: ein kleiner medianer Knoten wie bei der typischen Art konnte nicht nachgewiesen werden, ebenso wenig eine Öffnung oben am Mantelschilde. Die Kieme 4,5 mm. lang, nur ihr letzteres Drittel ragt frei hervor. Der Fuss wie gewöhnlich, der Vorderrand ohne Furche, der Hinterrand schräg.

Die Schale $8 \mathrm{~mm}$. lang bei einer Breite von 6, ziemlich stark erhärtet, aber sehr brüchig; ihre Form war, insoweit beurtheilt werden konnte, einigermaassen wie bei der typischen Art; die Nuclealpartie (Fig. 9) aber gleichsam eingesunken.

Das Centralnervensystem war typisch. Die Augen von einem Durchmesser von fast $0,08 \mathrm{~mm}$, ihr Pigment nicht reichlich.

Die Mundröhre war von einem starken Drüsenlager eingefasst. Der Schlundkopf von gewöhnlichen Formverhältnissen, $2 \mathrm{~mm}$. lang. Die Raspel der $\mathrm{Zunge} \mathrm{schwach} \mathrm{gelblich,}$ mit 8 Zahnplattenreihen, in der Scheide kamen 9 vor, von denen zwei unentwickelt, die Gesammtzahl der Reihen somit I 7. Die sichelförmigen Zahnplatten (Fig. Io) farblos, von einer Höhe von $0,28 \mathrm{~mm}$., von Form fast wie bei der typischen Art, mit einer ähnlichen langen Reihe von spitzen Dentikeln.

Die Speicheldrüsen kurz, keulenförmig.

Die Speiseröhre oberhalb ihrer Mitte zu einem dünnwandigen Sack von $3 \mathrm{~mm}$. Durchmesser erweitert. Der Kaumagen 5,5 mm. lang bei einem Durchmesser von 4, ein wenig rechts umgefallen, doch mehr an der unteren Platte ruhend, gegen die in situ fast sammtschwarzen Kauplatten contrastirten die zwischen liegenden, stark sehnenglänzenden, an den Rändern bläulich irisirenden Muskelmassen; die leere Magenhöhle hatte in der Mitte einen Durchmesser von 1,5 mm. Die Kauplatten waren sehr dunkel kastanienbraun; an der Aussenfläche eben, mit starken, etwas helleren Zähnchen an der Rändern (Fig. I I), welche von den erwähnten irisirenden Säumen gedeckt wurden (Fig. I2, I3); die abgenutzte, etwas längliche Mittelpartie der Innenfläche war weisslich. Die rechte Kauplatte war $5 \mathrm{~mm}$. lang, etwas eiformig (Fig. I $a$ ), an der freien Fläche etwas gewölbt, längs den Ründern etwas vertieft; die linke Platte 
(Fig. I I b) war ein wenig länger als die rechte, kurz sichelförmig, etwas gebogen, an der Aussenseite etwas ausgehöhlt; die dritte, die untere Platte (Fig. I1 c) war etwas kürzer als die anderen, 3,5 mm. lang, das Vorderende mehr zugespitzt, die Aussenseite ziemlich stark kahnartig ausgehöhlt, der Kauhöcker ragt stärker als bei den zwei anderen Platten hervor. - Die rohrartige Fortsetzung des Kaumagens $4 \mathrm{~mm}$. lang. - Die Leber $5 \mathrm{~mm}$. lang bei einer Breite von 3 und einer Dicke von 1,5, grünlichgrau.

Die Blutdrüse gelblichweiss, länglich, so lang wie das Pericardium.

Die hinter der Leber und an dem hinteren Theil der Oberseite derselben liegende

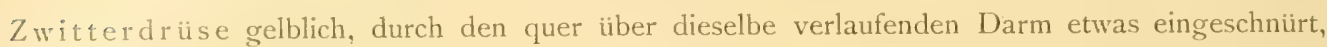
$5 \mathrm{~mm}$. lang; in ihren Läppchen reife Geschlechtselemente. Der Zwitterdrisengang einen ziemlich grossen Knäuel von Windungen bildend, dann nach vorne längs der Schleim-Eiweissdrüse verlaufend. Die sackförmige Spermatotheke 1,5 mm. lang, bräunlich; die Spermatocyste ebenso lang, stundenglasförmig, weisslich. Die Schleim-Eiweissdrüse wesentlich wie bei der typischen Art, weisslich, $6 \mathrm{~mm}$. lang bei einer Höhe von 3. Die Samenrille sehr ausgeprägt. Der Penissack weisslich, I,5 mm. lang und oben von derselben Breite; an dem vorderen Theil desselben heftet sich der lange, aussen durchschimmernde, von dem Diaphragma abdominale entspringende Retractor. An dem Scheitel des Sacks befestigt sich die Prostata, die kugelförmige Drüse und ein Nebensack. Die Prostata bildet einen grossen Knäuel von Windungen; die kugelförmige Drüse hatte einen Durchmesser von $0,30 \mathrm{~mm}$., ihr Gang war etwa 1,20 mm. lang; der Nebensack schien etwa halb so lang wie der letzterwähnte Gang. Die Glans penis schien wie bei der typischen Art hammerförmig zu sein.

Die Art wird durch ihre eigenthümlichen Magenplatten leicht wieder zu erkennen sein.

\section{Gastropteridae.}

Die äusserlich sehr eigenthümlich ausgeprägte Gruppe umfasst nur die Gattung Gastropteron.

\section{Gastropteron Kosse.}

R. Bergh, Die Gattung Gastropteron. Zool. Jahrb., VII, I893, p. 28 ז-308, Taf. 16, I7.

Diese durch die kolossalen Fussflügel besonders ausgeprägte und so leicht kenntliche generische Gruppe enthält bisher als Arten nur den:

I. Gastropteron Meckeli Blv. M. mediterr., atlant. or.

2. Gastropteron pacificum Bgh. M. pacific. bor.

3. Gastropteron Sibogae Bgh. n. sp. M. indic.

1. Gastroptcron Sibogae Bgh. n. sp. Taf. IX, Fig. 14-17.

Am ig Febr. wurden am Ankerplatz östlich von Sailus Besar, Paternoster-Inseln (St. 316 ) 
S Individuen dieser Art gefangen und (ausnahmsweise) in Alkohol aufbewahrt. Die zwei grössten wurden anatomisch untersucht.

Die Länge der Individuen variirte von $10-20-26 \mathrm{~mm}$. Bei der Lïnge der zwei grössten von $26 \mathrm{~mm}$. war die Breite bei ganz ausgeschlagenen Fussfligeln $40 \mathrm{~mm}$., dic Lïnge dieser letzteren war 24 bei einer Dicke am Grunde von 3; die Länge des Vorderschildes war 7 mm. bei einer Breite bis 8 , das mitunter fast Sipho-artig zusammengebogene Hinterende $2,5 \mathrm{~mm}$. lang; der Hinterkörper $10 \mathrm{~mm}$, breit bei einer Höhe von 9; der eigentliche Fuss $22 \mathrm{~mm}$. lang bei einer Breite von ro, die Länge des Schwanzes I $2 \mathrm{~mm}$; die Kieme 8, die Analpapille I,5, die (zusammengezogene) Peitsche $3 \mathrm{~mm}$. lang. - Die Farbe war (jetzt) durchgehends weiss; der Vorderrand des Stirnschildes und die Rhinophorien gelb; die Kieme gelblich, und die Analpapille meistens grau, die Vulva gelb. Innerhalb des Mantelgebräms schimmerten durch: die gelbliche Blutdriise, mehrere Windungen des grauen Darms mit der gelblichen Leber und hinten die gelbe Zwitterdruise.

Die Formverhältnisse waren wie früher bei anderen Arten beschrieben. Ganz vorne dicht unter dem Rande des Vorderschildes (Fig. I 4) das ovale, längs der Mitte etwas vertiefte, besonders an den Rändern quergestreifte und gelbe Rhinophor, hinter demselben fängt ein gelber schmaler oder breiter Streifen an, der sich bis an den Grund des Hinterendes des Schildes fortsetzt (Fig. I 4). Der kurz wurstförmige längere Hinterkörper wie früher beschrieben, so auch die Kieme (mit ihren etwa 20 Blättern), deren hinteres Drittel gelöst ist, und die ziemlich dicke Analpapille, die Nierenplatte oberhalb der letzteren yrau oder nur als einfache Pore sichtbar. Die Vulva und die Samenrille wie gewöhnlich; bei 5 der grösseren Individuen ragte die Vorhaut mit der Glans $2-3 \mathrm{~mm}$. frei hervor. Nedian am Schwanze die gelbliche grosse Schwanzdrüse ganz wie früher beschrieben, aber weniger deutlich ausgeprägt.

Die Schale schien sich ganz wie früher beschrieben zu verhalten, aber hatte keine verkalkte Spira.

Das leicht zu untersuchende Centralnervensystem wie früher beschrieben. So auch die aussen nie durchscheinenden $A$ ugen und die Ohrblasen; das Osphradium war nicht kennbar ausgeprägt.

Die Nundröhre I,5 mm. lang, von starkem Drüsenlager umfasst. - Der Schlundkopf $4 \mathrm{~mm}$. lang bei einer Höhe von 3 und einer Dicke von 2,5, von Form und Bau wie früher beschrieben. Die Lippenscheibe von einer dicken Cuticula überzogen. Die bräunlichgelben Mandibelplatten kïrzer und mehr dreieckig als in der typischen Art, ihre Elemente kürzer und dünner (von kaum $0,004 \mathrm{~mm}$. Durchmesser). In der schwärzlichbraunen (etwa I,5 mm. langen) Raspel kamen 8-9 Zahnplattenreihen vor, von welchen die meisten stark beschädigt; in der ( $3 \mathrm{~mm}$. langen) starken Scheide 17 - 8 , von welchen die 3 noch unreif; die Gesammtzahl der Reihen somit 25-27. In den Reihen kamen an jeder Seite der nicht schmalen Rhachis, wie gewöhnlich, eine starke sichelförmige Seitenplatte und 5 mehr hakenartige Aussenplatten vor. Die Platten waren von bräunlichgelber Farbe; die Länge der Seitenplatten (in gerader Linie von Grund zur Spitze gemessen) $0,6 \mathrm{~mm}$., die der letzten Aussenplatte etwa 0,10-0,12 mm. Die Seitenplatten (Fig. I5, I6) schlanker als bei der typischen Art, der Kamm der Innenseite weniger vorspringend und, wie es schien, ganz ohne Zähnchen; 
die Aussenplatten wie bei der typischen Art (Fig. I 7). Die langen weissen Speicheldrüsen wie gewöhnlich.

Die lange Speiseröhre wie früher beschrieben, ebenso der (in Durchmesser 5-6 mm. haltende) rundliche Magen, so wie der Darm, der sich in gewöhnlicher Art über die schmutziggelbe Leber schlängelt. Der ganze Verdauungskanal war in beiden Individuen, selbst die Mundhöhle, mit grauem, ziemlich hartem Inhalt gefuillt, der hauptsächlich aus feinen Sandkörnern mit Spongien-Spiculen und sparsamen Foraminiferen und Diatomeen vermischt bestand:

Die ovale, gelblichweisse Blutdrüse 5-6 mm. lang bei einer Breite von 3, mit feinlappiger glatter Oberfläche.

Die gelblichweisse bei einer Breite von 9 fast ro- I $\mathrm{mm}$. lange $\mathrm{Z}$ witterdrüse als ein ziemlich dicker Schild das Hinterende der Leber fast ganz deckend. Der Zwitterdruisengang bildet schnell eine (entwirrt etwa $5,5 \mathrm{~cm}$. lange) stark geschlängelte Ampulla. Die vordere Genitalmasse fast kugelförmig, von $3,5 \mathrm{~mm}$. Durchmesser, weisslich oder gelblichweiss; das starke Vestibulum genitale $3,5 \mathrm{~mm}$. lang; die kugelförmige Samenblase von 2,8-4 mm. Durchmesser. Die Vorhaut etwa $3 \mathrm{~mm}$. herausgestulpt mit der Spitze der glans penis entblösst; dieselbe und die starke gewundene weissliche Prostata ganz wie früher beschrieben. - Der Erhärtungszustand der Genitalorgane gestattete keine mehr eingehende Untersuchung.

Bei der St. 45 wurde mit der Tiefsee-Trawl noch ein Individuum derselben Form gefischt. Dasselbe zeigte den Hinterkörper bläulichgrau, war sonst von hell gelblicher (schwach röthlicher) Farbe; die Körperlänge betrug nur I I mm., die Breite bei ganz ausgeschlagenen Fussflügeln I9, die Länge des Vorderschildes $5 \mathrm{~mm}$. - Die Länge des Schlundkopfes fast $3 \mathrm{~mm}$; die Raspel schwärzlichbraun, die Anzahl der Zahnplattenreihen im Ganzen 22.

Wahrscheinlich liegt hier eine neue Art vor. Ihre Zungenbewaffnung ist von der der anderen Art etwas verschieden (die Seitenplatten ohne Zähnelung am Innenrande), die Farbe ist wahrscheinlich auch eine andere, so wie mehrere der anatomischen Verhältnisse auch sonst verschieden scheinen.

Gastropteron Sibogae Bgh. var. nigra. Taf. IX, Fig. 18-20.

Am Ankerplatz östlich von Sailus Besar, Paternoster-Inseln (St. 316), wurden 4 einander in Grösse- u. a. Verhältnissen fast ähnliche Individuen gefangen; ihre Fussflügel waren weit aus einander, fast horizontal ausgestreckt.

Die Farbe war durchgehends bläulich schwarz. Die Breite des grössten Individuum betrug $5 \mathrm{~cm}$., die Höhe 1,2 ; die Länge des Vorderschildes war $13 \mathrm{~mm}$. bei einer Breite von 8 , die des Hinterkörpers 2 I bei einer Breite von I2, die Länge der Peitsche $4 \mathrm{~mm}$; die Länge des Fusses war $23 \mathrm{~mm}$. bei einer Breite von 17 , die Länge der Fussflügel (von vorn nach hinten) $25 \mathrm{~mm}$., die Dicke derselben am Grunde $3,5 \mathrm{~mm}$., die Länge des freien Schwanzes I $3 \mathrm{~mm}$., die Länge der Schwanzdrüse I I bei einer Breite von 5; die Länge der Kieme $S$ mm. bei einer Breite bis 3. - Eingeweide schimmerten nirgends durch. 
Die Formverhältnisse wie oben, das Rhinophor aber weniger deutlich; das Hinterende des Stirnschildes $3 \mathrm{~mm}$. hervorragend; die Kieme mit 22 Blättern; der Penis 3 mm. hervorragend. - Die ganz diinne farblose cuticulare Schale zeigte keine Spur von Verkalkung der kleinen Spira.

Das Centralnervensystem ganz wie früher beschrieben; die Lage der Ganglien gegen einander bei den verschiedenen Individuen der Gastropteren aber sehr variabel (vgl. Fig. I8). Die Otocysten wie gewöhnlich (Fig. I 86 ).

Die Mundröhre wie gewöhnlich. Der Schlundkopf $4 \mathrm{~mm}$. lang. Die in ihren vorderen zwei Drittel braunen Mandibelplatten (Fig. I9) von $0,4 \mathrm{~mm}$. Länge, ihre diinnen Elemente von etwa $0,0035 \mathrm{~mm}$. Durchmesser. Die Zunge zeigte in der schwärzlichbrannen Raspel 6 Zahnplattenreihen, in der Scheide kamen deren noch 23 vor, von welchen die 3. noch unreif; die Gesammtzahl der Reihen somit 29. Zu jeder Seite der Rhachis die gewöhnliche grosse Seitenplatte und 5 Aussenplatten. Die Platten waren vollständig wie oben, die Chorda des Bogens der Seitenplatten (Fig. 20) auch $0,6 \mathrm{~mm}$.

Die hintere Eingeweidemasse $15 \mathrm{~mm}$. lang bei einer Höhe und Breite von IO; die Leber bräunlichgrau, die Zwitterdrüse etwas heller. Die sehr lange Ampulle des Zwitterdrüsenganges und die vordere Genitalmasse wie oben. - Die graue Prostata entwirrt $3 \mathrm{~cm}$. lang bei einem durchgehenden Diam. von $0,0 \$ \mathrm{~mm}$; der schwärzliche Penis mit starker Furche der Innenseite, die Glans ziemlich kurz.

\section{Ophthalmidae.}

Animal in testam non retractile. Clypeus frontalis distinctus, marginibus lateralibus rhinophoria e plicis perpendicularibus formata tegens. Notaeum anticum subcylindraceum; posticum (pallium) magis applanatum, testam includens vel minimum p.p. obtegens, postice (paullum) alatum. Podarium latum utrinque in epipodium alaeforme evolutum.

Testa pallio inclusa vel pro parte tecta, calcarea, fulcro (e parte mucleali prodiente) subtus inflexo, anfractu larga aperta.

Bulbus pharyngeus mandibulis parvis oblongato-ovalibus vel semilunaribus e columnis non altis margine culminis denticulatis compositis, instructus. Radula dentibus medianis parvis, lateralibus compluribus hamatis; formula radularis $\infty-\mathrm{I}-\infty$.

Diese kleine Gruppe umfasst die einander nahe stehenden Gattungen Plianerophtalmus, Smaragdinella und Cryptophthalmus.

Im Äusseren sehen sie einander sehr ähnlich. Sie zeigen ein scharf begrenztes, im Hinterrande meistens median ausgekerbtes oder ausgeschnittenes Stirnsegel, dessen Seitenränder über die von senkrechten feinen Falten gebildeten Rhinophorien hervorragen. Die Augen haben ihre Lage entweder oben in dem Stirnschilde (Phaneropthalmus, Smaragdinella), oder nach unten am Vorderende der Rhinophorien (Cryptophthalmus). Der Vorderruicken ziemlich gewölbt, vom Stirnschilde wie vom Hinterrücken stark geschieden. Dieser Hinterruicken ist 
mehr flach, von einem Mantel gebildet, der die Schale einschliesst (Cryptoplutalmus) oder wenigstens die Ränder derselben umfasst; hinten schiesst der Mantel über den Hinterrand der Schale hervor und bildet zwei kleine, gegen einander meistens grebogene Flügel, zwischen welchen der Eingang in die kleine Kiemenhöhle mit ihrer gestreckten Kieme. Der Fuss ist breit, geht ohne Grenze in seine Fliggel über, die einen grösseren oder kleineren Theil des Stirnsegels und des Rückens decken können. - Die in den Mantel eingeschlossene (Cryptophtalmus) oder von demselben an den Rändern gedeckte Schale ist von mehr rundlicher (Smaragdinclla) oder mehr gestreckter Form, immer ziemlich abgeplattet, kalkartig; von der Gegend der Nuclealpartie ragt innen ein gleichsam columellarer Fortsatz in die weite Höhle der Schale hinein.

Der Schlundkopf hat starke, etwas längliche Mandibelplatten, aus kleinen Säulen gebildet, deren obere Fläche im Rande etwas gezähnelt ist. Die schmale Rhachis trägt kleine mediane Platten, die Anzahl der hakenförmigen lateralen Platten ist nicht gross. - Der Kaumagen mit den gewöhnlichen 3 Platten.

Der Penis ist lang und mit Prostata versehen.

I. Phanerophthalmus A. Adams.

Phancropluthalmus A. Adams. Sow., Thes. („XI, 1850, p. 559"), II, I855, p. 559, 598, Pl. CXXV, Fig. $157,158$.

Phanerophthalmus Ad. Genera of recent moll. II, 1858, p. 25.

Xanthonclla Gray. Fig. of moll. anim. IV, I850, p. 95.

Xanthonella Gray. Guide. I, I857, p. I94.

Phancrophthalmus Ad. R. Bergh, Malacolog. Unters. V, I90I, p. 296-300, Taf. XXV, Fig. $4-23$.

Oculi superi, clypeo frontali affixi. - Testa irregulariter-oblonga, parte nucleali sinistra subtus inflexa, parte postica dextra nonnihil producta.

Die Phanerophthalmen tragen wie die Smaragdinellen die Augen oben, an der unteren Seite des Stirnsegels; ihre Schale ist aber von der der-Smaragdinellen sehr verschieden und stimmt wesentlich mit der des Cryptophthalmus.

Die Gattung ist bisher nur aus dem Indischen Meere bekannt.

1. Phanerophthalmus lutcus (Quoy et Gaim.) var. Taf. IX, Fig. $2 \mathrm{I}-28$.

Bullat lutca Quoy et Gaim. Voy. de l'Astrolabe. II, I832, p. 369, Pl. 26. Fig. 40-44.

Phancropluthalmus lutcus Quoy et Gaim. R. BERGI, 1. c. I90I, p. 2y,-300, Taf. X.IV, Fig. $4-23$.

Am Riffe an der Ostseite der Insel Pajunga in der Kwandang-Bai (St. I I 5) wurden 5 Individuen gefangen. Die zwei grössten wurden genauer untersucht.

Diese zwei grössten hatten eine Länge von $12 \mathrm{~mm}$. bei einer Breite von 8 und Höhe von 5-6 bei emporgeschlagenen Fussflugeln; die Länge des Stirnschildes so wie des Mantelschildes war $4 \mathrm{~mm}$. Die anderen Individuen waren nur etwa $10 \mathrm{~mm}$. lang. - Die Farbe aller dieser Individuen war gelblichweiss; der grössere hintere Theil des eigentlichen Rückens hell blaugrau; durch den Stirnschild schimmerten immer die schwarzen Augen, durch den Fuss ein blaugraues Eingeweide (Leber). 
Der Stirnschild wie gewöhnlich; die schmutziggelben Rhinophorien von etwa $15-20$ Blättern gebildet. Hinter diesem Schilde folgt der Riucken, dessen kleinerer flacher vordere. Theil (wie bei dem Cryptophthalmus olivaceus) mehr oder weniger stark vom Stirnschild und besonders vom iibrigen Theil des Rückens geschieden ist; der iibrige bläuliche Theil des Rückens ist gewölbt. Hinter dem Rücken folgt der Mantelschild mit der Schale; dieser umfasst ganz den Schalenrand, ist vorne und an den Seiten ganz dün, hinten etwas dicker und schiesst an den Seiten in die zwei gegen einander gebogenen Lajpen aus, zwischen welchen das Kiemenloch in die kleine Kiemenhöhle leitet. Die 4 mm. lange Schale von gewöhnlicher, auch etwas variabler Form, gelblichweiss, von duinner Cuticula überzogen, nicht ganz diinn, aber sehr zerbrechlich. Die weisse Kieme 4,25 mm. lang, mit einer Reihe von Knoten (Vesikeln) längs der Rhachis (Fig. 2I). Der Anus, die Vulva und die Samenrille wie gewöhnlich. Der Fuss ohne Grenze in die glatten Flügel übergehend, die zu niedrig sind um zusammenklappen zu können.

Das Centralnervensystem wie früher beschrieben. Die grossen Augen von 0,25 mm. Durchmesser.

Der Schlundkopf weisslich, $2 \mathrm{~mm}$. lang; hinten an der Unterseite ragt die Raspelscheide als eine kleine Papille hervor. Die gelben Mandibelplatten 0,55 mm. lang bei einer Breite von 0,24; ihre Elemente von eigenthumlicher plumper Form (Fig. 22, 23), von einer Höhe bis $0,05 \mathrm{~mm}$. bei einer Breite oben von fast 0,03 , der gebogene Kopf trug am Rande 2-3 Dentikel. Die blasse Raspel der Zunge enthielt 26-2S Zahnplattenreihen, in der Scheide kamen deren noch 20-2I vor; die Gesammtzahl der Reihen somit 46-49. An jeder Seite der medianen bis 20-22 Seitenzahnplatten. Die Platten fast farbloss; die Breite der medianen war $0,035 \mathrm{~mm}$; ; die Höhe der lateralen stieg bis 0,08 , die der äussersten war 0,04 mm. Die medianen Platten (Fig. 24a, 27) mit spitzem Haken; die lateralen hakenförmig, der Haken glattrandig, mit stumpfer Spitze (Fig. 24-26). - Die langen Speicheldrüsen wie gewöhnlich.

Der Kaumagen von gewöhnlicher Form, von 2,5-3 mm. Durchmesser; die Kauplatten I,2 mm. lang, ganz wie früher beschrieben.. - Die hintere Eingeweidemasse (Leber) aussen dunkel blaugrau, im Inneren gelblich, $6-7 \mathrm{~mm}$. lang bei einer Breite von 4 .

Die Zwitterdrüse bildet kleine weissliche Inseln an der Oberfläche der Leber. Lie vordere Genitalmasse etwas zusammengedruickt, gelblich und weiss, 6 mm. lang. Der Penis (Fig. 28) lang, zusammengebogen; die Glans mit starker Längsfurche.

Wahrscheinlich lag hier nur eine Varietït des $P /$. luteus vor.

2. Phanerophthalmus pauper Bgh. n. sp. Taf. IX, Fig. 29. Taf. X, Fig. I-S.

Am 23 Juli wurde am Ankerplatz vor den Kawio- und Kamboling-Inseln in der Karkaralong-Gruppe am Riffe (St. 129) ein Individuum gefangen.

In Formol bewahrt hatte dasselbe eine Länge von $\mathrm{I}_{4} \mathrm{~mm}$. bei einer Breite bei emporgeschlagenen Flügeln, von 7 und einer Höhe dann von $6 \mathrm{~mm}$. Die Farbe war durchgehends ziemlich dunkel olivengrau, nur am Vorderrïcken weisslich.

Die Formverhältnisse beiläufig die gewöhnlichen; die Länge des hinten zweilappigen 
Stirnschildes $4 \mathrm{~mm}$; die des Mantelschildes auch 4 mm. Am Stirnschilde schimmerten die Augen nicht durch; unter den Seitenrändern desselben die langen quergefurchten Rhinophorien. Der etwas gewölbte Vorderrïcken durch eine Einschnürung vom kleineren Hinterrücken geschieden. Der Mantelșchild etwas wappenschildförmig, weich, eben, mit etwas vortretenden Seitenrändem und Hinterrand, an seinem hinteren Theil (nicht am Hinterende) trägt der Schild eine von hohen Lippen eingefasste längliche Öffnung (Fig. 29); die Lippen setzen sich an dem Hinterende hinab fort, indem die grössere rechte die linke überklappt; die Lippen begrenzen die Kiemenspalte mit dem Eingang in die kleine Kiemenhöhle. Der Mantelschild enthält eine ganz düne, selbst unter der Loupe kaum sichtbare $\mathrm{Schale}$, die sich nur in Fetzen auslösen liess und deren Form sich gar nicht bestimmen liess; die Schale zeigte (Fig. 5) (0,016-0,02 mm. langen) Elemente, die auf den Anwuchslinien senkrecht standen; mit Säure brauste diese Andeutung von Schale nur ganz unbedeutend. Die längs des Randes des Mantelschildes liegende Kieme $5 \mathrm{~mm}$. lang (Fig. 29), mit Andeutung von Knotenbildung an der Rhachis. Die Samenrille sehr deutlich. Der Fuss mit medianem Einschnitt des Vorderrandes; die Fussflügel nicht stark.

Die Nervenzellen in den Centralganglien erreichten einen Durchmesser von 0,08 mm. Die vorne in der Tiefe des Stirnschildes liegenden schwarzen Augen hatten einen Diam. von $0,28 \mathrm{~mm}$.

Der Schlundkopf I,5 mm. lang, die Raspelscheide hinten etwas vorspringend. Die nach oben etwas verschmälerten braungelben Mandibelplatten 0,7 mm. lang bei einer Breite von 0,25 (Fig. I); ihre Elemente (Fig. 2) von einer Höhe von $0,0 S$ bei einem Durchmesser ron 0,016 mm., der hintere Rand der oberen Facette zeigte mitunter eine Andeutung von Dentikeln. Die breite Zunge mit schwach gelblicher Raspel, die etwa 30 Zahnplattenreihen enthielt; in der Scheide kamen deren noch is vor, die Gesammtzahl der Reihen somit 48 . In den Reihen fanden sich jederseits etwa 20 Platten. Die Zahnplatten waren fast farblos, die medianen von einer Breite von 0,04 , die lateralen erreichten eine Höhe von fast $0,08 \mathrm{~mm}$. Die medianen Platten zeigten (Fig. 3) mitunter einen kleinen Dentikel an jeder Seite des Hakens, die lateralen (Fig. 3, 4) waren von gewöhnlicher Hakenform.

Der Speicheldrisen weiss, lang und dünn, bis auf den Kaumagen reichend.

Die Speiseröhre (4 mm.) lang und diinn. Der $\mathrm{K}$ a umagen gerundet dreieckig, von 2 mm. Durchmesser, mit stark an der Aussenseite angedeuteten Kauplatten. Diese letzteren fast I,5 mm. lang, der Oberkörper kastanienbraun mit gelblichem Rande, der ziemlich schwache Unterkörper grau (Fig. 6); der Oberkörper von dichtstehenden, vom schwachen Kiele ausgehenden Querfurchen durchzogen (Fig. 7). Das vom Kaumagen an die Leber gehende Rohr $2.25 \mathrm{~mm}$. lang, ohne Erweiterung. - Die Leber $8 \mathrm{~mm}$. lang bei einer Breite vorne von 4, dunkel bleigrau.

Der Penis (Fig. 8) Io mm. lang, mit demselben durch einen kurzen Gang verbunden ist die $4,5 \mathrm{~mm}$. lange Prostata (Fig. $8 a$ ).

Durch die Form des Mantelschildes und die Art der Schale unterscheidet sich diese Art hinlänglich von der typischen. 


\section{Cryptophthalmus Ehrenberg.}

Ehrenierg, Symb. phys. Dec. I, isz8. Zool. II, Moll. Tab. X. II: A-G. - Cryptophthalmus olivacens Text (sine paginatura) 1831 .

R. Bergir, Malacalog. Unters. V, 1900, p. I63-I66, 234-236, I90I, p. 30I-302. erophthalmo.

Oculi inferi, infra clypeum frontalem, ante rhinophoria siti. - Testa quasi ut in Phan-

Die Cryptophthalmen haben die Augen unter dem Rande des Stirnsegels versteckt, am Vorderende der Rhinophorien liegend. Sonst stimmen sie auch in Bezug auf die Schale wesentlich mit den Phanerophthalmen.

Die Gattung mit einer einzigen Art ist bisher nur aus dem Rothen und dem Indischen Meere bekannt.

I. Cryptophthalmus olivacens Ehrenberg. Taf. X, Fig. 9-I3.

R. Bergh, Malacolog. Unters. Bd. V, I900-1902, p. I63-166, Taf. XIII, Figs. I-I5. p. 235-236, Taf. XIX, Figs. 29-38. - p. 301-302, Taf. XXV, Figs. 23-32.

Am I $_{3}$ Sept. wurden in der Sanana-Bai an der Ostkuste von Sula Besi am Riffe zwei Individuen gefangen. Am Riffe von Batjulmati (Java) war vorher eine grosse Anzahl (36) Individuen erbeute , die ganz zusammengerollt eine Länge von Io- I I mm. hatten und rothgelb oder ockergelb waren. - Noch 7 andere wurden am Ankerplatz von Kilsuin, an der Westküste der Insel Kur erbeutet; und noch mehrere (20) am Riffe von Gisser (St. 172), (dieselben erreichten eine Länge bis $3,2 \mathrm{~cm}$.).

Die beiden ersten Individuen wurden anatomisch untersucht.

Das kleinere war nur $16 \mathrm{~mm}$. lang. Das grössere maass $25 \mathrm{~mm}$. an Länge bei einer Breite von I I und einer Höhe von 9; die Länge des Stirnschildes war 4,5 mm., die des Vorderrückens I4, die des Mantelschildes mit der Schale $7 \mathrm{~mm}$; die Länge des Rhinophorien 5 , die der Kieme 8 bei einer Höhe am Grunde von 2,5 mm. - Die Farbe des Stirnschildes so wie des Fusses und der Aussenseite der Epipodien schmutzig röthlichgrau, die des Rückens grau, die der.Körperseiten und des unteren Theils der Innenseite der Fussflügel weisslich.

Die Formverhältnisse wie gewöhnlich; der Hinterrand des kleinen Stirnschildes mit medianem Einschnitte. Vorne unter dem Rande desselben die starken, dunkleren, quergefurchtem Rhinophorien; am Vorderende derselben schimmerten die schwarzen Augen mehr oder weniger deutlich durch. Der von Seite zu Seite gerundete lange Vorderrücken wie gewöhnlich; durch eine starke Einschnürung vom kleinen Hinterrücken, Mantelschilde, geschieden. Dieser trägt die vom dïnnen Mantel bedeckte Schale; die mehr vorne oder mehr hinten, mehr median oder mehr seitwärts, in einem ovalen (bis $2 \mathrm{~mm}$. weiten) Loch entblösst ist, und deren Hinterrand mit seinem vortretendem Ende in den Mantel hineinragt; der Mantel schiesst hinter der Schale jederseits in einen kurzen Flügel aus, der rechte ist (der Form der Schale entsprechend) mehr vortretend. - Die Schale, bei dem grossen Individuum $7 \mathrm{~mm}$. lang bei einer Breite von 4,5, war fest, stark verkalkt, von einer zähen, schmutzig gelben Cuticula überzogen; thinelt im 
Ganzen mehr der Schale von Plancrophthalmus luteus ${ }^{1}$ ); die Schale des kleineren Individuuns war hinten weniger stark ausgezogen. - Die Samenrille wie gewöhnlich, ebenso die Vulva, die Kieme (aber ohne deutliche Knoten längs der Rhachis) und die Analöffnung. Die Fussfligeln waren ziemlich niedrig, nur an den Rand des Vorderrickens reichend und den Hinterrücken ganz entblösst lassend; hinten verschmelzend bildeten sie einen kleinen Schwanz, auf den das freie Hinterende des Körpers ruht.

Die Augen von $0,30 \mathrm{~mm}$. Durchmesser; die ovalen Otocysten maassen an Länge etwa $0,12 \mathrm{~mm}$.

Der Schlundkopf $3 \mathrm{~mm}$. lang, die Raspelscheide hinten an der Unterseite etwas vorspringend. Die kurz-sichelförmigen, bräunlichen Mandibelplatten (Fig. 9) von einer Breite von $0,30 \mathrm{~mm}$., aus Stäbchen gebildet, die eine Höhe bis $0,065 \mathrm{~mm}$. erreichten, und deren schiefe freie Fläche im einem Rande meistens 2-3 zackig waren (Fig. IO, I I), sie ähnelten nicht ganz denen früher bei anderen Individuen gesehenen. Die breite Zunge mit bräunlichgelber schillernder Raspel, die 22 und 26 Zahnplattenreihen zeigte, in der Raspelscheide fanden sich noch 22 und 20 entwickelte und drei jüngere Reihen vor, die Gesammtzahl der Reihen somit 47 und 49. Zu jeder Seite der kleinen medianen kamen etwa 27 Seitenplatten gewöhnlicher Art vor ${ }^{2}$ ). Die Zahnplatten (Fig. I2, I3) waren wie früher beschrieben, nur die medianen (Fig. I2) nicht ganz von derselben Form, mit starkem Haken. Die Breite der medianen betrug $0,04 \mathrm{~mm}$; die Länge der Grundplatte der grössten lateralen betrug 0,07 bei einer Hakenhöhe von 0,08 mm., die Höhe des Hakens der äussersten Platte war 0,035.

Der Kaumagen von gewöhnlichem dreieckigem Umrisse, von 3,5-4 mm. Durchmesser, die Kauplatten an der Aussenseite sehr stark ausgeprägt. Diese letzteren in gerader Linie $2 \mathrm{~mm}$. messend, von gewöhnlicher Form, der Oberkörper kastanienbraun, der Unterkörper durchsichtig grau, die Sculptur des Rückens wie früher erwähnt. - Der gräulichweise Inhalt dieses Magens bestand aus klaren Algen mit Sandkörnern vermischt. - Die graubraune Leber I I mm. lang.

In der Zwitterdriise kaum reife Geschlechtselemente. Das Hinterende der hinteren Eingeweidemasse von der vorderen Genitalmasse gebildet. Dieselbe bestand aus einem hinteren, abstechend gelblichweissen, Meniscusförmigen, von einer Längsfurche durchzogenen Theile, von $5 \mathrm{~mm}$. Durchmesser, und einem vorn liegenden von unregelmässiger Kegelform von $4,5 \mathrm{~mm}$. Länge und ebenso breiter Grundfläche, von gräulicher und weisslicher Farbe. Die sackförmige Spermatotheke gross, von $4 \mathrm{~mm}$. Länge (der traurige Erhärtungszustand der Thiere gestattete kein genauere Untersuchung). - Der lange Penissack von I I mm. Länge bei einem Durchmesser von I; die grosse, fast cylindrische Prostata von $5 \mathrm{~mm}$. Länge bei einem Durchmesser von I, $5 \mathrm{~mm}$.

Die hier untersuchte Form scheint dem typischen Cryptophthalmus olivaceus an zu gehören.

1) R. Bergir, Malacolog. Unters. 1d. V, I902, Taf. XXV, Fig. S.

2) Bei den vier früher (1. c.) untersuchten Individuen war die Anzahl der Zahnplattenreihen 46 (17 + 29), 42 (1 $7+25$ ), 51 $(20+31)$ und $61(30+31)$. Die Anzahl der Seitenzahnplatten war $26,25,26$ und 50. 
Ob der Cr. cylindricas von Pease nur eine Varietät der typischen darstellt, muss vorlïufig dahingestellt bleiben ${ }^{1}$ ).

Cryptophthalmus olivaceus E. var. pallida. Taf. III, Fig. 4. Taf. IX, Fig. 4. Taf. X, Fig. $14-17$.

Von dieser Form wurde am I I März am Riffe von Batjulmati (Java) (St. 7) eine Reilie von (24) Individuen gesammelt.

Das nach dem Leben gemalte Thier (Taf. III, Fig. 4) ist etwa $3 \mathrm{~cm}$. lang gewesen; von schwach gelblicher Farbe mit dunklerem Stirnsegel, in der Mitte des Rückens (wegen eines durchschimmernden Eingeweides?) bläulich. Von den verschiedenen Formen und Stellungen der Thiere während ihres Schwimmens und ihren mannigfachen anderen Bewegungen im Wasser wurden Skizzen aufgenommen (Taf. IX, Fig. 4). - Zwei Individuen wurden genauer untersucht.

Die in Formol ( $4 \%$ ) aufbewahrten hatten eine Länge von $14-20 \mathrm{~mm}$; die grössten, am meisten ausgestreckten maassen (bei den immer aufgeklappten, nicht hohen fiussflügeln) an Breite 8 bei einer Höhe von $5 \mathrm{~mm}$; die Länge des Stirnschildes war 5, die des Hinterschildes mit der Schale 5-6, die Länge der Kieme war $5 \mathrm{~mm}$. - Die Farbe des eigentlichen Rückens war weisslich oder schwach bläulich weiss, der übrige Körper gelblichweiss, die RhinophorienFalten stärker gelb.

Vor den Rhinophorien schimmerten die Augen schwach durch, am Rücken mitunter ein dunkles Eingeweide (Leber).

Die Formverhältnisse (Fig. I4) wie oben. Die Rhinophorien von etwa Io Falten gebildet; vorne am eigentlichen Ruicken immer eine deutliche Querfurche. Der Mantelschild scharf abgegrenzt, den Rand der (inneren) Schale ïberragend, besonders ihren Hinterrand, und das rechte Ende desselben, hier fingerförmig vortretend, entweder gerade (Fig. 14) oder links gebogen (Fig. I5); die Seitenränder des Mantels und besonders der Hinterrand dicker, sonst ist derselbe dünn. Die kalkweisse ziemlich feste, leicht unbeschädigt abzulösende Schale in Bezug auf Länge und Breite etwas variabel, kalkweiss, bei den grösseren Individuen etwa $6,25 \mathrm{~mm}$. lang bei einer Breite von 4; der Hinterrand stark verdickt, nach oben gebogen (Fig. 16).

Der gelblichweisse Schlundkopf $2 \mathrm{~mm}$. lang. Die bräunlichen Mandibel ein wenig länger als oben dargestellt; ihre Länge 0,95 bei einer Breite sich bis auf $0,35 \mathrm{~mm}$. belaufend; die Zahl der Reihen von zusammensetzenden Elemente schien etwa 25 zu betragen; diese Stäbchen erreichten eine Höhe bis $0,08 \mathrm{~mm}$; die schiefe, in $2(-3)$ Zacken vortretende Endfacette von beiläufig $0,035 \mathrm{~mm}$. Länge. Die Zunge mit hell gräulichgelber Raspel, welche 20-22 Zahnplattenreihen zu enthalten schien, weiter nach hinten kamen deren noch I $8-20$ vor, die Gesammtzahl derselben somit $38-44$. In den Reihen fanden sich 22-24 Seitenplatten. Die Platten wie oben; die Breite der medianen etwa $0,35 \mathrm{~mm}$; die Höhe der Seitenplatten bis 0,08 , die der äussersten $0,04-0,05 \mathrm{~mm}$. Bei dem einen Individuum kamen im inneren

1) Eliot, Notes on Tectibranchs and naked Mollusks from Samoa. Proc. Ac. nat. sc. of Philadelphia. is99, p. 512. SIBOGA-EXPEDITIE L. 
Drittel der Reihen zwei ganz unregelmässige Seitenplatten (Fig. I $7 a, b$ ) vor, die übrigen Seitenplatten (Fig. I 7 C) waren normal

Der Kaumagen von $3 \mathrm{~mm}$. Durchmesser, die Kauplatten ganz wie oben beschrieben. Die grate Leber kurz-sackförmig, $7 \mathrm{~mm}$. lang bei einer Breite von 4 .

Der Penis 9-IO mm. lang, schlank; die gerade, gestreckt-schlauchartige Prostata 3$3,5 \mathrm{~mm}$. lang; der Verbindungsgang ziemlich kurz.

An der Ostseite der Insel Pajunga, Kwandang-Bai (St. I I5) wurde noch ein Individuum gefangen, das sich als mit dieser Form identisch zeigte. Die Grösse- und Formverhältnisse waren dieselben. Der Schlundkopf $2 \mathrm{~mm}$. lang, die Mandibelplatten wie oben. Die Raspel fast farblos, mit 24 Zahnplattenreihen, in der Scheide noch 20; die Zahl der Platten in den Reihen 22; die Breite der medianen etwa 0,03 , die Höhe der Seitenplatten bis $0,08 \mathrm{~mm}$. Der Durchmesser des Kaumagens $3 \mathrm{~mm}$. Die Leber braungelb. Die Prostata 2,5 mm. lang.

EL,oт hat (1.c. p. 5I2) eine helle, gräulichweisse Varietät der (sonst schwarzen) Cr. cylindricus von PEASE erwähnt.

\section{DORIDIIDAE.}

R. Bergit, Nalacolog. Unters. V, I900, p. I78-I8I.

Diese Familie umfasst nur die Gattungen Doridinm und Chelidonura.

Chelidonura A. Adams.

Chelidonura H. et A. Adams. The genera of recent moll. II, I858, p. 26-27.

Chelidomura. R. Bergh, Die Opisthobranchier. Schauinsland, Ergebn. einer Reise nach dem Pacific. Zoolog. Jahrb. X1II, 3, I900, P. 212-220.

Chelidomurd. R. Bergh, Malacolog. Unters. V, I900, p. 178-is I.

Hirundella Gray. Figures. IV, 1850, p. 95. - Guide. 1857, p. $193^{1}$ ).

Navarchus Cooper. Proc. Calif. Ac. Nat. Sc. II, I862, Nvb., p. 202.

Vazarchus. R. Bergh, Die Opisthobranchien. Rep. on - Albatross. I894, p. 213-222.

Forma corporis fere ut in Doridiis propriis; sed clypeus anterior utrinque rhinophorio (rudimentario) praeditus, clypeus posterior postice utrinque in processum elongatum compressum continuatus.

Über die Priorität-Berechtigung des Namens der Gattung (Chclidonura Ad.) vgl. meine frühere Angabe (1. c. 1900, p. 212). Wie schon früer (1.c. p. 212) angedeutet, ist die Gattung Nacarchus wahrscheinlich mit der Chelidonura identisch.

1) H. and A. ADAus (The genera of recent moll. II, IS 5 , p. 26) schreiben Hirundinella, ebenso M. Fiscirer (Man. de conchyl. 1887 , p. 564 ). 
Die im Äusseren sonst mit den ächten Doridien übercinstimmenden Chelidonuren unterscheiden sich von denselben auch fast nur durch Entwicklung von (rudimentiren) Fiihlern und von langen (Schwalbenschwanz-ähnlichen) Hinterflügeln.

Chelidonuren sind nur aus dem Indischen und Stillen Meere bekannt, und zwar nur wenige Arten.

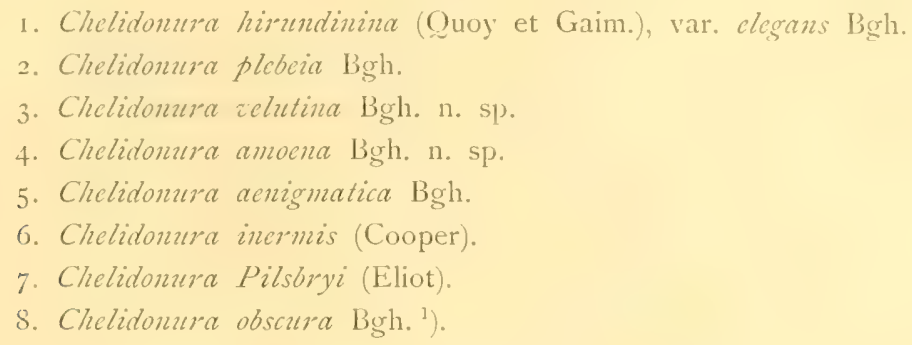

I. Chelidonura vielutina Bgh. n. sp. Taf, III, Fig. 5, 6. Taf. X, Fig. Is-24.

Von dieser Form wurde auf einem Riff bei Saleyer (St. 213) 7 Individuen gefangen, ein anderes war am Riffé von Haingsisi, ein drittes an dem in der Ruma-Kuda-Bucht bei der Insel Roma (St. 279) erworben und dasselbe wurde lebend abgebildet, was auch mit einem (von drei) auf dem Muaras-Riff (Borneo) gefangenen der Fall war.

Das bei St. 279 gefangene Individum war lebend $4 \mathrm{~cm}$. lang bei einer Breite, bei emporgeschlagenen Fussfliigeln, von I cm. Die Farbe war sammtschwarz; der Rand der Fussflügel und der obere Rand der Hinterfligel blau, bei dem einen Individuum (vom Muaras-Riff) war auch der Stirnrand blau, so wie eine mediane und laterale blaue Linien auch am Vorderschilde vorkamen; die Körperseiten (und der Zwischenraum zwischen Vorder- und Hinterschild) hell-gelblichweiss.

Drei Individuen wurden genauer untersucht; sie stimmten in äusseren und in inneren Verhältnissen ganz mit einander überein.

Von den a ufbewahrten Individuen hatte das eine ein Länge (vom Kopf zum Schwanzende, ohne die Hinterfluigel) von 3,2 , ein anderes von $4,3 \mathrm{~cm}$. Bei 7 anderen betrug die Länge constant $4 \mathrm{~cm}$. bei einer Breite bei (wie fast immer) ausgeschlagenen Fussflügeln von 3-3,2 (bei emporgeschlagenen von 1,2 ) und einer Höhe von etwa 0,8 ; die Länge des Vorderschildes $2-2,6 \mathrm{~cm}$. bei einer Breite von $0,8-\mathrm{I}, 2$, die Länge seines freien Hinterendes 6-IO mm.; die Länge des Hinterschildes $1,5-1,7 \mathrm{~cm}$, die der Hinterflügel $1,4-1,9 \mathrm{~cm}$.; die Länge der Kieme etwa $6-8 \mathrm{~mm}$. bei einer Höhe von $4-5$; die Breite der Fussflügel etwa I cm., die Länge des Schwanzes 1,4-1,6 cm. - Die Farbe im Ganzen schön sammtschwarz, bei mehreren Individuen fand sich am Vorderschilde ein medianer schmaler bläulicher Längsstreif und eine Andeutung von ähnlichen lateralen, und der Rand der Fussflugel zeigte sich hier und da mitunter ähnlich gefärbt; der Zwischenraum zwischen Vorder- und Hinterschild

r) Vgl. für die letzten zwei Arten: Malacol. Unters. V, 1902, p. 305-307. Taf. XXV, Fig. I-3. 
war schwärzlichgrau, die Körperseiten und die Unterseite des Hinterschildes gräulichweiss, die Kieme gelblichweiss oder bräunlichgelb, mit grauen Rhachispartien der viel grösseren oberen (IO-I 2) Blätter, die unteren viel kleiner.

Die Formverhältnisse die gewöhnlichen der Doridiiden. Der Vorderschild lang, nach hinten zugespitzt; die gerundeten Ecken (Fig. IS) des breiteren median etwas vortretenden Vorderrandes etwas vorspringend, mit Längsfurche (Andeutung von Tentakeln); die Seitenränder etwas gelöst; das Hinterende lappenartig vortretend, den Zwischenraum zwischen den Schildern und oft den Vorderrand des Hinterschildes deckend. Der Hinterschild etwas breiter, der Vorderrand kaum gelöst, die Seitenränder etwas mehr, das Hinterende aber stark und ein Dach über die Kieme bildend, dieses Hinterende verlängert sich jederseits in einen zusammengedrückten, langen, allmählig stark zugespitzten, an der Innenseite der Länge nach ausgehöhlten oder gefurchten Hinterfliigel, der linke ist immer länger und meistens spitzer als der rechte. Die Körperseiten niedrig; zwischen den Schildern gerundet in einandern übergehend; ganz vorne eine durch Farbe auch etwas bezeichnete (bis $9 \mathrm{~mm}$. langen) Rhinophorpartie mit feinen senkrechten Falten; unter dem vordersten Theil derselben die feine männliche Genitalöffnung; von derselben ab verläuft die ausgeprägte (weisse) Samenfurche nach hinten an die mehr graue Vulva-Papille. Hinter der letzteren die hübsche, mehr oder weniger gebogene, starke Kieme mit 10-12 zusammengesetzten Blättern an jeder Seite der Rhachis; wenigstens das hintere Drittel der Kieme ist gelöst. Am Grunde der Kieme, oberhalb der Vulva die Analöffnung. Der grosse Fuss vorne unter dem Aussenmunde ein wenig vortretend, von den Fussflügeln nicht deutlich abgegrenzt, der grosse und breite Schwanz den Hinterschild selbst überragend, von den Hinterfligeln aber stark iberragt. Die Fussfligel so wie die Schilder ganz glatt.

Die ganz dünne membranartige Schale (Fig. I9) mit Spur von Verkalkung der ganz kleinen Spira, rechts stark nach hinten (in die Wurzel des rechten Hinterflügels hinein) ausgezogen. Das weisse Centralnervensystem ganz wie früher von mir (1.c. p. 216, Taf. XIX, Fig. IO, II) bei der Ch. himundinina dargestellt. - In einer kleinen Vertiefung neben der medianen Randpartie des Vorderrandes des Vorderschildes (Fig. I 8 ) die kleinen weissen Augenflecken mit den Augen von einem Durchmesser von fast $0,30 \mathrm{~mm}$, mit hellgelber Linse. Die Ohrblasen an der Innenseite der Fussknoten hinter dem pleuro-pedalen Connective. Unter dem erwähnten Vorderrande ist die Gegend an beiden Seiten des senkrechten Aussenmundes flach, sich allmählig verschmälernd in die Tentakelfurche fortsetzend; diese weissliche Strecke ist äusserst fein höckerig durch die dichtstehenden Fühlerapparate mit ihren Borsten und Fühlerknospen (Fig. 20), ganz wie ich sie bei der typischen Art (1.c. p. 2 I 7 ) näher beschrieben habe. Die Haut ist überall mit Drïsenzellen stark ausgestattet, ganz besonders stark um die Augenflecken.

Um den Aussenmund und die kurze ( $1 \mathrm{~mm}$. lange) schwärzliche Mundröhre eine grosse graue Driisenmasse. Der Schlundkopf gräulich, am Vorderende und median längs einer Strecke der oberen und unteren Seite fast schwarz; mit (etwa 30) weisslichen Reifen, 5-5,25 mm. lang bei einer Höhe von 3 und einer Breite von 2-2,5; die untere Seite mehr abgeplattet; die Höhle wie gewöhnlich. - Die kleinem, länglichen, etwa $0,8 \mathrm{~mm}$. langen Speicheldrüsen wie bei der typischen Art. 
Die Speiseröhre 0,5-1 mm. lang. Der $\mathrm{M}$ agen ganz frei vor der Leber liegend, 6-7 mm. lang, bei einem Durchmesser von 3; an der Cardia- so wie an der Pylorus-Gegend graufarbig und mehr drüsig, mit feinen Längsfalten der Innenseite; durch ein kurzes Rohr öffnet sich der Magen durch eine mediane Längskluft vorne an der Unterseite der Leber gleichsam in eine kleine Leberhöhle mit mehreren Öfnungen. Links geht aus der Höhle der Darm heraus, durchbohtt die Leber und erscheint ganz links an der Oberfläche hinter der Nitte der Länge der oberen Seite, bildet einen queren Bogen, geht nach hinten an die linke Seite der schwarzen Blutdrise unter der Samenblase, und wird in seinem Verlaufe zwischen der Zwitterdrüse und der vorderen Genitalmasse zu dem Anus etwas weiter; die ganze Länge des Darmes betrug $12 \mathrm{~mm}$. Die Verdauungshöhle war immer ganz leer.

Die aussen und innen hellgrüne Leber vorne und hinten gerundet, 9 mm. lang bei einem Durchmesser von 6.

Die Gegend des Pericardiums schwarz. Die Niere gräulich.

Die grosse, gelbe oder weisslichgelbe Zwitterdrüse an der linken und unteren Seite der Leber liegend, $9 \mathrm{~mm}$. lang, $5 \mathrm{~mm}$. hoch und meistens $4-5$ dick, aus dicht gedrängten Läppchen gebildet; die rundlichen Follikel derselben wenigstens zum grossen Theile theils nur Samen, theils nur Eier enthaltend. Der vorne und unten von der Innenseite der Drüse ausgehende Zwitterdrüsengang bildet einen Knäuel von Windungen zwischen del Drüse und der vorderen Genitalmasse. Dieselbe (Fig. 2r) liegt an der rechten und unteren Seite der Leber, unten an die Zwitterdrise stossend; sie war weiss, $7-8 \mathrm{~mm}$. lang bei einer Höhe ron 5-6 und einer Dicke von 3, an der freien (rechten) Seite convex, an der linken concav; sie ist hauptsächlich von der milchweissen, langen, schlingenartig gebogenen Schleimdrïse gebildet, hinten die kleine, mehr gelbliche Eiweissdrüse. Die Samenblase (Fig. 2 I $a$ ) kugelförmig, von 2,5-3 mm. Durchmesser, farblos, leer; ihr Gang länger als die Blase, vor seinem Ende etwas weiter (Fig. 22a). An der inneren Seite der Eiweissdrüse (Fig. 2I b, 22) eine kleine Spermatocyste. — Der aussen und innen, schwarze, fast cylindrische Penis (Fig. 23a) $3 \mathrm{~mm}$. lang, an seinem oberen Ende sitzt kopfartig (Fig. 23b, 24) eine runde weissliche Prostata von I-I,5 mm. Durchmesser; eine Glans kommt kaum vor.

Eine neue Art scheint hier vorzuliegen.

2. Chelidonura amocna Bgh. n. sp. Taf. III, Fig. 7 .

Auf einem Riff bei Saleyer (St. 2I3) wurden 2 Individuen gefangen, und das grössere lebend abgebildet.

Dasselbe war le bend $4,3 \mathrm{~cm}$. lang bei einer Breite bis I. Der Vorderschild war punktirt bräunlichgrau mit gelbem Vorderrand, sonst weissgerandet; die Aussenseite der Fussflügel punktirt grau, weissgerandet, der Hinterschild wie der Vorderschild gefärbt, die Hinterflügel gelb.

Das kleinere der a ufbewahrten Individuen hatte eine Länge von is mm. Das grössere war $25 \mathrm{~mm}$. lang bei einer Breite (bei emporgeschlagenen Flügeln) von 7 und einer Höhe von 6,5 ; die Länge des Vorderschildes betrug $9 \mathrm{~mm}$, die Länge des linken Hinterfligels 
I 1,5; die Länge der Kieme 5 bei einer Höhe und Dicke von $2 \mathrm{~mm}$; die Länge des Fusses war I 3 , die des Schwanzes $3 \mathrm{~mm}$. - Der Vorderschild war (unter der Loupe) ganz fein punktirtschwarzgrau mit gelblichweissen Rändern, nur der Vorderrand mehr gelblich; die Mitte des Hinterschildes zeigte ähnliche Farbe, die gelblichweisse Einfassung aber breiter; die Hinterflïgel gelb; die Aussenseite der Fussflügel zeigte ähnliche Farbenverhältnisse wie die Schilder; die Körperseiten und die Innenseite der Fussflügel gelblich, die letzteren gegen den Rand gräulich; die Unterseite des Körpers gelblichweiss; die Kieme hell gräulichweiss. Die Farbenverhältnisse der beiden Individuen stimmten wesentlich überein, nur war bei dem kleineren Individuum die dunkle Farbe des Hinterschildes mehr verbreitet und setzte sich auf die Aussenseite der Hinterflügel fort.

Die Formverhältnisse die gewöhnlichen. Die Ecken des Vorderschildes nicht vorspringend, die Rhinophorien vorne am Grunde desselben $4 \mathrm{~mm}$. lang; das freie Hinterende desselben $2 \mathrm{~mm}$. lang. Der Hinterschild hinten den Schwanz stark überragend; die Hinterflügel zusammengedrückt, etwas zugespitzt, der linke fast doppelt so lang wie der rechte; ihre Innenseite etwas ausgehöhlt und am Grunde derselben eine feine, erhabene, gebogene Querleiste. Die Vulva stark, in derselben fängt die Samenfurche an. Die Kieme mit etwa 8 zusammengesetzten Blättern, ihre volle Hälfte frei hervorragend; hinten an ihrem Grunde die Analöffnung. Die Fusssohle von ihren Flügeln nicht deutlich abgegrenzt. Die Schilder und die Fussflügel ganz glatt.

Die membranartige, ganz dunne, sehr schwach gelbliche Schale etwa i I $\mathrm{mm}$. lang, fast ohne Spira, rechts nur wenig schwanzartig ausgezogen, ohne Spur von Verkalkung.

Das gelbliche Centralnervensystem wie gewöhnlich. Die Augen von o, 10 mm. Durchmesser auswendig. Die eigenthümlichen Fühlerapparate am Vorderende und um den Mund wie bei anderen Chelidonuren. Die stark pigmentirten Hautstrecken zeigten dichtstehende pigmentlose Punkte und in den pigmentirten Strecken eine Unmenge von Drüsenzellen.

Der bräunlichgelbe Schlundkopf 2,25 mm. lang, von gewöhnlicher Form und gewöhnlichem Bau. Die kleinen weissen Speicheldrusen wie bei verwandten Formen. Der cylindrische Magen $4 \mathrm{~mm}$. lang bei einem Durchmesser von $\mathrm{I}$. Die hell schmutziggelbe Leber hinten zugespitzt, i $2 \mathrm{~mm}$. lang bei einer Breite in der Mitte von 5. - Das farblose Pericardium von rundlichem Umrisse und $4 \mathrm{~mm}$. Durchmesser.

Die hauptsächlich von der weissen Schleim-Eiweissdrise gebildete vordere Genitalmasse von gewöhnlichen Formverhältnissen, $8 \mathrm{~mm}$. lang. Der schmutziggelbe Penis fast cylindrisch, 2,5 mm. lang; seine kopfartige kleine Prostata wie gewöhnlich. 


\section{NOTASPIDEA.}

Diese Gruppe umfasst die Pleurobranchiden, die Umbrelliden und vielleicht noch die Runciniden.

In Gegensatz zu den Anaspidea und den Cephalaspidea zeigen die Notaspidca die weibliche und männliche Genitalöffnung neben einander, und eine offene Samenfurche findet sich nicht.

\section{Pleurobranchidae.}

R. BErgit, Malacolog. Unters. V, I897-1898, p. I-I5S, 37I-380. Taf. I-XII.

Die Familie umfasst augenblicklich die Gattungen Pleurobranchaea, Oscaniopsis, Oscanius, Oscaniella, Pleurobranchus und Berthella. Die Pleurobranchaea und die Oscaniopsis haben keinen gesonderten Kopf, keine Schale, eine geklüftete praebranchiale Papille, und die Mandibel sind von kleinen Säulen aufgebaut; von den Pleurobranchaeen unterscheiden sich die Oscaniopsen durch eine doppelte Reihe von (blasenartigen) Knoten an der Rhachis der Kieme (wie bei den Oscanien). Die Oscanien, Oscaniellen und die ächten Pleurobranchen so wie die Berthellen zeigen einen gesonderten Kopf, entwickelte Schale und eine einfache praebranchiale Öffnung, ferner sind die Mandibel von kleinen Platten gebaut. Die Oscanien und Oscaniellen tragen (wie die Oscaniopsen) eine doppelte Reihe von Knoten an der Rhachis der Kieme; die Oscanien haben aber grosse äussere Genitalien und die Schale meistens mehr hinten liegend, während bei den Oscaniellen jene kleiner sind und die Schale meistens mehr vorne liegt. Bei den ächten Pleurobranchen ist die Rhachis der Kieme glatt, Genitalfalten fehlen und die Schale liegt meistens nach vorne, ihre Zahnplatten sind hakenartig, während die der Berthellen aufrecht und denticulirt sind.

\section{Pleurobranchaea Leue.}

R. BERGH, 1. c. V, I, I 897, p. $4(-5$ I $)$.

VAYSSIËRE, l. c. II, IgOI, p. $22-42$.

Caput discretum nullum; testa nulla; rhachis branchiae laevis; papilla praebranchialis postice fissa; apertura genitalis simplex.

Mandibulae e columnis altis confertis compositae. 
Der an obiger Stelle gelieferten Liste der beschriebenen Arten sind noch die Pl. capensis von VAYssière ${ }^{1}$ ) und die neue untenstehende hinzufügen.

\section{Pleurobranchaca morula Bgh. n. sp. Taf. X, Fig. 25-29.}

Am Ankerplatz östlich von Sailus Besar, Paternoster-Inseln (St. 3i6) wurden zwei Individuen dieser Art gefangen. Sie waren schlaff und weich, stimmten in den Formverhältnissen ganz ïberein.

Die Farbe war durchgehends schwärzlich, die Rückenseite dunkler. Die Länge des kleineren war $3,8 \mathrm{~cm}$. bei einer Breite von I,6 und einer Höhe von I cm., die Breite des Fusses vorne $\mathbf{I},+\mathrm{cm}$., die Länge des Schwanzes I, 8 . - Das grössere Individuum wurde genauer untersucht; seine Länge betrug $7 \mathrm{~cm}$. bei einer Höhe von 2, die Breite des Stirnschildes mit den Tentakeln war $2,5 \mathrm{~cm}$., die Höhe der Rhinophorien $7 \mathrm{~mm}$., die Breite des Rückens 2,7 cm.. die Länge der Kieme $16 \mathrm{~mm}$. bei einer Breite von 6; die Breite des Fusses war vorne 2,6 cm., hinten I, die Länge des Schwanzes $2,7 \mathrm{~cm}$.; die Höhe der Schwanzfingers $4 \mathrm{~mm}$. Die Mundröhre war ganz umgestiulpt $14 \mathrm{~mm}$. lang bei einem Durchmesser von I 2.

Die Formverhältnisse etwa die gewöhnlichen. Der $5 \mathrm{~mm}$. über den Mund vorspringende Stirnrand zeigte an der oberen Seite eine doppelte Reihe von (12) kleinen Kegeln (Fig. 25) mit etwas unebener Oberfäche, sonst war das Segel glatt. Die kürzere Furche der Tentakel und die etwas längere des Rhinophorien trugen feine Querfalten. Der-vorne nur undeutlich vom Kopf abgegrenzte, $43 \mathrm{~mm}$. lange, ganz glatte Ruicken ragte an der linken Seite 4 , hinten $S$ und rechts $7 \mathrm{~mm}$. über die Körperseiten und den Schwanz ein wenig gerundet hervor. Vorne an der (rechten) Seite die einfache doppelte Genitalöffnung, dahinter die Papille der (mit einer Länge von $3 \mathrm{~mm}$.) durchschimmernden praebranchialen Röhre; dann die schlanke Kieme mit ihren beiläufig 36 Blätterpaaren und fast mit ihrer Hälfte freiliegend, am Grunde des freien Theils der Anus und die Nierenpore. Der grosse Fuss vorne gerundet, mit starker Randfurche und $(1,5 \mathrm{~mm}$.) vorspringenden Ecken, das Fussgebräm bis $7 \mathrm{~mm}$. breit; der lange Schwanz ziemlich abgeplattet, die Schwanzdruise aussen nicht ausgeprägt, vielleicht fehlend, der Schwanzfinger sehr stark. - Die Fussmuskulatur schimmerte iiberall stark durch.

Die Centralganglien waren von grauer Farbe. Die Otocyste von 0,20 Durchmesser, mit einer grösseren und mehreren kleine Otokonien.

Die umgestulpte, den Schlundkopf einschliessende Mundröhre schwarz. Der Schlundkopf I $3 \mathrm{~mm}$. lang bei einer Breite von 10 und einer Höhe von 8; die schmale schwarze Lippenscheibe gegen den nicht umgebogenen weisslichen Vorderrand der Mandibelplatten stark abstechend; die Decke der Mundhöhle schwarz. Die matt-wachsweissen Mandibelplatten ro mm. lang bei einer Höhe von 6, sehr spröde; ihre Elemente bis wenigstens $0,25 \mathrm{~mm}$. hoch bei einem Durchmesser von 0,035 , die 5-6-eckige Endfacette mit meistens 3-9 ziemlich spitzen kurzen Dentikeln (Fig. 26). Die Zunge zeigte in der (lineär-) schillernd-kastanienbraunen Raspel 22 Zahnplattenreihen, in der Scheide kamen deren noch etwa 15 vor, die Gesammtzahl der

1) Vayssiére, Monographie de la famille des Pleurobranchidés. II. Ann. des sc. nat. 8 S. XII, I90I, p. 46-49. pl. IV, 11.2 $232-233$ 
Reihen somit gegen 40. Die Anzahl der Zahnplatten in den Reihen jederseits ungefuhr 50. Die Zahnplatten ganz wie bei anderen Pleurobranchaeen, vielleicht ein wenig schmaichtiger, die äussersten 0,25 mm. lang (Fig. 29), die Länge bis zu 0,64 steigend (Fig. 27, 28); die Farbe gelb, in der Grundpartie dunkler. Der Gaumen mit starken Längsfalten, zwischen denen kurze quergehende, alle mit starker Cuticula.

Die Nebenspeicheldrüse (Gl. ptyalina) sehr stark entwickelt; ihr Gang grau; dic Speicheldrüse (Gl. salivalis) wie gewöhnlich, jeder ihrer zwei weissen Gänge mit einer $3 \mathrm{~mm}$. langen flaschenförmigen Erweiterung endigend.

Die schwarze Speiseröhre $8 \mathrm{~mm}$. lang. Der aussen wie innen schwarze erste Magen $9 \mathrm{~mm}$. lang bei einem Durchmesser von 7 , mit dichtstehenden feinen Längsfalten der Innenseite; mit scharfer schwarzer Grenze scheidet sich dieser von dem folgenden, schmutzig gelben Abschnitt des Verdauungskanals (zweitem Magen?), welcher eine Länge von I 6 bei einem Durchmesser von $4,5-3 \mathrm{~mm}$. hatte und Längsfalten der Innenseite zeigt; diesem schliesst sich ein kleiner kugelförmiger Abschnitt von $3 \mathrm{~mm}$. Durchmesser (dritter Magen?) an, welcher stark durchschimmernde Längsfalten zeigt; links am Vorderende der Leber liegend geht dieser Magen in den schmutzig gelben Darm über, welcher längs des vorderen und des rechten Randes der Leber verläuft und wie die Analpapille in der letzten Strecke schwarz ist. - Der Inhalt der Verdauungshöhle war unbestimmbare thierische Masse.

Die schmutzig gelbbraune, gleichsam körnige Leber unregelmässig kugelförmig, I 2 mm. lang bei anderen Durchmessern von 9; sie öfent sich in die Verdauungshöhle am Grunde des dritten Magens.

Die starke weisse Niere mit ihren kurzzweigigen neben einander liegenden Bäumchen die ganze rechte Seite und das Hinterende der Leber iberziehend.

Das Genitalsystem wenig entwickelt, schien aber, insoweit beurtheilt werden konnte, sich wie bei der typischen Art zu verhalten. Die graue Prostata nur von I,5 mm. Durchmesser. Der (7 mm.) lange Penissack auch grau; die besonders unten abgeplattete und mit breiter Furche versehene Glans fast so lang wie der Sack.

Diese Form scheint von den bisher beschriebenen Pleurobranchaeen verschieden, besonders ist der Rücken vom Schwanze stark geschieden und überragt denselben.

\section{Oscaniopsis Bgh.}

R. BErGH, Die Pleurobranchiden I, I897, p. 53. (Malacolog. Unters. V, p. 53(-6I)). VAYSSIËRE, 1. c. II, I9OI, p. 6-I5.

Caput discretum nullum. Notaeum a velo (scuto) frontali (tentaculari) latissimo non discretum, applanatum, laeve, testa nulla; tentacula sicut rhinophoria distantia, lateralia, canaliculata. Rhachis branchiae serie nodulorum duplici instructa. Apertura genitalis simplex, Podarium magnum, infra massa glandulari caudali mediana magna praeditum.

Connectiva cerebro- et pleuro-pedalia brevia, sed distincta. - Mandibulae ex elementis applanatis compositae. - (Glans penis conulis seriatis armata). 
Diese Gruppe vermittelt einen Übergang von den Pleurobranchaeen zu den Oscanien. Der Rücken setzt sich wie bei jenen unmittelbar in den hier sehr breiten, mit den somit weit von einander entfernten Tentakeln endigenden Tentakelschild fort; die Rhinophorien stehen auch weit von einander; im Mantel fehlt auch jede Spur einer Schale. Die Oscaniopsen haben aber die kurze Form der Oscanien, und die Rhachis der Kieme trägt wie bei diesen eine doppelte Reihe von den Kiemenblättern entsprechenden Bläschen. Sie zeigen aber wie die Pleurobranchaeen einfache Genitalöffnung; auch, wie sowohl die Pleurobranchaeen wie die Oscanien, an dem sehr grossen Fusse eine Schwanzdrüse, eine fingerartige Papille fehlt aber wie bei den Oscanien. - Das Centralnervensystem stimmt mit dem der Oscanien, und ebenso der Bau der Mandibelplatten, die nicht wie bei den Pleurobranchaeen aus Säulen sondern aus Platten zusammengesetzt sind. Vielleicht ist die glans penis (wie sonst nicht bei den Pleurobranchiden gesehen) bei den Oscaniopsen mit gereihten Kegeln bedeckt.

Auf der Form des Tentakelschildes ihres Pleurobranchus luniceps gründeten H. und A. Adaxs (1 858) die Gattung $N e d a$, die von Gray (Guide, I, I857, p. 203) so wie fraglich auch von P. Fischer (Man. de conchyliol. i 887, p. 573) adoptirt worden ist. Die Gattung "Oscaniopsis" hat erst wirkliche generische Charactere geliefert, und es liegt kaum Grund vor die Benennung $\checkmark c d a$ wieder hervorzuziehen.

Die Gattung ist (s. unten) bisher nur durch ein Paar Formen aus dem Chinesischem und Indischen Meere (O. Semperi B.; O. compta B.; O. Amboinei Vayss. $\left.{ }^{1}\right)$ ) bekannt, welche vielleicht nicht einmal specifisch verschieden sind.

I. Oscaniopsis lnmiceps (Cuv.). Taf. III, Fig. 9. Taf. X, Fig. 30--37.

Pleurobranchus luniceps Cuv. Le règne animal. nouv. éd. III, I830, p. 59 note I, pl. XIV, fig 2. Pleurobranchus luniceps C. Voy. of the Samarang. AdAns and REEve, Moll. 1848, p. 66, pl. XVIII, fig. $6 a, b$.

Neda luniceps (C.). H. and A. AdAlis, the genera of recent moll., II, I858, p. 40, pl. 6I, fig. I, I $a$.

Oscaniopsis Amboinei Vayssière. Monogrr. de la fam. des Pleurobranchidés II. Ann. des sc. nat. S S., T. XII, I901, p. 15-20, pl. I.

Oscaniopsis Semperi Bgh. 1. c. 1897, p. 54-57, Taf. VI, Fig. 7-27.

Auf dem Riffe bei Ambon wurde ein Individum gefangen und lebend abgebildet.

Das lebende Thier hatte eine Länge von $4,8 \mathrm{~cm}$. bei einer Breite des Stirnsegels von 4,3 und einer Breite des Rückens von $2 \mathrm{~cm}$. Die Farbe des Oberkörpers war gelblich mit zahlreichen grösseren und kleineren rothbraunen Flecken, welche auch am Rande der sonst bläulichweissen oberen Fussseite vorkamen.

In Formol a ufbewahrt hatte das schlaffe Thier eine Länge von $4 \mathrm{~cm}$. bei. einer Breite (des Fusses) von 3 und einer Höhe von $1,7 \mathrm{~cm}$; der Stirnschild $3,7 \mathrm{~cm}$. breit, wovon die $8 \mathrm{~mm}$. jederseits den Tentakeln gehörten; die Länge und Breite des Rückens 23 mm., links ragte das Gebräm 4, rechts $8 \mathrm{~mm}$. frei hervor; die Länge der Rhinophorien 4; die Länge der Kieme $15 \mathrm{~mm}$. bei einer Höhe und Breite von 4, der Fuss ragte vorne $7 \mathrm{~mm}$. unter der 
Mundöffnung frei hervor. Die umgestuilpte Mundröhre war $x_{3} \mathrm{~mm}$. bei einer Breite von $\delta$ aus der Mundöfnung hervorgetreten. - Die Farbe war durchgehends hell schmutzig gelblich; am Rücken kamen (jetzt nicht reichlich zerstreute) kleine (bis $2 \mathrm{~mm}$. lange) rundliche und längliche schwarze Flecken vor, am Stirnsegel und oben am Fussrande ähnliche. - Die Muskulatur schimmerte überall stark durch, median vorne am Rücken und vorwärts besonders die Retractoren des Stirnsegels, durch die Nitte der Fusssohle schwarz die Eingeweide.

Die Form des Thieres war oval, nicht stark abgeplattet, mit grossem halbmondförmigem Stirnsegel, kleinem Rücken und grossem, ringsum den Körper überragendem Fuss. Der (ungenügend erhaltene) Vorderrand des Stirnsegels trägt eine einzelne, seltener doppelte Reihe von einfachen, seltener knotigen, 0,5-0,75 mm. hohen, weichen Zotten (Fig. 30), durch deren Axe ein Strang hinaufsteigt; das Aussenende des Segels zeigt eine Furche (Tentakel); das Stirnsegel ist sonst (wie die ganze Oberseite des Körpers) glatt. Zwischen den Rhinophorien geht der Rücken mit einer Breite von $8 \mathrm{~mm}$. in das Stirnsegel über; vom Grunde der Rhinophorien ab steht das Rückengebräm fluigelartig hervor und weiter nach hinten ragt es breit ïber die Körperseiten, stärker an der rechten Seite hinaus; der Rücken ist sehr wenig gewölbt; hinten ist er median ausgekerbt, und der umgeschlagene Rand der Einkerbung median zipfelartig ausgezogen (Fig. 3 I ). Am vorderen Ende der Kieme die praebranchiale Papille und unten an dieselbe stossend die Vulva. Nur das hintere ungefähre Fünftel der Kieme ragt frei hervor, die Anzahl ihrer Blätter etwa 50; am fast glasklaren Rande die zwei Reihen von Bläschen. Der Vorderrand des Fusses mit schwacher Furche und kleiner medianer Drüsenmasse; die Schwanzdrüse kaum ausgeprägt.

Das Centralnervensystem wie oben. Das Auge von 0,45 mm. Durchmesser, mit grosser, stark gelber Linse.

Die Mundröhre vorne grau. Der Schlundkopf dem des Osc. Semperi vollständig ähnlich; nur zeigte die Lippenscheibe (Fig. 32) eine kleine, sich dem Vorderende der Mandibelplatte anschliesende dunkelgraue dreieckige Fläche; die Länge des Schlundkopfs betrug I I mm. bei einer Breite von 7 und einer Höhe von $5 \mathrm{~mm}$. Die Mandibelplatten farblos; ihre Elemente bis $0,05 \mathrm{~mm}$. lang, ganz wie bei jener Art, nur war die Anzahl der Dentikel dieser Elemente vielleicht geringer. Die Wände der Mundhöhle sammtschwarz. Die Farbe der Raspel der Zunge wenn noch in situ auch schillernd schwarz mit kastanienbraunem Schimmer. In der Raspel kamen 62 Reihen vor, und in der Scheide noch 48, von denen die 12 noch nicht fertig entwickelt; die Gesammtzahl der Reihen somit I IO. In den Reihen wurden bis gegen 200 Zahnplatten gezählt. Die Platten der Zunge waren unten röthlichbraun, oben fast farblos; die Höhe der äussersten betrug $0,06 \mathrm{~mm}$, die der grössten war 0,20. In Formverhältnissen (Fig. 33, 34) stimmten sie ganz mit denen der O. Semperi.

Die sammtschwarze Speiseröhre $1,2 \mathrm{~cm}$. lang, in der hinteren Hälfte doppelt so breit wie in der vorderen. Der rundliche erste Magen hell schmutzig röthlichbraun, i I mm. lang bei anderen Durchmesser von Io; der zweite grau, $5 \mathrm{~mm}$. lang. Die Magen so wie der Darm mit Inhalt vollgestopft, der aus unbestimmbarer thierischer Nasse mit vielen Eiern bestand, nit Diatomeen und Sandkörnern vermischt.

Die Speicheldrüse weiss, $4 \mathrm{~mm}$. breit; ihre Gänge mit der gewöhnliche Ampulle vorne. 
Die Nebenspeicheldrüse wenig entwickelt, die bei der Osc. Semperi vorkommenden kleinen Endknospen fehlten; der weisse (gegen die schwarze Speiseröhre contrastirende) Ausführungsgang stark.

Die schwärzliche Leber $9 \mathrm{~mm}$, lang und breit bei einer Höhe von 7 .

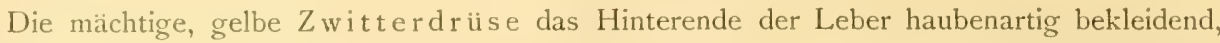
I $2 \mathrm{~mm}$. breit bei einer Dicke von 5; in den grossen Follikeln reife Eizellen. Die vordere Genitalmasse kugelförmig, von $7 \mathrm{~mm}$. Durchmesser, weiss und grau. In den oberhalb des Vestibulum genitale etwas eingeschnürten (3 mm. weiten) Schleimdrüsengang öfnet sich die kugelförmige braune Samenblase von $2 \mathrm{~mm}$. Durchmesser. Der grosse Knäuel des Samenleiters am Vorderende der Genitalmasse liegend; der Samenleiter milchweiss, weich mit zellenreicher ziemlich dünner (glandulöser?) Wand, im Grunde des Penissackes eintretend und durch den Penis bis an die Spitze fortlaufend. Die dünne, oben schwarz ringartig pigmentirte Vorhaut von der gelblichweissen Glans vollständig ausgefuillt. Dieselbe war (Fig. 35) kegelförmig, io mm. lang, bis an der Spitze mit meistens in Ringen gestellten weichen, niedrigen Kegeln (Fig. 36) bedeckt, welche meistens einen Durchmesser von $0,12-0,20 \mathrm{~mm}$. hatten und eine ähnliche Höhe; sie waren nur von dünner Cuticula überzogen (Fig. 37).

Es kann kaum bezweifelt werden, dass die hier vorliegende Form den Pleurobranchus laniceps von Cuvier (und Adams) darstellt. Sie ist ferner wohl mit der Oscaniopsis Amboinei von VayssiEke identisch, dann wohl auch mit meiner Osc. Semperi, und ob die Osc. compta von der letzteren verschieden sei, muss bei späterer Untersuchung von mehreren und gut erhaltenen Individuen abgemacht werden.

\section{Oscanius Leach.}

Oscaniuls. VAyssiÈre, 1. c. I, I 898 , p. 380.

Susania Gray. Guide. I857, p. 202.

Susania. VAYSSIÈRE, 1. c. I, I898, p. 357.

Vgl. R. Bergh, Malacolog. Unters. V, 3, 1898, p 62(-93).

Caput discretum; notaeum grosse tessellatum vel tuberculatum; testa interna ut plurimum magna, spira minuta, anfractu ultima applanata permagna; rhachis branchiae serie nodulorum duplici instructa; aperturae genitales, masculina et foeminina, sejunctae, lobis magnis, praesertim masculina, defensae. Podarium magnum, glandula caudali magna.

Connectiva cerebro- et pleuro-pedalia brevissima, commissura pediaea non longa. Mandibulae ex elementis applanatis elongatis compositae, hamo fere semper denticulato.

Die von Gray aufgestellte und von VAyssikere adoptirte Gattung Susania umfasst die mit kleinerem Fusse ausgestatteten Oscanien; dieselben unterscheiden sich aber in keiner typischen Weise von den Oscanien, und die Gattung wird wahrscheinlich als Synonym eingehen müssen.

Der fruher (1. c. p. 65-66) gelieferten Liste von Arten, von welchen mehrere Oscaniellen zu sein scheinen, werden die untenstehenden neuen Arten hinzuzufügen sein. 
I. Oscanius Woberi Bgh. n. sp. Taf. II, Fig. I. Taf. XI, Fig. I-6.

Am 26 Oct. wurde auf einem Riff bei Saleyer (St. 213) ein Individuum gefangen und dem Leben nach abgebildet.

Das Thier hatte 1 ebend eine Länge von $10,5 \mathrm{~cm}$. bei einer Breite von 7,5 ; dic Länge der Rhinophorien betrug I2, der Durchmesser der Rückenscheiben bis $20 \mathrm{~mm}$. - Die Farbe der Rückenseite war tief purpurroth; an derselben kam eine nicht grosse Anzahl (etwa 14) von grossen, wenig vortretenden Scheiben vor, die zwei ganz schmale, weisse Ringe zeigten; die Rhinophorien hatten die Farbe des Rückens.

Das a ufbewalirte Individuum war $8,5 \mathrm{~cm}$. lang bei einer Breite von 6,5 und einer Höhe von 2,8; die sehr flachen, ovalen Rückenscheiben bis I 3 mm. lang, ihre centrale Papille von $3 \mathrm{~mm}$. Durchmesser; das Rückengebrime von einer Breite bis 2,3 cm.; die Kieme $4 \mathrm{~cm}$. lang bei einer Breite bis 0,8 und einer Höhe bis I, $1 \mathrm{~cm}$; die Höhe der Rhinophorien I 2 mm., die Breite des Tentakelschildes $25 \mathrm{~mm}$. bei einer Höhe bis 9; die Breite des Fussgebräms 18, die Länge der Schwanzdrüse $17 \mathrm{~mm}$. - Die Farbe des Thieres war, wo nicht abgerieben, schwarzbraun, oben so wie unten; die Rückenscheiben zeigten eine (jetzt) mehr weissliche centrale Papille und einen undeutlichen dünnen, weisslichen Ring.

Die Formverhältnisse die gewöhnlichen der Oscanien. Der mediane Ausschnitt im Vorderrande des Ruickens aber wenig vortretend; die Scheiben der Rückenseite nur noch am eigentlichen Rücken sichtbar, die centrale Papille wenig vortretend; der Rücken sonst ziemlich eben, nur feinknotig. Fast die hintere Hälfte der grossen, schönen, mit 2 Reihen (à etwa 30) von rhachidialen Knoten versehenen Kieme frei (nicht angeheftet). Die Lappenbildungen an den genitalen Öffnungen ziemlich stark. Der Fuss etwa so lang und breit wie der Rücken, die Schwanzdrüse ziemlich stark ausgeprägt.

Die den vorderen Theil der Eingeweidemasse deckende Schale flach, oval, $25 \mathrm{~mm}$. lang bei einer Breite von 22; nur die mittlere Partie der Schale verkalkt, gelblichweiss, $13 \mathrm{~mm}$. lang bei einer Breite von Io, mit ganz kleiner weisser Spira; der übrige Theil der Schale ist ein breites cuticulares Gebräm (Fig. I).

Die Mundröhre $8 \mathrm{~mm}$. lang, weit. Der Schlundkopf von gewöhnlichen Formverhältnissen, ${ }_{5} \mathrm{~mm}$. lang bei einer Höhe und Breite von Io. Die schönen, hell kastanienbraunen Mandibel liegen im Innenmunde in einer Länge von $3 \mathrm{~mm}$. entblösst, und der nach aussen umgeschlagene Theil war auch $3 \mathrm{~mm}$. lang; iibrigens betrug die Länge derselben I I, $5 \mathrm{~mm}$. bei einer Höhe von 7. Die Elemente der Mandibel langgestreckt, bis o,38 mm. lang bei einer Breite (durch die Seitenhöcker) von O, I 3 und einer Höhe von 0,12; an jeder Seite des Grundes des spitzen Hakens ein kurzer spitzer Dentikel (Fig. 3). Die Zunge stark und breit, mit gelber Raspel, die Länge der letzteren mit sammt ihrer Fortsetzung von ihrer Unterlage gelöst betrug I $6 \mathrm{~mm}$. bei einer Breite von I3. In der Raspel mit ihrer Fortsetzung in die Scheide kamen in Allem gegen I 40 Zahnplattenreihen vor; und in den Reihen bis etwa 280 Platten. Die Zahnplatten von gelblicher Farbe; die Höhe der innersten betrug etwa 0,06 mm., und die Höhe der Platten stieg bis beiläufig 0,18 , die der äussersten betrug 0,05-0,06 mm. Die Formverhältnisse (Fig. 5) die gewöhnlichen, die äussersten mehr aufrecht und schlanker (Fig. 6). 
Ein Individuum, ebenso gross wie das obige wurde am Riffe von Haingsisi gefangen, und 2 etwas kleinere (von einer Länge von $7 \mathrm{~cm}$. bei einer Breite von 4,5) am „Riffe von St. 201" (Bara-Bai an der Nordküste der Insel Buru).

Bei einem dieser kleineren Individuen betrug die Anzahl der Zahnplattenreihen etwa 100, und die Zahl der Platten in den Reihen gegen 200.

Der mediane Einschnitt im Vorderrande des Rückens war bei dieser Form ziemlich gering, die Schale mehr nach vorne liegend, und die Falten an den Genitalöffnungen, insoweit beurtheilt werden konnte, nicht recht stark.

Diese Form steht jedenfalls in der Nähe des Pleurobranchus Perrieri von VAyssière 1. c., 1S9s, 1. 321-327, Pl. I3, Fig. 9; Pl. 23, Fig. 127-134; Pl. 24, Fig. 153-156).

Oscanius Weberi Bgh. var. Taf. XI, Fig. 2.

Auf dem Riffe von Ambon wurde ein Individuum gefangen. In Formol bewahrt war es ganz schlaff, etwas abgerieben.

Dasselbe hatte eine Länge der Rückenseite von $4,7 \mathrm{~cm}$. bei einer Breite von 3,4, die Körperhöhe betrug I,5 cm.; die Breite des Rückengebräms war I, I cm.; die Länge der Kieme $3,3 \mathrm{~cm}$. bei einer Höhe und Breite bis $7 \mathrm{~mm}$; die Breite des Tentakelschildes $9 \mathrm{~mm}$. und die Länge der Tentakel noch dazu 4 mm., die Länge der Rhinophorien 6 mm.; die Länge des Fusses $5 \mathrm{~cm}$. bei einer Breite von 3,5, die Breite des Fussgebräms $8 \mathrm{~mm}$, die Länge des Schwanzes IO, die der Schwanzdrüse etwa $6 \mathrm{~mm}$. - Die F arbe der Rückenseite war schwarz (oder bräunlichschwarz), die Unterseite des Rückengebräms so wie die Körperseiten bläulich, die Kieme röthlichgrau; die obere Seite des Fusses schwarzbraun, die Fusssohle gräulichblau.

Die Formverhältnisse die gewöhnlichen, der Fuss gross. Der Rücken zeigte etwa 6 unter einander verschobenen Reihen von wenig vortretenden einander an den Rändern meistens beruhrenden polygonal-ovalen Scheiben von einem Durchmesser von 3-9 mm., meistens mit ein wenig vortretender centraler Papille; der ganze Rücken war sonst überall mit ganz feinen Nöppchen bedeckt. Die Schale von der Mitte des Rückens sich nach vorne erstreckend, I I mm. lang, länglich, dünn, ihr Kalklager leicht zerbrechend, von farblosem Cuticular-Gebräm eingefasst (Fig. 2). - Die Kieme wie bei der typischen Form, mit 32 Blätterpaaren. Die Genitalfalten ziemlich stark und typischer Art.

Die runden, halbkugelförmigen Nöppchen des Rückens von einen Durchmesser von $0,16-0,20 \mathrm{~mm}$. In der Haut die bei den Oscanien meistens vorkommenden schlangenartigen Fäden reichlich zerstreut, aber weniger lang und etwas dicker.

Die weissliche Mundröhre $4 \mathrm{~mm}$. lang. Der hellgrüne Schlundkopf $7 \mathrm{~mm}$. lang bei einer Höhe und Breite von 6; die starken, röthlichcitrongelben Mandibelplatten wie oben und so auch ihre Elemente. Die Raspel der Zunge fast farblos, mit etwa 60 Zahnplattenreihen, von welchen die 12 ersten zu der mittleren Partie reducirt; die Gesammtzahl der Reihen etwa 100. In den Reihen kamen bis ungefähr 200 Platten an jeder Seite der ganz schmalen Rhachis vor. Die sehr schwach gelblichen Zahnplatten stimmten in ihren Verhältnissen ganz mit denén des typischen $O$. Weberi uberein. 
Die ganz schlaffe Eingeweidemasse war von grünlicher Farbe.

Noch eine andere Varietät war bei Elat an der Westküste der Insel Gross-Kei (St. 261) gefischt.

Dasselbe war 10,5 cm. lang bei einer Breite von 7 und einer Höhe von 3,7; die Breite des Tentakelschildes 2,6 cm., die Länge der Rhinophorien 1,6; die Breite des Rückengebräms 2,8 cm., die Länge der Kieme 5,3 bei einer Breite bis I, I und einer Höhe bis I,5; der Fuss etwa so lang und breit wie der Ruicken, sein Gebräm 2, I cm. breit, die Länge der Fussdruise 2,5 bei einer Breite von 1,2. - Die Farbe war auch durchgehends schwarzbraun; die Rückenscheiben weniger ausgeprägt. Der Länge des Rückens nach verliefen gleichsam zwei weisse, etwa I mm. breite Guirlanden, welche den Aussenrand von den kaum über die übrige Haut vortretenden, einander berührenden, ovalen (bis etwa I $6 \mathrm{~mm}$. langen) Scheiben bildeten; der übrige Contour der Scheiben war nur selten durch eine schwache weisse Linie angedeutet; eine centrale Papille war an den Scheiben kaum angedeutet. Der Rücken war übrigens feinknotig. - Die verkalkte Partie der Schale ganz zerbröckelt.

Trotz Abweichungen in Farbenverhältniss und Ordnung der Rückenscheiben so wie in Form der Schale liegen hier doch wohl nur Varietäten des $O$. Weberi vor.

2. Oscanius Sibogae Bgh. n. sp. Taf. XI, Fig. 7-9.

Am is Dec. wurde am Riffe von Elat an der Westküste der Insel Gross-Kei (St. 26I) ein Individuum gefischt.

Dasselbe hatte in Formol bewahrt und ganz schlaff eine Länge von $9 \mathrm{~cm}$. bei einer Breite von 5 und einer Höhe von 2,5; die Länge der Rhinophorien war 16 mm., die Breite des Tentakelschildes 20 bei einer Länge von I I mm. die Tiefe des medianen Einschnittes des vorderen Rückenrandes betrug $9 \mathrm{~mm}$., die Breite des Rückengebräms I 8 ; die Länge der schönen Kieme $4,5 \mathrm{~cm}$. bei einer Höhe von $9 \mathrm{~mm}$. und einer Breite bis $6 \mathrm{~mm}$; d das Fussgebräm bis $20 \mathrm{~mm}$. breit, die Länge der Schwanzdrüse $16 \mathrm{~mm}$. bei einer Breite von 6. -Die Farbe war jetzt hauptsächlich weiss (die Formol-Lösung war noch vollständig ungefärbt und klar), scheint aber röthlich violet gewesen zu sein, welche Farbe die Kieme, die Genitalfalten und die Rhinophorien noch bewahrt hatten, während.Spuren davon noch am vorderen Fussrande, am Ruickenrande, an der Schwanzdrüse und hier und da am Rücken und am Fussgebräme vorkamen.

Die Formverhältnisse die gewöhnlichen; der Rücken ganz eben, die mediane vordere Ausschweifung tief und breit. Die Rhachis der Kieme mit 30 Knotenpaaren, die Knoten der beiden Reihen schräge gegen einander gestellt; die secundären Rhachides mit ähnlichen kleineren Knoten; das verschmälerte ungefähre Drittel der Kieme frei hervorragend. Die Genitalfalten nicht stark. Der Fuss eben so lang und breit wie der Rücken; die Schwanzdrüse ziemlich stark.

Etwas vor der Mitte der Rückenlänge fand sich submedian und der Länge nach liegend die kleine, leicht zerbrechliche, kalkweisse Schale mit breitem cuticularem Gebräm; die verkalkte Partie maas an Länge $7 \mathrm{~mm}$. bei einer Breite von 5. die Anwuchslinien stark. 
Den Centralnervensystem gelblich, von $4 \mathrm{~mm}$. Breite, ganz wie bei anderen Oscanien. In der Haut konnten die bei den Oscanien sonst so häufig vorkommenden Schlangenartigen Fäden nicht nachgewiesen werden.

Die Mundröhre 4,5 mm. lang, an der Innenseite violetröthlich. - Der Schlundkopf $8,5 \mathrm{~mm}$. lang bei einer Höhe von 6 und einer Breite von 5, die Raspelscheide ziemlich stark vorspringend. Die Mandibel pomeranzfärbig, übrigens auch wie bei dem $O$. Weberi, so auch ihre Elemente, die nur kleiner waren, an Länge nur bis $0,20 \mathrm{~mm}$. bei einer Breite von 0,075 und einer Höhe von 0,09 messend (Fig. 7). Die Zunge wie gewöhnlich, in der blassgelben Raspel und ihrer Fortsetzung schienen in Allem etwa i Io Zahnplattenreihen vorzukommen, und in den Reihen bis beiläufig ${ }_{50}$ O Platten. Die gelblichen Zahnplatten (Fig. S) wie bei dem O. Weberi, vielleicht im Ganzen etwas schlanker, nur eine Höhe bis $0,1_{3} \mathrm{~mm}$. erreichend.

Die Speiseröhre $15 \mathrm{~mm}$. lang; der erste Magen länglich, $3 \mathrm{~cm}$. lang, bei einer Breite hinten von I,5; der zweite Magen kurz sackförmig, $2 \mathrm{~cm}$. lang bei einem Durchmesser von I,4; der dritte Magen mit stark durchschimmernden Längsfalten, etwa I,4 cm. lang bei einem Durchmesser von 0,9. Alle drei Magen waren mit Speise iberfüllt, hauptsächlich aus durch die Magenwand durchschimmernden, weisslichen, rundlichen und länglichen, meistens $6-12 \mathrm{~mm}$. langen, fast abgekalkten Individuen einer Synascidie (Didemnium sp.) gebildet,

Die schwarzgraue Leber, zum grössten Theil von der Zwitterdrüse und der Niere bedeckt, 2,5 cm. lang bei einer Breite von I, 8 und einer Dicke von $8 \mathrm{~mm}$.

Das von der Schale bedeckte Pericardium $16 \mathrm{~mm}$. lang, kurz-oval; die Vorkammer $8 \mathrm{~mm}$. lang. Die am Pericardium liegende gelblichweisse, gleichsam körnige Blutdrüse $12 \mathrm{~mm}$. lang, länglich oval. - Der fast farblose praebranchiale Sack in gerader Linie 6,5 mm. messend, an beiden Enden hornartig gebogen (Fig. 9); seine Innenseite mit schönem Wimperepithel mit Zellen von $0,03 \mathrm{~mm}$. Durchmesser bekleidet. - Die gräulichweise Niere etwa $2,5 \mathrm{~cm}$. lang bei einer Breite bis $6 \mathrm{~mm}$.

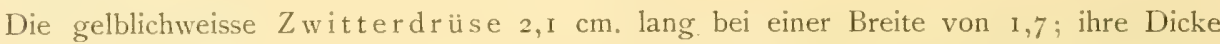
meistens nur $2 \mathrm{~mm}$. - Die vordere Genitalmasse $7 \mathrm{~mm}$. lang bei einer Breite von 5 und einer Höhe von 6; die fast kugelförmige, an der distalen Seite etwas vertiefte Prostata von $4 \mathrm{~mm}$. Durchmesser, weisslich; die Schleim-Eiweissdrüse weisslich.

Diese Form scheint von der Osc. Weberi verschieden.

\section{Oscanius papuligerus Bgh. n. sp.}

Am Riffe von Elat an der Westküste der Insel Gross-Kei (St. 26I) wurden Io Individuen gefischt.

Sie hatten eine Länge von 5-8,5 cm. Bei dem grössten Individuum betrug die Breite 6 und die Höhe $2 \mathrm{~cm}$; d die Länge der Rhinophorien war 15, die Breite des Tentakelschildes $25 \mathrm{~mm}$; die Breite des Rückengebrämes war 1,5 cm., die Länge der Kieme 5,5 cm. bei einer Höhe von 1,8 und einer Breite von $0,9 \mathrm{~cm}$; die Breite des Fussgebräms $2 \mathrm{~cm}$., die Länge der Fussdrüse war $2,2 \mathrm{~cm}$, bei einer Breite von I $\mathrm{cm}$. - Die Farbe war, wo nicht abgerieben, sammtschwarz (im Leben vielleicht dunkel purpurroth), die Kieme etwas mehr röthlich. 
Die Formverhältnisse im Ganzen die gewöhnlichen; die mediane vordere Einkerbung des Rückens ziemlich (etwa $13 \mathrm{~mm}$.) tief; am wenig gewölbten Rücken waren (bei keinem der Individuen) grössere Scheiben wie bei dem Osc. Webcri zu sehen und kleinere selten; derselbe war aber überall fein knotig, die Knoten rundlich, nicht stark vortretend, von $1-\mathrm{I}, 5 \mathrm{~m}$. Durchmesser mit kleiner centraler Papille; die Kieme sehr gross, mit 25 Kiemenblättern jederseits, die primären so wie die secundären rhachidialen Knoten sehr stark; die genitalen Lappenbildungen sehr entwickelt; der Fuss (bei den meisten Individuen) breiter als der Rücken, die Schwanzdriise sehr stark.

Die etwa in der Mitte der Körperlänge liegende Schale, deren Form- und andere Verhältnisse nicht bestimmt werden konnten, selır abgeplattet, ganz membranös (auch bei 3 anderen untersuchten Individuen war die Schale ganz membranös, (jetzt) ohne Spur ron Verkalkung).

Das Centralnervensystem wie bei anderen Oscanien. In der Rückenhaut die gewöhnlichen schlangenartigen Fäden.

Die Mundröhre $6 \mathrm{~mm}$. lang, ihre Innenseite schwarz. Der Schlundkopf $10 \mathrm{~mm}$. lang bei einer Breite (hinten) von 8 und Höhe von 7,5. Die bräunlichgelben Mandibel vorne in einer Breite von $3 \mathrm{~mm}$. umgeschlagen und ihre Innenseite noch in einer Breite von 2,5 $\mathrm{mm}$. entblösst; ihre Elemente bis $0,25 \mathrm{~mm}$. lang, von Form wie bei Osc. Weberi, der Haken jederseits mit $1-2$ kleinen Dentikeln. In der hell gelblichen Raspel schienen gegen So Zahnplattenreihen vorzukommen, die Anzahl derselben in der Scheide schien etwas grösser, die so hintersten nicht ganz entwickelt, die Gesammtzahl etwa 200; die Anzahl der Platten in den Reihen bedeutend. Die Zahnplatten schwach gelblich oder fast farblos; die äussersten aufrechten und geraden von einer Höhe bis 0,07 , die Höhe der Platten aber nur bis etwa O, I 2 steigend; die Form der Platten, der inneren, mittleren und äusseren, wie bei dem Osc. Wcberi.

Die ganz vorne an der Unterseite der Leber liegende, graue Speicheldruse klein (von $7 \mathrm{~mm}$. Breite); die Ausfuhrungsgänge schienen keine Ampulle zu haben. Die Nebenspeicheldrüse schwach entwickelt, ihre Röhre ziemlich dick; ihr sehr $(2,5 \mathrm{~cm}$.) langer Ausführungsgang mit kleiner Ampulle am Vorderende.

Die Speiseröhre $8 \mathrm{~mm}$. lang, bei einem Durchmesser von $2-2,5$. Der erste Magen an der rechten und unteren Seite der Leber liegend, $4 \mathrm{~cm}$. lang bei einer Höhe von $1_{5} 5$ und einer Dicke von 0,7 ; seine Wand duinn, und der Inhalt stark durchschimmernd; der $z$ weite, an der linken Seite des ersten liegende Magen $2 \mathrm{~cm}$. lang bei einer Breite von $I_{1}+$ und einer Dicke von 0,7 , seine Wand etwas dicker, etwas sehnenglänzend; der dritte, vom Vorderende des zweiten ausgehende Magen knieartig nach unten und rechts umbiegend, $1,4 \mathrm{~cm}$. lang mit anderen Durchmessern von 0,9 , mit stark durchschimmernden Längsfalten. Die Mägen, besonders der erste, mit Inhalt uiberfuillt, mit bis $15 \mathrm{~mm}$. langen weisslichen Synascidien-Stuicken. Der Darm $4 \mathrm{~cm}$. lang bei einem Durchmesser von 4-5 mm., fast leer. - Die dunkel schwarzgraue Leber $2,5 \mathrm{~cm}$. lang bei einer Breite von 2,2 und Dicke von $1,2 \mathrm{~cm}$.

Das Pericardium $2 \mathrm{~cm}$. lang bei einer Breite von $\mathrm{I}, 5$. Die am linken Rande desselben liegrende gelblichweisse Blutdrise $\mathrm{I}_{3} \mathrm{~mm}$. lang bei einer Breite von $\mathrm{I} 0$ und Dicke von 3 . Der praebranchiale Sack $8 \mathrm{~mm}$. lang bei einem Durchmesser von 2, gelblich. 
Die weissliche $\mathrm{N}$ iere so lang wie die Zwitterdrüse, $4 \mathrm{~mm}$. breit.

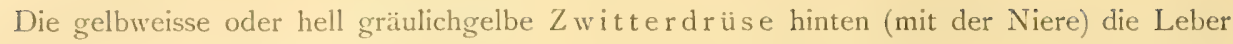
überragend, $2,8 \mathrm{~cm}$. lang bei einer Breite von $\mathrm{I}, 6 \mathrm{~cm}$. und einer Höhe (in der Mitte) bis 4,5 mm. Der von der Unterseite der Drüse hervortretende Zwitterdrüsengang mit seinen Korkzieherwindungen sich an die vordere Genitalmasse fortsetzend. Diese letztere rundlich, von $15 \mathrm{~mm}$. Durchmesser. Die Prostata rundlich, etwas abgeplattet, von $7 \mathrm{~mm}$. Durchmesser. Der dünne Samenleiter einen abgeplatteten Knäuel von Windungen bildend. Die kugelförmige Samenblase ron einem Durchmesser von $8 \mathrm{~mm}$; die stärker gelbliche Spermatocyste etwas gebogen (stark quergerunzelt), $6 \mathrm{~mm}$. lang bei anderen Durchmessern von 2. Die SchleimEiweissdrüse weisslich und gräulich. Der Zustand der ganzen Masse (auch bei den anderen Individuen) gestattete keine mehr eingehende Untersuchung.

Auch diese Form scheint von den vorigen verschieden.

\section{Oscaniella Bgh.}

R. Bergh, Die Pleurobranchiden. Malacol. Unters. V, 3, 1898, p. 94(-115).

Caput discretum; notaeum sat laeve, sed tessellatum; testa (interna) antica, sat parva, spira minuta, anfractu ultima applanata sat magna; rhachis branchiae serie nodulorum duplici instructa. Aperturae genitales, masculina et foeminina, sejunctae sed approximatae, lobis majoribus non defensae.

Connectiva cerebro- et pleuro-pedalia brevissima; commissura pediaea non longa.

Mandibulae ex elementis elongatis compositae.

Die Oscaniellen bilden gleichsam ein Übergangsglied zwischen den Oscanien und den ächten Pleurobranchen. Sie haben die allgemeine Körperform der Oscanien, auch den gefelderten Rücken derselben, die Felder sind aber viel kleiner; die Kieme, die Lage des Anus und die Schwanzdruse sind wie bei diesen. Den Oscaniellen fehlen aber die starken Faltenbildungen an den Genitalöffnungen, und die Schale ist kleiner und liegt (wie bei den ächten Pleurobranchen) meistens mehr noch vorne. In Bezug auf das Centralnervensystem, den Bau der Mandibelplatten und die Art der Speicheldrüse (Gland. salivalis) stimmen die Oscaniellen mit den Oscanien überein.

Die Gruppe gehört nur den wärmeren Meeresgegenden an besonders dem Indischen und Stillen Meere; von den wenigen angegebenen Arten (vgl. 1. c. p. 94-95) sind mehrere vielleicht nur Varietäten einer einzigen Art; und viele der als ächte Pleurobranchen beschriebenen Formen sind Oscaniellen ${ }^{1}$ ).

I. Oscaniella albiguttata Iigh. n. sp. Taf. II, Fig. 3. Taf. XI, Fig. 10-17.

Am Riffe von Pulu-Pasi-Tanette (St. 2 I3) und an der "Süd-Insel” wurden am 26 Oct. 3 Individuen gefangen, und das eine nach dem Leben abgebildet.

I) Solches gilt von einer ganzen Anzahl der bei VAYssiìre (1. c. I, ISgS, p. 30S-339) angeführten Formen (Pl. Peroni, Forskati, Perrieri, Moebci, Crossei, Giardi, areolatus, tessellatus). 
Das lebende Thier hatte eine Länge von $3,5 \mathrm{~cm}$. bei einer Breite von 2,2. Die Farbe des Rückens war röthlichbraun, heller und mehr gelblich am Gebrimt, überall mit kleinen, dunkler gerandeten Inselchen, ferner mit sparsam zerstreuten weissen Knötchen bedeckt: die ausgestülpte Mundröhre schien röthlichgelb, am Grunde bläulich.

Von den a ufbewahrten Individuen waren zwei fast ganz von desselben Grösse, das dritte kleiner. Die grösseren waren $25 \mathrm{~mm}$. lang bei einer Breite von 17 und einer Höhe von I4 mm.; die Höhe der Rhinophorien betrug 3,5, die Breite des Tentakelschildes (mit den Tentakeln) 8 mm.; die Breite des Rückengebräms war 3, die Länge der Kieme I3-I4 bei einer Breite von $3-4 \mathrm{~mm}$; der grosse Fuss hatte eine Breite von $\mathrm{I}_{3}-\mathrm{I} 4 \mathrm{~mm}$, das Fussgebräm von 2, die wenig ausgeprägte ovale Schwanzdrüse war etwa $5 \mathrm{~mm}$. lang. - Der Rücken war dunkelgrau, gegen diese Farbe contrastirten einige weisse Flecken; der Tentakelschild mit zahlreichen bräunlichen Fleckchen; die Körperseiten hell gräulich, ebenso die Fusssohle, die mit sehr zahlreichen bräunlichen Fleckchen ausgestattet war, so wie auch das Fussgebräm; die Ränder der Fussfurche rothbraun.

Die Formverhältnisse die gewöhnlichen. Der etwas gewölbte Rücken war mit dichtstehenden, kleinen und etwas grösseren Knötchen (von einem Durchmesser bis I,2 mm.) bedeckt, die rundlich, durch gegenseitigen Druck aber oft mehrkantig waren; sie waren meistens von einem dunkleren Hofe eingefasst; kleine Gruppen von diesen Paplen (von einem Durchmesser bis $3 \mathrm{~mm}$.) zeigten einen weisslichen Überzug (die weissen Flecken). Die schöne, lange, vorne etwas schmälere, nach hinten zugespitzte Kieme mit den 2 Reihen von klaren den 25-26 Blätterpaaren entsprechenden Knoten; nur das hintere ungefähre Viertel ragte frei hervor. Die Genitalöffnungen wie gewöhnlich. Der Vorderrand des Fusses mit der gewöhulichen langen Furche.

Ganz vorne, ein wenig links und fast querliegend die kleine, $4 \mathrm{~mm}$. lange, 2 breite, kalkweisse, stark erhärtete, sehr zerbrechliche Schale (Fig. 10); ihre Unterseite war hell röthlichgelb.

Das Centralnervensystem wie sonst bei den Oscaniellen. In der Haut des Rückens fanden sich in sehr grosser Menge die bei diesen Thierformen allgemein vorkommenden geschlängelten Fäden, besonders in und an den Papeln (Fig. I I).

Die Innenseite der Mundröhre rothbraun fleckig. Der Schlundkopf $7 \mathrm{~mm}$. lang bei einer Breite von 5 und einer Höhe von 4; die Raspelscheide hinten vortretend. Die Mandibel an den Wangen in einer Länge von $3 \mathrm{~mm}$. entblösst liegend, hier stark rothgelb, in der übrigen Strecke matt röthlichgelb; ihre rothgelben Elemente o, I $6 \mathrm{~mm}$. lang bei einer Breite von etwa $0,0 \&$ und einer Höhe von $0,09 \mathrm{~mm}$; an jeder Seite des Spitze ein, seltener zwei kurze Dentikel (Fig. I2, I3). In der fast farblosen Raspel des Zunge und ihrer Fortsetzung in die Scheide in Allem etwa 85 Zahnplattenreihen; in den Reihen kamen wenigstens So Platten vor. Die fast farblosen Zahnplatten erreichten eine Höhe bis wenigstens O, I4 mm. (Fig. 14-16), die äussersten hatten nur eine Höhe von $0,04-0,6 \mathrm{~mm}$. Die innersten Zahnplatten (Fig. I 4) waren ziemlich niedrig und einfach hakenförmig; danach wurde der Haken (Fig. I 5) höher und weniger gebogen, in der langen äusseren Strecke der Reihen entwickelte sich wieder die gewöhnliche Hakenform; die äussersten waren ganz niedrig (Fig. I6).

Die Speiseröhre fast $7 \mathrm{~mm}$. lang. Der erste Magen 15, der zweite $14 \mathrm{~mm}$. lang, der 
dritte kurz, mit den gewölnlichen Falten; der Darm mit gelblichweissem Speisebrei stark gefüllt, von unbestimmbarer thierischer Art. - Die Leber kurz kegelförmig, $15 \mathrm{~mm}$. lang, aussen und innen schwarz.

Der praebranchiale Sack $3 \mathrm{~mm}$. lang, mit weisslichen Kopf (Fig. I 7).

Die Zwitterdrüse grau, mit reifen Geschlechtselementen. Die vordere Genitalmasse oval, von $7 \mathrm{~mm}$. Lïnge weisslich und grau.

2. Oscaniella lugubris Bgh. n. sp. Taf. XI, Fig. I8-22.

Östlich von Dangar Besar in der Saleh-Bai (St. 3r3) wurden am Riffe 2 Individuen gefangen, die ziemlich zusammengezogen und wenig gut conservirt waren.

Das eine Individuum war etwas kleiner ( $4 \mathrm{~cm}$. lang) als das andere. Das grösste maas an Länge $5 \mathrm{~cm}$. bei einer Breite von 3 und einer Höhe von $2 \mathrm{~cm}$; die Breite des Rückengebräms war $7 \mathrm{~mm}$, die Länge der Rhinophorien $6 \mathrm{~mm}$; die Länge der Kieme $25 \mathrm{~mm}$. bei einer Höhe von 8 und einer Dicke von 6; die Breite des Tentakelschildes 24 mm., wovon jeder Tentakel 5 betrug, die Breite des Fussgebräms $6 \mathrm{~mm}$. - Die Farbe der Rückenseite war schwarzbraun, die der Unterseite viel heller, die Fusssohle fast gelblichweiss mit zahlreichen rothgrauen Fleckchen.

Die Formverhältnisse die gewöhnlichen. Der Rücken zeigte ziemlich scharf begrenzte, an einander stossende, runde oder ovale, oft polygonale (bis $9 \mathrm{~mm}$. in Durchmesser haltende) Felder, die mit gerundeten Knoten bedeckt waren. Die schöne grosse Kieme mit einer Doppeltreihe von (etwa 30) ziemlich grossen Blasen, ähnliche kamen ungewöhnlich stark entwickelt auch an den Rhachides der Pinnae vor. Der Fuss schien wenigstens so breit wie der Rücken, der Schwanz den letzteren überragend, eine Schwanzdrüse war nicht deutlich.

Die etwas vorne liegende röthlichweisse, sehr zerbrechliche, flache Schale (Fig. 18) $7 \mathrm{~mm}$. lang bei einer Breite von 5, mit breitem cuticularem Gebräm.

Die geschlängelten Fäden der Haut, die meistens bei den Oscaniellen vorkommen, zeigten sich im Rücken sehr stark entwickelt.

Der (schwach grülich-) graue Schlundkopf $7 \mathrm{~mm}$. lang bei einer Breite von 6 und Höhe von $5 \mathrm{~mm}$. Die Mandibelplatten matt gelb, $6 \mathrm{~mm}$. lang bei einer Höhe von 3, ihr Vorderrand nach aussen umgebogen; ihre Elemente bis $0,22 \mathrm{~mm}$. lang bei einer Breite bis 0,08 , der spitze Haken meistens mit 2-3 Dentikeln jederseits (Fig. I 9). In der bräunlichen Raspel der Zunge 30 Zahnplattenreihen, in der Scheide deren noch 38, von welchen die 3-4 hintersten unreif; die Gesammtzahl der Reihen somit 68. In den Reihen kamen jederseits wenigstens 200 Zahnplatten vor. Dieselben waren von gewöhnlicher Hakenform, von einer Höhe bis O, IO mm.; die (Fig. 20) inneren und äusseren (Fig. 22) mehr gebogen, die mittleren mehr aufrecht (Fig. 2I), alle glattrandig.

Die Speiseröhre $9 \mathrm{~mm}$. lang; der erste Magen $20 \mathrm{~mm}$. lang bei einem Durchmesser von 12; der zweite kugelförmig, von einem Diam. von $9 \mathrm{~mm}$.; der dritte $5 \mathrm{~mm}$. lang. Die beiden ersten Magen mit Stücken einer Synascidie gefüllt, die einen Durchmesser bis $6 \mathrm{~mm}$. erreichten. Die hintere Eingeweidemasse $2 \mathrm{~cm}$. lang bei einer Höhe von I und Breite von I,2. 
Die Leber schwarzgrau. - Die weisse an der Unterseite der Leber geheftete Zwitterdrüse $20 \mathrm{~mm}$. lang bei einer Breite von I2 und einer Dicke von 5. Die vordere Genitalmasse fast kugelförmig, von to mm. Durchmesser, gelblich und gelblich-grau. Der Penis zwischen den (masculinen) Faltenbildungen $4 \mathrm{~mm}$. frei hervorragend.

Diese Form scheint von den anderen Oscaniellen des Indischen Meeres verschieden.

3. Oscaniella purpurea Bgh. Taf. V, Fig. 4. Taf. XI, Fig. 24-28.

Oscaniella purpurea Bgh. 1. c. III, 3. I897, p. 95-98 (I03). Taf. VIII, Fig. 28-39.

Pleurobranchus Peronii v. Martens. Beitr. z. Meeresfauna d. Insel Mauritius und der Seychellen, 1890, p. 309.

Pleurobranchus Peronii Vayss. 1. c. I, I898, p. 308-3I5. Pl. XIIJ, Fig. 6-7; PI. XXI, Fig. $108-1 \mathrm{I} 3$.

Am Riffe zwischen Nusa Besi und der Nordostspitze von Timor (St. 282) wurde ein Individuum gefangen und dem Leben nach abgebildet.

Das lebende Thier hatte eine Länge von fast $7,5 \mathrm{~cm}$. bei einer Breite bis rolle 3 ; der Schwanz überragte den Körper mit I vollen $\mathrm{cm}$, die Länge der Rhinophorien betrug $7 \mathrm{~mm}$. - Der gleichsam feinknotige Rücken mit sammt der Rhinophorien war purpurroth, der Schwanz ein wenig heller.

Das a ufbewahrte, stark zusammengezogene und etwas verbogene Individuum war etwa $3,2 \mathrm{~cm}$. lang bei einer Breite von 2,2 und Höhe von 1,5 ; die Länge der Rhinophorien war 4, die Breite des Tentakelschildes 8, die Breite des Rückengebräms 5 mm, die Breite des Fusses 20, die des Fussgebrämes $5 \mathrm{~mm}$., die Länge des Schwanzes 7 und die der grossen, stark gerunzelten Fussdruise 1 I $\mathrm{mm}$. bei einer Breite von 6. Die Länge der Kieme $1_{5}$ bei einer Breite bis 4. - Die Farbe des Rückens war schmutzig purpurroth wegen der dichtstehenden, runden und ovalen, mitunter auch polygonalen, wenig vorragenden Flecken (Kinötchen) von einem Durchmesser bis $2 \mathrm{~mm}$; sie waren durch enge röthlichgelbe Zwischenräume (Fig. 24) immer von einander geschieden, oft mit kleiner dunklerer Papille; die Rhinophorien und das Tentakelschild purpurfarbig; die Unterseite des Rückengebrämes schmutzig purpurfarbig, aber heller als der Rücken, ebenso die Genitalfalten und die Kieme; das Fussgebräm oben und der Schwanzrücken purpurfarbig, die Fusssohle gelblich, die Fussdrüse mehr gräulich.

Die Formverhältnisse die gewöhnlichen, der Vorderrand des Rückens wenig ausgerandet; die Genitalfalten ziemlich stark, etwa $3 \mathrm{~mm}$. hoch; die Kieme mit etwa 30 rhachidialen Knotenpaaren, das letzte Viertel frei hervorragend.

Die vorne liegende kurz-ovale Schale ganz dünn, cuticular, mit schwachen Spuren von Verkalkung, die Nuclealpartie wenig ausgeprägt.

Die Haut des Ruickens enthielt Massen von den bei diesen Thieren vorkommenden schlangenartigen Fäden; die kleinen centralen Papillen der Rückenknötchen pigmentlos.

Der Schlundkopf (stark zusammengezogen) $6 \mathrm{~mm}$. lang bei anderen Durchmessern von 5; der umgebogene Theil der dunkel ambergelben Mandibel $2 \mathrm{~mm}$. breit, ihre Elemente (Fig. 25) 0,20 mm. lang bei einer Breite von 0,9 und fast derselben Höhe, der kurze Haken 
ziemlich unregelmässig denticulirt, an dem entblösst liegenden Theile fehlten die Dentikel meistens (abgerieben). In der gelblichen Raspel der Zunge wurden 48 Zahnplattenreihen gezählt, in der Scheide deren noch 56 , von denen die 6 hintersten unreif; die Gesammtzahl der Reihen somit 104. In den Reihen wurden bis 150 Platten gezählt. Die Zahnplatten fast farblos; die Höhe der innersten (Fig. 26) betrug 0,04 mm., die Höhe der Platten stieg bis 0,09 (Fig 27) um nach aussen wieder zu sinken, die der 8 . von aussen ab war 0,07 , und die äusserste (Fig. 28) maass an Höhe nur 0,0$\}-0,035 \mathrm{~mm}$. Die Form war die gewöhnliche hakenartige, aber ohne Spur von Denticulation.

Die Mägen waren vollgepackt mit Colonien von grünlichen Synascidien (Didemnium) von einem Durchmesser bis fast $5 \mathrm{~mm}$. Die Leber grau.

In den Läppchen der grossen gelbrothen Zwitterdriise reife Geschlechtselemente. Die weissliche und gelbliche vordere Genitalmasse unregelmässig rund, von $8 \mathrm{~mm}$. Durchmesser.

Diese Art steht dem Osc. Semonis ${ }^{1}$ ) ziemlich nahe, unterscheidet sich aber durch andere Zeichnung der Rückens so wie durch etwas verschiedenen Raspelbau.

Der Pleurobranchus Peronii von Cuvier wird unbestimmbar bleiben; der Name ist später auch von Quoy und Gaimard, von delle Chiaje, Sevox u. A. für verschiedene Formen angewendet. Ich habe deshalb vorgezogen der Art einen neuen specifischen Namen zu geben.

4. Oscaniella purpurascens Bgh. n. sp. Taf. XI, Fig. 29-37.

Am Riffe von Pulu-Pasi-Tanette (St. 213) wurden zwei Individuen von fast derselben Grösse gefangen.

Dieselben waren ziemlich stark zusammengezogen; das grösste $2,8 \mathrm{~cm}$. lang bei einer Breite bis I,5 und einer Höhe bis I,3; die Länge der Kieme war Io mm. bei einer Breite bis 3 , die letzten $3 \mathrm{~mm}$. frei hervorragend; die Höhe der Genitalfalten $2 \mathrm{~mm}$; die Breite des Fusses war I 5 mm., die Länge der Fussdrüse 5 bei einer Breite von 4. - Die Farbe des Ruickens war rothgrau, dichtstehende kleine weissliche, rothbraun eingefasste Fleckchen (Fig. 29) zeigend; der Kopf, die Unterseite des Mantelgebräms und der Fuss gräulich, die Kieme hell röthlichgrau.

Die Formverhältnisse wie bei der vorigen Art, die Kieme mit etwa 28 Knotenpaaren.

Die ziemlich vorne querliegende längliche Schale (Fig. 30) oben und unten kalkweiss, ziemlich hart, mit dünner gelblicher Cuticula, mit deutlicher Nuclealpartie, $5 \mathrm{~mm}$. lang bei einer Breite von 3,75 .

Die grossen Augen ron $0,30 \mathrm{~mm}$. Durchmesser. In der Rückenhaut die gewöhnlichen schlangenartigen Fäden (Fig. 3I), meistens von einem Durchmesser von 0,0055 mm.

Der stark zusammengezogene $\mathrm{Schlundkop/f} 5,5 \mathrm{~mm}$. lang. Die Elemente der gelben Mandibelplatten bis $0,16 \mathrm{~mm}$. lang, ihre vordere Hälfte etwas schmäler als bei der vorigen Art, sonst wie bei dieser (Fig. 32). In der gelblichen Raspel kamen 42 Zahnplattenreihen vor, in der Scheide 26 (von denen die 6 unreif), in Allem nur 68. In den Reihen fanden sich bis

I) Vgl. R. Bergil, Die Pleurobranchiden. 1.c. I897, p. 91-93. Taf. XIl, Fig. 21-31. 
etwa I 40 Platten. Die Platten waren gelb, die äussersten farblos; die Höhe der innersten betrug 0,04 , dieselbe erhob sich bis zu 0, I 3 mm.; die der drei äussersten war $0,06-0,07-0,08$. Die innersten kleinen Zahnplatten (Fig. 33) von gewöhnlicher Hakenform, und durch die grösste Länge der Reihen (Fig. 34, 35) war diese Form bewahrt, in der äussersten Strecke (Fig. 36) waren die Platten aber mehr gerade, und die äussersten aufrecht und fast gerade, mit reducirtem Grundtheil (Fig. 37).

Der dritte Magen und ein langer Theil des Darmes mit starken schmutzig gelben Längsfalten; die Mägen mit weisslichen und schwärzlichen Synascidien-Massen voll gepackt. Die hintere Eingeweidemasse I $2 \mathrm{~mm}$. lang bei einer Breite von 9; aussen grau (Zwitterdrüse), innen schwarz (Leber).

In den Zwitterdrüse-Läppchen reife Eier; die vordere Genitalmasse unregelmảssig rund, von $5 \mathrm{~mm}$. Durchmesser.

Diese Thierform steht der vorigen sehr nahe, scheint aber specifisch verschieden schon durch etwas andere Zeichnung des Rückens, besonders aber durch andere Beschaffenheit der Raspel.

5. Oscaniella dubia Bgh. n.? sp. Taf. XI, Fig. 23.

Am 28 Aug. wurde am Ankerplatz zwischen der Insel Gisser und Ceram-Laut (St. I 72) ein Individuum gefischt.

Dasselbe war schlecht conservirt und die (braune) Farbe fast iiberall abgerieben, $3 \mathrm{~cm}$. lang bei einer Breite von I,7 und einer Höhe von I; die Breite des Tentakelschildes 9 mm.; die Länge der Rhinophorien \& mm., die Breite des Rückengebräms 6 mm., der Durchmesser der Rückenknoten bis $3 . \mathrm{mm}$. betragend; die Länge der Kieme I I $\mathrm{mm}$. bei einer Breite in der Mitte von 3; die. Breite des Fusses $15 \mathrm{~mm}$., die des Fussgebrämes 5, des Schwanzes $8 \mathrm{~mm}$. - Die Farbe war schmutzig yräulich, die Papel des Ruickens zeigten oft eine schwärzliche schwache Einfassung; der Fussrand zeigte eine schwarze Linie.

Die Formverhältnisse die gewöhnlichen. Der Rücken mit zahlreichen, ziemlich grossen, gerundeten Knoten. Die 'schöne Kieme mit der gewöhnlichen Doppelreihe von klaren Knoten am Grunde der etwa 25 Blätterpaare. Die doppelte Genitalöffnung mit einfacher Einfassung der Genitalöffnungen. Die Schwanzdrüse wenig ausgeprägt.

Eine Schale fehlte, war aber in der Gegend des Pericardiums vielleicht durch Eindruck ihres Randes angedeutet, sie wäre dann kurz eiförmig gewesen, $8 \mathrm{~mm}$. lang.

Die bei den Oscaniellen sonst in Menge vorkommenden geschlängelten Fäden schienen hier sparsamer vertheilt und meistens stark aufgerollt.

Die Nundröhre 2,5 mm. lang. Der Schlundkopf stark zusammengezogen, $5 \mathrm{~mm}$. lang bei einer Breite von 4 und einer Höhe von 3,5. Die gelben Mandibelplatten wie gewöhnlich; ihre Elemente $0,12 \mathrm{~mm}$. lang bei einer Höhe von 0,05 und ähnlicher Breite, von gewöhnlicher Form, mit einem kleinen Dentikel an jeder Seite des kurzen Hakens. Die blasse Raspel der Zunge enthielt etwa 33 Zahnplattenreihen, in der Scheide fanden sich deren 21, die Gesammtzahl der Reihen somit 54; in den Reihen schienen bis etwa I50 Platten 
vorzukommen. Die Zahnplatten fast farblos, von gewöhnlicher Hakenform, bis $0,14 \mathrm{~mm}$. hoch; die äussersten 6 hatten nur eine Höhe von $0,020-0,04 \mathrm{~mm}$. Die innersten Platten zeigten den Haken glattrandig und ebenso die äussersten (etwa 20), bei den anderen (Fig. 23) kam eine äusserst feine Denticulation vor.

Die Leber grau. Die vordere Genitalmasse gelblichweiss.

Vielleicht liegt hier eine neue Art vor; sie scheint von der Osc. incrmis verschieden.

6. Oscaniclla inemis Bgh. n. sp. Taf. XII, Fig. 16-22.

Am 28 Aug. wurde am Ankerplatz zwischen der Insel Gisser und Ceram-Laut (St. 1 72 ) am Riffe ein Individuum gefangen.

Dasselbe war in (4\%) Formol bewahrt ziemlich zusammengezogen, verdreht und erhärtet. Die Länge betrug etwa $4,5 \mathrm{~cm}$. bei einer Breite von 3,5 und einer Höhe von 1,6; die Breite des Tentakelschildes (mit den Tentakeln) war I3 mm., die Länge der Rhinophorien 6; die Breite des gegen den Rand stark verdunnten Mantelgebrämes $13 \mathrm{~mm}$., die Länge der Kieme $23 \mathrm{~mm}$. bei einer Breite bis 7 , der Penis ragte $6 \mathrm{~mm}$. aus der Genitalöfnung hervor; der grosse Fuss hatte eine Breite von 25 mm., das Fussgebräm von 7 , der Schwanz eine Länge von 7 , die grosse ovale Fussdrüse war I I mm. lang bei einer Breite von 5,5. - Das Thier hatte sicherlich im Leben nicht die jetzige durchgehende Milchfarbe gehabt; die Knötchen und kleinen Felder des Rückens zeigten nämlich eine violetgraue Einfassung. In der Mitte des Rückens schimmerte ein Eingeweide graublau und an der Fusssohle ein anderes grau durch am Grunde der Rhinophorien hinten die grossen Augen.

Die Formverhältnisse wie gewöhnlich bei den Oscaniellen. Der mit seinem Gebräm den Fuss uiberragende, etwas gewölbte. Ruicken zeigte in seiner vorderen Hälfte reichliche Knötchen von einem Durchmesser von 0,5-I,25 mm., in der hinteren Hälfte waren sie kleiner und standen in kleinen polygonalen Feldern von einem Durchmesser bis $3 \mathrm{~mm}$. Der Vorderrand des Rückens median ein wenig ausgekerbt. Die männliche Genitalöffnung von einer ziemlich niedrigen Falte eingefasst; hinter derselben die weibliche mit wulstigem Rande. Die Kieme, deren hinteres fast Drittel frei hervorragte, mit etwa 22 Blätterpaaren mit entsprechenden klaren Knoten an der Rhachis. Oberhalb des Grundes der freien Spitze der Kieme der Anus. Der Vorderrand des Fusses mit starker Furche, die sich nach hinten eine Strecke längs der Seitenränder fortsetzt.

Es konnte keine Spur einer (membranösen) Schale nachgewiesen werden.

Das Centralnervensystem wie gewöhnlich. Die Augen von einem Durchmesser von (1,37 mm. In der $\mathrm{Haut}$ des Ruickens eine Menge der bei den Oscaniellen allgemein vorkom. menden geschlängelten, an den Enden oft eingerollten, bei dieser Art ungewöhnlich langen Fäden von einem Durchmesser bis fast 0,007 mm. (Fig. 16).

Die Mundröhre $5 \mathrm{~mm}$. lang, aussen grau, innen rothbraun. Der stark zusammengezogene Schlundkopf \& mm. lang, bei einer Breite von 5,5 und einer Höhe von 5. Die schön bräunlichgelben Mandibelplatten im $3 \mathrm{~mm}$. hohem Vorderende stark nach aussen umgebogen; 
ihre dunkle Elemente ron einer Länge von $0,16 \mathrm{~mm}$. bei einer Breite (durch die Höcker) von 0,065 und fast derselben Höhe, der Haken trug jederseits $1-3$ kleine Dentikeln (Fig. I7-19), an dem blossliegenden Theil der Mandibel waren dieselben abgenutzt (Fig. is). Die Z unge weisslich; in der fast farblosen Raspel kamen etwa 50 Zahnplattenreihen vor, in der Scheide, wie es schien, ungefähr 30. In den Zahnplattenreihen schienen etwa I 20 Platten vorzukommen. Die Platten waren von gewöhnlicher Hakenform (Fig. 20-22), der Haken der innersten (Fig. 20) war etwa $0,05 \mathrm{~mm}$. hoch, der Haken erreichte allmählig eine Höhe bis $0,15 \mathrm{~mm}$, die äussersten waren weniger gebogen (Fig. 22).

Die Speiseröhre $\mathrm{S} \mathrm{mm}$. lang bei einem Durchmesser von 2. Die Länge des ersten Magens so wie des zweiten betrug $15 \mathrm{~mm}$., sie waren beide grünlichschwarz; der dritte hatte die gewöhnlichen Falten. Die Leber $22 \mathrm{~mm}$. lang bei einer Breite von I I, weisslich. - Die grosse Herzkammer $8 \mathrm{~mm}$. lang.

Die vordere Genitalmasse I I mm. lang bei einer Dicke und Höhe von 9. Der sich durch den Penis schlängelnde Samengang trat mit der Spitze frei hervor.

Es lag hier ganz bestimmt, den verschiedenen Characteren nach, eine Oscaniclla vor, welcher aber eine Schale, wie bei der Plenrobranchaca und der Oscaniopsis, fehlte (so wie vielleicht auch bei einigen Pleurobranchen und Berthellen).

7. Oscaniella modesta Bgh. n. sp. Taf. XII, Fig. 23-27.

Am Ankerplatz zwischen Nusa Besi und der nordöstlichen Spitze von Timor (St. 2\$2) wurde ein Individuum aus einer Tiefe von 25-30 NI. gefischt.

Die Länge desselben betrug $14 \mathrm{~mm}$. bei einer Breite von 9 und Höhe von 5; die Länge der Kieme 6 bei einer Breite von 2; der Fuss $10 \mathrm{~mm}$. breit, die Länge der Fussdrüse 5 bei einer Breite von $2 \mathrm{~mm}$. - Die Grundfarbe war gelblichgrau; der Rücken mit kleinen, unbedeutend vortretenden Augenflecken von einem Durchmesser bis 0,25 mm. dicht bedeckt (Fig. 23), mit heller Pupille, bräunlicher Einfassung. Durch den Rücken schimmerte undeutlich die Schale.

Die Formverhältnisse die gewöhnlichen. Die Genitalfalten nicht stark, hinter denselben die praebranchiale Öffnung, die Kieme jederseits mit etwa 20 Blättern und entsprechenden Knoten, ihr hinteres ungefähre Drittel frei hervorragend. Der Fuss gross, die Fussdrüse sehr stark ausgeprägt.

Die weit nach hinten liegende, stark verkalkte Schale (Fig. 24) stark abgeplattet, mit fast parallelen Seitenrändern und kleiner Spira, $6 \mathrm{~mm}$. lang bei einer Breite von 3, kalkweiss, vorne und an der Unterseite mehr gelb.

Die Augen von 0,28 mm. Durchmesser, die Otocysten 0, I $2 \mathrm{~mm}$. messend, mit Otokonien voll gepackt. In der Haut kamen die gewöhnlichen geschlängelten Fäden vor.

Die Mundröhre 2,5 mm. lang. Der zusammengezogene Schlundkopf $5 \mathrm{~mm}$. lang bei einer Breite von 3 und Höhe von 3. Die Mandibelplatten bräunlichgelb; ihre Elemente (Fig. 25, 26) von einer Länge bis 0,14 bei einer Höhe und Breite von 0,07 mm., mit I- 3 feinen Dentikeln des Hakens. In der gelblichen Raspel to Zahnplattenreihen, in der Scheide 
deren noch 32, die Gesammtzahl desselben somit 72; zu jeder Seite der ganz schmalen Rhachis wenigstens 80 Platten. Die fast farblosen Platten (Fig. 27) von einer Höhe bis 0,06 mm., von gewöhnlichster Hakenform.

\section{Pleurobranchus Cuv.}

Pleurobranchus Cuv. Mém. sur la Phyllidic et sur le Pleurobranche. Ann. du MLus. V, I805, p. 266-277, Tab., Fig. I-6.

Plentrobranchus Cuv. Bgh. Malacolog. Unters. V, 3. I897, p. II7(-148), Pl. XLIII, Fig. I.

Eouvicria Vayssière. Mlonogr. de la fam. des Pleurobranchidés. I, I898, p. 280.

Caput discretum; notaeum quasi laeve; testa interna calcarea vel subcalcarea, spira minuta, anfractu ultima permagna, applanata; rhachis branchiae laevis; apertura genitalis simplex; podarium non magnum, sine massa glandulari caudali.

Connectiva cerebro- et pleuro-pedalia non longa, nec commissura pediaea longa.

Mandibulae ex elementis nonnihil applanatis confertis hamo ut plurimum laevi compositae. Dentes linguales humiles, hamiformes.

Die von VAysstère aufgestellte Gattung Bouvicria unterscheidet sich durch keinen der (etwas unsicher) angegebenen Charactere von dem ächten Pleurobranchus und muss als Synonym dieser jetzt expurgirten Gattung bleiben.

Im Äusseren unterscheiden sich die Pleurobranchen nicht viel von den Oscaniellen, zeigen aber die Rhachis der Kieme glatt (ohne Knoten) und haben keine Schwanzdrüse. Die Zahnplatten sind niedrig, hakenartig.

Eine Anzahl von zum grossen Theile zweifelhaften Arten (vgl. 1.c. I897, p. I I8-I 20) ist angegeben.

I. Pleurobranchus griseus Bgh. 11. sp. Taf. III, Fig. S. Taf: XI, Fig. $38-40$.

Am Riffe von Saleyer (St. 2I3) wurde ein Individuum gefangen und lebend abgebildet.

Lebend hatte dasselbe eine Länge von $3,3 \mathrm{~cm}$. bei einer Breite von 1,6 , das Tentakelschild war $12 \mathrm{~mm}$. breit, die Rhinophorien $5 \mathrm{~mm}$. lang. Die Farbe der Rückenseite war dunkelgrau mit zerstreuten dunkleren kleinen Flecken (die vielleicht im Centrum von kleinen Feldern standen); die Rhinophorien grau, der Tentakelschild weisslich.

Das a ufbewahrte Individuum hatte eine Länge von $2,5 \mathrm{~cm}$. (bei stark zurückgezogenem Kopfe) bei einer Breite von I,6 und einer Höhe von $0,8 \mathrm{~cm}$; die Breite des Tentakelschildes $6 \mathrm{~mm}$; die Breite des Mantelgebräms bis 5 (nur hinten bis 8 ) mm.; die Länge der Kieme 6,5 bei einer Breite bis 2,5 mm.; die Länge des Fusses 17 bei einer Breite von 9 , die Breite des Fussgebrämes bis $3 \mathrm{~mm}$. - Die Farbe des Mantels war hell grau mit dunkleren rundlichen Fleckchen, die (hier und da) das Centrum von kleinen rundlichen oder polygonalen, an einander stossenden Feldern zu bilden schienen, noch dazu kamen graue und weisse zerstreute Punkte vor; die Rhinophorien und die Kieme waren dunkel grau; die Unterseite des Thieres war heller, theilweis weisslich, am Mantel- und Fussgebräm fanden sich auch weisse Punkte vor. 
Die Formverhältnisse die gewöhnlichen, das Nantelgebräm ziemlich breit. Die Kieme ziemlich kurz, mit I 3 Blättern, nur das Hinterende frei; die Genitalöffnungen einfach. Der Fuss nicht klein.

Es fand sich keine Spur einer Schale oder von Verkalkungen an der obligaten Stelle einer solchen.

Das Centralnervensystem wie bei anderen Pleurobranchen.

Die Mundröhre $2 \mathrm{~mm}$. lang, grau. Der Schlundkopf 2,5 mm. lang, abgeplattet, weisslich. Die blassgelben Mandibel wie gewöhnlich; ihre Elemente (Fig. 38 ) gelblich, 0,06 mm. lang bei einer Breite von 0,03 und Höhe von 0,025 , mit spitzem Haken. In der fast farblosen Raspel etwa 33 Zahnplattenreihen, in der Scheide deren noch 25. In den Reihen schienen bis etwa I 20 Platten vorzukommen. Die Zahnplatten von gewöhnlichster Hakenform (Fig. 39, 40) eine Höhe bis $0,05 \mathrm{~mm}$. erreichend.

Die Leber etwas mehr als halbkugelförmig, $4 \mathrm{~mm}$. lang bei einer Höhe und Breite von 5, schwarz, die Farbe hier und da als fleck- und strichartige Insel in dem ziemlich dicken gelblichweissen überziehenden Lager der Zwitterdruse vortretend.

Die ziemlich abgeplattete, ovale, granulirte, weissliche Blutdriise $2,5 \mathrm{~mm}$. lang.

2. Pleurobranchus latipes Bgh. n. sp. Taf. XI, Fig. 4I-42.

Am I2 Febr. wurde $2^{1} \frac{1}{2}$ Meilen von der Küste des Gunong Api (St. 3 10) am Sandboden ein Individuum gedretscht.

Dasselbe war aufbewahrt sehr zusammengezogen, etwas verdreht, sehr erhärtet. Seine Länge betrug etwa 30 bei einer Breite von 20 und einer Höhe von $13 \mathrm{~mm}$; die Breite des Tentakelschildes war I I, die Höhe der Rhinophorien 4,5 mm,; die Länge des Rückens I 6 bei einer Breite von II, die Breite des Rückengebräms I-2 mm.; die Länge der Kieme I 7 bei einer Breite von $5 \mathrm{~mm}$, die Analpapille I mm. hoch; das Fussgebräm $5 \mathrm{~mm}$. breit, hinten (beim Schwanze) 8. - Die Farbe der Unterseite gelblichweiss, der Fussrand schwarz; die Körperseiten weisslich, die Kieme gelblich; auch die obere Seite (der Rücken, der Tentakelschild) und das Fussgebräm waren weisslich, oder mit vielen zerstreuten schwärzlichen Flecken, wahrscheinlich Überreste einer diffusen dunklen Farbe, versehen; die Rhinophorien schwarz und ebenso der Rückenrand.

In den allgemeinen Formverhältnissen erinnerte das Thier mit seinem grossen, den Rücken ringsum stark überragendem Fuss etwas an eine Oscaniopsis. Der Rücken nicht vorne ausgerandet, mit ziemlich schmalem Gebräm, wenig gewölbt, ganz eben. Die Rhinophorien stark; der Tentakelschild ziemlich abgeplattet, die Tentakelfurche $3,5 \mathrm{~mm}$. lang. Die etwas hervortretende Genitalpapille mit zwei einfachen Öfnungen. Dicht vor der Kieme die praebranchiale Öfnung. Die starke Kieme mit fast ihrem hinteren Drittel frei hervorragend, mit glatter Rhachis und etwa i 6 Blätterpaaren. Der Fuss gross, mit breitem Gebräme, ohne Schwanzdrüse.

Es fand sich keine Spur einer verkalkten oder cuticularen Schale.

Der Schlundkopf $6 \mathrm{~mm}$. lang bei einer Höhe und Breite ron 5; die Raspelscheide zwischen den Hinterenden der Mandibelplatten ziemlich stark hervorragend. Diese letzteren hell 
gelb; ihre gelben Elemente plump, O, I3 mm. lang bei einer Breite und Höhe von 0,075, mit glattrandigem Haken (Fig. 4I), ganz selten kam ein kleiner Dentikel an dem einen oder beiden Rändern vor. Die Raspel der Zunge fast farblos; weder die Anzahl der Zahnplattenreihen (wie es schien etwa 70 ) noch die Zahl der Platten (wenigstens I50) liess sich genau bestimmen. Die fast farblosen Zahnplatten einfach hakenförmig, mit glattrandigem Haken (Fig. +2), eine Höhe bis o, 10 mm. erreichend.

Die abgeplattete Speicheldrüse gelblich. Die hintere Eingeweidemasse (Leber) kurz kegelförmig, I I mm. lang bei einer Breite von 9, braungrau. - Die vordere Eing eweidemasse $7 \mathrm{~mm}$. lang bei einer Höhe und Breite von 4, grau und schwärzlichgrau (Eiweissdrüse); die Spermatotheke schwärzlichgrau.

Es liegt hier wieder ein wahrscheinlich schalenloser Pleurobranchus vor, und zwar ein von der anderen Art verschiedener.

\section{Berthella Blainv.}

Berthella Blainv. Man. de malacologie. 1825, p. 469, 627, Pl. XLIII, Fig. I.

Clanthuts Leach. Moll. Brit. Synopsis. 1852, p. 2 S.

Pleurobranchus, autt. p.p.

Forma corporis ut in Pleurobranchis propriis; notaeum quasi laeve, rhachis branchiae laevis; massa glandularis pediaea nulla.

Mandibulae ut in Pleurobranchis, elementa quoque ut plurimum margine laevi. Dentes linguales erecti, margine denticulato.

Die Berthellen stimmen in den Formverhältnissen so wie im inneren Bau fast ganz mit den ächten Pleurobranchen, von welchen sie sich eigentlich nur durch die aufrechten, am Rande denticulirten Zahnplatten unterscheiden; der Rand des Hakens der Elemente der Mandibel ist fast immer glatt (nicht denticulirt).

Der Gruppe, die vielleicht nur eine Untergattung der ächten Pleurobranchen bildet, gehört wohl eine Anzahl der nur dem Äusseren nach beschriebenen "Pleurobranchen” an ${ }^{1}$ ).

I. Berthella Cavieri Bgh.? Taf. XI, Fig. 43-44.

R. BERgh, 1. c. V, 3. (Die Pleurobranchiden, dritte Liefer.). I898, p. I29-I3I, Taf. XI, Fig. $19-27$.

Ein Individuum wurde am 28-29 Aug. in der Waru-Bai an der Nordküste von Ceram (St. I74) aus einer Tiefe von is M. gefischt.

Das in Formol bewahrte Individuum war etwas zusammengebogen und verbogen, etwa I $7 \mathrm{~mm}$. lang bei einer Höhe von Io und einer Breite von IO; die Breite des Kopfes mit den

1) VAyssière, (Monogr. de la fam. des Pleurobranchidés. I. Ann. sc. nat. Zool. \& S. VIII, 1898, p. 255-279) beschreibt eine kleine Reihe von Berthellen. 
Tentakeln 5. Die Höhe der Rhinophorien 3,5, die Länge der Kieme 7,5 bei einer Breite von 2; die Breite des Fusses $6 \mathrm{~mm}$. - Die Farbe des Thieres war durchgehends röthlichgrau. In der Mitte des Ruickens, etwas links, schimmerte das Hinterende der Schale weiss durch.

Die Formverhältnisse die gewöhnlichen. Die schöne Kieme jederseits mit 23-24 Blättern; oberhalb des Grundes des (nur, $2 \mathrm{~mm}$. langen) freien Theils derselben die Analöfnung.

Die sich von der Mitte des Rückens nach vorne erstreckende Schale $7 \mathrm{~mm}$. lang bei einer Breite bis 4, hinten kalkweiss, sonst hell röthlichgrau, flach, ziemlich fest, mit kleiner deutlicher Spira.

Der Schlundkopf von gewöhnlicher Form, $3 \mathrm{~mm}$. lang bei einer Breite von $\mathrm{I,25}$ und einer Höhe von I mm. Die schwach gelblichen Ma ndibel mit fast ihrem vorderen Viertel im Munde entblösst; ihre gelben Elemente $0,08 \mathrm{~mm}$. lang bei einer Breite bis 0,020 , der glattrandige Haken spitz (Fig. 43). Die Zunge mit fast farbloser Raspel, die 32 Zahnplattenreihen enthielt, in der Raspelscheide in Allem noch etwa 50; die Gesammtzahl somit beiläufig so. In den Reihen kamen jederseits etwa 150 Zahnplatten vor. Die Zahnplatten fast farblos; die innersten nur etwa $0,035 \mathrm{~mm}$. hoch, die Höhe sich bis etwa $0,12 \mathrm{~mm}$. erhebend; sie waren auch denen des $P l$. Cuvieri, diaphanus u. A. ähnlich, aufrecht, der Rand in etwa seiner halben Höhe mit (15-20) feinen Dentikeln versehen (Fig. 44).

Die Leber war schwärzlich-grau.

Möglicherweise liegt hier — trotz des Farbenunterschiedes — der Pleurobranchus Cuviori des Afrikanisch-Indischen Meeres vor; die Pleurobranchen variiren ja mitunter nicht unbedeutend in Farbenverhältnissen. In den wesentlichen Verhältnissen, in der Form (so wohl der Schale wie) der Elemente der Mandibelplatten und der Zahnplatten stimmen die zwei Thierformen wesentlichst überein.

2. Berthella borneensis Bgh. n. sp. Taf. V, Fig. 3. Taf. XI, Fig. 45-47.

Am Riffe von Pulu Sebangkatan, Borneo-Bank (St. 8I), wurden zwei Individuen gefangen, beide von derselben Grösse, und das eine abgebildet.

Das lebende Thier hatte eine Länge von fast $4 \mathrm{~cm}$. bei einer Breite von $\mathrm{I}, 6$. Die Farbe des Rückens war dunkelroth; die Rhinophorien, die Tentakel und der Schwanz etwas heller.

Die a ufbewahrten Thiere hatten eine Länge von 3,2 cm. bei einer Breite bis 2,2 und einer Höhe bis I,2; die Breite des Mantelgebräms 7 mm., die Breite des Tentakelschildes (mit den Tentakeln) 9, die Länge der Kieme 9 bei einer Breite von 3, die Breite des Fusses I I, die des Fussgebräms $3 \mathrm{~mm}$. - Die Farbe war gelblich, hier und da mit röthlichem Anflug, an der Rückenseite ziemlich zahlreiche weisse grössere und kleinere Punkte. Die Schale schimmerte sehr stark durch, unter und hinter derselben dunkel schmutziggrau die hintere Eingeweidemasse; die Unterseite des dünnen Mantelgebräms fein querstreifig.

Die vor der Mitte und nach vorn, median oder etwas schief liegende (Fig. 45) Schale Io $\mathrm{mm}$. lang bei einer Breite von 5, sehr flach, sehr zerbrechlich, mit ganz kleiner Spira, weiss an der oberen wie an der unteren Seite.

Die Formverhältnisse wie gewöhnlich; die Kieme mit etwa 30 Blättern (jederseits), nur ihre Spitze ragte frei hervor. 
Die Mundröhre etwa so lang wie der Schlundkopf, welcher eine Länge von 4,5 mm. hatte bei einer Breite von 3 und einer Höhe von 2, die Form die gewöhnliche, die Farbe schwach-röthlich gelblich. Die Mandibelplatten hell gelblich; ihre Elemente (Fig. 46) von einer Länge bis $\mathrm{O}, \mathrm{I}_{4}$ bei einer Breite von 0,029 und Höhe von $0,04 \mathrm{~mm}$; ihr Haken spitz, (fast) immer ohne Dentikel. Die Raspel hell gelblich, wie es schien 32 Zahnplattenreihen enthaltend, in der starken Scheide schienen deren noch etwa 42 vorzukommen; in den Reihen kamen wenigstens I 30 Platten vor. Die Zahnplatten (Fig. 47) fast farblos, eine Höhe bis fast o, 6 mm. erreichend, aufrecht, mit gebogener Spitze und fein gezähneltem Rande.

Die Magen schienen sich wie gewöhnlich zu verhalten. Die Leber gräulichbraun. - Die Blutdruse stark roth; die Niere weiss.

\section{Berthella minor Bgh. n. sp. Taf. XIII, Fig. I-3.}

Am 24-25 Juni wurde aus einer Tiefe von I 2 M. (Lithothamnion-Boden, Sand und Korallen) bei Pulu Sanguisiapo Tawi-Tawi-Inseln im Sulu-Archipel (St. 93) ein Individuum gefangen.

Das in Formol bewahrte Individuum war durchgehends von weisslicher Farbe, der Rücken sparsam ganz fein weiss punktirt. Die Länge betrug $14 \mathrm{~mm}$. bei einer Breite von 6,5 und einer Höhe von $6 \mathrm{~mm}$; die Breite des Kopfes mit den Tentakeln 4, die Höhe der Rhinophorien 2,5 mm.; die Länge der Kieme 4,5, die Breite des Fusses $6 \mathrm{~mm}$. - An der vorderen Hälfte des ebenen Rückens schimmerte die weisse Schale durch, hinter derselben der schwärzliche Inhalt der Magen.

Die Formverhältnisse wie gewöhnlich bei den ächten Pleurobranchen. Die Genitalpapille und die praebranchiale Öfnung wie gewöhnlich; die ziemlich lange und schmale Kieme mit etwa 20 Blätterpaaren; die Analöffnung oberhalb des Grundes der freien Spitze der Kieme.

Die kalkweisse Schale von $6 \mathrm{~mm}$. Länge bei einer Breite bis 2, länglich, flach, mit kleiner Spira (Fig. I); das düne Kalklager der Unterseite sehr brüchig.

Das Centralnervensystem wie bei den ächten Pleurobranchen. Die Punkte des Rückens waren von Drüsen mit weiter Öffnung gebildet.

Der Schlundkopf mit seiner stark vorspringenden Raspelscheide $3 \mathrm{~mm}$. lang, von gewöhnlicher Form. Die schwach gelblichen Mandibel mit fast ihrem vorderem und umgebogenem Viertel im Munde entblösst; ihre blassen Elemente bis $0,055 \mathrm{~mm}$. lang bei einer Breite von $\mathrm{O}, \mathrm{O} 2$, der Haken glattrandig (Fig. 2). Die abgeplattete Zunge mit fast farbloser Raspel, die etwa 35 Zahnplattenreihen zu enthalten schien; in der Raspelscheide beiläufig, wie es schien, 65 Reihen und die Gesammtzahl der Reihen somit etwa ıoo. In den Reihen schienen gegen I 50 Zahnplatten vorzukommen. Die Zahnplatten (Fig. 3) fast farblos; die innersten nur etwa $0,04 \mathrm{~mm}$. hoch, und die Höhe sich allmählig bis zu O, I $4 \mathrm{~mm}$. erhebend. Die Platten denen des $P$ l. diaphanus ähnlich ${ }^{1}$ ), aufrecht, der Rand in etwas mehr als seinem oberen Drittel ganz fein denticulirt, die Anzahl der spitzen Zähnchen meistens etwa I 5 .

Der schwarze Inhalt der Magen aus' unbestimmbarer thierischer Masse gebildet, stark mit langen spitzen Spiclen vermischt. Gegen die schwarze Farbe contrastirte stark die weisse

1) Vgl. meine Pleurobranchiden, 1. c. 1898, p. 142-144; Taf. $\mathrm{X}$, Fig. $38-46$ 
Farbe der Niere. Die Leber hell gelblichweiss. - In den Läppchen der Zwitterdrüse reife Geschlechtselemente.

Die Art erinnert, auch in Bezug auf die Schale, an den von mir friher beschriebenen $P l$. diaphanus, deren Mandibelelemente aber anderer Form sind.

Berthella minor Bgh. var. Taf. XIII, Fig. 4-6.

Am Riffe südlich von den Lucipara-Inseln (St. 225) wurden 4 wahrscheinlich hierher gehörende Individuen gefangen.

Sie waren von ziemlich verschiedener Grösse, sonst einander ähnlich. Das grösste war $25 \mathrm{~mm}$. lang bei einer Breite von 5 und Höhe von 8, die Länge der Kieme betrug $9 \mathrm{~mm}$. Die Farbe war weisslich, der Rücken zeigte sparsam zerstreute weisse Punkte; die Kieme gelblich. Vor der Mitte der Länge des Rückens schimmerte die Schale stark durch, hinter derselben die schwarze Leber mit der weissen Niere.

Die Schale (Fig. 6) 7,5 mm. lang bei einer Breite bis 4, hinten schmaler, vorne breiter, mit kleiner Spira, hinten kalkweiss, vorne oben wie unten röthlichgelb, ziemlich abgeplattet, stark verkalkt, nicht leicht brüchig.

Die Mundröhre $4 \mathrm{~mm}$. lang. Der schmale, längliche, gelbliche Schlundkopf von $3,75 \mathrm{~mm}$. Länge; die hellgelben Mandibelplatten zeigten ihre Elemente (Fig. 4) schmal, bis 0,10 mm. lang, mit glattrandigem Haken. In der gelblichen Raspel etwa 50 Zahnplattenreihen, in der Scheide deren noch 72; die Gesammtzahl der Reihen somit 122; in den Reihen schienen bis etwa 200 Platten vorzukommen. Die Platten fast farblos, wasserklar, von gewöhnlicher Form (Fig. 5); die Höhe der innersten betrug 0,06, und die Höhe der Platten erhob sich bis zu $0,20 \mathrm{~mm}$.

Die Speicheldrüse dick von $3 \mathrm{~mm}$. Durchmesser, orangeroth; die Ausführungsgänge weiss. Die Nebenspeicheldrüse nicht stark entwickelt, die Röhren nicht dünn.

Die Leber dunkel schmutzigbraun, gegen die weisse Niere contrastirend. - Die vordere Genitalmasse gelblich und weisslich, rundlich, von $5 \mathrm{~mm}$. Durchmesser.

Wahrscheinlich liegt hier nur eine Varietät der $P l$. minor vor.

Berthella minor Bgh. var.

Am I Febr. wurden in der Pepela-Bai an der Ostkiuste der Insel Rotti (St. 30I) 4 Individuen dieser Art gefangen, zwei grössere und zwei bedeutend kleinere (9-I $3 \mathrm{~mm}$. lang).

Die zwei grösseren hatten fast dieselbe Grösse; die Länge betrug $23-25$ bei einer Breite von I4 und einer Höhe von $9 \mathrm{~mm}$; die Breite des Kopfes mit den Tentakeln betrug 6, die Länge der Rhinophorien 4 mm., die Länge der Kieme (mit etwa 25 Blättern) \& bei einer Breite bis 2,5 mm.; die Breite des Fusses IO, des Fussgebrämes 2,25, die Länge des Schwanzes 4,5 mm. - Die Farbe war weisslich, der Rücken fein weiss punktirt, die Unterseite etwas mehr gräulich, die Kieme etwas gelblich. Vor der Mitte der Ruickenlänge und rechts 
von der Mittellinie schimmerte längsliegend die Schale weiss und rothgelb durch; hinter derselben und mehr links ein schwarzes Eingeweide.

Die Schale $8 \mathrm{~mm}$. lang bei einer Breite in der Mitte von 4; sie war hinten weiss, in $\%_{3}$ der Länge rothgelb, heller an der Unterseite; sie war stark verkalkt, nicht dünn, aber sehr zerbrechlich.

Der Schlundkopf sehr abgeplattet, $4 \mathrm{~mm}$. lang bei einer Breite von 3 und einer Höhe ron I. Die Elemente der gelben Mandibelplatten wie gewöhnlich, sehr oft kam aber an der einen oder an beiden Seiten derselben ein ganz kleiner, spitzer Dentikel vor. Die Zahnplatten waren wie gewöhnlich bei dieser Art.

Am Riffe an der Südspitze der Insel Kabaëna (St. 209) wurden noch zwei Individuen gefangen, die sicherlich hierhin gehören, das eine I3, das andere $20 \mathrm{~mm}$. lang, sonst einander vollständig ähnelnd, und im Äusseren ganz mit den oben beschriebenen übereinstimmend.

Das grössere war I I mm. breit bei einer Höhe von 6,5; die Breite des Rückengebräms war 2, die Länge der etwas gelblichen Kieme 6 bei einer Breite von I; die Breite des Tentakelschildes 4, des Fusses 7 .

Die schöne, ziemlich flache, aber feste Schale maas an Länge $6 \mathrm{~mm}$. bei einer Breite von 2,75 , sonst wie oben.

Der Durchmesser der grossen Augen $0,28 \mathrm{~mm}$. - Die Länge der Mundröhre 2,5 mm. Der Schlundkopf $3 \mathrm{~mm}$. lang bei einer Breite von 2; die Elemente der gelben Mandibelplatten $0,08 \mathrm{~mm}$. lang bei einer Breite von 0,025 und Höhe von 0,030 . Die blassen Zahnplatten wie oben, eine Höhe bis o, $16 \mathrm{~mm}$. erreichend.

Der aussen stark durchschimmernde schwarze Inhalt der Magen wie oben. Die Leber gelblichweiss.

Berthella minor Bgh, var. (monstrosa). Taf. XI, Fig. 48.

Von dieser Form wurden (bei der Station 220) am Ankerplatz von Pasir Pandjang, an der Westküste von Binongka, am I Nov. noch zwei Individuen gefangen.

Die Farbe der Rückenseite war weiss, ganz fein weiss punktirt, die der Unterseite gelblichweiss. Die Körperlänge betrug I $5 \mathrm{~mm}$. bei einer Breite von 9 und einer Höhe von 7 ; die Länge der Rhinophorien war 4, die der Kieme 6,5 mm., die Länge des Fusses I I bei einer Breite von $6 \mathrm{~mm}$.

Die Formverhältnisse die gewöhnlichen; die Kieme zeigte aber an beiden Individuen eine besondere Abnormität, indem sie (Fig. 48) einen oberen und einen unteren Ast trug. Die Schale erstreckte sich von der Mitte des Rückens ganz nach vorne, an der Aussenwie an der Innenseite war ihr hinteres Drittel weiss, sonst war sie gelbroth; die Länge betrug 8 bei einer Breite bis $4,5 \mathrm{~mm}$., die Nuclealpartie ganz klein; die Consistenz nicht fest.

Der ganz weisse Schlundkopf $4 \mathrm{~mm}$. lang bei einer Breite von 2 und einer Höhe von I,5 mm. Die Mandibelplatten ganz blass gelblich; ihre blassen Elemente bis 0,075 $\mathrm{mm}$. lang bei einer Breite von 0,025 , der Haken einfach, spitz. Die Raspel mit ihrer Fortsetzung 
enthielt eine sehr grosse Anzahl von Zahnplattenreihen, und die Reihen sehr viele Platten. Die Platten von gewöhnlicher Form, eine Höhe bis o, 14 mm. erreichend, die der ïussersten betrug 0,029. (Mtg.) wäre.

Möglich wäre es, dass die Berthella minor nur eine lokale Varietät der B. pbumula

4. Berthella inoperta Bgh. n. sp. Taf. XIII, Fig. 7-IO.

Am 9 Aug. wurde am Riffe beim Ankerplatz nördlich von Salomakië (Insel Damar) ein Individuum gefangen.

Das kleine Thier hatte eine Länge von $9,5 \mathrm{~mm}$. bei einer Breite von 4,5 und einer Höhe von 4. Die Farbe war durchgehends schmutzig gelblichgrau, in der Mitte des Rückens schimmerten Eingeweide schwärzlich durch:

Die Formverhältnisse vollständig wie bei den ächten Pleurobranchen. Der Rücken so lang und breit wie der Fuss; der vordere leicht ausgekerbte Rand war nach hinten von $4-5$ kleinen Höckern gleichsam eingefasst, sonst war der Rücken glatt. Keine Spur einer (verkalkten oder cuticularen) Schale konnte gefunden werden. Das Tentakelsegel mit den Tentakeln maass an Breite 2,5 mm. die zugespitzte Kieme $3 \mathrm{~mm}$. lang, mit glatter Rhachis.

Die Mundröhre I,5 mm. lang. Der Schlundkopf 2,5 mm. lang bei einer Breite von I,5, von gewöhnlicher Form. Die gelblichen Mandibelplatten zeigten Elemente (Fig. 7, 8) von einer Länge von $0,10 \mathrm{~mm}$. bei einer Höhe von 0,03 und eine Breite von 0,025 ; der Haken war spitz, meistens mit $1-3$ Dentikeln jederseits. Die Raspel der Zunge farblos; sie schien etwa 25 Zahnplattenreihen zu enthalten, und die Raspelscheide eine ähnliche Anzahl zu bergen. In den Reihen kamen jederseits über Ioo Platten vor. Die farblosen Platten aufrecht, bis wenigstens $0,07 \mathrm{~mm}$. hoch, an der oberen Hälfte fein gezähnelt (Fig. 9, Io).

Der (Formol-)Erhärtungszustand des Individuums gestattete keine genauere Untersuchung.

\section{UMBRELLIDAE.}

Umbrella Lamarck.

Umbrella Lam. Hist. des anim. s. vert. VI, I819, p. 343.

Umbraculum Schum. Essai. 1817, p. I77.

Die Benennung Umbrella wird wohl vorzuziehen sein, sie scheint als Name schon ISI2 von LAMARCK in seinem "Extr. d'un cours" angewendet zu sein und ist seit I 819 fixiert.

I. Umbrella picta (A. Adams). Taf. XIII, Fig. Ix.

Operculatum pictum A. Adams. Proc. zool. soc. XXII, I854, p. I37.

Ein Individuum war an der inneren Seite des Muaras-Riffes an der Ostkiiste von Borneo (St. 9I) gefangen. 
Dasselbe war sehr zusammengezogen und sehr durchhärtet. Seine Länge betrug $5 \mathrm{~cm}$. bei einer Breite von 4,8 und einer Höhe von $2,5 \mathrm{~cm}$; die Breite des warzigen Theils des Fusses bis $17 \mathrm{~mm}$., die des innerhalb desselben liegenden bis $7 \mathrm{~mm}$., die Länge des medianen Ausschnitts vorne I $2 \mathrm{~mm}$; die Länge des Mantels (nach Entfernung der Schale) $3,5 \mathrm{~cm}$. bei einer Breite von 2,6, davon betrug das Gebräm mit seinen hervorragenden (bis $3 \mathrm{~mm}$. langen) Zacken $7 \mathrm{~mm}$; die Länge der Rhinophorien $4 \mathrm{~mm}$; die Länge der Kieme $4 \mathrm{~cm}$, bei einer Breite bis $4 \mathrm{~mm}$., die freie Spitze derselben $4 \mathrm{~mm}$. lang, die Länge der Analpapille $3 \mathrm{~mm}$. Die obere Seite des Fusses weisslichgrau, die Unterseite weiss, die F a r be sonst weisslich.

Die Randpartie der Schale war mit einem schmutzig grauen, klebrigen, zähen, fest anhängenden Überzuge bedeckt; sie hatte eine Länge von $3,5 \mathrm{~cm}$. bei einer Breite von 2,6 , die Dicke betrug in der Gegend des Umbo $2 \mathrm{~mm}$; ihre obere Seite war, wenn noch von dem nicht ganz duinnen (schwach röthlich-) gelben Periostracum bedeckt, von der Farbe dieses letzteren, nur war die ganze Partie um den Umbo mehr bläulichgrau; Die Unterseite war kalkweiss. Die Form war die gewöhnliche eines ovalen Schildes mit dem kleinen Umbo ein wenig hinter der Mitte und etwas links liegend mit nach hinten (und links) gebogener Spitze; die concentrischen Linien sehr ausgeprägt, von den schwachen, von dem Umbo ausgehenden Rippen gekreuzt; die Unterseite mit vertiefter Nabelgegend und von derselben ausgehenden eradiirenden Linien, die Randpartie gleichsam mit Muskeleindruck, stärker an der (in dieser Stellung) linken Seite.

Die Formverhältnisse schienen, in so weit beurtheilt werden konnte, die gewöhnlichen. In der Kieme kamen bis an ihre Spitze gezählt 29 Blätter vor.

Die gelbliche Mundröhre $3 \mathrm{~mm}$. lang. Der Schlundkopf grau, die Raspelscheide aber hell gelblich; die Länge betrug $8 \mathrm{~mm}$. bei einer Höhe und Breite von 6. Die Zunge $5 \mathrm{~mm}$. lang bei einer Breite von 4 ; in der gelben Raspel kamen etwa 64 Zahnplattenreihen vor, in der starken Raspelscheide etwa 70, von denen die beiläufig 8 unreif; die Gesammtzahl der Reihen somit etwa 134. In den wellenförmig gebogenen Reihen mehrere (vielleicht 6-8-) hunderte von Zahnplatten. Dieselben waren gelblich, alle von derselben Art, hakenförmig (Fig. I I), eine Länge bis $0,08 \mathrm{~mm}$. bei einer Höhe bis 0,07 erreichend; die äussersten ein wenig kürzer und ein wenig niedriger.

Die Leber war schmutziggrau; die Zwitterdrüse schwefelgelb; die vordere Genitalmasse milchweiss.

Die Unterseite der Schale dieser Form ist weiss (nicht gelbbraun), dieselbe kann daher kaum die Umbrella Camingi von Deshayes ${ }^{1}$ ) sein. Adans hat seine Art von Lord Hood Island.

I) Desitayes, catal. des moll. de l'ile de la réunion. MaIllakd, notes sur l'ile de la réunion. 1863, p. 52-53, Pl. VIII, $(\mathrm{XXYV})$, Fig. $4-5$. 


\section{ASCOGLOSSA.}

H. v. JHering, Vers. eines nat. Systems d. Moll. Jahrb. d. D. malakozool. Ges. III, 2, I 876 , p. I 46 .

R. Bergh, Beitr. z. Kenntn. d. Aeolidiaden, V. Verh. d. k. k. zool. bot. Ges. in Wien. XXVII, IS77, p. $807-822$. - VIII, 1. c. XXXV, I885, p. I-23.

R. Bergh, Malacol. Unters. V, Igor, p. I $86-208$.

Die von H. v. JHering und von mir fast gleichzeitig aufgestellte Gruppe der Sacoglossen (Jher.) oder Ascoglossen (Bgh.) enthält mehrere im Äusseren von einander sehr abweichende Familien, die aber durch verschiedene gemeinschaftliche anatomische Charactere zusammengehalten zu werden scheinen.

Das Centralnervensystem zeigt sich aus (6-) t dicht zusammengedrängten Ganglien gebildet, und die Otocyste enthält nur einen einzelnen Otolith. Der Schlundkopf ist ein eigenthümlicher Saugapparat und durch die Persistenz der älteren Zungenzähne noch besonders ausgeprägt, welche sich in einem besonderen, an der Unterseite des Schlundkopfs liegenden Sack, entweder spiralig aufgerollt oder in einen Haufen gesammelt bis auf die erst gebildeten erhalten vorfinden. An der Speiseröhre kommt meistens ein Kropf vor, es finden sich zwei Samenblasen, und der Penis ist meistens mit einem Stachel bewaffnet.

Ein grosser Streit hat über die Berechtigung einer solchen Gruppe und uber den Inhalt derselben geherrscht. Die neueste hierhin gehörende Arbeit, die von Bruel ${ }^{1}$ ), scheint die Berechtigung wieder retabliren zu wollen.

Der Gruppe gehören an, erstens die Aeolidienartigen, mit Epinotidien (Rücken-Papillen) versehenen :

1. Hermaciden und

2. Phyllobranchiden,

dann die mit Rücken (Fuss-)flügeln ausgestatteten

3. Plakobranchiden und

4. Elysiiden, S. $1-116$.

1) L. BRUEL, iber die Geschlechts- und Verdauungsorgane von Caliphylla mediterranca Casta. Habilitationsschr. Halle, 1904, 
ferner die mehr Planarienähnlichen

$$
\text { 5. Limapontiiden, }
$$

endlich die Schalentragenden, mit Kieme versehenen

\section{Lophocerciden (Oxynoiden).}

Durch die letzteren knïpfen die Ascoglossen an die Tectibranchien an, durch die ersten an die Nudibranchien (Aeolidiiden).

In den Siboga-Einsammelungen sind die erste und die zwei letzten Gruppen nicht vertreten.

\section{Phyllobranchidae.}

R. Bergh, Malacalog. Unters. I, Heft 2. is7I, p. 49-iा8. - III, Heft XVI, I, I888, p. $760-77$ I.

Die den wärmeren (Mittelmeere), den subtropischen und tropischen Meeresstrecken angehörenden Phyllobranchiden umfassen die Gattungen Phyllobranchus, Cyerce und die den Übergang zu den Hermaciden vermittelnde Caliphylla.

\section{Phyllobranchus Ald. et Hanc.}

Anus lateralis; podarium continuum.

Dentes linguales hamo infra applanato marginibus denticulatis, caduci subtus fasciam spiralem formantes. - Ingluvies (suctoria) elongata; penis longior inermis.

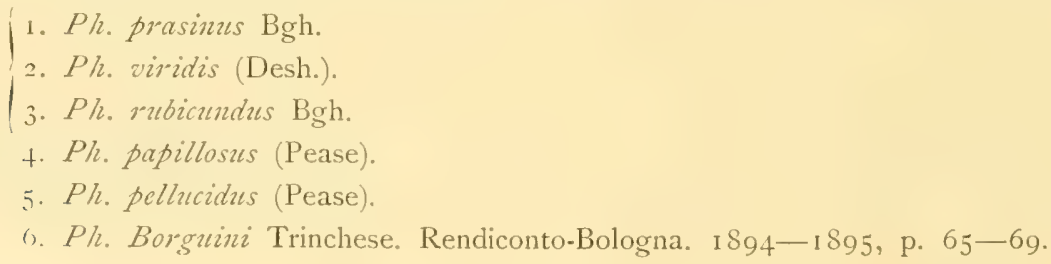

\section{Cyerce Bgh.}

Anus dorsalis; podarium transversaliter bipartitum.

Dentes linguales hamo elongato infra applanato marginibus denticulatis; caduci subtus acervum irregularem formantes. - Ingluvies brevior; penis sat brevis, hamo vel stylo instructus.

I. C. clegans (Semper).

2. C. nigra (Semper). var. ocellata Bgh.

3. C. pavonina Bgh.

+. C. Fheringi Pelseneer. 


\section{Caliphylla da Costa.}

Tentacula nulla; anus latero-dorsalis; papillae dorsales ut in Phyllobranchis, sed margine integro; podarium continuum.

Dentes linguales hamo nonnihil elongato non denticulato; caduci subtus acervum formantes. - Ingluvies brevior; penis brevior, inermis.

I. C. mediterranea da Costa.

2. C. tricolor (Trinchese).

\section{Phyllobranchus A. et $\mathrm{H}$.}

Phyllobranchus. A. et H. Trans. zool. soc. V, i 866 , p. I45.

Phyllobranchus A. et H. R. Bergh, 1. c. I, I870, p. 5 I-98, Taf. I, Fig. 6-8; Taf. V'-VIII, Taf. X-XII.

I. Phyllobranchus mbicundus B. ? Taf. XIII, Fig. I2.

Phyllobranchus mbicundus. B. 1. c. p. 87-92, Taf. X, Fig. IS-22; Taf. XI, Fig. I-2I.

? Proctonotus orientalis Kelaart. New - sp. of Ceylon nudibr. moll. Journ. R. As. Soc. (Ceylon Branch) III, 9, I857, p. 106. - Ann. Mag. n. h. 3 S., III, I859, p. 492.

Am 27-28 April wurde am Riffe von Haingsisi, Insel Samau bei Timor (St. 60) aus einer Tiefe von höchstens 3 M. 2 Individuen gefangen.

Die in Formol bewahrten zusammengezogenen und ziemlich erhärteten Individuen hatten eine Länge von IO-I I mm. bei einer Höhe und Breite des Körpers von 4; die Länge der Rhinophorien betrug $4 \mathrm{~mm}$., die der Rückenpapillen bis 7, die des Schwanzes 3. Die Farbe war durchgehends schmutzig röthlichbraun, die papillenbesetzten Seitentheile des Rückens mehr grau. Die Papillen hell röthlichbraun, dicht weisslich punktirt. Mit Ausnahme der alleräussersten kleinen waren alle Papillen abgefallen.

Die Formverhältnisse die gewöhnlichen, so der Kopf mit dem Aussenmunde, die Tentakel und die zweispaltigen Rhinophorien. Der Rücken etwas schmäler als der Fuss; die papillenbesetzten Seitentheile vorne durch den Kopf geschieden, hinten zusammenstossend, vorne waren sie nicht so breit wie der nackte Theil des Rückens. Die Vertheilung der Papillen an den Seitentheilen und die Grössenverhältnisse jener an derselben wie sonst bei den Phyllo. branchen. So waren auch die blattförmigen Papillen (Fig. I2), die etwas schmäler als lang waren; der an den grösseren Papillen ziemlich dicke Stiel betrug an denselben $1 / 3-1 / 4$ der Papillenlänge, an der oberen (inneren) Seite am Übergange in den Blatttheil eine trichterartige Vertiefung; der Rand des Blattes ist dünn, sehr dicht und regelmässig gezähnelt. Die Körperseiten nicht ganz niedrig; vorne an der rechten die männliche und die weibliche Genitalöffnung; mehr hinterwärts, etwa unterhalb der Gegend des vorderen Theils des Pericardiums die pokalartige Analpapille. Der Fuss ist breit, nach hinten verschmälert in einen kurzen Schwanz übergehend; der etwas dickere Vorderrand zweilippig, mit wenig vorspringenden Ecken; das dünne Fussgebräm nicht ganz schmal.

Mit Ausnahme der Augen schimmerten Eingeweide nirgends durch. 
Das Centralnervensystem zeigte die cerebro-pleuralen, die pedalen und die hinter denselben liegenden visceralen Ganglien wie gewöhnlich. Die Nervenzellen einen Durchmesser bis $0,25 \mathrm{~mm}$. erreichend.

Die Mundröhre kurz, ziemlich weit. Die grosse Munddrüsenmasse wie gewöhnlich. Der Schlundkopf I,5 mm. lang, von den gewöhnlichen Form- und Bauverhältnissen; die die untere WVand bildende Zungenmuskelmasse trägt vorne die kleine kurze $\mathrm{Zunge}$ mit zwei Zahnplatten, in der Raspelscheide kamen 4 entwickelte und 2 in Bildung begriffene vor; die Anzahl der Platten in der unteren Scheide mit ihrer kleinen Endspirale schien etwa 36. Die Zahnplatten waren hell gelb, erreichten (längs des Rückens gemessen) eine Länge bis $0,28 \mathrm{~mm}$., ihre Formverhältnisse waren wie früher genau beschrieben. - Der lange Saugkropf weisslich, gedreht, ausgestreckt etwa $6 \mathrm{~mm}$. lang bei einer Breite von I, die Form- und Bauverhältnisse wie früher angegeben

Der cylindrische Magen kürzer als der Kropf, von dem er theilweise umschlungen ist. - Die papillären Gallengänge wie früher von mir angegeben (vgl. pp. 71, 72, Taf. VIII, Fig. I).

Der Samengang war sehr lang und ebenso der unbewaffnete Penis.

Der Erhärtungszustand der Thiere gestattete sonst keine genauere Untersuchung.

Den Farbenverhältnissen nach gehörten diese Thiere vielleicht dem Phyllobranchus mbicundus (aus dem Rothen Meere) an, welcher wahrscheinlich doch nur ein Varietät der typischen Art ist. - Der von Kelaart angegebene "Proctonotus" ist wahrscheinlich ein Phyllobranchus und gehört zu der hier vorgelegten Art oder zu dem Ph. prasinus.

\section{Pluyllobranchus prasinus Bgh.}

Phyllobranchus prasinus. B. 1. c. p. 52-87, Taf. I, Fig. 6-8; Taf. V b-VIII, X.

Am Riffe nördlich vom Ankerplatz bei der Insel Salomakië (Damar) (St. I 44) wurde ein Individuum gefangen.

Dasselbe war (sehr erhärtet) fast $20 \mathrm{~mm}$. lang bei einer Rückenbreite von 6,5 und einer Höhe von 7 ; die Länge der Rhinophorien $3,5 \mathrm{~mm}$; mit Ausnahme von einigen der äussersten waren alle Papillen (im Glase lose liegend) abgefallen, die grössten maassen an Länge 15 bei einer Breite bis 10 mm; die Breite des Fusses bis 8, die Länge des Schwanzes $5 \mathrm{~mm}$. - Die Farbe des Körpers war grünlichgrau, die grössten Papillen grünlichweiss, die kleinsten und kleinen meistens grün.

Die Formverhältnisse ganz wie oben. Das relative Längen- und Breiten-Verhältniss der grossen Papillen war sehr variabel.

Der Schlundkopf $3,5 \mathrm{~mm}$. lang. In der oberen Zahnplattenreihe kamen 6 Platten vor, an der Zungenspitze eine und in der unteren Reihe bis an das Ende der kleinen Spirale etwa 40. Die Länge der gelben Zahnplatten bis $0,4 \mathrm{~mm}$., ihre Form die gewöhnliche, die Anzahl der Dentikel der Ränder I I-12.

Der um den Magen geschlungene Saugkropf weisslich, ausgestreckt $12 \mathrm{~mm}$. lang bei einer Breite von 1,5 . 


\section{Cyerce Bgh.}

Cyerce Bergh, 1. c. I, I870, p. 98-II8, Taf. I, Fig. 9-io; Taf. XIII-XVI.

I. Cyerce elcgans (Semper) Bgh. Taf. XIII, Fig. I3-I7.

R. Bergh, l. c. p. 99-II3, Taf. I, Fig. 9; Taf. IX, Fig. I3-I7; Taf. XVI, Fig. 24, 25, 29. - Heft XVI, I, I888, p. 769-77ı, Taf. LXXVII, Fig. 6, 7; Taf. LXXVIII, Fig. 8—9.

Am 27-28 April wurde am Riffe von Haingsisi, Insel Samau bei Timor (St. 60) aus einer Tiefe von höchstens 3 M. ein Individuum gefangen mit zwei von Phyllobranchus zusammen.

Das Individuum maass an Länge etwa $16 \mathrm{~mm}$. bei einer Breite des Rückens von 8; die Länge der Tentakel 2, der Rhinophorien 3, der Rückenpapillen (Epinotidien) bis Io mm. bei einer Breite von 5-6; die Breite des Fusses bis $10 \mathrm{~mm}$., die Länge der vorderen Abtheilung der Sohle etwa $1 / 3$ der ganzen Fusslänge betragend. Die Farbe des Rückens gräulich, die Unterseite heller, die Papillen weisslich. - Das in Formol bewahrte Individuum war zusammengezogen, etwas verdreht und hatte bis auf die äussersten kleinsten alle Papillen verloren, die aber in Glase beilagen.

Die Formverhältnisse die gewöhnlichen. Die grossen Augen zeigten sich hinten am Grunde der Rhinophorien stark durchschimmend. Vorne am Rücken rechts die niedrige cylindrische Analpapille. Die papillenbesetzten Seitentheile des Rückens wie bei dem Phyllobranchus; ebenso die Vertheilung und die Grössenverhältnisse der Papillen. Diese letzteren (Fig. I3) wie friiher beschrieben, im Ganzen dicker und, besonders der Stiel, gleichsam etwas aufgeblasen, eine Vertiefung am Übergange des Blattes in den Stiel war weniger ausgeprägt; am glatten (nicht feinzackigen) Rande kamen weisse Fleckchen, meistens ein Anzahl von 7-9, vor ${ }^{-1}$ ). Der kräftige Fuss zeigte die Querfurche stark ausgeprägt; das Gebräm breiter als bei Phyllobranchus.

Der Schlundkopf war fast $3 \mathrm{~mm}$. lang, in Formverhältnissen ganz wie fruher beschrieben. Die Zungen muskelmasse präsentirte sich in der Mundhöhle in ihrer ganzen Ausdehnung von grauer gegen die weissliche des übrigen Schlundkopfes contrastirender Farbe. In der langen oberen Raspelscheide fanden sich 6 entwickelte und eine in Entwicklung begriffene Zahnplatten, die vorderste ragte mit dem langen (Fig. 'I 4) gezähnelten Haken in die Mundspalte hinein; in der unteren Scheide lagen hinter einander 5 Platten und im gleichsam etwas aufgeblasenen Ende derselben eine grössere Anzahl von unter einander gemischten an Grösse abnehmenden Platten. Die Platten waren fast farblos, ihre Länge stieg bis $0,8 \mathrm{~mm}$. bei einer Breite am Ende des Grundstückes von 0,09. Ihre Formverhältnisse waren wie früher beschrieben, die Anzahl der gebogenen Dentikel an den langen Rändern des Hakens (Fig. I4) schien I 2 - I5 zu sein.

Die kugelförmige Ampulle am Ende des Ausführungsganges der langen Speicheldrüsen war recht gross.

Der schwach grünliche, ovale Sa ugkropf von 4,25 mm. Länge bei einer Breite von 3,5 und einer Dicke von 1,5 ; übrigens ganz wie früher beschrieben.

1) Zwischen den Anheftungsfacetten der äusseren Papillen sass ein kaum I mm. langer Copepode (Fig. 16) mit Endhaken an den zwei vorderen Beinen (Fig. 17) angeheftet. 
Der Magen und der gemeinschaftliche Gallengang von etwa $5,5 \mathrm{~mm}$. Länge.

Der gebogene, kegelförmige Pen is I,5 mm. lang; an der Spitze fand sich eine Kreisfalte, der vor derselben liegende Theil ist einziehbar und mit einem Haken, wie früher beschrieben, versehen (Fig. 15). Der am Grunde von einem schwarzbraunen Saume eingefasste Haken ist wasserhell, scharf gebogen, und der zurückgebogene Theil längs des Rückens von einer Spalte durchzogen, durch die sich der durch den Penis verlaufende Samenleiter öfnet.

Der Erhärtungszustand der Eingeweide gestattete keine genauere Untersuchung.

Wahrscheinlich hat hier die Cyerce elegans vorgelegen.

2. Cierece sp. Taf. II, Fig. $1 \%$.

Bei dem Riffe von Saleyer (St. 2I3) wurden am 26 Oct. drei vermuthliche Thiere gefangen und eine Abbildung nach dem Leben gemacht.

Die Länge derselben soll etwa $5 \mathrm{~mm}$. betragen haben. Die Farbe (der oberen Seite) scheint durch feinste schwärzliche Punkte weisslichgrau gewesen zu sein, mit zerstreuten weissen Papeln; der obere Rand des Körpers gelb und innerhalb desselben drei braungraue Flecken; am Grunde des breiteren oberen Theils des Körpers bei einem Individuum zwei braunschwarze Augenflecke, die wohl Augen simuliren könnten.

Diese Körper waren losgerissene Papillen einer Cyerce, gewissermassen eine Art Phoenicurus redivious. Solche können wohl wie die gewissermassen entsprechenden der Tethys, wegen ihrer eigenthümlichen Ausstattung mit Ganglien, nach der leicht stattfindenden Ablösung ${ }^{2}$ ) sich lange bewegen und selbstständige Thiere simuliren (Phoenicumus).

Die Papillen waren von etwa derselben Grösse, 5,5-6,5 mm. lang bei einer Breite von 3; sie waren weisslich, mit feinen schwarzen Punkten, an der einen kamen zwei etwas grössere Augenflecken vor; am oberen Rande ein längerer medianer und jederseits ein kleinerer braungrauer Fleck. Der Stiel war dicker und an der oberen Seite durch eine in der Mitte vertiefte Querfurche vom Blatte geschieden. Die Unterseite ist glatt; an der oberen fand sich etwa ein Dutzend stark vortretender gerundeter Papeln ${ }^{2}$ ), aus dicht gedrängten, flaschenförmigen Drüsenzellen gebildet.

\section{Plakobranchidae.}

R. BERGH, Malacolog. Unters. V, 1900, p. 206-208.

Forma corporis valde depressa. Caput applanatum fronte lata; tentacula breviora auriculata; oculi approximati. Pone tentaculum dextrum apertura genitalis duplex. Corpus alis

I) Vgl. R. Bergh, Beitr. z, Kenntn. d. Gatt. Melibe Rang. Ztsch. f. wiss. Zool. XLI, i 88.4. p. I43 Note.

2) Ähnliche Papel kommen auch an der oberen Seite anderer beschriebenen Cyercen vor. Vgl. meine Malacolog. Unters. Heft II, 187 I, Tab. XVI, Fig. 6; Heft XVI, 1, 1888, Taf. LXXVIII, Fig. II, I2; ferner: Mus. Godefiroy. Heft II, I873 (Neue Nackschnecken der Suidsee, Heft I), Taf. XII, Fig. 2, 3. 
lateralibus reflexilibus; pone nucham protuberantia pericardiaco-renalis distincta, sat magna, ad cuius latus dextrum apertura analis; facies supera notaei proprii et alarum lateralium plicis (lamellis) longitudinalibus confertis instructa. Podarium a reliquo corpore linea indistincta solum sejunctum, antice transverse bipartitum, angulis paullo prominentibus.

Bulbus pharyngeus suctorius fere ut in Phyllobranchidibus, prominentia ingluvieformi. Lingua cum dentibus fere ut in Phyllobranchis, dentes infra paullatim acervum irregularem formantes.

Folliculi hermaphrodisiaci soluti, in glandulam hermaphrodisiacam non connati. Penis hamo (curvato) armatus.

Die Plakobranchiden sind durch die Cyercen mit den Phyllobranchiden näher verwandt; sie haben wie jene eine quergetheilte Fusssohle, ihre älteren Zahnplatten bilden auch an der Unterseite der Zunge einen Haufen (keine Spirale), und sie zeigen einen bewaffneten Penis wie die Cyerce. Im Äusseren sind die Plakobranchiden von ganz eigenthümlich ausgeprägter Körperform und kaum mit irgend einer anderen Opisthobranchie zu verwechseln. Auch die Färbung ist eigenthümlich, obgleich, wie es scheint, sehr variabel.

Diese zuerst (1824) von vas HASSELt entdeckten Thiere sind erst viel später (1872) genauer bekannt geworden. Die Gruppe umfasst bisher nur die Gattung:

\section{Plakobranchus van Hasselt.}

Plakobranchus van Hasselt. Allg. Konst- en Letter-Bode voor het jaar 1824. I Deel, N". 3 . p. $34-35$.

Plakobranchus van H. R. BERGH, Malakolog. Unters. I (Heft III), I872, p. I46-I 47 .

Dieselbe ist nur aus dem Indo-Philippinisch-Australischen Meere bekannt. Eine kleine Reihe von theilweise zweifelhaften Arten ist beschrieben.

1. Plakobranchus priapinus Bgh. Taf. II, Fig. 21. Taf. XIII, Fig. IS, I9.

R. Bergh, Malacolog. Unters. Heft III, I872, p. 173-174, Taf. XVIII, Fig. 17, I8; Taf. XX, Fig. 8-I3.

Am 7 Sept. wurde am Riffe von Kilsuin an der Westküste der Insel Kur (St. 250) ein Individuum gefangen und nach dem Leben abgebildet.

Das lebende Thier scheint eine Länge von etwa 2 bei einer Breite von $0,5 \mathrm{~cm}$. gehabt zu haben. Die Grundfarbe ist grünlich gewesen, der Kopf und die Aussenseite der Fussfluggel zeigt ziemlich zahlreiche dunklere Augenflecken mit rother Papille (der Rand der Flügel wahrscheinlich röthlich).

Das ganz schlecht bewahrte abgeriebene Individuum war $20 \mathrm{~mm}$. lang bei einer Breite von 9 und einer Höhe (bei emporgeschlagenen Fussflügeln) von $6 \mathrm{~mm}$. Von der früheren Farbentracht war nichts übrig; die Farbe war durchgehends hell bräunlichgrau an der Unterseite, die zerstreute schwarze Fleckchen zeigte; die obere Seite (der Rücken und die Innenseite der Fussflügel) grün. 
Die Formverhältnisse die gewöhnlichen der Plakobranchen.

Das Centralnervensystem wie gewöhnlich. Der Durchmesser der Augen o, I3 mm.

Der Schlundkopf von einer Länge von 1,25 mm. In der oberen Zahnplattenreihe fanden sich \& Zahnplatten, von welchen die hinterste unentwickelt; in der unteren hinter einander 7 und eine grosse Anzahl abgestossener in dem kugelförmigen Raspelsack. Die fast farblosen Zahnplatten von eine Länge bis $0,16 \mathrm{~mm}$.

Der weisse Penis I mm. lang; sein Stachel lang, (Fig. I8) gebogen, die Chorda seines Bogens $0,5 \mathrm{~mm}$. betragend, der Durchmesser fast durchgehends $0,05 \mathrm{~mm}$, die Länge der Öffnung $0,12 \mathrm{~mm}$. (Fig. I9).

\section{Plakobranchus punctulatus Bgh.?}

R. BERgh, I. c. I (Heft III), I872, p. I69-I7I, Taf. IX, Fig. II-I2; Taf. XIX, Fig. 20-27.

Am Riffe in der Rumah-Kuda-Bai, Insel Roma (St. 279) wurden zwei Individuen gefangen. Sie waren schlecht conservirt.

Das grössere hatte aufbewahrt eine Länge von $27 \mathrm{~mm}$. bei einer Breite (bei hinaufgeschlagenen Epipodien) von Io und einer Höhe von 5; die Länge des Vorderstückes des Fusses war 5, die des Pericardialhöckers $3 \mathrm{~mm}$. - Die Farbe war durchgehends weiss, an der Aussenseite der Epipodien jedoch kleine schwarze Augenflecke, an der Fusssohle zerstreute schwarze Punkte, der Pericardialhöcker schwach gelblich, die Falten des Rückens und der Epipodien gelblich.

Die Formverhältnisse die gewöhnlichen. Die Anzahl der erwähnten Falten etwa 40.

Der Schlundkopf I mm. lang; in der oberen Zahnplattenreihe fanden sich Io Platten und noch eine an der Zunge, in der unteren 7 und in dem kugelförmigen, im Durchmesser $0,24 \mathrm{~mm}$. haltenden Raspelsack noch eine grosse Anzahl. Die fast farblosen Zahnplatten wie gewöhnlich, bis $0, I_{3} \mathrm{~mm}$. lang.

Die Chorda des Bogens des Penisstachels betrug etwa o,6 mm., der Durchmesser des Stachels 0,038 , die Länge der Öffnung seiner Spitze 0,065 .

Vielleicht lag hier der $P l$. punctulatus vor.

\section{Plakobranchus sp.}

Mit einem kleinen Individuum von Cryptophth. olivaceus zusammen wurde am Riffe bei der Insel Kur ein kleiner Plakobranchus gefangen.

Das Individuum hatte eine Länge von I $3 \mathrm{~mm}$. bei einer Breite von 8 und Höhe von 3,5; die Länge des Propodiums war 3, die Breite des Tentakelschildes $6 \mathrm{~mm}$. Die Farbe des Tentakelschildes und des ( $3 \mathrm{~mm}$. langen) Pericardialhöckers (mit dem stark durchschimmernden Herzen) war weiss, die der eigentlichen Rückenseite mit den (etwa 20) schnurartigen Falten grünrau; der Fuss mit der Aussenseite der Fussflügel weisslichgrau; nirgends fanden sich Spuren von Flecken, und das Thier sah anders aus als alle andere Plakobranchen, die ich gesehen habe. 
Das Centralnervensystem wie gewöhnlich, die Augen von $0,13 \mathrm{~mm}$. Durchmesser.

Der Schlundkopf wie gewöhnlich; in der oberen Zahnplattenreihe kamen 8 , in der unteren 9 Platten vor, und der Durchmesser des mit Zahnplatten prall gefuillten kugrelförnigen Raspelsackes war 0,16 mm. Die Länge der Zahnplatten betrug bis 0,12 mm.

Ein Penis-Stachel konnte nicht gefunden werden.

\section{Elysidide.}

R. Bergh, Malacolog. Unters. I (Heft IV), I872, p. I75-203, Tab. XXI-XXIV

R. Bergh, Beitr. z. Kenntn. d. Aeolidiaden VIII. Verh. d.·k. k. zool. bot. Ges. zu IVien. XXXV, I 885 , p. I6-23.

Forma corporis valde depressa. Caput angustius, fronte sat alta; tentacula breviora, ut plurimum auriformia, marginibus involutis; oculi sejuncti. Pone tentaculum dextrum apertura genitalis duplex. Corpus applanatum alis lateralibus reflexilibus; pone nucham protuberantia pericardio-renalis et anus ut in Plakobranchis, vel anus magis posterior in linea media situs. Notaeum proprium utrinque ab ala laterali linea elevata, extrorsum ramulos emittente sejunctum, laeve. Podarium ut in Plakobranchis sed angulis minus prominentibus.

Bulbus pharyngeus ut in Plakobranchis sed ut plurimum sine prominentia ingluvieformi. Lingua cum dentibus fere ut in Plakobranchis, dentes attamen magis compressi et margine inferiori hami acuto edentulo vel minutissime serrulato. Glandula hermaphrodisiaca ut in Plakobranchis; penis inermis.

In allgemeinen Formverhältnissen kommen die Elysiiden ziemlich nahe an die Plakobranchiden, sind aber noch mehr abgeplattet, mitunter bis zu Verwechselung gewissen Planarien ähnlich. Der Ruicken und die durch eine vortretende Linie oder Schnur von demselben abgegrenzten Flügel glatt; nur bei der Gattung Thuridilla liegt der Anus median. Der Schlundkopf wie bei den Plakobranchen aber meistens ohne kropfartigen Ansatz, der sich nur bei der Thuridilla findet. Die Zahnplatten von derselben Grundform wie bei den Plakobranchen, aber mehr dolchartig, mit fein gesägtem oder glattem Unterrand. Die Läppchen der Zwitterdruise wie bei den Plakobranchen; der Penis unbewaffnet.

Diese hübschen, lebhaften, Planarien-ähnlichen Thiere sind in allen Meeresgegenden, den nördlichen wie den tropischen, vertreten.

Die Gruppe umfasst die Gattungen Elysia und Tridachia mit vorne neben dem pericardio-renalen Höcker liegendem Anus, ferner die Thuridilla mit medio-dorsaler Öffnung; im Gegensatz zu den vorigen mit ihrem gerundeten Kopf und wohl entwickelten Tentakeln hat die Gattung Elysiella einen mehr keilförmigen Kopf mit ganz kleinen Tentakeln.

Von diesen Gattungen fanden sich nur ächte Elysien in den Siboga-Sammlungen repräsentirt. 
Elysia (Risso) autt.

Vgl. 1.c. 1872 , p. $176-$ - . c. 1885 , p. 16.

I. Elysia thysanopoda Bgh. 11. sp. Taf. XIII, Fig. 20-2I.

Am i6 Dcbr. wurden am Ankerplatz von Tual, Kei-Inseln (St. 258) zwei Individuen gedretscht.

Die in Formol bewahrten Individuen waren fast gleichgross, an Länge $4-4,2 \mathrm{~cm}$. messend bei einer Breite vorne von 2,7 hinten von $\mathrm{I}, 2$; die Dicke betrug vorne $3 \mathrm{~mm}$. (an dem Pericardialhöcker), war sonst viel geringer; der Kopf mit dem Pericardialhöcker $8 \mathrm{~mm}$. lang, die Länge der Tentakel 3,5; die Länge des Vorderfusses $7 \mathrm{~mm}$. bei derselben Breite. Die Farbe war durchgehends gräulichweiss; der Rand der Fussflügel (in einer Breite von $0,5 \mathrm{~mm}$.) sammtschwarz; kleine rundliche schwarze Fleckchen (von einem Durchmesser von etwa $0,2-0,3 \mathrm{~mm}$.) waren an der Rückenseite nicht zu reichlich zerstreut, ähnliche kamen längs der (undeutlichen) Fusssohle und hinten am Vorderfusse vor. Undeutliche Contouren von blassen Eingeweidemassen schimmerten undeutlich durch den Pericardialhöcker durch.

Das Thier ähnelte, fast zum Verwechseln, einer grossen Planarie, besonders der grossen Thysanoplana marginata ${ }^{1}$ ); es war ganz schlaff und weich, mit breiten, stark wellenartig gebogenen Fussfluggeln, nach hinten etwas verschmälert. Der Kopf ohne Grenze in den nach hinten etwas zugespitzten Pericardialhöcker übergehend, vorne an dem letzteren und rechts eine feine Öffnung (Anus), von Rückenschnüren war nichts zu sehen, und der Rücken überhaupt ganz eben. Der Vorderfuss sehr ausgeprägt, gleichsam waffenschildförmig, der Vorderrand mit medianem Einschnitt, der Hinterrand gerade; der uibrige Fuss von den Flügeln wenig abgegrenzt.

Das Centralnervensystem ganz deutlich von typischen Verhältnissen. Die Augen von 0,16 mm. Durchmesser.

Die Mundröhre (Schlundkopf) von einem starken Drüsenlager umgeben. Der Schlundkopf weisslich, I mm. lang, mit den gewöhnlichen Halbreifen (Fig. 20). Die Zunge von gewöhnlicher Form, in der oberen Zahnplattenreihe 8 Platten, von denen die hinterste unreif, in der unteren 9- Io und zahlreiche in dem Raspelsack, welcher oval eine Länge von o,30 mm. bei einem Durchmesser von o, I6 hatte, oder kugelförmig war mit einem Durchmesser von 0,20 (Fig. 20). Die farblosen Zahnplatten (Fig. 2 I) bis 0, I I mm. lang, der Rand des Hakens schien glatt zu sein; auch im Raspelsacke fanden sich ein Paar Zahnplatten von o, I I mm. Länge.

Die Speicheldrïsen weisslich, langgestreckt.

Der weisse starke Penis $2,5 \mathrm{~mm}$. lang.

2. Elysia ornata (Pease). Taf. II, Fig. 20. Taf. XIII, Fig. 22-23.

Pterogasteron ornatum Pease. Descr. of new sp. of Moll. from the Sandwich Islands. Proc. zool. soc. XXVIII, I860, p. 36.

Elysia ornata (Pease). R. BERGH, Malacol. Unters. Supplementheft II, ISS I, p. 79-80. Taf. G, Fig. Is (Originalzeichnung PEASE's).

I) M. PLEnn, Neue Polycladen. Jenaische Zeitschr. f. Naturw. XXX (N. Fr. XXIII), I896, p. 165, Taf. VIII, Fig. I-2, 
Am Riffe von Haingsisi sind 2 Individuen dieser Thierform gefangen, nach dem Leben gemalt und in Formol aufbewahrt. Beide wurden anatomisch untersucht.

Das lebende Thier hat eine Länge von gegen $4 \mathrm{~cm}$. gehabt und bei ausgeschlagenen Flügeln an Breite $2,8 \mathrm{~cm}$. Die Farbe des Rückens ist olivengriin gewesen mit zahlreichen zerstreuten schwarzen Punkten; die Flügeln sind von einer schwarzen Linie und innerhalb derselben von einem rothen Bande eingefasst; der Kopf ist auch grün, die Rhinophorien sind an der Spitze roth.

Die Länge der ganz schlaffen und ganz weichen a ufbewahrten Individuen war $2,2-2,4 \mathrm{~cm}$. bei einer Breite von 1,8 und einer Höhe des Körpers von $2 \mathrm{~mm}$.; die Länge der Rhinophorien war $2 \mathrm{~mm}$., die des Pericardialhöckers 2,5 bei einer Breite von I,25; die Länge des Vorderfusses $3-3,5 \mathrm{~mm}$. die Breite des Fusses vorne $5 \mathrm{~mm}$. - Der Kopf sowie der Fuss und die Mitte des Rückens seiner ganzen Länge nach weisslich; die grossen Fussflügel oben wie unten grüngrau, ihr Rand bei dem einen Individuum bräunlich, bei dem anderen tiefschwarz, innerhalb dieses Randes ein kaum breiteres, jetzt weissliches Band; das ganze Thier trägt fast überall eine Menge von rundlichen schwarzen Punkten und Fleckchen (von einem Durchmesser bis zu $0,4 \mathrm{~mm}$.), am Kopfe sowie am Fusse kamen sie sparsamer vor und gegen den Rand der Fussflugel hin fehlten sie fast so wohl an der oberen wie an der unteren Seite.

Die Formverhältnisse wie bei allen ächten Elysien, so der Kopf mit den Rhinophorien und der Fuss. Der Pericardialhöcker länglich, nicht gross, gewölbt vortretend; am Vorderende rechts die Analöffnung; von Rückenschnüren war (jetzt) nichts zu sehen. Die grossen Fussflüge machten $2-3$ grosse Wellenbiegungen.

Des Centralnervensystem zeigte die gewöhnlichen 7 Ganglien. Die Augen von einem Durchmesser von $0,12 \mathrm{~mm}$; der Otolith von $0,09 \mathrm{~mm}$. Diameter.

Der Schlundkopf vorne von den gewöhnlichen starken weissen Drüsenmassen bedeckt, fast I,5 mm. lang, von gewöhnlicher Form, oben mit den gewöhnlichen Halbreifen. Die eigentliche Zunge wie gewöhnlich ganz kurz, mit einer Zahnplatte; in der oberen Scheide kamen 8 Platten und eine unreife vor; in der unteren Reihe fanden sich in einer Reihe auch 8 , und in dem (im Durchmesser o,o8 mm. haltenden) Sacke noch etwa 6 (Fig. 22) Die schwach gelblichen Zahnplatten von gewöhnlicher Form, mit glatten Rändern (Flg. 23). Die Länge der jüngsten Platten betrug 0, I6 mm., die der ältesten im Sacke lose liegenden 0,0 I6-0,035.

Der kegelförmige weisse $\mathrm{Pen}$ is fast $2 \mathrm{~mm}$. lang.

Das untersuchte Thier gehörte wahrscheinlich der von PEASE erwähnten und abgebildeten Art an; nahe verwandt ist vielleicht die El. grandiflora Kelaart (vg1. 1. c. I857, p. 107).

3. Elysia? lineolata Bgh. n. sp. Taf. XIII, Fig. 25-26.

Am 26 Oct. wurde am Ankerplatz bei Saleyer (St. 2I3) auf einem Riffe eine kleine Anzahl (12) Individuen erbeutet.

Sie waren meistens so zusammengerollt, das sich an der Rückenseite, Kopf und Schwanz fast beruhrten. Die Länge schien meistens $4,5-6 \mathrm{~mm}$. zu betragen. Zwei Individuen hatten 
eine Länge von $10 \mathrm{~mm}$; bei dem einen waren die Fussflügel emporgeschlagen, die Breite betrug dann 3 und die Höhe auch $3 \mathrm{~mm}$; bei dem anderen waren die Flügel ausgeschlagen, und die Breite war fast $7 \mathrm{~mm}$; bei diesen zwei Individuen war die Breite der Fusssohle 1,75, die Länge des Vorderstiickes des Fusses $1 \mathrm{~mm}$. - Die Farbenverhältnisse waren bei allen Individuen vollständige übereinstimmend. Der Kopf war weisslich; hinter dem Vorderrande ein schwarzes, schmales Querband, die Rhinophorien trugen in der Mitte ein schwarzes Querband und meistens ein ähnliches an der Spitze. Der Pericardialhöcker war schwarz; der Rückenseite dunkel grau oder schwarzgrau, gegen den Rand der Flügel hin von einem schwarzen Bande eingefasst, der Rand (der Flügel) selbst weisslich. Die Fusssohle (Fig. 25) gräulich oder bläulichgrau, in ihrer ganzen Länge von einem schwarzem Bande eingefasst; die Innenseite der Fussflügel weisslich; nach innen zeigen sie eine mehr oder weniger starke, mit der Einfassung der Fusssohle parallele schwarze Linie, und nach aussen eine oft stärkere, mit dem (weisslichen) Rande parallele ähnliche.

Die Formverhältnisse die gewöhnlichen, der Vorderfuss war ziemlich klein; die zwei gegen den Pericardialhöcker convergirenden Rückenschnüren wenig vortretend. Anus und Genitalöffnung wie gewöhnlich.

Das Centralnervensystem zeigte die gewöhnlichen Ganglien.

Die Untersuchung des Schlundkopfes war wegen der starken schwarzen Pigmentirung der Mundröhre, theilweise auch des Bulbus selbst schwierig. Seine Länge betrug etwa $0,75 \mathrm{~mm}$; in seiner Höhle kam eine klare, hell citrongelbe, unbestimmbare Masse vor. In der oberen Zahnplattenreihe der Zungen muskelmasse schienen 7 entwickelte und eine unentwickelte Platte vorzukommen, in der unteren 12 in einer Reihe und mehrere in dem Raspelsacke, der einen Durchmesser von $0,08 \mathrm{~mm}$. hatte. Die farblosen Zahnplatten erreichten eine Länge bis zu $0,05 \mathrm{~mm}$, waren aber (im Gegensatz zu den meisten anderen Elysien) an beiden Seitenrändern äusserst fein denticulirt (Fig. 26).

Bei der ungenügenden Untersuchung dieser kleinen und in Formol bewahrten Individuen ist die Einreihung der Art unten die ächten Elysien nicht ganz sicher.

Taf. III, Fig. IO.

An einem Riffe von Saleyer (St. 2I3) wurden 8 Individuen, die wahrscheinlich zu dieser Art gehören, gefangen und eines lebend abgebildet.

Das lebende Thier hatte eine Länge von is bei einer Breite (bei emporgeschlagenen Fussfluggeln) von $3 \mathrm{~mm}$. gehabt. Die Farben sind recht prachtvoll gewesen; die Fussflügel blau, ihr innerer so wie ihr äusserer Rand roth: der Kopf blau, die Spitze der Rhinophorien roth.

Die a ufbewahrten Individuen hatten eine Länge von 6- ro mm., das grösste maass bei aufgeschlagenen Flügeln an Breite (vorne) 4 und an Höhe 3,25 mm. - In Farbenverhältnissen schienen die Individuen alle übereinzustimmen. Der Kopf weisslich; die ganze obere Seite (Rücken mit den ausgeschlagenen Fussflügeln) war sonst schwarzgrau, der Rand der Fligel weisslich und innerhalb desselben verlief eine schwarze Linie. Der Vorderrand des ziemlich 
kleinen Vorderfusses von einer schwarzen Linie eingefasst; der ganze Fuss grau von cinem schwarzen Bande eingefasst, ausserhalb desselben ein breiteres weissliches, mitunter durch eine schwärzliche Linie von einem blaugrauen geschieden, das nach aussen an eine schwarze starke Linie stösst, die hinten in die schwarze Einfassung der Fusssohle übergeht; ausserhalb dieser Linie der weissliche Flügelrand. In der Mitte der Rhinophorien ein schwarzes Querband und meistens ein kleineres ähnliches an ihrer Spitze.

Die Augen gross, von $0,14 \mathrm{~mm}$. Durchmesser; auch bei dieser Art schienen eine Linse und ein Glaskörper differenzirt.

Die starke schwarze Pigmentirung der Umgebung und der Conservationszustand erschwerten die Untersuchung des Schlundkopfes sehr, der kurz birnförmig und etwa 0,45 mm. lang war. In der oberen Zahnplattenreihe schienen 9 und in der unteren ro Zahnplatten vorzukommen, dazu noch viele in dem in Durchmesser $0,10 \mathrm{~mm}$. haltenden Raspelsack. Die gelben Zahnplatten auch bis $0,05 \mathrm{~mm}$. lang, auch an beiden Rändern gezähnelt.

4. Elysia Haingsisiana Bgh. n. sp. Taf. XIII, Fig. 24.

Am Riffe von Haingsisi wurde ein Individuum gefangen.

Dasselbe hatte eine Länge von $14 \mathrm{~mm}$. bei einer Höhe und Breite von 3,5. - Der Kopf mit den $(2,5 \mathrm{~mm}$. langen) Rhinophorien schwarz, die letzteren mit feinen bläulichen Längslinien, die Spitze milchweiss (Fig. 24), der (2,25 mm. lange) Pericardialhöcker auch schwarz, seine Öffnungen weiss; der Rücken mit der oberen Seite der Fussfluggel schwarzgrau, hinten schwarz, innerhalb des schwarzen Flügelrandes ein mit demselbes paralleles weisses Band; die 4 an den Pericardialhöcker verlaufenden Schnüren schwarz. Das Vorderende des Fusses weiss, derselbe sonst schwarz; die untere Seite der Fussflügel schmutzig grau mit mehreren dunkleren Längsstreifen, der Rand weisslich.

Der Schlundkopf etwa 0,4 mm. lang. In der oberen Zahnplattenreihe schienen 9, in der unteren 5 Platten vorzukommen, und in dem kugelförmigen, im Durchmesser $0,08 \mathrm{~mm}$. haltenden Raspelsack eine Anzahl. Es glïckte nicht die Zahnplatten klar darzulegen; sie waren farblos, schienen eine Länge bis $0,045 \mathrm{~mm}$. zu erreichen, und zeigten den Haken an beiden Rändern äusserst fein denticulirt.

Die kegelförmige glans penis war weiss. 


\section{NUDIBRANCHIATA. \\ R. BERGH, System der nudibranchiaten Gasteropoden. Malacol. Untersuchungen. III (Heft XVIII), I892, p. 996-I I65.}

\section{NUDIBRANCHIATA HOLOHEPATICA.}

R. BERGH, 1. c. I892, p. $1070-1160$

Branchia medio-dorsalis, retractilis vel non retractilis, ut plurimum paucifoliata, foliolis simpliciter pinnatis vel compositis.

Bulbus pharyngeus validus, mandibulis propriis destitutus. Hepar nunquam ramulosum. Glandula sanguinea. Vesiculae seminales duae.

Die Holohepatiker tragen median am Rücken eine meistens aus einer nicht grossen Anzahl von Blättern gebildete Kieme. Der starke Schlundkopf fast immer ohne seitliche Mandibel. Die Leber ist solide, ganz ohne abgehende Äste; immer findet sich eine an oder auf dem Centralnervensystem gelagerte Blutdrüse und immer zwei Samenblasen.

$$
\begin{aligned}
& \text { Dorididae cryptobranchiatae. } \\
& \text { R. BERGH, 1. c. r892, p. 1075-1r29. }
\end{aligned}
$$

Branchia e foliis pinnatis in arcu vel circulo positis basi fere semper conjunctis formata, cavitate communi fere semper retractilis; rhinophoria semper retractilia et clavo perfoliato.

Bulbus pharyngeus nunquam suctorius.

Mit Ausnahme der Bathydoriden und der Hexabranchen haben alle die anderen Gattungen dieser Dorididen eine in eine gemeinschaftliche Höhle zurückziehbare Kieme. 


\section{HEXABRANCHIDAE.}

R. BERGH, System der nudibr. Gasteropoden. 1. c. IS92, p. Iogr.

Corpus magnum, sat molle, sat applanatum, elongato-ovale; dorso laevi, limbo palliali lato undulato margine tenui undulato; tentacula sat magna, foliacea margine crispato; branchia e fasciculis discretis fruticulosis compluribus $(6-8)$ foveis discretis contractilibus formata; podarium non parvum attamen dorso magnopere angustius.

Armatura labialis fortissima, utrinque enim lamina crassa e baculis minutissimis formata. Radula rhachide nuda, pleuris multidentatis dentibus hamatis. - Penis longissimus, inermis.

Die Hexabranchiden scheinen die Nudibranchien zu sein, die die bedeutenste Grösse (Länge) erreichen ${ }^{1}$ ); sie sind ziemlich abgeplattet, weich. Der Rücken ist glatt, mit wellenförmig gebogenem Gebräm mit gekräuseltem dünnem Rande; die Tentakel sind gross, lappenartig, mit gekräuseltem Rande; die Kieme aus mehreren ((5) 6-8) in einen Kreis gestellten Büscheln bestehend, welche jedes für sich gegen ein Grübchen contractil sind; hinten im Kiemenkreis die Analpapille, rechts und vor desselben die Nierenpore, links ein eigenthuimlicher Porus. Der Fuss ziemlich stark, aber viel schmäler als der Rücken. - Die Lippenplatten sehr stark. Die Zunge mit einer nicht grossen Anzahl (16-29) von Zahnplattenreihen, die Anzahl der hakenförmigen Zahnplatten zu jeder Seite der schmalen nackten Rhachis nicht sehr gross (57-100). - Es findet sich nur eine Blutdrüse. - Der unbewaffnete Penis ist sehr lang und dementsprechend die Vagina.

Diese recht prachtvoll (roth-)gefärbten Thiere, die mit Hülfe ihres breiten Rückengebräms schwimmen können, scheinen nur im Rothen, Indischen und Stillen Meer vorzukommen.

Die Familie enthält bisher nur die Gattung:

\section{Hexabranchus Ehrenberg.}

Hemirich et Ehrenberg, Symb. phys, anim. evertebr. Ser. I, i83r. Decas Tab. I. Moll. Tab. I, Fig. I $A, C$.

R. BERGH, Krit. Unters. d. E.'schen Doriden. Jahrb. d. d. malakozool. Ges. IV, I877, p. 72.

R. BERGH, Malacol. Unters. II (Heft XIII, I878), p. 547-566.

R. Bergh, Die Opistobranchier. Ergebn. einer Reise nach dem Pacific (Schauinsland). I90o. Zoolog. Jahrb. XIII, 3. p. 226-233.

Eine Reihe von (etwa 20) Arten ist (meistens nach Untersuchungen an Spiritusexemplaren) angegeben (), welche zum allergrössten Theil doch wohl nur Varietäten oder Localformen einer und derselben sehr verbreiteten Art sind, die der H. (Doris) lacer von Cuvier kaum sein $\left.k^{2}{ }^{2}\right)$

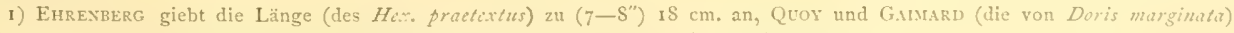
zu $\left(6-8^{\prime \prime}\right) 16-18 \mathrm{~cm}$. und Rïlpelt und LeUCKART (die von D. sangrinca zu (etwa $6^{\circ}$ ) $16 \mathrm{~cm}$. an.

2) V'gl. R. BERGH, l. c. II (Heft XIII), IS78, p. $54 \mathrm{~S}-550$.

3) Die Doris lacera von Cuvier ist ein Hexabranchus, durch die (zweifelhaften??) Knoten des Rückens aber von anderen IIexabranchen verschielen; mit Unrecht habe ich diesen Namen (1.c. Igoo, p. 226) fur einez von mir untersuchten Hexabranchus angewendet. SHROG A.EXPEDITIE, L, 
1. Hexabranchus marginatus (Q. et G.). Taf. I, Fig. 2.

Doris marginata Quoy et Gaim. Voy. de l'Astrolabe. Zool. II, 1832, p. 255, Pl. 17, Fig. I-5. Hexabranchus lacer (Cuv.)? BERGi, 1. c. I900, p. 226-233.

Von dieser prachtvollen Thierform wurde am I7 Januar am Riffe von Ost-Timor (St. 282) ein grosses Individuum gefangen und lebend abgebildet, ferner bei Pulu-Pasi-Tanette (St. 2 I 3) 4 Individuen und am Riffe von Haingsisi eins, am Riffe der Süd-Inseln (St. 2 I 3) zwei grosse, so wie ein etwas kleineres am Riffe von Gisser (St. I 72) zwischen dieser Insel und Ceram-Laut.

Das grosse Individuum hatte lebend eine Länge von gegen I I $\mathrm{cm}$. bei einer Breite von 7. Der Durchmesser des Kiemenkreises war (bei ausgeschlagenen Blättern) 2,5. Die Farbe des eigentlichen Ruickens war carmoisin-roth mit einigen dunkleren Zungen in die breite weisse, rothpunktirte Einfassung hinaustretend; dieser weissen Einfassung schloss sich ein schmaleies dunkel carmoisinrothes Band an, das ziemlich zahlreiche Zungen in das weisse hinein sandte; dieses Band war wieder von einem rothgelben eingefasst, das innen blässer war; der stark wellenförmig gebogene breite Rückenrand war weiss; hinten waren diese (4) Bänder bogenartig geschlossen, vorne durch die Fortsetzung der Farbe des eigentlichen Rückens abgebrochen. Die Keule der Rhinophorien war braun, die Kiemenblätter hell röthlichgelb, die Analpapille weiss.

Das a ufbewahrte, durchgehends ganz weissliche Individuum hatte jede Spur der früheren Farbenpracht verloren. Die Länge betrug $9 \mathrm{~cm}$. bei einer Breite von 7 und einer Höhe von 2; die Breite des eigentlichen Rückens 1,7 , die des Rückengebräms bis $2,5 \mathrm{~cm}$.; die Länge der Rhinophorien $5 \mathrm{~mm}$, die der einzelnen Kiemenblätter bis $9 \mathrm{~mm}$., der Durchmesser des Kiemensterns $2,5 \mathrm{~cm}$; die Länge der Tentakel $7 \mathrm{~mm}$, die des Fusses $7 \mathrm{~cm}$. bei einer Breite von $\mathbf{I}, 8$, die Länge des Schwanzes $8 \mathrm{~mm}$.

Die Formverhältnisse waren die gewöhnlichen; die grossen blattartigen Tentakel mit stark gekräuseltem Rande; die Kieme aus 6 Blättern gebildet, die wie gewöhnlich zusammengesetzt waren, die Analpapille niedrig, an ihrem Grunde rechts und vorne die Nierenpore, links die kleine adanale perforirte Papille; des Fuss wie gewöhnlich.

Das Centralnervensystem ganz wie früher beschrieben.

Die Mundröhre $5 \mathrm{~mm}$. lang. Der Schlundkopf von der fruher beschriebenen Form, Io mm. lang bei einer Höhe und Breite von 7, die Raspelscheicle hinten etwas hervortretend. Die starken, gelben Lippenplatten $4 \mathrm{~mm}$. hoch, $2 \mathrm{~mm}$. breit, mit etwa 15 starken Querrippen; die sie zusammensetzenden dicht gedrängten Stäbchen von etwa 0,004 mm. Breite. Die starke Zunge enthielt in der gelben Raspel etwa 25 Zahnplattenreihen und ebenso viele kamen in der Scheide mit ihrer starken Lingula vor, die Gesammtzahl der Reihen war somit 50. In den Reihen schienen bis etwa 60 Platten vorzukommen ${ }^{1}$ ). Die schwach gelblichen Zahnplatten wie friher mehrmals von mir beschrieben.

Die (bis etwa $3 \mathrm{~cm}$.) langen, dïnnen, weissen Speicheldrüsen bis auf den Magen reichend. Die Speiseröhre $2,8 \mathrm{~cm}$. lang, von einem Durchmesser bis $4 \mathrm{~mm}$, vorne und hinten

1) Die Anzahl der Zahnplattenreihen betrug bei HTox. faustus $48-49(25+24)$, bei $H$. anailous $48(29+19)$, bei H. Potersi $44(28+16)$, bei $H$. notatus $34(19+15)$ und bei H. marginatus $41-33(19+22,36+17)$.

Die Anzahl der Zahnplatten in den Reihen war bei H. faustus $\mathrm{S}_{2}-84$, bei $H$. anaiteus stieg sie bis zu 92 , bei $H$. Petersi war sie 66, bei $H$. norntus 57 und belief sich bei $H$. marginatus auf $70-100$. 
etwas weiter ${ }^{1}$ ). Der Magen $r_{3}$ mm. lang bei einem Durchmesser von 7 ; der Darm $3,3 \mathrm{~cm}$. lang bei einen Durchmesser von $3-2 \mathrm{~mm}$. Die hintere Eingeweidemasse (Leber) grïulich, schlauchförmig, vorne mit tiefer Kluft für den Magen, 2,5 cm. lang bei einem Durchmesser von I, I. Die kugelförmige Gallenblase von einem Durchmesser von $4 \mathrm{~mm}$.

Die gräulichbraune Blutdrüse hinter dem Centralnervensysteme liegend, 6 mm..lang bei einer Breite bis 5 , aus 3 hinter einander liegenden Lappen bestehend.

Die kleine, $7 \mathrm{~mm}$. lange vordere Genital $\mathrm{masse}$ wenig entwickelt.

Diese Form scheint mit dem H. (Doris) marginatus von Quoy und GaIxrard übereinzustimmen. Sie ist in Farbe von dem H. marginatus von Möbus verschiedem, dem das weisse Mantelgebräm fehlt; der $H$. praetextus von EHRENBERg zeigt solches, aber ist sonst ganz roth wie der $H$. sanguineus von Rüppell ${ }^{2}$ ), der $H$. Petersi von Bergh, und vielleicht der $H$. anaiteus von BERGH; der H. faustus ist, wie von SEMPER gemaIt, olne das weisse Randgebräm, stimmt aber sonst etwas mit der hier untersuchten Form überein.

Hexabranchus marginatus (Q. et G.), var. Taf. I, Fig. I.

Bei Haingsisi auf Samau in der Nähe von Timor wurde ein noch grösseres Individuum einer Varietät derselben Art gefangen und lebend abgebildet.

Dasselbe war 1 ebend I $3,5 \mathrm{~cm}$. lang bei einer Breite von 8,5 , die Breite des eigentlichen Rückens war $2,3 \mathrm{~cm}$, der Durchmesser des Kiemenkreises $4 \mathrm{~cm}$.; die Höhe der Rhinophorien war I2 mm.; die Anzahl der Kiemenblätter 7 ; die Höhe der Analpapille $7 \mathrm{~mm}$. - Der eigentliche Rücken war hier mehr gelb, an seinem Rande jeclerseits einige (2) weisse Flecken; sonst fehlte eine weisse Einfassung des Ruickens, dem sich ein breites dunkel karmoisinrothes Band anschloss, ausserhalb desselben war der ebenso breite Überrest des Rückengebräms hell violet, der Rand selbst weiss; die Rhinophorien und die Kiemenblätter waren heller als bei den anderen Individuen.

Hexabranchus marginatus (Q. et G.), var. Taf. V, Fig. 8.

Am Riffe der Pepela-Bai an der Ostkuiste der Insel Rotti (St. 301) wurde ein Individuum gefangen und lebend abgebildet.

Lebend hatte das Thier eine Lünge von fast $5 \mathrm{~cm}$. bei einer Breite von fast $\mathrm{I}, 5$. Der eigentliche Rücken war karmoisinroth, diese Strecke etwas unregelmässig gebogen und mit einigen Ausläufern gegen den Rückenrand; das Rückengebräm gelb mit karmoisinrothen Flecken ringsum längs des Randes; die Rhinophorkeule und die Kieme hellroth, der Schwanz roth mit weisslichem medianem Kiel.

Das a ufbewahrte Individuum war fast $2 \mathrm{~cm}$. lang bei einer Breite von I und Höhe

1) Vgl. R. Bergir, Erg. einer Reise nach dem Pacific (Schauinsland). 1. c. 1900, Taf, 2I, Fig. 65.

2) Fravexpeld (Naturh. Fragmente. Sitzungsber. d. math. naturw. Classe d. k. Ak. d. Wissenscl. (Wien) XVIII, I, I855, p. (66) 79) giebt an auch ein Individuum der Doris sanguinea ohne weissen Saum gesehen zu haben (meistens war dieser Saum sehr ausgeprägt. vgl. Taf. I). 
von 0,5 ; das Rückengebräm $3 \mathrm{~mm}$. breit; die Höhe der ganz ausgestreckten Rhinophorien 2,5 mm., der Durchmesser des Kiemensterns 5, die Länge der Tentakel 2, die Breite des Fusses 4, und die Länge des Schwanzes $3 \mathrm{~mm}_{1}$ - Von den schönen Farben war absolut Nichts übrig; das Thier war durchgehends weisslich, die Keule der Rhinophorien und die Kieme gräulich.

Die Formverhältnisse ganz wie gewöhnlich, so auch die der grossen Tentakeln; die Kieme aus 5 Blättern gebildet.

Der weissliche, $4 \mathrm{~mm}$. lange Schlundk opf wie gewöhnlich; die schmutzig braungelben breiten Lippenplatten mit den gewöhnlichen Querfalten vom gewöhnlichen Bau. Die schwach gelbliche Raspel der Zunge trug 25 Zahnplattenreihen, in der Scheide fanden sich deren noch 20, die Gesammtzahl der Reihen somit 45. In den Reihen kamen bis etwa 40 Zahnplatten vor. Dieselben waren von den gewöhnlichen Formverhältnissen.

Die querliegende, $2 \mathrm{~mm}$. breite Blutdrise braungrau. Die gelblichgraue hintere Eingeweidemasse $7 \mathrm{~mm}$. lang bei einer Breite von 3,5. Die kugelförmige graue Gallenblase von I,25 mm. Durchmesser.

Auch diese Form stellt nur eine Varietät des Hex. marginatus vor.

2. Hexabranchus punctatus Bgh. n. sp. Taf. XII, Fig. 27.

Am Riffe von Pulu-Kabala-dua, Borneo-Bank (St. $79^{b}$ ) wurde ein Individuum gefangen.

Dasselbe war aufbewahrt etwas steiff, schmutzig gelblich, an der Rückenseite sparsam zerstreute punktartige schwarze Flecken, sowie auch an der Unterseite des Rückengebräms. Die Länge betrug $20 \mathrm{~mm}$. bei einer Breite von I I und Höhe von 5; die Breite des Rückengebräms 2, des Kiemenkranzes 7 , des Fusses $5 \mathrm{~mm}$.

Die Formverhältnisse die gewöhnlichen, das Rückengebräm jedoch nicht breit und nicht stark wellenartig gebogen. Die Anzahl der Kiemenblätter 6 (7); der Anus, die Nierenpore und die adanale Pore links wie gewöhnlich. Der Rand der grossen Tentakel stark gekräuselt; die Keule der Rhinophorien stark rückwärts gebogen.

Die Mundröhre röthlichbraun, $2 \mathrm{~mm}$. lang. Der Schlundkopf auch röthlichbraun, $3 \mathrm{~mm}$. lang; die starken braungelben Lippenplatten mit schwachen Querrippen, aus fast verschmelzenden diinnen Elementen gebildet. In der gelblichen Raspel i 7 Zahnplattenreihen, in der starken Scheide deren noch im Ganzen 21, die Gesammtzahl der Reihen somit 38 ; in den Reihen kamen bis 37 Platten vor. Dieselben waren schwach gelblich, bis $0,12 \mathrm{~mm}$. hoch, von den gewöhnlichen Formverhältnissen (Fig. 27).

Weitere Untersuchung wurde, um das einzige vorliegenden Individuum zu schonen unterlassen.

Die Form scheint von den bisher beschriebenen Hexabranchen verschieden. 


\section{Archidorididae.}

R. BERGH, System der nudibr. Gasteropoden. 1. c. I892, p. 1092.

Corpus non durum, nonnihil depressum; notaeum tuberculatum vel granulatum, limbo marginali non angusto; tentacula parva, folia branchialia fere semper tri-vel quadripinnata; podarium sat latum.

Armatura labialis nulla; radula rhachide nuda, pleuris multidentatis, dentibus hamatis.

Penis ut plurimum inermis.

Diese Familie umfasst die Gattungen Archidoris, Staurodoris, Echinodoris, Artachaca, Petalodoris, und vielleicht noch Aporodoris und Ethidoris.

Nur bei Staurodoris kommen einfach gefiederte Kiemenblätter vor. Bei Echinodor is und Artachaea ist der Penis bewaffnet.

\section{Archidoris Bgh.}

R. BERGH, System. I892, p. I092.

I. Archidoris kurana Bgh. n. sp. Taf. XII, Fig. 28-29.

Bei der Insel Kur (Stat. 250) wurden 2 Individuen dieser Form gefangen, jetzt leider ganz steif und erhärtet.

Das kleinere war $10 \mathrm{~mm}$. lang. Das andere maass an Länge $\mathrm{I}_{3}$ bei einer Breite von 6 und Höhe von 3,5 mm., die Breite des Ruickengebräms war I,5, der Durchmesser des Kiemensternes 2,5, die Breite des Fusses 4,5, seines Gebräms I, die Länge des Schwanzes 2 mm. Die Farbe war durchgehends weiss.

Die Rhinophorien stark, ihre Blätter durch reichliche starke Spikel steif gemacht. Der Rücken mit medianem knotigem Kiele, mit 2-3 Längsreihen von kleinen Knoten, und zwischen denselben dichtstehenden kleineren (Fig. 28). Die Kieme 5-blätterig. Der Aussenmund mit je einem seitlichem Höcker (Tentakel).

Die Mundröhre I mm. lang. Der gedrungene weissliche Schlundkopf $2 \mathrm{~mm}$. lang, mit kurzer hinten hervorragender Raspelscheide; die Lippenscheibe mit farbloser Cuticula. Die starke Zunge mit gelblicher Raspel, die i 8-20 Zahnplattenreihen enthielt, in der Scheide deren noch I $_{5}$, von denen 2 unreif, die Gesammtzahl der Reihen somit 33-35; in den Reihen kamen jederseits etwa 70 Platten vor. Die Zahnplatten fast farblos; die Höhe der äussersten $0,04 \mathrm{~mm}$. betragend, die Höhe bis $0,12 \mathrm{~mm}$. steigend; die Form die gewöhnliche hakenartige (Fig. 29).

Die hintere Eingeweidemasse so wie die vordere Genitalmasse weiss.

Eine Archidoris lag hier vor und wahrscheinlich eine neue $\operatorname{Art}^{1}$ ).

1) Eliot, on some Nudibranchs from East Africa and Zanzibar, 1II, 1904. (Proc. 200l. 50c. I903, 11. p. 36I-362) erwähnt zwei Arten von Zanzibar (A. africana E.; A. minor E.). 
Aporodoris Jhering.

Jinering, Zur Kenntn. der Nudibranchien der Brasilianischen Küste. MIalacolog. Jahrb. XIII, ISSo, p. 238. Taf. 9, Fig. 3, 4.

Corpus sat molle, sat applanatum, limbo palliali sat lato; notaeum parce granulatum, minutissime villosum; branchia e foliis paucis, simpliciter (?) pinnatis composita.

Armatura labialis nulla. Radula rhachide nuda, pleuris multidentatis, dentibus hamatis, externis pectiniformibus.

Penis armatus?

JHERING hat diese Gattung auf die sehr unvollständig gekannte Doris millegrana von Alder und HANCOCK aufgestellt, von welcher er eine "var. mediterranea" des Mittelmeeres (wahrscheinlich aus der Gegend von Neapel) vor sich gehabt zu haben meint. Seine Untersuchung ist leider ziemlich ungenügend, und die mitgegebenen Abbildungen (Fig. 3, 4) wenig brauchbar.

Ob die untenstehende, vielleicht neue Doride hierhin gehört, ist vorläufig sehr zweifelhaft.

I. Aporodoris? mbra Bgh. n. sp. Taf. XIII, Fig. $2 S-30$.

Am 28-29 Juni wurde am Ankerplatz bei Nord Ubian (St. 99) aus einer Tiefe von 16-23 M. (Lithothamnion-Boden) ein Individuum gedredscht.

Dasselbe hatte in Formol bewahrt eine Länge von 22 bei einer Breite von I 4 und einer Höhe bis $9 \mathrm{~mm}$; die Breite des Rückengebräms ringsum $4 \mathrm{~mm}$; die Höhe der Keule der Rhinophorien I, der Kieme 2 mm.; die Länge des Fusses 16 bei einer Breite von 4 mm., die Länge des Schwanzes 2,5. - Die Farbe des Rückens schmutzig rothbraun, am Rande des eigentlichen Rückens jederseits zwei hellere Flecken; die ganze Unterseite gräulichweiss, ein wenig äusserst fein dunkler punktirt, besonders längs der oberen Seite des Fussrandes; die Keule der Rhinophorien röthlichgrau, die Kieme weisslich.

Die Form war oval; der ziemlich glatte, breit gebrämte Rücken ziemlich gewölbt; median kam ein Paar spitzer Höcker vor und einige wenige ähnliche am Rande des eigentlichen Rückens; die Tentakel kurz, fingerförmig; die Keule der (stark zurückgezogenen) Rhinophorien breit durchblättert; die stark zurückgezogene Kieme scheint aus 8 einfach(?) gefiederten Blättern gebildet, die Analpapille ziemlich hoch; der Fuss langgestreckt, schmal, vorne gerundet und mit Randfurche, sein Rand wenig vortretend, der Schwanz etwas zugespitzt.

Das Centralnervensystem wie gewöhnlich, (seine Hülle) stark ockerroth punktirt; seine Nervenzellen erreichten einen Durchmesser bis 0,25 mm. - Die Augen von 0, I $2 \mathrm{~mm}$. Durchmesser, mit dunkelgelber Linse. Die Ohrblasen von einem Diam. von 0,075 mm., mit Otokonien von einem Durchmesser von 0,013-0,016 mm. prall gefüllt. Die Blätter der Rhinophorien waren durch lange, klare Spikel steif gemacht. Die dunkelbraun pigmentirte Rückenhaut zeigte sich unter dem Mikroskope überall mit dichtstehenden, einfachen oder zusammengesetzten klaren Zotten (Fig. 2S) bedeckt, die eine Höhe bis etwa 0,12 mm. erreichten; 
sie trugen kleine Höcker, in welche die klaren Spikel hinaufstiegen, welche sonst vom Grunde der Zotten hinausstrahlten ${ }^{2}$ ).

Die Nundröhre $3 \mathrm{~mm}$. lang. Der gedrungene Schlundkopf mit der hinten etwas vortretenden Raspelscheide 4,5 mm. lang. Die Lippenscheibe von einer schwach gelblichen Cuticula uiberzogen. Die Zu nge enthielt in der schwach gelblichen Raspel i 1 Zahnplattenreihen, in der Raspelscheide kamen noch is vor, von denen die 3 hintersten unreif; die Gesammtzalıl der Reihen somit 29. In den Reihen kamen zu jeder Seite der schmalen nackten Rhachis 30 Zahnplatten vor. Dieselben waren ganz schwach gelblich; die Höhe der 4 äussersten betrug 0,06-0,07-0,08 und 0,09 mm., die Höhe erhob sich bis zu 0,It (bei einer Länge der Grundplatte von $0, I$ S) mm. um nach innen wieder abzunehmen. Die Zahnplatten waren von gewöhnlichster Hakenform (Fig. 29), nur die + äussersten am Ende fein gezähnelt, und ihre Grundplatte kurz (Fig. $30 a$ ).

Der aus der breiten Kluft der hinteren Eingeweidemasse frei hervorragende Magen etwas abgeplattet-blasenförmig, von $5 \mathrm{~mm}$. Durchmesser; der aus seinem Vorderende ausgehende Darm $10 \mathrm{~mm}$. lang bei einer durchgehenden Breite von 0,4. Der Inhalt der Verdauungshöhle unbestimmbare thierische Masse, worin viele lange, spitze Kieselnadeln und einzelne Polythalamien. - Die aussen und innen rothbraune, vorne abgestutzte und ausgehöhlte, hinten gerundete hintere Eingeweidemasse (Leber) $8 \mathrm{~mm}$. lang bei einer Breite vorne von 6; an der linken Seite des Magens ragte die gelblichweisse Facette der Gallenblase mit einem Durchmesser von $2,5 \mathrm{~mm}$. hervor.

Das Pericardium gross, von $4 \mathrm{~mm}$. Länge, die schlaffe Herzkammer sehr gross (3 mm. lang). Die vordere Blutdrüse länglich, die hintere gerundet viereckig. Das pericardiorenale Organ (Nierenspritze) von 0,4 mm. Länge.

In der Zwitterdriise kamen reife Geschlechtselemente kaum vor. Die vordere Genital masse klein, kaum $3 \mathrm{~mm}$. lang; weisslich, schmal und dünn. Der lange, in den kleinen Penissack übergehende Samengang schien in seiner letzten fast $2 \mathrm{~mm}$. langen Strecke mit dicht an einander stossenden, weisslichen, ziemlich weichen, niedrigen Kegeln mit einer Grundfläche von meistens $0.04 \mathrm{~mm}$. Durchmesser besetzt. Der Conversationszustand gestattete keine mehr eingehende Untersuchung.

Es ist vorläufig zweifelhaft, ob diese Form zur der ungeniigend gekannten Gattung Aporodoris hingebracht werden kann. Sie hat die allgemeine Körperform derselben, eine Lippenbewaffnung fehlt und die rhachidiale Partie der Raspel ist nackt; die äussersten Zahnplatten sind an der Spitze kammförmig (doch denen. der Etidoris Ladislaviz ${ }^{3}$ ) mehr als denen der Aporodoris ähnlich). Die Krieme ist aber von der der D. millegrana vielleicht verschieden, und der Samengang mit dem Penis ist vielleicht bewaffnet. - Auch mit der Artachaca mbida des Philippinischen Meeres ${ }^{3}$ ) scheint diese Form verwandt.

I) Diese Zotten erinnerten an die der Rostanga (coccinca). Vgl. R. Bergir, I. c. 1II (Supplementheft II, ISSI), p. IO2, Taf. H, Fis. 22, 23.

2) Vgl. Jiterixg, 1. c. Taf. 9, Fig. 2.

3) Vgl. R. Bergh, Beitr. zur Kenntn. der Japanischen Nudibranchien. II. Verh. d. k, k. zool. bot. Ges. in Wien. X.X.XI, I, I881, p. 23I-235. Taf. VII, Fig. 16-21; Taf. VIII, Fig. I-6. 


\section{Anisodoris Bgh.}

R. BERGH, Die Opisthobranchien d. Sammlung PLATE. Zoolog. Jahrb. Supplement IV, 3, I898, p. 508(-520), Taf. 29, Fig. 31-34; Taf. 30, Fig. I-II.

Forma corporis, tentacula et branchia ut in Archidoridibus propriis.

Prostata magna; vagina fortis, sed inermis.

Durch das Vorhandensein einer grossen Prostata, wie solche auch bei der Homoiodoris vorkommt, unterscheidet sich diese Gattung von der Archidoris, und von jener Homoiodoris durch Fehlen einer Bewaffnung der übrigens auch sehr starken Vagina.

Von der Gattung war bisher nur eine Art, die Doris punctuolata von A. D'Orbigny aus der Westküste Amerikas, bekannt.

I. Anisodoris Sibogae Bgh. n. sp. Taf. III, Fig. II. 'Taf. XIII, Fig. 3I-33.

Bei der Süd-Insel und am Riffe von Pulu-Pasi-Tanette in der Nähe der Nordspitze der Insel Saleyer (St. 213) wurden 3 Individuen dieser Form gefangen und nach dem Leben eine Abbildung gemacht.

Das lebende Thier hatte eine Länge von $3,8 \mathrm{~cm}$. bei einer Breite von 2. Die Farbe ist bräunlichgelb gewesen mit dunklerer Einfassung des eigentlichen Rückens so wie der Knoten der Rückenseite; die Kieme ist von hellerer Farbe gewesen.

Die Länge der aufbewahrten Individuen betrug 2,6-3,5 und $4,3 \mathrm{~cm}$; sie ähnelten in Farben- und Formverhältnissen einander ganz. Sie waren etwas steif und rauh anzufuhlen. Das grösste wurde genauer untersucht.

Die Breite betrug $2,7 \mathrm{~cm}$., die Höhe 1,3 ; die Breite des Rückengebräms war $9 \mathrm{~mm}$., die Weite der zusammengezogenen Kiemenspalte $6 \mathrm{~mm}$; d die Länge des Fusses $26 \mathrm{~mm}$. bei einer Breite von II, die Breite des Fussgebräms 3; die Länge der Tentakel 0,4 , die Höhe der Rhinophorien 4,2 und die der Kieme $6 \mathrm{~mm}$. - Die Farbe der Rückenseite war hell gräulichgelb, schwärzlichbraun ringsum den eigentlichen Rücken und um die Rückenknoten; die Unterseite gräulich, am Rückengebräme mit zahlreichen grösseren und kleineren braungrauen Flecken, ähnliche aber hellere, kleinere und mehr dichtstehende fanden sich an der Fusssohle. Der Aussenmund (bei allen 3 Individuen) schwarz. Die Keule der Rhinophorien fein braun punktirt.

Die Formverhältnisse waren die gewöhnlichen. Der Rücken überall mit Papeln bedeckt, die meistens einen Durchmesser von $\mathrm{I}, 5-2 \mathrm{~mm}$. hatten, zwischen den grösseren kamen kleinere vor, und im Ganzen waren die Knoten gegen den Rückenrand hin kleiner. Der Rand der Rhinophorhöhlen und der Kiemenspalte vortretend. Die Kieme von 5 Blättern gebildet, hinten die ziemlich hohe, abgestutzte Analpapille. Die Tentakel nur als kleine Höcker neben dem Aussenmund. Der Fuss vorne gerundet, mit Randfurche, der kurze Schwanz gerundet.

Das Centralnervensystem weisslich, seine Zellen von einem Durchmesser bis 0,20 mm. - Die kurz gestielten Augen von O, I 2 mm. Durchmesser, mit grosser gelber Linse; die Ohrblasen von $0,10 \mathrm{~mm}$. Diam., mit Otokonien von einem Durchmesser bis o,o I prall 
gefült. Die Haut des Rückens mit stark verkalkten Zellen und Zellengruppen überfült, welche auch sonst überall in der Haut vorkamen, auch in den Blättern der Rhinophorien neben entkalkten langen Spikeln.

Die Mundröhre schwarz. Der weissliche Schlundkopf $5 \mathrm{~mm}$. lang bei einer Höhe und Breite von 3,5; die Lippenscheibe von starker, fast farbloser Cuticula überzogen. Die Raspel der Zunge fast farblos; dieselbe und ihre Fortsetzung enthielten in Allem 26 Zahn. plattenreihen; in den Reihen kamen bis $6_{5}$ Platten vor. Dieselben waren fast farblos, von gewöhnlicher Hakenform; die Höhe der innersten (Fig. 31) betrug O, I I mm. und die Höhe der Platten stieg allmählig bis 0,22 (Fig. 32), die der kleineren äussersten 5 (Fig. 33) war $0,05-0,06-0,08-0,12$ und $0,16 \mathrm{~mm}$.

Die Speicheldrüsen wie gewöhnlich. Die Speiseröhre $7 \mathrm{~mm}$. lang bei einer Breite von 4: der abgeplattete Magen $5 \mathrm{~mm}$. lang und breit. - Die hintere Eingeweidemasse $\mathrm{I} 7 \mathrm{~mm}$. lang bei einer Breite von 8, hinten zugespitzt; die Leber aussen und innen grü, mit Ausnahme des Vorderendes ganz von der gelblichweissen Zwitterdrüse überzogen.

Die vordere Genitalmasse weiss und gelblichweiss, $7 \mathrm{~mm}$. lang bei einer Höhe von 6 und Dicke von 4. Die Prostata $3 \mathrm{~mm}$. lang bei einem Durchmesser von I, 5, der stark geschlängelte Samenleiter in den 1,5 mm. langen Penis übergehend. Die kugelförmige Spermatotheke von $4 \mathrm{~mm}$. Durchmesser, die birnförmige Spermatocyste I, $5 \mathrm{~mm}$. lang, die Vagina mit starken Längsfalten, das Vestibulum mit schwarzbraunen Punkten mit Fleckchen übersäet.

\section{Anisodoris ? timorensis Bgh. n. sp. Taf. XII, Fig. 33-35.}

Am Ankerplatz zwischen Nusa Besi uud dem nordöstlichen Punkte von Timor (St. 282) wurde aus einer Tiefe von 25-30 M. ein einziges Individuum gefangen.

Dasselbe hatte eine Länge von 20, bei einer Breite von I 6 und einer Höhe von $7 \mathrm{~mm}$.; der eigentliche Rücken war $8 \mathrm{~mm}$. breit, sein Gebräm 4, das Kiemenloch 3. mm. weit, die Kieme $3 \mathrm{~mm}$. hoch, die Rhinophorien 2,5; die Breite des Fusses 4, der Schwanz $4 \mathrm{~mm}$. lang. Die Farbe des Rückens war grau, hauptsächlich gegen den Rand (röthlich-)braunfleckig; das Gebräm dunkler grau, am Rande schwarzfleckig; die Keule der Rhinophorien und die Kieme weisslich; die äussere ungefähre Hälfte der Unterseite des Rückengebräms von einem dunklen (braun-)schwarzen Bande, aus confluirenden grossen Flecken gebildet, eingenommen; innerhalb desselben noch einige braunschwarze runde Flecken von einem Durchmesser von I mm.; die niedrigen Körperseiten braungrau; der Fussrand oben braunschwarz, der Fuss sonst grau.

Die Form oval, etwas niedergedrückt. Der eigentliche, ebene Rücken über das Gebräm, von welchem er ringsum recht scharf abgegrenzt ist, erhaben; das Gebräm abgeplattet, etwas nach unten gebogen, an der oberen wie an der unteren Seite eben; die weit nach vorne liegenden Rhinophorlöcher rund, ebenso das Kiemenloch, die Anzahl der Kiemenblätter 5. Die Tentakel klein, lappenartig. Der Fuss schmal, der. Vorderrand mit Querfurche, in der Mitte ein wenig ausgekerbt, der Fussrand wenig vortretend, der Schwanz den Rücken ein wenig überragend. - Die Consistenz etwas weich.

Die Hülle des im Übrigen gewöhnlichen Centralnervensystems mit zahlreichen 
schwarzen Zellen und Zellengruppen ausgestattet; die Nervenzellen von einem Durchmesser bis 0,16 mm. Der Durchmesser der sessilen Augen 0, IO, der Otocysten etwa 0,06, dieselben mit Otokonien voll gepackt. Die Anzahl der Blätter der Keule etwa 20, unter einer starken Loupe zeigten dieselben ihren Rand fein weiss punktirt; in denselben kamen zahlreiche ziemlich lange, zum Theile schwarz pigmentirte Spikel so wie zerstreutes schwarzes Pigment vor. - Die Haut (des Rückens) zeigte unter dem Mikroskope kleine halbkugelförmige Nöppchen von einem Durchmesser von meistens $0,08-0,12 \mathrm{~mm}$; in denselben kam zerstreutes Pigment so wie etwas sparsam stabförmige, aber nicht stark erhärtete Spikel vor. - In der interstitiellen Bindesubstanz überall eine Menge von schwarzen Punkten und Fäden, so wie etwas erhärtete Spikel.

Die durch ihre braune Farbe gegen den gelblichweissen Schlundkopf contrastirende Nundröhre $2,5 \mathrm{~mm}$. lang. Der $\mathrm{Schlundkopf} \mathrm{kurz,} \mathrm{gedrungen,} \mathrm{mit} \mathrm{wenig} \mathrm{vorspringender}$ Raspelscheide, $3 \mathrm{~mm}$. lang bei einer Breite von 3 und Höhe von 2,5; die Lippenscheibe von gelblicher Cuticula ïberzogen. Die grosse Zunge mit gelblicher Raspel, die 17 Zahnplattenreihen enthielt, in der dicken Scheide kamen deren noch 22 vor, die Gesammtzahl der Reihen somit 39. Zu jeder Seite der ganz schmalen nackten Rhachis etwa 45 Zahnplatten. Diese waren fast farblos, die Höhe der drei äussersten betrug 0,06-0,08-0, IO, und die Höhe stieg bis O, I 2 um nach innen wieder bis $\mathrm{zu}$ etwa $0,035 \mathrm{~mm}$. zu sinken. Sie waren von gewöhnlichster Hakenform (Fig. 33-35), der Haken trug eine geringe Anzahl von feinen Dentikeln, meistens 3-5, an den innersten (Fig. 33) war die Anzahl geringer, die äusserste war aufrecht mit abgestutztem, gezähneltem Ende (Fig. 35).

Die weisslichen Speicheldriisen klein. Der fast kugelförmige Magen von $3 \mathrm{~mm}$. Diam., stark aus der Leberkluft hervorragend; der Darm fast gerade, $8 \mathrm{~mm}$. lang bei einem Durchmesser von meistens 0,5 . Die hintere Eingeweidemasse (Leber) kegelförmig, $8 \mathrm{~mm}$. lang bei einem Durchmesser vorne von 4,5 , auswendig wegen des dünnen weisslichen Lagers der Zwitterdruise hell grügrau, ihre Substanz dunkel grïgrau. Die links liegende weissliche Gallenblase $2 \mathrm{~mm}$. hoch.

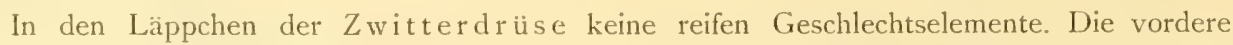
Genitalmasse ganz unentwickelt; in den Ausführungsgängen keine Spur von Bewaffnung.

Die generische Bestimmung der Art ist nach den Resultaten dieser Untersuchung kaum möglich, vielleicht wird sie sich in die Gattung Anisodoris unterbringen lassen.

\section{Discodorididae.}

R. BERGH, System d. nudibr. Gasteropoden. 1. c. 1892, p. 1094.

Corpus depressum, non durum; notaeum minute granuligerum, limbo marginali sat lato; tentacula digitiformia; folia branchialia fere semper tri-vel quadripinnata; podarium sat latum.

Lamellae labiales e baculis minutissimis formatae. Radula rhachide nuda, pleuris multidentatis, dentibus hamatis.

Penis armatus vel inermis. 
Die Discodorididen umfassen die Gattungen Discodoris (B.), Gcitodoris (B.), Carminodoris (B.), Fracassa (B.), Paradoris (B.), Hoplodoris (B.) und Audura (B.); vielleicht gehören hierhin noch die mit einfach fiederigen Kiemenblättern versehenen Halla (B.) und Rostanga (B.).

\section{Discodoris Bgh.}

R. BERGH, 1. c. p. IO94.

Corpus sat molle, circumferentia rotundata vel ovali; apertura branchialis leviter crenulata, stellata vel bilabiata; margo anterior podarii bilabiatus, labium superius plus minusve fissum.

Prostata magna.

Eine Reihe von Arten ist aus dem Indo-Philippinischen-Pacifischen Meere bekannt, einige auch aus dem Mittelmeere und dem Antillenmeere.

I. Discodoris Boholiensis Bgh. Taf. I, Fig. 9. Taf. XIII, Fig. 34-35. Taf. XIV, Fig. I-2.

R. Bergh, Malacol. Unters. I (Heft XII, I877), p. 519-522; Taf. LX, Fig. 23; Taf. LXI, Fig. 6-12. - III (Heft XVII, 1890), p. 897-900, Taf. LXXXVII, Fig. 28-31.

ELIOT, 1. c. III, 1904, p. 362.

Auf einem Riffe bei Ambon wurde ein Individuum dieser Art gefangen, nach dem Leben gemalt und in Formol bewahrt. Ein anderes, der typischen noch mehr ähnliches wurde am Riffe in der Rumah Kuda-Bai, Insel Roma, erbeutet.

Das lebende Thier scheint nach der Abbildung eine Länge von $4 \mathrm{~cm}$. bei einer Breite von 2,5 gehabt zu haben, der Durchmesser der vorgestreckten Kieme war I cm. Die Farbe des Rückens ist hell röthlichgelb areolirt gewesen; der Rückenkamm ist kastanienbraun gewesen, ebenso die Kiemenblätter, das breite wellenartig gebogene Rückengebräme mit quergehenden kastanienbraunen Flecken versehen, die Keule der Rhinophorien braun.

Das a ufbewahrte Individuum hatte eine Länge von $23 \mathrm{~mm}$. bei einer Breite von I 6 und einer Dicke von nur $5 \mathrm{~mm}$; die Länge der ganz vorgestreckten Rhinophorien betrug 3,5, die Breite der vorgestreckten und ausgebreiteten Kieme $8 \mathrm{~mm}$., die Breite des Riickengebrämes war 5,5, die Länge des Fusses I $7 \mathrm{~mm}$. bei einer Breite von 7,5, die Länge des Schwanzes $3 \mathrm{~mm}$. - Die Grundfarbe war gelblich, am Rücken kamen zerstreute mehr weissliche Flecken vor, und die Umrisse des eigentlichen Rückens waren mehr bräunlich; der Rückenrand war schwarz, von demselben ab erstreckten sich mit kleinen Zwischenräumen Flammen-ähnlicher Farbe quer nach innen durch die Hälfte des Rückengebräms, dieselben schienen stark an der Unterseite durch; der Stiel der Rhinophorien gräulich, die Keule bräunlich mit weisser Endpapille; die Kiemenblätter aussen (Rhachis) gelblich, innen braun; der Rückenkamm schwarzbraun. Der Fussrand ringsum mit ähnlichen, aber kürzeren Flammen wie das Rückengebräm. - Die Consistenz weich und ganz schlaff.

Die Form etwas länglich oval, ziemlich abgeplattet. Der Rand der Rhinophorlöcher so wie der quer-ovalen Kiemenspalte ganz fein zackig. Der nicht starke Rückenkamm $8 \mathrm{~mm}$. lang, schwach wellenartig gebogen. Die Krieme aus 6 Blättern gebildet. Der Rücken überall 
mit ganz feinen Wärzchen mit braunschwarzer Papille (Fig. 34) bedeckt. Die Unterseite des Rückengebräms glatt. Die Mundlippen so wie die Spitze der fingerförmigen (I;5 mm. langen) Tentakel braunschwarz. Der Fuss vorne gerundet und mit Randfurche, das Fussgebräm etwas vortretend, der Schwanz nicht ganz kurz.

Das Centralnervensystem wie gewöhnlich. - In den stark pigmentirten Blättern der Rhinophorien waren Spikel kaum zu sehen, dagegen reichlich in dem Stiele und hier etwas stärker als in der (Rücken-)Haut erhärtet; da kamen sie sehr reichlich vor, auch in den Wärzchen aufsteigend, sie waren aber wenig verkalkt, von einem Durchmesser von 0,015-0,02 mm.

Die Mundröhre $2 \mathrm{~mm}$. lang, aussen blauschwarz, innen schwärzlich braun. Der Schlundkopf weisslich, 2,5 mm. lang bei einer Breite von 2,5 und einer Höhe von $2 \mathrm{~mm}$., die Raspelscheide stark vorspringend. Die Stäbchen der hell gräulichgelben Lippenplatten von einer Höhe bis $0,04 \mathrm{~mm}$. bei einem Durchmesser bis O,OI 3 (Fig. 3). In der hell gelblichen Raspel der Zunge kamen etwa I2 Zahnplattenreihen vor und in der Scheide vielleicht I5. In den Reihen vielleicht etwa 30 Platten. Die fast farblosen Platten von gewöhnlicher Hakenform (Fig. 35); die Höhe des Hakens der innersten betrug 0,08 mm., und sie stieg bis 0, I6, die der äussersten war $0,075-0,08 \mathrm{~mm}$. (Fig. 2a).

Die zwei durch das Centralnervensystem geschiedenen Blutdrüsen bzw. oval und rund, $0,75 \mathrm{~mm}$. lang, bräunlich.

Die hintere Eingeweidemasse (Leber) $9 \mathrm{~mm}$. lang bei einer Breite vorne von 5, gelblich. In den Läppchen der helleren Zwitterdrüse reife Geschlechtselemente.

Es liegt hier eine Varietät der im Indischen Meere sehr verbreiteten $D$. Boholiensis vor.

Am 16 Febr. wurde am Ankerplatz von Dangar Besar Saleh-Bai (St. 2 I3) noch ein etwas dunkleres, bei einer Breite von 20 fast $28 \mathrm{~mm}$. langes Individuum gefangen.

Aus einer Tiefe von 1o M. wurde noch am 26 Dec. bei Pulu-Jedan an der Ostküste der Aru-Inseln (St. 273) ein Individuum erbeutet, das mit der typischen Form ubereinstimmt. Die Länge betrug $6 \mathrm{~cm}$. (die der Semper'schen Exx. $5-7 \mathrm{~cm}$.) bei einer Breite von 5 und einer Höhe von 1,8 ; die Länge des Fusses $3,5 \mathrm{~cm}$. bei einer Breite von 1,8 , die Breite des Rückengebrämes I,5 cm. Die Farbenverhältnisse ganz wie früher (1. c. p. 520) beschrieben. - Die Formverhältnisse waren wie gewöhnlich; der Rückenkamm sehr ausgeprägt, mit mehreren (3-4) Höckern.

Ferner wurde am I I Juli an der Ostküste der Insel Pajunga, Kwandang-Bai (St. I I 5) noch ein Exemplar gefangen, das eine Länge von $5,2 \mathrm{~cm}$. bei einer Breite von 3,7 und einer Höhe von $1,2 \mathrm{~cm}$. hatte, die Breite des Rückengebräms bis $15 \mathrm{~mm}$. Die kleinen dunkel pupillirten Papeln des Rücken-(gebräms) sehr dicht stehend (Fig. 34).

2. Discodoris concinniformis Bgh. Taf. XIV, Fig. 3-5.

R. BERgh, Malacolog. Unters. III (Heft XIV, I, I888), p. 807-SIr, Taf. LXXXIII, Fig. I-5; III (Heft XVII, I890). p. 900-902.

Am xy Jan. I 900 wurden am Riffe zwischen Nusa Besi und der N.O. Spitze von Timor 
(St. 282) zwei Individuen gefangen, das eine ein wenig kleiner als das andere, noch ein kleines wurde auf dem Riff bei Ambon erbentet.

Das grösste hatte in Formol bewahrt eine Länge von $35 \mathrm{~mm}$. bei einer Breite von 20 und einer Höhe von $4 \mathrm{~mm}$; die Rhinophorien 4, die Kieme auch $4 \mathrm{~mm}$. hoch; das Rückengebräm $7 \mathrm{~mm}$. breit; die Tentakel fast $1 \mathrm{~mm}$. lang; die Länge des Fusses betrug $24 \mathrm{~mm}$. bei einer fast durchgehenden Breite von 6, das Fussgebräme I mm. breit, der Schwanz $3 \mathrm{~mm}$. lang. - Die Grundfarbe war hell schmutzig gelblich, dunkler an der Rückenseite. Der Rücken war überall mit zahlreichen kleinen und grossen (in Durchmesser bis $2 \mathrm{~mm}$. messenden) hell schmutzig braunen, meistens rundlichen Flecken bedeckt; dazu kamen noch (besonders bei dem grösseren Individuum ausgeprägt) jederseits an der Grenze des eigentlichen Ruickens 3 mit schwarzer Randpartie versehene Flecken und einzelne sparsam zerstreute, schwarze Punkte: der Stiel der Rhinophorien braun, die Keule von mehr grauer Farbe und mit weisser Endpapille. die Kieme bräunlichgrau. Die Unterseite des breiten Rückengebräms mit ziemlich zahlreichen und nicht kleinen, matt bräunlichgrauen Flecken; die Fusssohle mit ähnlichen, aber zahlreicheren und kleinéren Flecken; die Tentakel weisslich.

Die Gestalt war länglich-eiförmig, vorne schmäler, stark abgeplattet mit breitem Rückengebräm. Der Rücken überall dicht mit feinsten Nöppchen bedeckt; der Rand der Rhinophorlöcher so wie des querovalen Kiemenlochs wenig vortretend; die Kieme aus 6 tripinnaten Blättern gebildet, die kleine weissliche Analpapille subcentral. Die Unterseite des Rückengebräms ganz eben. Die kleinen Tentakel fingerförmig. Der Fuss ringsum vom Rücken stark uberragt. Der gerundete Vorderrand mit starker Furche und ein wenig vorspringenden Ecken, das Gebräm schmal; der ein wenig zugespitzte Schwanz kurz. — Die Consistenz war ziemlich steif.

Das Centralnervensystem wie gewöhnlich, seine Zellen einen Durchmesser bis wenigstens 0,20 mm. erreichend. - Die kurzgestielten Augen von einem Diam. von 0,14 mm. Die Blätter der Rhinophorien durch Spikel in gewöhnlicher Weise steif. Die Haut des Rückens nicht sehr reich an Spikeln, die wenig verkalkt schienen und einen Durchmesser bis 0,025 mm. erreichten; in den Nöppchen feine Spikel.

Die Mundröhre $3 \mathrm{~mm}$. lang, röthlichgrau. Der weissliche, gedrungene Schlundkopf 2,5 mm. lang; im Munde die starken gelblichen Mandibelplatten, von gewöhnlichen, schwach gelblichen Stäbchen gebildet, die von einer Länge bis $0,06 \mathrm{~mm}$. bei einer Breite von $0,0035-$ 0,0055 (Fig. 3) waren. Die Zunge mit fast farbloser Raspel, welche 25 Zahnplattenreihen enthielt, in der Raspelscheide I5, die Gesammtzahl der Reihen somit 40. In den Reihen schienen jederseits $5^{8}$ Platten vorzukommen. Die Platten fast farblos, von gewöhnlicher Hakenform (Fig. 4), die äussersten schlanker (Fig. 5); die Höhe dieser (4) letzteren betrug 0,05$0,065-0,08-0,09$, und die Höhe stieg allmählig bis zu 0,15 mm.

Die Speiseröhre $5 \mathrm{~mm}$. lang. Der kurz sackförmige Magen $4 \mathrm{~mm}$. lang, an seiner linken Seite die ziemlich schmale, $2 \mathrm{~mm}$. lange, weissliche Gallenblase. Aus dem Vorderende des Magens trat der stark geschlängelte, im Ganzen $2 \mathrm{~cm}$. lange Darm (mit einem Durchmesser von $0,3-0,4 \mathrm{~mm}$.) hervor. Der Magen und das Rectum mit bräunlichem und schwarzem Inhalt von vegetabilischer und animalischer Natur mit Sandkörnchen vermischt. 
Die hintere Eingeweidemasse (Leber) $8 \mathrm{~mm}$. lang bei einer Breite vorne von 5, gelblichgrau, im Inneren bräunlich, mit tiefer und breiter Kluft für den Magen.

Die convex-planen, weisslichen, durch das Centralnervensystem geschiedenen, dreieckigovalen Blutdrüsen von je $2 \mathrm{~mm}$. Länge.

Die vordere Genitalmasse $2 \mathrm{~mm}$. lang, weisslich und gelblich (Eiweissdruise). Der lange, geschlungene Samenleiter durch die ziemlich lange Glans fortgesetzt, die cylindrisch war, von $0,10 \mathrm{~mm}$. Durchmesser und mit ihrem Ende aus der Genitalöfnung hervorragte.

Hier lag wahrscheinlich die von mir früher beschriebene Discodoris concinniformis vor. Möglicherweise wäre sie mit der Doris concinna von Alder und $\mathrm{HANCOCK}^{1}$ ) identisch.

\section{Discodoris Ellioti (Alder et Hanc.). Taf. XIV, Fig. 6-8.}

Doris Ellioti Ald. et Hanc. Notice of a coll. of nudibr. Moll. Trans, zool. soc. of London. V, 3, I864, p. II6, Pl. XXVIII, Fig. I-2.

Bei „de Brill" bei Makassar wurde ein Individuum gefangen.

Dasselbe maass in Formol bewahrt an Länge $5 \mathrm{~cm}$. bei einer Breite von 3,5 und einer Höhe von I,4; die Breite des Rückengebräms war $13 \mathrm{~mm}$., die Breite des Kiemenloches 6; die Länge der Tentakel $5 \mathrm{~mm}$., die Länge des Fusses $4 \mathrm{~cm}$. bei einer Breite von 1,5, die Breite des Fussgebräms $3 \mathrm{~mm}$; die Höhe der (zurückgezogenen) Rhinophorien 5, der (zurückgezogenen) Kieme $6 \mathrm{~mm}$. - Die Grundfarbe des Rückens war schmutziggrau mit zahlreichen, grösseren und kleineren verschwimmenden, schwärzlichen Flecken, gegen den Rand kleiner, dichter stehend und mehr verschwimmend; die innere Hälfte der Unterseite des Rückengebrämes zeigte grössere und mehr scharf begrenzte ähnliche Flecken, die Randpartie feiner- und dicht braunfleckig; die Fusssohle schmutziggrau, ebenso die Rhinophorien und die Kieme.

Die Formverhältnisse wie gewöhnlich. Der Rücken ganz fein granulirt, die. Unterseite des Gebrämes glatt; die Kiemenspalte kurz-nierenförmig, etwas wellenartig gebogen, die Kieme mit 6 starken Blättern. Die Tentakel abgeplattet fingerförmig, schmäler am Grunde und an der Spitze. Der Fuss wie gewöhnlich.

Die Mundröhre röthlichbraun, $3 \mathrm{~mm}$. lang. - Der weissliche Schlundk opf $6 \mathrm{~mm}$. lang bei einer Höhe von 4,25 und einer Breite von 4; die Raspelscheide hinten etwas vorspringend. Oben im Innenmund die länglich-dreieckigen Lippenplatten von braungrauer Farbe, aus dichtstehenden stabförmigen Elementen gebildet, die bei einer Höhe bis O, I 2 mm. einen Durchmesser bis 0,005 hatten (Fig. 6). Die starke Zunge mit braungelber Raspel. welche 3 I Zahnplattenreihen enthielt, von welchen die 9 vordersten mehr oder weniger beschädigt; in der Scheide kamen noch 19 vor, von welchen die 3-4 hintersten noch unreif; die Gesammtzahl der Reihen somit 50. In den Reihen wurden bis So Platten gezählt. Die gelben Platten von gewöhnlicher Form (Fig. 7); die äussersten drei aber farblos, ganz klein, dünn, blattartig

1) Alder und Hancock, Notice of - nudibr, moll. Trans. 2001. soc. of London V, 3. IS64, p. xis, Pl. XXVIII, Fig. 4-6. Elıot, Nudibranchiata. 1.c. 1903 , p. 553. 
(Fig. 8), von einer Höhe von 0,035-0,04 mm., die Höhe der folgenden Platten (Fig. 8) allmählig $0,06-0,08-0,10-0,12 \mathrm{~mm}$. und sich bis zu 0,1 $8 \mathrm{~mm}$. erhebend (Fig. 7).

Der Magen stark vortretend, sackartig, $10 \mathrm{~mm}$. lang bei anderen Durchmessern von 7. Die hintere Eingeweidemasse (Leber) kegelförmig, $26 \mathrm{~mm}$. lang bei anderen Durchmessern von 13, aussen grau, innen braun mit röthlichem Anfluge. Die Gallenblase grau, $3 \mathrm{~mm}$. hoch.

Das pericardio-renale Organ röthlichgrau, birnförmig, $3 \mathrm{~mm}$. lang.

Die vordere Genitalmasse grau, Meniscusförmig, $9 \mathrm{~mm}$. lang bei einer Höhe von 9 und einer Dicke von 4. Die röthlichgraue, etwas zusammengedrückte Prostata von $4 \mathrm{~mm}$. Durchmesser. Die leere, kugelförmige Spermatotheke von $7 \mathrm{~mm}$. Durchmesser.

Wahrscheinlich lag hier die von Alder und HANcock dargestellte Form vor.

Discodoris Ellioti (Ald. et H.) „Var." Taf. XIV, Fig. 9-io.

Auf dem Riffe der Ruma-Kuda-Bai bei der Insel Roma (St. 279) wurde ein Individuum erbeutet.

Dasselbe hatte eine Länge von $8 \mathrm{~cm}$. bei einer Breite von 4,5 und einer Höhe von I,7; die Breite des Rückengebrämes war an der oberen Seite 1,5 , an der unteren 2 cm.; die Länge der ausgestreckten Rhinophorien $6 \mathrm{~mm}$; der Durchmesser des ganz ausgestreckten Kiemensterns $2,8 \mathrm{~cm}$; die Länge der Tentakel $2 \mathrm{~mm}$; die Länge des Fusses $6 \mathrm{~cm}$. bei einer Breite von 2,2, die Breite des Fussgebrämes $6 \mathrm{~mm}$., die Länge des Schwanzes IO. - Die Farbe der Ruickenseite war etwas scheckig dunkel olivenbraun, ganz fein (weisslich) granulirt, am Rande mehr hell wegen der zwischen den Flecken durchschimmernden, gelblich weissen Grundfarbe; von ähnlicher, etwas hellerer Farbe waren auch die Rhinophorien und das Laub der Kieme. Die Unterseite des breiten Rückengebräms weisslich, welche Farbe aber an den inneren zwei Drittel durch grosse, unregelmässige, dunkel graubraune, oft in einander übergehende Flecken zum grossen Theile verdrängt war; zwischen den grösseren fanden sich auch kleinere Flecken. Die Tentakel so wie die obere Seite des Fussgebräms fein braungrau punktirt und fleckig; die Fusssohle gelblichweiss, durch schwache, helle, bräunlichgraue Punkte und Fleckchen ganz leicht scheckig. - Die Consistenz des Thieres ziemlich weich.

Die Formverhältnisse die gewöhnlichen; das ro mm. weite Kiemenloch schwach gerundetlappig; die Kieme mit 6 starken tripinnaten Blättern. Der Fuss vorne und hinten gerundet.

Die Mundröhre war vollständig umgestulpt, feinfleckig braungrau, I $5 \mathrm{~mm}$. lang bei einem Durchmesser von $\mathrm{r} 2 \mathrm{~mm}$. aus dem Aussenmund hervorragend. Der ganz vorne in derselben liegende Schlundkopf weiss, $7 \mathrm{~mm}$. lang bei einer Höhe und Breite von 5,5; hinten an der Unterseite ragte die Raspelscheide ein wenig hervor. Die Mandibelplatten (Fig. IO) lang, halbmondförmig, ihre Elemente ganz wie oben. In der fast farblosen Raspel der Zunge 27 Zahnplattenreihen, in der Scheide noch 25, die Gesammtzahl der Reihen somit 52. In den Reihen kamen bis etwa 90 Zahnplatten vor. Dieselben waren fast farblos, eine Höhe bis $0,20 \mathrm{~mm}$. erreichend; die äussersten (Fig. 9) schlanker und nicht unregelmässig wie bei dem friher untersuchten Individuum.

Vielleicht lag hier die von Alder und HAxcock (1. c.) erwähnte dunklere Varietät vor. 
4. Discodoris? Sibogae Bgh. n. sp. Taf. I, Fig. S. Taf. XIV; Fig. II-I4.

Am 3 Nvbr. wurde am Riffe von Pasir Pandjang an der Westküste von Binongka (St. 220) ein Individuum gefangen und lebend abgebildet.

Dasselbe hatte eine Länge von $7,5 \mathrm{~cm}$. bei einer Breite von 4,5; die Höhe der Rhinophorien betrug $8 \mathrm{~mm}$., der Durchmesser des Kiemensterns $30 \mathrm{~mm}$. Die Farbe der Rückenseite war etwas marmorirt roth, mit zwei Reihen von einigen (3) dunkleren grossen Flecken; das Laub der Kieme hell gelb.

Das a ufbewahrte Individuum zeigte noch ganz gut seine frühere Farbentracht und war im Ganzen äusserlich ganz gut bewahrt. Seine Länge betrug $7,8 \mathrm{~cm}$. bei einer Breite von 4 und einer Höhe von I,7; die Breite des Rückengebräms meistens II, hinten I 7 mm.; die Höhe der (vorgestreckten) Rhinophorien $5,5 \mathrm{~mm}$, die Länge der Tentakel fast $2 \mathrm{~mm}$; der Durchmesser des Kiemensterns I 8 mm, die Länge der Kiemenblätter 8 ; die Länge des Fusses 5,5 cm. bei einer Breite von 2, die Breite des Fussgebräms $4 \mathrm{~mm}$., die Länge des Schwanzes 6. Die hervorgestiilpte Mundröhre $2 \mathrm{~cm}$. lang bei einem Durchmesser von I. - Die Grundfarbe war weisslich, am Rücken aber meistens durch eine rothbraune Marmorirung verdrängt, die am Gebräm, besonders am Schwanzgebräm einen gegen den Rand ausstrahlenden Character hatte; am eigentlichen Rücken kamen 3 (2) Reihen von (zu je 3-4) grösseren schwärzlichbraunen Flecken vor. Der Rücken zeigte sich überall mit kleinen, kaum vortretenden weissen Papeln von einem Durchmesser bis $0,5 \mathrm{~mm}$. bedeckt, welche zum grossen Theile einen tief schwarzen centralen Punkt trugen (Fig. I I). Die Rhinophorien mit rothbraunem Stiele und hellerer Keule. Die Rhachides der 5 Kiemenblätter rothgrau, ebenso die weissgerandete Analpapille; das Laub der Kieme weisslich. Die Unterseite des Rückengebräms weisslich, mit zahlreichen, selten mit einander verbundenen, rundlichen oder mehr unregelmässigen schwärzlich-rothbraunen Flecken von einem Durchmesser bis $4 \mathrm{~mm}$; ähnliche, aber kleinere, viel zahlreichere und öfter in einander übergehende Flecken kamen an der weisslichen Fusssohle vor; das Fussgebräm an der unteren Seite weisslich, ungefleckt, an der oberen mit ähnlichen Flecken wie die Sohle.

Die Körperform war länglich-oval, ziemlich abgeplattet; die Consistenz ziemlich weich. Der Rücken fast eben, der Rand des breiten Gebräms etwas wellenförmig gebogen; die Rhinophorien stark, die Keule etwas nach hinten gebogen; das Kiemenloch rundlich, von $8 \mathrm{~mm}$. Durchmesser, der Rand I mm. vortretend, die 5 Kiemenblätter am Grunde mit einander verbunden. Die Tentakel klein, fast kegelförmig. Der ringsum vom Rückengebräm stark überragte Fuss hinten wie vorne gerundet, das Fussgebräm ziemlich schmal, der Vorderrand mit starker Randfurche, der Schwanz kurz.

Das weisse Centralnervensystem in eine ganze lose farblose Kapsel gehüllt, $3 \mathrm{~mm}$. breit, seine Ganglien nicht recht scharf von einander geschieden; die Nervenzellen (in den Ganglia gastro-oesophag.) einen Durchmesser bis 0,25 mm. erreichend. - Die Augen von einem Durchmesser von $0,16 \mathrm{~mm}$, fast sessil. In den dünnen Blättern der Keule der Rhinophorien die gewöhnlichen langen, meistens auf den Rand senkrecht stehenden Spikel; sie waren wenig erhärtet (decalcinirt?), von einem Durchmesser bis 0,OI $3 \mathrm{~mm}$. In der Haut kamen ähnliche Spikel in Menge vor, auch in die feine Papel aufsteigend, meistens etwas stärker erhärtet und 
ein wenig dicker (von einem Durchmesser bis $0,020 \mathrm{~mm}$.). In der Haut des Riickens, wie auch, aber weniger ausgepraigt, in dem Fussgebräme, uberall Gruppen von Drüsenzellen, die um eine centrale Öfnung gestellt waren (Fig. I2); die Gruppen hatten meistens einen Durchmesser von $0,08 \mathrm{~mm}$., und die stundenglas- oder kurz flaschen-förmigen Druischen von $0,02-0,03 \mathrm{~mm}$.

Die grosse, gleichsam etwas aufgeblasene, herausgestuilpte Mundröhre ganz weiss; an der Spitze eine senkrechte Spalte, den Innenmund (des Schlundkopfes) zeigend; in der Mundröhre lagen frei der Schlundkopf, die Speiseröhre mit dem Centralnervensystem und den Speicheldrüsen. Der Schlundk opf von ovaler Form, $7 \mathrm{~mm}$. lang bei einer Höhe und Breite von 4, weisslich, die Raspelscheide nicht aussen vorspringend; sein Mund jederseits mit einer stark gelben, bei einer Breite von o,8 mm., 2,25 mm. hohen Lippenplatte eingefasst, ihre Elemente $0,075 \mathrm{~mm}$. lang bei einem Durchmesser von 0,005 . Die sehr starke Zunge zeigte hinter der oberen Seite eine kurze Raspelscheide; die tiefe Kluft mit ihren Rändern von der schwach gelblichen Raspel überzogen; dieselbe enthielt. 32 Zahnplattenreihen, in der zusammengedrückten Scheide noch i2 Reihen, von welchen 3 noch in Entwicklung begriffen; die Gesammtzahl der Reihen somit 44. In den Reihen wurden bis wenigstens ro5 Platten gezählt. Die Platten waren fast farblos; die Höhe des Hakens der innersten betrug o, 10 mm., und dic Höhe der Platten erhob sich bis zu 0.22 um nach aussen wieder zu sinken, die der $6^{\text {ten }}$ von aussen ab war 0,16 , und sie sank weiter (Fig. I 4) bis $0,1 \mathrm{I}-0,08 \mathrm{~mm}$. Die Platten hatten alle die gewöhnliche Hakenform (Fig. I3).

Die Speicheldruisen weiss, (20 mm.) lang, bis auf den Magen reichend; in der vorderen Strecke von einem Durchmesser von I mm., sonst von 0,25, fast fadenförmig; die Länge des Ausführungsganges $3 \mathrm{~mm}$.

Die Speiseröhre bei einem Durchmesser von $1,5-2 \mathrm{~mm}$., I $5 \mathrm{~mm}$. lang. Der aus der Leberkluft stark hervorragende Magen sackförmig, I $\mathrm{cm}$. lang bei einer Breite von I $\mathrm{cm}$. Der Darm aus dem Vorderende des Magens hervorgehend, fast $4 \mathrm{~cm}$. lang bei einem Durchmesser von $2 \mathrm{~mm}$.

Die hintere Eingeweidemasse (Leber) kegelförmig $3,3 \mathrm{~cm}$. lang, vorne $1,7 \mathrm{~cm}$. breit, tief geklüftet, der rechte Lappen stärker vortretend, gelblichweiss.

Das Nierensystem sehr stark entwickelt.

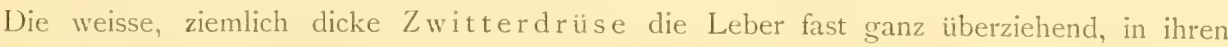
Läppchen reife Geschlechtselemente. Die weisse vordere Genitalmasse $9 \mathrm{~mm}$. lang und hoch bei einer Breite von IO; an der Vorderseite der grosse Knäuel der opaken Windungen der Ampulle des Zwitterdrüsenganges; die kugelförmige weissliche Spermatotheke von $5 \mathrm{~mm}$. Durchmesser.

Bei der Unmöglichkeit die vordere Genitalmasse genauer zu untersuchen ist die generische Bestimmung dieser Thierform etwas zweifelhaft; es wäre möglich, das sie der Gattung Diaulula angehörte.

Am 28 Aug. wurde noch ein Exemplar dieser Art am Ankerplatz zwischen der Insel Gisser und Ceram Laut (St. I72) erbeutet. 
Dasselbe war schlecht conservirt, erhärtet, fast von desselben Grösse, $8 \mathrm{~cm}$. lang bei einer Breite von 4 und einer Höhe von $\mathrm{I}, 5$, der Fuss $5 \mathrm{~cm}$. lang bei einer Breite von $2,5 .-$ Die Farbe des Rückens war theilweise abgerieben; die drei Fleckenreihen wie oben, die kleinen fast alle ohne die schwarze Pupille; das Laub der Kieme grau. An der Unterseite des Rückengebrämes waren die schwarzbraunen Flecken in ein ringsum fast continuirliches breites, etwas zackiges Band zusammengeschmolzen; an den Rändern des Bandes kamen noch einzelne Flecken wie die oben beschriebenen vor. An der Fusssohle war die Farbe in ihrer grössten Strecke abgerieben, sie war ubrigens in derselben Weise wie oben beschrieben gefärbt.

Die Formverhältnisse waren wie oben; die Consistenz aber härter. Die Kieme aus 5 Blättern zusammengesetzt. Auch hier war die Mundröhre hervorgestülpt, $10 \mathrm{~mm}$. lang bei einem Durchmesser von 5,5, aber gräulichgelb mit dichtstehenden bräunlichschwarzen Punkten und Fleckchen.

Der weisse Schlundkopf von Form ganz wie oben, $6 \mathrm{~mm}$. lang bei einer Höhe und Breite von 4; die Einfassung des Mundes wie oben. Die sehr starke weisse $\mathrm{Zunge}$ mit sammt ihrer kurzen Raspelscheide ganz wie oben. Die Anzahl der Zahnplattenreihen und die Zahl der Platten in den Reihen schienen etwa dieselben wie bei dem anderen Individuum. - Die Speicheldrusen ganz wie oben.

Die vordere Genitalmasse weiss und weisslichgelb, $17 \mathrm{~mm}$. lang bei einer Höhe von I I und einer Breite von 9.

\section{Discodoris? liturata Bgh. n. sp. Taf. XIV, Fig. 15-20.}

Bei Sailus-Besar, Paternoster-Inseln (St. 315) wurde ein Exemplar dieser Form gefangen

Aufbewahrt hatte dasselbe eine Länge von $14 \mathrm{~mm}$. bei einer Breite von 7 und Höhe von 4; der Durchmesser des Kiemensterns war 4, die Breite des Fusses 3,5, die Breite des Rückengebräms I,25 mm. - Die Grundfarbe des Rückens war schwarz, von derselben erhob sich, undeutlich in 4 Reihen geordnet, eine nicht bedeutende Anzahl von rundlichen weissen Flecken von einem Durchmesser von 0,5 mm.; das gräuliche Rückengebräme durch viele, von der Grundfarbe ausstrahlende ziemlich breite Querstreifen unterbrochen; die Rhinophorien schwarz, die Kieme hell gräulichweiss; die ganze Unterseite gräulich, am Rückengebräm schimmerten die schwarzen Querstriche stark durch.

Die Form (Fig. 15) länglich-oval, der Rücken etwas gewölbt, sein Gebräm ringsum den Fuss überragend; der Kiemenstern von 5 Blättern gebildet; der Kopf nicht klein, mit fingerförmigen Tentakeln; der Fuss vorne fast gerade, das Gebräm schmal, der Schwanz kurz. Die Consistenz nicht hart, aber etwas steif.

Die Blätter der aus je einem weissen Fleck austretenden Rhinophorien durch lange Spiclen steif. In der Rückenhaut eine Menge von erhärteten kleinen Zellen und längeren Spiclen.

Die weissliche Mundröhre $2 \mathrm{~mm}$, lang. Der weissliche Schlundkopf von ovalen Umrissen, $3 \mathrm{~mm}$. lang; die nach oben gebogene lange Raspelscheide noch fast I mm. hervorragend. Die Lippenscheibe mit starker gelber Cuticula und breiten gelben Lippenplatten, deren Elemente bis $0,08 \mathrm{~mm}$. lang waren und einen plumpen umgebogenen Kopf von einer Höhe 
von 0,025 hatten ( $\mathrm{Fig}$. I6). In der schwach gelblichen Raspel der Zunge fanden sich $2 \%$ Zahnplattenreilhen, in der Scheide deren noch 52, von welchen die 6 hintersten noch unreif: die Gesammtzahl der Platten somit 79. An den Seiten der ganz schmalen Rhachis kamen nur bis 20 Zahnplatten vor. Dieselben waren schwach gelblich, von einfacher, plumper Hakenform, die innersten (Fig. I 7 ) hatten eine Höhe von $0,05 \mathrm{~mm}$., die Höhe der Platten sticg bis zu O, IO (Fig. IS), die der äussersten betrug nur 0.04 mm. (Fig. 19, 20).

Die hintere Eingeweidemasse (Leber) hell gelb. - Die vordere Genitalmasse weisslich und braungelb; der Penis ganz bestimmt unbewaffnet.

Es ist wohl, sowohl in Bezug auf äussere Form (als auf den Bau der Lippenplatten) etwas zweifelhaft, ob diese Thierform in die Gattung Discodoris unterbracht werden kann. Ihre Farbentracht wird sie leicht wieder kenntlich machen. Sie simulirte bei flichtiger Betrachtung eine Phylidiclla was noch mehr in der untenstehenden Varietät hervortrat.

Discodoris? liturata Bgh. var. Taf. XIV, Fig. $2 \mathrm{I}$.

Am Ankerplatz bei Seget am westlichen Eingang in die Scle (Galewo-)Strasse (St. 164) wurde ein Individuum gefangen.

Dasselbe hatte aufbewahrt (sehr erhärtet und steif) eine Länge von etwa $22 \mathrm{~mm}$. bei einer Breite von $I_{3}$ und Höhe von 5; die Breite des Rückengebräms war 4, die des Fusses $7 \mathrm{~mm}$. - Die Grundfarbe war tief schwarz; die gräulichweissen Flecken waren aber (Fig. 2I) grösser, von einem Durchmesser bis $4 \mathrm{~mm}$., und trugen $2-3$ weisse Knötchen, wie sie auch am Rückengebräm vorkamen; die ganze Unterseite mehr gelblich, sonst waren die Farbenverhältnisse wie oben.

Der Schlundkopf wie oben, somit auch die lange gebogene Raspelscheide, die breiten Lippenplatten und der Raspelbau; detailirte Untersuchung war wegen das Erhärtungszustandes unmöglich.

\section{Discodoris? lutesceus Bgh, n. sp. Taf. XIV, Fig. 22-28.}

Am Riffe zwischen Nusa Besi und der Nordostspitze von Timor (St. 282) wurde am 17 Jan. ein Individuum gefangen.

Dasselbe hatte aufbewahrt eine Länge von it $\mathrm{mm}$. bei einer Breite von 7 und einer Höhe von 3; die Breite des Rückengebräms 2 mm., die Länge des Fusses 12 bei einer Breite von 2, die Länge des Schwanzes $3 \mathrm{~mm}$. - Die Farbe war durchgehends gelblich, das Rückengebräm zeigte zahlreiche schwärzliche Punkte. Die Eingeweide schimmerten dunkelgrau durch.

Die Form war länglich-oval, mit breitem Riickengebräm, das Vorderencle ein wenig schmäler als das Hinterende; der Rücken eben. Die kleine Kieme ron, wie es schien, 6 vielleicht tripinnaten Blättern von 1,5 mm. Höhe gebildet. Die Tentakel klein, höckerartig. Der schmale Fuss vorne gerundet, mit Randfurche; der Schwanz nicht kurz, hinten das Ruickengebräm iiberragend. Das Thier war nicht hart, aber ziemlich steif.

Das Centralnervensystem wie bei verwandten Formen. Die grossen Augen ron 
O, I 4 mm. Durchmesser, mit grosser gelber Linse; die Otocysten etwas kleiner. Die Blätter der Rhinophorien mit den gewöhnlichen langen, aber wenig erhärteten (decalcinirten?) Spiclen. Die Rückenhaut zeigte unter dem Mikroskope ganz feine gerundete Kegel; sie enthielt eine Menge von wenig erhärteten langen Spiclen, meistens von einem Durchmesser von 0,013 mm.

Die Mundröhre so lang wie der Schlundkopf. Dieser letztere $2 \mathrm{~mm}$. lang, von gewöhnlichen Formverhältnissen; die Raspelscheide hinten etwas vortretend. Die kleinen gelblichen Lippenplatten von einer Breite bis 0,14 mm., von stabartigen Elementen gebildet (Fig. 22), die eine Länge von 0,05 bei einem Durchmesser von $0,008 \mathrm{~mm}$. hatten. Die gelbliche Raspel der Zunge schien 25 Zahnplattenreihen zu enthalten, in der Scheide schienen 29 gezählt zu werden, von denen die 6 hintersten unreif. In den Reihen kam eine sehr grosse Anzahl von Platten vor. Es gliickte nicht den Bau der Raspel genauer zu bestimmen. Die Rhachispartie war ganz schmal. Die innersten (vielleicht etwa 40) Platten waren (Fig. 23) von gewöhnlicher Hakenform mit einem Dentikel in der Nähe des Hakenspitze; der Haken wurde allmählig höher und löste sich pinselförmig in 3-4 Spitzen (Fig. 24) auf, danach wurde die Hakenspitze gabelig (Fig. 26) und gegen den Rand kehrte die Form der inneren Platten zurück, mit oder ohne einen Dentikel (Fig. 27, 28). Die Zahnplatten waren fast farblos, die langen erreichten (in grerader Linie gemessen eine Höhe von $0,20 \mathrm{~mm}$., die äussersten maassen nur etwa 0,06 .

Die hintere Eingeweidemasse wurstförmig, $7 \mathrm{~mm}$. lang bei einem Durchmesser von 3,5; die Leber graubraun, besonders an der oberen Seite von der ockerrothen Zwitterdrüse überzogen, in deren Läppchen reife Geschlechtselemente. - Die vordere Genitalmasse von ovaler Form, 2,5 mm. lang, gelbroth und weiss.

Diese Form wird durch ihre eigenthimlichen Zahnplatten wahrscheinlich später wieder erkennbar sein. Ob sie der Gattung Discodoris gehört, ist sehr zweifelhaft; nicht einmal die Beschaffenheit der Kiemenblätter konnte mit Sicherkeit eruirt werden.

7. Discodoris?? versicolor Bgh. n. sp. Taf. IV, Fig. I. Taf. XIV, Fig. 29-3I.

Am Riffe bei Elat an der Westküste der Insel Hoch-Kei (St. 26I) wurde ein Individuum erbeutet und nach dem Leben abgebildet.

Das lebende Thier hatte eine Länge von fast $6 \mathrm{~cm}$. bei einer Breite bis 3,5, der Durchmesser der grossen Kieme war 2,5 cm. Die Rückenseite scheint sehr bunt gefärbt gewesen zu sein, die Grundfarbe grün mit braunen, weissen und röthlichen Zeichnungen, die Randpartie rothbraun; das Kiemenlaub weiss mit yrünen Rhachides; der Rückenrand grünlichgelb.

Das a ufbewahrte Individum hatte eine Länge von $5,2 \mathrm{~cm}$. bei einer Breite von 3,5 und einer Höhe von $1,5 \mathrm{~cm}$; die Breite des Rückengebräms war $\mathrm{r}_{2} \mathrm{~mm}$., die Höhe der vorgestreckten Rhinophorien $5 \mathrm{~mm}$., der Durchmesser des ausgestreckten Kiemensterns 2,4 cm. bei einer Länge der einzelnen Blätter von I I mm.; die Länge des Fusses $4,3 \mathrm{~cm}$. bei einer Breite von 0,9, die Breite des Fussgebrämes $1,5 \mathrm{~mm}$, die Länge des Schwanzes $4 \mathrm{~mm}$. Die Consistenz war nicht weich, ziemlich steif. - Die Farbe des eigentlichen Rückens war jetzt weisslich, schien aber wahrscheinlich röthlich oder rosenroth gewesen wie noch der Scheitel 
der Tuberkel und wie das Gebram ${ }^{2}$ ); die Rhinophorien röthlich, das Laub cler Kiemenblätter weiss, ihre Rhachicles roth, die Analpapille weiss, die intrabranchiale Platte roth. Die Unterseite des Rückengebräms weiss, die Übergangsfurche an den Körperseiten aber blutroth; diese Ietzteren sowie der Kopf und der Fuss weiss.

Der gewölbte Rücken war sehr uneben. Am eigentlichen Rücken schienen drei Reihen von grösseren, unebenen Knoten vorzukommen; die mediane enthielt einen vor den Rhinophorien, dann zwei und zwei hinter der Kieme; die lateralen zeigten jede 2; das Rückengebrim war stark mit kleineren und grösseren Knoten bedeckt, besonders in der Gegend dicht ausserhalb der lateralen Reihen. Die Keule der Rhinophorien stark durchblättert. Das quer-oval-herzförmige Kiemenloch von $13 \mathrm{~mm}$. Weite, mit vorspringendem Rande; die Kieme von 5 starken Blättern gebildet; die Analpapille hinten stehend, 3,5 mm. hoch, abgestutzt. Der Kopf mit kleinen, an der Spitze gleichsam eingestulpten Tentakeln. Die Körperseiten ziemlich (bis $7 \mathrm{~mm}$.) hoch, nach innen abfallend. Der Fuss nicht breit, vorne gerundet und mit Randfurche, das Gebräm schmal, der Schwanz kurz.

Das röthlich weisse Centralnervensystem wie gewöhnlich, die Grösse der gastro-ocsophagalen Ganglien (mit einer Zelle von einem Durchmesser von 0,24 mm.) betrug etwa $1 / 4$ der buccalen. - Der Durchmesser der kurggestielten Augen war 0,12 mm. In den (etwa 30) dünnen Blättern der Rhinophorien wurden keine Spikel, ebenso wenig in den Tuberkeln des Rückens gesehen.

Die Länge der weissen Mundröhre betrug $5 \mathrm{~mm}$. - Der weisse Schlundkopf $9 \mathrm{~mm}$. lang bei einer Höhe und Breite von 7 , die Raspelscheide stark vorspringend; die schön citrongelben oben und unten in einander übergehenden Lippenplatten etwas convex, $5 \mathrm{~mm}$. hoch bei einer Breite von 3, ziemlich dick, ihre gebogenen Elemente (Fig. 29) bis 0,07 mm. hoch. Die Raspel der Zunge gelblich, mit etwa 7o Zahnplattenreihen, von welchen alle die vorderen sehr beschädigt; in der starken Raspelscheide noch 70 Reihen, von welchen die 3 hintersten unreif; die Gesammtzahl der Reihen somit r 40. In den in der Mittenlinie dicht an einander stossenden Reihen wurden bis etwa I 25 Zahnplatten gezählt. Die schwach gelblichen Platten von der gewöhnlichsten Hakenform (Fig. 30), bis 0,14 mm. hoch; nach aussen in den Reihen wurden sie niedriger und mehr plump (Fig. 31), die Höhe der 4 äussersten betrug 0,0350,04-0,05-0,06 mm. (Fig. 3I a).

Die weissen $\mathrm{S}$ peicheldrüsen $8 \mathrm{~mm}$. lang, ziemlich grobknotig.

Die Speiseröhre weisslich, $12 \mathrm{~mm}$. lang. Der etwas abgeplattete (leere) Magen $15 \mathrm{~mm}$. lang bei einem Durchmesser von 5, sich vorne in den kurz umbiegenden Darm fortsetzend, der eine Länge von $3,5 \mathrm{~cm}$. hatte bei einem Durchmesser von 2,5 mm. - Die hintere Eingeweidemasse länglich-oval, 2, I cm. lang bei einer Breite von I, 3 und einer Dicke von I, I $\mathrm{cm}$. Die grüne Leber nur am Vorderende und an der Unterseite entblösst, sonst von den körnigen, gelblichen, an einander stossenden Lappen der Zwitterdrüse bedeckt, welche zungenförmige Verlängerungen an die Unterseite schickte.

I) Die Abbildung des lebenden Thieres stimmt gar nicht mit den Farbenvethaltnissen des aufbewahrten; die dem letzteren mitgegebenen Notizen stimmen aber vollständig mit denen, welche die Zeichnung begleiten. 
Die querliegende, weissliche, gestreckt-ovale Blutdruse von $8 \mathrm{~mm}$. Länge bei einer Dicke ron 2. Das kurz-birnförmige pericardio-renale Organ (Nierenspritze) $2 \mathrm{~mm}$. lang.

In den Läppchen des bis $2 . \mathrm{mm}$. dicken $\mathrm{Z}$ witterdrüsenlagers reife Geschlechtselemente. - Die vordere Genitalmasse $9 \mathrm{~mm}$. lang bei einer Höhe von 7 und Breite von 6,5, gelb: an der inneren Seite derselben die S-förmig gebogene, $6 \mathrm{~mm}$. lange Ampulle des Zwitterdriisenganges: am Vorderende die kugelförmige, in Durchmesser $5 \mathrm{~mm}$. haltende, graue Spermatotheke und unterhalb derselben die zusammengebogene, ausgestreckt $5 \mathrm{~mm}$. lange, wurstförmige Spermatocyste. Der dünne, weisse Samenleiter einen grossen Knäuel bildend, in den 4,5 langen, weissen unbewaffneten Penis übergehend.

Diese Form lässt sich kaum in eine der bisher aufgestellten Doriden-Gattungen einfügen, vielleicht steht sie den Discodoriden am nächsten.

S. Discodoris sp. Taf. XIV, Fig. $32-36$.

Bei Nord-Ubian (St. 99) war ein Individuum gefangen.

Aufbewahrt war dasselbe $23 \mathrm{~mm}$. lang bei einer Breite von 9 und Höhe von 8; die Höhe der Rhinophorien 3, der Kieme 3,5 mm., die Breite des Fusses S. - Die Farbe des Rückens war hell bräunlichgrau, die der Rhinophorien mehr braun, die der ganzen Unterseite etwas heller, an der Fusssohle kamen sparsam zerstreute braune Fleckchen vor.

Die Form etwas länglich, das (beschädigte) Rücken- so wie das Fussgebräm ziemlich schmal; der Fuss nicht schmal, vorne gerundet, mit Randfurche, der kurze Schwanz überragte nur wenig den Körper. Der etwas gewölbte Rücken ist mit dichtstehenden kleinen Papeln meistens von einem Durchmesser von etwa 0,20 mm. bedeckt. Die Rhinophorien weit nach vorne, und die Kieme weit nach hinten stehend, die letzte aus 5 Blättern gebildet. Die Tentakel klein, fingerförmig. - Die Consistenz ein wenig steif:

Das Centralnervensystem mit den Augen wie gewöhnlich. Die Blätter der Rhinophorkeule mit langen Spiclen stark ausgestattet; die Haut des Rückens mit stark erhärteten kurzen und langen Spiclen von einem Durchmesser bis $0,02 \mathrm{~mm}$., Spiclen stiegen auch in die kleinen Papel hinauf.

Die Mundröhre $3 \mathrm{~mm}$. lang. Der stark zusammengezogene weissliche Schlundkopf 4 mm. lang bei einer Breite von 4 und Höhe von 3,5 ; hinten an der Unterseite trat die Raspelscheide ein wenig hervor. Die gelben Lippenplatten ziemlich schmal, oben etwas breiter, aus clicht gedrängten, bei einem Durchmesser von O,OIO bis O,I 2 mm. langen Stäbchen (Fig. 32) zusammengesetzt. In der blassen Raspel der Zunge 12 Zahnplattenreihen, in der Scheide deren I2, von welchen die 2 hintersten unreif; die Gesammtzahl der Reihen somit nur 24. In den Reihen kamen an jeder Seite der ganz schmalen Rhachis bis 33 Platten vor. Die Zahnplatten hell gelb oder gelblich, von der allergewöhnlichsten Hakenform; die Höhe des Hakens der innersten (Fig. 33) betrug 0,05, sie stieg durch die Reihen bis 0, 16 (Fig. 34, 35), die der 2 äussersten (Fig. 36) war 0,08-0, $10 \mathrm{~mm}$.

Der leere Magen etwas abgeplattet, rundlich ron $5 \mathrm{~mm}$. Durchmesser; der etwas 
geschlängelte Darm i $7 \mathrm{~mm}$. lang. Die hintere Eingeweidemasse (L e b e r) kegelförmig, weisslich, $12 \mathrm{~mm}$. lang bei einem Durchmesser von 6, mit tiefer Kluft für den Magren; die weisse querliegende Gallenblase $2 \mathrm{~mm}$. lang.

Die Blutdrüsen weisslich; die vordere von rundlichem, die hintere von querovalem Umrisse.

In den Läppchen der einen dünnen Überzug über den grössten Theile der Leber bilden-

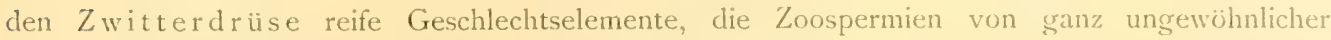
Länge. Die unregelmässig kugelige vordere Genitalmasse von 6,5 mm. Länge, weiss; die Samenblasen wie gewöhnlich.

Eine Discodoris lag hier vor, vielleicht eine Varietät einer der friiher aus dem Indischen Meere beschriebenen Arten.

\section{Carminodoris Bgh.}

R. BERGH, Malacolog. Unters. III (Heft XVI, 2, I\$89), p. 8I\$-\$2I. Taf. LXXX, Fig. 27; Taf. LXXI, Fig. I-I2.

Notaeum papulatum; tentacula parva, conica; branchia e foliolis non multis tripinnatis formata. Radula rhachide angusta nuda; pleuris multidentatis, dentibus hamatis (minute serrulatis). Prostata magna. Glans penis conulis solidis vel hamulis armata.

Von den anderen Gattungen der Discodorididen unterscheidet sich diese hauptsächlich durch eine Bewaffnung der glans penis, die an die der Doriopsididen und Phyllidiiden erinnert; ferner von mehreren der anderen Gattungen durch ihre Mandibelplatten und die Bewaffnung cler Raspel.

Bisher war nur eine einzige Art (C. mauritiana B.) aus der Umgegend der Insel Mauritius bekannt.

Camminodoris blandula Bgh. n. sp. Taf. XIV, Fig. 37-40.

Am 26 Oct. wurde (Station 213) am Riffe von Pulu-Pasi-Tanette und am Riffe der Süd-Insel je ein Individuum gefangen.

Dieselben waren in Formol bewahrt und ziemlich stark erhärtet. Sie waren fast von denselben Grössen-, Form- und Farbenverhältnissen; von einer Länge von (3-) 3,2 cm. bei einer Breite von $(\mathrm{I}, 7-)_{2}$ und einer Höhe von $0,9 \mathrm{~cm}$; die Länge des Fusses betrug $1,6 \mathrm{~cm}$. bei einer Breite von 0,9 ; die Breite des Rückengebrämes war $6 \mathrm{~mm}$; d der Durchmesser der querovalen Kiemenspalte (bei halb zurückgezogener Kieme) 8 mm., die Höhe der Blätter bis 5 mm., die Höhe der Rhinophorien 4. - Die Grundfarbe war weiss; am Rande des eigentlichen Rückens standen drei zackig-rundliche braune Flecken von einem Durchmesser von etwa f mm.; vor und zwischen den Rhinophorien fand sich ein ähnlicher, etwas breiterer lileck; grössere und kleinere Fleckchen ähnlicher Farbe kamen sonst zerstreut am Rücken vor; an der Unterseite des Rückengebrämes fanden sich ähnliche, aber etwas hellere Fleckichen so wie 
auch an den Körperseiten; die Fusssohle war stark hell bräunlichgrau getüpfelt; die Kieme und die Rhinophorien weisslich.

Die Form war oval, etwas niedergedrückt, der Körper überragt ringsum stark den Fuss. Der Rücken war uberall mit kleinen und grösseren Tuberkelen (bis zu einem Durchmesser von I mm.) bedeckt. Der Rand der Rhinophorhöhlen glatt, etwas vortretend; ebenso der Rand der Kiemenspalte; die Kieme aus etwa Io trippinnaten Blättern gebildet, hinten, den Kiemenkreis completirend, die abgestutzte Analpapille. Zu jeder Seite des (fein braungefleckten) Aussenmundes der tuberkelartige Tentakel. Der Fuss vorne und hinten gerundet, mit Furche des Vorderrandes, mit schmalem Fussgebräme, kurzem Schwanze. - Die Consistenz des Thieres ziemlich steif (vielleicht von der Conservierungsart herrührend).

Das weissliche Centralnervensystem wie gewöhnlich; die Ganglienzellen erreichten einen Durchmesser bis $0,25 \mathrm{~mm}$. Die Augen (beide) zeigten die Linse an der Vorderseite eigenthümlich abgeplattet. Die Blätter der Rhinophorien wegen der dicht gedrängten langen, klaren, stark erhärteten Spikeln sehr steif. Ähnliche Spikel kamen überall in der Rückenhaut vor, stiegen auch bündelweise in die Tuberkel bis an ihre Oberfläche hinauf.

Die kurz-birnförmige Mundröhre $3 \mathrm{~mm}$. lang, aussen bläulichgrau, an der Innenseite braunschwarz. Der Schlundk opf $6 \mathrm{~mm}$. lang bei einer Höhe von 5,5 und einer Breite von 4, die Raspelscheide hinten an der Unterseite etwas vortretend. Die oben breiteren, etwas sichelförmigen, bräunlichgelben Nandibelplatten aus dicht gedrängten, bis wenigstens $0,20 \mathrm{~mm}$. hohen Stäbchen gebildet (Fig. 37). Die breite Zunge zeigte in der gelblichen Raspel I5 Zahnplattenreihen, in der Scheide weiter 15 entwickelte und 3 jüngere Reihen, die Gesammtzahl derselben somit 33. In den Reihen kamen an jeder Seite der ganz schmalen Rhachis bis 87 Platten vor. Die gelblichen Platten von gewöhnlicher Hakenform; der Haken trug eine Reihe von ganz feinen Dentikeln (Fig. 38, 39). Die Länge der Grundplatte der innersten (Fig. 38 ) betrug $0,18 \mathrm{~mm}$. bei einer Hakenhöhe von 0,12 , an der folgenden waren die entsprechenden Maasse 0,22 und 0,14 , und stiegen bis zu 0,25 und 0,16 ; die Höhe des Hakens der äussersten Platte war $0,06 \mathrm{~mm}$.

Die Länge der hinteren Eingeweidemasse (Leber) war $19 \mathrm{~mm}$. bei einer Breite von 9 und einer Höhe von 8,5. Die Länge des Darmes war $3 \mathrm{~cm}$. bei einem Durchmesser von I- 1,5 mm.

Die aussen mehr gräuliche Farbe der Leber war in ihrer ganzen Ausdehnung und ringsum fast verdrängt durch ziemlich dicht stehende, abstechende Inseln, die von gelben Körnern gebildet waren; es waren die Läppchen der $\mathrm{Z}$ witterdrüse; sie enthielten reife Eier. - Die gelbliche vordere Genitalmasse i m mm. lang bei einer Höhe ron $S$ und einer Breite von 7,5 . Vorne an der oberen Seite die ziemlich grosse, gebogene, weissliche Prostata und hinter derselben die $1 \mathrm{~mm}$. in Diam. haltende kugelförmige Spermatotheke; von der letzteren gedeckt die kleine birnförmige Spermatocyste. Der aus der Prostata hervorgehende Samenleiter einen Knäuel von feinen Windungen bildend, schliesslich gestreckt in den Pen is übergehend. Dieser letztere $2,5 \mathrm{~mm}$. lang, ziemlich schlank; die kaum I $\mathrm{mm}$. lange glans zeigt wie der untere Theil des Samenleiters eine Bewaffnung mit (IO-I2) Quincunx-Keihen von plumpen niedrigen, gelben Kegeln, die mitunter ein wenig gebogen waren und eine Höhe von etwa $0,06 \mathrm{~mm}$. 
erreichten (Fig. 40). Der vaginale Gang der Spermatotheke kräftig, die Innenscite des Vestibulum genitale braun.

Diese Thierform scheint der Gattung Carminodoris an zu gehören und eine neue Art derselben zu bilden, welche durch andere Form der Bewaffnung der glans penis, so wie durch Verschiedenheit des Raspelbaues sich hauptsäichlich von der älteren Art unterscheidet.

\section{Hoplodoris 13gh.}

R. Bergir, Malacolog. Unters. III (Supplementheft I, I880), p. 5 r.

Forma corporis fere ut in Discodoridibus; tentacula falciformia.

Armatura labialis e baculis minutissimis formata. Radula fere ut in Discodoriclibus.

Ventriculus liber. - Prostata magna. Penis fere ut in Platydoridibus armatus. Glandula hastatoria et hasta cornuformis.

Im Äusseren ähneln die Hoplodoriden im Ganzen den Discodoriden, sind jedoch weniger abgeplattet und weniger weich, haben aber auch den granulirten Rücken; die Tentakel sind kurz-sichelförmig. Die Lippenplatten sind aus dünnen Stäbchen, zusammengesetzt; die Raspel ist fast wie bei der Discodoris, ohne mediane Platten, mit zahireichen, hakenförmigen Seitenplatten. Der freiliegende Magen ist gross. - Die Prostata stark entwickelt; der Penis zeigt wie bei der Platydoris Reihen von mit einem Dorn versehenen Kegeln; es findet sich eine Stacheldrüse mit sehr starkem hornförmigem (füllhornartigem) Stachel.

Die Gattung gehört der grossen Gruppe der Discodorididen ${ }^{1}$ ) und bildet nebenbei gewissermaassen ein Übergangsglied zwischen der Platydoris und dem Astoronotus.

Von der Gattung ist bisher nur die untenstehende Art aus dem Philippinisch-Indischen Neere bekannt.

Hoplodoris desmoparypha Bgh. Taf. XIV, Fig. 4I-46. Taf. XV, Fig. I-2.

R. Berghi, l. c. isSo, p. 5I-56, Taf. C, Fig. 5-9; Taf. F, Fig. $1-18$.

Am 2 I Juli wurde am Riffe der Taruna-Bai, auf Gross Sangir (St. 127) ein Individuum gefangen.

Aufbewahrt hatte dasselbe eine Länge von $5,5 \mathrm{~cm}$. bei einer Breite von 3 und einer Höhe von I,4; die Breite des Rückengebräms bis 9 mm., die Höhe der Rhinophorscheiden 2 , die Weite der grob-rundzackigen Kiemenspalte I I mm; die Länge des Fusses $4,5 \mathrm{~cm}$. bei einer Breite von 1,1 .

Die Farbe der Rückenseite schwarz; an der etwas helleren Unterseite des Gebräms ein ziemlich breites schwarzes Band; an den weisslichen Körperseiten ein (bis 4 mm.) breites, an

1) R. LERgr, System d. nudibr. Gasteropoden. IS92, 1. c. p. 1094-1096.

SILOGA-EXYEDITIE I. 
den Rändern rundzackiges Band von bräunlichschwarzer Farbe, ausserhalb wie innerhalb desselben einzelne zerstreute Fleckchen ähnlicher Farbe; die Fusssohle schmutzig schwärzlichbraun. Die Consistenz nicht hart, sondern etwas steif.

Die Formverhältnisse die gewöhnlichen. Der Rücken ïberall mit feinen Körnchen bedeckt, zwischen denen zerstreut kleine Knoten (von einem Durchmesser bis fast I mm.) vorkamen; die Unterseite des Gebräms glatt. Die (zurückgezogenen) Rhinophorien $5 \mathrm{~mm}$. hoch; die (halb zurückgezogene) Kieme aus 7 tripinnaten, $5 \mathrm{~mm}$. hohen Blättern gebildet; die subcentrale Analpapille ziemlich niedrig, an der Öffnung lappig. Die Tentakel $3 \mathrm{~mm}$. lang, kurz-sichelförmig, etwas gebogen, mit dickerem vorderem, dünnerem und farblosem hinterem Rand (Fig. I). Der Fuss ringsum vom breiten Rückengebräm überragt, vorne gerundet, mit tiefer Randfurche, der Schwanz kurz.

Das Centralnervensystem wie bei verwandten Formen. Der Durchmesser der Augen betrug 0,12 mm. Die Blätter der Keule der braunen Rhinophorien am Rande weissfleckig, mit den gewöhnlichen (jetzt decalcinirten) langen Spiklen. In der Haut des Rückens kamen Spikel sehr sparsam vor, dagegen reichliches Sterne bildendes Pigment.

Die Mundröhre $3 \mathrm{~mm}$. lang, aussen grau; die Innenseite in ihrer ganzen Länge schwarzbraun. Der Schlundkopf weisslich, 5,25 mm. lang bei einer Breite von 5 und einer Höhe von $5 \mathrm{~mm}$., die Raspelscheide am Hinterende etwas hervorragend; die braungelben Lippenplatten in der unteren Hälfte der Mundspalte, fast I $\mathrm{mm}$. hoch, unten breiter, nach oben zugespitzt (Fig. 44), durch ein starkes cuticulares Zwischenstück unten verbunden, aus stabför. migen Elementen (Fig. 43) zusammengesetzt, die eine Länge von $0,05 \mathrm{~mm}$. bei einer Breite bis $0,0035 \mathrm{~mm}$. hatten. Die Zunge mit gräulichgelber Raspel, die etwa 30 Zahnplattenreihen enthielt; in der Scheide kamen noch 20 vor; die Gesammtzahl der Reihen somit etwa 50. In den Reihen wurden bis etwa 85 Zahnplatten gezählt. Dieselben (Fig. 41) waren gelblich, eine Höhe bis $0,20 \mathrm{~mm}$. erreichend, die Höhe der drei äussersten betrug 0,07-0,09-0,10 mm. (Fig. 42).

Die langen, weissen Speicheldrüsen sich bis an die Unterseite der hinteren Eingeweidemasse erstreckend.

Die Speiseröhre $15 \mathrm{~mm}$. lang bei einem Durchmesser von 2. Der kurz-sackförmige gräuliche Magen fast ganz frei liegend, $8 \mathrm{~mm}$. lang bei einem Durchmesser von 6; sein Inhalt war ganz unbestimmbare thierische Masse. Die hintere Eingeweidemasse kurz-kegelförmig, $20 \mathrm{~mm}$. lang bei einer Breite am abgeplatteten Vorderende von I4. Die von der bis I,5 mm. dicken gräulichweissen Zwitterdrüse überzogene Leber braungrau. Die weissliche Gallenblase $3 \mathrm{~mm}$. hoch bei einem Durchmesser oben von $\mathrm{r}, 5$. Der leere $\mathrm{Darm} 3 \mathrm{~cm}$. lang bei einem Durchmesser von $2 \mathrm{~mm}$.

Die Blutdrüsen braungrau; die vordere gerundet-viereckig, von $3,5 \mathrm{~mm}$. Durchmesser; die hintere gestreckt-dreieckig, $4 \mathrm{~mm}$. lang, bei einer Breite vorne von 2.

In den Läppchen der Zwitterdrüse reife Geschlechtselemente. Die vordere Genital. masse $15 \mathrm{~mm}$. lang bei einer Breite von 8 und einer Höhe von $12 \mathrm{~mm}$. Der obere Rand und die hintere Seite der Masse wird von den Windungen der Ampulle des Zwitterdrüsenganges gebildet, das Vorderende von der grossen Prostata mit seinem Gange (dem Samenleiter) und dem Penis; hinter denselben finden sich an der Vorderseite die Samenblasen mit ihren 
Ausfïhrungsgängen, ganz hinten der hinterste Theil der Schleim-Eiweissdrüse. Der diinne Zwitterdrüsengang schwillt fast plötzlich zu seiner kalkweissen Ampulle an, die mit ihren fast parallelen, auf- und absteigenden Windungen einen flachen Knäuel von $\mathrm{IO}$ mm. Länge und $9 \mathrm{~mm}$. Höhe bildet, die Windungen hatten meistens einen Durchmesser von I,5 mm.; aus dem verdünten Vorderende geht der Samenleiter in die grosse Prostata iiber. Dieselbe war nierenförmig (vgl. 1. c. Taf. F, Fig. $7 a$ ), $9 \mathrm{~mm}$. lang bei einer Breite von 7 und einer Dicke von $6 \mathrm{~mm}$; sie zeigt feine Furchen, aber keine grössere Höhle; aus dem vertieften Hilus tritt der $6 \mathrm{~mm}$. lange, im Durchmesser $\mathrm{I} \mathrm{mm}$. haltende Gang hervor, durch welchen sich der Samenleiter hinab an den Boden der Vorhauthöhle schlängelt. Der Gang geht olne Grenze in den bei einem Durchmesser von 2 fast $4,5 \mathrm{~mm}$. langen Penis über. Derselbe (die Vorhaut) ist sehr dickwandig; am Scheitel der Höhle öffnet sich auf einer kleinen Papille der Samenleiter. Die Wand der Höhle zeigte starke Längsfalten und ist von einer starken, gelben Cuticula uiberzogen, die sich auf den kurz-kegelförmigen Kegeln in eine starke Spitze verlängert. Von solchen Kegeln kamen etwa I 2 (undeutlich geschiedene Quincunx-)Reihen vor, in jeder Reihe etwa ro-r2; die Cuticula hatte eine Dicke von $0,04 \mathrm{~mm}$; die Kegel erreichten eine Höhe bis etwa 0,28 , von welchen die harte Spitze $0,12 \mathrm{~mm}$. betrug (Fig. 45, 46). Die (etwas zusammengefallene, leere) Spermatotheke $9 \mathrm{~mm}$. lang, die zusammengebogene weisse Spermatocyste ausgestreckt fast ebenso lang. Der vaginale Ausführungsgang etwas länger als die Spermatotheke, unten erweitert eine von gelber Cuticula ausgekleidete Vagina bildend. An der Seite der Vagina findet sich ein kleiner, fast kugelförmiger Sack von einem Durchmesser von etwa 2 mm.; an der Wand dieses Stachelsacks zeigt sich eine Papille, die einen eigenthümlichen Stachel trägt, welcher mit der Spitze in die Vagina hineinragt; am Scheitel des Sackes tritt ein duinner, geschlängelter Gang ein, welcher aus dem Hilus einer etwas abgeplattet-kugelförmigen weisslichen Stacheldrüse von $3 \mathrm{~mm}$. Durchmesser hervortritt (vgl. l. c. Taf. F, Fig. $5 \mathrm{fg} / \mathrm{h}$ ). Der (Fig. 2) Stachel, dessen Wurzelpartie von den Rändern der Papille ganz umfasst ist, war ganz wie früher dargestellt (1.c. Fig. 12-I4), ziemlich hart, etwas verkalkt, 2 mm. hoch, die querovale, sattelförmige Grundfläche $2 \mathrm{~mm}$. breit, an der Spitze die feine Öffnung. Die Schleim-Eiweissdriise gelblichweiss und weiss. Das Vestibulum genitale graubraun.

Es liegt hier sicherlich nur eine dunkle Varietät der typischen Art vor.

\section{Halla Bgh.}

R. BERGH, Malacolog. Unters. II (Heft XIII, I878), p. 572-574. Taf. LVIII, Fig. 19-29. R. BERGH, System d. nudibr. Gaster. 1. c. I 892, p. 1097.

Corpus nonnihil depressum, sat molle, dorso laevi; tentacula nulla; branchia e foliolis simpliciter lamellatis composita; podarium non latum, antice emarginatum.

Armatura labialis e spinis minutis formata. Radula rhachide nuda; pleuris non multidentatis; dens primus latus a reliquis diversus; reliqui hamati erecti, denticulati. - Penis inermis.

Die wahrscheinlich in die grosse Gruppe der Discodorididen gehörenden Hallen sind 
von etwas niedergedrückter Form, etwas weich, mit glattem Rücken. Tentakel fehlen. Die Kieme ist aus einfach lamellirten Blättern gebildet. Des Fuss nicht breit. - Die Lippenplatten sind aus dicht gedrängten Dornen zusammengesetzt. Die Rhachis der Raspel nackt; die Anzahl der Zahnplatten der Pleurae ist nicht gross; die erste Zahnplatte in Form von den anderen sehr abweichend, breit; die anderen hakenförmig, aufrecht, mit gezähneltem Rande. - Der Penis ist unbewaffnet.

Von der Gattung war bisher nur eine einzige Art, die $H$. decorata, auch aus dem Indischen (Philippinischen) Neere, bekannt.

\section{Halla indecora Bgh. n. sp. Taf. XV, Fig. 3-6.}

Am Ankerplatz bei Pulu Jedan an der Ostküste der Aru-Inseln (St. 273) wurden 9 Individuen gefangen, von welchen 3 ganz klein; die 2 grössten wurden genauer untersucht. Sie waren mit (5) Exemplaren von Marsenia perspicua zusammen gefischt und wegen oberflächlicher Ähnlichkeit mit solchen im Glase gemischt.

Das grösste Individuum hatte eine Länge von I 5 bei einer Breite von I 3 und Höhe ron $7 \mathrm{~mm}$; das Rückengebräme war $3 \mathrm{~mm}$. breit; der Durchmesser der runden Kiemenspalte war 2, die Höhe der Kieme $2 \mathrm{~mm}$; die Breite des Fusses war 4, die Länge des Schwanzes $2 \mathrm{~mm}$. - Die Farbe war durchgehends weiss, so auch die kleinen Rhinophorien und die kleine Kieme.

Die Form war oval; der ganz glatte Rücken etwas gewölbt, mit breitem, mitunter wellenartig gebogenem, den Fuss ringsum überragendem Gebräm; die Rhinophorien klein, die Kieme aus 10 einfachen ziemlich kleinen Blättern gebildet; Tentakel fehlten; der Fuss ziemlich schmal, mit schmalem Gebräm, der nicht ganz kurze Schwanz zugespitzt.

Die Leber schimmerte schwach durch. Die Consistenz (wegen der Erhärtung?) etwas steif.

Das Centralnervensystem wie gewöhnlich. - Weder in den Blättern der Rhinophorien noch in der zähen Haut wurden erhärtete Zellen oder Spikel nachgewiessen.

Die von einem starken Drüsenlager umgebene Mundröhre fast so lang wie der Schlundkopf. Derselbe ist weiss, fast kugelartig, $2 \mathrm{~mm}$. lang, die Raspelscheide hinten ein wenig vortretend; die Lipp'enplatten röthlichgelb, bis $0,29 \mathrm{~mm}$. breit; ihre gedrängten Elemente sind ein wenig gebogene Dornen (Fig. 3), die sich von einer rundlichen, im Durchmesser bis o,O I 3 mm. haltenden Grundplatte bis zu einer Höhe vom 0,037 erheben, ihre Spitze ist meistens gekliftet, oft unregelmässig. In der ganz blassen Raspel der $\mathrm{Zunge} \mathrm{wurden} \mathrm{25--20} \mathrm{Zahnplattenreihen}$ gezählt, in der Scheide noch 35-45, die Gesammtzahl der Reihen somit 60-65. In den Reihen kamen ausserhalb der grossen Seitenplatten 15-20 Aussenplatten vor. Die gelblichen Seitenplatten 0, I25 mm. lang; die Aussenplatten farblos, die innersten etwa O, IO mm. hoch, die Höhe nach aussen allmählig sinkend, die der äussersten betrug nur $0,04 \mathrm{~mm}$. Die nackte Rhachis ziemlich schmal. Die Seitenplatten (Fig. 4a, 5) von eigenthümlicher Form, aussen breit und ausgerandet, nach innen verschmälert und mit 2 Haken endigend; alle die Aussenplatten mit gebogener Spitze und fein gezähneltem Rande, die inneren (Fig. 4b) mit flügelartiger Entwicklung, nach aussen in den Reihen wurde dieselbe kleiner (Fig. 6). 
Die gelbliche Leber kegelförmig, $7 \mathrm{~mm}$. lang bei einer Brcite vorne bis 4,5. - Die vordere Genitalmasse fast kugelförmig, von $3 \mathrm{~mm}$. Durchmesser, weisslich; die Samenblasen wie gewöhnlich; der Penis schien unbewaffnet.

Diese Form ist deutlich von der früher beschriebenen specifisch verschieden.

\section{Nirva Bgh. n. gen.}

Corpus nonnihil depressum; notaeum sat laeve: branchia paucifoliata, foliolis simpliciter pinnatis.

Armatura labialis e baculis minutis formata. Dentes linguales hamati. - P'enis inermis.

Diese ganz unvollständig gekannte Gattung steht durch ihre einfach gefiederten Kiemenblätter wohl in der Nähe der Halla und der Rostanga, welche aber eine ganz andere Zungenbewaffnung zeigen.

1. Nirva Brockii Bgh. Taf. XV, Fig. 7-9.

?Doris gen.? R. Bergil, Nudibranchien des Sunda-Meeres. 1. c. I890, Taf. LXXXV, Fig. 9.

Am 26 Oct. wurde bei Pulu-Pasi-Tanette am Nordende der Insel Saleyer (St. 2I3) auf einem Koralriffe aus einer Tiefe bis $36 \mathrm{M}$. ein Individuum gefangen.

Dasselbe maass in Formol bewahrt in Länge I I mm. bei einer Breite von 4,5, und einer Höhe von 3; der Durchmesser des Kiemenloches 2, die Höhe der Kiemenblätter 2 mm. Die Farbe des Rückens war gräulich mit zahlreichen dichtstehenden dunkler grauen, feinpunktirten, wenig vorragenden rundlichen Flecken von einem Durchmesser von I mm., darunter kamen, besonders am Rückenrande, einzehne zerstreute schwarze vor. Die Farbe war übrigens gelblichweiss mit zerstreuten grauen Punkten, zahlreicher an der Fusssohle.

Die Form war länglich, vorne und hinten gerundet, etwas abgeplattet, der Rückenrand wenig vortretend; der Rücken fast eben, die Rhinophorien ganz vorne, und die Kieme ganz hinten stehend, die letztere aus 6 einfachen Blättern gebildet. Die Tentakel fingerförmig. Die Körperseiten ziemlich niedrig; der Fuss vorne gerundet, der Fussrand stärker als der Rückenrand vortretend, der Schwanz etwa $2 \mathrm{~mm}$. lang, ein wenig zugespitzt.

Die Ganglien des Centralnervensystems wie gewöhnlich. Die Augen von 0,16 mm. Durchmesser, mit grosser dunkelgelber Linse. Die etwa $0,75 \mathrm{~mm}$. hohe Keule der Rhinophorien mit, wie es schien, etwa I5 Blätterpaaren und starker Endpapille, die Blätter in gewöhnlicher Weise durch Spikel steif gemacht. Die Haut des Rückens zeigte in den erwähnten Flecken schöne grosse Sternbildungen, durch vom Centrum ausstrahlende Spikel gebildet; dieselben waren lang, von einem Durchmesser bis $0,03 \mathrm{~mm}$., mehr oder weniger erhärtet; auch in den Kiemenblättern kamen Spikel vor, ebenso in den Tentakeln und sonst in der Haut.

Die Mundröhre nur wenig kürzer als der Schlundkopf. Der Schlundkopf kurz und dick, $2 \mathrm{~mm}$. lang, weisslich, die Raspelscheide mit ihrem Hinterende hinten an der Unterseite 
etwas vortretend; die Lippenscheibe von einer, nach aussen etwas dickeren, gelblicher Cuticula uiberzogen; die Mundspalte ringsum mit einer schwach gelblichen Lippenplatte versehen, aus dicht gedrängten, dünnen, geraden Stäbchen (Fig. 7) gebildet, die eine Länge bis wenigstens $0,05 \mathrm{~mm}$. erreichten. Die Zunge abgeplattet, mit farbloser Raspel, die eine nicht grosse Anzahl von Zahnplattenreihen zu enthalten schien, auch die der Raspelscheide schien nicht gross. In den Zahnplattenreihen kamen zu jeder Seite der schmalen nackten Rhachis bis 27 Seitenplatten vor. Die farblosen Zahnplatten (Fig. 8, 9) alle von der gewöhnlichsten Hakenform, mit glattrandigem Haken; die Länge der innersten betrug 0,06 , die der grössten 0,16 , der äussersten fast O, I $2 \mathrm{~mm}$, die Höhe des Hakens der grössten $0,12 \mathrm{~mm}$.

Die vordere und die hintere Blutdrüse fast gleichgross, gerundet-viereckig, weisslich, ganz fein schwarz punktirt.

Die Leber von gräulicher Farbe.

Die vordere Genitalmasse rundlich, von $3 \mathrm{~mm}$. Durchmesser, von gräulicher und weisslicher Farbe; die ziemlich lange, gebogene Ampulle des Zwitterdrüsenganges schien gelbbraun; die Hauptausführungsgänge des Genitalapparats schienen unbervaffnet.

Vielleicht ist diese Form identisch mit einem vom verstorbenen Brock gefischten Thiere, das verloren gegangen ist, von welchem aber (1.c.) eine farbige Abbildung vorliegt.

\section{Diaululidae.}

R. BERGH, System d. nudibranch. Gasteropoden. 1. c. 1892, p. 1097(-1100).

Corpus depressum vel subdepressum; notaeum ut plurimum minute villosum, saepe holosericeum; tentacula digitiformia; apertura branchialis rotundata, crenulata, folia branchialia tripinnata.

Armatura labialis nulla. Lingua rhachide nuda, pleuris multidentatis; dentibus minimum pro majore parte hamatis. - Penis ut plurimum inermis.

Von den dieser Familie angehörenden Gattungen zeigen die Gargamella (B.), Aldisa (B.), Baptodoris (B.) und Phialodoris (B.) den Penis in verschiedener Weise bewaffnet.

Die Familie, wie jetzt formulirt, umfasst die Gattungen Diaulula (B.), Gargamella (B.), Thordisa (B.), Aldisa (B.), Trippa (B.), Halgerda (B.), Baptodoris (B.), Peltodoris (B.) und Plialodoris (B).

\section{Diaulula Bgh.}

R. BERGH, System der nudibr. Gasteropoden, I892, p. I097.

Notaeum holosericeum.

Dentes pleurales hamati. - Prostata magna. 
Die Gattung war bisher nur durch die D. Sandiegensis (Cooper) vertreten, vielleicht kommen hier zwei neue Arten dazu.

I. Diaulula? gigantea Bgh. n. sp. Taf. XV, Fig. I I-i6.

In der Ruma-Kuda-Bai, Insel Roma (St. 279) wurde ein Individuum gefangen. Dasselbe war etwas zerdrüickt und abgerieben; neben demselben lag ein $8,5 \mathrm{~cm}$. langes, $2 \mathrm{~cm}$. breites (abgestossenes?) Stuick des Rückengebräms. Die Consistenz war nicht steif.

Das Individuum hatte eine Länge von $14,5 \mathrm{~cm}$. bei einer Breite von 9 und einer Höhe von $2,5 \mathrm{~cm}$; die Höhe der Rhinophorien betrug $13 \mathrm{~mm}$, die Länge der Tentakel 7 ; die Breite des Rückengebräms bis $3,5 \mathrm{~cm}$; d der Durchmesser der Kiemenspalte is mm., die Höhe der Kieme 22, der Analpapille $5 \mathrm{~mm}$; die Länge des Fusses $12 \mathrm{~cm}$. bei einer Breite von 4 , die Breite des Fussgebräms $8 \mathrm{~mm}$., die Länge des Schwanzes 8. - Die Farbe des Rückens war braungrau mit zahlreichen kleineren dunkleren Flecken so wie mit sparsamen grösseren schwärzlichgrauen vermischt; die Kieme aussen weisslich, das Laub violetgrau; die Analpapille weiss; die Randpartie der Unterseite des Rückengebräms zeigte ein am Innenrande rundzackiges, (8-10 mm.) breites, schwärzlich chocoladebraunes Band, und das Gebräm sonst auf hellgelblichem Grunde grosse unregelmässige, am Rande verschwimmende, etwas hellere Flecken und zerstreute kleinere; Flecken dieser Arten kamen auch an der oberen Seite des Fussgebrämes vor; die Fusssohle gelb mit zahlreich zerstreuten, hier und da confluirenden unregelmässigen violetbraunen Flecken von meistens $2-5 \mathrm{~mm}$. Durchmesser; ähnliche kamen auch am Kopf vor; die Keule der Rhinophorien braungrau, der Stiel dunkler fleckig, die Tentakel grelb.

Die Form des Thieres ist oval, ziemlich abgeplattet, das Rückengebräm sehr breit, die Kieme von 6 tripinnaten Blättern gebildet; die Spitze der fingerförmigen Tentakel gleichsam eingestuilpt; der starke Fuss viel schmäler als der Rücken, vorne und hinten gerundet, der Vorderrand mit tiefer Randfurche und die obere Lippe desselben median geklüftet. Der Rücken ist überall fein und dicht granulirt, die Nöppchen gerundet, hier und da auch kegelförmig (bis $2 \mathrm{~mm}$. hoch).

Das in eine eng anschliesende Kapsel eingeschlossene Centralnervensystem $\delta \mathrm{mm}$. breit (gelblich-)weiss, seine Ganglien wenig von einander geschieden. - Die Keule der Rhinophorien mit wenigstens Ioo dünnen, durch dünne Spikel steif gemachten Blättern. In der Haut (des Rückens) kamen Spikel viel sparsamer vor.

Die Mundröhre $14 \mathrm{~mm}$. lang. - Der auch weissliche Schlundkopf $15 \mathrm{~mm}$. lang bei einer Höhe und Breite von 13; die grosse Lippenscheibe von einer weissen, dicken, einfachen Cuticula iiberzogen. Die Zunge mit (ganz erhärteter) blassgelber Raspel, welche etwa 40 Zahnplattenreihen enthielt; in der Scheide kamen deren noch beiläufig 30 vor; die Gesammtzahl der Reihen somit ungefähr 70. In den Reihen schienen I50-200 Platten vorzukommen. Dieselben waren fast farblos, alle einander ähnlich, von gewöhnlicher Hakenform (Fig. 12), nur die äusserste von den anderen etwas verschieden (Fig. I I, I $3 a$ ); der Haken dieser letzteren hatte nur eine Höhe von $0,08 \mathrm{~mm}$., durch die Reihe stieg dieselbe bis zu 0,30 mm.

Die gelblichen Speicheldrüsen $3 \mathrm{~cm}$. lang, in ihrer vorderen Hälfte abgeplattet, $3 \mathrm{~mm}$. breit, in der übrigen Strecke viel schmächtiger. 
Die Länge des Speiseröhre $3 \mathrm{~cm}$. bei einem Durchmesser von $8 \mathrm{~mm}$. Der weit hervorragende $\mathrm{M}$ ag en sack-artig, 2,5 cm. lang bei einen Durchmesser von 1,5 , mit einem Gemisch von vegetabilischer und animalischer Masse prall gefullt. Der vorne etwas schlangenartig gebogene Darm $9 \mathrm{~cm}$. lang bei einem Durchmesser von 3 - $4 \mathrm{~mm}$.

Die gelblichweisse hintere Eingeweidemasse $5,8 \mathrm{~cm}$. lang bei einer Breite von 3,2 und einer Dicke von $2 \mathrm{~cm}$, hinten gerundet. Die Zwitterdruise sich in Farbe kaum von der Leber unterscheidend.

Die Blutdrüsen gelblichgrau mit einzelnen zerstreuten braunen Flecken; die rordere dreieckig, mit der Spitze nach vorn, randlappig, $17 \mathrm{~mm}$. breit, bei einer Länge von 7 ; die hintere queroval, von $10 \mathrm{~mm}$. grösstem Durchmesser.

Die grosse vordere Genitalmasse weisslich und gelblich, $2,3 \mathrm{~cm}$. lang bei einer Höhe auch von 2,3 und einer Dicke von $1,5 \mathrm{~cm}$; am Hinterrande und unten die Windungen des sehr langen Zwitterdrüsenganges, am Unterrande die Prostata und vorne der Penis. Die grosse Prostata (Fig. I $4 a$ ) I $5 \mathrm{~mm}$. lang bei anderen Durchmessern von 6, gelblich; ihre Höhle nicht eng, mit starken Längsfalten der Wand; ihr starker Ausführungsgang, der Samenleiter, (Fig. I 4 ) lang, einen Knäuel von Windungen bildend, am Übergange in den Penissack etwas düner. Dieser letztere (Fig. $\mathrm{I}+c$ ) $13 \mathrm{~mm}$. lang bei einem Durchmesser am Grunde von 4, am letzteren heften sich zwei Muskeln; die Innenseite der nicht dünen Vorhaut zeigte Längsfalten, von einfacher Cuticula iiberzogen. Die gebogene Glans (Fig. I5) 7 mm. lang, ziemlich kegelfömig, am einen Rande gleichsam stark gekrüuselt und an den dicken Krausen kegelförmige oder mehr gerundete weiche Höcker von einer Höhe bis o,30 mm. tragend. Die bräunliche, kugelförmige Spermatotheke (Fig. 16a) von $9 \mathrm{~mm}$. Durchmesser, ihr (vaginaler) Ausfihhrungsgang $15 \mathrm{~mm}$. lang bei einem Durchmesser von 2 (Fig. I6b); am Gange hängt die knäuelartig aufgerollte Spermatocyste, einen Knäuel von $8 \mathrm{~mm}$. Durchmesser bildend (Fig. 16c). Die Vagina von einfacher Cuticula uiberzogen.

Die generische Stellung dieser Form ist, so weit die Dorididen bisher bekannt sind, sehr zweifelhaft; sie gehört wohl in die Nachbarschaft der Diaulula. Ihr Penis ist aber sehr verschieden.

2. Diaulula? rubra Bgh. n. sp. Taf. II, Fig. 5. Taf. XV, Fig. Io.

Am I 4 Sptbr. wurde am Riffe in der Sanana-Bai an der Ostküste von Sula-Besi (St. I 93) ein Individuum erbeutet und lebend abgebildet.

Dasselbe war lebend $8 \mathrm{~mm}$. lang bei einer Breite von 3. Die Farbe der oberen Seite war gelbroth mit mehr gelblichem Rande; an jeder Seite des eigentlichen Rückens standen symmetrisch drei schwarze Flecken.

Das aufbewahrte, etwas zusammengezogene und erhärtete Individuum hatte eine Länge von $8 \mathrm{~mm}$. bei einer Breite von 5 und einer Höhe von 2,25 mm. Die Farbe war durchgehends gelblich. Zwischen und zum Theil an den Rückenpapeln jederseits drei schwärzliche Flecken. Die Consistenz etwas steif und brüchig.

Die Form oval, etwas niedergedrückt; das Rückengebräm ziemlich breit, jederseits die 
volle Hälfte der Breite des eigentlichen Rückens betragend, ringsum den I"uss stark überragend, seine untere Seite glatt; die Grenze des eigentlichen Rückens ist durch eine Reihe von einigen gerundeten oder mehr zugespitzten Papeln bezeichnet, längs des Rückens verläuft ein medianer Kamm; der Rücken ist überall mit zahlreichen, ganz kleinen kurzen Kegeln von einer Höhe von $0,04-0,06 \mathrm{~mm}$. bedeckt, in welche die langen (decalcinirten) Spikel des Rückens auch hinaufsteigen. Die Kieme von 6 Blättern gebildet, die Analpapille subcentral. Die Tentakel kurz-kegelförmig. Der Fuss hinten wie vorne gerundet, 2,25 $\mathrm{mm}$. breit; der Vorderrand mit Furche, die obere Lippe median gespalten; das Fussgebräm schmal und der Schwanz kurz.

Die hell gelbliche Mundröhre I,5 mm. lang. Der schwach gelbliche Schlundkopf fast $2 \mathrm{~mm}$. lang, mit hinten etwas vorspringender Raspelscheide; die dreieckige Mundöffnung von einer ziemlich starken, fast farblosen Cuticula iberzogen. In der schwach gelblichen Raspel der Zunge schienen etwa 30 Zahnplattenreihen vorzukommen, in der Scheide noch etwa $I_{\gamma}$, die Gesammtzahl der Reihen somit 47; in den Reihen wurden wenigstens 70 Platten gezählt. Die Platten ron gewöhnlichster Hakenform; die Höhe des Hakens der innersten betrug 0,04, und die Höhe erhob sich durch die Reihe bis $0,075 \mathrm{~mm}$, die der 2 äussersten betrug $0,04-$ 0,06. Die 2-3 äussersten Platten (Fig. IO) waren mehr aufrecht, fast hakenlos.

Die Leber war gelblichweiss. Die vordere Genitalmasse auch gelblichweiss; der Penis schien unbewaffnet.

Vielleicht gehört diese Thierform der Gattung Diaulula an.

\section{Thordisa Bgh.}

R. BERgir, Malacolog. Unters. II (Heft XII), IS77, p. 540-542. Taf, LXI, Fig. 19-24; Taf. LXII, Fig. 1-2. - III (Heft XVII), I890, p. 902-904. Taf. LXXXVIII, Fig. 13-I8. R. BERGH, System. 1. c. I\$92, p. 1098 .

Forma corporis fere ut in Discodoridibus, dorso fere villoso; tentacula parva.

Armatura labialis nulla. Radula rhachide nuda; dentes pleurales hamati, extimi denticulati. - Penis inermis.

Die Gattung, die in die Familie der Diaululiden zu gehören scheint, zeichnet sich im Äusseren besonders durch die villöse Beschaffenheit des Rückens aus. Die äusseren pleuralen Zahnplatten sind sehr schmächtig und kammförmig entwickelt. - Der Penis ist unbewaffnet.

Mit Sicherheit können bisher nur Th, maculigera des Philippinischen Meeres, und Th. carinata $^{1}$ ) des Indischen zu der Gattung hingefuhrt werden; hierzu kommen jetzt die untenstehenden.

I. Thordisa tristis Bgh. n. sp. Taf. XV, Fig. I $7-21$.

Am Ankerplatz von Pulu Jedan an der Ostkuiste der Aru-Inseln (St. 273) wurde aus einer Tiefe von IO M. ein Individuum gefangen. 
Dasselbe war stark erhärtet und verbogen, von einer Länge von etwa $17 \mathrm{~mm}$. bei einer Breite von 15 und Höhe von 5; die Breite des Rückengebräms war 3, die Höhe der Rhinophorien I und der Kieme 2,5 mm., die Breite der Kiemenspalte bei zuriickgezogener Kieme I,5; die Breite des Fusses 6, seines Gebräms 2 und die Länge des Schwanzes 3 mm. - Die Farbe der Riickenseite war grau, dunkler marmorirt und am Rande mit durchschimmernden, fast schwärzlichen Flecken, die Rhinophorien und die Kieme sowie die ganze Unterseite gelblichweiss.

Die Formverhältnisse die gewöhnlichen. Der Rücken ganz dicht und fein spitz-nöppig, (kurz-villös), das Gebräm ringsum den Unterkörper überragend. Die Rhinophorien klein, die Kieme aus 6 Blättern gebildet; die kleinen Tentakel fingerförmig; der Schwanz hinten etwas zugespitzt.

In den Blättern der Rhinophorien wurden Spikel nicht gesehen. Die Haut brauste kaum mit Essigsäure auf und schien keine Spikel zu enthalten; ringsum den Fuss der O, IO-O, I 2 mm. hohen Nöppchen standen mehrere dieselben überragende feine Fäden (Fig. I 7). In der Haut des Rückens überall dicht gedrängte Gruppen von schwarzem Pigment und schwarz pigmentirten Zellen.

Die Mundröhre $1,5 \mathrm{~mm}$. lang. Der Schlundkopf kurz, gedrungen, $2 \mathrm{~mm}$. lang und mit noch fast I mm. hervorragender Raspelscheide; die Lippenscheibe von gelblicher Cuticula ïberzogen. In der farblosen Raspel der Zunge 19 Zahnplattenreihen und in der-Scheide deren noch 23, die Gesammtzahl der Reihen somit 42. In den Reihen wurden bis 33 Zahnplatten gezählt. Dieselben waren farblos und erreichten eine Höhe bis $0,14 \mathrm{~mm}$, die der äussersten war 0,04 . Sie hatten die gewöhnliche Hakenform, mit sehı spitzem Haken (Fig. IS, I9); die 5-6 äussersten waren ganz dünne, am Rande pinselartig denticulirte Blätter (Fig. 20, 2 I).

Die Leber ein wenig abgeplattet, gelblichweiss, $7 \mathrm{~mm}$. lang bei einer Breite von 5. Die Blutdruisen weisslich.

Die vordere Genitalmasse ein wenig zusammengedrückt, von $5 \mathrm{~mm}$. Länge, weisslich und gelblich; die Samenblasen wie gewöhnlich, der Penis unbewaffnet.

Diese Form ist ganz sicher eine Thordisa und eine der typischen Th. maculigera des Philippinischen Meeres nahestehende.

2. Thordisa hilaris Bgh. n. sp. Taf. V, Fig. 9. Taf. XV, Fig. 22-25.

Auf einem Riff bei Saleyer (St. 213) wurde ein Individuum gefangen und nach dem Leben abgebildet.

Das lebende Thier hatte eine Länge von $2,6 \mathrm{~cm}$. bei einer Breite bis 1,5. Die Farbe der Rückenseite war gelblichroth mit zahlreich zerstreuten gräulichen Punkten, die Rhinophorien dunkler, die Kieme heller.

Das aufbewahrte Individuum war $18 \mathrm{~mm}$. lang bei einer Breite von I I und Höhe bis $5 \mathrm{~mm}$; die Weite des querovalen Kiemenloches (bei zuruickgezogener Kieme) 2,5 mm.; die Breite des Rückengebräms bis 4 , die des Fusses bis $7 \mathrm{~mm}$. Die Farbe war durchgehends schmutzig brïunlichgrau, die Unterseite des Rückengebräms fein grau punktirt. Die Consistenz weich. 
Die Form oval, etwas niedergedrückt, der Rücken eben, das Gebräm etwas wellenförmig; die Kieme aus $6(7) 2 \mathrm{~mm}$, hohen Blättern gebildet.

Das graue Centralnervensystem zeigte die pedalen Ganglien an der Aussenseite der cerebro-pleuralen liegend. - Die 'Rückenhaut mit kleinen, bis $0,10 \mathrm{~mm}$. hohen, cylindrischen (Fig. 25) oder kurz keulenartigen Villi bedeckt, die auch von diunnen Fäden umstellt waren. Die Haut zeigte eine Menge von meistens in unregelmässigen Sternformen geordneten langen, glatten, wenig verkalkten, gelblichen Spikeln, die einen Durchmesser bis 0,025 mm. erreichten.

Die graue Mundröhre ein wenig kürzer als der Schlundkopf, der auch grau war, $3 \mathrm{~mm}$. lang; die Lippenscheibe von dicker, gelblicher Cuticula überzogen. Die gelbliche Raspel zeigte 22 Zahnplattenreihen, in der dicken Scheide fanden sich deren noch I 8 , die Gesammtzahl der Reihen somit 40; in den Reihen kamen bis 3 I Platten vor. Dieselben waren von der gewöhnlichsten Hakenform (Fig. 22), der Haken eine Höhe bis $0,10 \mathrm{~mm}$. erreichend; die $6-8$ äussersten in der Spitze pinselartig (Fig. 23), der innerste derselben constant mit Andeutung eines kleinen Hakens, der äusserste mitunter ohne Pinsel (Fig. 23a); die Höhe der 5 äussersten betrug 0,05-0,08-0,09-0,09 und $0,10 \mathrm{~mm}$.

Die Speiseröhre $4 \mathrm{~mm}$. lang, der sackartige Magen von einer Länge von 5 . Die hintere Eingeweidemasse (Leber) $7 \mathrm{~mm}$. lang, gelbgrau.

Die Blutdrüsen grau, die vordere längsliegend, oval; die hintere etwas kleiner, querliegend.

Die vordere Genitalmasse gräulich und weisslich, Meniscusförmig, 4,5 mm. lang. Der graue Penis I mm. lang.

Diese Form ist vielleicht von der vorigen verschieden, die Beschaffenheit der äussersten Zahnplatten scheint solches anzudeuten.

3. Thordisa ? maculosa. Bgh. n. sp. Taf, XV, Fig. $26-28$.

Bei Pulu-Kabala-dua, Borneo-Bank (St. $79^{\mathrm{b}}$ ) wurde ein Individuum erbeutet.

Aufbewahrt hatte das etwas zuzammengezogene, ziemlich weiche Individuum eine Länge von $I_{5}$ bei einer Breite von I I und Höhe von $+\mathrm{mm}$; die Breite des Rückengebräms 3, des Fusses $4 \mathrm{~mm}$. Die Farbe war röthlichgelb; der eigentliche Rücken trug der Länge nach 2 Reihen von je drei eckig-rundlichen schwarzen Flecken von meistens I,5 mm. Durchmesser, median vor den Rhinophorien noch ein Fleck und ein hinter der Kieme; dazu kamen noch zerstreute kleinere Flecken vor, besonders am Gebräm, meistens quergerichtet und confluirend; am Fussrande eine Reihe von kleinen schwarzen Flecken. Der Rücken war überall mit kleinen kegelförmigen oder cylindrischen Papeln von einer Höhe bis $0,0 \$$ mm. bedeckt. - Der Fuss vorne gerundet, die kleinen Tentakel fingerförmig. Die $2 \mathrm{~mm}$. hohe Kieme aus 6 Blättem mit schwärzlichen Rhachides gebildet.

Der röthlichgelbe Schlundkopf 2,5 mm. lang; die Lippenscheibe mit starker gelber Cuticula. An der gelblichen Raspel I4 Zahnplattenreihen, in der Scheide deren noch I3, die Gesammtzahl der Reihen somit 27 ; in den Reihen kamen bis 45 Platten vor. Die Zahnplatten fast farblos; die Höhe der 3 äussersten betrug $0,035-0,05-0,06$ und die Höhe der Platten 


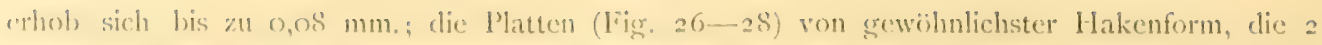
itussersten klein, schwach, fast blattatige (lïg, 28 ar $)$.

Diese liorm scheint auch von der T\%. maculigera des l'hilippinischen Mecres verschiecien ${ }^{3}$ ).

\section{Halgerda Bglı.}

R. BBRcil, Beitr. zur Kennen. der Japan. Nudibr. I. Verh, d. k. k. zool. bot. Ges. in IVien. XXX, I8so, 1), roo-195. Taf. $1 \mathrm{~V}$, lig. 15-20; Taf. V, lïg. 10-12.

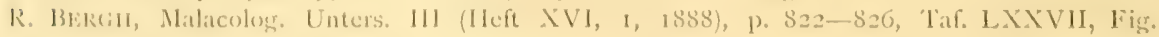
$10-11$; Taf. I.XXX1, lig. $13-17$.

Eitor, On some Nudibanchs from last Africa and Zanzibar. Proc. zool. soc, 1903, 11, 1). $372-374$.

Corpus sublepressum, subrigidum, cancellato dorso. Branchia paucifoliata, foliis tripinnatis. Tentacula parva, conica.

Armatura labialis nulla. Lingua rhachide anerusta nuda, pleuris multiseriatis et multidentatis, dentibus hamatis, externis interdum serrulatis. - Prostata magna, penis inermis.

Die llalgerden") haben einen etwas niedergedrückten, etwas steifen körper mit gefeldertem Rieken. 1)ie Kieme ist aus wenigen, dreifach gefiedenten Blittern gebildet. Die Tentakel kein, kur\%-kegelformig. - Die Lippenscheibe ist von einer einfachen Cuticula iblorzogen. Die schmale Rhachis der Raspel ist unbewaffnet; die Pleurac tragen zahlreiche Zahnplattenreihen und viele Zahnplatten in den Reihen; die Zahmplatten hakenfömig, die äussersten mit feinzackiger Splize. - lis komme eine stark entwickelte Prostata vor, ded P'enis ist unbewaffnet.

Die Stellumg dieser Gattung im System der cryptobranchiaten Dorididen ist sehr zwcifelhaft.

Abgeschen von den nenen, hierhergehörigen Arten sind bisher folgende bekannt:

1. Malgerdir formesa ligh. M. africano-indic. (Mauritius).

2. Halgerda elegerns Bgh. 11. sp. M. indicum.

3. Mergereda rubar Begh. n. sp. M. indicum.

4. Ilatgerda II illeyi Eliot. M. africano-indic.

5. Mlalecred II asimensis liliot. M. africano-indic.

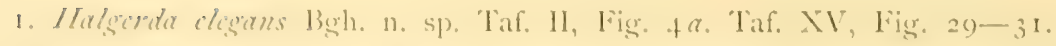

Am 12 liebr. warde $2 \%$ Mleilen von der Küiste des Gunong-Api (St. 310 ) cin Individumm gefangen, nach dem Leben gezeichnet und in formol bewahrt.

Dasselbe hatte lebend, der \%eichmung nach, eine Linge von it bei ciner Breite von $6 \mathrm{~mm}$. Die Grundfarbe des Rückens scheint hell grinlich gewesen zu sein, und die der den Riicken durchzichenden Balken gell); das Riickengebräm ist von queren schwarzen Streifen

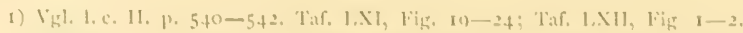

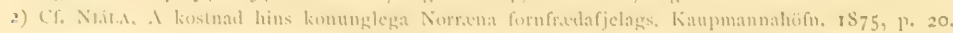

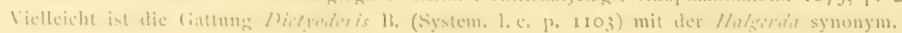




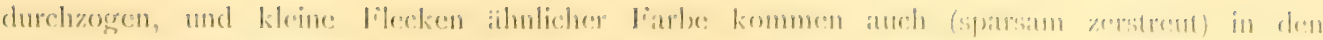
fiektern des Riokens vor; die Rhinophorien und die: Kieme schwarkhann.

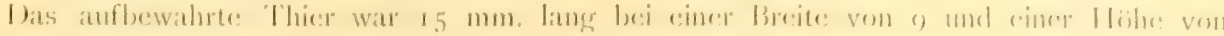

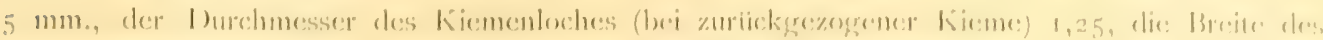

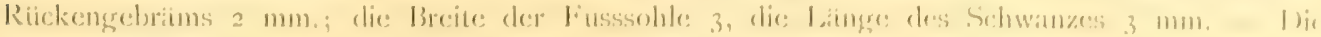

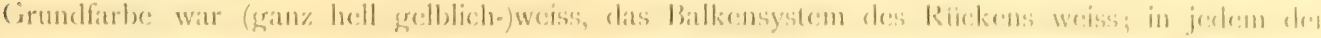

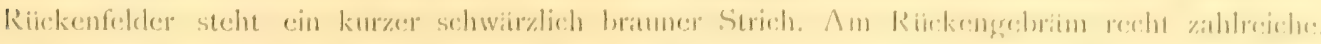

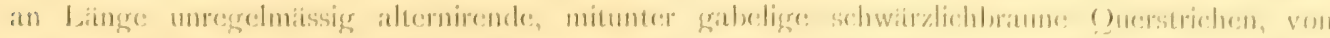

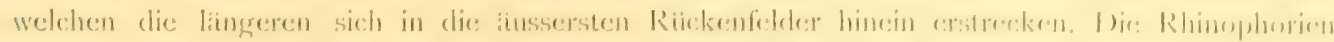

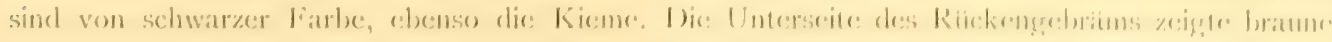

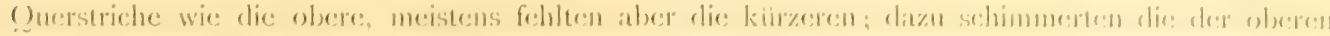

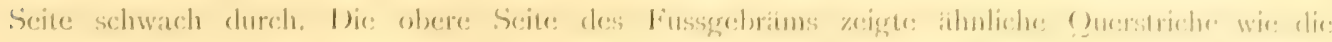

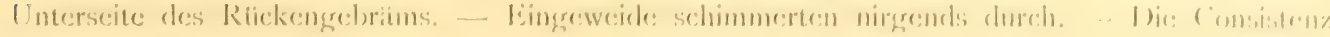
etwas steif, aber nicht hart.

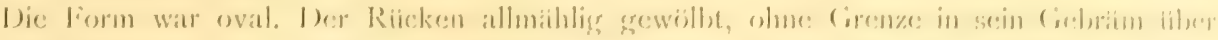

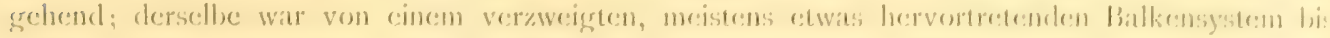

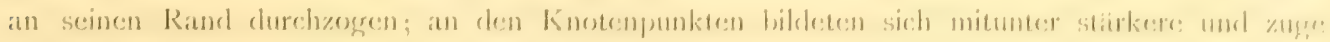

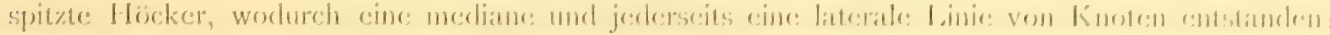

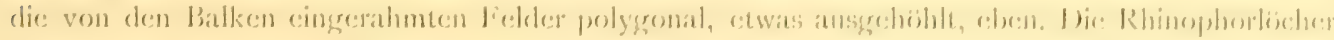
grlattrandig; die $1,5 \mathrm{~mm}$. hohen Rhinophorien truesen am Sticle: melurere: braume Strichedehen unel

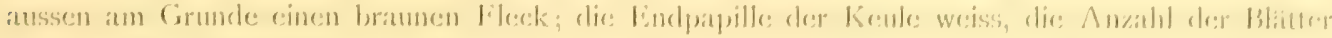

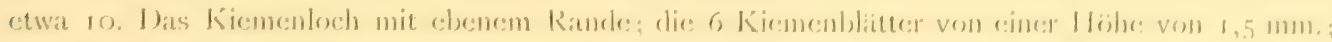

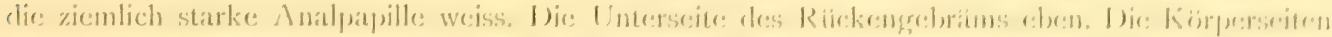

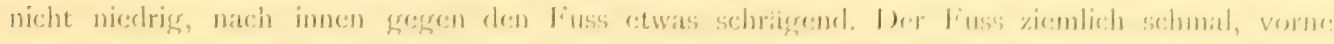

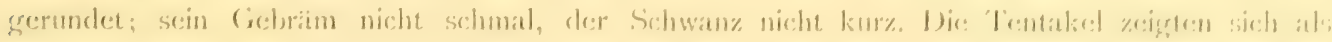
Heine Heicker.

1)as Centralnervensystem gan\% wir: friber beschrieben, bic: fast sacsilen Augen von

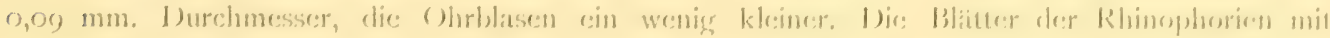

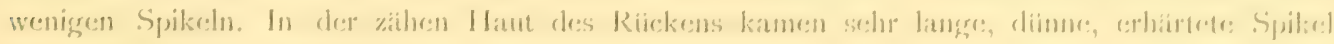
zorerstreut meluen kleinceren vor.

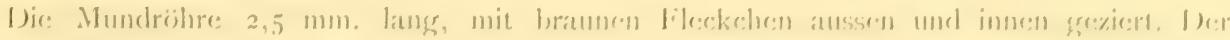

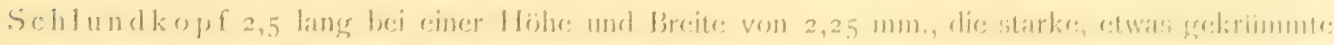

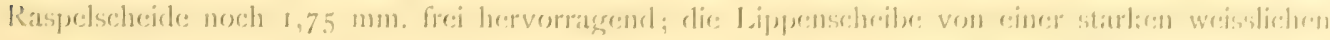

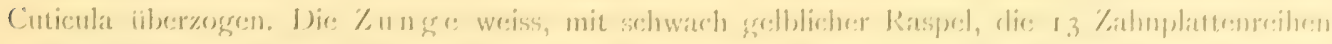

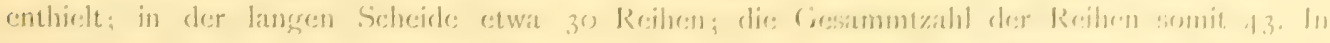

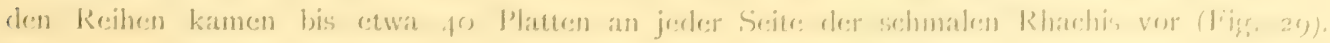

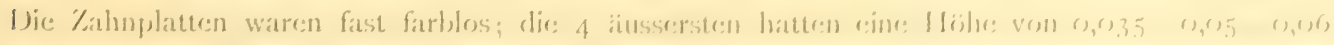

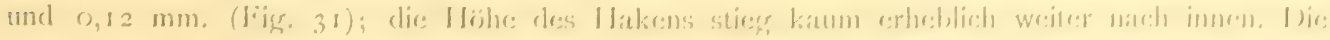

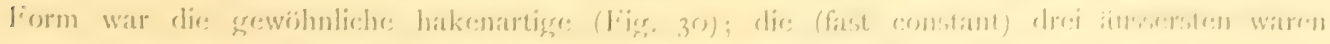

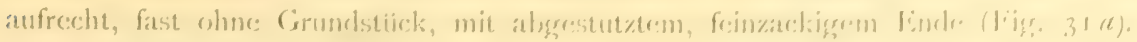

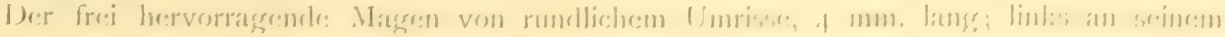


Grunde die (wegen ihres Inhalts) braune, grosse Gallenblase, deren bloss liegende Facette einen Durchmesser von $0,75 \mathrm{~mm}$. hatte. Die hintere Eingeweidemasse (Leber) kurz, hinten gerundet, $6 \mathrm{~mm}$. lang bei einer Breite vorne von 4, aussen weisslich, auf Schnitten braunlichgelb. In der Zwitterdruse keine reifen Geschlechtselemente; die vordere Genitalmasse ganz atrophisch.

Diese Form ist von der friher beschriebenen vielleicht verschieden.

Halgerda elegans Bgh. var.? Taf. II, Fig. 4b. Taf. XII, Fig. 36-40.

Unweit von der Küste von Gunong-Api (St. 3 10 ) wurde ein Individuum mit einer Phyllidia zusammen erbeutet.

Dasselbe scheint lebend ein wenig kürzer und etwas breiter gewesen zu sein; die Grundfarbe des Rückens war auch grünlichgrau, statt des gelben Balkenwerks kamen aber nur ziemlich grosse gelbe Flecken vor, noch dazu kleine schwarze Striche, am Rückengebräm nur einzelne schwarze Querstriche; die Rhinophorien und die Kieme schienen schwarz.

Das a ufbewahrte Individuum hatte eine Länge von I 3 bei einer Breite von 8 . und einer Höhe von $6 \mathrm{~mm}$.; der Durchmesser des Kiemenlochs 2, die Breite des Fusses $2 \mathrm{~mm}$. Die Grundfarbe war milchweiss, am Rücken kamen sparsam zerstreute Fleckchen und Striche vor; die Rhinophorien und die Rhachides der Kieme schwarz; an der Unterseite des Rückengebräms, und besonders der Körperseiten schwarze Flecken.

Am Rücken fanden sich 3 Reihen von gerundeten Knoten, eine mediane und jederseits eine laterale, am Gebräm noch einige kleinere, vor den klaffenden runden Rhinophoröffnungen ein medianer Knoten und hinter der (ähnlichen) Kiemenöffnung 2 laterale. Die Knoten durch niedrige Leisten verbunden, und der Rücken dadurch undeutlich gefeldert.

Die Mundröhre $2 \mathrm{~mm}$. lang. Der Schlundkopf zusammen mit der stark vorspringenden rechts gerichteten Raspelscheide $5 \mathrm{~mm}$. lang. In der gelblichen Raspel 20 Zahnplattenreihen; in der Raspelscheide, die doppelt so lang wie die Raspel war, 22, von welchen die 2 hintersten unreif; die Gesammtzahl der Reihen somit 42. An jeder Seite der ganz schmalen Rhachis bis 65 Platten. Die Platten farblos; die Höhe der 5 äussersten war $0,013-0,02-0,03-0,045-0,08$ und stieg bis 0,28 um in der ungefähren inneren Raspel-Hälfte bis auf etwa 0,035 zu sinken. Die Form die gewöhnliche (Fig. 36-40); die 3-4 äussersten im Rande gezähnelt, aufrecht (Fig. 40):

Vielleicht liegt hier nur eine Varietät der Halgerda clegans vor.

2. Halgerda mubra Bgh. n. sp. Taf. IV, Fig. 2. Taf. XV, Fig. $34-36$.

Aus einer Tiefe von 36 M. wurde bei Bandas ein Individuum erbeutet und lebend abgebildet.

Lebend hatte dasselbe eine Länge von $5 \mathrm{~cm}$. bei einer Breite von 2,5; der Durchmesser des Kiemensterns war 1,5 cm. Die Farbe der Rückenseite war lebhaft roth, an der Grenze des eigentlichen Rückens $3(-4)$ grössere, sternartige gräulichweisse Flecken; das Laub der Kieme gelb mit braunen Strichelchen.

Das a ufbewahrte Individuum zeigte eine Länge von $4 \mathrm{~cm}$. bei einer Breite von 2,2 und einer Höhe von I, I; die Breite des Rückengebräms war $6 \mathrm{~mm}$., die Breite der querovalen 
Kiemenspalte 7 , die Höhe der (zurückgezogenen) Kieme $5 \mathrm{~mm}$; die Länge des fiusses $3 \mathrm{~cm}$. bei einer Breite vorne von 6 , hinten von $9 \mathrm{~mm}$., die Breite des F'ussgebräms $1,25 \mathrm{~mm}$. Die Farbe war durchgehends schmutzig gelblich; am Ruicken kamen sparsam zerstreute schwarze Punkte vor, meistens an der Spitze der kleinen Kegel. Die Keule der Rhinophorien röthlich. Das Laub der Kieme gelblichweiss mit brïunlichen Rhachides.

Die Form war länglich-oval, hinten etwas breiter; das Rückengebräm ziemlich breit, wellenartig gebogen; die Kieme aus 8 Blättern gebildet; am Rücken kamen 3 Reihen von wenigen kleinen Kegeln vor, die hinterste mediane derselben entwickelte sich gleichsam in einen niedrigen Rahmen um eine $(5 \mathrm{~mm}$. lange) ovale Fläche (welche auch am lebenden Thiere deutlich gewesen ist); am Gebräm kamen sie zerstreut und reichlicher vor, oft auch hier kleine eingerahmte Felder bildend. Die Tentakel waren kurze Kegel. Die Körperseiten ziemlich niedrig. Der Fuss nicht breit, vorne schmäler als am gerundeten Hinterende. - Die Consistenz steif.

Das kleine röthlichgelbe Centralnervensystem von $2 \mathrm{~mm}$. Breite. Die Augen von 0,14 mm. Durchmesser. Die dünnen Blätter der Rhinophorien durch lange verkalkte Spikel steif gemacht. Die Haut enthielt überall, besonders die des Ruickens mit seinen Kegelchen, eine Unmasse von stark verkalkten, meistens langen, stabförmigen Spikeln von einem Durchrnesser bis wenigstens $0,02 \mathrm{~mm}$. Auch in der interstitiellen Bindesubstanz kamen solche reichlich vor, auch in den Wänden der Ausführungsgänge des Genitalapparats und in der Genitalpapille.

Der gelbliche Schlundkopf $5 \mathrm{~mm}$. lang bei einer Breite von 5 und einer Höhe von 3 ; die Lippenscheibe von starker farbloser Cuticula überzogen. In der gelblichen Raspel der Zunge 22 Zahnplattenreihen, in der Scheide deren noch 23, von welchen die 3 hintersten unreif; die Gesammtzahl der Platten somit 45. Zu jeder Seite der fast verstrichenen Rhachis bis etwa 60 Zahnplatten. Dieselben waren sehr schwach gelblich; die Höhe der innersten betrug etwa $0,12 \mathrm{~mm}$., die Höhe der Platten stieg bis 0,20 ; die der 7 äussersten war $0,08-0,10-$ $0,12-0,12-0,14-0,16-0,18 \mathrm{~mm}$. Die Zahnplatten hatten die gewöhnliche Hakenform (Fig. $34,35)$; die 4 äussersten waren ganz schwach, fast ohne Grundplatte, an der Spitze schräge abgestutzt, Serrulirung wurde aber nicht gesehen (Fig. 36).

Die weissen Speicheldrüsen nicht lang, etwas abgeplattet.

Der stark hervorragende Magen II mm. lang bei einer Breite von 8, leer. - Die hintere Eingeweidemasse $20 \mathrm{~mm}$. lang bei einer Höhe und Breite von IO. Die gelbe Leber mit Ausnahme des Vorderendes von dem dünnen, weissgelben, gleichsam etwas gefelderten Lager der Zwitterdrüse bedeckt. In den Läppchen der letzteren reife Geschlechtselemente. — Die Niere sehr stark entwickelt.

Die ziemlich zusammengedrückte vordere Genitalmasse $\mathrm{r} 2 \mathrm{~mm}$. lang, weisslich und gelb; der erhärtete Zustand derselben gestattete keine genauere Untersuchung derselben. Der fast $2 \mathrm{~mm}$. lange Penis ganz bestimmt unberwaffnet. Neben dem Vestibulum schien eine rundliche, im Durchmesser I $\mathrm{mm}$. haltende, gelblichbraune Drüsenmasse (mit grossen Drüsenzellen) vorzukommen.

Diese Form scheint trotz der viel geringeren Felderung des Rückens der Gattung Halgerda anzugehören. 
3. Halgorda inornata Bgh. n. sp. Taf, XV, Fig. 32, 33.

Bei Beo, Karakelang-Inseln (St. I3I) wurde ein Individuum gefangen.

Aufbewahrt hatte dasselbe eine Länge von $3 \mathrm{~cm}$. bei einer Breite von 2,5 und einer Höhe von 0,6; der Durchmesser des Kiemensterns war $8 \mathrm{~mm}$., die Höhe der Kieme 7 ; die Breite des Rückengebräms 8 ; die Breite des Fusses 8 , die Länge des Schwanzes $\delta$ mm. Die Farbe war hell schmutzig gelblich, die des eigentlichen Rückens, des Fusses, der Rhinophorien und der Kieme grau.

Die Form war länglich oval, niedergedrückt, mit breitem Rückengebräm. Der eigentliche Rücken zeigte einen medianen und jederseits einen lateralen niedrigen Kamm; die Kämme waren durch schräge, querverlaufende ähnliche verbunden, die Schneidepunkte traten als gerundete Knoten hervor. Das wellenartig gebogene Rückengebräm zeigte ein ähnliches aber weniger vortretendes und mehr strangartiges Netzwerk, auch mit Knotenbildungen, und dasselbe schimmerte an der ebenen Unterseite des Gebräms durch. Die Kieme von 5 Blättern gebildet. Der Fuss lang, ziemlich schmal, vorn gerundet. Die Tentakel ziemlich kurz, fingerförmig. Die Consistenz ziemlich weich.

Das Centralnervensystem wie gewöhnlich. Die Rückenhaut zeigte uiberall zerstreut, ausser den grösseren Knoten kleinere; in diese so wie in jene stiegen Spikel hinauf. Das ganze Balkenwerk war von starken, schmutzig gelblichen, langen Spikel von einem Durchmesser bis $0,025 \mathrm{~mm}$. gebildet.

Die graue Mundröhre $3 \mathrm{~mm}$. lang. Der gräuliche Schlundkopf $3,25 \mathrm{~mm}$. lang, die Lippenscheibe von gelblicher Cuticula überzogen. Die gelbliche Raspel trug 2 I Zahnplattenreihen, in der Scheide deren noch I8, die Gesammtzahl der Reihen somit 39; in den Reihen kamen bis 55 Zahnplatten vor. Die Zahnplatten fast farblos; die Höhe der 3 äussersten betrug 0,04$0,06-0,7$, und die Höhe der Platten erhob sich bis zu 0,12 mm; ihre Form (Fig. 32) war die gewöhnliche hakenartige, die 2 äussersten waren schwach, mehr blattartig (Fig. 33a).

Die Speicheldrüsen lang und duinn, besonders nach hinten zu. - Der aus der Leberkluft stark hervorragende sackförmige, leere Magen $6 \mathrm{~mm}$. lang; der dünne Darm I $5 \mathrm{~mm}$. lang. Die hintere Eingeweidemasse kegelförmig, I3 $\mathrm{mm}$. lang bei einer Breite vorne von 6 , aussen gelblichgrau, auf Schnitten röthlichgelb. - Die Blutdruisen stark abgeplattet, dünn, gräulich. - Die etwas zusammengedrückte vordere Genitalmasse $6 \mathrm{~mm}$. lang, weisslich und gräulich.

Vielleicht ist diese Form von der H. rubra specifisch verschieden.

\section{Trippa Bgh.}

Trippa R. Bergh, l.c. II (Heft XII, I877), p. 543-546; - III (Heft XVII, I850), p. 904-908. Phlegmodoris R. Bergh, 1. c. II (Heft XIII, I878), p. 592-597.

Corpus sat molle; notaeum tuberculosum, grosse nodulosum vel villosum; tentacula parva. Glandulae ptyalinae parvae circa fundum tubi oralis externe insertae. 
Die Gattung Trippa, die sicherlich mit der generischen Gruppe Phlegmodoris identisch ist, gehört der Subfamilie Diaululidae an und hat wie die derselben angehörenden Formen den nicht ebenen Rücken, eine aus wenigen, tripinnaten Blättern gebildete Ǩieme und kleine Tentakel. Die Lippenscheibe ist unbewaffnet; die Rhachis der Raspel ist nackt und die Zahnplatten sind hakenförmig. Der Penis ist unbewaffnet.

Von den anderen Gattungen der Gruppe (Diaulula, Gargamella, Thordisa, Aldisa, Halgerda, Pcltodoris, Phialodoris) unterscheidet sich die Trippa durch ihre eigenthümlichen Rücken-Tuberkel, vor Allem aber durch die sonderbaren kleinen Glandulae ptyalinae an der A ussenseite des Grundes der Mundröhre.

Die Gattung scheint auf die warmen Meeresgegenden beschränkt zu sein. Nur ganz wenige Arten sind bekannt.

1. Trippa ornata B. M. indicum.

2. Trippa mephitica B. M. philippin.

3. Trippa arcolata (Ald, et Hanc.). M. indic, pacific.

ELIot, Notes on Tectibranchs and naked moll. from Samoa. Proc. ac. nat. sc. Philadelphia, Dec. I 899 , p. 519 ,

4. Trippa? spongiosa (Kelaart). M. indicum (Ceylon).

5. Trippa? hispida B. M. pacific. or.

Die Opisthobranchien d. Samml. Plate. Zool. Jahrb. Suppl. IV, 3, I898, p. 527-530, Taf. 30, Fig. 30-36; Taf. 3I, Fig. I-3.

6. Trippa Monsoni Eliot.

Eliot, On some nudibranchs from east Africa and Zanzibar. III. Proc. zool. soc. I903, II, p. 37 I, Pl. XXXII, Fig. 4 .

I. Trippe ornate Bgh. Taf. I, Fig. 6. Taf. XV, Fig. 37.

Trippa ornata Bergh. MIalakolog. Unters. II (Heft XII, 1877), p. 543-546, Taf. LVIII, Fig. 3-8.

Trippa ornata B. ELIOT, Nudibranchiata. Fauna and Geogr. of the Maldive and Laccadive Archipelagoes. II, I, I903, p. 358 .

Am $I_{4}$ Sptbr. wurde am Riffe der Sanana-Bai an der Ostküste von Sula Besi (St. I 93) ein Individuum gefangen, nach dem Leben abgebildet und in Formol bewahrt.

Das lebende Thier hat eine Länge von $37 \mathrm{~mm}$. bei einer Breite von is gehabt. Die Farbe der oberen Seite ist braun mit weisser Randlinie und einer starken, weissen, medianen Längslinie, die Rhinophorien waren schwarz.

Das a ufbewahrte Individu um hatte eine Länge von $27 \mathrm{~mm}$. bei einer Breite von I 8 und einer Höhe von IO; die Rhinophorscheiden ragten (bei zurückgezogenen Rhinophorien) $2 \mathrm{~mm}$. hervor, die Weite der Kiemenspalte war (bei zurückgezogener) Kieme $4 \mathrm{~mm}$; die Breite des Rückengebrämes 6, die des Fusses bis $7 \mathrm{~mm}$., die Länge des Schwanzes etwa $5 \mathrm{~mm}$. - Die Farbe war durchgehends schmutzig braungrau, heller an der Unterseite, eine hellere Randlinie war kaum angedeutet, dagegen zog sich über die ganze Länge des eigentlichen Rückens bis an das Kiemenloch ein sehr ausgeprägtes $(0,75 \mathrm{~mm}$. breites) weisses Band. Die Consistenz des Thieres war ziemlich weich. 
Die Form war oval, ziemlich niedergedrückt, mit breitem Rückengebräm. Am Rücken kamen iberall zerstreut rundliche, am Grunde meistens ein wenig eingeschnürte, sonst fein höckerige Tuberkel yon einem Durchmesser von meistens $2-2,5 \mathrm{~mm}$. vor; zwischen denselben fanden sich kleinere vor und ganz kleine an den Rhinophorscheiden und an den Lippen der Kiemenspalte. Die Keule der Rhinophorien schwarz mit weisslicher Endpapille, I,75 mm. hoch, stark durchblättert. Die 6 Kiemenblätter von $3 \mathrm{~mm}$. Höhe, aussen mit weisslicher Rhachis, mit schwarzem Laub. Die Unterseite des Rückengebrämes eben. Am Aussenmunde eine Andeutung von Tentakeln. Der Fuss fast so lang wie der Rücken, vorne gerundet, durchgehends fast von derselben Breite, der Fussrand wenig vortretend.

Das Centralnervensystem gelblichweiss. Die Augen von einem Durchmesser von o, I 2, der der Ohrblasen war 0,16 mm. Die Blätter der Keule der Rhinophorien zeigten nur sparsame und wenig erhärtete Spikel. Auch die wieder mit feinen Höckerchen bedeckten Höckern waren weder übermässig mit Spikeln versehen, noch waren diese (jetzt) stärker erhärtet.

Das hell röthlichgelbe Mundrohr 2,5 mm. lang. Der Schlundkopf von derselben Farbe, 2,5 mm. lang bei einer Höhe und Breite von 3, die Raspelscheide nur eben aussen sichtbar; die Lippenscheibe von einer röthlichgelben Cuticula ibberzogen. Die breite Zunge mit gelber Raspel, welche etwa is Zahnplattenreihen enthielt, in der Scheide kamen deren noch 16 vor, die Gesammtzahl derselben somit 31. In den Reihen wurden etwa 30 Platten gezählt. Die Zahnplatten waren hell gelblich, von gewöhnlichster Hakenform (Fig. 37), der Haken erreichte eine Höhe bis 0,16 mm., die der zwei äussersten betrug meistens 0,035 und 0,04 .

Die Speiseröhre röthlichgrau. Die hintere Eingeweidemasse wurstförmig, $16 \mathrm{~mm}$. lang bei einem Durchmesser von \$; auf Schnitten dunkel schmutzig chocoladefarbig, an der Oberfläche war die Farbe fast verdrängt durch das nicht dünne, gelbweisse Lager der Zwitterdrüse. In den Läppchen derselben reife Geschlechtselemente. Die vordere Genitalmasse rundlich, etwas zusammengedrückt, von $5 \mathrm{~mm}$. grösstem Durchmesser, gelbweiss; die genitalen Ausführungsgänge rothbraun ${ }^{1}$ ).

So weit nach der ungenügenden Untersuchung geurtheilt werden kann, ist die hier untersuchte Form die Trippa ornata, die auch aus demselben Meeresgegenden stammt.

Ein ganz ähnliches, bei einer Breite von 19 etwa $25 \mathrm{~mm}$. langes Individuum wurde am I 7 Jan. zwischen Nusa Besi nnd der östlichen Spitze von Timor (St. 282) am Riffe gefangen.

In der Badjo-Bai an der Westkiiste von Flores (St. 50) wurde noch ein Individuum erbeutet, das wegen seines etwas abweichenden Äusseren genauer untersucht wurde. - Die Farbe war durchgehends röthlichgelb, so auch der ziemlich starke Rückenkamm, nur die Rhinophorien und die Kieme schmutzig braun. Die Länge betrug is mm., die Höhe der Rhinophorien 2, der (5) Kiemenblätter 2,5, die Breite des Rückengebräms $3 \mathrm{~mm}$. Die Rückenknoten ziemlich gross, stark abgestutzt, gleichsam dornig; die Tentakel kurz fingerförmig. — Die Mundröhre $2 \mathrm{~mm}$. lang, die Drisemassen am Grunde derselben kaum angedeutet. Der Schlundkopf $2,5 \mathrm{~mm}$. lang, die Lippenscheibe mit starker gelber Cuticula uiberzogen; die gelbliche Raspel 
mit I 3 Zahnplattenreihen, in der Scheide deren 14, die Gesammtzahl der Reihen somit 27; in den Reihen kamen bis 32 Platten vor; die Zahnplatten wie oben. Die Länge des sackartigen Magens 5; die der kurz schlauchartigen, gelblichgrauen hinteren Eingeweidemasse 8 mm.

2. Trippa affinis Bgh. n. sp. Taf. XV, Fig. $38-42$.

Trippa ornata Bgh. R. BerGH, 1. c. III (Heft XVII, I89o), p. 905-9oS. Taf, LXXXV, Fig. 7; Taf. LXXXVII, Fig. $16-22$.

Bei dem Ankerplatz von Seba, Savu (St. 58) wurde am 25 April auf Sandboden ein Individuum erbeutet.

Dasselbe hatte in Formollösung bewahrt, sehr stark zusammengebogen und erhärtet, eine Länge von $6 \mathrm{~cm}$. bei einer Breite bis 3,5 und einer Höhe bis $2 \mathrm{~cm}$. Die Breite des Ruickengebrämes betrug $\mathrm{I}_{4} \mathrm{~mm}$; die Höhe der Rhinophorscheiden $5 \mathrm{~mm}$, die der Keule der stark zurückgezogenen Rhinophorien 5; die Höhe der Rückenknoten bis $4 \mathrm{~mm}$. betragend; die Breite der querovalen Kiemenspalte $1+$ mm., die Höhe der tief zurückgezogenen Kieme 8 mm.; die Länge des Fusses etwa $4,75 \mathrm{~cm}$. bei einer fast durchgehenden Breite von $2 \mathrm{~cm}$, die Breite des Fussgebräms $6 \mathrm{~mm}$., die Länge des Schwanzes 6. - Die Farbe war durchgehends schmutzig dunkel grau oder gelblichgrau. - Die Consistenz des Thieres ursprünglich wahrscheinlich nicht hart.

Die Form des Thieres oval, etwas niedergedriickt, mit breitem Rückengebräm. Der Rücken überall mit dichtstehenden, (jetzt) an einander stossenden, (bis 4) hohen und (bis $6 \mathrm{~mm}$.) breiten Knoten bedeckt, die oberflächlich in kleinere Lappen getheilt waren, welche wieder feinste Nöppchen zeigten; gegen den Rückenrand hin waren die Knoten kleiner und mehr einfach; die Aussenseite der stark vortretenden Rhinophorscheiden und die Aussenseite des etwas umgeschlagenen Randes der Kiemenspalte fein noppig. Die Keule der Rhinophorien stark durchblättert. Die Kieme aus 5 deutlich geschiedenen tripinnaten Blättern gebildet; hinten im Kreise die $3,5 \mathrm{~mm}$. hohe Analpapille, die aus am Grunde verschmelzenden fingerähnlichen Lappen bestand. Tentakel waren als kleine Lappen angedeutet. Der Fuss vorne und hinten gerundet.

Innerhalb der zähen, fest anhängenden, etwas sparsam körnig schwarz pigmentirten Kapsel das $4 \mathrm{~mm}$. breite Centralnervensystem, dessen Ganglien wenig deutlich von einander geschieden waren. Die in eine gemeinschaftliche enge Scheide gehiullten Commissuren nicht zwei Mal so lang wie die Breite der Ganglien.

Die fast sessilen A ug en von ovaler Form, von $0,25 \mathrm{~mm}$. Länge, mit grosser sehr hellgelblicher Linse. Die Otocysten von etwa O, $6 \mathrm{~mm}$. Durchmesser, mit klaren Otokonien gefuillt. Die Blätter der Keule der Rhinophorien steif wegen der Menge von langen und stark erhärteten Spikel. Die Haut des Rückens mit sammt den Nöppchen der Tuberkel mit oft langen, immer stark erhärteten Spikeln überfüllt, die einen Durchmesser bis $0, \mathrm{O}_{4} \mathrm{~mm}$. erreichten.

Die hinten an der Aussenseite hell bläulichgraue, an der Innenseite bräunlichgraue Mundröhre I I mm. lang bei einer Breite hinten von 7,5; am Grunde derselben hefteten sich jederseits 
zwei starke Retractoren. Dicht vor den Insertionsstellen dieser letzteren oben jederseits 5 kleine gelbliche, meistens kurz-fingerige drüsige Organe (Gl. ptyalinae) von einem grössten Durchmesser von I-I,5 mm. Der mächtige, weisse Schlundkopf von einer Länge von I 2 bei einer Breite bis 9 und Höhe von $8 \mathrm{~mm}$; die dicke Raspelscheide stark hinten an der Unterseite vorspringend. Die grosse Lippenscheibe von einer schwach gelblichen (bis $0,05 \mathrm{~mm}$. dicken) Cuticula überzogen. Die sehr starke Zunge mit gelber Raspel. In dieser letzteren kamen I 2 Zahnplattenreihen vor; in der Scheide noch 20, von welchen die 3 unreif; die Gesammtzahl der Reihen somit 32. In den Reihen fanden sich zu jeder Seite der ganz schmalen nackten Rhachis bis $5^{\mathrm{I}}$ laterale Platten. Dieselben waren gelb. Die Höhe der zwei innersten betrug meistens nur 0,06 und $0,08 \mathrm{~mm}$; die Höhe des Hakens der Platten stieg bis zu 0,45 bei einer Länge des Grundstückes von $0,55 \mathrm{~mm}$; die Höhe der leicht abfallenden äussersten Zahnplatte betrug nur 0,08 , der folgenden 0,16 bei einer Länge von $0,20 \mathrm{~mm}$. Die innersten meistens 5 Zahnplatten (Fig. 38) klein und von eigenthümlicher Form, besonders die zwei innersten, mit kurzem Grundstuicke. Sonst waren die Zahnplatten (Fig. 39, 40) von gewöhnlichster Hakenform, die äussersten kleiner, besonders die (leicht abfallende) äusserste (Fig. 39a).

Die weissen Speicheldrüsen etwa I $6 \mathrm{~mm}$. lang, in ihrer vorderen ungefähren Hälfte flach, bis $3 \mathrm{~mm}$. breit, in der hinteren viel dünner.

Die Speiseröhre I $4 \mathrm{~mm}$. lang bei einer fast durchgehenden Breite von 3. Der Magen weit aus der kurzen und breiten Leberkluft hervorragend, I4 $\mathrm{mm}$. lang bei einer Breite von IO, mit Speisebrei gefüllt; der Darm $4,5 \mathrm{~cm}$. lang bei einem Durchmesser von $\mathrm{I}-2 \mathrm{~mm}$. Der Inhalt des Magens schien aus Spongienmasse, mit einer Unmenge von spitzen Nadeln ausgestattet, gebildet.

Die hintere Eingeweidemasse (Leber) $2,4 \mathrm{~cm}$. lang bei einer Breite von $\mathrm{I}, 4$ und einer Höhe von $1 \mathrm{~cm}$; sie war grünlichgelb mit vielen verzweigten helleren Strichen (der Zwitterdrüse), vorne schräge abgestutzt und (für den Magen) etwas ausgehöhlt; hinten gerundet. - Die links unter dem Magen liegende Gallenblase $6 \mathrm{~mm}$. lang, sackförmig, vorne von einem Durchmesser von $2 \mathrm{~mm}$., gelb.

Die obere Wand des I $3 \mathrm{~mm}$. langen Pericardiums rothbraun; die Herzkammer $5 \mathrm{~mm}$. lang. Die schmutzig chocoladebraune, abgeplattete Blutdrüse ro $\mathrm{mm}$. lang bei einer Breite vorne von 7 . - Die kurz-birnförmige Nierenspritze $3 \mathrm{~mm}$. lang.

In den Läppchen der hellen $Z$ witterdrüse reife Geschlechtselemente; die Ampulle des Ausführungsganges bildete mit ihren Windungen einen Knäuel an der inneren Seite der vorderen Genitalmasse. Diese letztere plan-convex, I I mm. lang bei einer Breite von 5 und einer Höhe von Io mm., weisslich und gelblichweiss. Der lange Samenleiter bildete einen Knäuel von Windungen und langen Schlingen, in den $4 \mathrm{~mm}$. langen grauen Penis (Vorhaut) endigend, dessen Innenseite schwärzlich war; die weissliche, fast cylindrische glans 1,5 mm. lang, unbewaffnet. Die ovale sackförmige Spermatotheke $5 \mathrm{~mm}$. lang, gräulich; die zestreckt-birnförmige Spermatocyste $6 \mathrm{~mm}$. lang, gelblichweiss. Die Vagina und der Ausführungsgang der Schleimdrüse aussen und innen schwärzlich.

Fast unzweifelhaft ist die hier untersuchte Form von der Trippa ornata verschieden, auch im Äusseren durch Fehlen des medianen Rückenbandes. 
Von derselben Form wurde in der Bai von Pidjot, Lombok (St. 33) ein Individuum gefangen, mit Essigsäure (55\%) behandelt und in Formol bewahrt.

Dasselbe war weich, $3,8 \mathrm{~cm}$. lang bei einer Breite von 2,5 und einer Höhe von I cm.: die Knoten des Rückens von einer Höhe bis 2 bei einem Durchmesser bis 4 mm.; die Rhinophorscheiden (bei zurickgezogenen Organen) $2 \mathrm{~mm}$. hoch, die Keule der Rhinophorien $2 \mathrm{~mm}$. hoch; die Weite der Kiemenspalte $5 \mathrm{~mm}$., die Höhe der Kiemenblätter 4; die Breite des Rückengebräms $9 \mathrm{~mm}$; die Länge des Fusses $3 \mathrm{~cm}$. bei einer Breite von I, die Breite des Fussgebräms $2 \mathrm{~mm}$, die Länge des Schwanzes 3. - Die Grundfarbe der Rückenseite war gelb weisslich, aber durch die nicht recht dichtstehenden graubraunen Knoten stark verdrängt, der Ruickenrand fast schwarz; die Rhinophorien schwarz mit weisser Spitze, die Kieme schwarz; die Unterseite des Körpers hell schmutzig gelb, die obere Seite des Fussgebräms schwärzlich, der Rand meistens schwarz.

Die Formverhältnisse die gewöhnlichen, am Rücken war ein medianer Kamm kaum angedeutet, gegen den Rückenrand hin standen die Knoten dichter und waren kleiner, der Rand der Rhinophorscheiden feinknotig, der stark hervortretende. Rand der querovalen Kiemenspalte mit lappig vorragenden Knoten, die Kieme aus 5 starken Blättern gebildet; Tentakel waren kaum angedeutet.

Das Centralnervensystem von braungrauer Farbe.

Die $2 \mathrm{~mm}$. lange Mundröhre aussen hell bläulichgrau, innen braungrau; am Grunde jederseits 4-5 durch gegenseitigen Druck länglich-weisse Drüsenkörper (Gl. ptyalinae). Der Schlundkopf von einer Länge, Höhe und Breite von $3 \mathrm{~mm}$., röthlichgrau, die Raspelscheide hinten etwas vorspringend. Die Zunge mit hell röthlichgrauer Raspel, welche ${ }_{1} 3$ Zahnplattenreihen enthielt, in der Scheide kamen noch 15 vor, die Gesammtzahl der Reihen somit 28. In den Reihen wurde bis 32 Zahnplatten gezählt. Die schwach gelblichen Platten ganz wie früher beschrieben; nur die innersten unregelmässig (Fig. 41), die äusserste klein und schlank (Fig. 42a).

Der wegen seines (spongiösen) Inhalts violetgrave $\mathrm{Magen}$ Io $\mathrm{mm}$. lang bei einem Durchmesser von 6; der Darm 2,3 cm. lang, in seinem vorderen Drittel doppelt so dick wie in der übrigen Strecke. - Die hintere Eingeweidemasse i $7 \mathrm{~mm}$. lang bei Durchmessern von IO; die Leber schwarzbraun, ganz von dem dünen Lager der gelben Zwitterdrüse überzogen; die Gallenblase $5 \mathrm{~mm}$. hoch bei einem Durchmesser von 2, wegen ihres Inhalt schwärzlichbraun.

Die vordere Genitalmasse zusammengedrückt-kugelförmig, $6 \mathrm{~mm}$. lang bei anderen Durchmessern von 5; rothbraun, gelb und gelblichweiss. Die Samenblasen fast von derselben Länge, die Spermatotheke weisslich, die Spermatocyste gelblich.

\section{Peltodoris Bgh.}

R. BERGH, System der nudibranch. Gasteropoden. 1. c. I892, p. Io99.

Eliot, On some Nudibranchs. III. I904. 1. c. p. $365-367$.

Corpus subrigidum, notaeo minutissime granulato.

Dentes pleurales hamati. 
Von der Gattung waren bisher 5 Arten bekannt:

I. Peltodoris atromaculata B. M. mediterr.

2. Peltodoris crucis (Örst.). M. antill.

3. Peltodoris manritiana B. M. africano-indic. (Mauritius).

4. Peltodoris? angulate Eliot. M. africano-indic.

5. Peltodoris? aurea Eliot. M. africano-indic.

r. Peltodoris mbescens Bgh. n. sp. Taf. III, Fig. 12. Taf. XVI, Fig. I-2.

Am Riffe an der Südspitze der Insel Kabaëna (St. 209) wurde ein Individuum gefangen und lebend abgebildet.

Lebend hatte dasselbe eine Länge von 28 bei einer Breite von $\mathrm{I}_{3} \mathrm{~mm}$. Die Farbe der Ruickenseite war gräulich-roth mit dunkleren Fleckchen und einer medianen Reihe von weissen Punkten; die Rhinophorien waren heller und die Kieme weisslich.

Das a ufbewahrte Individuum war $23 \mathrm{~mm}$. lang bei einer Breite von $\mathrm{I} 3$ und Höhe von 5; die Breite des Rückengebräms war 4, der Durchmesser des Kiemensterns auch 4 mm., der Fuss $17 \mathrm{~mm}$. lang bei einer Breite von 6,5. - Die Farbe war röthlichbraun wegen dichtstehender Fleckchen auf etwas hellerem Grunde, die obere Seite dunkler als die untere, weil die Fleckchen der letzteren kleiner waren; die Kieme weisslich.

Die Form war oval, etwas niedergedrückt, mit ziemlich breitem Rückengebräm, die Rhinophorien weit nach vorne stehend, die Kieme aus 6 Blättern gebildet, der Rücken äusserst fein noppig, der Rückenrand kaum wellenförmig; Tentakel als kleine Knoten angedeutet; der Fuss kürzer als der Rücken, vorne und hinten gerundet, der Schwanz ganz kurz ( I,5 mm. lang). Die Consistenz kaum steif.

Die kurzgestielten Augen von O, I 2 mm. Durchmesser, mit stark gelber Linse. Die Rhinophorien mit etwa 20 Blättern, die durch lange Spikel steif waren. Ähnliche (farblose) Spikel von einem Durchmesser bis wenigstens $0,03 \mathrm{~mm}$. kamen in der (Rücken-)Haut vor und stiegen in die (bis 0, I2 mm. hohen) Nöppchen hinauf.

Die aussen und innen schmutzig violette Mundröhre 2,5 $\mathrm{mm}$. lang. Der weisse Schlundkopf kurz, $3 \mathrm{~mm}$. lang. Die Lippenscheibe von einer starken Cuticula mit darunterliegendem sehr starkem Epithel überzogen. Die gelbliche Raspel der Zunge mit ${ }_{5}$ Zahnplattenreihen, in der Scheide deren noch 9, die Gesammtzahl der Reihen somit 24. In den Reihen bis 35 Zahnplatten an jeder Seite der schmalen Rhachis. Die blassen Platten durchgehends von der gewöhnlichsten Hakenform (Fig. I), die innerste $0,075 \mathrm{~mm}$. hoch, die Höhe der Platten stieg bis 0,14 , die der äussersten (Fig. 2), war nur $0,08 \mathrm{~mm}$.

Die weissen Speicheldrüsen wie gewöhnlich: - Der Magen kurz sackförmig, 4,5 mm. lang; der weissliche Inhalt aus Kieselschwammmasse gebildet. Der stark geschlängelte Darm $22 \mathrm{~mm}$. lang bei einem durchgehenden Diam. von 0,75. - Die aussen und innen braune Leber abgestutzt kegelförmig, Io mm. lang bei einer Breite von 5; links in ihrer Kluft die kolossale, sackartige, $3 \mathrm{~mm}$. lange, grüne Gallenblase.

Die vordere Blutdrüse dreieckig, die hintere queroval, beide weisslich. 
In den Läppchen des dünnen, in Farbe kaum von der Leber unterscheidbaren Lagers der Zwitterdriise keine reifen Geschlechtselemente. Die vordere Genitalmasse sehr wenig entwickelt, weiss, $1,5 \mathrm{~mm}$. lang; der Penis unbewaffnet.

\section{Platydorididae.}

R. Bergh, System d. nudibr. Gasteropoden. 1.c. I892, p. IIOO(-IIO3).

ELIOT, Nudibranchiata. 1.c. 1903, p. $555-556$.

Corpus applanatum, coriaceum, rigidum, fragile, circumferentia ovali vel rotundata; notaeo quasi laevi vel minutissime granulato, limbo dorsali lato; apertura branchialis ut plurimum paucilobata, stellata; tentacula digitiformia; podarium margine anteriori bilabiatum, labio superiore profunde fisso.

Armatura labialis nulla. Radula rhachide nuda, pleuris multidentatis, dentibus hamatis.

Prostata magna.

Diese durch die Form und Beschaffenheit des Körpers äusserlich schon ausgeprägte Gruppe umfasst die Gattungen Platydoris (B.), Asteronotus (E.) (und Dictyodoris (B.)).

\section{Platydoris Bgh.}

R. BERGH, System. I. c. I892, p. IIOI.

Eliot, On some Nudibranchs. III, 1904, l. c. p. 374-380.

Facies interna praeputii (sicut glans) orbiculis duris hamigeris armata; vagina armatura simili vel cuticula crassiori instructa.

Eine Reihe von (theilweise zweifelhaften) Arten ist angegeben (vgl. 1.c. p. I IO2-1 (103) $\left.{ }^{1}\right)$, auch einige der untenstehenden sind vielleicht nur Varianten einer ziemlich variablen Art.

1. Platydoris argo (L.)?? Taf. XII, Fig. 30-32.

Doris argo L. S. N. ed. XII. I767, I, 2, p. $108_{3}$.

Platydoris argo (L.). R. BERGH, Malacolog. Unters. I (Heft XII), I877, p. 497-503; Taf. LVIII, Fig. I-2; Taf. LIX, Fig. $1-10$.

Mit Exemplaren der Archidoris Kurana zusammen wurden bei der Insel Kur zwei (jetzt stark erhärtete) ganz gleichgrosse Individuen gefangen.

Dieselben hatten eine Länge von I7-18 mm, bei einer Breite von Io und Höhe von 4; die Rhinophorien $2 \mathrm{~mm}$. hoch, die Weite der Kiemenspalte bei ausgestreckten Blättern der Kieme 2, die Höhe derselben 3; die Breite des Rückengebräms $+\mathrm{mm}$; ; die Länge des Fusses I 3 bei einer Breite von 4, die Länge des Schwanzes $2,5 \mathrm{~mm}$. - Die Fiarbe des Rückens

1) Eltor, On some Nudibranchs III, 1904, 1. c. p. 374-3So (Pl. eurychlamys B.; 1'l. scatira (Cuv.); Pl. formosa (A. u. 1I.) var.; 1 l. pulchra E.; Pl.incerta E.; Pl. papillata E.). 
war ganz fein punktirt graubraun mit zerstreuten runden weissen Flecken (Fig. 3I); die Rhinophorien braun mit weisser Endpapille, die untere Hälfte der Kiemenblätter an der äusseren wie an der inneren Seite braun, sonst waren sie weisslich, die Unterseite des Rückengebräms gelblichweiss mit zahlreichen ganz feinen, graubraunen Flecken; der Fussrand graubraun.

Die Formverhältnisse die gewöhnlichen; der Rücken auch unter sehr starker Loupe ganz glatt; die Rhinophorlöcher so wie das Kiemenloch an den Rändern fein rundzackig; die Kieme 6-fiederig; die Tentakel (Fig. 30) fingerförmig.

Das Centralnervensystem wie gewöhnlich; der Durchmesser der Augen war O, I 5 mm., der Otocysten O, IO, mit Otokonien voll gepackt; die Blätter der Rhinophorien durch lange stark erhärtete Spikel steif. Die Haut mit langen, stark erhärteten Spikeln überfüllt, ähnliche überall in der interstitiellen Bindesubstanz.

Die starke weisse Mundröhre $2 \mathrm{~mm}$. lang. - Der weisse Schlundkopf 2,5 mm. lang; gedrungen, mit wenig vortretender Raspelscheide; die Cuticula der Lippenscheibe fast farblos. In der schwach gelblichen Raspel 20-I8 Zahnplattenreihen, in der Scheide noch 19-20, die Gesammtzahl der Reihen somit $39-38$; in den Reihen kamen jederseits etwa So Platten vor. Die Zahnplatten von gewöhnlicher Hakenform (Fig. 32, 32), eine Höhe bis o, ro mm. erreichend.

Die langen weissen Speicheldrüsen wie gewöhnlich. - Der kurz-sackförmige Magen $3 \mathrm{~mm}$. lang. Die hintere Eingeweidemasse (Leber) an der Oberfläche gelblichweiss, in der Substanz gelb, $5 \mathrm{~mm}$. lang bei einer Breite vorne von 4 .

Die gerundet-viereckigen Blutdrüsen grau.

Die Zwitterdrüse die Leber fast ganz überziehend, in ihren Läppchen reife Geschlechtselemente. - Die weisse vordere Genitalmasse convex-concav, 2,5 mm. lang, zum grossen Theil von der Prostata gebildet. Der Penis $3 \mathrm{~mm}$. lang bei einem Durchmesser von 0,25; ihre lange Höhle von einer sehr starken gelben Cuticula überzogen, die sich in einige (2-4) Längswilste erhebt, die sich in gerundete Höcker erheben, von welchen einige sich als die gewöhnlichen Dornentragenden Scheiben präsentirten; dieselben waren meistens von einer Länge von 0,20 bei einer Höhe von 0,16 mm. Die Vagina fast so lang wie der Penis, in ganz derselben Weise ausgefuttert; Dornentragende Scheiben wurden aber nicht gesehen. Eine kleine Vestibular-Drüse war dentlich.

Von den bekannten Arten der Platydoris scheint diese Form der Platydoris argo des Nittelmeeres am nächsten zu stehen.

2. Platydoris crucnta (Q. et G.). Taf. I, Fig. 3.

Doris cruenta Quoy et Gaimard. Voy. de l'Astrolabe. II, IS32, p. 260, PI. I8, fig. 5-7.

Platydoris arrogans Bgh. IIalacolog. Unters. III (Heft XVII, I890), p. 9I2-9I4, Taf. LXXXVI, Fig. 6; Taf. LXXXVII, Fig. 32-33.

Am i I Juni wurde am Riffe von Lumu-Lumu-Shoal am Borneo-Bank (St. 78 ) ein Individuum gefangen und nach dem Leben abgebildet.

Das Thier hatte lebend eine Länge von $8 \mathrm{~cm}$. bei einer Breite von 6. Die schwachgelblichweisse Farbe der Rückenseite zeigte sich überall von dichtstehenden, meistens der Länge 
nach gehenden, dünnen und nicht langen, schwärzlich grauen Strichen durchbrochen; ferner kamen hier sparsam zerstreute kleinere und grössere karminrothe Flecken vor.

Das zugehörige Glas war zerbrochen, und das Thier, ganz eingetrocknet, noch volle $7 \mathrm{~cm}$. lang bei einer Breite von 4 und einer Höhe von etwa $1,1 \mathrm{~cm}$.; die Breite des Kiemenlochs war I 4 und die Breite des Rückengebräms $16 \mathrm{~mm}$., die Breite des fast zusammengeklappten Fusses S. Die Farbe war jetzt kalkweiss; die feinen oft anastomosirenden grauen Striche am Rücken, besonders am Gebräme, fernerhin an der inneren Hälfte der Unterseite des Gebräms so wie an der oberen Seite des Fusses noch stark.

Zwei gute Abbildungen des lebenden Thieres liegen ausser den von Quov und Gatarakd schon vor, die von Sexper (1. c. Taf. XLI, Fig. 2) und die von Brock (1. c. Taf. LXXXVI, Fig. 6); die drei zusammen zeigen, wie stark die rothen Flecken in Bezug auf Anzahl und Grösse variiren. SEMPER zufolge (1.c. p. 5I4) ist die Farbe übrigens meistens scharlachroth, seine Abbildung soll ein weisse Varietät mit rothen Flecken darstellen ${ }^{1}$ ). Nach voN Martens (1. c. p. 514 ) ist das Thier an der Rückenseite rosenröthlichgrau mit rothen Flecken. Constant ist nur die verbreitete, feine (schwärzliche) Strichelung, die wahrscheinlich das wesentliche specifische Merkmal des Thieres bildet.

Am I 3 Jan. wurde am Riffe in der Ruma-Kuda-Bai, Insel Roma (St. 279) noch ein Individuum von etwa derselben Grösse erbeutet, so wie je ein ähnliches am Riffe in der Sanana-Bai an der Ostküste von Sula Besi (St. 193), und am Riffe von Pulu-Pasi-Tanette (St. 2I 3), so wie an der Südspitze der Insel Kabaëna (St. 209).

Eine dunklere, in der Formol-Lösung schmutzig-bräunliche (im Leben wahrscheinlich rothe) Varietät war am 25 Juli am Riffe von Beo bei den Karakelang-Inseln (St. I 3 I) gefangen.

\section{Platydoris eurychlamy's Bgh.}

R. Bergh, Malacolog. Unters. III (Heft XVI, I, i 888), p. So2-804. Taf. LXXXIII, Fig. 30-32.

Am ${ }_{5} 5$ Juli wurde am Riffe an der Ostseite von Pajunga in der Kwandang-Bai (St. I I5) ein Individuum gefangen.

In Formol bewahrt hatte dasselbe eine Länge von $5,5 \mathrm{~cm}$. bei einer Breite von 4,3 und einer Höhe von I,5 cm., die Breite des Rückengebräms betrug bis I 6 mm., die Länge des Fusses $3,5 \mathrm{~cm}$. bei einer Breite bis $13 \mathrm{~mm}$, die Breite des Fussgebräms bis 4,5; der Durchmesser der sechszackigen Kiemenspalte $10 \mathrm{~mm}$., ihr Rand $2 \mathrm{~mm}$. vortretend, die Kiemenblätter $6 \mathrm{~mm}$. hoch; die Rhinophorhöcker (bei zurückgezogenen 4. mm. hohen Organen) $2 \mathrm{~mm}$. hoch. - Die Farbe des Riickens war (wo dieselbe nicht abgerieben war) gräulichschwarz, ebenso die des Fussgebräms; die der Unterseite des Rückengebräms gräulichweiss; das Laub der Kiemenblätter streifig schwärzlichgrau, die Keule der Rhinophorien gelblich. — Die Consistenz des Thieres lederartig, steif.

1) Es ist doch wohl fraglich, ob Sestrer nicht diese Form mit der $\ell^{\prime} \%$ sanguiner verwachselt hat. Die Abbildungen ron QL'oY nnd Gamard so wie die hiesige stimmen mit der „Varietät" bei Semer überein. 
Die Formverhältnisse die gewöhnlichen. Die Kieme von 6 starken Blättern gebildet.

Die Nundröhre $6 \mathrm{~mm}$. lang. Der Schlundkopf $6 \mathrm{~mm}$. lang bei einer Höhe von 3,5 und einer Breite von 3; die Lippenscheibe von weisslicher Cuticula überzogen. Die starke Zunge mit farbloser Raspel, die etwa 32 Zahnplattenreihen zu enthalten schien, in der Scheide kamen etwa 18 vor, die Gesammtzahl der Reihen somit 50; die Anzahl der Platten in den Reihen etwa gegen I00. Die sehr blassen Zahnplatten von der früher beschriebenen Hakenform, bis $0,2 \mathrm{~mm}$. hoch.

Der Magen kurz-sackförmig, $9 \mathrm{~mm}$. lang bei einer Breite von 5,5, aus einer tiefen und breiten Kluft oben an der hinteren Eingeweidemasse hervorragend. Der Darm $22 \mathrm{~mm}$. lang. - Die hintere Eingeweidemasse kegelförmig $22 \mathrm{~mm}$. lang bei einer Breite von 8,5, röthlichbraun. Die kurzgestielte, kugelförmige Gallenblase von einem Durchmesser von 2,5 mm.

Das Pericardium gross, $9 \mathrm{~mm}$. lang. Die vordere Blutdrüse oval, $3 \mathrm{~mm}$. lang; die hintere ein wenig grösser, mehr länglich.

Die vordere Genitalmasse $6 \mathrm{~mm}$. Jang bei einer Höhe und Breite von 3. Der Penis mit den gewöhnlichen Reihen von Haken-tragenden Scheiben; die Vagina mit stark vortretenden Höckern mit gerundetem Scheitel.

4. Platydoris flammulata Bgh. n. sp. Taf. I, Fig. 4. Taf. XVI, Fig. 3.

Am I I Juli wurde am Riffe von Lumu-Lumu auf der Borneo-Bank (St. $7 \delta$ ) ein Individuum gefangen und lebend abgebildet.

Lebend hat dasselbe eine Länge von 9,5 bei einer Breite von 7,5 cm. gehabt; der Durchmesser des Kiemenlochs hat $2 \mathrm{~cm}$. betragen. Die Grundfarbe des Rückens ist braun gewesen; dieselbe war von unregelmässigen, anastomosirenden, flammenartigen weissen Figuren durchzogen, und zerstreut kamen ziemlich grosse blutrothe Flecken vor, der Rand des Kiemenloches weiss.

Das a ufbewahrte Individuum hatte eine Länge von 9 bei einer Breite von 5,5 und einer Höhe von I,6; der Durchmesser des Kiemenlochs war $2 \mathrm{~cm}$., die Höhe der Krieme bis Io mm.; die Breite des Rückengebräms bis 2,5 cm.; die Länge des Fusses 6,3 bei einer Breite von etwa I cm., die Länge des Schwanzes $5 \mathrm{~mm}$. Die Länge des Tentakel 2, die Höhe der Rhinophorien $5 \mathrm{~mm}$. - Die Farbe der Rückenseite war fast ganz wie beim lebenden Thiere, nur fehlte jede Spur der rothen Flecken; die Unterseite des Rückengebräms (gelblich-)weiss, die niedrigen Körperseiten und die obere Seite des Fusses (fein punktirt-)schwärzlichbraun, die Fusssohle weisslich, fein schwärzlich punktirt; die Kieme mit feinen, der Verzweigung der Blätter folgenden schwarzen Streifchen.

Die Formverhältnisse ganz wie bei der typischen Art. Das Kiemenloch mit einer vorderen und einer hinteren Klappe und jederseits 2 seitlichen. Die Kieme von 5 starken Blättern gebildet.

Die Nundröhre $9 \mathrm{~mm}$. lang bei einem Durchmesser hinten von 5; die Innenseite vorne mit schwärzlichen Strichen. Der Schlundk opf weiss, $9 \mathrm{~mm}$. lang bei einer Höhe von 6 und einer Breite von 5; die Raspelscheide ziemlich stark vorspringend. Die starke Zunge zeigte 
in der schön pommeranz-farbigen Raspel 22 Zahnplattenreihen; weiter nach hinten kamen deren 32 vor, von welchen die etwa 6 hintersten noch unfertig; die Gesammtzahl derselben ist somit 54. In den Reihen kamen bis etwa 100 Platten vor. Die Zahnplatten denen der Pl. crucnta ganz ähnlich; die innerste hatte eine Höhe von beiläufig 0,12 , und die Höhe der Platten stieg bis zu 0,25, die der äussersten 2 (Fig. 3) betrug $0,12-0,14 \mathrm{~mm}$.

Die diunne Speiseröhre etwa $18 \mathrm{~mm}$. lang; der etwas abgeplattete Magen $14 \mathrm{~mm}$. lang bei einer Breite von II; der Darm $4 \mathrm{~cm}$. lang bei einem Durchmesser von 2-3 mm. Die hintere Eingeweidemasse (Leber) röthlich braungelb, 2,8 cm. lang bei einer Breite von I, 8 und einer Höhe von I,4.

Die Blutdrüsen gross, länglich, gelb.

Die vordere Genitalmasse I $_{3} \mathrm{~mm}$. lang bei einer Höhe und Breite von I I; fast steinhart erhärtet. Die gelbliche Prostata etwas abgeplattet-herzförmig, von 5 mn. Länge. Der Penis etwa $15 \mathrm{~mm}$. lang bei einem Durchmesser von 4; seine Höhle von einer ungewöhnlich dicken, gelben, Längsfalten bildenden Cuticula ausgekleidet mit spitzen und gerundeten Höckern versehen, aber ohne die gewöhnlichen Dorntragenden Scheiben. Auch die Vagina mit starker Cuticula ausgefuttert. Das Vestibulum genitale mit schwärzlichen Strichelchen und Fleckchen ausgestattet; die gelbliche (Penis-)druise rundlich von $3 \mathrm{~mm}$. Durchmesser.

Diese Form scheint von der $P l$. cruenta specifich verschieden.

5. Platydoris sangumea Bgh. n. sp. Taf. II, Fig. 9. Taf. XVI, Fig. 4-5.

Am 26 Oct. wurde am Riffe der Süd-Insel bei Saleyer (St. 213) ein Individuum erbeutet und nach dem Leben abgebildet.

Das lebende Thier hatte eine Länge von 9 bei einer Breite von fast $6,5 \mathrm{~cm}$; der Durchmesser des Kiemensterns war $2,5 \mathrm{~cm}$., die Höhe der Rhinophorien $7 \mathrm{~mm}$. - Die Farbe der Rückenseite dunkel blutroth auf einem unterliegenden feinen schwarzen Netzwerke; die Blätter der Keule der Rhinophorien weissgerandet, die Kieme weiss mit röthlichen rhachidialen Partien.

Das a ufbewahrte Individuum hatte eine Länge von $9,3 \mathrm{~cm}$. bei einer Breite von 7 und einer Höhe von $2,5 \mathrm{~cm}$; die Höhe der (zurückgezogenen) Rhinophorien betrug $6 \mathrm{~mm}$., der Durchmesser des Kiemenloches 1,6 cm., die Höhe der (zurückgezogenen) Kieme 10 mm.; die Breite des Rückengebräms $2,7 \mathrm{~cm}$; die Länge der Tentakel 3; die Länge des Fusses $7,5 \mathrm{~cm}$. bei einer Breite von etwa 2, die Länge des Schwanzes $9 \mathrm{~mm}$. - Die Farbe der Rückenseite war jetzt schmutzigbraun, unter der Loupe äusserst fein schwarz punktirt; die Rhinophorien bräunlichgrau mit weisser Spitze; der Rand der Lappen des Kiemenlochs abstechend weiss, die Kiemenblätter an der Aussenseite weisslich, an der Innenseite schwärzlich. Die Unterseite des Rückengebräms hellgelb; die Körperseiten braun, der Fuss gelblich.

Die Formverhältnisse die gewöhnlichen. Das Kiemenloch mit 5 ungleichgrossen Lappen; die Kieme aus 6 starken Federn gebildet; die Analpapille $3 \mathrm{~mm}$. hoch, schlank.

Die Mundröhre I $2 \mathrm{~mm}$. lang bei einem Durchmesser hinten von 5, weisslich. Der weissliche Schlundkopf ro mm. lang bei einer Breite von 9 und einer Höhe von 6; die starke Cuticula der Lippenscheibe weisslich. Die starke Zunge mit gelblicher Raspel, welche 
23 Zahnplattenreihen enthielt; in der starken Scheide kamen 36 vor, von welchen die 5-6 noch unfertig; die Gesammtzahl somit etwa 59. Die Zahl der Platten in den Reihen schien bis etwa I $30_{3}$ zu steigen. Die Zahnplatten von den gewöhnlichen Formverhältnissen, vielleicht ein wenig schlanker (Fig. 4), die äussersten 3-4 mit kürzerem Körper (Fig. 5), unregelmässige Platten fehlten nicht (Fig. 5). Die Höhe der innersten betrug etwa 0,14 mm., und die Höhe der Platten stieg bis zu 0,28, die der 5 äussersten war beiläufig O, I6-O, I 4-O, I 2-0,06-0,05 mm.

Der Magen I $2 \mathrm{~mm}$. lang bei einer Breite von $\delta$, der Darm 3,5 cm. lang bei einem Durchmesser von 2-I,5 mm. - Die hintere Eingeweidemasse (Leber) 2,8 cm. lang bei einer Breite von 1,6; aussen grau gelblich, median längs der Rückenseite bis an den Ursprung der Aorta dunkel schwarzbraun; die Leber selbst schmutziggelb, mit weiter Höhle. Die Gallenblase mit weisslicher, im Durchmesser $2 \mathrm{~mm}$. haltender Facette an der Oberfläche der Leber.

Das Pericardium I $6 \mathrm{~mm}$. lang bei einer Breite von I5; die Herzkammer $9 \mathrm{~mm}$. lang. Das pericardio-renale Organ kurz-birnförmig, $3 \mathrm{~mm}$. lang. - Die Blutdrüsen gelblich, gross.

Die vordere Genitalmasse gross, $12 \mathrm{~mm}$. lang bei einer Höhe von io und einer Breite von $12 \mathrm{~mm}$., weiss und gelblich, ganz erhärtet. Die gelblichweisse Prostaıa herzförmig, von $5 \mathrm{~mm}$. Länge; der Penis $15 \mathrm{~mm}$. lang bei einem Durchmesser von 1,5-2, wie es schien an seiner Cuticula mit Reihen von Hakentragenden Scheiben versehen. Der vaginale Gang (der Spermatotheke) und die Vagina mit einer starken, gefalteten und Höckertragenden Cuticula versehen. Die kleine Drüse am Grunde des Vestibulum genitale gelb, rundlich, von 3 mim. Länge.

Diese Form bildet vielleicht eine von der $P l$. flammulata verschiedene Art.

Am 25 Juni wurden ferner 3 Exx. an der Küste von Pulu Sanguisiapo im Sulu-Archipel (St. 93) 3 Individuen erbeutet; ferner eins bei Ambon; 2 am Riffe von Pulu-Pasi-Tanette (St. 2 I 3).

\section{Asteronotus Ehrenberg.}

EHREnberg, Symb. phys. Anim. evert. exclusis insectis. Series prima c. tabularum decade prima. I 83 I.

R. Bergh, Krit. Unters, d. EhrenberG'schen Doriden. Jahrb. d. D. malacozool. Ges. IV, I, 1877 , p. 70 .

R. Bergh, Üb. das Geschlecht Asteronotus E. Jahrb. d. D. malacozool. IV, I877, p. I6II73, Taf. I-II.

R. BERGH, Malacolog. Unters. II (Heft XIV, I878), p. 626-645; III (Heft XVII, I890), p. $917-921$.

R. BERGH, Opisthobranchien (Kükenthal). Abh. d. Senckenberg. naturf. Ges. XXIV, r897, p. I02-IOg, Taf. XII, Fig. 7-I2.

Corpus magnum coriaceum (non durum vel fragile); notaeum glabrum, saepe nodosum et carina mediana instructum; apertura branchialis stellata.

Penis inermis; glandula et hasta amatoria.

Innerhalb der Gruppe der Platydorididen zeichnen sich die Asteronoten, ausser der eigenen lederartigen Consistenz und der sternförmigen Kiemenöffnung, durch den unebenen Rücken und das Auftreten einer eigenthümlichen Hasta amatoria mit angehörender Drüse aus. 
Die Gattung ist bisher nur im Rothen und Indischen so wie in dem Stillen Meere nachgewiesen, durch ein Paar Formen vertreten, die vielleicht nur einer Art gehören:

$$
\left\{\begin{array}{l}
\text { 1. Asteronotus Memprichi E. M. rubr. } \\
\text { 2. Asteronotus cespitosns (v. Hass.). M. philipp., indic. } \\
\text { 3. Asteronotus mabilla Bgh. M. indic. (Ins. Seychellen). }
\end{array}\right.
$$

\section{Asteronotus cespitosus (van Hass.). Taf. I, Fig. 5.}

Doris cespitosa van Hass., 1.c. p. 307, Taf. 6, Fig. 9.

Asteronotus cespitosus (v. H.), 1. c. III (Heft XVII, I89o), p. 9I8-92I, Taf. LXXXV, Fig. 7 IS. Asteronotus bertrana Bgh. 1.c. Il (Heft XIV, I873), p. 629-644, Taf. LXVII, Fig. 10-22

Taf. LXVIII, Fig. 6-I4.

Asteronotus Hemprichi Ehrenb. ELIOT, 1. c. III, I904, p. 384, Pl. XXIV, Fig. 6.

Am 26 Oct. wurde am Riffe der Süd-Insel bei Saleyer (St. 2 I3) ein Individuum erbeutet und nach dem Leben abgebildet.

Lebend hatte dasselbe eine Länge von 7,5 bei einer Breite von $4,8 \mathrm{~cm}$; d der Durchmesser des Kiemensterns fast I,5 cm. Die Grundfarbe war röthlich olivenbraun; die vortretenden Theile des Rückens, der mediane Kamm, die Tentakel und die Bogenstiicke des Rückengebräms hell olivenfarbig, mitunter mit hellerem Scheitel; das Laub der Kieme weisslich, die rhachidialen Partien griunlichbraun ${ }^{3}$ ).

Die Länge des a ufbewahrten Individuums betrug 6,5 bei einer Breite von 3,8 und einer Höhe von I, 8 cm., die Breite des Rückengebräms bis Io mm., der Durchmesser des Kiemensterns $1_{3}$, die der Kiemenspalte I I; die Länge des Fusses $5 \mathrm{~cm}$. bei einer Breite von I,7, die Breite des Fussgebräms $2 \mathrm{~mm}$., die Länge des Schwanzes 4; die Länge der Tentakel $3 \mathrm{~mm}$. - Die Farbe des Rückens war schmutzig olivengrün mit hellerem Rückenkamm mit dunkleren Knoten, alle die Knoten des Riickens mit hellerem Halo; der Kiemenstern hell röthlichbraun; die Unterseite des Rückengebräms in der grösseren äusseren Strecke gräulich, mehr nach innen von einem $3,5 \mathrm{~mm}$. breiten, bräunlichgrauen, aussen schwarzgerandeten, ununterbrochenen, ringslaufenden Bande eingenommen, der Fuss gräulichweiss.

Die Formverhältnisse die gewöhnlichen. Der von vorn nach hinten wie vom Rande nach innen allmählig gewölbte Rücken mit ausgeprägtem Rủckenkamm, der sich in einigen (6) Knoten erhob; ausserhalb desselben standen in einer gebuchteten Linie 5 Knoten, deren Halo mitunter unter einander oder mit dem Rückenkamm verbunden war; ausserhalb derselben kamen 4-5 kleinere Knoten vor, deren Halones durch Verschmelzen jederseits einen vorne und hinten unterbrochenen, bogenartigen Perlschnurartigen Kamm bildeten; aussen am Rückengebräm endlich 2-3 concentrische, ringslaufende, hier und da unterbrochene, seltener Knotentragende Falten. Der Rand der runden Kiemenöfnung in 6 Lappen hervorschiessend, von welchen der mediane vordere der grösste; die Kieme von 6 Blättern gebildet. Die Unterseite des Ruickengebräms glatt. Der Fuss wie früher beschrieben. - Die Consistenz lederartig, die des Randes des Kiemenloches fast knorpelartig.

I) Im Ganzen ähnelte die Abbildung so ziemlich der von vax HAsselt gelieferten (R. Bergir, die vax Hasselt'schen Nudibranchien. Notes from the Leyden Museum. ISS7, PI. 6, Fig. 9). 
Das Centralnervensystem wie friher beschrieben, $2 \mathrm{~mm}$. breit.

Die starke Mundröhre $6,5 \mathrm{~mm}$. lang. - Der gedrungene Schlundkopf $9 \mathrm{~mm}$. lang bei einer Breite von 7 und einer Höhe von 5,5. Der Innenmund mit starken Querfurchen, von einer weisslichen Cuticula überzogen. Die gelbe Raspel der starke Zunge enthielt I6 Zahnplattenreihen; in der dicken Raspelscheide kamen noch 20 Reihen vor, die Gesammtzahl derselben somit 36; die Anzahl der Platten in den Reihen schien gegen 50 zu betragen ${ }^{1}$ ). Die Höhe der äussersten Platte war $0,06-0,08$, die der grössten $0,28 \mathrm{~mm}$; die Formverhältnisse waren ganz wie friher beschrieben. - Die Speicheldrüsen wie gewönlich.

Der aus der Leberkluft hervorragende Magen fast kugelförmig, von 9 mm. Durchmesser. Der Darm $35 \mathrm{~mm}$. Iang bei einem Durchmesser von I,25- I mm. - Die hintere Eingeweidemasse wegen der dieselbe fast ganz überziehenden Zwitterdrüse gelblichgrau, $22 \mathrm{~mm}$. lang bei einer vorderen Breite von I2; die Leber selbst dunkel grau, die gelbe Gallenblase links am Grunde des Magens fast kugelförmig, $4 \mathrm{~mm}$. hoch bei einem Durchmesser von 2.

Das Pericardium sehr gross, $14 \mathrm{~mm}$. lang bei einem Durchmesser von II. Die Blutdrüsen hellgelb, abgeplattet; die vordere gerundet-viereckig, von $4 \mathrm{~mm}$. grösstem Durchmesser, die hintere schmäler, $6 \mathrm{~mm}$. lang. - Das Nierensystem stark entwickelt, die Urinkammer ziemlich weit; das pericardio-renale Organ birnförmig, $3 \mathrm{~mm}$. lang.

In den Läppchen der Zwitterdrüse kaum entwickelte Geschlechtselemente. - Die vordere Genitalmasse nur 4,5 mm. lang bei einer Höhe und Breite von 2; der Conservationszustand gestattete keine genauere Untersuchung derselben; der Stachel mit seiner Drüse war aber deutlich.

\section{Chromodorididae.}

R. BERGH, System. 1. c. I892, p. IIO3(-III2).

Corpus elongato-compressum, consistentiae mollioris; coloribus hilaribus, saepe magnificis, ut plurimum striatis vel maculatis; notaeum fere semper laeve, limbo marginali antice et praesertim postice sat lato, caeterum sat angusto; tentacula parva, conica, ut plurimum quasi evertilia; folia branchialia ut plurimum simpliciter pinnata.

Armatura labialis ut plurimum fortis e hamulis minutissimis composita. Rhachis radulae angustissima saepe dentibus spuriis compressis minutis instructa; pleurae multidentatae, dentibus hamatis ut plurimum externo margine denticulatis, primo utrinque denticulato. - Ventriculus proprius nullus.

Penis inermis.

Diese hauptsächlich in den wärmeren und tropischen Meeresgegenden verbreitete Gruppe umfasst die Gattungen Chromodoris (A. et H.), Casella (H. et Adams), Ceratosona (A. et H.), Thormma (B.) und die mit mehrfach gefiederten Kiemenblättern versehene Aphelodoris (B.).

1) 1 ei den in Allem 9 Individuen, die ich untersucht habe, variirte die Anzahl der Zahnplaltenreihen der Zunge von 16-27, die Gesammtzahl der Reihen von 35-50, und die Anzahl der Platten in den Reihen von 47-68. 
Chromodoris Alder et Hanc.

R. BERGH, System 1.c. p. IIO4(-IIIO).

Limbus marginalis angustus simplex; folia branchialia simpliciter pinnata.

Ein ziemlich grosse Anzahl (wenigstens etwa 150) von Arten ist angegeben worden, deren Specificität aber zum Theil sehr zweifelhaft ist, auch weil viele in Farbentracht sehr zu variiren scheinen.

I. Chromodoris quadricolor (Rüppell). Taf. II, Fig. 7 .

Doris quadricolor Rüppell. Atlas. $1 \mathrm{~S} 2 \mathrm{~S}$, p. $3 \mathrm{I}$. Tab. IX, Fig. 2.

Actinodoris sponse Ehrenberg. Symbolae, I, I8 $3 \mathrm{I}$.

Chromodoris clisabethina Bgh. Malacolog. Unters. II (Heft XI, I877), p. 466-473, Taf. LI, Fig. 6-I5; - III (Heft XVII, I89o), p. 929-93I. Taf. LXXXIX, Fig. 15-17.

Chromodoris annae Bgh. 1. C. II (Heft XI, IS77), p. 473-474. Taf. LI, Fig. 4-23.

Am 7 Dcbr. wurde am Riffe beim Ankerplatze von Kilsuin, an der Westküste der Insel Kur (St. 250) ein Individuum erbeutet, nach dem Leben abgebildet und in Formol bewahrt.

Das lebende Thier war von hell-(grülicher oder) bläulicher Grundfarbe; der eigentliche Rücken ringsum von einem schwarzem Bande eingefasst und mit einem starken medianen, von der Gegend der Rhinophorien bis an die Kieme verlaufenden Streifen, zwischen diesem und dem Randbande einzelne kleine längliche Fleckchen; der Schwanzrücken mit zwei schwarzen Längsbändern; die Rhinophorien und die Kieme roth. - Die Länge hat gegen $5 \mathrm{~cm}$. betragen bei einer fast durchgehenden Breite von $8 \mathrm{~mm}$.

Das a ufbewahrte Individuum war stark erhärtet, zusammengezogen und verdreht. Die Länge desselben betrug 23 bei einer Breite von 7 und einer Höhe von 4 mm., die Höhe der Rhinophorien und der Kieme war 2, die Breite des Riickengebräms 1,25 mm.; die Breite des Fusses 3, die Länge des Schwanzes 4 mm. - Die Grundfarbe war (schwach bläulich-)grau; der eigentliche Rücken von dem schwarzen Bande ringsum eingefasst und mit dem starken medianen Streifen, zwischen jenem und diesem einzelne schwarze Flecken; die Körperseiten von einem schwarzen Längsbande durchzogen, welches sich auf den Schwanzrücken hinaus fortsetzt, oberhalb dieses Bandes verlief dicht am Rückenrande ein anderes, schmäleres und etwas kuirzeres; die Rhinophorien und die Kieme ganz hell gelblichweiss.

Die Formverhältnisse ganz wie früher beschrieben, keine Spur von Punktirung am Rücken oder an den Körperseiten. Es fanden sich ganz bestimmt nur 6 Kiemenblätter, von welchen die zwei hintersten gabelig (während bei den früher untersuchten Individuen der Chr. clisabethina wenigstens I 2 - I4 vorkamen).

Die Mundröhre $2 \mathrm{~mm}$. lang. Der Schlundkopf gelblich, 2,5 mm. lang; die breiten, hell citrongelben Mandibelplatten wie gewöhnlich aus schwach gelblichen, gebogenen, in der Spitze meistens kurz gabeligen Elementen von einer Länge bis 0,05 mm. zusammengesetzt. Die Raspel der Zunge fast farblos; weder die Anzahl der Zahnplattenreihen noch die Zahl der Platten in den Reihen liess sich bestimmen. An der schmalen Rhachis die gewöhnlichen 
Verdickungen; die fast farblosen Zahnplatten wie früher beschrieben, die Länge der ersten Seitenplatten betrug $0,08 \mathrm{~mm}$; die Höhe des Hakens stieg bis 0,08 mm., die Anzahl der Dentikel des Hakens bis 6-9.

Die hintere Eingeweidemasse (Leber) $9 \mathrm{~mm}$. lang, vorn $4 \mathrm{~mm}$. breit, schlauchförmig, wegen ihrer Hülle schmutzig bräunlichgelb, auf Schnitten gelblichweiss. Die vordere Genitalmasse fast kugelförmig, von $3 \mathrm{~mm}$. Durchmesser, aus der eben erwähnten Hülle gelöst weisslich.

Die (I 4) frïher untersuchten Individuen der Chromodoris clisabethina hatten alle 3 Seitenbänder, sonst stimmten sie mit dem hier untersuchten überein.

Diese in Farbe ziemlich variable Form ist sicherlich mit der alten Doris quadricolor von RÜPPELL-LeUCKaRT specifisch identisch.

Chromodoris elisabethina Bgh. var. Taf. IV, Fig. 3. Taf. XVI, Fig. 6.

Chromodoris Annae Bgh., Malacolog. Unters. III (Heft XVII, I89o), p. 93I-933. 'Taf. LXXXVI, Fig. 5 ; Taf. LXXXIX, Fig. I2-I4.

Auf einem Riff bei Ambon wurden zwei Individuen gefangen, und das grössere lebend abgebildet. Die Abbildung ist der von BRock (1. c. Taf. LXXXVI, Fig. 5) gelieferten im IV'esentlichen ganz ähnlich.

Von dieser Form wurden ferner am Riffe von Haingsisi 3 Individuen gefangen und auch in $(4 \%)$ Formol bewahrt, wobei sie theilweise die Farben ungewöhnlich lebhaft bewahrt hatten. Das eine (grösste) wurde anatomisch untersucht.

Lebend zeigt das Thier den eigentlichen Rücken blau mit einem schwärzlichen länglichen Fleck zwischen den Rhinophorien und vor der Kieme; das Blaue ist von einem schwarzen Bande längs der Seiten eingefasst; diesem folgt eine weisse ringslaufende Linie, an die ein starkes gelbes Band stösst, der Rückenrand ist weiss; die Rhinophorien und die Kieme roth. Der Schwanzrücken blau, auch mit medianem dunklem Fleck hinten; am Grunde des Schwanzes jederseits auch eine schwarze Einfassung (Verlängerung der Bänder der Körperseiten), dann die weisse Linie, das gelbe Band und der weisse Rand.

Diese Individuen waren so ziemlich gleichgross. Das grösste maass an Länge $35 \mathrm{~mm}$. bei einer Breite von 10 und einer Höhe von $8 \mathrm{~mm}$; die ausgestreckten Rhinophorien waren $4,5 \mathrm{~mm}$. hoch, die vorgestreckte Kieme $5 \mathrm{~mm}$., die Breite des Rückengebräms 2; die Breite der Fusssohle 2, des Fussgebräms 0 ,5, die Länge des Schwanzes $6 \mathrm{~mm}$. - Die Farbe des eigentlichen Riickens war (schwach-)violetgrau, zwischen den Rhinophorien kam bei den zwei Individuen ein rundlicher, kastanienbrauner Fleck und vor der Kieme ein länglicher vor. Der ganze Rücken ist von einem ziemlich breiten, ringslaufenden (vorne und hinten geschlossenen) dunkel-fast schwärzlich-kastanienbraunen Band eingefasst, welchem sich das schön rothgelbe Rückengebräm anschliesst. Die Keule der Rhinophorien schön rothgelb; ihr Stiel heller. Die Ǩieme schön rothgelb. Die Körperseiten waren violetgrau mit drei starken dunkel kastanienbraunen, fast schwarzen Längsbändern, von welchen das oberste sich dem gelben Rückengebräm 
anschliesst und ringslaufend ist; das mittlere, stärkste fängt in der Gegend des Kopfes an und setzt sich auf den Schwanz fort, wo cliese Bänder beider Seiten verschmelzen; das untere, das schwächste und kürzeste schliesst sich dem schwach gelblichen I'ussrande an. Die Genitalpapille weisslich. Der Kopf hell röthlichgelb. Die Fusssohle hell gelblichweiss.

Die Formverhältnisse die gewöhnlichen. Der Rücken eben, die feine Punktirung desselben wenig ausgeprägt; das Rückengebräm über dem Kopf und dem Schwanz nicht breiter als anderswo; der Rand der Rhinophorscheiden so wie des Kiemenloches etwas vortretend, der Durchmesser der runden Kiemenspalte $4 \mathrm{~mm}$; die Enden des Kiemenbogens gleichsam etwas eingerollt; die Anzahl der Kiemenblätter bei dem grossen Individuum 1 2, von welchen die 3 hintersten jederseits allmählig kleiner, bei den kleineren Individuen kamen $\&$ und 9 vor. Zwischen den eingerollten Enden des Kiemenbogens die vortretende röthlichgelbe Analpapille. Der Kopf hinten jederseits in einen kurzen kegelförmigen Tentakel auslaufend. Der schmale Fuss vorne gerundet, mit Randfurche; der Schwanz den Rücken überragend.

Die Eingeweidehöhle nur bis an den Hinterrand des Kịmenloches reichend; die Huille der Eingeweidemasse rothbraun, an der Rückenseite stärkel farbig.

Das weissliche Centralnervensystem mit den Augen und Ohrblasen wie gewöhnlich. Die Keule der Rhinophorien mit 25-30 Blättern.

Die gelblichweisse Mundröhre so lang wie der $\mathrm{Schlundkop}$. Dieser letztere $3 \mathrm{~mm}$. lang, von ähnlicher Farbe, von gewöhnlicher Form; der Mund I mm. hoch, dreieckig, von der gewöhnlichen gelben Lippenplatte iberzogen, die rom breiten unteren Mittelstücke ab sich nach oben etwas verschmälert; ihre Elemente wie gewöhnlich, etwas gebogen, in der Spitze gabelig, bis $0,055 \mathrm{~mm}$. lang. Die Zunge mit fast farbloser Raspel, welche 25 Zahnplattenreihen enthielt, in der Scheide kamen noch 33 vor, von welchen die 4 hintersten unreif; die Gesammtzahl der Reihen somit 58. In den Reihen wurden bis 75 Platten gezählt ${ }^{1}$ ). Die fast farblosen Zahnplatten von gewöhnlichen Verhältnissen; die innerste hatte eine Höhe von etwa $0.05 \mathrm{~mm}$, die Höhe stieg bis O, IO, die der drei äussersten betrug 0,06-0,075 und 0,0S mm. Durch die ganz schmale Rhachis verlief eine feine Falte mit kleinen Verdickungen zwischen den beiderseitigen Zahnplattenreihen. Die innerste Zahnplatte war an beiden Rändern des Hakens gezähnt, die anderen nur am äusseren, und die äussersten nur an der Spitze (Fig. 6).

Die langen Speicheldrïsen wie gewöhnlich. - Die lange Blutdrüse rothbraun.

Der sehr lange Darm in der ersten Strecke weiter und mehrere Biegungen bildend. Die hintere Eingeweidemasse (Leber) violetgrau, auf Schnitten grüngrau, wurstförmig, i I mm. lang bei einer fast durchgehenden Breite von 5. Ihre ganze obere Seite so wie das Hinterende war von der in Farbe contrastirenden rothgelben $\mathrm{Z}$ witterdruse überzogen. - Die vordere Genitalmasse eiförmig, von $3 \mathrm{~mm}$. Länge, mit rothbraunem Überzug, im Inneren weisslich.

Die Chromodoriden des Mittelmeeres sind in Farbenzeichnung ziemlich variabel. Dasselbe wird zweifellos mit den prachtvollen tropischen Arten der Fall sein, und eine Anzahl der

1) Bei den friiher untersuchten Individuen der Chrom. disahthina betrug die Anzahl der Zahuplattenreihen S2 und 79 , und die Anzahl der Platten in den Reihen 62 und 67 
zahlreichen angegebenen Arten wird sich sicherlich als Varietäten erweisen, so auch diese Chr. Annae und die Chr. elisabcthina als Varianten der Chr. quadricolor.

\section{Taf. IV, Fig. 4 .}

Noch ein Individuum dieser Chr. Annae wurde am Riffe in der Pepela-Bai, Insel Rotti (St. 30r) gefangen und lebend abgebildet.

Lebend hatte das Thier eine Länge von 5,5 bei einer Breite von $1,2 \mathrm{~cm}$. Die Farbe des eigentlichen Rückens so wie der Mitte des Schwanzrückens war ultramarinblau, ringsum von einem breiten schwarzen Bande eingefasst; auf dieses folgt hier wie dort eine weisse Linie und dann ein ziemlich breites gelbes Band, die Rhinophorien so wie die Kieme waren roth.

Das a ufbewahrte Individuum hatte eine Länge von 3,3 bei einer Breite bis $\mathrm{I}, 4 \mathrm{~cm}$. und einer Höhe bis 0,8 ; die schönen Rhinophorien 3,5 mm. hoch. - Der eigentliche Rücken bläulichgrau, ringsum vom schwarzen Bande eingefasst; diesem folgt ein weisse Linie, dann das gelbe Randband. Der Rand der Rhinophorscheiden gelb; die Keule der Rhinophorien so wie die (ziemlich zurückgezogene) Kieme feuerroth. Die Unterseite des Rückengebräms auch rnit dem gelben Bande und der weissen Linie; dieser zunächst, ganz oben an der Körperseite, ein schwarzes Band, die gleichfalls bläulichgraue Farbe der Seite durch ein längslaufendes mittleres und ein unteres Band oberhalb des Fussrandes unterbrochen; von diesen schwarzen Bändern setzt sich das mediane über den Schwanz fort, der sonst die Rückenfarbe hatte; der Fussrand stark gelb, die Fusssohle gräulich.

Die Formverhältnisse wie gewöhnlich. Die bei dem erst untersuchten Individuum (1.c. 1877, Fig. 21) gesehene feine Punktirung des Rückens war hier nicht zu sehen.

Diese Form, die sich wohl nur durch das vollständige Fehlen eines medianen Rückenbandes von der Chr. elisabethinza unterscheidet, wird sich schliesslich als nur eine Varietät derselben und somit der Chr. quadricolor ausweisen. Auch mit der Chr. hilaris (1. c. Heft XVII, IS9o, p. 935-937. Taf. LXXXVI, Fig 4; Taf. LXXXVII, Fig. I I-15) könnte dasselbe der Fall sein.

2. Chromodoris Crossei (Angas). Taf. IV, Fig. 6. Taf. XVI, Fig. 7-8.

Goniodoris Crossei Angas. Descr. d'espèces nouv. de moll. nudibr. Journ. de conchyl. $3 \mathrm{~S}$. IV, I, I864, p. 54. Pl. V, Fig. I.

?Chromodoris Crossei (Angas). R. BERGH, Malacolog. Unters. III, I884, p. 648-650. Die dazu gehörenden Figuren finden sich in meinen Bcitr. zu einer Monogr. d. Polyceraden. III. Verh. d. k. k. zool. bot. Ges. in Wien. XXXIII, 1883. Taf. VII, Fig.4-8; Taf. VIII, Fig. I.

Am Riffe von Atjatuning an der Westküste von Neu-Guinea (St. 169) wurde ein Individuum gefangen und lebend abgebildet.

Das lebende Thier hatte eine Länge von 25 bei einer Breite von $4 \mathrm{~mm}$,, der Schwanz betrug elwa $1 /$ s der ganzen Körperlänge. -- Die Farbe war prachtvoll, aber sehr bunt; die Grundfarbe der Rückenseite scheint grün zu sein, aber mit gelben runden Flecken 
und dunkelblauen Punkten ïbersäet, am Rückengebräm noch dazu mit blauen Iilecken; die Keule der Rhinophorien und die Kieme roth.

Das stark erhärtete a ufbewahrte Individuum war $20 \mathrm{~mm}$. lang bei einer Breite von 5,5 und Höhe von 5; die Breite des Rückengebräms 0,5 mm., das Stirn- und besonders das Schwanzsegel ziemlich stark; die Höhe der (vorgestreckten) Kieme $3 \mathrm{~mm}$; die Breite des Fusses 2,5, die Länge des Schwanzes $6 \mathrm{~mm}$. - Die Farbe der Rückens so wie der Körperseiten grünlich, aber überall mit weissen Knötchen und dunkelgrinen Punkten bedeckt, grössere ähnlicher Art kamen am Rückengebräm vor, sowie auch am Fusstande; die Unterseite des Rückengebräms gelblich; die Rhinophorkeulen so wie die Kieme rothbraun; die Fusssohle gelblichweiss.

Die Formverhältnisse wie gewöhnlich, der Schwanz lang; die Kieme aus io Blättern gebildet. An der Unterseite des Schwanzsegels eine Andeutung von Blasenbildungen, die bei dem früher untersuchten Individuum (vgl. 1. c. Taf. VII, Fig. 4) so ausgeprägt waren.

Die Nundröhre 2,5 mm. lang, mit von der Innenseite stark durchschimmernden blaten Flecken. Der Schlundkopf weisslich, 2,5 mm. lang; die stark gelben, (I mm.) breiten Lippenplatten aus zusammengedrückten, spitzen Elementen (Fig. 7 ) wie bei der Chr. Semperi gebildet, von einer Länge bis 0,030 mm. Die gelbliche Raspel mit sammt der Scheide schien etwa 100 Zahnplattenreihen zu enthalten und in den Reihen wenigstens Ioo Platten. Die fast farblosen Platten mit geklüftetem, gebogenem Haken (Fig. 8) wie bei der Chr. Sempori, bis $0,05 \mathrm{~mm}$. hoch.

Die hintere Eingeweidemasse (Leber) kurz-wurstförmig, rothgelb, an der Oberfläche heller, $6 \mathrm{~mm}$. lang bei einem Durchmesser von 3 .

Die vordere Genitalmasse von ovalen Umrissen, $4 \mathrm{~mm}$. lang, röthlichweiss.

Die Chronodoris Semperi ist vielleicht mit dieser Form identisch, kaum aber die von mir früher ${ }^{1}$ ) beschriebene, jedenfalls nahestehende Chr. Crossci, die sich durch andere Form der Elemente der Lippenplatten und anderes Verhältniss des Aussenendes der Zahnplattenreihen unterscheidet.

3. Chromodoris Semperi Bgh. var. Taf. IV, Fig. 5. Taf. XVI, Fig. 9-Io.

R. Bergil, Malacol. Unters. II (Heft XI, I877), p. 482-484. Taf. LII, Fig. I-2; Taf. LiII, Fig. 13-14; Taf. LV, Fig. 2-7.

An Ankerplatz östlich von Dangar Besar, Saleh-Bai (St. 3 I3) wurden aus einer Tiefe von $36 \mathrm{M}$. zwei ganz gleichgrosse Individuen gefischt und lebend abgebilclet.

Lebend hatte das Thier eine Länge von $3 \mathrm{~cm}$. bei einer Körperhöhe bis $8 \mathrm{~mm}$; die Kieme bis $4 \mathrm{~mm}$. hoch. Die Farbe des Rückens war grün mit zahlreichen gelben Punkten, ähnlich war auch die obere Seite des Fusses, die aber stärker als der Rücken mit feinsten schwarzen Punkten versehen war; der Stiel der Rhinophorien weiss, die Keule roth: die Kieme roth.

I) Malacolog. Unters. $11 \mathrm{I}$ (Heft $\mathrm{XV}$ ), $\mathbf{1} \mathrm{SS}_{4}$, p. 648-650. - Beitr. zu einer Monogr. d. Polyceraden. IlI. Verl. d. k. k. zool. bot. Ges, in Wien. XXXIII, $\mathrm{ISS}_{3}$. Taf. VII, Fig. 4-S; Taf. VII, Hig. 1. 
Die a ufbewahrten Individuen waren $25 \mathrm{~mm}$. lang bei einer Höhe von 8 und einer Breite von 7; die Höhe der Kieme war 3, die Länge des Schwanzsegels 2,5, die Breite des Fusses 2, die Länge des Schwanzes $7 \mathrm{~mm}$. - Die Farbe war durchgehends gräulich, heller an den Körperseiten; der Rücken wie die Körperseiten mit rundlichen weissen Fleckchen und mit meistens rundlichen schwarzen Punkten übersäet, so auch der Schwanz und das Fussgebräm; besonders stark waren die schwarzen Punkte längs des Ruickenrandes und theilweise röthlich; die Kieme und die Keule der Rhinophorien roth.

Die Formverhältnisse die gewöhnlichen; das Stirn- und Schwanzsegel ziemlich stark; die Kieme aus IO-I2 Blättern gebildet; die Tentakel kegelförmig; der kräftige Schwanz den Rücken stark überragend.

Das Centralnervensystem röthlichweiss, sonsî wie gewölnnlich. Die schöne (zugespitzte) Keule der Rhinophorien mit etwa 25 Blättern.

Die starke Mundröhre $3 \mathrm{~mm}$. lang. Der weissliche Schlundkopf $+\mathrm{mm}$. lang bei einer Höhe und Breite von 3; die am Hinterende hervorragende Raspelscheide am Grunde schwärzlich. Die grossen, bis fast $2 \mathrm{~mm}$. breiten, gelben Lippenplatten aus (Fig. 9) zusammengedrückten, spitz auslaufenden Elementen gebildet, die eine Länge bis $0,025 \mathrm{~mm}$. bei einer Höhe von 0, о 6 hatten. Die hellgelbe Raspel der Zunge enthielt etwa Ioo Zahnplattenreihen, in der Raspelscheide schienen deren noch 40 vorzukommen von welchen die 7 hintersten mehr oder weniger farblos. In den Reihen kamen wenigstens i 50 Platten neben der Rhachis vor. Die gelblichen Zahnplatten von gewöhnlichen Formverhältnissen, eine Höhe bis $0,065 \mathrm{~mm}$. erreichend, die äusserste mass nur 0,02 ; sie zeigten alle (Fig. Io) einen starken Dentikel unterhalb des Hakens, nur mit Ausnahme der äussersten.

Die langen Speicheldrüsen weiss. - Die hintere Eingeweidemasse kurz kegelförmig, I I $\mathrm{mm}$. lang bei einer Breite vorne von 5,5, wegen des dünnen Lagers der Zwitterdrüse an der Aussenseite röthlichgelb; die Leber rothbraun.

Die vordere Genitalmasse herzförmig, von 5,5 mm. grösstem Durchmesser; die Ampulle des Zwitterdrüsenganges bräunlichgrau, die Schleimdruise röthlich.

Trotz wahrscheinlichen Abweichungen in der Farbe der Rhinophorien und der Kieme liegt hier doch wohl nur eine Varietät der Chr. Semperi vor.

4. Chromodoris lincolate (van Hass.). Taf. IV, Fig. 7. Taf. XVI, Fig. I1-I 2.

Doris lineolata van Hass. Brief. 1. c. I $824, \mathrm{~N}^{0} 2$, p. 22.

Chromodoris lincolata Bgh. MIalacolog. Unters. I (Heft VI), i874, Tab. XXXIII, Fig. 4 (SEMPER). Chromodoris lineolata (van Hass.). BERGH, Die VAN HASSELT'schen Nudibranchien. Notes from the Leyden Mus. 1887, p. $388-389$.

Chromodoris striatclla Bgh., 1. c. II (Heft XI), IS77, p. 474-478. Taf. LI, Fig. 24-25.

Chromodoris striatella Bgh. Rep. (Challenger-Exped. Zool. X) I884, p. 73-76. Pl. III, Fig. 26-29; Pl. IV, Fig. I-4.

Chromodoris funerea Collingwood. On some new sp. of nudibr. moll. Trans. Linn. Soc. II, 2. 1881 , p. 131-132. P1. IX, Fig. 11-12.

In der Nähe von Gunong.Api (St. 310 ) wurde in $73 \mathrm{MI}$. Tiefe ein Individuum gefischt 
und lebend abgebildet; die Abbildung ist der von SEMrer gegebenen ziemlich ähnlich und weicht nicht sehr von der von Collingwoon ab.

Das lebende Thier scheint eine Länge von 5,2 cm. bei einer Breite bis I gehabt zu haben. Die Grundfarbe der Rückenseite hell gräulich, aber fast verdrängt clurch dichtstehencle feine gelbliche Längslinien; nach aussen am Rückengebräm feine schwärzliche Lïngsstriche, der Rückenrand gelb; die Rhinophorien und die Kieme roth; der Fussrücken mit schwärzlichen Längsstrichen, der Fussrand gelb.

Das a ufbewahrte Individuum hatte eine Länge von 32 bei einer Breite von $12 \mathrm{~mm}$. und einer Höhe bis 8 , die Höhe der Kieme bis $5 \mathrm{~mm}$. Die Grundfarbe des Rückens war schmutzig gelblich mit vielen dünnen, bräunlichen, continuirlichen oder in Stücke gebrochenen Linien; am Rückengebräm ringsum längere oder kürzere Längsstriche. Die Körperseiten schmutzig hell gelblich mit mehreren (etwa 7) stark in Stiicke gebrochenen Langslinien, von welchen mehrere sich auf den Schwanz fortsetzten.

Die Formverhältnisse die gewöhnlichen; die Kieme zeigte sich von I 2 Blättern gebildet.

Diese Form ist schon mehrmals anatomisch untersucht worden (1. c. XI, 1877, p. 477. Journ. d. Mus. Godeffroy. Heft XIV, I878, p. 5. - 1. c. I $88+$, p. $7+-76$. Pl. III, Fig. $26-2-21$ : Pl. IV, Fig. I-4).

\section{Taf. XVI, Fig. I I-I 2 .}

Am 25 Juli wurde an Riffe von Beo auf der Insel Karakelang (St. I31) ein Individuum gefangen. In der Sanana-Bai an der Ostküste von Sula Besi (St. I93) wurden später zwei kleinere Individuen erbeutet.

Die Länge des stark zusammengezogenen Thieres betrug $24 \mathrm{~mm}$. bei einer Breite von I 3 und einer Höhe von 7 ; die Breite des Rückengebräms war 4 ; die Höhe der ganz zurickgezogenen Rhinophorien fast 2, der ebenso verborgenen Kieme 2,5 mm.; die Breite des Fusses war 6, die Länge des Schwanzes 4. - Die Fusssohle war schmutzig gelblichweiss; die Grundfarbe des Thieres sonst schmutzig braun. Der Rücken war von einer ziemlich grossen Anzahl von (in der Mitte der Länge etwa 40) weissen Lingslinien durchzogen, die mehr nach aussen liegenden gehen vor den Rhinophorien und hinter der Kieme bogenartig in einander über. An der Unterseite des Rückengebräms fanden sich etwa 5-6 ähnliche Linien, an den Körperseiten beiläufig 8 und am Fussgebräm 3. Die demselben Körpertheil angełörenden Linien waren meistens von derselben Breite, die der Körperseiten waren die breitesten; die Linien waren meistens continuirlich, seltener in mehrere Stiicke getheilt, mitunter anastomosirten sie. Der Rückenrand stark rothgelb, und der schmalere Fussrand von ähnlicher Farbe. Die Keule der Rhinophorien unten braunschwarz, oben rothbraun, aber nur mit Spuren von weissen Flecken oder Ringen; die Kieme an der Aussenseite unten schwarzbraun, oben rothgelb, ebenso die Innenseite und hier mit Spur von weissen Fleckchen; die Analpapille braun mit rothgelber Spitze; die kleinen Tentakel schwarzbraun am Grunde, sonst rothgelb.

Die Form war länglich-oval. Der Rücken glatt, mit nicht schmalem Gebräm; die Kiemenspalte queroval, von $2 \mathrm{~mm}$. Durchmesser, von ihrem Rande gleichsam strahlten die weissen 
Linien ringsum aus. Die Kiemenblätter in 4 Gruppen undeutlich geordnet, ihre Zahl im Ganzen etwa 19, die hintersten die kleinsten, und einige Blätter in der Spitze gespalten.

Die Mundröhre 2,5 mm. lang. Der gleichfalls gelblichweisse Schlundkopf $4 \mathrm{~mm}$. lang bei einer Breite von 3,5 und einer Höhe von 2,5; die Raspelscheide hinten etwas vortretend. Die bis $0,5 \mathrm{~mm}$. breiten, hellgelblichen Mandibelplatten von den gewöhnlichen, gebogenen, an der Spitze geklufteten Elementen von einer Höhe bis $0,05 \mathrm{~mm}$. gebildet (Fig. I I). Bei dem Erhärtungszustande war es unmöglich die Anzahl der Zahnplattenreihen der Zunge oder die Zahl der Platten in den Reihen zu bestimmen; in der Raspelscheide kamen wenigstens 7o Reihen ror. Die Zahnplatten von der bei anderen Chromodoriden gewöhnlichen Form, mit einigen Dentikeln des Hakenrandes (Fig. 12); sie waren fast farblos, von einer Höhe bis O, IO mm.

Die Eingeweidemassen nach oben von einer schwarzbraunem Hülle bedeckt.

Die hintere Eingeweidemasse (Leber) schlauchförmig, aussen wie innen gelblich, Io mm. lang bei einer Breite vorne von 5; die schwarze Gallenblase $1 \mathrm{~mm}$. lang. - Die Nierenspritze weisslich, I,5 mm. lang. Die weissliche vordere Genitalmasse von $4 \mathrm{~mm}$. Durchmesser, weisslich.

Die hier untersuchte Form gehört sicherlich der von Colcrwawood dargestellten Art an, hat nur viel weniger ausgeprägte weisse Punkte an den Rhinophorien und an den Kiemenblättern.

5. Chromodoris marginata (Pease). Taf. III, Fig. I3. Taf. XVI, Fing. 13-15.

Doris marginata Pease. Proc. zool. soc. XXVIII, I860, p. 30.

Chromodoris marginata (Pease). R. BERGH, Malacolog. Unters. IV (Supplementheft I), ISSO, p. 27. Taf. B, Fig. 22-23 (PEASE).

Auf einem Riffe bei Saleyer (St. 213) wurden zwei Individuen gefangen und das eine lebend abgebildet.

Das lebende Thier soll eine Länge von $\mathrm{I}_{3} \mathrm{~mm}$. bei einer Breite von fast 3 haben. Die Farbe der Rückenseite soll weisslich, längs der Mitte mehr gelblich und gräulich gewesen sein, der Rückenrand ringsum roth; die Rhinophorien, die Kieme und der Schwanz hell violet.

Die a ufbewahrten Individuen waren $8-9 \mathrm{~mm}$. lang bei einer Breite von 5 und Höhe von 3. Die Farbe war durchgehends gelblich, der Rand des Rückens meistens noch rothgelb. - Die Formverhältnisse die gewöhnlichen, die Kieme bei beiden von 7 Blättern gebildet. In den inneren, selbst in den Farben-Verhältnissen stimmten die beiden Individuen auffallend mit einander überein.

Das weissliche Centralnervensystem mit den Augen und Ohrblasen wie gewöhnlich. In den Blättern der Rhinophorien so wenig wie in der Haut kamen (wenigstens grössere) Spikel nicht vor.

Die Mundröhre $1,2 \mathrm{~mm}$. lang. Der gleichfalls weissliche Schlundk opf I mm. lang; die ziemlich breiten Lippenplatten gelb, von den gewöhnlichen, verschiedenartig gebogenen, in der Spitze oft ein wenig geklüfteten Elementen (Fig. I3) gebildet, die eine Länge bis 0,035 mm. bei einem Durchmesser von 0,006 hatten. In der schwach gelblichen Raspel der Zunge 22 Zahnplattenreihen und in der Scheide deren noch 32, die Gesammtzahl der Reihen somit 54. 
In den Reihen kamen bis 35 Platten an jeder Seite der schmalen Rhachis vor, deren dreieckige falsche Platten eine Läinge von o,ort mm. hatten. Die Platten von der gewöhnlichen Form, die innerste an beiden Rändern des Hakens gezähnelt, die nächste zeigte noch $1-2$ Dentikel am Innenrande, alle die folgenden mit gewöhnlicher Denticulation des Aussenrandes (Fig. 1 + ), die äussersten (etwa 8) nur an der Spitze gezähnelt (Fig. I5). Die fast farblosen Platten erreichten eine Höhe bis o,o6, die der äussersten betrug 0,0,t mm. - Die langen, fast cylindrischen Speicheldrisen schwarz oder schwarzbraun.

Die heller oder dunkler olivenfarbige Leber abgestutzt kegelförmig, $+\mathrm{mm}$. lang bei anderen Durchmessern von 2. Die fast kugelförmige Gallenblase an der rechten Seite der Cardia liegend, schwärzlich oder gräulich.

Die röthlichgelbe $Z$ witterdrüse mit ihren Läppchen die untere und die rechte Seite der Leber überziehend; in den Läppchen reife Geschlechtselemente. Die etwas längliche vordere Genitalmasse weisslich und braun; die Samenblasen gross.

Vielleicht ist diese Form die von PEaSE dargestellte Doris marginata.

6. Chromodoris flammlata Bgh. n. sp. Taf. IV, Fig. 9. Taf. XVI, Fig. I6-ig

Ein einziges Individuum dieser kleinen schönen Form wurde am Riffe der Insel Pajunga in der Kwandang-Bai (St. I I5) gefangen und lebend abgebildet.

Das lebende Thier hatte eine Länge von 12 bei einer Breite von $3,5 \mathrm{~mm}$. Die Grundfarbe der Rückenseite war karminroth, dunkler längs des medianen Rückenbandes; dasselbe war weisslich, breiter am Vorder- und Hinterende (um die schwärzlichen Rhinophorien und die schwärzliche Kieme) und noch dazu mit (4) symmetrischen seitlichen Erweiterungen; die Rückenseite des Schwanzes weisslich.

Das a ufbewahrte Individuum hatte eine Länge von 9 bei einer Breite von 3.5 und einer Höhe von 2,5 mm.; die Breite des Fusses vorne 2, sonst I, $25 \mathrm{~mm}$., die Höhe der vorgestreckten Rhinophorkeule I mm. - Die Farbe war durchgehends hell schmutzig gelb (mit schwachen, blassen, im Detail erhaltenen Spuren vom erwähnten Bande), die Rhinophorkeule schwarz, und die Kieme grünlich schwarz. Eingeweide schimmerten nicht durch.

Das Thier war von länglich-ovaler Form; der fast ebene Rücken vorne und hinten breitgerundet; das Gebräm vorne und hinten mehr als an den Seiten aber im Ganzen nicht sehr vortretend, sehr wenig gebogen; das weit nach hinten liegende runde Kiemenloch von 0,5 mm. Durchmesser, die Kieme aus 7 Federn gebildet. Die Tentakel kurz, fingerförmig. Die Körperseiten ziemlich hoch, gegen den Fuss etwas schräge abfallend. Der Fuss vorne etwas breiter, gerundet, sonst fast ebenbreit; der Schwanz den Körper überragend, etwas zugespitzt.

Das Centralnervensystem wie bei anderen Chromodoriden. Die Rhinophorkeule mit etwa 15 diunnen Blättern.

Der Schlundkopf schmutzig gelblich, fast kugelförmig, I,5 mm. lang; die Raspelscheide hinten hervorragend. Die Lippenplatten stark bräunlichgelb; ihre Elemente (Fig. I6) gebogen, bis $0,025 \mathrm{~mm}$. lang, gekliftet in der Spitze. In der fast farblosen Raspel der Zunge 
wurden 25 Zahnplattenreihen gezählt und in der Scheide 26, die Gesammtzahl der Reihen wäre somit 51. In den Reihen wurden bis 40 Zahnplatten gezählt. Die Zahnplatten fast farblos, eine Höhe bis fast $0,06 \mathrm{~mm}$. erreichend, die der äussersten betrug 0,02-0,025. Die Form der innersten (Fig. I 7 ), der grössten (Fig. IS) und der äussersten (Fig. 19) wie bei den meisten Chromodoriden. Der spitze Haken trug mehrere (5-10) ganz feine Dentikel, an den (4-5) äussersten fehlte der Haken (Fig. 19).

Die Leber war fast schwarz. Die vordere Genitalmasse grau.

Diese Form scheint mit keiner der bisher abgebildeten Chromodoriden ubereinzustimmen.

7. Chromodoris marpessa Bgh. n. sp. Taf. IV, Fig. 10. Taf. XVI, Fig. 20-2I.

Am Ankerplatz von Nord-Ubian (St. 99) wurde ein Individuum gefangen und lebend abgebildet.

Lebend soll dasselbe eine Länge von 12,5 bei einer Breite von 3,5 mm. gehabt haben. Die Farbe der Rückenseite scheint gelblich gewesen zu sein; der Rückenrand weiss, innerhalb desselben ein schmales violettes und dann ein gelbes Band; die Keule der Rhinophorien karminroth; die Kiemenblätter gelb.

Das a ufbewahrte Individum hatte eine Länge von I I bei einer Breite von 5 und einer Höhe von $3.5 \mathrm{~mm}$; das runde Kiemenloch bei vorgestreckter Kieme von einem Durchmesser von 2,5, die Kiemenblïtter bis $2 \mathrm{~mm}$. hoch. Die Farbe war gelblich, das Riickengebräm aussen roth, die Rhinophorien stark roth, die Kieme röthlichgelb.

Die Formverhältnisse die gewöhnlichen, das Rïckengebräm nicht schmal, das Stirn- und Schwanzsegel ziemlich stark; ron den to Kiemenblättern waren die vordersten die stärksten; die Tentakel klein, fingerförmig.

Das Centralnervensystem hell gelblich.

Die Nundröhre I mm. lang. - Der weissliche Schlundk opf kurz-birnförmig, 2,5 mm. lang und breit, mit hinten etwas vortretender Raspelscheide; der hohe und breite Lippenring gräulichgelb, mit Elementen gewöhnlicher Art bis $0,02 \mathrm{~mm}$. hoch und in der Spitze geklüftet (Fic. 20). Die Raspel der Zunge hell gelblich; die genauere Bestimmung der Anzahl der rielen Zahnplattenreihen und die Zahl der vielen Platten in den Reihen war nicht möglich. Die Zahnplatten, die innersten so wie die mittleren (Fig. 2 I) und äussersten, von den gewöhnlichsten Formverhältnissen; sie erreichten eine Höhe bis $0,0 S$, die äussersten waren etwa $0,035 \mathrm{~mm}$. hoch. - Die Speicheldrüsen wenigstens doppelt so lang wie der Schlundkopf, fast cylindrisch, dem Anscheine nach schwarz, genauer untersucht zeigten sie sich dunkel schmutzig grün.

Die graue, kurz kegelfömige Leber maass an Länge $5 \mathrm{~mm}$., ihr Vorderende und ein grosser Theil der oberen Seite war von der gelblichweissen Zwitterdruise überzogen. - Die weissliche vordere Genitalmasse $3 \mathrm{~mm}$. lang.

Diese Form wird vielleicht später (an den Speicheldruisen) wieder erkannt werden können. 
S. Chromodoris venuste Bgh. n. Sp. Taf. XVI, Fig. $22-25$

Am Ankerplatz östlich von Sailus Besar, Paternoster-Inseln (St. 3i5) wurde ein Individuum gefangen.

Dasselbe war schlecht bewahrt, die Bedeckungen des Rückens und der Körperseiten theilweise abgenutzt. Die Länge betrug 33 bei einer Breite von 9 und Höhe von 8 mm.; das Rückengebram bis $4 \mathrm{~mm}$. breit, die Höhe der Rhinophorien 4, der Kieme 5, die Länge des Schwanzes $9 \mathrm{~mm}$. - Die Farbe war gelblichweiss, am Körper fanclen sich zerstreute kleine rundliche blutrothe Flecken von einem Durchmesser bis fast $0,4 \mathrm{~mm}$., an der oberen Seite des Rückengebräms kamen sie häufiger vor, ebenso am Fussgebräm.

Die Formverhältnisse die gewöhnlichen; das Rückengebräm stark wellenartig gebogen; die Kieme von 12 Blättern gebildet, einige der grösseren an der Spitze gabelig.

Die starke Mundröhre $4 \mathrm{~mm}$. lang. Der gelbliche $\mathrm{Schlundkopf} 5 \mathrm{~mm}$. lang bei einer Höhe und Breite von 4,5; die kräftige Raspelscheide stark nach hinten und unten vortretend. Die oben und unten zusammenstossenden, dunkel chocoladefarbigen Lippenplatten oben breiter, nach unten verschmälert, 2,5 $\mathrm{mm}$. hoch bei einer Breite bis 1,5 ; ihrè gebogenen Elemente (Fig. 22) bis O, I I mm. lang bei einem Durchmesser von etwa 0,007 , in der Spitze mit $2-\hat{3}$ schwachen Einkerbungen. Die gelbrothe Raspel der $\mathrm{Zunge}$ und ihre Fortsetzung maassen zusammen 5,5 mm. an Länge. In der Raspel selbst kamen 24, in der Scheide 60 Zahnplattenreihen vor, die Gesammtzahl derselben somit 84. In den Reihen kamen wenigstens etwa 100 Platten an jeder Seite der dreieckigen rhachidialen (Fig. 23a) Verdickungen vor; diese letzteren etwa $0,06 \mathrm{~mm}$. lang bei einer Breite bis 0,034 . Die Zahnplatten wie bei anderen Chromodoriden hakenartig mit fein denticulirtem Haken, eine Höhe bis $0,12 \mathrm{~mm}$. erreichend (Fig. 24); die äussersten nicht denticulirt (Fig. 24), die äusserste von einer Höhe von 0,04-0,05 mm. (Fig. 25).

Die langen dünnen weisslichen Speicheldrüsen wie gewöhnlich. - Die Speiseröhre schwarzbraun. Der Darm stark geschlängelt, $4 \mathrm{~cm}$. lang bei einem Durchmesser von 0,5-I mm. Die hintere Eingeweidemasse wurstförmig, I $3 \mathrm{~mm}$. lang bei einer Breite von 7; an der Oberfläche feinkörnig, chocoladebraun (dünnes Zwitterdrüsenlager), im Inneren schwarz (Leber); die Niere weisslich.

Die vordere Genitalmasse fast kugelig; von $5,5 \mathrm{~mm}$. Durchmesser; die Ampulle des Zwitterdruisenganges schwarzbraun; die Masse sonst mitsammt den Samenblasen hellgelb.

9. Chromodoris ophthalmica Bgh. n. sp. Taf. IV, Fig. 8. Taf. XVI, Fig. 26-27.

Am Ankerplatz bei der Insel Salomakië (Damar) (Stat. 144) wurde ein Individuum erbeutet und lebend abgebildet.

Lebend hatte dasselbe eine Länge von 3,5 bei einer Breite von I cm. Die Grundfarbe der Rückenseite war hell gelblich, aber vom Roth fast verdrängt, das am eigentlichen Ruicken heller, am Gebräm stärker, fast karminroth war; der Rückenrand gelb; an beiden Rändern des eigentlichen Rückens 4 schöne Augenflecke mit dunkler Pupille; die Rhinophorien mit weissem Stiele und rother Keule; die Kieme gelb; der Schwanzrïcken bläulich mit gelbem Rande.

Das a ufbewahrte Individuum war $23 \mathrm{~mm}$. lang bei einer Breite von 12 und Höhe 
von 8 ; die Breite des Rückengebräms 3,5, die Breite des ausgeschlagenen Kiemensterns 5, die Höhe seiner Blätter bis 2,25 mm; die Breite des Fusses 6, die Länge des Schwanzes 4 mm. Von der früheren Farbenpracht war absolut nichts übrig, in ein allgemeines Weiss übergegangen, nur die Keule der Rhinophorien röthlich. Die Eingeweide schimmerten grau durch die Körperseiten.

Die Formverhältnisse die gewöhnlichen, Stirn- und Schwanzsegel nicht gross, der Rückenrand wenig hinauf- und hinabgebogen; die Kieme aus ro Blättern gebildet, der Kreis hinten durch die wenig vorspringende Analpapille geschlossen; der Schwanz überragte den Körper.

Die starke Mundröhre röthlich, 2,5 mm. lang. Der schwach röthlichweisse Schlundkopf von kurzer Birnform, $3 \mathrm{~mm}$. lang; die schmutzig braunen Lippenplatten von den gewöhnlichen gebogenen, in der Spitze geklüfteten Elementen (Fig. 26) gebildet, die eine Lïnge bis $0,05 \mathrm{~mm}$. erreichten. Die schwach gelbliche Raspel enthielt etwa 50 Zahnplattenreihen, in der Scheide schienen deren noch etwa 30 vorzukommen. An jeder Seite der ganz schmalen Rhachis kamen etwa IOO Platten vor. Die innerste Platte wie gewöhnlich an beiden Seiten des Hakens gezähnelt; die anderen von gewöhnlicher Form, am Aussenrande des Hakens fein denticulirt (Fig. 27), eine Höhe bis $0,09 \mathrm{~mm}$. erreichend; die äussersten Zahnplatten wie gewöhnlich.

Die hintere Eingeweidemasse kurz-wurstförmig, Io mm. lang bei einer Breite von 6; die schwarze Leber von den (Quer-)Strichen der gelblichen Zwitterdruse zum grossen Theil bedeckt.

Die weissliche vordere Genitalmasse 4 mm. lang; der Penissack von 1,5 mm. Länge.

ro. Chromodoris nodulosa Bgh. n. sp. Taf. XVI, Fig. $28-3 \mathrm{r}$.

Auf einem Riff bei Ambon wurden zwei Individuen gefangen.

Das kleinere hatte nur eine Länge von $4,2 \mathrm{~cm}$., stimmte sonst in allen Verhältnissen mit dem grösseren überein. Dieses letztere, näher untersuchte war $5 \mathrm{~cm}$. lang bei einer Breite von 2,8 und einer Höhe von 1,3; die Breite des Rückengebräms 9 mm., die Höhe der Rhinophorien 5, die Weite der Kiemenspalte 8, die Höhe der Kiemenblätter bis 7; die Breite des Fusses 15, die des Fussgebräms 6, die Länge des Schwanzes $9 \mathrm{~mm}$. - Die Farbe war durchgehends schwach-gelblichweiss, die Rhinophorien und die Kieme mehr gräulich. Die Consistenz ganz weich, schlaff.

Die Form länglich-oval, etwas abgeplattet. Der Rücken überall mit rundlichen ebenen weissen Knoten meistens von einer Höhe und einem Durchmesser von $2 \mathrm{~mm}$. bedeckt, am breiten Gebräm waren sie kleiner; der Rand ein wenig wellenförmig gebogen, dünn; der Rand der Rhinophor- und der Kiemenhöhle eben; der Durchmesser der Kiemenspalte war 7 mm.; die Anzahl der Kiemenblätter 16, von welchen die 3 hintersten jederseits klein, die grösseren waren oft oben in 2-3 längere oder kürzere Zipfel gespalten; die Analpapille central stehend, vorne und rechts neben ihr die kleinere Renalpapille. Die Tentakel klein fingerförmig. Der Fuss vorne gerade, mit starker Randfurche; das Gebräm breit; der hinten gerundete Schwanz den Rücken ein wenig ibberragend.

Das Centralnervensystem gelblich. Die Rhinophorien mit etwa 25 Blättern der Keule. Die Haut ohne (grössere) Spikel. 
Die starke Mundröhre weiss, $5 \mathrm{~mm}$. lang. Der weisse Schlundkopf $6 \mathrm{~mm}$. lang bei einer Höhe und Breite von 5; die Lippenplatten $1,5 \mathrm{~mm}$. breit, chocoladefarbig, ihre bei einer Breite von 0,005 bis $0,05 \mathrm{~mm}$. langen Elementen (Fig. 28) verschiedenartig gebogen, meistens in der Spitze ein wenig gekluftet. Die hell röthlichbraune Raspel enthiclt $4+$ Zahnplattenreihen und in der Scheide kamen noch 5 I vor, die Gesammtzahl der Reihen somit 95; in den Reihen fanden sich etwa roo Platten. Die Höhe derselben stieg bis 0,14 , die der äussersten betruy $0,08 \mathrm{~mm}$; ihre Formverhältnisse waren wie bei anderen Chromodoriden, die innerste war an beiden Seiten des Hakens denticulirt, auch die nächste trug 2 Dentikel am Innenrande (Fig. 29), die anderen waren alle nur an Aussenrande denticulirt (Fig. 30), die (Fig. 31) äussersten nur an der Spitze, und die gebogene Spitze des Hakens reducirt. - Die Speicheldriisen braungelb.

Die Speiseröhre schwarz, $12 \mathrm{~mm}$. lang. Der sackartige schwärzliche Magen Io mm. lang, mit unbestimmbarer thierischer, mit Eiern vermischter dunkler Masse; der etwas geschlängelte Darm ausgestreckt $4 \mathrm{~cm}$. lang bei einem Durchmesser von $2 \mathrm{~mm}$. - Die kurz-wurstförmige hintere Eingeweidemasse $16 \mathrm{~mm}$. lang bei anderen Durchmessern von 9; die schwarze Leber war am Vorderende entblösst, sonst hier und da inselartig von dem schwach röthlichgelben Lager der Zwitterdrüse bedeckt; in den Läppchen derselben reife Geschlechtselemente. Die kurz-sackförmige Gallenblase weisslich, $4 \mathrm{~mm}$. lang.

Der Herzkammer $3 \mathrm{~mm}$. lang; die Blutdrüsen weisslich, gross, mit viellappiger Oberfläche. Die Niere mit stark entwickelten Röhren; die gelbliche Nierenspritze I,5 mm. lang.

Die vordere Genitalmasse von ovalen Umrissen, $7,5 \mathrm{~mm}$. lang, gelblichweiss; die Ampulle des Zwitterdrüsenganges nicht lang, bräunlich; die gräuliche Spermatotheke von 2 mm. Durchmesser, die gelbliche Spermatocyste etwas grösser.

Durch ihr breites Rückengebräm unterscheidet sich diese Art auffallend von anderen Chromodoriden.

II. Chromodoris pantherina Bgh. n. sp. Taf. XVI, Fig. 32-34.

Mit Exemplaren von Marsenia perspicua und Halla indecora zusammen fand sich ein am Ankerplatz von Pulu Jedan an der Ostkiste der Aru-Inseln (St. 273) gefangenes Individuum.

Dasselbe war (ziemlich stark zusammengezogen) $7 \mathrm{~mm}$. lang bei einer Breite von 5 und Höhe von 3. - Die Farbe war durchgehends weiss; gegen dieselbe contrastirten sehr stark mehrere (S) am Rücken zerstreute runde, scharf begrenzte, rothe, ein wenig papelartig vortretende Flecken von einem Durchmesser von $0,4 \mathrm{~mm}$; die Rhinophorien roth, ebenso und noch stärker die Kiemenblätter, die Schwanzspitze roth.

Die Formverhältnisse die gewöhnlichen; das Rückengebräm ziemlich breit, seine Unterseite ganz glatt; die $1 \mathrm{~mm}$. hohe Kieme aus 7 Blättern gebildet; der Fuss ziemlich schmal, der Schwanz I,5 mm. lang. - Die Eingeweide schimmerten nirgends durch.

Der weissliche Schlundkopf I, $25 \mathrm{~mm}$. lang; die Elemente der breiten gelben Lippenplatten etwas abgeplattet, von $0,03 \mathrm{~mm}$. Länge, in der Spitze gabelig (Fig. 32). Die Raspel fast farblos, mit vielen Zahnplattenreihen und in der Scheide deren noch etwa 50. Die Anzahl der Platten in den Reihen gross, wenigstens 150. Die Platten fast farblos; die Höhe der 
innersten betrug 0,0I6, sie stieg bis 0,045 um nach aussen bis zu 0,013 mm. zu fallen. Die Zahnplatten waren denen der meisten Chromodoriden ganz ähnlich (Fig. 3t), die innersten (Fig. 33) wie die äussersten.

Die Leber gelblich, 3,25 mm. lang.

12. Chromodoris papulosa Bgh. n. sp. Taf. XVI, Fig. 35-37.

Mit Casella mbra zusammen wurden in der Bai von Labuan Badjo zwei Individuen dieser neuen Chromodoris gefangen.

Dieselben hatten aufbewahrt eine Länge von IO-I I bei einer Breite von 5 und einer Höhe von 4 mm., die Breite des Rückengebräms war I,5, der Durchmesser der querovalen Kiemenspalte I mm.; die Breite des Fusses (vorne) 2, die Länge des Schwanzes 2,5 mm. - Die Farbe des Fusses und des Rückens rothgelb, an dem letzteren kamen zahlreiche dunklere Papel vor; die (I mm. hohen) Rhinophorien, die Kieme und die Körperseiten von etwas hellerer Farbe.

Die Form des Rückens oval; die erwähnten Papel kamen in ziemlich grosser Anzahl vor, meistens klein mit einigen grösseren (von einem Durchmesser bis $0,4 \mathrm{~mm}$.) vermischt. Die Anzahl der $(1,5 \mathrm{~mm}$. hohen) Kiemenblätter bei den zwei Individuen $6-8$, von welchen die hintersten kleiner. An der Unterseite des Schwanzsegels kam nach aussen jederseits eine (dunklere) grössere Cyste vor, und mehr median eine ebenso grosse oder kleinere, der Art wie bei verschiedenen anderen Chromodoriden ${ }^{1}$ ). Die Körperseiten nicht niedrig; der Kopf mit kleinen kegelförmigen Tentakeln. Der Fussrand vorne mit Randfurche und wenig vortretenden Ecken, das Fussgebräm schmal; der das Schwanzsegel überragende starke Schwanz zugespitzt.

Das Centralnervensystem wie gewöhnlich. Die Augen von o, $10 \mathrm{~mm}$. Durchmesser, mit grosser röthlichgelber Linse. In den Blättern der Rhinophorien wurden keine Spikel gesehen. In den Papeln des Rückens dicht gedrängte Drüschen. In den Knoten an der Unterseite des Schwanzsegels die gewöhnlichen Bälge.

Die Mundröhre etwas länger als der I mm. lange Schlundkopf. Die fast farblosen (etwa 0,I6 mm.) breiten Mandibel aus etwa 0,02 mm. hohen, etwas gebogenen, in der Spitze geklüfteten Elementen (Fig. 35) zusammengesetzt. Die breite Zunge mit fast farbloser Raspel; weder die Zahl der Zahnplattenreihen, noch die Anzahl der Platten in den Reihen konnten bestimmt werden. Die farblosen Zahnplatten erreichten eine Höhe von $0, \mathrm{O}_{3} \mathrm{~mm}$; sie waren von gewöhnlichen Formverhältnissen, zeigten an der Spitze einen kleinen gebogenen Haken und am Aussenrande neben demselben einige wenige (3-5) kleine Dentikel (Fig. 36); die niedrigen äusseren zeigten nur die Spitze fein denticulirt (Fig. 37).

Die Speicheldriisen wie gewöhnlich lang und dün, ziemlich stark knotig.

Die hintere Eingeweidemasse (Leber) $4,5 \mathrm{~mm}$. lang, hell graugelblich; die Zwitterdrüse mehr gelb. - Die vordere Genitalmasse Meniscusartig, $3 \mathrm{~mm}$. lang, graugelblich mit brauner Eiweissdrise.

Eine neue Art scheint hier vorzuliegen.

1) Chromodoris runcinati, picturata, camoena, ilesans, slanca, fanthasellu, californicnsis, sonatophora, juzrenca, Agassizii, stcilla, Marenzilleri, sannio. 
13. Chromodoris Sibogae Bgh. n. sp. Taf. XVI, Fig. $38-39$.

Am 26 Jan. wurde am Ankerplatz von Noimini an der Suidkiiste von Timor (St. 296) am Riffe ein Individuum gefangen, das in Formol bewahrt etwas verdreht und sehr erhirtet war.

Dasselbe hatte eine Länge, von etwa $30 \mathrm{~mm}$. bei einer Breite von i 7 und einer Höhe von 6; das Rückengebräm bis $5 \mathrm{~mm}$. breit; die Rhinophorscheiden 1, der Kiemenhügel 2 mm. hoch (bei zurickgezogenen Organen); die Rhinophorien 2, die Kiemenblätter bis $2,5 \mathrm{~mm}$. hoch: die Fusssohle $5 \mathrm{~mm}$. breit, der Schwanz $6 \mathrm{~mm}$. lang. - Die Farbe war durchgehends weisslich, vorne und hinten am Rücken so wie an den Körperseiten schmutzig gelblich; oben am Rückengebräme, dessen Rand eine graue sehr ausgeprägte Linie zeigte, kamen sparsam zerstreute, runde und mehr unregelmässige, kalkweisse Flecke von einem Durchmesser bis 2 mm. vor: die Keule der Rhinophorien so wie die Kiemenblätter braungrau.

Die Form oval; das breite Rückengebräm (jetzt) stark aufwärts und abwärts gebogen, an der Unterseite glatt; der Kiemenhügel von vorne nach hinten etwas zusammengedrückt, mit 2 mm. breiter Querspalte, die Zahl der Kiemenblätter genau 12; die Breite dés Kopfes mit den gleichsam eingestülpten Tentakeln 4 mm., der Fuss ziemlich schmal.

Das Centralnervensystem wie gewöhnlich. Die Augen von einem Durchmesser von o, ro mm.

Die starke Mundröhre $6 \mathrm{~mm}$. lang bei einem Durchmesser hinten von 3. Der weissliche Schlundkopf $3 \mathrm{~mm}$. lang; die hohen und breiten, blass gelblichen Lippenplatten aus den gewöhnlichen, etwas gebogenen, bis $0,03 \mathrm{~mm}$. langen, in der Spitze geklüfteten Elementen (Fig. 38 ) gebildet. Die ganz blass gelbliche Raspel der Zu nge enthielt 109 Zahnplattenreihen, die Scheide noch dazu 97, von welchen die 6 hintersten noch unreif; die Gesammtzahl der Reihen somit 206. In den Reihen kamen aber nur bis 55 Platten vor. Die fast farblosen Platten zeigten meistens die Grundplatte von einer Länge von 0,020 , und die Höhe des Hakens war auch etwa $0,020 \mathrm{~mm}$. Die innerste Platte an beiden Rändern gezähnelt, die folgenden nur am Aussenrande (Fig. 39), und die des ungefähr äussersten Fünftels der Reihen zeigten die Grundplatte verkürzt und den Haken nicht oder nur an der Spitze denticulirt.

Die Speicheldrüsen, der Magen und der Darm wie gewöhnlich. Die gelbliche Leber kurz-kegelförmig, $9 \mathrm{~mm}$. lang bei einer Breite vorne ron 3. - Die vordere Genitalmasse kugelförmig, von einem Durchmesser von $3 \mathrm{~mm}$, weisslich und gelblich.

Die Art scheint in der Nähe von Chr. vibrata (Pease) ${ }^{2}$ ) und von Chr. albonotata von BERGH ${ }^{2}$ zu stehen, von beiden aber doch verschieden zu sein.

I4. Chromodoris inopinata Bgh. n. sp. Taf. II, Fig. 6. Taf. XVI, Fig. $48-52$.

Am 26 October wurde auf einem Riffe in der Nähe des nördlichsten Punkts der Insel Saleyer (St. 213) ein Individuum gefangen, nach dem Leben abgebildet und in Formol bewahrt.

I) Proc. zool. soc. of L.ondon. XXVIII, IS60, p. 28 .

R. Bergi, Malacol. Linters. III (Supplementheft 1) rSSo, p. 26. Taf. B, Hig. IS-21.

2) Journ. d. Mus. Godeffroy. Heft VIII, IS75, p. 24. Taf. VII, Fig. I. - Ifeft XIV, IS7S, p. 5. 
Dasselbe hatte lebend eine Länge von vollen $6 \mathrm{~cm}$. bei einer durchgehenden Breite ron 2,5, der Durchmesser der ausgebreiteten Kieme ist $2 \mathrm{~cm}$. gewesen. - Die Grundfarbe des Thieres scheint gelblich gewesen zu sein, aber durch dichtstehende kleinste rothbraune oder purpurfarbige Ringe fast ganz verdrängt, am Rücken kommen noch zerstreut mehrere grössere. hell gelbliche, runde Flecken vor; der Rücken ist ringsum von einem Doppeltbande eingefasst; einem etwas breiteren purpurfarbigen inneren und einem schmaleren weissen äusseren; die grosse Kieme ist weisslich, die Keule der Rhinophorien röthlich.

Das a ufbewahrte ganz schlaffe und weiche Thier hatte eine Länge von $6 \mathrm{~cm}$. bei einer fast durchgehenden Breite von 3 und einer Höhe von 1,2 ; die Breite des Rückengebräms war 8 mm., die Höhe der vorgestreckten Kieme 6, der Rhinophorien 4; der Fuss etwa so lang und breit wie der Rücken, das Fussgebräm 4-5 mm. breit, der Schwanz $9 \mathrm{~mm}$. lang. Die Farbe war durchgehends hell schmutzig gelb, die Kieme so wie die Keule der Rhinophorien hell bräunlichgelb; von der vorigen Farbenpracht existirten nur Spur des rothen und des weissen Bandes.

Die Form war länglich-oval, ähnlich am Vorderende wie am Hinterende gerundet. Der Rücken eben mit einzelnen zerstreuten runden etwas vorspringenden weichen Papeln von einem Durchmesser von $2 \mathrm{~mm}$; die runden Rhinophorlöcher einfach. Der Rand des Kiemenloches etwas vortretend. Die Kieme aus vielen Blättern gebildet, die in 5 Gruppen auf ziemlich dicken Stielen gleichsam vertheilt waren; die einfach gefiederten Blätter (Fig. 52) waren an der Spitze oft getheilt, oder sie hatten Seitenästen; von den 5 Gruppen hatte eine etwa 5 , die folgenden S, S, 5 und 3 Blätter; die hintersten waren die kleinsten. Die Analpapille fast central, abgestutzt. Das Rückengebräm ziemlich breit, glatt an der Unterseite. Die Körperseiten ziemlich niedrig. Die Tentakel als kleine Kegel von einer Höhe von I,75 mm., an der Spitze gleichsam eingestuilpt. Der starke Fuss mit geradem Vorderrand mit Furche, die Ecken ein wenig vorspringend; das Fussgebräm breit; der Schwanz nicht kurz, hinten gerundet.

Die Eingeweide waren durch reichliche lockere, filzige Bindesubstanz in der Art innig mit den Körperwänden verbunden, dass sie ohne den Rücken und den Fuss zu beschädigen nicht blossgelegt werden konnten. Die Dicke dieser Einhüllung war so bedeutend, dass die herauspräpirte Eingeweidemasse mit derselben in Durchmesser $\mathrm{I}_{4} \mathrm{~mm}$. betrug, aus derselben herausgelöst nur $8-9$.

Das röthliche Centralnervensystem hatte einen Durchmesser von 2,5 mm., war sonst wie bei anderen Chromodoriden. Die A ugen von 0,16 mm. Diam. mit grosser, röthlichgelber, kugeliger Linse von einem Durchmesser von $0, I_{3} \mathrm{~mm}$. Die Keule der Rhinophorien mit etwa 40 Blättern, in denselben keine Spikel. Auch in der $\mathrm{Haut}$ des Rückens fanden sich keine Spikel und ïberhaupt kaum erhärtete Zellen, dagegen eine Unmasse von dicht gedrängten kleinen Drüsenzellen. - In der mit Wasser aufquillenden filzigen Bindesubstanz kaum erhärtete Zellen.

Die ausgestilpte Mundröhre von einer Länge von 6 bei einer Breite von $9 \mathrm{~mm}$. Der Schlundkopf von einer Länge von $5,5 \mathrm{~mm}$. bei einer Höhe und Breite von 3,5; hinten an der Unterseite ragte das Ende der Raspelscheide hervor; im Innenmunde die röthlichbraunen, starken, $3 \mathrm{~mm}$. hohen, $1 \mathrm{~mm}$. breiten Lippenplatten, aus Elementen gewöhnlicher Art gebildet, die gebogen, etwa $0,065 \mathrm{~mm}$. lang bei einem Durchmesser von 0,0055 und an 
der Spitze geklüftet waren (Fig. 48 ). Die starke Zunge mit sehr schwach gelblicher Raspel, die 52 Zahnplattenreihen enthielt; in der Raspelscheide kamen deren noch etwa 6o vor, die Gesammtzahl der Reihen somit 112. In den Reihen fanden sich etwa roo P’atten an jeder Seite der ganz schmalen Rhachis. Die Zahnplatten fast farblos; die Höhe der innersten betrug 0,04 mm, und die Höhe des Hakens stieg bis etwa 0,12 , die der äussersten war etwa 0,05. Die Platten wie bei anderen Chromodoriden (Fig. 49-51), in der äusseren Hälfte der Reihen war der Haken etwas schlanker (Fig. 50); die innerste war wie gewöhnlich an beiden Rändern gezähnelt (Fig. 49), die anderen nur einerseits und auch mit meistens 5-7 spitzen Dentikeln; an den äussersten zwei war die Grundplatte stark reducirt, und die schräge Spitze des Hakens gezähnelt (Fig. 5I).

Die rothen, (22 mm.) langen, etwas geschlängelten, schmalen, bandartigen Speicheldrüsen mit wenig höckeriger Oberfläche, hinten neben einander liegend sind sie an der Leber befestigt; der Ausfuhrungsgang ganz kurz.

Die Speiseröhre $12 \mathrm{~mm}$. lang. Der dicht vor der Mitte der Länge der Leber vortretende Darm in der nach vorn gehenden Strecke röthlich, ro mm. lang bei einem Durchmesser von 4; der nach hinten verlaufende Theil in der ersten Strecke geschlängelt, seine ganze Länge betrug $27 \mathrm{~mm}$. bei einem Durchmesser von 2. Die Verdauungshöhle war leer. - Die hintere Eingeweidemasse schlauchförmig, vorne ein wenig breiter als hinten, $18 \mathrm{~mm}$. lang bei einer Breite vorne von 9. Die Leber fast schwarz, mit Ausnahme des grössten Theils der Unterseite aber ganz von dem ziemlich dünnen Lager der gräulichrothen Zwitterdrüse überzogen.

Die röthlichen Blutdrisen durch das Centralnervensystem geschieden, $(2,5 \mathrm{~mm}$.) dick, gerundet-dreieckig; die vordere 3, die hintere $4,5 \mathrm{~mm}$. lang. - Das etwas röthliche pericardiorenale Organ klein von $0,75 \mathrm{~mm}$. Durchmesser.

In den Läppchen der Zwitterdrüse grosse Eizellen. Die vordere Genitalmasse fast kugelig, von $6 \mathrm{~mm}$. Durchmesser. Die gebogene Ampulle des Zwitterdrüsenganges braun und schwarz, $5 \mathrm{~mm}$. lang bei einem Durchmesser von I. Die schwarze kugelförmige Spermatotheke von einem Durchmesser von $2 \mathrm{~mm}$; die rothgelbliche, birnförmige Spermatocyste ein wenig kürzer. Der $2,3 \mathrm{~cm}$. lange Samenleiter in einen wenig dickeren Penissack übergehend, die glans kurz. Die grosse Schleim-Eiweissdrüse rothgelb.

Dem Äusseren nach war es kaum möglich in diesem Thiere eine Chromodoris-Art zu vermuthen als welche es sich doch bei der für generische Bestimmung der allermeisten Nudibranchien meistens unumgänglichen anatomischen Untersuchung zu entpuppen schien.

I5. Chromodoris lactea Bgh. n. sp. Taf. XVI, Fig. 40-43.

Corpus coloris lactei, rhinophoria et branchia nigerrima.

In der Sapeh-Bai an der Ostkiste von Sumbawa (St. 3 I I) wurde ein Individuum gefischt.

Das in Formol bewahrte Individuum hatte eine Länge von $10 \mathrm{~mm}$. bei einer Breite von 4 und einer Höhe von 2,5. Die Farbe war durchgehends milchweiss mit kohlschwarzer Kieme und Rhinophorien; an der Körperseiten und an der Fusssohle schimmerte die hintere Eingeweidemasse schwarz durch. 
Der ganz ebene Ruicken überragte ringsum den Unterkörper, besonders war das Gebräm hinten stark vortretend, dasselbe war etwas wellenförmig gebogen. Die etwa $\mathrm{I}, 5 \mathrm{~mm}$. hohen Rhinophorien stark vorgetreten, stark perfoliirt; die auch etwa I,5 mm. hohe Kieme halb zurückgezogen, wie es schien, aus 5 pinnaten Blättern gebildet. Die Tentakel sehr klein; der vorne gerundete schmale Fuss uiberragte mit dem Schwanze hinten den Rücken.

Die Mundröhre etwas länger als der Schlundkopf. Dieser letztere etwa 1,5 mm. lang, weisslich; die starken und breiten schwarzen Lippenplatten aus hakenartigen Elementen gebildet, die eine Länge bis $0,03 \mathrm{~mm}$. erreichten. Die Z unge mit ganz schwach gelblicher Raspel, welche 2 I Zahnplattenreihen enthielt, in der Scheide noch 20 entwickelte und 3 jüngere Reihen, die Gesammtzahl derselben somitt 44. In den Reihen kamen jederseits etwa 40 Platten vor. An der schmalen Rhachis (Fig. 4Oa) wurden dreieckige falsche Platten von einer Breite bis 0,013 mm. gesehen (Fig. 4I). Die innerste Zahnplatte mit einem Dentikel am inneren Rande des Hakens und zwei am äusseren (Fig. 40), die übrigen trugen am Aussenrande mehrere (meistens 5-6) feine Dentikel (Fig. 42), die äussersten zeigten die Grundplatte kürzer und den Haken nur an der Spitze gezähnelt (Fig. 43). Die Zahnplatten waren fast farblos; die Länge der grössten Platten betrug etwa $0,06 \mathrm{~mm}$, und die Höhe des Hakens war nicht viel geringer; die Höhe der zwei äussersten war ungefähr 0,06 und $0,04 \mathrm{~mm}$.

Die hintere Eingeweidemasse (Leber) war kurz kegelförmig, $4 \mathrm{~mm}$. lang, schwarz.

16. Chromodoris clitonota Bgh. n. sp. Taf. V, Fig. I6.

Am Riff von Batjulmati auf Java (St. $\zeta$ ) wurde ein einzelnes Individuum gefangen und lebend abgebildet.

Dasselbe hatte (stark erhärtet) aufbewahrt eine Länge von 9 bei einer Breite von 5 und Höhe von $3 \mathrm{~mm}$; die Breite des Rückengebräms I, die des Fusses $2 \mathrm{~mm}$. Die Farbe war durchgehends gräulichweiss, der Rücken aber durch zwei schmale noch ganz blutrothe Linien geziert, die sich von den Rhinophorien bis an das Kiemenloch erstreckten. Die Formverhältnisse die gewöhnlichen; der Rücken etwas gewölbt; das vortretende, etwas wellenartig gebogene Gebräm ringsum mit deutlich durchschimmernden, dichtstehenden kleinen Bälgen ausgestattet, die einen Durchmesser bis 0,45 mm. hatten.

Der kleine Schlundkopf zeigte ziemlich breite, gelbliche Lippenplatten von gewöhn. lichen Elementen von einer Länge bis o,or6 mm. gebildet. Die Raspel fast farblos; die Zahnplatten von der bei den Chromodoriden gewöhnlichen Form, bis 0,025 mm. lang, die äusseren nur an der Spitze gezähnelt.

Die hintere Eingeweidemasse $+\mathrm{mm}$. lang, gelblichgrau. In den Läppchen der Zwitterdriise reife Geschlechtselemente; die weissliche vordere Genitalmasse stark entwickelt.

17. Chromodoris bimaonsis Bgh. n. sp. Taf. V, Fig. II. Taf. XVI, Fig. 44-46.

Auf einem Riffe in der Bai von Bima (St. 47) wurde ein Individuum erbeutet und lebend abgebildet.

Das lebende Thier hatte eine Länge von $16 \mathrm{~mm}$. bei einer Breite von 6. Die Farbe 
der Rückenseite war hell griinlich, in der Nitte mehr röthlichgelb, klcinere uncl grössere schwarzbraune Flecken kamen zerstreut vor; der Rückenrand weiss, innerhalb desselben stark rothe Fleckchen; die, Rhinophorien und die (ro) Kiemenblatter bräunlich, alle mit weisser Spitze.

Das a ufbewahrte Individuum hatte eine Länge von I 3 bei einer Breite von 6 und Höhe von $3 \mathrm{~mm}$., die Breite des Fusses 2,25. Die Farbe war durchgehends gelblichgrau; am eigentlichen Ruicken fanden sich mehr gelbe, rundliche Flecken zerstreut, lïngs seiner Seiten in einer Reihe geordnet. - Die Form länglich-oval, ein wenig abgeplattet; der Rüicken wenig gewölbt, mit ziemlich breitem, am Rande fein-rundzackigem Gebräm, dessen Unterseite ganz eben war. Die Körperseiten einwärts gegen den ziemlich schmalen Fuss abfallend, das Gebräim des letzteren wenig vortretend, der Schwanz den Rücken kaum überragend. I)as Kiemenloch rund, klein; die Kieme von ro kleinen einfachen Blättern gebildet. Die Eingeweicle schimmerten nirgends durch.

Die Augen von einem Durchmesser ron $0,08 \mathrm{~mm}$.

Der geàrungene Schlundkopf $1,5 \mathrm{~mm}$. lang; die kreisförmige, bis $0,37 \mathrm{~mm}$. breite, schwarze Bekleidung der Lippenscheibe aus schwach gebogenen, in der Spitze schwach gekluifteten, bis $0,035 \mathrm{~mm}$. hohen Stäbchen (Fig. 44) gebildet. Die Radulapartie der Zung e schwarz. in derselben etwa 24 Zahnplattenreihen; in der mit ihrem Hinterende vorspringenden Raspelscheide noch etwa to Reihen; die Anzahl der Platten in den Reihen ziemlich gross. Die Zahnplatten hell schmutzig bräunlichgelb; die Höhe der äussersten betrug 0,05-0,06 mm., die Höhe der Platten stieg bis o,o8; die Form die gewöhnliche, der Haken äusserst fein serrulirt (Fig. 45), die äusseren weniger gebogen, und die Serrulirung kürzer, die äussersten meistens nicht gezähnelt (Fig. 46).

Die Leber war aussen und innen schwarz.

Die Zwitterdrüse mit einem diinnen, gelblichweissen Lager die obere Seite der Leber überziehend. Die vordere Genitalmasse etwa so gross wie der Schlundkopf, schmutzig gelblich und grau.

Die Art scheint bisher (in dieser Farbentracht) unbeschrieben.

18. Chronodoris virgata Bgh. n. sp. Taf. IV, Fig. 11. Taf, XVI, Fig. 47.

Am Ankerplatz östlich von Dangar Besar, Saleh-Bai (St. 3I3) wurden zwei Individuen gefangen und das eine lebend abgebildet.

Lebend hatte dasselbe eine Länge von etwa $9 \mathrm{~mm}$. bei einer Breite bis 3. Die Färbung der Rückenseite war sehr schön dunkel violet; längs des Rückens eine mediane röthlichweisse Linie und zu jeder Seite derselben eine ähnliche kürzere; die Rhinophorien und die Kiemenblätter roth; der Fuss schien weissgerandet.

Die a ufbewahrten (harten) Individuen waren von gleicher Grösse, $7 \mathrm{~mm}$. lang bei einer Breite von fast 3 und Höhe von 1,5. Die Farbe war jetzt hell bräunlichgelb, die drei jetzt weisslichen Rückenbänder noch sehr deutlich, die Rhinophorien und die Kiemenblätter roth; an der Unterseite des Schwanzsegels symmetrisch jederseits ein weisslicher kleiner Sack und eine Reihe von solchen an den Seitentheilen des Rückengebräms so wie am Stirnsegel.

Die Kieme schien von 10 Blättern gebildet.

Der Erhärtungszustand gestattete keine Untersuchung des gegen I mm. langen wreiss- 
lichen Schlundkopfs. Die farblosen Zahnplatten schienen $0,025 \mathrm{~mm}$. lang bei einer Breite von 0,0I6; der Rand des Hakens stark gezähnelt (Fig. 47). - Die kegelförmige gelbe Leber $3 \mathrm{~mm}$. lang.

Wahrscheinlich lag hier eine Chromodoris vor.

Casella H. et A. Adams.

R. BERGiI, System. 1.c. I892, p. IOIO-IOII.

Forma corporis Chromodoridibus fere omnino similis, sed limbo marginali dorsi undulato et revoluto.

Die Casellen sind, so zu sagen, nur Chromodoriden mit stärker entwickeltem und wellenartig gebogenem Rückengebräm.

Einige wenige Arten aus dem Indischen Meere sind bekannt.

I. Casella atromarginata (Cuv.). Taf. II, Fig. 8.

Doris atromarginata Cuv. Ann. du Mus. IV, 1884, p. 473. PI. 2, Fig. 6.

Doris atromarginata Cuv. Quor et Gaimard, Voy. de l'Astrolabe. II. I834, p. 25I, Pl. I6, Fig. 6, 7 .

Goniodoris atromarginata Cuv. ANGAS, Journ. de conchyl. 3 S. IV, r. IS64, p. 5 I.

Casella atromarginata (Cuv.). BERGH, Journ. des Mus. Godeffroy. Heft VI, I874, p. 102-109. Taf. II, Fig. I5-29; Taf. III, Fig. 2I-32.

Casella atromarginata (Cuv.). BERGH, Malacolog. Unters. Heft VI, I874, p. I02-IO9, Taf. XXXIII, Fig. I. - Heft XI, 1877, p. 463. Taf. XLV, Fig. I. - Heft XVII, I89o, p. 942-943. Taf. LXXXVI, Fig. 9; Taf. LXXXIX, Fig. 23-24.

Auf einer Lithothamnion-Bank zwischen Bahuluwang und Tambolungang, suidlich von Saleyer (St, 66) wurde am 7-8 Mai aus einer Tiefe von 8 M. (todte Kiorallen, Halimeda, Lithothamnion) ein Individuum dieser Form gedretscht; später in der Sanana-Bai an der Ostküste von Sula Besi noch zwei; ferner bei Ambon (St. 21I) vier, bei St. 26 I vier, bei Kur ein und bei St. I 33 ein Exemplar.

Das (erst erwähnte) in Formol bewahrte ziemlich ausgestreckte Individuum hatte eine Länge von 35 bei einer Breite von $\mathrm{I}_{3}$ und einer Höhe von $9 \mathrm{~mm}$; die Höhe der Keule der zurickgezogenen Rhinophorien betrug $2 \mathrm{~mm}$., der Durchmesser des Kiemensterns 7 , und die Länge der Kiemenblätter bis $3,5 \mathrm{~mm}$; die Breite des wellenartig gebogenen Rückengebräms bis $5 \mathrm{~mm}$; die Breite des Fusses bis 4, die Länge des Schwanzes $+\mathrm{mm}$. - Die Farbe war durchgehends weisslich, hier und da oben und an den Seiten mit schwach gräulichem Anflug; das Rückengebräm ringsum von einer schmalen schwarzen Linie eingefasst; die Keule der Rhinophorien und die Kiemenblätter bräunlich.

Die Formverhältnisse die gewöhnlichen; das Ruickengebräm vorn und hinten wenig vortretend, an den Seiten breit. Die kleinen Tentakel in Vertiefungen zurïckgezogen; die Keule der Rhinophorien stark durchblättert. Die Kieme aus 12 Blättern gebildet, die nach hinten an Grösse abnehmen. 
Das Centralnervensystem wie gewöhnlich. Die Augen von cinem Durchmesser von O, $12 \mathrm{~mm}$, mit grosser, gelber Linse.

Die II undröhre sehr stark, $8 \mathrm{~mm}$. lang; hinten bis $5 \mathrm{~mm}$. breit, becherförmig fast die Hälfte des Schlundkopfes umfassend. Der kleine, weissliche Schlundkopf nur 3 mm. lang, von gewöhnlicher IForm, sein dreieckiger Mund mit der gewöhnlichen, ganz schwach gelblichen Lippenplatte, deren hakenartige, in der Spitze gekluftete Elemente eine Länge bis $0,035 \mathrm{~mm}$. erreichten. Die Zunge mit fast farbloser Raspel; dieselbe schien (insoweit solches sich bei dem Erhärtungszustande bestimmen liess) etwa 60-70 Zahnplattenreihen zu enthalten; in der langen Raspelscheide kamen noch etwa 125 Reihen vor. In den Reihen schienen an jeder Seite der schmalen Rhachis beiläufig 60 Seitenplatten vorzukommen. Die fast farblosen Platten wie friher beschrieben, bis $0,04 \mathrm{~mm}$. hoch.

Die lange Speiseröhre und der Darm wie gewöhnlich. Die weissliche, bei einer Breite vorne von 6 , volle I $3 \mathrm{~mm}$. lange, cylindrisch-kegelförmige hintere Eingeweidemasse (L e ber) vorne durch die vordere Genitalmasse stark ausgehöhlt.

Die vordere Genitalmasse weisslich, kugelförmig, von 4,5 mm. Durchmesser. Die Ampulle des Zwitterdrisenganges und der Samengang wie gewöhnlich; ebenso die kugelförmige Spermatotheke von I,5 mm. Durchmesser (mit schwärzlichem Inhalte durchschimmernd) und die Spermatocyste.

Ein anderes Individuum wurde am 25 Juli (St. I3I) am Ankerplatz von Beo, Insel Karakelang erbeutet, nach dem Leben abgebildet (Taf. II, Fig. 8). - Dasselbe zeigte die Ruickenseite braungelb, den Ruickenrand blau, stimmte mit den von SEMrer (1874) und von Brock (1890) gegebenen farbigen Figuren uberein.

Noch ein ähnliches, ziemlich grosses Individuum wurde am Riffe bei den Lucipara-Inseln (St. 225) erlecutert.

Casclla atromarginata (Cuv.), var. pallida. Taf. IV, Fig. I 2.

In der Nähe von Makassar wurde aus einer Tiefe von 27-32 M. ein Individuum gefangen und nach dem Leben abgebildet.

Lebend hatte das Thier eine Länge von 5.5 bei einer Breite bis $1,7 \mathrm{~cm}$. Die Farbe der Rückenseite war längs der Mitte violetgrau, sonst gelb, der ganz schmale Rückenrand schwarz.

Das a ufbewahrte stark zusammengezogene Individuum war fast $19 \mathrm{~mm}$. lang bei einer Breite von I0. Die Farbe des eigentlichen Rückens war hell bräunlichgelb, sonst gelblichweiss, der Rückenrand schwarz, die Keule der Rhinophorien sammtschwarz mit weisser Spitze; die aus I 2 Federn gebildete Kieme hell bräunlich.

2. Casclla mbra Bgh. n. sp. Taf. XVI, Fig. 53-55.

Am 18 April wurde in der Badjo-Bai an der Westkiiste von Flores (St. 50) aus einer Tiefe von $40 \mathrm{M}$. ein Individuum gefischt und mit Eisessig fixirt.

Das aufbewahrte Individuum hatte eine Länge von 16 bei einer Breite von 7 und einer Höhe von $3 \mathrm{~mm}$; die Breite des Rückengebräms war 2,5, hinten 3,5 mm.; der Durchmesser 
des Kiemenkreises war 4 mm., die Länge der Kiemenblätter 1,5 mm.; der Kopf 2,5 mm. breit; die Breite des Fusses 3,75, die Länge des Schwanzes $3 \mathrm{~mm}$. - Die Farbe war durchgehends schön gelbroth, die Kiemenblätter und die Keule der Rhinophorien dunkler.

Die Form war länglich-oval, wenig hoch. Das wellenförmig gebogene Rückengebräm war breit, überragte den Kopf und ringsum den Fuss, der Rücken war eben; die Anzahl der Kiemenblätter 12, die hintersten ein wenig kleiner; die Analpapille subcentral. Der Kopf zeigte kaum deutliche Tentakel. Der Fuss vorne ein wenig brẻiter, mit Randfurche, ohne vortretende Ecken, der Schwanz etwas zugespitzt.

Das Centralnervensystem wie gewöhnlich. Die fast sessilen Augen von 0,12 mm. Durchmesser.

Die Mundröhre von einem mächtigen rothen Drüsenlager umgeben. Der röthlichgelbe Schlundkopf 1,5 mm. lang; die Mandibelplatten dunkel kastanienbraun, (0,26 mm.) breit, oben schmaler; ihre Elemente schmutziggelb mit schwarzem, hakenartig gebogenem Kopfe (Fig. 53), von einer Höhe bis $0,05 \mathrm{~mm}$. Die breite $\mathrm{Zunge}$ fast farblos. Die Anzahl der Zahnplattenreihen liess sich bei dem Erhärtungszustande nicht bestimmen, sie schien kleiner als gewöhnlich bei den Casellen zu sein. In den Reihen schien die Anzahl der Platten bis etwa 50 zu betragen. Die Platten waren von hell gelblicher Farbe, die Höhe der drei äussersten war 0,02-0,035-0,04, und die der Platten stieg bis $0,06 \mathrm{~mm}$. Die farblose schmale Rhachis (Fig. 5 $4 a$ ) von einer Breite von $0,0 \mathrm{I} 4 \mathrm{~mm}$, mit nach hinten sehenden zugespitzten schwachen Verdickungen. Der kurze Haken der ersten Zahnplatte wie gewöhnlich an beiden Seiten gezähnelt (Fig. 54); die iibrigen mit kurz gabeliger Spitze und unterhalb derselben mit einigen wenigen (2-4) Dentikeln des Aussenrandes, welche aber auch fehlen konnten (Fig. 55); die äussersten nur in der Spitze gezähnelt.

Die Speicheldrüsen lang und dünn.

Die hintere Eingeweidemasse (Leber) $6 \mathrm{~mm}$. lang bei einer Breite vorne von 3, schwärzlich kastanienbraun; am Vorderende gelbroth durch die iberziehende $\mathrm{Z}$ witterdrüse, die auch ähnliche farbige Querstreifen an der Oberseite bildete. Die vordere etwas zusammengedrückte Genitalmasse, $3 \mathrm{~mm}$. lang, weisslich und rothgelb.

Es liegt hier eine neue Art von Casella vor.

\section{Ceratosoma Ad. et Reeve.}

A. ADAM:, Voy. of the Samarang. Moll. is 48, p. $\left.67^{1}\right)$.

R. BERGH, Malacolog. Unters. II (Heft X, IS76), p. 39I-4IO; - III (Supplementheft I). I880, p. 28-3I; Heft XVII. I 890 , p. 945-948; Heft XVIII. I 892 , p. IIII.

R. BERGi, Rep. (Challenger). 1884, p. $79-84$.

R. BERGH, System. 1. c. I892, p. I I I I.

Corpus elongatum, nonnihil compressum; notaeum proprium limbo laterali angusto, postice quasi trilobatum, lobi laterales breves rotundati, posterior (pone branchiam) fortis, linguiformis; podarium angustius, cauda elongata. 
Innerhalb der Gruppe der Chromodorididen zeichnen sich die Ceratosomen durch eigen. thümliche Körperform aus, indem das Schwanzsegel in einen wenig vortretenden seitlichen und einen starken zungen- oder fast hornartigen hinteren Fortsatz entwickelt ist; der Schwanz ist lang, und der Fuss sehr schmal.

Die meistens ziemlich grossen Ceratosomen gehören den tropischen und subtropischen Meeresgegenden an. Eine kleine Anzahl von Arten ist angegeben.

I. Ceratosoma cornigerum (Ad.), Bgh. M. indicum.

2. Coratosoma trilobatum Gray. M. rubrum.

3. Ceratosoma gracillimum Semper. M. philippinense.

4. Coratosoma polyomma Bgh. M. pacific.

5. Ceratosoma ornatum Bgh. M. pacific.

[Ceratosoma caledonicum Fischer. N. pacific.

Ceratosona brevicaudatum Abraham. M. pacific.

Ceratosoma oblongzum Abr. M. pacific.

Coratosoma tenue Abr. M. pacific.].

I. Ceratosoma cornigerum Adams (Bergh). Taf. XVI, Fig. 56. Taf. XVII, Fig. I.

A. Adans, Voy, of the Samarang. Moll. I848, p. 68. Pl. XIX, Fig. 5.

R. Bergh, Malacolog. Unters. II (Heft X), 1876 , p. 393-403. Taf. XLVIII, Fig. 15-27; Taf. XLIX, Fig. I- -5 .

R. Bergh, Rep. on the Nudibranchiata (Challenger). I884, p. $80-84$. Pl. II, Fig. 14 -i7; Pl. III, Fig. I4-20.

Von dieser Form wurden zwei Individuen am Riffe in der Nähe von Seget, am westlichen Eingang der Selee-(Galewo-)Strasse (St. 164) gefangen.

Das kleinere war $4 \mathrm{~cm}$. lang, ähnelte vollständig dem anderen; nur fehlte der hintere Rückenfortsatz, das Horn, vollständig, und eine Spur von einer Narbe zwischen den Seitenfortsätzen fand sich nicht (Fig. I).

Das andere Individuum hatte eine Länge von $5,5 \mathrm{~cm}$., wovon der Schwanz 2,5 betrug (seine Höhe am Grunde war $9 \mathrm{~mm}$.); die Breite betrug 2, I cm., die Höhe (bis an den Grund des Hornes) I, 8 ; die Seitenlappen traten $5 \mathrm{~mm}$. hervor, die Höhe des Hornes war 7 ; die Weite der Kiemenspalte bei zurückgezogener Kieme 1,5 mm; die Breite des Kopfes war I 2 mm., die des Fusses 4. - Die Farbe war schmutzig bräunlichgelb, an dem Rücken und an Jen Körperseiten kamen grosse, verschwimmende, röthliche Flecken zahlreich vor. Die Kieme röthlichgelb. Hinter dem Kopfe schimmerten (an beiden Individuen) die schwarzen Augen stark durch.

Die Formverhältnisse die gewöhnlichen; der Stirnrand mit ausgeprägter Randfurche, die kleinen Tentakel eingestullpt; an den Körperseiten zerstreute Knötchen. Die Kieme zeigte jederseits sein Hinterende wie gewöhnlich gleichsam gegen die Mittellinie eingerollt; sie bestand aus zwei vorderen medianen bis $3,5 \mathrm{~mm}$. hohen Blättern und jederseits $8-9$ kleineren, von welchen die mittleren bifid oder trifid waren, die hintersten gleichsam auf $2-3$ gemeinschaftlichen Stämmen stehend. 
Die gelbliche Mundröhre $6,5 \mathrm{~mm}$. lang, mit hell röthlichgelber Innenseite. - Der Schlundkopf $6 \mathrm{~mm}$. lang bei einer Höhe und Breite von 5, schwach gelblich; die Mandibelplatten braunroth, $3 \mathrm{~mm}$. lang bei einer Breite von 2, wie friher (1. c. 1876. Taf. XLIX, Fig. I) dargestellt, ebenso auch (1. c. Taf. XLVIII, Fig. I7-19) ihre Elemente, die eine Länge von $0,04 \mathrm{~mm}$. erreichten bei einer Höhe des umgebogenen Endes von 0,016. In der (schwach röthlich-)gelblichen Raspel der Zunge kamen etwa 40 Zahnplattenreihen vor, in der Scheide noch etwa 64, von denen die hintersten 4 unreif, die Gesammtzahl der Reihen somit etwa I04. Die Anzahl der Platten in den Reihen schien gegen 200 zu betragen. Die sehr hell gelblichen Platten ganz wie früher beschrieben, mit ganz kleinem feinem Dentikel an der Aussenseite (Fig. 56).

Die Speiseröhrè röthlichgelb. Der Magen $9 \mathrm{~mm}$. lang bei einer Breite von 6. Die hintere Eingeweidemasse hell röthlichgrau, $\Upsilon_{5} \mathrm{~mm}$. lang bei einer Breite von I I und Höhe von Io mm. Die Leber braun, mit weiter Höhle; von dem dünnen Lager der Zwitterdrüse ganz überzogen. Die vordere Genitalmasse hell braun und gelblich, gerundet-viereckig, von $4,5 \mathrm{~mm}$. Durchmesser.

Hierbei gehörte sicherlich auch ein bei Nord-Ubian (St. 99) erbeutetes $5,5 \mathrm{~cm}$. langes Individuum, das fast roth war mit dichtstehenden stärker rothen Punkten längs des ganzen Rückenrandes mit sammt den drei Lappen des Schwanzsegels und mit einer Reihe von purpurrothen runden Fleckchen längs des sonst gelblichen Fussrandes.

Ceratosoma cornigerum Adams (Bgh.) var.? Taf. IV, Fig. I2.

Am Riffe von Haingsisi wurde ein Individuum gefangen und lebend abgebildet.

Dasselbe hatte eine Länge von $2.5 \mathrm{~mm}$. Die Farbe war ockerroth mit weissen Flecken, von welchen sich 3 median am Schwanzrücken fanden; die Rhinophorien so wie die Kieme waren weiss, der Fussrand vielleicht bläulich.

Das a ufbewahrte Individuum war $23 \mathrm{~mm}$. lang, wovon der Schwanz die volle Hälfte betrug, die Höhe vorne am Grunde des Hinterhorns 5,5 und die des letzteren (hinten gemessen) $5 \mathrm{~mm}$, die Breite durch die Seitenhörner 6,5, die Höhe der herausgestreckten Kieme I mm. Die Farbe war durchgehends grüngrau (ohne Spur von Flecken).

Die Formverhältnisse die gewöhnlichen. Der Haut überall ganz glatt.

Das Thier repräsentirt wohl nur eine der Varietäten der typischen Art.

$$
\text { Taf. I, Iig. I } 2 \text {. }
$$

Noch ein anderes Individuum wurde an der S.O. Seite der Pearl-Bank im Sulu-Archipel (St. 96) erbeutet und auch lebend abgebildet.

Lebend hatte dasselbe eine Länge von $4,7 \mathrm{~cm}$. Die Farbe war rothbraun; die Rückenseite zeigte Gruppen von ganz feinen weissen Punkten, am Fussiande eine Reihe von dunkleren rundlichen Flecken.

Das a ufbewahrte, stark erhärtete Individuum war $4 \mathrm{~cm}$. lang bei einer Höhe des 
Rückens von I und einer Breite durch den Seitenhöcker auch von I; dic Breite der Stirne 6 , die Höhe des Hornes $7 \mathrm{~mm}$. Die Farbe war durchgehends schmutzig bräunlichgelb. Die Formverhältnisse die gewöhnlichen.

2. Ceratosoma bicorne Bgh. n. sp. Taf. IV, Fig. 16. Taf, XVII, Fing. 2-3.

Am 12 Febr. wurde auf St. 3 ro in der Sapehstrasse aus 7.3 M. Tiefe ein Individuum gedretscht und nach dem Leben abgebildet.

Dasselbe hatte lebend eine Länge von $7,5 \mathrm{~cm}$. bei einer Körperhöhe bis $\mathrm{I}, 4$, die Höhe des vorderen Rückenfortsatzes betrug I $3 \mathrm{~mm}$., die des hinteren 8, und die Länge des Schwanzes I5; die Höhe der Rhinophorien gegen 4 und der Durchmesser des Kiemensterns gegen $15 \mathrm{~mm}$. Die Grundfarbe war hell violetbraun von grossen grülich-weisslichen Flecken durchbrochen; an der oberen Seite kamen iiberall rothbraune grössere und kleinere P'unkte vor; am Rückenrande, am Kopfrande und an den Rändern des vorderen Rückenfortsatzes schwärzlichbraune Flecken, am Fussrande dunkler rothbraune Flecken; die Rhinophorien rothbraun, die Kieme hell gelblichweiss mit rothen Rhachides.

Das a ufbewahrte Individuum hatte eine Länge von $7 \mathrm{~cm}$. bei einer Körperhöhe bis I,4, die Breite des Körpers (durch die Seitenlappen) 1,2 cni.; die Höhe des vorderen Rückenfortsatzes I3, des hinteren $9 \mathrm{~mm}$., die Länge des Schwanzes $15 \mathrm{~mm}$. (bei einer Breite am Grunde von 4), die Höhe der (halb zurückgezogenen) Kieme im Ganzen 6 mm.; die Breite des Fusses (vorne) bis $5 \mathrm{~mm}$. - Die Farbe war durchgehends hell gelblich, der ganze obere Körper (mit den Körperseiten) mit kleinen runden weissen (Fleckchen) Knötchen bedeckt, am Rücken besonders dicht stehend, die dem Fussrande angrenzenden waren die grössten; das schmale Kopfsegel am Rande mit länglichen, oft confluirenden rothbraunen Fleckchen geziert, ähnliche kamen am schmalen Rückenrande und an den Rändern der Rückenfortsätze vor; am Fussrande fanden sich ähnliche, aber grössere, mehr rundliche und mehr isolirte Fleckchen vor: die Kieme schwach gelblich.

Die Formverhältnisse die gewöhnlichen der Ceratosomen. Der Rand des Kopfsegels wenig vortretend so wie auch der Ruickenrand, auch die gerundeten Seitenlappen, womit der allmählig nach hinten etwas breitere und schräg aufsteigende flache Rücken abschliesst, wenig hervorragend; dagegen ragt der hintere Rückenfortsatz stark hinauf, wie gewöhnlich etwas zusammengefaltet mit etwas hohler Hinterflache; ganz ähnlicher Art ist der am Grunde des Schwanzes stehende $z$ weite R iickenfortsatz. Das runde Kiemenloch von 2,5 mm. Durchmesser. Die Kieme wie gewöhnlich, mit etwa 2 I schmalen Blättern, von welchen nur die 2 vordersten $(5 \mathrm{~mm}$. hohen) ungetheilt, 2 an der Spitze dreitheilig, die iibrigen (hintersten) von 2 gemeinschaftlichen Stämmen ausgehend. Die Analpapille $3 \mathrm{~mm}$. hoch. Die kurzen Tentakel mit eingestiilpter Spitze. Der Fuss wie gewöhnlich.

Die Eingeweidehöhle sich nur bis an die Gegend des gewöhnlichen hinteren Ruickenfortsatzes erstreckend.

Das Centralnervensystem wie gewöhnlich, ziemlich dick, grobknotig.

Die Nundröhre $5 \mathrm{~mm}$. lang. Der Schlundkopf weiss, 6,5 mm. lang bei einer Höhe 
ron,+ 5 und einer Breite von 4 ; die oben und unten mit einander verbundenen festen Lippenplatten stark gelb, $3 \mathrm{~mm}$. hoch bei einer Breite bis fast 2 , ihre zusammensetzenden Elemente von gewöhnlicher Hakenform (Fig. 2), bis $0,03 \mathrm{~mm}$. lang. Die starke Zunge mit hellgelber Raspel, die etwa 55 Zahnplattenreihen enthielt, in der Scheide deren noch 35, die Gesammtzahl der Reihen somit etwa go. In den Reihen schienen wenigstens etwa I50 Platten vorzukommen ${ }^{2}$ ). I) ie Platten (Fig. 3) von gewöhnlicher Hakenform, die allermeisten mit einigen (3-6) sehr feinen Dentikeln am Aussenrande des Hakens; ihre Farbe sehr hell gelb, die Länge bis $0,12 \mathrm{~mm}$. bei ciner Höhe bis $0,1.4$.

Die sehr (etwa $10 \mathrm{~mm}$.) langen Speicheldriisen weiss, vorne und hinten etwas dicker, an der oberen Seite der Speiseröhre vor der Cardia zusammenstossend.

Die Speiseröhre i $\mathrm{mm}$. lang. Der Magen mit + mm. aus der Leberkluft hervorragend. Ler aus dem Vorderende des Magens hervorgehende Darm $16 \mathrm{~mm}$. lang bei einem Durchmesser von 2,5-r. Die hintere Eingeweidemasse kurz-wurstfömig, hinten ein wenig schmäler, $15 \mathrm{~mm}$. lang bei einem Durchmesser von $\delta$, aussen röthlichgelb wegen der überziehenden Zwitterdriise; die Leber selbst rothbraun; die kugelformige Gallenblase von $2 \mathrm{~mm}$. Durch. messer, röthlichrgelb.

In den Läppchen der Zwitterdrïe reife Geschlechtselemente. - Die vordere Genitalmasse 7 mm. lang bei einer Höhe von + und einer Breite von 3,5, weisslich und (Eiweissdruise) gelblich. Die kugelfömige graue Spermatotheke von $3 \mathrm{~mm}$. Durchmesser; die zusammengebogene, gelbliche Spermatocyste wenigstens ebenso lang. Der Samengang einen ziemlich grossen Knituel bildend; die kurz-kegelförmige Glans $0,5 \mathrm{~mm}$. lang, aus der Genitalpapille hervorragend.

Diese Form schien nicht eine Monstrosität zu sein und muss dann eine neue Art bilden; sie erimnerte sonst an die Cer. poljomma.

(Dorididae cryptobranchiatae).

Porostomata.

R. Berih, System. 1. c. I892, p. III3(-II25).

Diese mit den cryptobranchiaten Dorididen verwandte Gruppe umfasst die Doriopsididcn und die Phyllidizden, welche trotz ihrer so verschiedenen Formverhältnisse doch nicht allein in Bezug auf die porenfömige Nundöfnung übereinstimmen, sondern auch in der eigenthümlichen Concentration des Centralnervensystems, in der Entwicklung eines saugenden Schlundkopfs ohne Kiefer und Zunge, im Vorhandensein einer eigenthümlichen Pericardialkieme und im Bau des Genitalsystems, vorziiglich des bewaffneten Penis.

1) Lei dem Cir. comizcrum betrug die Anzahl der Zahnjlattenreihen 77 (Challenger)-97- 104, bei $C \%$.

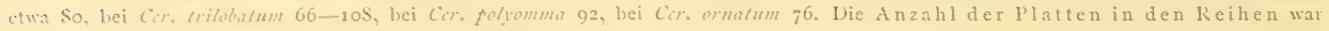
b21:. 172 (Challenger) $-230-239,130-140,160-242,190,176$. 
Von den zwei Familien stehen die Doriopsididen in unmittellsares Nithe der crypto. branchiaten Dorididen und sind wahrscheinlich aus denselben durch eigenthimliche Reduction des Schlundkopfes und Umbildung desselben in einen Saugajparat entstanden. Die I'ly llidizden dagegen stehen innerhalb der holohepatischen Nudibranchien sonst bisher ohne besondere: Anknüpfung, ihre höher organisirten Verwandten sind entweder noch nicht enteleckt oder sind schon ausgefallen. Die intimere Zusammenstellung mit den Doriopsididen ist daher viclleicht unberechtigt, und die Gruppe der l'orostomata vielleicht eine wenig natiirliche.

\section{I)RTOPSIDINAE. \\ System. 1. c. p. 1114-1123.}

Corpus fere semper sat molle, forma fere omnino ut in Doridibus propriis. Apertura oralis poriformis, tentacula brevissima affixa; rhinophoria et branchia ut in Doridibus propriis. Notacum laeve vel tuberculatum, limbo marginali ut plurimum latiori undulato. P’odarim sat latum.

Tubus oralis simplex, non glandulosus. Bulbus pharyngeus suctorius elongatus, cylindraceus. Extremitas posterior hepatis profunde fissa. - Penis hamis seriatis armatus.

Die Doriopsididen gehören den wärmeren und tropischen Meeresgegenden an, besonders dem Indischen und Stillen Neere.

Die Gruppe umfasst die Gattungen Doriopsis und Doriopsilla.

Doriopsis (P'ease) Bgh.

System. I. c. p. IIIS-1122.

Corpus molle, notaeo ut plurimum laevi.

Ganglia buccalia in posteriori parte bulbi pharyngei sita.

Die Gattung enthält eine ganze Reihe von Arten, die aber besonders wergen der waltenden grossen Variabilität der Varben zum grossen Theil sehr unsicher sind.

\section{Doriopsis nigra (Stimpson).}

Doris nigra Stimpson. P'roc. ac. nat. sc. of Philad. VII, 1856, p. 380.

Doris nigra (St.). K. BERGII, Nalacolog. Unters. III (Heft XVI, 2) I88g, p. $842-843$.

Doriopsis nigra (Stimps.). Ar.Dek et H.ANCock, Notice of - nudibr. Moll, Trans. zool. soc. V, 3, 1864, p. I28. I1. XXXI, Figg. 13-I6.

Am Riffe von Pulu-Pasi-Tanette (St. 2 I3) wurden 3 Individuen mittlerer Grösse der, wie es schien, typischen Form dieser weit verbreiteten Art gefangen.

Doriopsis nigra Stimpson. var. Taf. II, ligg. I3.

Ein Individuum wurde in der Nähe des Riffes von Batjulmati, Java (St. 7 ) am il MIärz aus einer Tiefe von 15 M. gedretscht. 
Der nach dem lebenden Thiere gemachten Abbildung zufolge (Fig. $\mathbf{1}_{3}$ ) ist dasselbe an der Ruickenseite von dunkel kastanienbrauner Farbe gewesen, mit schmalem gelbem Bande innerhalb des noch schmäleren dunklen des Randes des Rückengebräms; die Kieme und der den Rücken überragende Schwanz scheinen von dunkelgrauer Farbe gewesen zu sein. - Die Länge scheint etwa $17 \mathrm{~mm}$. betragen $z u$ haben bei einer Breite bis 5 .

Das in $55 \%$ Essigsäure fixirte Individuum war fast $10,5 \mathrm{~mm}$. lang bei einer Breite von 5 und einer Höhe von 3,25. Die Farbe der Rückenseite war jetzt schwarz mit einem ziemlich schmalen weisslichen Bande innerhalb des schwarzen Rückenrandes; die Kieme schwarz, ebenso die starken Rhinophorien, deren Endpapille weisslich war; die Körperseiten und die Fusssohle schwärzlich grau. Die Eingeweide schimmerten nirgends durch.

Die Form des Thieres war länglich-oval, der Rücken ein wenig breiter als der Fuss, dessen Schwanz denselben unbedeutend überragte. Der Rücken war eben, das ziemlich schmale Gebräm gekräuselt; die weit nach vorne liegenden, fast I mm. hohen Rhinophorien mit stark durchblätterter Keule mit io Blättern; die ganz hinten stehende Kieme aus 8-10 Blättern gebildet; hinten, den Kiemenkreis completirend, die abgestutzt kurz-kegelförmige gräuliche Analpapille. Zu jeder Seite des porenförmigen Mundes der niedrige tuberkelartige Tentakel. Der Fuss vorne gerundet.

Das Centralnervensystem mit Augen und Otocysten wie gewöhnlich; ebenso der Mundapparat. Die Leber mit der gewöhnlichen Kluft im Hinterende. Die Bewaffnung des Samenleiters und des Penis wie gewöhnilich.

Wahrscheinlich lag hier eine der vielen Variationen der Doriopsis nigra vor ${ }^{1}$ ).

Doriopsis nigra Stimpson. var. luteo-punctata. Taf. II, Fig. I4.

Am 8 November wurde 5700 M. N. $279^{\circ}$ O. von der suidlichen Lucipara Insel (St. 225) am Riff ein Individuum gefangen, nach dem Leben abgebildet und in Formol bewahrt.

Das lebende Thier scheint eine Länge von 5,5 bei einer Breite von $2,5 \mathrm{~cm}$. gehabt zu haben, die Höhe der Kiemenblätter I cm. Die Farbe des Rückens ist schwarz gewesen, überall aber mit einer Unmenge von gelben Punkten versehen, dabei kam noch eine Anzahl von etwas grösseren gelben Punkten vor, die kleine Haufen bildeten; das Rückengebräm war schön blau; die Spitze der Rhinophorien gelb, die Kieme grau.

Die Länge des a ufbewahrten Individuums betrug $4 \mathrm{~cm}$. bei einer Breite von 2,2 und einer Höhe von $1,4^{\circ} \mathrm{cm}$; die Breite des Rückengebrämes $2 \mathrm{~mm}$; der Fuss fast so lang wie der Rücken bei einer fast durchgehenden Breite von $9 \mathrm{~mm}$; die Höhe der Keule der stark zurückgezogenen Rhinophorien 3, der zurückgezogenen Kieme $6 \mathrm{~mm}$. Das Aussehen des Rückens war noch fast wie beim lebenden Thiere, nur waren die Punkte und Gruppen von Punkten mehr weisslich, das Rückengebräm zeigte noch einen Anstrich der blauen Farbe;

1) Vgl. ItDEk and HAxcock, Note on a collection of nudibr, moll. Trans. zool, soc. of London V, 3. 1864, p. 128. Pl. XXXI, Fig. 13-16.

Vigl. Colliximood, On some new sp. of nudibranch. moll. Trans. Linn. Soc. II, part 2. 1881, p. 134. Pl X, Fig. $15-17$ (Doriopsis arborescins C.). 
die Körperseiten waren heller, die Rhinophorien schwarz nit weisser Endpapille, die Kieme und die Analpapille schwarz.

Die Formverhältnisse die gewöhnlichen, das Rückengebräm stark wellenartig gebogen, der Rücken ganz eben, Die Kieme aus 8 Blättern gebildet, die Analpapille abgestutzt kurzkegelförmig; Tentakel waren kaum angedeutet, die Rhinophorien mit etwa 20 Blättern. - Die Consistenz des Thieres ungewöhnlich weich.

Das Centralnervensystem wie gewöhnlich. - Die Augen von fast o, I6 mm. Durchmesser; in den Blättern der Keule der Rhinophorien wenige und wenig verkalkte Spikel, dagegen eine Unmenge von Drüsenzellen.

Die Mundröhre schwarz, $2 \mathrm{~mm}$. lang, von dem gelblichen Schlundkegel fast ganz ausgefüllt. Der $\mathrm{Schlundkopf}$ etwa $7 \mathrm{~mm}$. lang bei einem meistens durchgehenden Lurchmesser von I, gelblich. - Die dicht an einander stossenden, weisslichen, dunkel grau pigmentirten, ( $2 \mathrm{~mm}$.) dicken M undröhrendrüsen (Gl. ptyalinae) zusammen an Breite 6 mm. messend am Hinterende des Schlundkopfes wie gewöhnlich die kleinen, gelblichen $\mathrm{S} p$ eicheldrüsen (Gl. salivales). - Die Speiseröhre gelblich, $15 \mathrm{~mm}$. lang, vorne und hinten diunner, in der grössten Länge aber von einem Durchmesser von $4 \mathrm{~mm}$, sie war wie auch der Magen mit weicher, weisslicher, in $\mathrm{W}$ asser stark aufquellender Nasse von unbestimmbarer thierischer Natur gefüllt. - Die hintere Eingeweidemasse fast ganz ron der Leber gebildet, kurz-wurstförmig, $23 \mathrm{~mm}$. lang bei einer Breite von ro, gräulichgelb; die starke Spalte im Hinterende $4 \mathrm{~mm}$. lang.

Das Pericardium $9 \mathrm{~mm}$. lang bei einer Breite hinten von 5 ; die Falten am Vorderende (Pericardialdrüse) ziemlich stark. Die tief schwarze Blutdrüse ziemlich dick, dreieckig, von $3,5 \mathrm{~mm}$. grösstem Durchmesser. - Das pericardio-renale Organ (Nierenspritze) abgeplattet-melonenförmig von $2 \mathrm{~mm}$. Durchmesser.

Das Vorderende der Leber so wie seine obere Seite bis an das Pericardium war zum grössten Theil von den grossen hell wachsgelben Lappen der Zwitterdrüse bekleidet; dieselben waren meistens länglich, isolirt oder an einander stossend. In den Läppchen fanden sich reife Geschlechtselemente. - Die vordere Genitalmasse biconvex, 6 mm. lang bei einer Höhe von 5 und einer Breite ron 4, gelblich; der Penis so wie der vaginale Ausführungsgang der Spermatotheke (sammt der Vagina) schwarz.

Am Riffe der Station I 15 und am Riffe von Pulu-Pasi-Tanette (St. 2 I3) wurde je ein ziemlich ähnliches, $2-2,5 \mathrm{~cm}$. langes Individuum erbeutet, ganz schwarz mit zahlreichen weissen, aber nicht gruppirten Punkten und ohne Spur von Blau am Ruickengebrïm. Die Kieme enthielt 5 Blätter.

Der Schlundkegel $3 \mathrm{~mm}$. lang, gelblich. Der lange gerundet-dreieckige Schlundkopf in der ersten Strecke dünner. Die abgeplattete, $4 \mathrm{~mm}$. breite, hell gelblichweisse Mundröhre mit dünnem Ausführungsgang. Die schmutzig graugelbe Leber etwa $16 \mathrm{~mm}$. lang bei einer Höhe und Breite von 10, im Hinterende die gewöhnliche Kluft. - Die vordere Genitalmasse Meniscusförmig, $7 \mathrm{~mm}$. lang, in den verschiedenen Partien weisslich, grau und gelb.

Es liegt wohl hier nur eine der vielen Varietiten der Doriopsis nigra vor; sie erinnert 
an eine von Alder und Haxcock (Trans, zool, soc. of London. V, 3. I864. (P. I 28 , P1. 31, Fig. I 3) dargestellte.

2. Doriopsis tuberculosa (Quoy et Gaim.). Taf. XVII, Fig. 4, 5.

Doris tuberculosa Q. et G. Voy. de l'Astrolabe. II, I832, p. 248. Pl. 16, Fig. I-2.

Doriopsis tuberculosa (Q. et G.). R. BERGH, Neue Nacktschnecken der Südsee. IV. Journ. d. Mus. Godeffroy. Heft XIV, is78. p. 38-40. Taf. I, Fig. 2 I; Taf. II, Fig. 18-20; Taf. III, Fig. I.

?Doriopsis tuberculosa (Q. et G.), var. R. BERGH, Malacolog. Unters. III (Heft XVI, 2). IS89 (Nudibr. vom Meere d. Insel Mauritius). p. 845-848. Taf. LXXXIII, Fig. 42; Taf. LXXXIV, Fig. 5-10 ').

In der Rumah Kuda-Bai auf der Insel Roma (St. 279) wurden zwei grössere, am Ankerplatz von Nord-Ubian (St. 99) ein kleineres ( $5 \mathrm{~cm}$. langes) und am Riffe von Beo auf der Insel Karakelang (St. 1 31) auch ein kleineres $(5,5 \mathrm{~cm}$. langen) Individuum gefangen.

Dieselben stimmten in den äusseren Verhältnissen alle so ziemlich mit einander überein.

Das grösste hatte eine Länge von $8 \mathrm{~cm}$. bei einer Breite von 4,5 und einer Höhe bis 2,6, die Breite des Ruickengebräms war 1,6 cm.; die Höhe der vorgestreckten Rhinophorkeulen war $7 \mathrm{~mm}$., die Höhe der grossen Rückenknoten bis $9 \mathrm{~mm}$. bei einem Durchrnesser bis 10 ; die Weite des Kiemenloches 1o, der Durchmesser des Kiemensterns $15 \mathrm{~mm}$; die Länge des Fusses 7 bei einer Breite von $2 \mathrm{~cm}$., die Breite des Fussgebräms $5 \mathrm{~mm}$., die Länge des Schwanzes auch 5. - Die Farbe der oberen Seite war gelblichgrau, die grossen Rückenknoten mitunter schwärzlichgrau oder fast schwarz eingefasst und der Scheitel der Knoten mitunter grau; der Stiel der Rhinophorien schwärzlichbraun, die Rhachides der Kiemenblätter schwärzlichgrau. Die Unterseite des Rückengebräms weisslich; an derselben kam eine Anzahl (jederseits 12-I5) von scharf begrenzten, gleichsam ein wenig vortretenden, runden und ovalen, hell olivengrauen, weissgerandeten Flecken, mitunter mit hellem Centrum, und von einem Durchmesser von 4-6 mm., vor. Der Fuss gelblich.

Die Formverhältnisse die gewöhnlichen. Der Rücken überall bis an den wellenartig gebogenen Rand mit ziemlich groben, rundlichen Papeln bedeckt, die dichter gedrängt die grossen Knoten bilden, deren Anzahl wahrscheinlich sehr variabel ist; sie scheinen besonders nach hinten gegen die Ǩiemengegend entwickelt. Der Rand der Rhinophorlöcher vortretend, rundzackig. Das querovale Kiemenloch mit 5 stark (3 mm.) vorspringenden, etwas zusammengedrïckten Knoten; die 5 Kiemenblätter wie gewöhnlich. Der Fuss ein wenig nach vorne und nach hinten verschmälert. Die Tentakel klein (kaum I,5 mm. lang).

Das weissliche, in Durchmesser $3 \mathrm{~mm}$. haltende Centralnervensystem wie gewöhnlich.

Die Mundröhre und der schwach gelbliche, $4 \mathrm{~mm}$. lange Schlundkegel wie gewöhnlich. Die hellgelbe $\mathrm{M}$ undröhrendriise $7 \mathrm{~mm}$. breit bei einer Länge von 3,5 und einer Dicke von 3 ; aus zwei gleichgrossen, an einander gehefteten Hälften bestehend, aus vielen Lappen zusammengesetzt. Der Schlundkopf I $5 \mathrm{~mm}$. lang bei einem Durchmesser von 1,5 (bei einem kleineren Individuum betrug die Länge $19 \mathrm{~mm}$. bei Durchmesser von 1,25); an seinem Hinterende

:) Bei dieser Form schienen die Augenflecken an der Unterseite des Rückengebräms zu fehlen. 
die etwa I mm. langen, weisslichen Speicheldrüsen. Die Speiseröhre $1,8 \mathrm{~cm}$. lang bei einem Durchmesser bis $4 \mathrm{~mm}$., vorne und hinten düner (bei dem kleinen Individuum betrugen die entsprechenden Maasse I I und $3 \mathrm{~mm}$.). Die hintere Eingeweidemasse (Fig. 4) $4 \mathrm{~cm}$. lang bei einer Breite bis 2 und einer Höhe bis $\mathrm{I}, 8$, die Kluft am Hinterende I $\mathrm{mm}$. lang (bei dem kleinen Individuum betrugen die entsprechenden Maasse 27, 15, I4 und $10 \mathrm{~mm}$.). Die Leber grünlichgrau aussen wie innen (bei dem anderen Individuum gelbgrau); in mehr als der vorderen Hälfte von dem ziemlich dünnen, gelblichweissen Lager der Zwitterdrüse uiberzogen, welches sich die Seiten hinab an die Unterseite fortsetzte (Fig. 4). Der Darm $2,3 \mathrm{~cm}$. lang bei einem Durchmesser von I mm.; die Analpapille $3 \mathrm{~mm}$. hoch mit rundzackigem Rande.

Die Pericardialfalten stark; die Herzkammer $7 \mathrm{~mm}$. lang; die Blutdruse dreieckigrundlich, abgeplattet, bei einer Dicke von $2 \mathrm{~mm}$. $7 \mathrm{~mm}$. lang, gräulichgelb, von einer grauen dünnen Kapsel umgeben. - Das weissliche pericardio-renale Organ (Nierenspritze) fast halbkugelförmig, von $5 \mathrm{~mm}$. grösstem Durchmesser.

Die vordere Genitalmasse $14 \mathrm{~mm}$. lang bei einer Breite von $\&$ und einer Höhe von $10 \mathrm{~mm}$. (bei dem kleineren Individuum waren die entsprechenden Maasse $\mathrm{I}_{3}, 6$ und $9 \mathrm{~mm}$.) gelblichweiss. Die dünne, geschlängelte, an der Genitalmasse liegende Strecke des Zwitterdrüsenganges $8 \mathrm{~mm}$. lang bei einem Durchmesser von 0,8 mit schwarzer Hülle. Die grosse, weissliche sich an die Spermatotheke anschmiegende Prostata (Fig. 5) an beiden Enden zusammengebogen, ausgestreckt an Länge $25 \mathrm{~mm}$. bei einem Durchmesser bis 2,5 messend. Der lange, einen Knäuel bildende Samenleiter in den nur wenig dickeren Penis übergehend, welcher mitsammt seiner Hakenbewaffnung wie bei anderen Doriopsiden war. Die kugelförmige Spermatotheke von $7 \mathrm{~mm}$. Durchmesser, die ebenfalls kugelige Spermatocyste in Diam. $3 \mathrm{~mm}$. haltend.

Bei Pulu-Sanguisiapo einer der Tawi-Tawi-Inseln im Sulu-Archipel (St. 93) wurden noch 3 sehr grosse Individuen erbeutet. Die Länge des grössten ${ }^{1}$ ) betrug $13,5 \mathrm{~cm}$. bei einer Breite von 9,5 und einer Höhe von 3,5; der Durchmesser des Kiemensterns war 4 cm.; der Durchmesser der grossen Rückenknoten war I, $6 \mathrm{~cm}$. Bei den zwei anderen Individuen betrugen die erwähnten ersten Maasse $10,5-10,5,5-6,5$ und 2,5-3 cm. - Die Farbe war durchgehends wie oben, die Flecken der Unterseite des Rückengebräms nur bei dem einem Individuum sehr vortretend. - Die Anzahl der grossen Kiemenbüsche war immer 5.

3. Doriopsis emubescens Bgh. n. sp. Taf. III, Fig. I5.

Auf einem Riff bei Saleyer (St. 2 I3) wurde ein Individuum gefangen und lebend abgebildet.

Das lebende Thier war $2 \mathrm{~cm}$. lang bei einer Breite von 1 . Die Farbe der Rückenseite war hell violetroth, in der ganzen Länge des eigentlichen Rückens schimmerten die Eingeweide grünlichgrau durch.

Das a ufbewahrte Individuum war I $3 \mathrm{~mm}$. lang bei einer Breite von 8 und Höhe von 4,5; die Breite des Rückengebräms 2, die Höhe der Rhinophorien 1,5, der Durchmesser des Kiemensterns 2,5, die Höhe der Kiemenblätter $1 \mathrm{~mm}$; der Fuss 9,5 mm. lang bei einer 
Breite von 2, die Länge des Schwanzes 1,5 mm. - Die Farbe war durchgehends weiss, längs der Mitte des Rückens (wegen durchschimmernder Eingeweide) etwas gräulich; die Rhinophorien und die Kieme etwas bräunlich. Die Consistenz kaum steif.

Die Form war oval, etwas niedergedrückt, mit breitem Rückengebräm, der Rücken ganz glatt; die Kieme aus 7 Blättern gebildet, die niedrige Analpapille den Kreis completirend. Die Tentakel kurz, fingerformig. Der Fuss vorne fast gerade, der kurze Schwanz gerundet, der Fussrand schmal.

Das Centralnervensystem wie gewöhnlich. Die schöne, stark nach hinten gebogene Rhinophorkeule mit etwa is Blättern.

Der Schlundkegel I mm. lang. Der wie dieser weisse Schlundkopf $3 \mathrm{~mm}$. lang bei einem Durchmesser von 0,4 . Die neben einander liegenden Nebenspeicheldrüsen weiss, die rechte I,5 mm. quer gemessen, ein wenig grösser als die linke. Die weissen Speicheldrüsen ausserhalb der runden buccalen Ganglien liegend. Die Speiseröhre 4,5 mm. lang bei einem 1) urchmesser von 0,75. Die Leber gelblich, 7,5 mm. lang bei einer Breite von 3, die Kluft im Hinterende $\mathrm{I}, 5 \mathrm{~mm}$. lang.

Das dünne Lager der Zwitterdrüse gelblichgrau, einen grossen Theil der Leber überzichend; in den Läppchen reife Geschlechtselemente. Es glückte nicht die Theile der kleinen vorderen Genitalmasse zu eruiren.

Die Art ist vielleicht mit einer der nach Alkohol-Exemplaren schon aufgestellten Arten identisch.

4. Doriopsis amoena Bgh. n. sp. Taf. XVII, Fig. 6.

Am I 7 Jan. wurde am Riffe gegenüber Nusa Besi an der Nordost-Ecke von Timor (St. 282) ein Individuum gefangen, es befand sich in Formol sehr stark erhärtet und steif.

Dasselbe hatte eine Länge von $7 \mathrm{~mm}$. bei einer Breite von 3,25 und einer Höhe von 2 ; die Länge des Fusșes war 5,25 bei einer Breite von 2. - Die Farbe war durchgehends rothgelb mit schwarzen Flecken am Rückengebräme, die an der Unterseite stark durchschimmerten, und mit einer medianen Reihe von ähnlichen am Rücken; die Rhinophorien rothgelb.

Die Form war länglich-oval, nach vorne ein wenig mehr zugespitzt. Der Ruicken etwas gewölbt, mit den Fuss ringsum überragendem Gebräm; der eigentliche Rücken zeigte (Fig. 6) drei Reihen von grösseren gerundeten Knoten, von welchen einige der mittleren Reihe stark schwarz pigmentirt; am Gebräm kamen zerstreute kleinere, theilweise pigmentirte Knoten vor; die Rhinophoröffnungen so wie die Kiemenöffnung sehr stark zusammengezogen. Die Unterseite des Rückengebräms glatt. An jeder Seite der kleinen Mundöffnung kurze lappenartige Tentakel. Der Fuss nach vorn und nach hinten ein wenig zugespitzt; der Schwanz ganz kurz. Die Art der Kieme konnte nicht bestimmt werden.

Das Centralnervensystem schien wie bei anderen Doriopsen. Die Augen von o,o $8 \mathrm{~mm}$. Durchmesser. Die Keule der Rhinophorien mit wenigen Blättern. Die Haut mit Massen von Drüschen und (decalcinirten) Spiklen.

Die Mundröhrendrüsen fast farblos; ebenso die am Hinterende des ziemlich langen, 
gelblichen Schlundkopfs liegenden Speicheldrüsen. Die hintere Eingeweidemasse (Leber) + mm. lang, dunkel chocoladebraun, gegen beide Enden etwas zugespitzt, mit schwacher Spalte im Hinterende. Das pericardio-renale Organ 0,25 mm. lang.

\section{Doriopsis flaccida Bgh. n. sp.}

Am I 3 Jan. wurde in der Rumah-Kuda-Bai auf der Insel Roma (St. 279) zwei Individuen gefangen, ein grösseres und ein viel kleineres. Sie waren beide sehr stark zusammengebogen, sehr verdreht und das Aussere ganz ungewöhnlich erhärtet. Im inneren Bau stimmten sie mit einander überein.

Das grosse Individuum hatte eine Breite bis $32 \mathrm{~mm}$, bei einer Höhe bis I , die Breite des Rückengebräms war 8; die Höhe der Rhinophorien und der Kieme $3 \mathrm{~mm}$. - Die Farbe war weisslich, der Rücken mit ziemlich zahlreich zerstreuten grauen Punkten; die Rhinophorien und die Kieme gelblichweiss.

Die Formverhältnisse schienen die gewöhnlichen. Der Rücken ganz eben. Die Kieme aus 8 grossen Blättern gebildet, die Analpapille gross, oben weiter, $2 \mathrm{~mm}$. hoch.

Das weissliche Centralnervensystem wie gewöhnlich. Die Augen von einem Durchmesser von $\mathrm{O}, \mathrm{I} 4 \mathrm{~mm}$.

Die Mundröhre $3 \mathrm{~mm}$. lang, graubraun; der gelbe Schlundkegel dieselbe füllend. Die Glandulae ptyalinae durch den Schlundkopf ganz von einander geschieden, etwas abgeplattet, + und $5 \mathrm{~mm}$. lang bei einer Breite von 3 und 2, graubraun. Der gelbliche Schlundkopf in der ersten Strecke fast nur halb so dick wie in der folgenden, $16 \mathrm{~mm}$. lang bei einer Dicke von $0,6-$ I mm; am hinteren Ende desselben die kleinen gelben Gl. salivales. Die gelbliche Speiseröhre $25 \mathrm{~mm}$. lang bei einem Durchmesser von 1,2. - Die hintere Eingeweidemasse (Leber) in ihrer vorderen Hälfte an der rechten Seite durch die vordere Genitalmasse sehr abgeplattet, i $6 \mathrm{~mm}$. lang bei einer Breite von 7 , die submediane Spalte im gerundeten Hinterende nur $3 \mathrm{~mm}$. lang. Die Leber braungrau, ihr hinteres Drittel nackt, sonst war sie mit Ausnahme der Cardia-Gegend und einzelnen Flecken von der weissgelben Zwitterdrüse iiberzogen. - Die grosse vordere Genitalmasse 1 I $\mathrm{mm}$. lang bei einer Höhe von 6 und einer Dicke von 5, weiss und gelblichweiss.

\section{Doriopsis WVeberi Bgh. n. sp.}

Von dieser Thierform wurde auf Stat, 10 in der Madura-See aus einer Tiefe von 600 MI. auf Schlammboden ein Individuum gefangen, das in 55\% Essigsäure fixirt wurde.

Dasselbe war von hell röthlichgelber Farbe mit etwas dunklerem Ruickenrande, die Rhinophorien und die Kieme dunkel braunroth. Die Länge betrug $9 \mathrm{~mm}$, bei einer Breite von 6 und einer Höhe von 3,5; der Fuss etwas kürzer als der Rücken, bis 2,25 mm. breit.

Die Form oval; der Rücken ringsum den Fuss überragend, sein Rand gar nicht gekräuselt. Der Rücken ganz eben, ganz vorne die ( $\mathrm{m} \mathrm{mm}$. hohen) Rhinophorien; ganz hinten stand die ganz vorgestreckte Kieme, aus 7 (etwa I mm. hohen) tripinnaten Blättern gebildet, subcentral 
die starke Analpapille. Tentakel wurden nicht gesehen. Der Fuss schmal, vorne und hinten gerundet, der Vorderrand mit Furche, der Schwanz kurz.

Das rothbraune Centralnervensystem wie bei anderen Doriopsen. Die grossen Augen von $0,12 \mathrm{~mm}$. Durchmesser, mit grosser gelber Linse.

Der kurz-birnförmige, I mm. lange, zwiebelförmige Schlundkegel gelblich mit röthlichem Anfluge. Die weisslichen Mundröhrendrüsen von $0,75 \mathrm{~mm}$. Länge, ziemlich dick, ganz geschieden; der gemeinschaftliche Ausfuhrungsgang stark. Der lange Schlundkopf wie gewöhnlich, an seinem Hinterende die zwei kleinen gelblichen Speicheldrüsen. - Die Leber $5 \mathrm{~mm}$. lang, ihr Hinterende (im etwa letzten Viertel) in gewöhnlicher Weise geklüftet.

Die Rhachis der Kiemenblätter ungewöhnlich breit. Das pericardio-renale Organ stark, $0,75 \mathrm{~mm}$. lang.

Die Läppchen der Zwitterdruise etwas gräulich, mit reifen Geschlechtselementen. Die dornenbewaffnete Strecke des Samenleiters $0,30 \mathrm{~mm}$. lang; die Dornen gewöhnlicher Art, bis etwa $0,0 \mathrm{r} 3 \mathrm{~mm}$. lang, gelb.

Das Thier war einer Doriopsis gar nicht ähnlich, das Rückengebräm gar nicht gekräuselt, und es war ganz merkwürdig, das es sich als zu dieser Gattung gehörend entpuppte. Es ist kaum eine Varietät der Doriopsis mubra.

Hierhin gehörten wahrscheinlich auch drei am Ankerplatz von Bima (St. 47) gefangene Individuen. Das grösste hatte eine Länge von 22 bei einer Breite von 13 und Höhe von 5 mm. Die Rhinophorien so wie die 6 Kiemenblätter dunkel graubraun. - Die Gl. ptyalinae fast kugelförmig, gelb, knotig. Der Schlundkopf so wie die Speiseröhre gelb, fast von gleicher Länge. Die knotige hintere Eingeweidemasse gelb, I I, $5 \mathrm{~mm}$. lang, ihre Kluft im Hinterende $3 \mathrm{~mm}$. lang.

\section{Doriopsis Weberi Bgh, var. nigra?.}

Am Ankerplatz von Noimini an der Südküste von Timor (St. 296) wurde am 26 Dec. ein Individuum gefangen.

Dasselbe hatte in Formol eine Länge von $22 \mathrm{~mm}$. bei einer Breite von $\mathrm{I}_{4}$ und einer Höhe von 6, die Breite des Rückengebrämes betrug bis 4,5, die des Fussgebräms 3,5 und die Länge des Schwanzes $3 \mathrm{~mm}$. - Die Farbe des eigentlichen Rückens war schwarz; das Rücken. gebräm grau, so auch der Fuss; die Rhinophorien tief schwarz mit weisser Endpapille, die Kieme tief schwarz

Die Form oval, ziemlich stark abgeplattet, der Rücken ganz eben, das Gebräm nicht gebogen, im Ganzen machte das Äussere des Thieres nicht den Eindruck einer Doriopsis. Die Kieme mit 8 starken Blättern. Zu jeder Seite des Aussenmundes ein kurzer, lappenartiger Tentakel.

Die Mundröhre schwarz; der Schlundkegel weiss, ebenso der lange Schlundkopf. Die Mundröhrendrüse weiss, gross, aus zwei neben einander liegenden Hälften gebildet; die gelblichweissen Speicheldrüsen am Ende des Schlundkopfes. Die gräulichweisse Speiseröhre fast so lang wie der Schlundkopf, von der doppelten Dicke. - Die hintere Eingeweidemasse (Leber) schlauchartig, $8 \mathrm{~mm}$. lang bei einer fast durchgehenden Breite von 4,25, gelb, mit tiefer Kluft des Hinterendes. Die längliche Blutdrüse $2 \mathrm{~mm}$. lang, grau. 
Die kleine vordere Genitalmasse 2,25 mm. lang, weisslich; die Bewaffnung des Penis gewöhnlicher Art.

Möglicherweise liegt hier eine schwarze Varietät der Dor. Webcri vor.

\section{Doriopsis sp.}

Am Riffe der Nalahia-Bai, Insel Nusa-Laut (St. 234) wurden 4 Individuen gefangen.

Dieselben waren ziemlich zusammengezogen und erhärtet, aber einander ähnlich. Sie waren durchgehends weisslich, die zwei zeigten den Rïcken mit feinen rundlichen violetgrauen Fleckchen verschiedener Grösse bedeckt, und bei den anderen fanden sich schwache Spuren von solchen; die Kieme war bräunlich, die Rhinophorien weisslich. Die Länge des kleinsten Individuums betrug etwa $2,2 \mathrm{~cm}$., des grössten ungefähr $4 \mathrm{~cm}$. bei einer Breite von 2,5 und einer Höhe von I cm.; die Breite des stark wellenartig gebogenen Rückengebräms $7 \mathrm{~mm}$.; die Höhe der ausgestreckten Rhinophorien $3,5 \mathrm{~mm}$.

Die Formverhältnisse die gewöhnlichen; die Kieme 6-blätterig.

Der Verdauungsapparat wie gewöhnlich; die Nebenspeicheldrüsen braungrau; die Leber schmutziggelb, die Spalte des Hinterendes nicht stark.

\section{Doriopsis sp.}

Bei Lamakera (St. 6r) wurde ein Individuum erbeutet.

Dasselbe hatte in Formol eine Länge von $4,5 \mathrm{~cm}$. bei einer Breite von 2,3 und einer Höhe von I cm., die Breite des Rückengebräms war 6,5 mm., der Fuss fast so lang wie der Rücken bei einer Breite von Io mm. Die Grundfarbe war schmutzig weisslich; der eigentliche Rücken braungrau mit dunkleren Flecken, das Gebräm zeigte sich oben sparsam braungrau punktirt; die Körperseiten und die Fusssohle mit mehr oder weniger grossen, grauen Fleckchen bedeckt.

Der eigentliche Rücken war mit weichen Knötchen bedeckt; die Kieme zeigte 6 Federn.

Der weisse, abgestutzt-kegelförmige Schlundkegel $5 \mathrm{~mm}$. lang. Die zwei ganz gesonderten, zugespitzt-ovalen Nebenspeicheldrüsen braungelb, 5 und $6 \mathrm{~mm}$. lang, abgeplattet. Der Schlundkopf $\mathrm{r}_{7} \mathrm{~mm}$. lang, in der hinteren Hälfte doppelt so dick ( $1,5 \mathrm{~mm}$. Diam.) wie in der vorderen. Die Speicheldrüsen weisslich. Die Speiseröhre I $7 \mathrm{~mm}$. lang, ein wenig dicker als der Schlundkopf. - Die hintere Eingeweidemasse $3,2 \mathrm{~cm}$. lang, bei anderen Durchmessern von $7 \mathrm{~mm}$; das vordere Drittel an der rechten Seite (wegen der vorderen Genitalmasse) stark abgeplattet, das Hinterende ein wenig zugespitzt, seine Kluft $5 \mathrm{~mm}$. lang; die Oberfläche weisslichgelb, gleichsam ganz fein getäfelt. Die Leber bräunlich, ihre Höhle weit. - Die vordere Genitalmasse $\mathrm{I} 2 \mathrm{~mm}$. lang bei einer Höhe von 7 und Dicke von 4 , grau und weisslich; der Erhärtungszustand gestattete keine Differenzirung der Organe derselben.

\section{Doriopsis sp.}

Am Riffe bei der Insel Kur wurde zusammen mit einem Exemplar der Casclla atromarginata (Cuv.) ein Individuum gefangen. 
Dasselbe hatte eine Länge von $3,5 \mathrm{~cm}$, bei einer Breite von 1,7 und Höhe von 0,9 ; die Höhe der Rhinophorien war 3, die Breite des Rückengebräms 4 mm.; der Durchmesser des Kiemensterns I 4 mm., die Breite des Fusses 7, die Länge des Schwanzes 2 mm. - Die Farbe des Rückens war gräulichweiss, mit zwei undeutlich geschiedenen Reihen von verschwimmenden, dunkelgrauen Flecken, neben dem Gebräme ähnliche kleinere Flecken; das Gebräme selbst weisslich; die Rhinophorien mit braungrauem Stiele, weisslicher Keule, die Kieme gräulichweisslich. Die ganze Unterseite gelblichweiss.

Die Form länglich-oval, etwas abgeplattet. Der Rücken ganz eben, mit stark wellenartig gebogenem Gebräm. Die Kieme aus 6 starken Federn gebildet; die weisse, $3 \mathrm{~mm}$. hohe Pokalartige Analpapille hinten den Kiemenkreis completirend. Tentakel waren kaum angedeutet. Das Fussgebräm nicht schmal.

Der Schlundkegel gelblich, $3 \mathrm{~mm}$. lang. Der lange Schlundkopf ausgestreckt $2 \mathrm{~cm}$. lang bei einem Durchmesser in der vorderen Strecke von 1,5 , in der hinteren von $5 \mathrm{~mm}$. Die G1. ptyalinae gelblich, abgeplattet, von ovaler Form, 4 mm. lang, ganz von einander geschieden; die G1. salivales wie gewöhnlich. Die Speiseröhre 1,5 cm. lang bei einem Durchmesser von 2. Die Magenhöhle klein und eng. Der Darm in der Nitte der hinteren Hälfte der Leber hervortretend, I $\mathrm{cm}$. lang bei einem Durchmesser von $\mathrm{I}, 5 \mathrm{~mm}$.

Die hintere Eingeweidemasse (Leber) bräunlichgelb, $27 \mathrm{~mm}$. lang bei einer Breite und Länge von 8; ihre hintere Hälfte kegelförmig; ihre vordere an der unteren rechten Seite (durch die vordere Genitalmasse) stark abgeplattet, hinten nur $4 \mathrm{~mm}$. dick, nach vorne verdünnt. Die sonst bei den Doriopsen so ausgeprägte Kluft im Hinterende der Leber fehlte; an der oberen Seite fand sich eine tiefe Furche für den Darm. - Mit Ausnahme des flachen Vorderendes war die Unterseite der vorderen Hälfte der Leber und ihre Seitenränder von dem 2,5$3 \mathrm{~mm}$. dicken gelblichweissen Lager der Zwitterdrüsenlappen bekleidet, das noch vorne die Mitte der Rückenseite der hinteren Hälfte deckte und sich eine kleine Strecke längs des einen Randes nach hinten fortsetzte. In den Läppchen der $Z_{w}$ itterdrüse reife Geschlechtselemente.

Die vordere Genitalmasse (ganz erhärtet) I $2 \mathrm{~mm}$. lang bei einer Breite von 6 und Höhe von 5,5; der stark wellenartig verlaufende Zwitterdrüsengang in der ersten Strecke schwarzbraun, dann gelbbraun; die kugelförmige Spermatotheke von 4 mm. Durchmesser, die birnförmige Spermatocyste I,5 mm. lang; die Schleimdrüse weiss, die Eiweissdrüse grüngrau, der Penis konnte nicht auspräparirt werden, eine Vestibulardrüse war deutlich.

\section{Doriopsilla Bgh.}

R. Bergh, System. l. c. 1892, p. II23.

Corpus nonnihil rigidum, supra granulosum.

Ganglia buccalia in anteriore parte bulbi pharyngei sita.

Die Doriopsillen unterscheiden sich wesentlichst von den Doriopsen nur durch die Lage der buccalen Ganglien am Vorder- (nicht am Hinter-)Ende des Schlundkopfes. 
Von der Gattung sind als Arten bekannt:

1. Doriopsilla arcolata Bgh. M. mediterr., M. atlant. or. (Portugal).

2. Doriopsilla Pclsenecri P. d'Olivereira.

Opisthobr. du Portugal (l'instituto XLII, 9). I \$95, p. I2. M. atlant. or. (Portugal).

3. Doriopsilla? granulosa (Pease). M. pacific. (ins. Sandwich).

Hierzu kommt als neue Art noch die untenstehende.

I. Doriopsilla? lacuis Bgh. n. sp. Taf. XVII, Fig. 7 .

Am 17 Jan. wurde am Ankerplatz zwischen Nusa Besi und der N. O. Ecke von Timor (St. 282) am Riffe ein Individuum gefangen.

Dasselbe hatte in Formol bewahrt eine Länge von i2,5 bei einer Breite von 8 und einer Höhe von $3 \mathrm{~mm}$., die Breite des Rückengebräms ringsum $2 \mathrm{~mm}$., der Durchmesser des Kiemenlochs I mm., die Länge des Fusses I I bei einer Breite bis $5 \mathrm{~mm}$. - Die Farbe des eigentlichen Rückens war schmutzig braungelb, die des Rückengebrämes und der ganzen Unterseite gelblich, am ganzen Rücken so wie an der Unterseite seines Gebrämes kamen ganz feine dunklere Punkte vor; am letzteren, besonders an der Unterseite, schimmerten stark meistens etwas verzweigte, stärker gelbliche, gegen den Rand ausstrahlende Spikel-Züge durch. Die Rhinophorien und die Kieme weiss. Durch die Fusssohle schimmerten Eingeweide dunkel durch. Das Thier war ziemlich steif.

Die Form war oval, ziemlich stark abgeplattet, der ebene Rücken mit breitem, ringsum den Fuss überragendem Gebräm. Der Fuss oval, gegen vorn und hinten ein wenig verschmälert, der Schwanz ganz kurz. Tentakel waren kaum angedeutet. Die Rhinophorien I mm, hoch, nicht stark durchblättert; die Kieme auch etwa I mm. hoch, aus 5 Blättern gebildet.

Das Centralnervensystem wie bei den anderen Doriopsillen. Die Augen von einem Durchmesser von 0,20 mm., mit grosser gelber Linse von einem Diam. von o, Io. Die Haut mit einer Menge von meistens gelblichen, mehr oder weniger erhärteten, langen Spikeln von einem Durchmesser bis 0,06 mm. ausgestattet; ferner mit einer Menge von kugel- und kurzflaschenförmigen Drüsenzellen (Fig. 7) von einem grössten Diam. bis 0, 12 mm; die dunkleren Punkte waren von kleinen Pigmentzellen und kleinen runden Drüschen gebildet.

Wegen des starken Formol-Erhärtungszustandes war eine einigermaassen genaue Bestimmung des Schlundkopfes unmöglich, um so weniger als die Speicheldrüsen nicht nachgewiesen werden konnten. Ein zugespitzter Schlundkegel schien unmittelbar in einen $4 \mathrm{~mm}$. langen Schlundkopf überzugehen, der ganz wie bei der Doriopsilla arcolata ${ }^{1}$ ) eine Ampullenartige Erweiterung bildete, an welcher sich auch wie bei dieser (vgl. 1. c. Fig. Sc) Muskelbündel hefteten. Die stark muskulöse, viel dünnere Fortsetzung der Ampulle etwa $10 \mathrm{~mm}$. lang, geschlängelt, mit einer Einschnürung vor der Nitte ihrer Länge. — W'eder Mundröhrendrüsen noch Speicheldrüsen konnten unterschieden werden.

Die hintere Eingeweidemasse (Leber) 7,5 mm. lang bei einer Breite von 3, gelblich-

1) V'gl. R. Berg1r, Die Doriopsen des Mittelmeeres. D. malacozool. Ges. VII. rSSo, p. 26. Taf. I1, Fig. 76. 
grau, mit der gewöhnlichen Kluft des Hinterendes. - Die vordere Genitalmasse weisslich. Der Penis wie gewöhnlich bewaffnet.

Es liegt hier eine Doriopsilla (oder ein Repräsentant einer neuen Gattung) vor.

\section{Phyllididdae.}

R. BERGH, System. 1. c. IS92, p. I123-II29.

Eliot, Nudibranchiata. 1. c. 1903 , p. $560-563$.

Diese eigenthümliche mit keiner anderen zu verwechselnde Gruppe enthält die Gattungen Phyllidia (Cuv.), Phyllidiella (B.), Fryeria (Gr.) und Phyllidiopsis (B.) ${ }^{2}$ ). Die zwei ersten sind in den Siboga-Einsammlungen vertreten.

Phyllidia Cuv., Bgh.

R. BERGH, 1. c. p. II27-II28.

Notaeum tuberculis elongatis plus minusve confluentibus obsitum, medio varicositates longitudinales formantibus. A pertura analis dorsalis.

Forma tubi analis glandula ptyalina obtecti symmetrica.

Nur ganz wenige Arten sind bekannt.

I. Phyllidia varicosa Lmck.

R. Bergh, Malacolog. Unters. II (Heft X). i876. p. 380-38 I. Supplementheft I. i880, p. 8.

Am 16 Febr. wurde östlich von Dangar Besar in der Saleh-Bai (St. 3I3) am Riffe ein Individuum erbeutet.

Dasselbe hatte, in $4 \%$ Formol-Lösung bewahrt, eine Länge von fast $5 \mathrm{~cm}$. bei einer Breite von 2,2 und einer Höhe bis $\mathrm{I}, 4 \mathrm{~cm}$. Die Form-Verhältnisse waren die ganz typischen, und die der Farben fast wie bei in Alkohol bewahrten Individuen.

Ein etwa ebenso grosses Individuum wurde am I4 Juni am Riffe von Pulu Sebangkatan,

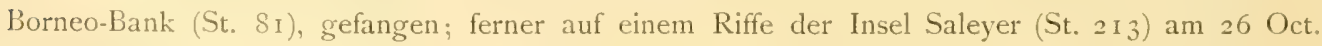
sechs Individuen von einer Länge von $2-4,8-7,5 \mathrm{~cm}$; am 2 I Juni zwei an der Küste von Pulu Kaniungan ketjil (St. 89); am Riffe der Fau gegenüber der Westküste der Insel Gebé (St. I 49) ein etwa $9 \mathrm{~cm}$. langes schönes Individuum; am Riffe von Haingsisi noch eins, je ein anderes von etwa derselben Grösse am Riffe bei Beo, Insel Karakelang (St. I 3 I) und am Riffe in der Ruma-Kuda-Bai, Roma (St. 279); zwei etwas kleinere wurden in der Pepela-Bai, Insel Rotti (St. 30I), eins am Riffe von St. 79 und 2 bei Makassar erbeutet.

1) Die Ciratophyllidia von Elior (On some Nudibranchs from East Africa and Zanzibar. II. Proc. zool. soc. of London, r9o3, 1. 1. 250. Ci\% africana E.) ist wohl mit der Phyllidiopsis identisch. 
Phyllidia varicosa Lmk. var. Taf. XVII, Fig. 8.

Am Riffe Sawan, Insel Siau (St. I 25), wurde ein Individuum gefangen.

Dasselbe war $9 \mathrm{~mm}$. lang bei einer Breite von 4 und Höhe von 2. Die Rückenseite zeigte gleichsam 9 Bänder, alternirend weisse und schwarze; das am Rande des Gebrams war ringsverlaufend weiss; dann folgt ein schwarzes, vorne abgebrochen, hinten in das der anderen Seite übergehend: innerhalb desselben ein weisses, vorne in das Randband übergehend, hinten in das entsprechende der anderen Seite, in diesem Bande liegt das Rhinophorloch und median hinten die Analöffnung; jetzt folgt wieder ein schwarzes Band, vorne mit dem der anderen Seite verbunden, zwischen beiden liegt das mediane weisse Band, hinten in die inneren weissen Seitenbänder übergehend; ausserhalb des rechten schwarzen Bandes folgen dann ein weisses, ein schwarzes und das Randband. Die weissen Bänder sind alle ganz fein nopprig, die schwarzen mehr eben. - Die Kieme ist grau, ausserhalb derselben ist die Unterseite des Rückens (querstreifig-)schwarz, innerhalb der Kieme der schmale Fussrand dunkelgrau; die Fusssohle gräulichweiss.

Dieses Individuum stimmte mit keiner der von verschiedenen Untersuchern (CuviER, Blainville, Quoy und Gaimard, Bergh, Brock) gelieferten Abbildungen iberein, und scheint doch der so sehr variablen typischen Art anzugehören, obgleich die marginalen Keile ganz fehlten.

Phyllidia varicosa Lam. var. quadrilineata. Taf. XII, Fig. +1-42.

W. N.W. von Gunong-Api $2^{1} / 2$ Meile von der Kuste (St. 310) wurde ein Individuum zusammen mit einer Varietät der Halgerda elegans (Taf. II, Fig. 4b) gedretscht.

Dasselbe war 10,5 mm. lang bei einer Breite von 5 und einer Höhe von 3 (Fig. 4I). Die Grundfarbe des Rückens war hell gräulichweiss; median verliefen zwei vorne zusammenstossende, hinten geschiedene schmale schwarze Streifen und jederseits ein laterales, beide vorne wie hinten von einander geschieden, nach aussen je drei kurze Queräste abgebend, zwischen diesen letzteren eine (oder 2) rundliche Flecken, ganz vorne noch zwei Fleckchen und ganz hinten ein medianes; die Streifen und Flecken alle tief schwarz. Die ganze Unterseite ein wenig mehr gelblich, am Rückengebräm schienen die Queräste und die Flecken stark schwarz durch.

Die Formverhältnisse die gewöhnlichen, zwischen den Streifen war die Haut ganz fein höckerig, der Rückenrand fein querstreifig. Die Rhinophoröffnungen zwischen den medianen und den lateralen Streifen liegend, die anale zwischen dem Hinterende der zwei medianen. Die sehr zahlreichen dünnen Kiemenlamellen ganz niedrig. Aus der Genitalpapille ragte Fortsetzung des Samenleiters (in der Mitte etwas dicker) 1,5 mm. hervor (Fig. 42) mit einem Durchmesser von $0,10-0,16 \mathrm{~mm}$, aber zeigte keine Spur von Haken-Bewaffnung. Tentakel waren aber nur angedeutet.

Eine Untersuchung des Schlundkopfs oder Bestimmung der Form desselben war bei dem Erhärtungszustande und der Brüchigkeit des Organs unmöglich.

Diese Form gehört wohl der so in Form und Farben variablen Phyllidia varicose an. Die drei medianen Varicositäten sind doch angedeutet und ebenso die marginalen Keile. 
2. Phyllidia loricata Bgh. Taf. XVII, Fig. 9-10.

R. Bergit, Neue Nacktschnecken der Südsee. I. Journ. d. Mius. Godeffroy. Heft II. I873, p. S-11. Taf. X, Fig. 7, 9, 19-21; Taf. XI, Fig. 1-2.

Aus einer Tiefe von I 2 M. wurde bei Pulu Sanguisiapo, Tawi-Tawi-Inseln im Sulu-Archipel (St. 93) ein Individuum gefangen.

Dasselbe war $3 \mathrm{~mm}$. lang bei einer Breite von 2 und einer Höhe von I,25 (Fig. 9). Die Farbe war weiss; der Rücken zeigte aber drei Reihen von tiefschwarzen, meistens runden scharf begrenzten Flecken; in den lateralen 5 ; in der medianen eigentlich auch 5 , an der Mitte 3 , einen hinter dem Analloche, und vorne einen vor jeder Rhinophoröffung, am Rückenrande kam noch dazu ein vereinzelter Fleck vor. Am Rückenschilde traten wie bei dem früher untersuchten Individuum eine mediane und zwei laterale feine, ganz fein-höckerige Linien hervor, und das Rückengebräm war fein querstreifig. An der Unterseite des Rückengebräms schimmerten die schwarzen Flecken stark durch. Am Grunde des vorgestülpten Mundkegels eine Andeutung von Tentakeln. Die niedrigen Kiemenblätter sich nur bis an die Genitalpapille und an die entsprechende Gegend der anderen Seite erstreckend. Der Fuss wie gewöhnlich. - Die Consistenz steif, etwas hart.

Das Centralnervensystem wie bei anderen ächten Phyllidien, die buccalen Ganglien nach hinten zwischen den Speicheldrüsen liegend. Das Rückenschild sehr stark mit erhärteten, meistens in grösseren und kleineren Haufen liegenden Zellen so wie mit verschiedenartigen Spiklen ausgestattet; Drüsenzellen kamen auch massenweise, besonders in den schwarzen Flecken vor.

Der Schlundkopf mit den Speicheldrüsen und die Speiseröhre wie gewöhnlich; die hintere Eingeweidemasse (Leber) weisslich.

Die dunkle, hakentragende Strecke des Penis 0,65 mm. lang, 0,06-0,08 mm. breit; die sehr verschiedenartigen, mehr geraden oder mehr gebogenen Haken (Fig. IO) von einer Höhe bis $0,020 \mathrm{~mm}$., gelb.

Es lag hier sicherlich nur ein kleineres Individuum der kleinen $P /$. loricata vor, nur mit ein wenig geänderter Farbenzeichnung.

3. Phyllidia coelestis Bgh. n. sp. Taf. III, Fig. 16 .

Von dieser Form wurde auf einem Riffe bei Saleyer (St. 2 I3) ein einzelnes Individuum gefangen und nach dem Leben abgebildet.

Lebend ist dasselbe von schönen Farbenverhältnissen gewesen. Die Rückenseite war himmelblau; der eigentliche Rücken (innerhalb des breiten Gebräms) von 3 sammtschwarzen Bändern durchzogen, von welchen das mittlere gelbe Ǩnoten trug, während die zwischenliegenden blauen Bänder ähnliche zeigten; die Rhinophorien gelb.

Das aufbewahrte Thier hatte eine Länge von 32 bei einer Breite an der Mitte von I I und einer Höhe von $7 \mathrm{~mm}$; die Länge des Fusses war 30 bei einer Breite von $6 \mathrm{~mm}$., die Höhe der vorgestreckten Rhinophorien $2,5 \mathrm{~mm}$. - Die Farbenverhältnisse stimmten mit denen des erwähnten sehr genauen Bildes überein, waren nur viel blässer, das Blaue war bläulichgrau 
geworden und die Knoten der Rüickenbänder gelblich. Die die drei schwarzen Bänder scheidenden graublauen waren an 2 (3) Stellen mit einander verbunden und gingen hinten, hinter dem analen Loch, in einander über, an diesen Stellen kamen gelbliche rundliche Knoten, also - der Länge nach - stehend, vor, vor und hinter dem Analloche stand einer und einer zwischen den Rhinophorien; an den zwei gräulichblauen Bändern kamen auch gelbliche Knoten vor, besonders am rechten. Das gräulichblaue Gebräm war mit ganz kleinen grauen Knötchen bedeckt, dicht an dem schwarzen Bande kamen einzelne grössere und schwach gelbliche vor. Die Rhinophorien gelblich. Die ganze Unterseite des Thieres ist gräulich, die niedrigen Kiemenblätter mehr brïunlich, kein medianer Längsstreif an der Fusssohle, die Tentakel und der Fussrand weisslich.

Um das Aussere des Individuums zu bewahren wurde nur der Schlundkopf herausgenommen. Derselbe hatte eine Länge und Höhe von 3,5 bei einer Breite von 4 mm., war gelblichweiss, seine Hülle wenig pigmentirt. Seine Form war wie in der typischen Plyyllidia, zeigte jederseits die (hier etwa 6) kurzfingerigen Geschwuilste; der innere Bau desselben war auch, insoweit beurtheilt werden konnte, der gewöhnliche.

Diese Form ist eine ächte Phyllidia (proprie) dem Äusseren und dem Schlundkopf nach, von der typischen (und verwandten) aber so verschieden, dass ihre Aufstellung als besondere Art wohl berechtigt sein wird.

Phyllidiella Bgh.

R. BERGH, System. 1.c. p. II 28 .

Notaeum proprium tuberculis discretis vel pro parte confluentibus quincunces formantibus obsitum. Apertura analis dorsalis.

Forma tubi oralis glandula ptyalina obtecti asymmetrica.

Es ist wohl zweifelhaft, ob die angegebenen Arten dieser Gattung doch nicht nur Varietäten einer und derselben Art sein.

\section{Phyllidiclla pustulosa (Cuv.).}

Cuvier, Ann. du Mus. V. I804, p. 268. PI. XVili A, Fig. S. - Mém. p. 3. Pl. Fig. 8.

R. BERGH, Nalacolog. Unters. II (Heft X). I876, p. $382-383$. Taf. XXV, Fig. 4, 5. III (Heft XVII). I890, p. 973.

Am I 3 Juni wurde bei Pulu Kabala-dua (Borneo-Bank) (St. $79^{\text {b) }}$ ein 3,6 cm. langes Individuum dieser im Indischen Meere verbreiteten und häufig vorkommenden Art gefangen. Dasselbe stimmte im Äusseren ganz mit früher untersuchten Individuen überein. - Zwei ähnliche Individuen wurden ferner am 22 Juni am Muaras-Riff erbeutet; ähnliche am I 6 Febr. an Riffe von Dangar Besar, Saleh-Bai (I Ex.); am Ankerplatz bei der Lucipara-Gruppe (St. 225) (2 Exx.); am Riffe an der Ostseite der Insel Pajunga in der Kwandang-Bai (St. I I5) (1 Ex.); an einem Riffe der Insel Saleyer (St. 213) (4 Exx.); am Riffe von Haingsisi ( I Ex.), an der Küuste von Pulu Kaniungan ketjil (St. S9) eins; am Riffe von Beo, Karakelang.Inseln (St. I 3 I) 6 Individuen, und am Riffe von Lirung, Insel Salibabu (St. I33) 10. Oft kamen sie mit Ph. caricosa zusammen vor. 
2. Phyllidiclla nobilis Bgh.

R. BERGH, Bidrag til Monographi af Phyllidierne. Naturh. Tidskr. 3 R. V, I869, p. 485-492, 512-5I3. Tab. XXIV, Fig. S-12.

R. Bergh, Neue Beitr. zur Kenntn. der Phyllidiaden. Verh. d. k. k. zool. bot. Ges. in Wien. XXV. 1876, p. 661 .

R. BERGh, Malacolog. Unters. III (Heft XVI, 2. I889, p. S60-862. - Heft XVII. IS90) p. 973. Taf. LXXXV, Fig. 4; Taf. LXXXIX, Fig. 48.

Am Ankerplatz von Nord-Ubian (St. 99) wurde am 28 Juni aus einer Tiefe von 16-23 M. (Lithothamnion-Boden) ein Individuum gefischt, ferner am Riff von Pulu-Pasi-Tanette je ein nur wenig grösseres und ein etwas kleineres; ferner zwei Individuen am Riffe von Haingsisi und zwei vom Riffe bei Elat an der Westküste der Insel Gross-Kei (St. 26I) erbeutet; drei an einem Riffe dèr Insel Saleyer (St. 2I3) in Gesellschafft mit Ph. pustulosa und Phyllidia varicosa; eins am Ankerplatz von Lirung auf der Insel Salibabu (St. I33); ein anderes bei Sailus Besar, Paternoster-Inseln. (St. 315); ferner eins am Riffe von Noimini an der Suidküste von Timor (St. 296), dieses wurde lebend abgebildet (vgl. Taf. III, Fig. I 7).

Das in Formol-Lösung bewahrte Individuum hatte eine Länge von I $3_{3}$ bei einer Breite bis 5,25 und einer Höhe von $3 \mathrm{~mm}$. Gegen die sammtschwarze Grundfarbe des Rückens contrastirten die grauweissen Tuberkel. Die Unterseite des Rückengebrämes mit den Kiemen sammtschwarz; der Fuss dunkelgrau.

Die Vertheilung, Form und Zusammensetzung der drei Fünfkreuze des Rückens und seiner lateralen Felder waren ganz typisch.

Diese ursprünglich aus dem Philippinischen Meere beschriebene Form ist später von den Palau-Inseln so wie aus dem Meere um Mauritius bekannt, hat somit eine ziemlich weite Verbreitung.

Phyllidiclla nobilis B. var. Taf. III, Fig. I7.

Am Riffe von Noimini an der Südküste von Timor wurde ein Individuum gefangen und lebend abgebildet.

Lèbend hatte das Thier eine Länge von 40 bei einer Breite von I $3 \mathrm{~mm}$. Der eigentliche Rücken war von starken schwarzen Linien eingerahmt und durch eine ähnliche Querlinie in eine grössere vordere und hintere kleinere Partie geschieden; das Rückengebräm durch 4 schwarze Querlinien jederseits in 3 Felder geschieden, von welchen das hintere das kleinere, dazu kommen ein noch kleineres Stirn- und ein Schwanzschild. Die von den Linien eingerahmten Partien waren grün mit dichtstehenden etwas helleren Knoten; hier und da brachen schwarze Striche oder Flecken durch das Grüne durch; die Rhinophorien schwarz.

Das a ufbewahrte Individuum hatte eine Länge von 20 bei einer Breite von 9 und einer Höhe von $5 \mathrm{~mm}$. Die wie gewöhnlich sehr genau gezeichnete Figur gab die Verhältnisse bei diesem Individuum wieder, nur war das Grüne in ein mattes Weissliches übergangen, auch trugen die Knoten alle am Scheitel einen gelblichen Punkt; die Rhinophorien waren zurückgezogen; die Unterseite mit den Kiemenblättern von gräulichweisser Farbe. 
Dorididae phanerobranchiatae.

R. BERGH, System. 1.c. I892, p. II $29(-1160)$.

Branchia e foliis pinnatis in arcu vel circulo positis, basi conjunctis vel discretis formata, cavitate nunquam retractilis. Clavus rhinophoriorum ut plurimum perfoliatus.

Bulbus pharyngeus interdum ingluvie suctoria instructus.

Diese grosse Familie scheint in zwei Gruppen zu zerfallen, von denen die eine sich durch Entwicklung eines Schlundkopfkropfes von der anderen besonders unterscheidet. Jene, die saugenden Formen, gruppiren sich um die längst bekannten Goniodoriden und kommen besonders in den mehr nördlichen Meeresgegenden vor. Diese, die nicht saugenden haben als Hauptrepräsentanten die auch lange bekannten Polyceren und haben auch zahlreiche Repräsentanten in den tropischen Meeren. Die von der Siboga-Expedition erbeuteten phanerobranchiaten Dorididen gehören alle zu den

Dorididae phanerobranchiatae non suctoriae

s.

Polyceridae.

R. BERGH, l. c. P. II34-II47.

Einige der zu dieser Gruppe gehörenden Gattungen, Notodoris (B.), Triopella (G. O. Sars), Aegires (Lovén) haben nur uniforme pleurale Zahnplatten an der Radula; die übrigen zeigen Unterschiede zwischen den inneren und den äusseren.

Triopa Johnston.

R. BERGH, 1. c. p. 1139 .

Corpus vix depressum; limbus frontalis angustior cirrhis granulosis ornatus; margo dorsalis cirrhis simplicibus subclavatis instructus; rhinophoria retractilia clavo perfoliato; branchia paucifoliata foliolis bi-vel tripinnatis; tentacula sat brevia, obtusa, canaliculata.

Armatura labialis (buccalis) nulla. Radula sat angusta; rhachide nuda; pleuris dentibus lateralibus duobus majoribus, quorum extimus multo major, et serie dentium externorum (I2 - I 3) quorum modo intimus hamo rudimentario praeditus.

Glans penis armata.

Diese im Ausseren so wie im inneren Baue ziemlich ausgeprägte Gattung umfasst nur ganz wenige Arten; vielleicht kommen hier eine oder zwei Arten dazu. 
I. Triopa longicornis Bgh. n. sp. Taf. XVII, Fig. II-I4.

Von dieser Form wurde am $28-29$ Juni (St. 99) $6^{\circ} 7^{\prime} .5$ N.B., I $20^{\circ} 26^{\prime}$ Ö.L. aus einer Tiefe von $16-23 \mathrm{M}$. (Lithothamnion-Boden) ein Individuum gedretscht.

Das durchscheinend-weissliche, in Formol bewahrte Individuum hatte eine Länge (des eigentlichen Körpers) von $12 \mathrm{~mm}$. bei einer Breite und Höhe von 4; die Höhe der Rhinophorien betrug I,25, die der Kieme I mm., die Länge der Rückenanhängsel bis 4,5 mm. - Die Formverhältnisse die gewöhnlichen. Am Stirnrande 4 Anhängsel; die starke Keule der Rhinophorien länger als ihr Stiel; der Rücken glatt; die Kieme aus 5 Blättern gebildet, die Analpapille hinten den Kreis completirend; am Rückenrande jederseits 5 lange Anhängsel, von welchen das 3 . und 4. etwas länger als die anderen, fast doppelt so lang wie die Stirnanhängsel waren; alle diese Anhängsel, die des Stirnes wie des Rückens, starke knotige Äste (Fig. I I) tragend. Die Tentakel kurz, lappenartig. Der Fuss schmaler als der Rücken; der Schwanz kurz, zugespitzt.

Am Rücken schimmerte das Centralnervensystem mit den Augen und der Schlundkopf durch.

Das Centralnervensystem wie gewöhnlich. Die Augen von $0,12 \mathrm{~mm}$. Durchmesser, mit grosser, stark gelber Linse.

Der Schlundkopf ziemlich gedrungen, von 2,5 mm. Länge; die Raspelscheide hinten an der Unterseite vorspringend. Unten im Innenmunde jederseits eine kleine gelbliche Platte, aus (Fig. I3) dicht gedrängten, länglichen Elementen von einer Breite bis $0,0045 \mathrm{~mm}$. zusammengesetzt. Die Zunge breit, abgeplattet, mit gelblicher Raspel, welche etwa ${ }_{5}$ Zahnplattenreihen zu enthalten schien, während etwa eben so viele in der Scheide vorkamen, insoweit die Verhältnisse Solches bei dem Erhärtungszustand des Schlundkopfes bestimmen liessen. Die Zahnplatten von sehr hell gelblicher Farbe; die Länge des Aussenplatten 0,08 mm., nur die äusserste ein wenig kürzer, und die Länge der Basalplatte der drei Seitenplatten nur wenig länger als die der Aussenplatten. Die nackte Rhachis war nicht schmal. Es kamen drei einander in Form und Grösse fast ganz ähnliche Seitenplatten vor (Fig. I 2), von derselben Grundform wie bei der typischen Art; und ausserhalb derselben eine Reihe von I3-I4 plattenartige Aussenplatten, die länger als breit waren (Fig. I 2).

Die Speicheldrüsen wie bei der typischen Art.

Die rundliche, weissliche vordere Genitalmasse ein wenig kleiner als der Schlundkopf. Der letzte Theil des durch die (0,30 mm. lange) glans pen is fortgesetzte Samenleiters in einer Länge von $0,55 \mathrm{~mm}$. mit etwa I 2 Quincunx-Reihen von ziemlich plumpen, schmutziggelben Haken (Fig. I4) besetzt, deren Grundfläche einen Durchmesser von 0,3 und deren Höhe bis $0,05 \mathrm{~mm}$. betrug. Die $\mathrm{V}$ a g in a mit einer ziemlich starken gelblichen Cuticula ausgefuttert.

Falls diese Form wirklich eine Triopa ist, ist sie wahrscheinlich von den zwei anderen bisher bekannten des Pacific's (Tr. Catalinae Cooper; Tr. Yatesi Angas) verschieden.

2. Triopa? tristis Bgh. n. sp. Taf. XVII, Fig. I5.

Am 28 Aug. wurde am Riffe in der Waru-Bai an der Nordküste von Ceram (zusammen mit Individuen der Acolidiella drusilla) ein Individuum dieser Thierform gefangen. 
Dasselbe hatte in Formol bewahrt eine Länge von $8 \mathrm{~mm}$. bei einer Breite von 2,5 und einer Höhe ron $3 \mathrm{~mm}$., die Breite des Fusses betrug I,5 mm. Die Grundfarbe war grau; am Rücken fand sich vor der Kieme ein grosser schwarzer Fleck und zwischen den Rhinophorien ein ähnlicher sich nach vorne erstreckender; gegen den Rückenrand hin kam noch ein unregelmässiges schwarzes Längsband und sonst am ganzen Rücken kleinere schwarze Flecken vor.

Die Formverhältnisse die gewöhnlichen der Triopa. Am abgeplatteten Vorderende des Kopfes zu jeder Seite des Aussenmundes die lappenartigen, etwas zusammengebogenen Tentakel. Der nicht sehr vorspringende, gebogene Stirnrand trug 6 an der Spitze feinknotige Anhängsel. Die ziemlich weit von einander stehenden Rhinophorscheiden abgestutzt, mit glattem Rande: die Keule der Rhinophorien ziemlich stark perfoliirt. Der Rücken ganz eben; an seinem Rande jederseits 3 Anhängsel, von denen die 2 vordersten fast cylindrisch, oben gerundet, das hinterste dicht hinter der Kiemengegend stehend, grösser (o,6 mm. hoch), kurzkeulenförmig, die Anhängsel zeigten alle eine ebene Oberfläche. Die Kieme aus 3 (5) Blätter gebildet. Hinter der Kieme fängt ein medianer Kamm an, der sich bis an die Schwanzspitze fortsetzte. Der Fuss kräftig, vorne gerundet, mit Randfurche; das Fussgebräm etwas vortretend.

Das Centralnervensystem wie früher beschrieben. Die fast sessilen Augen von o, IO mm. Durchmesser.

Der weissliche Schlundkopf $2 \mathrm{~mm}$. lang, kurz, gedrungen, mit hinten etwas vortretender Raspelscheide; die Lippenscheibe von einer starken, gelblichen, unten besonders verdickten Cuticula überzogen. Die abgeplattete $\mathrm{Zunge}$ schien in der gelblichen Raspel nur Io Plattenreihen zu enthalten, in der Scheide I3, von welchen die 3 hintersten unreif; die Gesammtzahl der Reihen somit nur 23. Die nackte Rhachispartie nicht schmal, zu jeder Seite derselben drei Seitenplatten und eine kurze Reihe von $(6-7)$ Aussenplatten. Im Ganzen ist der Raspelbau mit dem von Euplocamus mehr verwandt. Die Seitenplatten (Fig. I5) sind hakenartig mit einer flügelartigen Entwicklung des Körpers; die innerste ist etwas kleiner als die zwei anderen gleichgrossen. Die flachen, hakenlosen Aussenplatten nehmen nach aussen an Länge ab (Fig. I 5). Die Zahnplatten sind hell gelb; die Länge der innersten Seitenplatte betrug etwa O, IO mm., die der zwei anderen 0,16 ; die Länge der innersten Aussenplatte war 0,10 , die der äussersten $0,035-0,04 \mathrm{~mm}$.

Die hintere Eingeweidemasse (Leber) war aussen gräulichweiss, auf Schnitten bräunlich. Der Erhärtungsgrad und die Brüchigkeit der vorderen Genitalmasse gestattete keine Untersuchung derselben.

Es ist zweifelhaft, ob diese Thierform der Triopa angehört; im Raspelbau stimmte sie mehr mit dem Euplocamus überein, und eine Andeutung von Lippenplatten kommt vor.

\section{Trevelyana Kelaart.}

KelaART, Journ. R. A. S. (Ceylon). III. I 857 , p. Ioo.

R. BERGH, System der nudibranch. Gasteropoden. 1. c. I 892 , p. I I43-II44.

Corpus limaciforme, fere laeve; rhinophoria retractilia clavo perfoliato; branchia in medio dorsi sita, multifoliata foliolis tripinnatis; tentacula brevia; podarium angustius. 
Armatura labialis (buccalis) nulla. Radula latiuscula; rhachis nuda; pleurae multidentatae, dens intimus fortior, uncinatus, reliqui hamo subulato.

Glandula hermaphrodisiaca a hepate discreta, prostata sat magna; glans penis aculeis armata.

Die Gattung unterscheidet sich von der in den Formverhältnissen ähnlichen Nembrotha äusserlich durch ein grössere Anzahl von Kiemenblätter, hauptsächlich aber im inneren Bau. Die Rhachis der Raspel ist unbewaffnet, und die Seitenplatten zeigen andere Verhältnisse als in jener Gattung. Die $\mathrm{Z}$ witterdrüse ist von der Leber gesondert.

Von der Gattung, die nur den wärmeren und warmen Meeren angehört, ist eine Reihe von Arten angegeben, von welchen die meisten ziemlich zweifelhaft.

I. Trevelyana inornata Bgh.? Taf. XVII, Fig. I6-I9.

R. Bergh, Beitr. z. Kenntn. d. japan. Nudibr. I. Verh. d. zool. bot. Ges. Wien. XXX. 1880, p. 186-190. Taf. III, Fig. 14-17; Taf. IV, Fig. 8-14; Taf. V, Fig. I-9.

Auf einem Riff bei Saleyer (St. 213), wo auch die Tr. mbropapulosa erbeutet wurde, wurden 2 Individuen gefangen, das eine ein wenig grösser als das andere. Beide wurden anatomisch untersucht.

Sie waren durchgehends weiss. Das grösste maass an Länge $2,5 \mathrm{~cm}$. bei einer Höhe von 0,8 und Breite von $0,8 \mathrm{~cm}$; die Höhe der Kiemenblätter 2,5, die Breite des Fusses bis $4 \mathrm{~mm}$.

Die Formverhältnisse die gewöhnlichen. In der Keule der Rhinophorien etwa I 5 dünne Blätter. Der Kiemenkreis von 12 Blättern gebildet.

Der kurz-birnförmige weissliche Schlundk opf $4 \mathrm{~mm}$. lang, die Raspelscheide äusserlich nicht sichtbar, die Lippenscheibe mit farbloser Cuticula. In der schwach gelblichen Raspel der Zunge 20 Zahnplattenreihen, in der nach unten gebogenen Scheide I2, die Gesammtzahl der Reihen somit 32. In den Reihen wurden bis 33 Platten gezählt. Die Zahnplatten ganz schwach gelblich; die Höhe der innersten betrug $0,08 \mathrm{~mm}$., der nächsten $0,01 \mathrm{I}$, und die Höhe der Platten stieg bis zu 0,20 , die der äussersten war nur etwa $0,12 \mathrm{~mm}$. Die innerste hakenartige Platte (Fig. I6) wie gewöhnlich, so auch die Form der übrigen (Fig. I 7), die äussersten etwas dünner (Fig. I $8 a a$ ),

Die Leber kurz-kegelförmig, vorne abgeplattet, hinten gerundet, $6 \mathrm{~mm}$. lang, (schwach violet-)grau, auf Schnitten mehr braun.

Die stark baumartig verzweigten, gelben, an der Aussenseite des Thieres schon durchschimmernden Nier en röhren stiegen an den Seiten der Eingeweidemassen an den Rücken hinauf, und zeigten sich sonst ganz wie früher gesehen (vgl. 1. c. p. I88, Note 2. Taf. V, Fig. 7) und wie bei der Tr. rubropapulosa.

Vor der Leber neben einander die zwei fein granulirten gelblichen, etwa gleich grossen, Meniscusförmigen $Z$ witterdrüsen von einem Durchmesser von $5 \mathrm{~mm}$. - Die vordere Genitalmasse in einer von den Zwitterdrüsen geformten Schale ruhend, etwas kugelig, von 5 mm. Durchmesser, weisslich. Die Prostata ziemlich gross, abgeplattet; mit weiter Höhle; der von derselben ausgehende dünne Samenleiter in einen Knäuel aufgerollt und in den Pen is 
übergehend; die Bewaffnung desselben mit ihren bis etwa 0,025 langen spitzen Dornen (Fig. I9) sich ziemlich weit hinauf in den Samenleiter fortsetzend. Die Spermatotheke birnförmig, von 2,5 mm. Länge; die Spermatocyste von ähnlicher Form, aber viel kleiner, grau.

Die hier untersuchte Form ist vielleicht mit der von mir frïher beschriebenen aus dem japanischen Meere identisch.

2. Trevelyana mbra Bgh. n. sp. Taf. XVII, Fig. 20.

Mit der Doriopsis Weberi zusammen wurde aus einer Tiefe von 600 M. auf Schlammboden (St. IO) in der Madura-See ein Individuum gefangen.

Dasselbe war hell rothgelb; der Fuss etwas dunkler. Die Länge des stark zusammengezogenen Individuums war $7 \mathrm{~mm}$. bei einer Höhe von 4,5 und einer Breite von 3; die Breite der Fusssohle $2 \mathrm{~mm}$.

Die Formverhältnisse die gewöhnlichen. Die Rhinophorien ziemlich stark, die Keule mit Io Blättern; die vor der Mitte des Rückens stehende Kieme aus Io Blättern gebildet; die Analpapille fast central; ein Rückenrand war kaum angedeutet. Der Fuss vorne gerundet, hinten zugespitzt, der Vorderrand mit Andeutung einer Furche.

Das Centralnervensystem wie gewöhnlich. Die grossen Augen grösser als die proximalen Riechknoten, von einem Durchmesser von 0,16 mm., mit grosser gelber Linse; die Ohrblasen nur von einem Diam. von $0,08 \mathrm{~mm}$.

Der gelbliche Schlundkopf von $2 \mathrm{~mm}$. Länge, die Raspelscheide hinten unbedeutend vorspringend; keine Bewaffnung des Innenmundes. Die etwas abgeplattete Zunge mit sehr schwach gelblicher Raspel; der Erhärtungszustand gestattete keine Bestimmung der Anzahl der Zahnplattenreihen so wenig wie die der Platten in den Reihen. Die glasklaren Zahnplatten (Fig. 20) schienen in Form mit denen anderer Trevelyanen überein zu stimmen; sie erreichten eine Höhe bis $0,20 \mathrm{~mm}$, die äussersten maassen nur 0,06.

Es kamen vielleicht auch hier drei, aber nur wenig geschiedene gräulichweisse $Z$ witter$\mathrm{d}$ rüsen vor. Die schlanken, geraden, glasklaren Stachel des Penis eine Höhe bis wenigstens $0,04 \mathrm{~mm}$. erreichend.

Eine mehr eingehende Untersuchung war unmöglich.

3. Trevelyana rubromaculata Bgh. n. sp. Taf. III, Fig. I4. Taf. XVII, Fig. $2 \mathrm{I}-23$.

Am Riffe der Pepela-Bai an der Ostküste der Insel Rotti (St. 301) wurden 5 Individuen dieser Art gefangen und nach dem Leben abgebildet.

Das lebende Thier hat eine Länge von $6,6 \mathrm{~cm}$. gehabt bei einer Körperhöhe bis I,6, die Höhe der Kieme fast $2 \mathrm{~cm}$. Die Farbe der Nitte des Rückens bläulich, derselbe war sonst gelblich, überall kamen sparsam zerstreute, stark rothe, rundliche Flecken vor; die Tentakel und die Rhinophorien roth, die Kieme (bläulich-)weiss mit rothen Rhachides, die obere Seite des Fusses blau mit gelbem Rande.

Die a ufbewahrten ganz schlaffen Individuen hatten eine Länge von $3-4-4,5 \mathrm{~cm}$., 
ähnelten sonst einander in allen Verhältnissen ganz. Das grösste wurde genauer untersucht; die Höhe des Körpers betrug I,3 cm., die Breite 1,5, die Höhe der Kieme I cm.; die Höhe der Rhinophorien war $3 \mathrm{~mm}$; die Breite des Fusses $16 \mathrm{~mm}$., wovon jederseits 5 auf das Gebräm kamen. - Die Farbe war durchgehends hell schmutzig weisslich.

Die Formverhältnisse die gewöhnlichen. Tentakel waren kaum nachweisbar; die ziemlich kleinen Rhinophorien mit etwa 30 Blättern der Keule. Am Rücken und an den Körperseiten kam eine kleine Anzahl von (gegen 20) gerundeten Papeln vor (im Leben roth), theils in Querreihen, theils ungeordnet; etwa an der Mitte stand die schöne grosse Kieme, (bei den drei Individuen) von I 3-I4 grösseren tripinnaten Federn gebildet, 2-3 kleinere kamen noch zwischen den grossen vor; ein wenig vor der Mitte der (in Durchmesser $5,5 \mathrm{~mm}$. haltenden) etwas kuppelartigen intrabrachialen Scheibe die ein Schnürloch bildende Analöffnung und vor derselben, ein wenig rechts die Nierenpore. Die vortretende Genitalpapille am Ruickenrande. Der Fuss vorne gerundet und mit Randfurche, das Gebräm nicht schmal, der Schwanz etwas zugespitzt.

Die grösseren Eingeweide schimmerten deutlich durch die Körperwände.

Die fast sessilen Augen von 0,08 mm. Durchmesser, mit grosser gelber Linse; die Ohrblasen ein wenig grösser. In den (etwa 30) Blättern der Rhinophorien keine Spikel. Die Papel der Rückenhaut zeigten keine besondere Structurverhältnisse, nur waren die Drüschenzellen mehr gedrängt und ein wenig Pigment vorhanden.

Die Mundröhre kurz. Der weissliche Schlundkopf fast kugelförmig, von $4 \mathrm{~mm}$. Länge. Die Zunge mit fast farbloser Raspel, die 16 Zahnplattenreihen enthielt, von denen die 6 vordersten incomplet; in der Scheide kamen noch 15 Reihen vor, von welchen die 3 unreif; die Gesammtzahl der Reihen somit 3I. In den Reihen wurden bis 32 Platten gezählt. Die Platten waren von sehr hell gelblicher Farbe; die Höhe der innersten betrug o, I4 mm., die Länge der folgenden 0,10 ; die Höhe des Hakens der 4 äussersten $0,05-0,06-0,08-0,08$. Die Zahnplatten wie bei anderen Trevelyanen; die innerste (Fig. 2 I $a$ ) von den anderen abweichend, die anderen (Fig. 21) stimmten in Form überein, nur waren die äussersten kleiner mit höherem und dünnerem Haken (Fig. 22).

Die weissen Speicheldrüsen 6,5 $\mathrm{mm}$. lang bei einer Breite von I,25, etwas abgeplattet.

Die Speiseröhre fast doppelt so lang wie der Schlundkopf. - Die gelbe Leber von ovaler Form, $15 \mathrm{~mm}$. lang bei anderen Durchmessern von 8 ; vorne gerundet, hinten abgestutzt; ihre Höhle weit, aus dem hinteren Drittel derselben tritt der dünne Darm hervor, der einen grossen Bogen bildet und im Ganzen eine Länge von $2 \mathrm{~cm}$, hatte. - Die Verdauungshöhle leer.

Das Hinterende der Körperhöhle mit einem gelblichem Filz erfüllt, von den starken Nieren röhren gebildet.

Am Hinterende der Leber, an dieselbe angeheftet, lagen etwas links neben einander die zwei gleichgrossen, grauen $\mathrm{Z}$ witterdrüsen, die von Meniscus-Form waren, jede von einem Durchmesser von $9 \mathrm{~mm}$. bei einer Dicke von 3 ; in ihren Läppchen reife Geschlechtselemente. Die vordere Genitalmasse weisslich und grau, von ovaler Form, i I mm. lang, ihre vordere Hälfte von den an einander gehefteten Prostata und Spermatotheke gebildet. Der ziemlich starke, aus der abgeplatteten Prostata ausgehende geschlungene Samenleiter ausgestreckt $2 \mathrm{~cm}$. lang; der unterste Theil desselben so wie die glans des kurzen Pen is (in einer Strecke 
von wenigstens $2 \mathrm{~mm}$.) mit (gegen 25) unregelmässigen Längsreihen von plumpen, meistens etwas gebogenen Haken oder Dornen von einer Höhe von 0,012-0,016 mm. (Fig. 23) besetzt. Die Spermatotheke von $7 \mathrm{~mm}$. Durchmesser, etwas stundenglasförmig, die untere Abtheilung aber viel kleiner; die birnförmige Spermatocyste nur von 1,5 mm. Länge ${ }^{1}$ ).

4. Trevelyana rubropapulosa Bgh. n. sp. Taf. IV, Fig. I5. Taf. XVII, Fig. 27-3I; Taf. XVIII, Fig. $1-3$.

Auf einem Riff bei Saleyer (St. 2 I3) wurde ein Individuum erbeutet und lebend abgebildet.

Lebend hatte dasselbe eine Länge von 6,5 bei einer Breite von I cm, die Breite des Kiemensterns betrug $\& \mathrm{~mm}$. Die Grundfarbe der Rückenseite scheint hell gelblich gewesen zu sein, mit zahlreichen runden und ovalen rothen (Augen-)Flecken (oder Knoten), die Kieme roth, die Keule der Rhinophorien rothbraun.

Das a ufbewahrte ganz schlaffe Individuum hatte eine Länge von $5,3 \mathrm{~cm}$. bei einer Höhe von 1,3 und einer Dicke von I cm.; die Höhe der Rhinophorien betrug 2, der Durchmesser des Kiemenkreises $8 \mathrm{~mm}$., die Länge der Kiemenblätter 3; die Länge des Schwanzes war $2,3 \mathrm{~cm}$., die Breite des Fusses bis $7 \mathrm{~mm}$. - Die Farbe war durchgehends bläulichgrau, die Rhinophorien dunkler.

Die Formverhältnisse die gewöhnlichen; der Rücken und die Körperseiten mit zahlreichen runden und ovalen, gerundeten Papeln bedeckt von einem Durchmesser von $1,5-2 \mathrm{~mm}$., vorne standen sie besonders etwas dichter gedrängt. Die Rhinophorien ziemlich klein. Der runde Kiemenkreis von I I Blättern gebildet; central die wenig vortretende Analpapille und rechts die Nierenpore. Tentakel konnten nicht entdeckt werden. An der rechten Seite mehr oben die Vulva und unterhalb derselben der ( $1,5 \mathrm{~mm}$. hervorragende) Penis. Das Fussgebräm schmal. - Durch die Körperseiten schimmerten sehr deutlich die baumartig aufsteigenden gelben Nierenstämme.

Das Centralnervensystem wie bei anderen Trevelyanen.

Die Mundröhre 2,5 mm. lang. - Der ebenfalls weissliche Schlundkopf kurz-birnförmig, 4 mm. lang; die Lippenscheibe mit weisslicher Cuticula. In der bräunlichgelben Raspel der Zunge is Zahnplattenreihen, in der nach unten gebogenen Scheide deren 22, die Gesammtzahl der Reihen somit 40. In den Reihen wurden bis 33 Platten gezählt. Die Zahnplatten hell gelb, wenigstens in der Grundplatte; die Höhe der innersten betrug 0,10 , die der nächsten 0, I6 mm., und die Höhe stieg bis 0,20, die der äussersten war 0,10-0,12 mm. Die Form der innersten Platte (Fig. 27a) wie sonst bei den Trevelyanen, so auch die der folgenden (Fig. 276, 28) die äussersten ganz schlank und dünn (Fig. 29).

Die weissen Speicheldrüsen sich längs der Speiseröhre erstreckend, 6,5 mm. lang bei einer Breite von I, ziemlich abgeplattet, etwas knotig.

Die über den Zwitterdrüsen verlaufende Speiseröhre (Fig. 3 I $a$ ) I $2 \mathrm{~mm}$. lang bei einem Durchmesser von 1,5 , hinten in den dünnwandigen MIagen übergehend, aus dessen hinterem

I) An der Genitalöfnung so wie zwischen zwei Kiemenblättern fanden sich Individuen einer 1,5 mm. langen schönen Copepode mit Eiermassen angeheftet. 
Theil der kurze gebogene (Fig. 3 I c) Darm hervorgeht. Mit Ausnahme seines Vorderendes ist der Magen von den Leberlappen bedeckt. Die ganze hintere Eingeweidemasse bei einem Durchmesser von 7 fast $22 \mathrm{~mm}$. lang, cylindrisch, hinten gerundet, ist fast nur von der Leber gebildet. Die dünne Wand ihrer weiten Höhle ist mit grösseren Gruppen von hell bräunlichgrauen runden und ovalen Knoten bedeckt (Fig. 3 I $b$ ), die um eine kleine Höhle stehen, welche sich in den Magen und in die Leberhöhle öffnet. Der fast unmittelbar in die Leberhöhle übergehende Magen zeigt, besonders in der Pyloruspartie, starke gegen den Darm convergirende Falten; und die Leberhöhle hat hier unvollständige Scheidewände und grössere Knoten von Lebersubstanz. - Die Höhlen waren alle ganz leer.

Die länglich-ovale, abgeplattete, granulirte Blutdrüse grau, $4 \mathrm{~mm}$. lang.

Die inniger an die Körperwand anhängenden Nierenstämme sind gelblich, sehr stark verästelt (Fig. I) und an der Oberfläche überall mit sessilen oder kurz-gestielten, kugeligen Zellen von einem Durchmesser von 0,02-0,03 mm. dicht bedeckt (Fig. 2).

Vor der hinteren Eingeweidemasse neben einander die zwei grossen, im Durchmesser

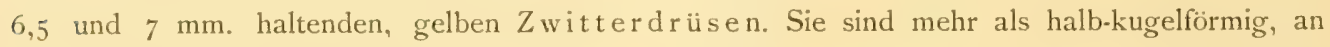
der vorderen Seite abgeplattet mit Nabel, aus welchem der dünne weisse Ausführungsgang hervorgeht (Fig. 3); die Oberfläche ist überall und dicht fein granulirt. In diesen Körnern kommen reife Eizellen vor; auf Schnitten der Drüse graue Partien Zoospermien enthaltend, ringsum welche die Körner ansitzen. - Die vordere Genitalmasse kugelförmig, von $7 \mathrm{~mm}$. Durchmesser, weisslich. Die flache Prostata an die Samenblasen geheftet, mit weiter Höhle, vorne in den Knäuel des dünnen Samenleiters übergehend, welcher ausgestreckt an Länge $15 \mathrm{~mm}$. maass. Der graue Penissack I,5 mm. lang; am Grund der Vorhaut die flache Glans; die Bewaffnung derselben die gewöhnlichen (Fig. 30), bis 0,025 mm. langen Stachel; die Bewaffnung setzte sich eine Strecke in den Samenleiter hinauf fort. Die graue kugelförmige Spermatotheke von $3,5 \mathrm{~mm}$. Durchmesser, die ebenfalls kugelförmige Spermatocyste etwas kleiner.

5. Trevelyana? defensa Bgh. n. sp. Taf. II, Fig. 12. Taf. XVII, Fig. 24-26.

Am 29 Aug. wurde am Riffe in der Waru-Bai an der Nordküste von Ceram (St. I74) ein Individuum gefangen und nach dem Leben abgebildet.

Das lebende Thier hatte eine Länge von 28 bei einer Breite bis $5 \mathrm{~mm}$. Die Farbe der Ruickenseite war grelblich mit röthlichen Fleckchen und Strichelchen, röthlichen Rhinophorien und weisser Kieme, der Fussrand bläulich.

Das stark zusammengezogene und erhärtete aufbewahrte Thier hatte eine Länge von I 3 bei einer Körperhöhe von 4 und einer Dicke von 3,5 mm., die Breite des Fusses war 2, die Länge des Schwanzes $5 \mathrm{~mm}$. Die Farbe war durchgehends bräunlichgrau.

Die Formverhältnisse die gewöhnlichen der Trevelyanen. Ein wenig vor der Mitte der Länge der Rückenseite stand aber eine aufrechte, durchbohrte Papille und hinter derselben ein hervorragender, unbedeutend nach vorne gebogener, einen Bogen bildender, breiter Schirm (Fig. 26). Bei der geringen Grösse des Thieres scheint dieses bei dem Zeichnen des lebenden 
Thieres übersehen $\left.{ }^{2}\right)$. Die Kieme schien I 2, einen fast geschlossenen Ring bildende Blätter zu enthalten.

Der Schlundkopf $3 \mathrm{~mm}$. lang bei einer Breite von 2,25 und einer Körperhöhe von 2, die Raspelscheide am Hinterende kaum vortretend. Die Lippenscheibe mit düner, farbloser Cuticula. Die starke Zunge zeigte in der blassen Raspel i 4 Zahnplattenreihen, in der kurzen Scheide noch 6 Reihen, von welchen die 2 unreif; die Gesammtzahl der Reihen somit 20. Die Rhachis vorne $(0,30 \mathrm{~mm}$.) breit, mit der gewöhnlichen starken, medianen Falte. Die Seitenplatten waren gelblich, die anderen farblos; die Höhe der Seitenplatten $0,18 \mathrm{~mm}$, die der innersten Aussenplatten 0,08 , der folgenden $0,09-0,10$; die der äussersten $0,029 \mathrm{~mm}$. Die Seitenplatten (Fig. 24a) von gewöhnlicher Hakenform; die innerste plumpe Aussenplatte (Fig. 24b) mit einem spitzen Dentikel aussen am Grunde; die übrigen Platten (Fig. 24) mit allmählig schlankerem, vom Hinterende der Grundplatte aufsteigendem Haken; die äussersten Zahnplatten allmählig kleiner (Fig. $25 a a$ ).

Der Erhärtungszustand des Individuums gestattete keine genauere Untersuchung, eine Bewaffnung des Penis wurde nicht nachgewiesen.

Während diese Thierform übrigens mit den Trevelyanen in den Formverhältnissen der Körpertheile und im Raspelbaue übereinstimmt, weicht sie durch die mediane Rückenpapille (Anus?) mit ihrem Schirm von denselben bedeutend $a b$ und wird vielleicht eine Gattung $\left(T_{\text {timna }}^{2}\right)$ ) bilden.

In den Farbenverhältnissen scheint sie mit den Trev. citrina ${ }^{3}$ ) ziemlich übereinzustimmen, weicht aber im Raspelbau ab.

\section{Nembrotha Bgh.}

R. BERGi, System d, nudibr. Gasteropoden. 1. c. I892, p. II44-II45.

Corpus limaciforme fere laeve; rhinophoria retractilia, clavo perfoliato; branchia in medio dorsi sita, paucifoliata, foliolis bi-vel tripinnatis; tentacula brevia, lobiformia; podarium angustius.

Armatura labialis debilis vel nulla. Radula sat angusta; rhachis dente depresso subquadrato; pleurae dente intimo majore falciformi et dentibus externis depressis simplicibus compluribus.

Glandula hermaphrodisiaca hepate connata; prostata discreta nulla; glans penis aculeis vel hamis armata.

Die Nembrothen sind äusserlich nicht immer leicht von den Trevelyanen zu unterscheiden, ihre $\mathrm{K}$ ieme hat nur eine geringere Anzahl von Blättern. Um so mehr unterscheiden sie sich von denselben im inneren Baue. Der Raspelba $u$ ist sehr verschieden; die Zwitterdrüse überzieht wie sonst bei verwandten Thierformen die Leber; - die Prostata ist nicht gesondert und der Penis bewaffnet.

I) Die Notizen bei der Zeichnung stimmten vollständig überein mit denen der Zettel im Glase, welches das Thier enthielt; ein Verwechslung von Objecten scheint somit unwahrscheinlich.

2) Mose. I. X.VVI, 40.

3) Vgl. Malacolog. Lnters. Heft XI, IS77, p. 442-443. Taf. XLI, Fig. 5; Taf. LVI, Fig. IS-25.

SIBOGA-EXPEDITIE L. 
Von der Gattung ist eine kleine Reihe von Arten bekannt, die alle aus dem Philippinischen und Stillen Meere stammen, nur mit Ausnahme der nicht von den anderen wesentlich abweichenden $N$. gratiosa ${ }^{7}$ ) aus dem Mexicanischen Golfe, wozu jetzt noch eine $N$. capensis des Neeres um das Kap kommt.

I. Nembrotha cristata Bgh. Taf. XVIII, Fig. 4-8.

R. BERgh, Malacolog. Unters. II (Heft XI). I877, p. 458. Taf. XXXIII, Fig. 6.

Color nigerrimus, dorsum et latera tuberculis smaragdinis (maculis) pro parte seriatis ornata; margo anterior capitis maculis smaragdinis, vaginae rhinophoriorum et branchia similis coloris.

SEMrper hatte im "Philippinischen Meere" von dieser Form ein Individuum gefangen und lebend abgebildet; dasselbe war verloren gegangen, und die Art somit bisher nur durch die erwähnte Abbildung bekannt.

Am Riffe bei Tual auf der Insel Niedrig-Kei (St. 25S) wurden 3 Individuen gefangen; das eine war kleiner, stark zusammengezogen und verdreht, die zwei anderen fast gleichgross (5 und $5,8 \mathrm{~cm}$. lang) und einander ganz ähnlich.

Das grösste hatte eine Höhe von $1,3 \mathrm{~cm}$. und eine ähnliche Dicke; die Länge des Schwanzes betrug $3 \mathrm{~cm}$; ; der Durchmesser des Kiemenbuckels war $8 \mathrm{~mm}$., die Höhe der Kiemenblätter 6 mm. die Höhe der Rhinophorien 4; die Breite des Fusses 3 mm. - Die Grundfarbe war sammtschwarz; gegen dieselbe stachen hell-grünliche, rundliche, längliche und unregelmässig geformte, fast nicht erhabene (bis $4 \mathrm{~mm}$. lange) Flecken ab, die am Rücken und Schwanze eine nicht ausgeprägte mediane Längsreihe bilden und an den Körperseiten vielleicht zwei; der Vorderrand des Kopfes, der Rand der Rhinophorien und der Fussrand waren auch grün.

Die Formverhältnisse die gewöhnlichen; die drei Kiemenblätter stark.

Das mitsammt dem Schlundkopfe in sehr reichliche blaue, fibrilläre Bindesubstanz gehüllte gelbliche Centralnervensystem zeigte jedes cerebro-pleurale Ganglion gleichsam 8-förmig mit gleichgrossen Abtheilungen; die rundlichen pedalen Ganglien etwas grösser als jede dieser, durch eine breite Commissur verbunden, die halb so lang wie der Durchmesser jedes Ganglions war. - Die ganz kurz-gestielten Augen von 0,08 mm. Durchmesser.

Die sammtblauschwarze Mundröhre $6 \mathrm{~mm}$. lang bei einem Durchmesser von 2,5. Der Schlundkopf $3 \mathrm{~mm}$. lang bei einer Höhe und Breite von 2,5; an und für sich gelblich, nur der Gaumen blauschwarz; die Raspelscheide hinten hervortretend. Der Innenrand der Lippenscheibe dunkel, von starker, gelber Cuticula überzogen. In der bräunlichgelben Raspel der Zunge I I Zahnplattenreihen, in der Scheide deren noch I 7, die Gesammtzahl der Reihen somit 2 S. Zu jeder Seite der medianen Platte die hakenartige Seitenplatte und ro Aussenplatten. Die Platten waren gelb; die Breite der medianen betrug 0,28 mm., die Länge der Seitenplatte 0,35 , die der 2 innersten Aussenplatten 0,16-O, I3 mm. Die medianen Platten (Fig. 4) mit (4-)5 kurzen Dentikeln, die Seitenplatten (Fig. 5) und die Aussenplatten (Fig. 5) ganz wie bei anderen Nembrothen.

I) R. BERGH, Report on the Nudibranchs. (Blake-Exped.) (Bull. of the Mus. of compar. zoölogy of Harvard College. NIX, 3 ISgo), p. $172-175$. Taf. II, Fig. I-5; Taf. III, Fig. I-4. 
Die blauschwarze Speiseröhre $9 \mathrm{~mm}$. lang bei einem Durchmesser von 0,75. Der die Mitte der Leber durchbrechende schwarzblaue Darm in der ersten, bis an den Schlundkopf reichenden Strecke $12 \mathrm{~mm}$. lang, in der nach hinten gehenden auch $12 \mathrm{~mm}$. lang. Die hintere Eingeweidemasse vorne und hinten gerundet, I $2 \mathrm{~mm}$. lang bei anderen Durchmessern von 8 , wo sie nicht von der gelben Zwitterdrüse bekleidet ist, schwarzblau. Die Leber auf Schnitten fast schwarz, mit kleiner Höhle.

Die ovale Blutdriise ziemlich dick, oval, blau, $3 \mathrm{~mm}$. lang, fein granulirt.

Die gegen die Farbe der Leber stark contrastirende gelbe $Z_{\text {w }}$ it terdr üse zeigte überall zahlreich zerstreute Haufen von dicht gedrängten Kügelchen; am Hinterende der Leber und an ihrer linken Seite bildeten sie ein zusammenhängendes, etwa I,5 mm. dickes Lager; in den Läppchen reife Geschlechtselemente. - Die vordere Genitalmasse bildete einen ovalen Meniscus von $8 \mathrm{~mm}$. Länge; rothgelb und weisslich, die Hauptausführungsgänge schwarz. Die Vagina (Fig. 6b) mit starken Längsfalten der sammtschwarzen Innenseite. Ebenso der $3 \mathrm{~mm}$. lange Penis, in welchen der geschlängelte lange dünne Samenleiter endet (Fig. 6a). Durch die grösste Länge desselben lag etwas gebogen die $2 \mathrm{~mm}$. lange, etwas gelbliche Glans, welche am Grunde (Fig. 7) einen Durchmesser von 0, I2, am Ende (Fig. 8) von 0,10 mm. hatte; sie trug IO-I2 Längsreihen von schwach gebogenen Dornen, die am Grunde der Glans bis 0,05, sonst meistens nur $0,025 \mathrm{~mm}$. maassen; die Bewaffnung erstreckte sich kaum höher in den Samengang hinauf.

Die Eingeweide, besonders die vordere Genitalmasse, waren in reichliche lose filzige bläuliche Bindesubstanz gehüllt.

2. Nembrotha morosa Bgh. Taf. IV, Fig. I3. Taf. XVIII, Fig. 9-I2.

R. Bergh, Malacolog. Unters. II (Heft XI, IS77), p. 457-458. Taf. XXXIII, Fig. 7; Taf. XXV, Fig. 9 (Heft VI, I874).

Auf einen Riff bei Saleyer (St. 213) wurde ein Individuum gefangen und lebend abgebildet; die Abbildung stimmt wesentlich mit der von SEMPER gelieferten uiberein.

Lebend hatte dasselbe eine Länge von fast $7 \mathrm{~cm}$. bei einer Höhe des Körpers von etwa I, die Kieme ragt nach I $\mathrm{cm}$. empor. Die Farbe war metallglänzend dunkelgrün hier und da mit röthlichem Schimmer, das Stirngebräm dunkel blau eingefasst, der Schwanzrücken ebenso blau wie auch der Fussrand; die Rhinophorien und die Kieme hell grünlich.

Das a ufbewahrte Individuum war $5 \mathrm{~cm}$. lang bei einer Körperhöhe bis I und Breite bis $0,8 \mathrm{~cm}$., die Länge des Schwanzes betrug 2,8 cm., die Höhe der Kieme 0,5. Die Farbe war durchgehends dunkel bläulichschwarz; der Grund der Kieme (Kiemenhügel) gräulichweiss, am Schwanzrücken ein länglicher Fleck ähnlicher Farbe, so wie das Stirnsegel und der Fussrand hier und da ähnlich gefärbt.

Die Formverhältnisse die gewöhnlichen; die Kieme aus drei Blättern gebildet, der Schwanz mehr als die Hälfte der ganzen Körperlänge betragend.

Der Schlundkopf weisslich mit schwach grünlichem Anflug, $4 \mathrm{~mm}$. lang bei einer Breite von 2, mit hinten vorspringender Raspelscheide; die Lippenscheibe mit gelblicher Cuticula 
uiberzogen. Die braunschwarze Raspel enthielt i I Zahnplattenreihen, in der Scheide fanden sich deren noch etwa 12, die Gesammtzahl der Reihen somit 23. Die medianen und die Aussenplatten gelb, die Seitenplatten glasklar farblos; die Breite der medianen betrug 0,24 bei einer Länge bis $0,20 \mathrm{~mm}$; die Länge der Seitenplatten $0,45 \mathrm{~mm}$; die Länge der drei Aussenplatten 0,26-O, IS-O,I $4 \mathrm{~mm}$. Die medianen Platten (Fig. 9) subquadratisch, mit schwachem, umgeschlagenem, glattem Rande; die etwas verdrehten Seitenplatten (Fig. 9, I0) mit geklüfteter Spitze; es fanden sich absolut nur drei Aussenplatten (Fig. IO), von welchen die grösste, mit nach innen vorspringendem Flügel (Fig. Io b).

Die hintere Eingeweidemasse kurz-wurstförmig, 7,5 mm. lang; die graue Leber erschien entblösst hier und da an der Oberfläche, war sonst von dem gelblichen dicken körnigen Lager der Zwitterdruse bedeckt; in den Läppchen derselben reife Geschlechtselemente.

Die vordere Genitalmasse von ovalem Umrisse 3,5 $\mathrm{mm}$. lang, gelblichgrau und weiss; die Hauptausführungsgänge grünlichblau. Die Bewaffnung des Penis aus dichtstehenden, bis O, I4 mm. hohen, klaren, gleichsam dicht gekammerten Dornen (Fig. I I, I2) gebildet. Die Vagina mit sehr starken Längsfalten.

Diese Thierform war bisher nur durch die Abbildung SEMPER's bekannt, das Original fiir dieselbe schien verloren gegangen.

\section{Nembrotha nigerrima Bgh. Taf. XVIII, Fig. I $3-$ I 4 .}

R. Bergh, Malacolog. Unters. I (Heft XI, IS77) p. 45I-454. Taf. XXXIII, Fig. 5 (Heft VI, I874); Taf. LV, Fig. 8-I4; Taf. LVI, Fig. 2-5.

Eltot, Nudibranchiata. 1.c. 1903 , p. 549.

Auf einem Riff bei Banda wurde ein Individuum gefangen; ein anderes in der Sanana-Bai an der Ostküste der Insel Sula Besi (Stat. I93).

Das erste hatte (etwas verbogen) eine Länge von $2 \mathrm{~cm}$. bei einer Breite von 6,5 mm. und einer Höhe von 7 , die Kieme hatte noch dazu eine Höhe von 2,5, die der Rhinophorien von $3 \mathrm{~mm}$., die Breite der Fusssohle war $2 \mathrm{~mm}$. - Die Farbe war durchgehends schwarz.

Die Formverhältnisse die gewöhnlichen. Der Kopfrand wenig vortretend; die Tentakel kurz. Die Keule der (vollständig ausgestreckten) Rhinophorien schlank, kegelförmig, mit 20-25 Blättern. Die (stark zusammengezogene) Kieme schien von 5 Blättern gebildet. Die Fusssohle vorne gerundet, gleichbreit, das Hinterende zugespitzt.

Das Centralnervensystem mit seiner. Hülle gräulichschwarz. Die kleinen, ganz kurzgestielten Augen von o, Io mm. Durchmesser. Die Blätter der Rhinophorien ohne Spikel.

Der Schlundkopf mit seiner losen Hülle grauschwarz, $2 \mathrm{~mm}$. lang, mit hinten vorspringender Raspelscheide; die Lippenscheibe von einer ziemlich starken, schwach gelblichen Cuticula überzogen. Die Zunge hell röthlichgelb, mit braungelber zugespitzter Raspel; die letztere enthielt is Zahnplattenreihen, in der cylindrischen Scheide fanden sich noch 8 entwickelte und 3 jüngere Reihen, die Gesammtzahl der Reihen somit 26. Die Platten waren von hellgelber Farbe; die Breite der medianen betrug 0, 16 mm., die Länge der ersten hakenartigen Seitenplatte 0,28 , der zweiten Zahnplatte 0,10 und der äussersten $0,04 \mathrm{~mm}$. Die Platten waren ganz 
wie fruher (1. c.) beschrieben; die medianen hatten meistens nur \& kurze Dentikel (Fig. I3), die Anzahl der ausserhalb der ersten hakenförmigen Seitenplatte (Fig. 14) liegenden Platten war meistens II (Fig. I4).

Die schwarze Speiseröhre mehr als doppelt so lang wie der Schlundkopf. Die röthlichbraune Leber wie die Eingeweidemassen im Ganzen in eine lose schwärzliche Hülle eingebettet; die Leber von ovalem Umriss, $7 \mathrm{~mm}$. lang; der Darm schwarz.

In den Läppchen der Zwitterdrüse reife Eizellen. - Die vordere Genitalmasse von $6 \mathrm{~mm}$. grösstem Durchmesser. Bei dem Erhärtungszustande, noch dazu bei der schwarzen Farbe des Penis, konnte die Bewaffnung der Glans nicht nachgewiesen werden.

Von den blaugrünen Flecken des Rückens, von dem brennend rothen Streifen längs des Fussrandes und der ähnlichen Farbe an den Rhinophorien, die (nach SEMPER) am lebenden Thieren zu sehen sind, war an diesem wie an dem früher untersuchten Individuum nichts zu bemerken.

4. Nembrotha Kubaryana Bgh. Taf. V, Fig. I3.

Malacolog. Unters. II (Heft XI), I877, p. 454.

Beitr. zu einer Monogr. d. Polyceraden. II. (Verh. d. k. k. zool. bot. Ges. in Wien. XXX, I880). p. 659-663. Taf. XIV, Fig. I3-16; Taf. XV, Fig. I-IO.

Dorsum colore atro-violaceo, infra versus podarium linea rubra cinctum, maculis majoribus viridibus pro parte seriatis et confluentibus ornatum; rhinophoria nigra, vaginae rhinophoriorum rubrae, sicut tentacula et margo anterior capitis et rhachides foliorum branchialium rubra; podarium coerulescens.

Armatura lingvalis fere ut in $N$. nigerrima.

Von dieser Form wurde am Riffe von Pulu Sebangkatan (Borneo-Bank) (St. 8I) ein Individuum gefangen und lebend abgebildet.

Das lebende Individuum hatte eine Länge von etwa $6 \mathrm{~cm}$. und stimmte in Farbenverhältnissen fast ganz mit der obenstehenden Beschreibung iberein.

A ufbewahrt war dasselbe $3,7 \mathrm{~cm}$. lang bei einer Höhe des Körpers bis I und einer Dicke bis 0,9 ; die Höhe der Kieme $6,5 \mathrm{~mm}$.

Die Formverhältnisse die gewöhnlichen; die Kieme von 3 starken Blättern gebildet, von denen die lateralen fast in 2 aufgelöst.

Der Schlundkopf wie gewöhnlich; der Rand der Lippenscheibe mit gelblicher Verdickung des cuticularen Überzuges. An der bräunlichen Raspel I4 Zahnplattenreihen, in der Scheide deren noch 12, die Gesammtzahl der Reihen somit $26^{1}$ ). Der Raspelbau ganz wie früher beschrieben. Die subquadratischen, medianen Platten wie bei der $N$. nigerrima, auch mit 5 Dentikeln, ihre Breite 0,20. Die sichelförmige Seitenplatte von $0,30 \mathrm{~mm}$. Länge; die erste der Io Aussenplatten $0,14 \mathrm{~mm}$. lang. Die Platten waren alle gelb.

1) Bei den früher untersuchten Individuen war die Anzahl der Zahnplattenreihen $29-31$. 
Die Speiseröhre $9 \mathrm{~mm}$. lang; der Darm $16 \mathrm{~mm}$. lang, schwärzlich. Die hintere Eingeweidemasse (Leber) fast kurz-birnförmig, $9 \mathrm{~mm}$. lang, ihre Aussenseite grünlichgrau, an Schnitten gelblich.

Der Samenleiter gelblich, i $3 \mathrm{~mm}$. lang. Der Penis schwarz, I,5 mm. lang.

Bei der St. 225 wurden ferner ein und bei St. 9 I ein weiteres Individuum erbeutet; ihre Länge betrug 4,75 und $5 \mathrm{~cm}$.

5. Nembrotha rubropapulosa Bgh. n. sp. Taf. V, Fig. 14. Taf. XVIII, Fig. I9-22.

Am Riffe von Pulu Pasi-Tanette bei Saleyer (St. 2 I3) wurde ein Individuum gefangen und lebend abgebildet.

Lebend war das Thier $13 \mathrm{~mm}$. lang bei einer Breite von kaum 2; die Grundfarbe der Ruickenseite war schwarz, aber zum grossen Theil durch eine Menge von hellrothen Fleckchen verdrängt; die Tentakel, die Rhinophorien und die Kieme hell bläulich.

Das a ufbewahrte, stark erhärtete Individuum hatte eine Länge von 9 bei einer Höhe von 3 und Breite von 2,5 mm., die Höhe der Kieme 1,5 mm. Die Grundfarbe des Thieres war überall tief schwarz, an der Rücken- wie an den Körperseiten überall gräuliche, runde Fleckchen oder eigentlich Knötchen (aber grösser als in der angegebenen Figur [von einem Durchmesser bis I $\mathrm{mm}$.] und weniger dichtstehend), mit Andeutung von Anordnung in Längsreihen; die Rhinophorien und die Kieme schmutzig bläulich.

Die Formverhältnisse die gewöhnlichen, die Kieme von 3 Blättern gebildet, von welchen das mittlere tief gespalten.

Das Centralnervensystem röthlichbraun.

Der Schlundkopf I $\mathrm{mm}$. lang, röthlichbraun, mit vortretender Raspelscheide. In der gelblichen Raspel fanden sich Io Zahnplattenreihen, in der Scheide deren noch 19, die Gesammtzahl der Reihen somit 29. Die Platten waren gelblich; die Breite der medianen betrug o,o8, die Höhe der Seitenplatten 0,0\$ und die Breite der Aussenplatten 0,05 mm. Der Raspelbau war dem der $N$. gracilis $^{1}$ ) sehr ähnlich. Die (bei diesem Individuen) sehr zerbrechlichen und schwer zu untersuchenden medianen (Fig. I9) Platten mit einer kleinen medianen und zwei starken lateralen Spitzen; die Seitenplatten von gewöhnlicher Form (Fig. 20, 21 a ), die Aussenplatten breit und dün, etwas gebogen (Fig. 2I bb); mitunter schien noch eine kleinere Aussenplatte, wie bei der $N$. gracilis, vorzukommen, falls nicht ein abgebrochener Theil des Aussenendes der grossen Aussenplatte eine andere vortäuschte.

Die kurz-wurstförmige hintere Eingeweidemasse 2,5 $\mathrm{mm}$. lang, rothbraun.

Die vordere Genitalmasse röthlichbraun, ebenso der lange Samenleiter; der Penis schwarz, die lange dunkelbraune Bewaffnung des Inneren der Glans und weiter zurück aus braunen Haken gebildet, die (Fig. 22) von sehr verschiedener Form waren und eine Länge bis 0,04 erreichten. 
6. Nembrotha lineolata Bgh. n. sp. Taf. II, Fig. IO. Taf. XVIII, Fig. 15-is.

Auf einem Riff bei Saleyer (St. 2I3) wurden am 26 Oct. drei Individuen dieser Form gefangen, und das grösste lebend abgebildet.

Die Länge des lebenden Thieres hat (der Figur nach) fast $6 \mathrm{~cm}$. betragen bei einer Körperhöhe bis $7 \mathrm{~mm}$., wozu noch die $7 \mathrm{~mm}$. hohe Kieme kommt, die Höhe der Rhinophorien ist etwa $2 \mathrm{~mm}$. gewesen. Die Grundfarbe der oberen Seite scheint gelblich gewesen zu sein, aber fast verdrängt durch eine Menge von feinen rothbraunen Längstrichelchen; der Grund der Kieme scheint blau gewesen zu sein, die Blätter rothbraun; die Rhinophorien blau und ebenso der Fussrand.

Die Länge des grössten der in Formol bewahrten Individuen betrug $28 \mathrm{~mm}$. be; einer Breite bis 5 und einer Höhe bis $6 \mathrm{~mm}$, die Höhe der Kieme 5, die der Rhinophorscheiden $3 \mathrm{~mm}$. Die zwei anderen, ziemlich stark zusammengebogenen Individuen waren ein wenig kleiner. - In Farbenverhältnissen stimmten alle drei Individuen ganz überein. Die Grundfarbe war hell gelblich; an der oberen Seite kam eine grosse Menge von feinen, der Länge nach laufenden, dunkel kastanienbraunen Strichen vor, an den Seiten drei mitunter fast ununterbrochene Linien, welche sich auf den Anfang des Schwanzes hinaus fortsetzten, zwischen diesen fanden sich vereinzelt oder $\mathrm{zu} 2-3$ vereinigt kürzere Striche; am Schwanze bildeten sie gleichsam schöne Querbänder, aus Längsstrichelchen zusammen gesetzt, zwischen den Bändern trat die gelbe Grundfarbe hervor; der Vorderrand des Kopfes rothbraun, hinter dem Rande einige rothbraune Querstriche. Die Rhinophorscheiden blau, ebenso blau waren die Tentakel und der Vorderrand des Fusses, so wie auch die Seitenränder und besonders das Schwanzende; der Stiel der Kiemenblätter blau, dieselben aber meistens rothbraun.

Die Formverhältnisse die gewöhnlichen. Die bei allen drei Individuen stark vortretende blaue Scheide der Rhinophorien liess die Spitze der schwach gelblichen (4 mm. hohen) Keule erkennen. Die in der Mitte des Rückens stehende Kieme zeigte bei allen drei Individuen drei tripinnate $(4 \mathrm{~mm}$. hohe) Blätter mit breiter Rhachis; hinten den Bogen completirend die Analöffnung. $\mathrm{Zu}$ jeder Seite des Aussenmundes die wenig vorspringenden länglichen gleichsam eingestuilpten Tentakel (Fig. I8). Der Fuss schmal, mit kaum vorspringenden Rändern.

Die Eingeweide schimmerten nirgends durch. Die Eingeweidehöhle sich nur bis an die Mitte des Hinterkörpers (hinter dem Kiemenhügel) erstreckend. - Die zwei Individuen wurden anatomisch untersucht.

Das gelbliche Centralnervensystem mit sehr zusammengedrängten Ganglien und somit kurzen Commissuren. Die fast sessilen Augen von fast 0,08 mm. Durchmesser, mit grosser gelber Linse. Die Rhinophorien mit etwa 25 Blättern.

Die ziemlich $(2,5-3 \mathrm{~mm}$.) lange Mundröhre vorne weisslich, sonst blauschwarz. Der weissliche Schlundkopf in lose Bindesubstanz gehüllt, 2-2,5 mm. lang, mit etwas vorspringender Scheide; im Innenmunde jederseits eine braune sichelförmige Platte, von einer Breite von 0,I2 mm., aus ganz kleinen Elementen gebildet (Fig. I5). Die kräftige Zung ge mit gelblicher Raspel, welche I 8-20 Zahnplattenreihen enthielt, in der Scheide kamen noch I I-12 entwickelte und 3 jüngere Reihen vor, die Gesammtzahl derselben somit 32-36. Die 
Zahnplatten waren fast farblos, aber stark; die Breite der medianen betrug o, ro mm., die Länge der grossen Seitenplatte $0,12 \mathrm{~mm}$., und die der ersten Aussenplatte $0,06 \mathrm{~mm}$. Die medianen Platten (Fig. I6) von gewöhnlicher Form, mit 4-5 starken Dentikeln; die Seitenplatten (Fig. I 7) ziemlich kurz; die Anzahl der Aussenplatten war 7, dieselben (Fig. I 7 ) zeigten übrigens die gewöhnlichen Verhältnisse.

Die Speiseröhre lang und dünn. - Die kegelförmige hintere Eingeweidemasse $6-7 \mathrm{~mm}$. lang bei einer Breite von 4, aussen grünlich wegen der die Leber überziehenden Zwitterdrüse. Die Leber selbst grauschwarz, am Vorderende schimmerte diese Farbe durch.

In den Läppchen der Zwitterdrüse reife Geschlechtselemente. - Die vordere Genitalmasse kurz wurstförmig, stärker als die hintere Eingeweidemasse in lose, fest anhängende Bindesubstanz gehüllt, 5,5-7 mm. lang bei Durchmessern von 3 ; zum sehr grossen Theil von der gräulich-gelblichen, $5 \mathrm{~mm}$. langen Spermatotheke gebildet, an deren Unterseite die ziemlich kurzen schwarzen Windungen des Zwitterdrüsenganges und vorne die Schleimdrüse angeheftet sind. Die Schleim-Eiweissdrüse selbst $3-4 \mathrm{~mm}$. lang, abgeplattet. Der vaginale Gang der Spermatotheke lang, gewunden, in seiner mehr als letzten Hälfte dicker; an dem auch gewundenen uterinen Gang war die graue, kugelförmige, im Durchmesser I,5 mm. haltende Spermatocyste befestigt. Der Samenleiter lang und gewunden; es glückte nicht den Penis zu isoliren und die Bewaffnung der Glans zu sehen.

Ein ganz ähnliches etwa $25 \mathrm{~mm}$. langes Individuum wurde später am Riff bei Haingsisi erbeutet.

\section{Nembrotha lineolata Bgh. var. Taf. II, Fig. I I.}

Ein anderes Individuum wurde in der Bucht von Badjo an der Westküste von Flores (St. 50) gefangen und lebend abgebildet.

Dasselbe zeigte dieselben Farbenverhältnisse wie oben, nur vorne die braunen Linien mehr unregelmässig und mehr zerstïckelt. Die Länge betrug $30 \mathrm{~mm}$. bei einer Höhe von 9 und einer Breite von 6; am Rücken ein Kiemenhügel von $2 \mathrm{~mm}$. Höhe, in welche die Kieme ganz zurückgezogen war.

Die $2,5 \mathrm{~mm}$. lange Mundröhre aussen wie innen gelblich. Der Schlundkopf $2 \mathrm{~mm}$. lang; dicht innerhalb der senkrechten Mundöffnnng eine $0,12 \mathrm{~mm}$. breite, feste, braungelbe Platte, aus fest verbundenen, etwa $0,007 \mathrm{~mm}$. breiten, stabförmigen Elementen zusammengesetzt. In der gelblichen Raspel der Zunge 16 Zahnplattenreihen, in der Scheide I 4, die Gesammt. zahl der Reihen somit 30. Die Form der Zahnplatten ganz wie oben, sie waren aber etwas grösser, die Anzahl der Aussenplatten 8-9. Die Breite der medianen Platten betrug 0,14 mm., die Länge der Seitenplatten 0,20 , die Länge der ersten Aussenplatte $0,08 \mathrm{~mm}$.

Die vordere Genitalmasse unregelmässig-kugelförmig, von $4 \mathrm{~mm}$. Durchmesser; die Schleim-Eiweisdrüse bräunlichgelb und weiss.

Es liegt hier nur eine (unwesentliche) Varietät der typischen Art vor. 
7. Nembrotha amitina Bgh. n, sp. Taf. XVIII, Fig. 23-28.

Mit dem Schleppnetz wurde auf der Borneo-Bank (St. So) ein Individuum gefangen. Dasselbe war schlecht bewahrt, etwas abgerieben.

Die Länge desselben schien etwa I $5 \mathrm{~mm}$. betragen zu haben bei einer Breite von 7 und Höhe von 6; die Rhinophorien 2 hoch, die Kieme 2,5; die Breite des Fusses $4 \mathrm{~mm}$. Die Farbe des Rückens war dunkel blaugrau, die Rhinophorien aber rothgelb, und die Innenseite (das Laub) der Kieme sammtschwarz; der Fuss röthlichgelb.

Die Formverhältnisse schienen die gewöhnlichen; die Kieme von 2 Blättern gebildet, von welchen das eine ziemlich tief geklüftet; die weissliche Analpapille klein.

Die Mundröhre $2 \mathrm{~mm}$. lang. Der Schlundk opf gelblich, $3 \mathrm{~mm}$. lang bei einer Höhe von 2,5 und Breite von 2,25; die Raspelscheide hinten an der Unterseite stark hervortretend. Die Lippenscheibe von einer tief in den Mund eintretenden, vorne schwarzbraunen, sonst gelben, dicken Cuticula von etwa 1,5 mm. Breite überzogen; der Vorderrand derselben ziemlich stark beschädigt. Die Raspel der Zunge an den Rändern fast rothgelb; dieselbe enthielt I 2 Zahnplattenreihen, in der Scheide deren noch 6; die Gesammtzahl der Reihen somit nur I8. Der Raspelbau (Fig. 23) etwa der gewöhnliche. Die medianen Platten gelb; die lateralen glasklar, farblos; die Aussenplatten stark gelb. Die Breite der medianen Platten 0,28 mm., die Länge der Seitenplatten 0,43 , die Länge der 3 Aussenplatten $0,20-0,1 S-0, r_{3} \mathrm{~mm}$. Die medianen Platten (Fig. 23, 24) fast ohne Verdickung des Vorderrandes; die Seitenplatten stark, aber der Haken ziemlich kurz (Fig. 23, 25); die 3 Aussenplatten wie gewöhnlich (Fig. 23, 26), mitunter kam eine ganz schwache vierte vor (Fig. $23 a$ ).

Die hintere Eingeweidemasse $10 \mathrm{~mm}$. lang bei einer Breite von 5; die schwarze Leber von dem dünnen feinkörnigen Lager der gelblichweissen Zwitterdrüse überzogen, welche hier und da streifenartig von der Leber durchbrochen war.

In der Zwitterdrüse reife Geschlechtselemente. Die vordere Genitalmasse fast kugelförmig, von 2,5 mm. Durchmesser, gelblich. Der weisse Penis $3,5 \mathrm{~mm}$. lang; die nicht lange Glans von $0,40 \mathrm{~mm}$. Durchmesser, dieselbe so wie der angrenzende Theil der Vorhaut mit farblosen, nicht steifen, etwas eigenthümlichen Dornen (Fig. 27, 28) von einer Höhe bis 0,04 mm. ganz dicht besetzt.

Diese Form scheint von den bisher bekannten Arten verschieden.

\section{Nembrotha? rubroocellata Bgh. n. sp. Taf. IV, Fig. I4.}

Am Riffe von Nusa-Besi (St. 282) wurde ein Individuum gefangen und lebend abgebildet. Dasselbe hatte eine Länge von I $4 \mathrm{~mm}$. Die Grundfarbe der oberen Seite war schwarz, aber durch dichtstehende, meistens etwas längliche rothe Fleckchen fast verdrängt; die Tentakel, die Rhinophorien und die Kiemenblätter schienen schwarz und grau zu sein.

Das a ufbewahrte Individuum hatte eine Länge von 14 bei einer Höhe von 4 und einer Dicke von 2,5 mm.; die Höhe der Rhinophorien und der Kieme war fast I mm. Die Grundfarbe war dunkel schmutziggrau; am Rücken kamen meistens zu Linien confluirende 
schwarze Längsstriche vor; der Rücken war von einer schwarzen Linie eingefasst, hinter der Kieme vereinigten sich beide und bildeten eine mediane Linie längs des Rückens des langen Schwanzes. An den Körperseiten 2-3 schwarze anastomosirende Linien und zwischen denselben ziemlich gedrängt runde und ovale, unbedeutend vortretende, nabelartig vertiefte Scheibchen. Die Tentakel, die Rhinophorien und die Kieme schwarz. Des Fussrand schwarz.

Die Formverhältnisse waren die verwandter Formen, nur sehr langgestreckt. Die Tentakel mit eingestülpter Spitze. Die Kieme von 3 Blättern gebildet.

Das Centralnervensystem röthlichgelb, mit schwarzer Hülle. In der starken Keule der Rhinophorien etwa 25 Blätter. Die erwähnten Scheibchen der Körperseiten zeigten sich unter dem Mikroskope röthlichgelb, von feinem und dichtem schwarzem Netzwerke umgeben.

Der rothgelbe $\mathrm{Schlundk}$ opf von $0,5 \mathrm{~mm}$. Länge. Auf der Zunge schienen i 8 , in der (O, I $2 \mathrm{~mm}$. breiten) Scheide I5 Zahnplattenreihen vorzukommen. Durch einen Unfall ging die sehr schwer zu eruirende Raspel mitsammt der Scheide verloren; der Raspelbau stimmte kaum ganz mit dem der Nembrothen überein, die Höhe der hakenförmigen Seitenplatten war 0,06 mm. - Die Speiseröhre war schwarz.

Die kurz-kegelförmige hintere Eingeweidemasse $3,5 \mathrm{~mm}$. lang; die schwarze Leber fast vollständig von dem körnigen rothgelben Lager der Zwitterdrüse eingehüllt, in den Läppchen der letzteren reife Geschlechtselemente. - Die vordere Genitalmasse rothgelb; es glückte nicht an dem schwarzen Penis eine Bewaffnung nachzuweissen.

Dem Äusseren nach lag eine Nembrotha vor. 


\section{NUDIBRANCHIATA KLADOHEPATICA.}

R. BERGH, System. 1. c. IS92, p. 999(-1070).

Organa respiratoria (epinotidia) latero-dorsalia, raro lateralia elongato-conica vel arborescentia vel foliacea (lamelliformia).

Bulbus pharyngeus validus mandibulis lateralibus instructus. Hepar (fere semper) ramulosum, rami organis respiratoriis inclusi. Glandula sanguinea nulla. Vesicula seminalis unica.

Das Hauptmerkmal dieser grossen Gruppe ist die verzweigte, diffuse Leber; dieser Character ist ganz selten wenig ausgeprägt oder ist ganz ausgefallen. So wie trotz des Fehlens der Leberlappen in den Rückenpillen die Lobiancoia eine Hermaeide ist, so bleiben die Pleuroleuriden trotz desselben Mangels innig mit den Pleurophyllidien verwandt. In ähnlicher Weise gehören alle Bornellen zusammen, trotzdem Leberlappen bei einer Art (B.excepta) sehr reducirt sind, und andere Arten Übergänge zu diesem Verhältnisse zeigen. Bei den Tritoniiden bildet die Leber eine ganz zusammenhängende, ganz unverzweigte Masse; diese Familie hat aber alle die anderen Charactern der Kladohepatiker, wenn auch sie die den Holohepatikern zunächst stehende Gruppe ist. Auch bei den (so aberranten) Phylliroiden weichen die Verhältnisse der Leber von denen anderen Kladohepatiker nicht wesentlich ab.

TrtTuNidD.a.

R. BERGH, System 1.c. p. 1067-IO70.

Die Gruppe enthält zwei Gattungen, die Tritonien (die vielleicht wieder in zwei zerfallen) und die Marionien.

Tritonia Cuv. '(proprie).

R. BERGH, l, c. p. 1068.

Margo veli frontalis papilligerus.

Radula ut plurimum dentibus lateralibus numerosis. - Ventriculus inermis. ist bekannt.

Eine kleine Reihe von Arten, aus den verschiedensten Meeresgegenden stammend, 
1. Tritonia olivacea Bgh. n. sp. Taf. II, Fig. I 8.

Von dieser Form wurde bei Seget, westlichem Eingang der Selee-(Galewo-)Strasse (St. 164), ein Individuum gefangen, nach dem Leben abgebildet und in (4\%) Formol bewahrt.

Das lebende Thier (Taf. II, Fig. I 8 ) ist gräulich-olivenfarbig gewesen, der Rückenrand und der obere Theil der Rückenanhänge (Kiemen) weisslich, und die Spitze der letzteren schwarz. Die Länge des Körpers hat $4,3 \mathrm{~cm}$. betragen bei einer Breite desselben von I, die Höhe der Rhinophorien 3, der Anhänge (Kiemen) bis $4 \mathrm{~mm}$. - Das in Formollösung bewahrte Individuum war durchgehends von schwach-grünlichgrauer Farbe, die Spitze der Rückenanhängsel (Kiemen) schwarzbraun. Die Länge betrug $3,5 \mathrm{~cm}$. bei einer Breite des Rückens bis 1, die Höhe der Rückenanhängsel bis $2 \mathrm{~mm}$, die Höhe des Körpers bis $10 \mathrm{~mm}$.

Die Formverhältnisse die gewöhnlichen. Das Stirnsegel wenig vorspringend, mit, wie es șchien, Io kleinen kegelförmigen Papillen, von denen die äussersten die grössten, und die äusserste mit ihrer Löffelform den Tentakel darstellend. Die degenquastförmigen Rhinophorien wie gewöhnlich. Der wenig gewölbte Rücken ganz glatt; der ein wenig vortretende Rückenrand trug jederseits 8 Kiemenbüschel, von welchen die zwei vordersten und der hinterste etwas kleiner. Diese Kiemen waren kurzstämmig, die kleine Krone wenig verbreitet, sonst, insoweit beurtheilt werden konnte, wie gewöhnlich. Die Körperseiten und der Fuss wie gewöhnlich.

Das wie gewöhnlich kleine Centralnervensystem weiss.

Der weissliche Schlundkopf von gewöhnlicher Form, $7 \mathrm{~mm}$. lang bei einer Breite von 6,5 und einer Höhe von 5 ; die Bauverhältnisse die gewöhnlichen. Die Nandibel von gewöhnlicher Form, hellgelb, die Strecke neben dem Kaurande sowie derselbe aber schön dunkel purpurfarbig; der Kaurand fein streifig, ohne Höcker. Die Wände der Mundhöhle weisslich. Die Zunge mit hell gelblicher Raspel, welche etwa 25 Zahnplattenreihen zeigte, während noch etwa 20 in der Scheide vorkamen, die Gesammtzahl der Reihen war somit 45. In den Reihen schienen gegen 90 Zahnplatten vorzukommen. Die Platten waren von sehr hellgelber Farbe; die Breite der medianen betrug 0,13 mm. bei einer Länge (von vorne nach hinten) von 0,06 , die Höhe der Seitenplatten schien bis $0,14 \mathrm{~mm}$. zu steigen. Die Formverhältnisse der Platten waren sonst ganz wie bei anderen Tritonien.

Die Speiseröhre in ihrer ganze Länge (magenartig) zu einem Durchmesser von $5 \mathrm{~mm}$. erweitert, voll gestopft mit röthlichgelben kleinen harten Klumpen von thierischer Natur. Die hintere Eingeweidemasse, hauptsächlich von der $\mathrm{Hauptleber}$ gebildet, kegelförmig, von $16 \mathrm{~mm}$. Länge bei einem Durchmesser von 9, schmutzig weisslich; die sich zwischen Speiseröhre und Darm einschiebende vordere Leber viel kleiner, von $4 \mathrm{~mm}$. Durchmesser.

Die grosse weissliche biconvexe vordere Genital masse $9 \mathrm{~mm}$. lang bei einer Breite von 6 und einer Höhe von $5 \mathrm{~mm}$.

Am Ankerplatz in der Nähe von Seget am westlichen Eingange in die Selee-(Galewo-) Strasse (St. 164) wurden noch 2 Individuen dieser Form erbeutet.

Das kleinen hatte eine Länge von $17 \mathrm{~mm}$. Das grössere war $33 \mathrm{~mm}$. lang bei einer Breite ron 9 und Höhe von 8; die Farbe war schmutzig gelblich, das Laub der 
Rückenanhängsel (der Kiemen) schwarzbraun. Der Rand des Stirnsegels trug \& Papillen, die äusserste jederseits mit Furche; am Rückenrande Io-II Anhängsel, an Höhe theilweise alternirend.

Der weissliche Schlundkopf $6 \mathrm{~mm}$. lang; die Mandibel stark gelb, die Kaurandpartie schön dunkel purpurfarbig; die Wände der Mundhöhle weisslich. In der gelblichen Raspel 23, in der Scheide noch 2x Zahnplattenreihen. Die Zahnplatten wie gewöhnlich.

\section{Tritonia irrorata Bgh. n. sp. Taf. XVIII, Fig. 29-32.}

Am 5 Mai wurde in der Kambaragi-Bai, Tanah-Djampeah (St. 64) aus einer Tiefe von 32 M. ein Individuum heraufgeholt.

Dasselbe hatte in Formol bewahrt eine Länge von $32 \mathrm{~mm}$. bei einer Breite von 9 und einer Höhe von $8 \mathrm{~mm}$, die Breite des Stirnsegels war 4, die Höhe der Rhinophorien 3 und die der Kiemenbüschel 2,5 mm.; die Breite der Fussohle 4,5 mm. - Die Farbe war bräunlich, aber, mit Ausnahme der Sohle, durch eine gelbliche dichte Tüpfelung meistens verdrängt, am Rücken noch dazu schwarzscheckig.

Die Form war länglich, nach vorne und besonders nach hinten etwas zugespitzt. Das in der Mitte tief eingekerbte Stirnsegel jederseits mit 5 Papillen, von denen die äusserste eine schwache Längsfurche zeigte. Die Scheide der Rhinophorien ziemlich hoch. Der wenig gewölbte Rücken fein höckerig, besonders seine hintere Hälfte; der wenig vortretende Rand trug 7-S niedrige Kiemenbüschel mit kleinen Kronen. Der Fuss schmäler als der Rücken, vorne gerundet.

Das kleine Centralnervensystem wie gewöhnlich. Die Otocysten von einem Durchmesser von $0,09 \mathrm{~mm}$.

Der Schlundkopf von gewöhnlichen Formverhältnissen, $6,5 \mathrm{~mm}$. lang bei einer Breite von 4 und einer Höhe bis 3,5. Die gelben Mandibel von gewöhnlicher Form, der Kaurand zeigte (Fig. 29) am Rande gleichsam kleine Schuppen, Endfacetten von kleinen Säulen und dann 2 Reihen von starken, bis O,I4 mm. hohen Dentikel (Fig. 30). Die Wände der Mundhöhle weisslich. Die breite Zunge mit gelblicher Raspel, welche 2 I Zahnplattenreihen enthielt, während in der Scheide noch 19 vorkamen, von welchen die 3 hintersten noch unreif; die Gesammtzalıl der Reihen somit 40. In den Reihen kamen kaum mehr als 70 Platten vor. Die Zahnplatten von gewöhnlichen Formverhältnissen; die medianen $0,28 \mathrm{~mm}$. breit, die ersten Seitenplatten von $0,17 \mathrm{~mm}$. Länge, die Höhe der Seitenplatten stieg bis $0,12 \mathrm{~mm}$. Die medianen Platten (Fig. 3I) mit den gewöhnlichen plumpen und stumpfen Dentikel, die erste Seitenplatte (Fig. 3I) von gewöhnlicher plumper Form und die übrigen Seitenplatten (Fig. 32) hakenförmig.

Die kurze Speiseröhre, der S. mm. lange Magen und der Darm waren leer. Die kegelförmige Hauptleber $13 \mathrm{~mm}$. lang, bräunlichgrau, innen braun; die Nebenleber nur von $4 \mathrm{~mm}$. grösstem Durchmesser.

Die grosse vordere Genitalmasse rundlich, weisslich und gelblichweiss, von $7 \mathrm{~mm}$. Durchmesser. Das Vestibulum genitale so wie der Penis braun. 


\title{
Marionia Vayss.
}

\author{
R. BERGH, System. 1.c. p. I069.
}

Limbus frontalis digitatus, ut plurimum digitis compositis numerosis.

Ventriculus dentibus armatus.

Eine Reihe von Arten aus den wärmeren Meeresgegenden ist bekannt.

I. Marionia distincta Bgh. n. sp. Taf. IV, Fig. I9. Taf. XVIII, Fig. 33-34. Taf. $\mathrm{XIX}$, Fig. $\mathrm{I}-2$.

Am is Febr. wurde am Ankerplatz östlich vom Sailus Besar, Paternoster-Inseln (St. 3 I5), ein Individuum gefangen, nach dem Leben abgebildet und in Formol aufbewahrt.

Das lebende Thier scheint eine Länge von $36 \mathrm{~mm}$. bei einer Breite von 7 gehabt zu haben. Die Farbe ist röthlichgrau gewesen, der Rückenrand mit schwarzen Querstrichen, und das Laub der Papillen schwarz.

Das a ufbewahrte Individuum hatte eine Körperlänge von 30 bei einer Breite von 7 und einer Höhe von $9 \mathrm{~mm}$; d die Höhe der vorgestreckten Rhinophorien (mit der Scheide) 4,5 mm., die Breite des Stirnsegels 5, die Höhe der Rückenpapillen bis $4 \mathrm{~mm}$; die Breite des Fusses fast durchgehends 3 , die Länge des Schwanzes fast $2 \mathrm{~mm}$. — Die Farbe war durchgehends gelblich, das Laub der Rückenpapillen meistens grünlich schwarz, von schwarzen Strichelchen an den Rückenrändern fand sich keine Spur. Eingeweide schimmerten undeutlich durch.

Die Form wie gewöhnlich. Das Stirnsegel nicht stark entwickelt, an dem Rande ein wenig median ausgekerbt, mit I I fast cylindrischen, besonders an der Unterseite fein höckerigen Anhängseln, von welchen das äusserste mit Längsfurche. Die Rhinophorien wie gewöhnlich. Der ebene Rücken mehr als doppelt so breit wie der Fuss, sich jederseits in 9 armförmige Papillen erhebend, die ziemlich tief gespalten waren, und jeder Ast laubtragend. Von diesen Armen alternirten die 6 ersten an Grösse; die 3 hintersten waren kleiner, an Grösse nach hinten abnehmend; der zweite und besonders der vierte Arm waren die grössten. Die Analpapille aussen am Grunde des vierten Arms stehend; die Genitalpapille mehr vorne, der Gegend zwischen 2. und 3. Arme entsprechend. Der schmale Fuss vorne gerundet, der Schwanz kurz. - Die Leibeshöhle sich nur bis an die Gegend des fünften Armes erstreckend.

Das weisse Centralnervensystem von einem Durchmesser von 1,6 mm., ganz wie gewöhnlich, so auch die Augen und die Ohrblasen.

Der Schlundkopf 5,25 mm. lang bei einer Höhe bis 4 und einer Breite bis 4,25, von gewöhnlicher Form, weisslich. Die Mandibel hellgelb, von gewöhnlicher Form; der Kaurand oben glatt, sonst mit mehreren (14) sehr starken, nach hinten höheren bis $0,20 \mathrm{~mm}$. hohen, oben gerundeten Zähnen versehen (Fig. 1). In der schwach gelblichen Raspel der Zunge 28 Zahnplattenreihen, in der Scheide noch 24, die Gesammtzahl der Reihen somit 52. In den Reihen kamen bis etwa I 20-I 30 Platten jederseits vor. Die schwach gelblichen Platten hatten, die medianen eine Breite bis O, I5 mm., die lateralen eine Höhe bis O, I $2 \mathrm{~mm}$. Die medianen Platten (Fig. 33) von gewöhnlicher Form, ebenso die lateralen (Fig. 34). 
Die weisslichen, 5 mm. langen, die Speiseröhre begleitenden Spcich eldrüs en etwas lappig.

Die Speiseröhre abgeplattet, bei einer Breite von 2 fast I I mm. lang. Der fast kugelförmige Mag en von $4 \mathrm{~mm}$. Durchmesser, in seiner grössten Strecke mit starker Ringmusculatur und mit einem Gürtel von vielen dichtstehenden schmutzig grïlichgelben schmalen Platten (Fig. 2), meistens von einer Länge von $1,5 \mathrm{~mm}$. bei einer Höhe von fast I $\mathrm{mm}$.

Die hintere Eingeweidemasse (Leber) mit der links liegenden Nebenleber $15 \mathrm{~mm}$. lang bei einem Durchmesser von 6,5, hinten gerundet. Die Hauptleber ist mit Ausnahme des Vorderendes von dem dicken gelblichweissen Lager der Zwitterdrüsenlappen überzogen; für sich ist die Leber grünlichschwarz.

In den Läppchen der Zwitterdruise reife Geschlechtselemente. - Die vordere Genitalmasse gross, $6 \mathrm{~mm}$. lang, bei einer Breite von 3 und einer Höhe von 5, weisslich und weiss, die stundenglasförmige Samenblase $+\mathrm{mm}$. lang, die gestreckt-kegelförmige Glans von I,5 mm. Länge.

Die Art ist (besonders durch die Mandibel) von der aus der Gegend von Amboina beschriebenen $\boldsymbol{M}$. arborescens verschieden, so wie von der $\boldsymbol{M}$. chloanthes des Siamesischen Meeres ${ }^{1}$ ).

2. Marionia tessellata Bgh. n. sp. Taf. XVIII, Fig. 35-36. Taf. XIX, Fig. 3-6.

Am 25 April wurde am Riffe von Seba (Savu, Stat. 52) ein Individuum gefangen.

Dasselbe war aufbewahrt von einer Länge von $25 \mathrm{~mm}$. bei einer Höhe und Breite von 7; die Breite des Stirnsegels war 5, die Höhe der Rhinophorscheiden I und die der Kiemen bis $3 \mathrm{~mm}$; die Breite der Fussohle vorne $3 \mathrm{~mm}$. - Die Grundfarbe war weisslich, am Rücken und an den Körperseiten aber fast durch die kleinen, mehr gelblichen Felder desselben verdrängt.

Die Formverhältnisse die gewöhnlichen; das in der Mitte etwas ausgekerbte Stirnsegel jederseits mit 7 Fortsätzen, von denen der äusserste mit Längsfurche. Der Rücken mit kleinen polygonalen und rundlichen, fast nicht über das Niveau erhabenen Feldern von einem Durchmesser bis $0,8 \mathrm{~mm}$. überall bedeckt (Fig. 3). Der Rückenrand trug jederseits I 3 Kiemenbüschel mit ziemlich hohem Stiele; mit Ausnahme der hintersten alternirten sie ziemlich regelmässig in Höhe, so wie die kleineren meistens gleichsam etwas mehr nach aussen gerückt waren. Die Analöfnung unter dem Grunde der fünften (rechten) Kieme. Die Körperseiten zeigten dieselben Felder wie der Rücken. Der Fuss schmal, der Schwanz ganz kurz.

Das weissliche Centralnervensystem $2 \mathrm{~mm}$. breit, vollständig wie bei anderen Tritonien. - Die erwähnten Felder aus dicht gedrängten klaren Schläuchen (Fig. 4) von einer Länge bis $0,05 \mathrm{~mm}$. gebildet.

Der Schlundkopf weisslich, 4,5 mm. lang bei einer Höhe und Breite von 2,5. Die hell gelben Mandibel ziemlich lang, der lange Kaurand mit 3 Reihen von kurz-kegelförmigen, spitzen, bis $0,04 \mathrm{~mm}$. hohen Dentikeln (Fig. 5). Die Zunge zeigte in der fast farblosen Raspel 20 Zahnplattenreihen, in der Scheide noch I5, die Gesammtzahl der Reihen somit 35;

I) Vgl. R. Bergi, Gastcropoda opisthotranchiata (the Danish expedition to Siam, I899-1900. I. p. I96-19S). I902.p.38-40. P1. II, Fig. $25-27$. 
in den Reihen kam eine grosse Anzahl von Platten vor. Die Platten waren fast farblos; die Breite der medianen betrug bis $0,18 \mathrm{~mm}$; die Länge der lateralen (längs des Rückens) o, 6 bei einer Höhe (vom Hinterende der Grundplatte bis zur Hakenspitze) von o, I I mm. Die medianen Platten (Fig. 35) von gewöhnlicher Form, die lateralen mit längeren und mehr geraden Haken (Fig. 36).

Der Magen 6,5 mm. lang, der stark musculäre Theil mit dem Plattengürtel der kürzerste; die Platten kürzer (Fig. 6) und höher als bei der vorigen Art; der dünnwandige Theil des Magens mit (I I) kleinen Polypen von einer Höhe von I-2 mm. gefüllt. Der Darm ausgestreckt $7 \mathrm{~mm}$. lang.

Die kleine dreieckige vordere Leber $3 \mathrm{~mm}$. lang, die kegelförmige hintere bei einer vorderen Breite von 4 etwa $7,5 \mathrm{~mm}$. an Länge messend. Sie waren beide grünlich grau, die hintere aber in ihren hinteren $2 / 3$ von den rundlichen gelblichen Läppchen der $Z$ witterdrüse überzogen, in denselben reife Geschlechtselemente. Die vordere Genitalmasse rundlich, von $4,5 \mathrm{~mm}$. Durchmesser, weisslich und weiss.

\section{Pleuroleuridae.}

R. BERGH, System der nudibranchiaten Gasteropoden. 1.c. 1892, p. 1065-1066.

Diese mit den Pleurophyllidien verwandte Familie, die fast nur Pleurophyllidien ohne Kiemen und ohne Seitenlamellen darstellt, umfasst nur die Gattung ${ }^{1}$ ):

\section{Pleuroleura Bgh.}

Dermatobrancluls van Hass. Uittreksel uit eenen brief van Dr. J. C. VAN HASSELT aan Prof. VAN Sininderen in: Allgem. Konst- en Letter-Bode. 1824. (2. p. 20-24) 3. p. 34-39. Pleuroleura Bgh. Malacolog. Unters. I (Heft VI), I874, p. 276-285. Taf. XXV, Fig. 3; Taf. XXXIV, Fig. 27-32; Taf. XXXV.

Pleuroleura Bgh. Die Pleuroleuriden. Zool. Jahrb. III. I888. p. 348-364. Taf. X-XI.

Die hauptsächlich im indischen Meere vertretene Gattung umfasst bisher

I. Plenroleura ornata B. M. indic.

2. Pleuroleura fortunata B. M. indic.

3. Pleuroleura pustulosa (van Hass.). M. indic.

4. Pleuroleura gonatophora (van Hass.). M. indic.

5. Pleuroleura striata (van Hass.) M. indic.

6. Pleuroleura pallida Bgh. n. sp.

I) Auf ein in Alkohol bewahrtes Thier hat Elıot (On some Nudibranchs from East Africa and Zanzibar II. Proc, zool. soc. of London. IS93, I. p. 25I-252) eine mit den Pleurophyllidien verwandte Form Pleurophyllidiella (Horatii E.) aufgestellt. Während jene Kieme und Seitenlamellen, die Pleuroleuriden weder Kieme noch Lamellen haben, sollten die Pleurophyllidiellen Lamellen, aber keine Kieme besitzen. Mitunter ist die Kieme bei Alkohol-Exemplaren von Pleurophyllidien aber so tief eingezogen, dass sie kaum zu entdecken sind. 
7. Pleuroleura Picteti André. M. indicum.

André, Moll. d'Amboine. Revue suisse de Zool. IV, 2. I896, p. 402, Pl. XXII, Fig. 6, 7.

8. Pleuroleura Suluensis Bgh. n. sp. M. indicum.

9. Pleuroleura Walteri Krause. M. atlant. bor.

Krause, Moll. von Ostspitzbergen. Zool. Jahrb. VI. I892, p. 366-367. Taf. 14, Fig. 6-9.

I. Pleuroleura striata (van Hass.). Taf. IV, Fig. 22. Taf. XIX, Fig. 7-9.

Dermatobranchus striatus van Hass. 1. c. $1824 . \mathrm{N}^{0} .3$, p. 38.

Plenroleura striata (van Hass.). BerGi, l. c. I887, p. 3 II, Taf. 6, Fig. I-2.

Auf einem Riff bei Haingsisi wurde ein Individuum gefangen, nach dem Leben abgebildet und in Formol bewahrt.

Die Länge des lebenden Thieres scheint etwa $23 \mathrm{~mm}$. betragen zu haben bei einer Breite von 5, die Länge der Rhinophorien ist wenigstens 2,5 mm. gewesen (Fig. 22). Die Grundfarbe scheint gelblich gewesen zu sein, der Rücken mit zahlreichen, dunkel violetten Längslinien, die Spitze der Rhinophorien violet. - Die Länge des a ufbewahrten Individuums betrug 20 bei einer Breite von $7 \mathrm{~mm}$, die Breite des Tentakelschildes und der Fusssohle fast 4, die Höhe der Rhinophorien 2,5 mm. Die Grundfarbe war weisslich, am Rücken fast verdrängt durch die dichtstehenden, meistens ununterbrochenen, feinen, bräunlichen, hier und da auch schmutzig violetten Längslinien; die Keule der Rhinophorien bräunlich. Die Eingeweide schimmerten nirgends durch.

Das Thier war im Ganzen der von vas Hasselt (1.c. Fig. 2) gelieferten Abbildung ziemlich ähnlich (nur ist in dieser der Fussrand im Widerspruche mit dem Text roth). Die Form war die gewöhnliche, der Rücken überragte stark den Fuss. Der starke Tentakelschild an den Seiten lappenartig vorspringend; hinter demselben eine kleine Glatze und dann in einem Ausschnitte des Vorderrandes des Rückens die stark vorgestreckten Rhinophorien, an deren Grunde innen die schwarzen Augen durchschimmerten. Die schönen Rhinophorien mit kurzem Stiele, ziemlich langer Keule, die eine gerundete. Endpapille und etwa I 2 wieder getheilte, der Höhe nach verlaufende Blätter zeigte. Der Rücken eben, der ziemlich dicke Rand zeigte unter der Loupe eine Menge von feinen, den Nesselsäcken angehörenden Öffnungen. Die Unterseite des Rückengebräms ganz glatt. Die Körperseiten nach hinten fast verschwunden; vorne an der rechten die Genitalpapille, unweit nach hinten und mehr nach oben die feine Analöfnung. Der Fuss vorne gerundet und mit Randfurche, das Fussgebräm nicht schmal, durch das hintere Drittel der Sohle eine Andeutung einer medianen Längsfurche.

Das weissliche Centralnervensystem wie früher von mir dargestellt. Der $N$. opticus 3 mal so lang wie die cerebro-pleuralen Ganglien; das Auge von 0,08 mm. Durchmesser, mit hellgelber Linse; die Ohrblasen ein wenig kleiner, mit vielen kleinen Otokonien. Die Nesselsäcke meistens rundlich, von einem Durchmesser von $0,12-0,16 \mathrm{~mm}$., mit Nesselelementen gewöhnlicher Art (Fig. 7) in gewöhnlicher Art vollgepackt.

Der weissliche Schlundkopf fast $2 \mathrm{~mm}$. lang, kaum so lang wie die Mundröhre. Die von der starken Muskelplatte bedeckten gelben Mandibel von gewöhnlicher Form, der Kaufortsatz 
ziemlich stark; der Kaurand mit ziemlich zahlreichen (etwa 15) Reihen von bis 0,025 mm. hohen spitzen Dentikeln (Fig. 8). Die Anzahl der Zahnplattenreihen an der Zunge war I4, in der Scheide kamen I 5 entwickelte und 2 jüngere vor; die Gesammtzahl der Reihen somit 3 I. In den Reihen fanden sich an jeder Seite der medianen 17 laterale. Die Platten waren fast farblos; die Breite der medianen betrug 0,05 mm., die der ersten Seitenplatte auch so und die Höhe der Aussenplatten 0,Of mm. Die medianen Platten (Fig. 9a) ziemlich niedergedrückt und breit, mit medianem Haken und an jeder Seite desselben eine Reihe von feinen spitzen Dentikeln. Die erste Seitenplatte (Fig. 9b) auch breit, aber asymmetrisch, mit dem Haken gegen innen, an den inneren Seite desselben 2-3, an der äusseren eine Reihe von spitzen Dentikeln. Alle die Aussenplatten (Fig. 9c) einer Art, hakenartig, ohne Dentikel und alle fast von derselben Grösse. Der Raspelbau dieser Art ist also von dem der anderen verschieden.

Die auf der Speiseröhre ruhenden weissen Speicheldrüsen bilden eine abgeplattete Masse.

Die Speiseröhre länger als der Schlundkopf. Der Magen mit dem Hauptgallengang und der Darm wie gewöhnlich. Die geschlängelten und verästelten, weisslichen Le ber röhren füllten das Rückengebräme, an und zwischen den Nesselsäckchen eindringend, und hüllten den Magen und den Hauptlebergang ein.

Die vordere Genitalmasse $3,5 \mathrm{~mm}$. lang, weisslich.

\section{Pleuroleura striata (van Hass.) var.}

Am Riffe an der WVestseite der Insel Taam (St. 252) wurden zwei Individuen gefangen.

Aufbewahrt und ziemlich stark erhärtet hatten dieselben eine Länge von $7,5-8$ bei einer Breite von 5 und Höhe von 2 mm.; die Breite des Tentakelschildes war 2, die des Fusses 2,5 mm. Die Farbe der Rückenseite war graubraun, das Rückengebräm schmutzig gelblich; die Nesselsäcke schimmerten schwarz durch.

Die Formverhältnisse die gewöhnlichen. Vorne am Rücken wurden etwa 15 ziemlich starke, etwas vortretende längslaufende Falten gesehen, die medianen verliefen gerade bis an das Körperende, die anderen mehr schräge nach aussen.

Die dunklen Nesselsäcke mit den gewöhnlichen, aber stärker schmutzig-gelben Fäden vollgepackt.

Der bräunliche Schlundkopf etwa $0,75 \mathrm{~mm}$. lang; die gelben Mandibel mit schwarzbraunem Kaurand, der mehrere Reihen von kleinen Dentikeln trug. Die gelbliche Raspel und ihre Fortsetzung trugen etwa 30 Zahnplattenreihen, in den Reihen schienen bis 20 Platten vorzukommen. Die medianen und angrenzenden lateralen Platten gelblich, die übrigen farblos; die Breite der medianen Platten betrug 0,035 mm., die Höhe der lateralen stieg bis 0,037, die der äussersten war $0,020 \mathrm{~mm}$. Die Zahnplatten waren ganz wie oben beschrieben, so die mediane, die erste ebenfalls gezähnelte Seitenplatte und alle die anderen, die ohne Dentikel waren.

2. Pleuroleura gonatophora (van Hass.). Taf. IV, Fig. 21. Taf. XIX, Fig. 10-I3. Dermatobranchus gonatophorus van Hass. Brief. I\$24. $\mathrm{N}^{0} .3$, p. 38 . Plenroleura gonatophora (van Hass.). R. BERGH, 1. c. I888, p. 36I-362. Taf. XI, Fig. I8-2I. 
Bei Banda und zwar in einer Tiefe von $36 \mathrm{M}$. wurde cin Individuum gefangen und lebend abgebildet.

Lebend war dasselbe $34 \mathrm{~mm}$. lang bei einer Breite bis 12. Die Farbe der Rücken. seite war hellgrün mit dunkleren verschwimmenden Flecken und weissen Längslinien; der Ruickenrand roth; der Stiel der Rhinophorien weiss, die Keule schwarz.

Das schlecht a ufbewahrte Individuum hatte eine Länge von 27 bei einer Breite bis I I und einer Höhe bis $4 \mathrm{~mm}$; die Breite des Stirnschildes war 6, die des Rückengebräms bis 4,5 mm., die der Fusssohle bis 6, die Länge der Schwanzfurche 8,5 mm. - Die Grundfarbe der Rückenseite war weisslich mit grossen, besonders am Gebräme starken, schwarzen, verschwim. menden Flecken, dazu kamen kleine längliche, in Längsreihen unregelmässig geordnete schwarze Fleckchen vor, nach hinten trat eine mediane Linie besonders hervor; die Keule der Rhinophorien schwarz, das Stirnsegel mit Ausnahme der Ecken und des Vorderrandes schwarz. Die Unterseite des Körpers weisslich; die Körperseiten und das Fussgebräm mit vielen kleineren und grösseren schwarzen Flecken; die Schwanzfurche gelblichweiss.

Die Formverhältnisse die gewöhnlichen; das Rückengebräme stark wellenförmig gebogen, im Rande sehr deutliche Nesselporen; die schönen Rhinophorien wie gewöhnlich; die Analpapille etwas weiter als gewöhnlich nach hinten liegend; die Schwanzfurche ungewöhnlich lang und stark.

Das weisse Centralnervensystem wie gewöhnlich.

Der Schlundk o p weisslich, von ovalen Umrissen, 3,5 mm. lang. Die gelben Mandibel ziemlich gebogen, die Saite des Bogens I, $8 \mathrm{~mm}$. messend, die Breite betrug 0,75 mm., die Form die gewöhnliche, der nicht sehr beschädigte Kaurand zeigte aber nirgends Höcker. Die Raspel der Zunge gelb, enthielt 14 Zahnplattenreihen; in der Scheide kamen deren noch 20 vor, von welchen die 3 hintersten unreif; die Gesammtzahl der Reihen somit 34 . Auf jeder Seite der medianen kamen bis 47 Seitenplatten vor. Die Platten waren von gelblicher Farbe; die Breite der medianen betrug 0,08 bei einer Höhe bis 0,06 mm., die Höhe der ersten Seitenplatte 0,05 , die Höhe der Platten stieg bis $0,1 \mathrm{I}$, die der äussersten betrug 0,07 mm. Die medianen Platten (Fig. IO, II) nicht breit, der Haken fast bis an die Spitze fein gezähnelt; die erste Seitenplatte (Fig. IO) der medianen ähnlich, aber kleiner, unsymmetrisch denticulirt; alle die folgende Platten (Fig. I2) mit fein denticulirtem Haken, nur die 9-II äussersten ohne Dentikel (Fig. I 3 )

Der Magen mit dem Hauptgallengang wie gewöhnlich. Die geschlängelten und verästelten, weisslichen Leberröhren füllten das Rückengebräm, zwischen und an die Nesselsäcke eindringend. Diese letzteren mit gewöhnlichen langen Nesselfäden von einem Durchmesser bis 0,02 mm. vollgepackt.

Die wurstförmige, gelblichweisse $Z$ witterdruise $S \mathrm{~mm}$. lang bei einem Durchmesser von 3 ; in den Läppchen reife Geschlechtselemente. Die vordere Genitalmasse fast kugelförmig, von $3 \mathrm{~mm}$. Durchmesser, weisslich.

Diese Art ist wahrscheinlich die $P l$. gonatophora von vAN HASSELT, jedenfalls von den anderen hier beschriebenen verschieden. 
3. Plenroleura pallida Bgh. n. sp. Taf. XII, Fig. 47-52.

Bei der Insel Kur wurde ein Individuum in einer Tiefe von 27 M. gefangen.

Dasselbe hatte eine Länge von $5 \mathrm{~mm}$. bei einer Breite von 2 und Höhe von 2,5. Die Farbe war durchgehends weiss, die Rhinophorien gräulich.

Die Formverhältnisse die gewöhnlichen (Fig. 47, 48); der Tentakelschild stark, ebenso die Rhinophorien; der Rücken überragte stark den Fuss, unter einer starken Loupe zeigte derselbe ganz feine Längslinien.

Im Rückenrande kamen ziemlich grosse rundliche und flaschenförmige Bälge mit zelligem Inhalt vor, aber nirgends die gewöhnlichen Nesselfaden. Der Durchmesser des Auges 0,06 mm.

Der weissliche Schlundkopf I mm. lang. Die gelben Mandibelplatten wie gewöhnlich. In der fast farblosen Raspel und der wenig vorspringenden Raspelscheide zusammen 24 Zahnplattenreihen; zu jeder Seite der medianen bis 20 laterale Platten. Diese ganz schwach gelblich; die Breite der medianen $0,03 \mathrm{~mm}$., die Höhe der lateralen bis 0,04 . Die Platten von gewöhnlicher Form (Fig. 49-52), ihre Dentikel aber ungewöhnlich lang und der Haken der medianen sehr lang (Fig. 49, 5I).

Diese Form scheint von der folgenden verschieden.

4. Pleuroleura Suluensis Bgh. n. sp. Taf. XIX, Fig. I4.

Aus einer Tiefe von 12 M. wurden bei Pulu Sanguisiapo, Tawi-Tawi-Inseln im SuluArchipel (St. 93) zwei Individuen gefangen.

Sie stimmten in Farben-, Grössen- und Formverhältnissen überein, waren ziemlich stark erhärtet. Sie maassen an Länge 6,5-7 mm. bei einer Breite von 2,25 und einer Höhe von 1,5, die Breite des Tentakelschildes war I,5, die Breite des Fusses 1,5 mm. Die Thiere ähnelten auffallend blassen Exemplaren der Pleuropliyllidia undulata; die Rückenseite war milchweiss, die ganze Unterseite dunkel blaugrau.

Die Formverhältnisse die gewöhnlichen der Pleuroleuriden. Der Rücken war ganz wie bei der Pl. undulata bis an die Spitze von erhabenen Linien durchzogen, deren Anzahl vor der Mitte der Rückenlänge etwa I $5_{5}$ betrug. Die Unterseite des Rückengebräms war durch eine sehr feine weisse Linie in einen äusseren und inneren Theil geschieden; im äusseren standen, wie es unter der Loupe schien, die grossen Nesselsäcke (Fig. I4) in einer einzelnen Reihe, oft ziemlich stark sackartig hervorragend (Fig. I4); der innere Theil des Gebräms glatt. Die Genitalpapille und der Anus wie gewöhnlich. Am hinteren Theile der Fusssohle eine schwache mediane Längsfurche.

In den Nesselsäcken die gewöhnlichen Massen der langen Fäden; Leberröhren konnten bis an den Grund der Säcke verfolgt werden.

Die Mundröhre schwärzlich. Der $0,75 \mathrm{~mm}$. lange Schlundkopf weisslich; die hellgelben Mandibel zeigten am Kaurande viele Reihen von spitzen Dentikel. Die gelbliche Raspel und ihre Fortsetzung in die Scheide trugen in Allem etwa 30 Zahnplattenreihen; die Anzahl der Platten in den Reihen nicht gering. Die Platten waren gelblich, die Breite der medianen 
betrug etwa $0,03 \mathrm{~mm}$; die medianen ähnelten denen der anderen Pleuroleuren, die inneren lateralen waren .gezähnelt, die äusseren ohne Dentikel. - Der Erhärtungszustand gestattete, noch dazu bei der winzigen Grösse, keine genauere Eruirung.

\section{Pleurophyllidimae.}

R. BERGH, System. 1.c. I892, p. I060(-1064).

Die im Äusseren sehr ausgeprägte Familie enthält die Gattungen Pleurophyllidia (Meckel), Linguella (Blv.) und Camarga (B.).

Pleurophyllidia Mleckel.

R. BERGH, System. 1.c. p. 1063 .

Corpus elongatum; caruncula nuchalis vel papillae nuchales distinctae.

Eine Reihe von Arten ist angegeben, hauptsächlich aus den wärmeren Meeresgegenden stammend; denselben sind noch die untenstehenden, wahrscheinlich neuen Arten hinzufuigen.

I. Pleurophyllidia rosea Bgh. n. sp. Taf. V, Fig. 7. Taf. XIX, Fig. 15-r8.

In der Strasse zwischen Makian und Halmaheira (St. I37) wurde ein Individuum erbeutet und nach dem Leben abgebildet.

Das lebende Thier ist nur $12 \mathrm{~mm}$. lang gewesen bei einer Breite von kaum 3; die ganze obere Seite war hell rosaroth.

Das a $\mathrm{fbew}$ a h r te (etwas eingetrocknete) Individuum zeigte sich Io mm. lang bei einer Breite von 3,5 und Höhe von 2; die Farbe war jetzt durchgehends gräulichgrau, längs des Rückens kamen ganz schwache, dichtstehende, hellere Längslinien vor (wie auch in der gemalten Figur angedeutet).

Die Formverhältnisse wie gewöhnlich. Der Tentakelschild deckte eine kleine, wie es schien, kurz-kegelförmige Carunkel; die Rhinophorien nicht ganz dicht bei einander stehend. Die Nesselsäcke im Rückenrande deutlich; die Kiemengrube mit ihren Blättern wie gewöhnlich; die Seitenlamellen vorne hauptsächlich der Länge nach gerichtet. Der Fuss wie gewöhnlich, die Ecken etwas vortretend, die Schwanzfurche sehr ausgeprägt.

Der Schlundkopf gräulichweiss, fast $2 \mathrm{~mm}$. lang. Die schmutzig grünlichgelben, nur in der Schlosspartie dunkleren Mandibel von gewöhnlicher Form, der Kaurand (Fig. I5) mit wenigen Reihen von Spitzen, die bis zu 0,OI $3 \mathrm{~mm}$. frei hervorragten. Die Raspel der Zunge gelb, 5 Zahnplattenreihen enthaltend, in der Scheide kamen deren noch i 9 vor, die Gesammtzahl der Reihen somit 34. In den Reihen fanden sich bis 20 Platten vor. Dieselben waren gelb; die Breite der medianen betrug $0,08 \mathrm{~mm}$. bei einer Höhe von 0,065 , die Höhe der ersten Seitenplatte 0,04 , der nächsten 0,05 und die Höhe erhob sich durch die Reihe bis zu O, IO mm., um nach aussen bis zu 0,05 zu sinken. Die medianen Platten mit starker Spitze 
und einer ganzen Reihe von Dentikeln (Fig. I6, I7a); die plumpe, fast hakenlose erste Seitenplatte auch denticulirt (Fig. I 7 ) , die folgende mit anfangendem Haken (Fig. I $7 c$ ), alle die folgenden von der bei den Pleurophyllidien gewöhnlichen Form, stark denticulirt (Fig. I \&), nur an den äussersten war die Anzahl der Dentikel geringer.

Der Zustand des Individuums gestattete keine weitergehende Untersuchung.

2. Plourophyllidia stonidia Bgh. n. sp. Taf. II, Fig. I5. Taf. XIX, Fig. 19-20.

Auf der Station 5I, Madura-Bai (Molo-Strasse) wurde am ig Aug. aus einer Tiefe von 69-91 M. (grauer Sandboden) ein Individuum heraufgezogen, nach dem Leben gezeichnet und mit gesättigter Essigsäure fixirt.

Das lebende Thier hat eine Länge von is mm. gehabt bei einer Breite von 4,5; die Grundfarbe des Rückens scheint gräulichbraun gewesen zu sein, von mehreren weissen Längslinien durchzogen, der Kopf ist gräulich gewesen. - Die Länge des in Formol bewahrten zusammengebogenen, stark erhärteten In dividuums war etwa $I_{3} \mathrm{~mm}$. bei einer Breite (vorne) von 4,5 und einer Höhe von $4 \mathrm{~mm}$; die Breite des Tentakelschildes 3,5, des Fusses 3,5 mm.; die Länge der Kieme $2 \mathrm{~mm}$. Die Farbe des Rückens war rothgrau, dieselbe von gelblichweissen Linien durchzogen, die an Dicke meistens alternirten, vorne am Rücken kamen deren 22 vor; von derselben rothgrauen Farbe war auch der Fuss, und die Körperseiten nur ein wenig mehr gräulich, die Rhinophorien von dunklerer Farbe mit hellerer Spitze:

Die Formverhältnisse die gewöhnlichen. Der Tentakelschild mit spitzen Ecken, von dem Hinterrande desselben bedeckt zwei kleine Papillen als Repräsentanten der Carunkel; die Rhinophorien nicht ganz dicht bei einander stehend. Der Rücken vorne seicht ausgerandet, die Ränder sonst ziemlich scharf. Die Kiemengrube wie gewöhnlich; die zahlreichen dünnen ziemlich hohen Blätter von gewöhnlicher Form. Die Seitenlamellen (von einer Dicke von 0,5 mm.) sehr reducirt; an der linken Seite erstreckte sich eine solche ununterbrochen durch die hinteren zwei Drittel der Körperlänge, und unter der hinteren Hälfte derselben kam eine ähnliche Lamelle vor; an der rechten Seite trat in der hinteren Hälfte der Körperlänge eine der vorigen ähnliche Lamelle vor $^{1}$ ). Die genitale so wie die anale Papille wie gewöhnlich. Der Fuss mit Randfurche des Vorderrandes und etwas vortretenden Ecken, das Fussgebräm nicht schmal, die hintere mediane Furche der Fusssohle deutlich.

Das schwach röthlichgelbe, etwas abgeplattete Centralnervensystem vollständig typisch. - Im Rückenrande schienen die gewöhnlichen Nesselsäcke vorzukommen.

Der schwach röthlichgelbliche Schlundkopf von typischer Form, 2,5 mm. lang bei einer Höhe und Breite von 1,5. Die hellgelben, nur in der starken Schlosspartie dunkleren Mandibel von gewöhnlicher Form; der Kaurand mit ganz wenigen Reihen von Höckern und Spitzen, die eine Höhe von o,0035 mm. erreichten. Die Cuticula der Mundhöhle stark. Die Zunge von gewöhnlicher kurzer und breiter Form, mit hellgelber Raspel; die Zunge war ganz

1) Auch die Pl. comta (Beitr. zur Kenntn. d. japan. Nudibranchien. I. p. 2I-24. Verh. d. k. k. zool. bot. Ges. in Wien. ISSo, p. 173-176), die überhaupt der hier untersuchten form nahe steht, hat nur eine lange Seitenlamelle, ebenso die Pl. pallida (Malacol. Unters. I (Heft VI). IS74, p. 262). 
erhärtet, und es gliickte nicht jene abzulösen, nicht die Anzahl der Zahnplattenreihen zu bestimmen (in der Raspel kamen vielleicht etwa 52 vor) noch die Anzahl der Platten in den Reihen. Die Zahnplatten waren fast farblos; die Breite der medianen schien $0,10 \mathrm{~mm}$. zu betragen, die Höhe der lateralen bis zu 0,09 zu steigen. Die medianen Platten (deren Kaurand nie vollständig gesehen wurde) trug eine Reihe ganz feiner Dentikel (Fig. I9); die innerste Seitenzahnplatte wie gewöhnlich plumper, ohne Dentikel; die anderen von gewöhnlicher Form, meistens gezähnelt (Fig. 20), nur die äussersten (wenigstens 14) ohne Dentikel, übrigens kamen solche zerstreut auch zwischen den gezähnelten vor.

Keine weiter gehende Untersuchung war bei dem Erhärtungszustande des Individuums möglich.

\section{Phyllikoidae.}

R. BERGII, I. C. IS92, p. $1057(-1060)$.

Diese ganz eigenthümlichen, ganz zusammengedrückten, pelagischen und schwimmenden Kladohepatiker bilden die Gattung Phyllirö (mit der Untergattung Acura).

Phylliroë Pér. et Les.

R. BERGH, 1. c. p. IO59.

Eine kleine Reihe von Arten ist angegeben; es wäre aber möglich, das dieselben nur einer einzigen circumaequatorialen Form angehören.

I. Phyllirö̈ atlantica Bgh.?

Phylliroë bucephala Souleyet (nec PÉron et Lesuevr). Voy. de la Bonite. Zool. II. 1852 , p. 399-4I5. Pl. XXXV, Fig. I-IS.

Phylliroë atlantica Bgh. Verh. d. k. k. zool. bot. Ges. in Wien. XXI. I87I, p. 1302-I305.

Auf der Station 185 (Manipa-Strasse) wurden am I 2 Sept. im Plankton fünf (ohne die Rhinophorien) $6-8 \mathrm{~mm}$. lange, stark zusammengezogene, schlecht erhaltene Individuen gefangen; ferner bei Ternate (St. I 36 ) drei.

Die hinteren Lebersäcke waren nicht an der Nitte eingeschnürt, und die (immer drei und geschiedenen) Zwitterdrüsen nicht an der Unterseite dunkelfarbig; bei zwei war der Penis ausgestreckt.

Es ist somit nicht sicher, dass diese Thiere der $P$. atlantica angehören ${ }^{1}$ ).

\section{Scyllaeidae.}

R. Bergh, System. 1. c. p. $1054-1056$.

Diese ganz eigenthümlich ausgeprägte Gruppe von pelagischen Kladohepatiker umfasst nur die Gattung:

1) R. BrRgh, Die Opisthobranchien. Ergebn. einer Reise nach dem Pacific (Schauinsland). Zoolog. Jahrb. Xill, 3. 1900, p. 239-24 I. 


\section{Scyllaea L.}

R. BERGH, 1. c. p. 1056 .

Von den aufgestellten "Arten" gehören die meisten wohl einer und derselben circumae. quatorialen Art an, der

I. Seyllaea pelagica (L.). Taf. XIX, Fig. $2 \mathrm{I}-22$.

R. Bergh, Malacol. Unters. Heft VIII. I875, p. 319-342. Taf. XL, XLII, XLIII, Fig. I-29; Taf. XLIV, Fig. I-I8.

R. Bergi, Report (Challenger), I884, p. 33-34. Plate XI, Fig. 20. PI. XIX, Fig. 2I-22.

Am 26 Dcbr. wurde am Ankerplatz von Pulu Jedan an der Ostküste der Aru-Inseln (St. 273) aus einer Tiefe von 40 M. ein Individuum gefangen.

Dasselbe hatte aufbewahrt eine Länge von 12 bei einer Körperhöhe von 4 und einer Dicke von $2 \mathrm{~mm}$; die Höhe der mächtigen Rhinophorstiele war I,5, die der Rückenpapillen I,75, die des Schwanzkammes $0,75 \mathrm{~mm}$. Die Farbe war ausgeprägt grünlichgelb mit überall sparsam zerstreuten bräunlichen Punkten.

Die Formverhältnisse die gewöhnlichen. Die vordere Rückenpapille ein wenig grösser als die zweite; ihre Ränder nicht zackig, an der Innenseite trugen sie 4-5 Kiemen, von welchen die zwei unteren grösser, fast so hoch wie die Papillen selbst. Der Schwanzkamm mit geradem Rande, unterhalb des letzteren 6 Kiemenbuische jederseits in einer Reihe. Die Analpapille ausserhalb des Rückenrandes, gerade in der Mitte zwischen den beiden Papillen.

Das Centralnervensystem mit den Augen und die Keule der Rhinophorien ganz wie früher dargestellt.

Der Schlundkopf 1,25 mm. lang, von hell grinlichweisser Farbe, von gewöhnlicher Form und Bau. Die schwach gelblichen Mandibel wie gewöhnlich; die Schlosspartie nicht stark, der Kaurand und die an dieselben stossende Strecke mit vielen (etwa 50) (Quincunx-) Reihen vun schuppenartigen, gefurchten und am Rande gezähnelten Höckern von einer Höhe bis O,O I mm. (Fig. 2 I) besetzt. Die Zunge mit fast farbloser Raspel; es glückte nicht die Anzahl der Zahnplattenreihen oder die Zahl der Platten in den Reihen zu bestimmen. Die fast farblosen Zahnplatten bis 0, I $2 \mathrm{~mm}$. lang bei einer Höhe von 0,05; sie waren von den gewöhnlichen Formverhältnissen (Fig. 22).

Der erste so wie der zweite Magen mit seinen Kauplatten wie gewöhnlich; am Darm die gewöhnliche, hier nur ungewöhnlich lange Erweiterung mit ihrem pennaten Faltensystem. Die Leber wie gewöhnlich in zwei Abtheilungen zerfallen.

Es kam 5 Zwitterdrüsenlappen vor.

Das Thier stellt eine (Varietät der) Scyllaca pelagica vor.

Pelagisch wurden ferner am 22 August. und im Sargasso (St. 230) eine. Anzahl (I 5) von 4-I $5 \mathrm{~mm}$. langen, stark zusammengezogenen, durch $(4 \%)$ Formol schwarzgrauen Individuen gefischt. 


\section{Fam. Bornellidae.}

R. BERGH, System d. nudibranchiaten Gasteropoden. 1. c. I892, p. I05 I-1054.

Diese pelagisch lebende Gruppe umfasst nur die Gattung:

\section{Bornella Gray.}

GRAX, Fig. of moll. anim. IV, IS50, p. 107.

R. Bergh, Malacolog. Unters. I (Heft VII). I874, p. 287-308. - III (Heft XVII). I890, p. $884-889$.

R. BERGH, Neue Nacktschnecken d. Südsee, II. Journ. d. Mus. Godeffroy. Heft VI. I874, p. $95-102$.

R. BERGH, Report on Nudibranchiata. Challenger-Exp. 1.c. I884, p. 34-43.

Eine Reihe von Arten dieser Thierform ist nach und nach angegeben worden. Die meisten sind ganz unsicher und gehören wahrscheinlich der typischen Art der Gattung an. Specifisch sicher sind nur die

I. Bornella digitata Ad. et Reeve (Bgh.). M. indic., pacific.

2. Bornella excepta Bgh. M. indic., pacific.

3. Bornella calcarata Mörch. M. Antillense.

I. Bornella digitata Ad. et Reeve. Taf. IV, Fig. 20. Taf. XIX, Fig. 23-24.

Bornella digitata Ad. et Reeve. Voy. of the Samarang. I848, p. 67. Pl. XIX, Fig. I.

Bornella digitata Ad. et R. Alder and HANCOCK, Notice of a coll. Trans. zool. soc. V, I866, p. I39-14I. Pl. XXXIII, Fig. 8, 9.

Bornella digitata Ad., Alder et Hanc. R. BERGi, I. c. I. I874, p. 30I-308. Taf. XXXVII, Fig. 14-19; Taf, XXXVIII, Fig. I3-22; Taf. XXXIX, Fig. I-I3.

Bornella arborescens Pease. Amer. Journ. of conchology. VI. 187I, p. 302, PI. 20, Fig. 3a, b, c. Bornella arborescens Pease. Neue Nacktschnecken d. Südsee. II. Journ. d. Mus. Godeffroy, Heft VI, I874, p. 96-Io2. Taf. I, Fig. 3-4; Taf. II, Fig. 30-33; Taf. IV, Fig. I-28. Bornella arborescens P. R. BERGH, Die Nudibr, d. Sunda-Meeres. Malacolog. Unters. IIJ (Heft XVII). I890, p. 86-89. Taf. LXXXVIII, Fig. 26-30; Taf. LXXXIX, Fig. I-2.

In der Nähe des Riffes von Batjulmati (Java) (St. 7) wurde in einer Tiefe von I5 M. ein Individuum gefangen und nach dem Leben abgebildet.

Das lebende Thier hatte eine Länge von etwa $21 \mathrm{~mm}$. Die Farbe der Rückenseite war röthlichgelb, etwas roth punktirt; das obere Ende der Rückenpapillen roth, die Körperseiten bläulich.

Das sehr schlecht a ufbewahrte erhärtete Individuum hatte eine Länge von $15 \mathrm{~mm}$. bei einer Breite des Körpers von. 2 und einer Höhe von 3. Die Farbe war durchgehends hell gelblichgrau. - Die Formverhältnisse die gewöhnlichen. Die Tentakel aus je 8 (stark zusammengezogenen) Kegelchen gebildet; die Scheide der Rhinophorien wie gewöhnlich dreifingerig und mit der ersten, die Finger stark überragenden, einfachen Rückenpapille verschmolzen. Am Rückenrande 4 Papillen; das erste Paar ist zweifingerig, die anderen 3 einfach, alle ohne Anhängsel aussen am Grunde; die zwei ersten trugen an der Innenseite eine Kieme, die anderen nicht; am Grunde des kurzen Schwanzes eine unpaare Papille. 
Der N. opticus schwarz; die grosse Linse des Auges stark gelb, von einem Durchmesser von $0,12 \mathrm{~mm}$.

Die breite Bewaffnung der Lippenscheibe des Schlundkopfes gelblich, aus den gewöhnlichen gereihten kleinen Schuppen von einer Breite von 0,0045 mm. gebildet. Die vorne dunkel bräunlichgelben Nandibel wie gewöhnlich. Die Zunge trug an der Raspel I3 Zahnplattenreihen, in der Scheide kamen in Allem 22 vor; die Gesammtzahl der Reihen somit 35. Die medianen Platten waren gelb, die lateralen farblos; die Breite jener betrug 0,035 mm. Die medianen von gewöhnlicher Form, mit den gewöhnlichen Furchen und Zähnchen, nur war der vordere Rand ziemlich stark ausgeschweift. Von lateralen Platten kamen jederseits bis Io vor, von gewöhnlichen Formverhältnissen.

Der erste Magen dünnwandig; der zweite mit den gewöhnlichen Längsreihen von schmutzig bräunlichgelben spitzen Dornen, die eine Länge bis 0,45 bei einem Durchmesser bis 0,06 mm. erreichten.

Von dieser, in seinen Formverhältnissen, wie es scheint, ziemlich variablen Art habe ich noch eine kleine Reihe von Individuen, von der Siboga-Expedition herrührend, untersuchen können. Sie (3) stammten von der Lucipara-Gruppe (St. 225), vom Riffe von der Insel Pajunga, Kwandang-Bai (St. I I5) (3), von einem Riffe bei Banda (I) und (I) von der Buka-Bai, Insel Rotti (St. 299); noch andere (in Allem 8) von den Stationen 50, 796, 234, 248 (Riff) und von einem Riffe bei Ambon. - Drei wurden wenigstens theilweise anatomisch untersucht.

Diese $(S(\mathrm{I} 6))$ Individuen hatten meistens eine Länge von $20-23 \mathrm{~mm}$. bei einer Höhe des Körpers von etwa 4; die Höhe der Rhinophorien mit samt ihrer Papille bis $5-7 \mathrm{~mm}$. und diese Höhe erreichten meistens auch die 2--3 vordersten Papillen. Die Farbe war durchgehends mehr gelblich oder mehr weisslich. - In den allgemeinen Formverhältnissen stimmten die Individuen mit einander überein. Die Anzahl der Kegelchen der Tentakelbildungen variirt von (5) 7-12 und war meistens nicht dieselbe an beiden Organen. Die Scheide der Rhinophorien endete immer mit drei Fingern und die mit denselben verbundene Papille war immer einfach. Die Anzahl der Papillen des Rückenrandes varïrte von 4-6. Die erste Papille war bei den 7 Individuen tief geklüftet, bei einem an der einen Seite einfach; eine trug ein kleines Anhängsel an der Aussenseite; an der Innenseite standen 2 kleine Kiemen, bei einem Individuum am linken Organe 3. Die zweite Papille war bei den 7 Individuen geklüftet, bei einem an der einen Seite einfach; an der Innenseite 2 Kiemen. Die dritte Papille war bei einem Individuum auch geklüftet, bei den anderen einfach; bei einem kam eine, bei einem drei, bei den anderen 2 Kiemen vor. Die vierte Papille war immer einfach; bei dem einen Individuum fehlten Kiemen, bei 2 kam nur eine, bei den übrigen 2 vor. Die fünfte Papille war einfach, mit einer Kieme; bei zwei Individuen fehlte aber eine solche Papille, und sie trugen hinter der vierten nur eine mediane Papille. Eine solche mediane (sechste) Papille kam noch bei 2 Individuen vor, bei dem einem gekluftet und mit einer kleinen Kieme. Hinter der medianen Papille fanden sich bei 2 Individuen noch $1-2$ kleine Höcker am Schwanzrücken. Die kleine Analpapille lag immer zwischen der ersten und der zweiten dieser Papillen, der letzteren etwas mehr genähert. - Die Körperhaut war immer eben. 
Das Centralnervensystem ganz wie früher beschrieben. Der $\mathbb{N}$. opticus immer lang; die ziemlich grossen Augen von $0,20 \mathrm{~mm}$. Durchmesser.

Die Lippenscheibe des $\mathrm{I}, 5-2 \mathrm{~mm}$. langen Schlundkopfes zeigte immer die Bedeckung mit den langen Reihen von einander dachziegelartig deckenden, etwa 0,008 mm. breiten Schuppen. Die Mandibel immer mit schwarzbraunem Vorderrand. Die Breite der Raspel meistens etwa 0,16 mm. betragend; an derselben kamen I2-I5 Zahnplattenreihen vor, und in der Scheide I 8-2 I; die Gesammtzahl der Reihen somit 30-36. Die Anzahl der Seitenplatten war I I-I3. Die Zahnplatten ganz wie früher beschrieben.

Der cylindrische Magen $3 \mathrm{~mm}$. lang bei einem Durchmesser von $\mathrm{I}, 5$, mit I2-I 3 Reihen von Dornen, in jeder Reihe kamen 8-9 nach hinten gerichtete, schmutzigbraune Dornen vor, die eine Länge bis $0,43 \mathrm{~mm}$. bei einem Durchmesser am Grunde von 0, I 2 hatten. - Die Rückenpapillen enthielten mit Ausnahme der $1-2$ hintersten einen hoch und bis in die Theilung hinaufsteigenden Leberlappen.

Die vordere Genitalmasse $3,5-4 \mathrm{~mm}$. lang. Der Grund der Pen ishöhle zeigte um die Öffnung des Samenleiters die gewöhnliche ringartige Einfassung (Fig. 23) mit 2-3 Reihen von schmutzig dunkelbraunen, in der Spitze gebogenen Haken, die der äusseren Reihe waren im Ganzen zahlreicher (etwa 34) und grösser (Fig. 23, 24), die der inneren weniger zahlreich und oft kleiner, die grössten erreichten eine Höhe bis $0,08 \mathrm{~mm}$.

Die $B$. arborescens scheint mit der $B$. digitata identisch, und die Art muss somit den älteren Namen tragen.

Bornella digitata Ad. et Reeve. var.

Bei Sailus-Ketjil, Paternoster-Inseln (St. 37) wurde ein Individuum gefangen.

Dasselbe war aufbewahrt $\mathrm{I}_{5} \mathrm{~mm}$. lang bei einer Körperhöhe von 5 und Breite von 3 , noch dazu betrug die Höhe der Rhinophorien (mit der ersten Papille) 2,5 und der vordersten, grössten Rückenpapille 2. Die Farbe war durchgehends schmutzig röthlichgelb. - Die Formverhältnisse die gewöhnlichen; die Tentakel von je 12 Kegelchen gebildet; die 3-fingerige Rhinophorscheide wie gewöhnlich mit der ersten Rückenpapille verschmolzen. Am Rückenrande 4 kleine, freie Papillen, alle ohne äusseres Anhängsel, in Grösse nach hinten abnehmend, die zwei ersten 2-fingerig, die anderen einfach, alle mit Kieme innen am Grunde; vor dem Körperende noch eine kleine unpaare Papille. Der Anus im rechten ersten interpapillären Raume.

Das Centralnervensystem wie gewöhnlich, die langen Nn. optici aber nicht schwarz.

Der Schlundk opf 1,5 mm. lang, gräulichweiss; die Schuppen-Bewaffnung der Lippenscheibe wie gewöhnlich; die Schlosspartie und der Kaurand der Mandibel dunkel kastanienbraun. In der Raspel der Zunge io Zahnplattenreihen, in der Scheide deren noch 34, die Gesammtzahl derselben somit 44. Die medianen Platten waren hellgelb, die anderen fast farblos; die Breite der medianen betrug $0,035 \mathrm{~mm}$. bei einer Höhe von 0,038 . Die Anzahl der Seitenplatten war nur 7-8. Die Zahnplatten waren nicht von denen der typischen Art verschieden.

Der $\mathrm{K}$ aumagen $3 \mathrm{~mm}$. lang, mit den gewöhnlichen starken und stark gefalteten, dornentragenden Falten; die Dornen dolchförmig, gelb, bis $0,45 \mathrm{~mm}$. lang. Der Magen war 
mit thierischem Inhalt prall gefuillt; in demselben fanden sich Stücke von Copepoden, eine kleine Nereide, Diatomeen und eine Unmenge von Cnidae. - Der lange, bis an die Schwanzpapille reichende, schmutzig gelbliche Hauptleberstamm gab den drei hinteren Rückenpapillen einen starken, in die Papillen aufsteigenden Stamm.

Vor dem Hauptleberstamm, an der Seite des Kaumagens 4 dicht an einander liegende, kugelförmige, gelbliche, feinkörnige $Z_{w}$ itterdrüsen von einem Durchmesser von $1,5-2 \mathrm{~mm}$. in den Körnern reife Geschlechtselemente. - Die vordere Genitalmasse gräulichweiss, von $4 \mathrm{~mm}$. Länge; der fast die Hälfte derselben betragende, gebogene, sackartige Pen is sack $3 \mathrm{~mm}$. lang; um die Öffnung des Samenleiters der gewöhnliche Ring mit $2(-3)$ Reihen von dunkelbraunen, in der Spitze gebogenen Haken, die eine Höhe bis $0,04 \mathrm{~mm}$. erreichten.

Diese Varietät der typischen Art zeigte auffallend kleine Rückenpapillen.

2. Bornella excepta Bgh. Taf. XIX, Fig. 25-27.

R. Bergh, Rep. 1. c. I884, p. 36-43. Pl. VII, Fig. I3-22; PI. VIII, Fig. I-I3.

Mit einem Individuum der vorigen Art zusammen wurde am Riffe der Buka-Bai, Insel Rotti (St. 299) ein Individuum gefangen.

Dasselbe war $20 \mathrm{~mm}$. lang bei einer. Höhe von 4, von gewöhnlicher Farbe. In den Tentakelbildungen kamen je 7 Kegel vor; die Scheide der Rhinophorien oben dreifingerig, die mit derselben verschmolzene und hoch hinaufragende Papille vierfingerig, der eine Finger viel länger als die anderen (Fig. 25). Die erste Papille des Rückens der Rhinophorpapille ähnlich auch mit 4 Fingern (Fig. 26), (ohne Anhängsel) an der Innenseite mit 3 Kiemen; die zweite Papille wie die vorige, mit zwei Kiemen aussen und 2 innen; die dritte war der vorigen ähnlich; die vierte stand median, war an der Spitze geklüftet, ohne Kieme; die fünfte, auch median war wie die vorige, nur kleiner; am Schwanzrücken hinter der letzteren noch ein Höcker. Die Papillen der beiden Seiten waren einander fast ganz ähnlich; sie nahmen gegen hinten an Höhe allmählig $a b$, die Höhe der vordersten betrug 5, die der vierten I,5 mm.; die Papillen waren alle etwas runzelig. Die Analpapille an gewöhnlicher Stelle (Fig. 26). Oben an den Körperseiten 2 nicht recht geschiedene Reihen von weissen Papeln (Fig. 26).

Der Schlundkopf 2 mm. lang; die eigenthümliche Schuppenbekleidung der Lippenscheibe wie gewöhnlich, so auch die Mandibel mit ihrem dunklem Vorderrand. Die Anzahl der Zahnplatten der Zunge konnte nicht bestimmt werden, in der Scheide schienen 2 I vorzukommen. Die medianen Platten wie bei der typischen Art; ihre Breite 0,08 bei einer Höhe von 0,075 betragend. Von Seitenplatten kamen bis I $_{3}$ vor.

Der bewaffnete Magen $3 \mathrm{~mm}$. lang, ein wenig gebogen; mit vielen (etwa 50) Reihen von Dornen, und in jeder Reihe eine bedeutende Anzahl von solchen, sie erreichten eine Länge bis wenigstens $0,4 \mathrm{~mm}$.

Während bei dem typischen Individuum keine Leberzweige an die Papillen des Rückens abgegeben wurden, stiegen solche bei dem hier untersuchten dagegen eine Strecke in die Höhle der drei ersten Paare hinauf. 
Der Penis schien in ähnlicher Weise wie bei dem typischen Individuum bewaffnet, was sich aber nicht genauer bestimmen liess; die spitzen schwarzen Dornen (Fig. 27) waren wie bei jenem, erreichten eine Höhe bis wenigstens $0,12 \mathrm{~mm}$.

Die hier untersuchte Form scheint mit der früher beschriebenen B. excepta identisch.

\section{Dotonidae.}

R. BERGH, System. 1. c. p. 1044-1048.

Forma corporis fere ut in Aeolidiidis; clavus rhinophoriorum simplex, vagina retractilis: frons sat lata, angulis tentacularibus rotundatis; epinotidia uniseriata, inflata, tuberculis ut plurimum annulatim dispositis obtecta, facile caduca, bursa cnidophora nulla; anus latero-dorsalis.

Bulbus pharyngeus cum mandibulis ut in Aeolidiidis, margo masticatorius laevis; radula ut plurimum uniseriata. - Penis inermis.

Die Familie enthält fast nur Formen von geringer Grösse. Sie umfasst die Gattungen Doto (Ok.), Dotilla (B.), Gellina (Gr.), Caecinella (B.), Heromorpha (B.) und vielleicht die Govia (Trinchese).

\section{Doto Oken.}

R. BERGH, 1.c. p. 1046 .

Radula uniseriata.

Eine Reihe von meistens als solche sehr zweifelhaften Arten ist, besonders aus dem Mittelmeere, beschrieben.

1. Doto annuligera Bgh. Taf. XII, Fig. 3-5(6).

Bei Nord-Ubian (St. 99) wurde ein Individuum dieser Form gefangen ${ }^{1}$ ).

Das in Formol aufbewahrte Individuum war etwas steif, zusammengebogen, etwa $9 \mathrm{~mm}$. lang bei einer Breite von 6 und Höhe bis 5 (des eigentliche Körpers bis 2); die Breite des Kopfes war 2, des Fusses I mm., die Länge des Schwanzes I, die Höhe der Rückenpapillen bis $4 \mathrm{~mm}$, - Die Farbe schwach gelblichweiss, der Stirnrand und die Rhinophorien grau, die Ringe der Papillen schwarz, ebenso der Schwanzruicken.

Die Formverhältnisse die gewöhnlichen der Doto'en (Fig. 3). Die aus ihren Scheiden etwas vortretenden Rhinophorkeulen einfach (geringelt). An den Seitenrändern des etwas gewölbten Ruickens 4 colossale Papillen (Fig. 3-5), an der linken Seite noch eine fuinfte kleinere vor der letzten. Die Papillen ganz kurzgestielt, meistens ein wenig und etwas schief abgeplattet,

I) Es schien von der Doto indica vom Mauritius-Meere (Malacolog. Unters. IIeft XVI, 1. 1888, p. 795. Taf. LAXVIII, Fig. 23-27) verschieden. 
mit 4 Reihen von kleineren und grösseren Tuberkel, die am Scheitel einen schwarzen Ring trugen; die Anheftungsfacette klein, queroval. Die Analpapille vor der zweiten (rechten) Papille.

Der Schlundkopf ging leider durch einen Unfall verloren. Die Leberlappen der Papillen stark und in die Tuberkel hinein verzweigt.

Die weissliche Zwitterdrüse mit reifen Geschlechtselementen; die weissliche vordere Genitalmasse rundlich, von I $\mathrm{mm}$. Durchmesser; der Penis kegelförmig.

\section{A Eolididide.}

R. BERGH, System. 1.c. I 892 , p. I002-1039.

Diese, die Formreichste und grösste Gruppe der Nudibranchien zerfällt in eine Anzahl von von einander ziemlich ausgeprägten Familien, die eigentlichen Aeolidiiden, Crateniden, Tergipedinen, Coryphelliden, Favoriniden, Faceliniden, Flabelliniden, Fioniden, Glauciden, Janiden und Heroiden.

A eolidiidae propriae.

R. BERGH, System. 1.c. p. IOIS(-IO2I).

Corpus nonnihil depressum. Epinotidia (papillae dorsales) plus minusve compressa.

Margo masticatorius mandibularis laevigatus. Dentes lingvales uniseriati, lati, pectiniformes. - Penis inermis.

Diese Gruppe umfasst die Gattungen Aeolidia (Cuv.), Baeolidia (B.), Acolidiella (B.), Spurilla (B.), Berghia (Trinchese), Cerberilla (B.), Fenrisia(B.) und vielleicht Phyllodesmium (Ehrenb.).

\section{Aeolidiella Bgh.}

R. BERGH, l. c. p. IOIg.

Forma ut in Aeolidiis (propriis); rhinophoria simplicia.

Dentes (pectiniformes) medio emarginati. Glandulae ptyalinae magnae.

Einige Arten der Gattung sind bekannt.

Aeolidiella drusilla Bgh. juv.? Taf. XIX, Fig. 28.

R. BERGH, Die Opisthobranchier (Schauinsland). Zool. Jahrb. XIII, 3. 1900, p. 233-235. Taf. 20, Fig. 4i-46.

Am 28 Aug. wurden auf einem Riff in der Waru-Bai an der Nordküste von Ceram (Stat. 174) zusammen mit einem Individuum der Triopa tristis (s. oben) drei Exx. dieser Thierform gefangen. Die Individuen waren leider durch Formol in der Art erhärtet und brüchig, das eine genaue Untersuchung trotz Aufopferung aller drei unmöglich war. 
Die Individuen hatten eine Länge von $6-8 \mathrm{~mm}$., bei den grössten betrug die Breite 2,5 und die Höhe des Körpers 2; die Länge der Papillen stieg bis etwa 2,5 mm. Die Farbe des Körpers war gräulich, die der Papillen mehr bräunlich.

Die Formverhältnisse wie gewöhnlich. Die Tentakel stark, fast länger als die glatten Rhinophorien, hinter denselben schimmerten die schwarzen Augen durch. Die nicht leicht abfallenden, cylindrischen, oben ein wenig zugespitzten Papillen schienen in $13-14$ Schrägreihen gestellt, von welchen die vordersten und hintersten nur 3-4, die anderen etwa Io dieser Epinotidien enthielt. Der Fuss fast so breit wie der Rücken, das Vorderende mit Randfurche und wenig vorspringenden Ecken, das Fussgebräm schmal, der Schwanz kurz.

Das Centralnervensystem wie früher beschrieben.

Der weisse $\mathrm{Schlundk}$ opf I,5 mm. lang; die gelblichen Mandibel wie gewöhnlich, der Kaurand feinstreifig. Die Zunge wie gewöhnlich; in der schwach gelblichen Raspel 6-8 Zahnplatten, in der Scheide noch 7-S, die Gesammtzahl derselben somit 13-I6. Die schwach gelblichen Platten maassen, die ältesten 0,09 , die fünfte 0, IO mm., und die Breite stieg bis 0,16 bei einer Höhe (Fig. 28) bis 0,08 mm. Die Zahnplatten zeigten eine starke mediane Spitze und zu jeder Seite derselben bis I5 Dentikel, von welchen die innersten kurz und ziemlich grob, die übrigen länger, feiner und mehr spitz waren (Fig. 28).

Die Mundröhrendrüsen (Gl. ptyalinae) milchweiss, langgestreckt.

Die bräunlichen, an der Oberfläche feinknotigen Leberröhren füllten fast ganz die Höhle der Papillen. Die ovalen Nesselsäcke mit länglichen und rundlichen Cnidae gefüllt.

Wahrscheinlich stellte diese Form nur jüngere Individuen der Ae. drusilla vor.

\section{Spurilla Bgh.}

R. BERGH, System der nudibr. Gasteropoden. 1. c. IS92, p. Iozo.

Corpus non depressum; rhinophoria perfoliata; podarium antice angulis prominentibus.

Margo masticatorius mandibularum serie denticulorum praeditus. Dentes lingvales uniseriati, pectiniformes, medio emarginati. (Glandulae ptyalinae).

Die Spurillen bilden mit den Aeolidiellen und Berghien zusammen eine besondere kleine Gruppe innerhalb der ächten Aeolidiiden, indem sie sich durch die ausgerandeten Zahnplatten und das Vorhandensein von Mundspeicheldrüsen (Gl. ptyalinae) von den anderen Gattungen unterscheidet. Von den Spurillen unterscheiden sich die Aeolidiellen durch einfache Rhinophorien, stärker vortretende Fussecken und glattrandigen Kaurand; die Berghien haben moriforme Rhinophorien, auch Fuss-Tentakel und gezähnelten Kaurand.

Von der Gattung waren bisher nur zwei Arten bekannt, die Sp. neapolitana (d'Ch.) und die Sp. sargassicola (Kröyer), die vielleicht nicht einmal specifisch verschieden sind.

Spurilla orientalis Bgh. n. sp. Taf. XIX, Fig. 29-3I.

Auf dem Riff von Tual bei der Insel Kei (St. 258) wurden 5 Individuen gefangen. Die 2 grössten wurden genauer untersucht. 
Das grösste derselben hatte eine Länge von Io $\mathrm{mm}$., wozu noch die I $\mathrm{mm}$. langen Tentakel kamen, bei einer Breite des Rückens von 2 und einer Körperhöhe von I,5; die Höhe der Papillen betrug bis 2,5, die Länge des Schwanzes $2 \mathrm{~mm}$. - Die Farbe war durchgehends bräunlichgrau.

Der Rücken war etwas breiter als der Fuss; die Tentakel lang, die Rhinophorien etwas kürzer als diese, stark durchblättert. Der Rücken wenig gewölbt, der nackte mittlere Theil breiter als die mit Papillen besetzten Seitentheile; diese letzteren trugen $7-8$ Reihen von Papillen. Die zwei vorderen Reihen convergirten nach oben in einen spitzen Winkel; dasselbe war mit der dritten und vierten der Fall; in den vordersten kamen 5-6 Papillen vor, in den folgenden $4-5$, in den hintersten 2-3. Die Papillen waren kegelförmig, nicht leicht abfallend. Der Anus am Rückenrande hinter der vierten Reihe. Die Genitalpapille unter dem Zwischenraume zwischen erster und zweiter Reihe.

Das Centralnervensystem wie gewöhnlich. Die grossen Augen von einem Durchmesser von $0,10 \mathrm{~mm}$., die zellige Structur der Cornea (?) sehr ausgeprägt, die grosse Linse stark gelb. Die Otocysten kleiner als die Augen, mit vielen Otokonien.

Der kurze plumpe Schlundkopf von 2,5 mm. Länge. Die hellgelben Mandibel zeigten am Kaurande feine, bis o,OI3 mm. hohe Dentikel (Fig. 29). Die Nebenmundhöhle gross. In der Raspel der schmalen Zunge 12-14 Zahnplatten, in der Scheide deren noch 5. Die Basalpartie der Platten schwarzbraun, sonst waren sie gelb; die Breite der vordersten war $0,1_{2}$, der hintersten $0,30 \mathrm{~mm}$; die Form war die gewöhnliche der Spurillen; an jeder Seite der Einkerbung bei den kleinsten (Fig. 30) etwa I 3, bei den grössten 20 spitze Dentikel (Fig. 3I).

Die Nebenspeicheldrüsen stark. - Die etwas knotigen Leberstämme der Papillen füllten fast ganz dieselben an. Die Nesselsäcke gross; die meistens länglichen Cnidae gross, bis fast $0,04 \mathrm{~mm}$. lang.

\section{Cerberilla Bgh.}

R. Bergir, Neue Nacktschnecken d. Südsee, I. Journ. d. Mus. Godeffroy. Heft II. I873, p. S8.

Forma corporis non compressa. Rhinophoria perfoliata, tentacula elongata. Papillae dorsales (epinotidia) pedamentis humilibus impositae, non caducae. Podarium sat latum, sulco marginali antice forti et angulis tentaculatim productum.

Margo masticatorius mandibulae laevis. Radula dentibus uniseriatis; dentes depressi, acie pectiniformi irregulari, denticulis longissimis. - Penis inermis.

Die wesentlichen äusseren Merkmale dieser Gattung sind neben den perfoliirten Rhinophorien die langen Tentakel, die Gegenwart von niedrigen Fussgestellen, die die fest anhängenden Papillen tragen, und das Vorhandensein von langen Fühlern an dem breitem Fusse. Der Kaurand der Mandibel ist glatt. Die Zunge hat eine Reihe von Zahnplatten; dieselben sind gross, stark, niedergedrückt, mit langen und starken Dentikeln des kammartigen Schneiderandes. Der Penis ist unbewaffnet.

Die Gattung scheint in die Familie der ächten Aeolidiiden zu gehören. Von der Gattung 
waren schon zwei Arten aus dem indo-pacifischen Meere bekannt, jetzt kommt eine dritte dazu; alle schienen sie, besonders in den Farbenverhältnissen, von einander verschieden.

I. Cerberilla longicirrha Bgh.

R. Bergh, Neue Nacktschnecken. 1. c. 1873 . p. 89-92. Taf. XII, Fig. 6-16 ${ }^{2}$.

2. Cerberilla anmulata (Quoy et Gaim.).

Voy, de l'Astrolabe. Zool. II, I. I832. p. 287. PI, 2I, Fig. 15-IS.

R. Bergrr, Beitr. zur Kenntn. d. Aeolidiaden. III. Verh. d. k. k. zool. bot. Ges. in Wien. XXV. I876, p. 653-655. Taf. XIII, Fig. 14-I7; Taf. XIV, Fig. I.

var. affinis Bgh.

R. Bergir, Beitr. IX. 1. c. XXXVI. I885. p. 684-688. Taf. XVI, Fig. I5-I6. Taf. XVII Fig. 6-9; Taf. XVIII, Fig. 7 .

3. Cerberilla ambonensis B. n. sp.

I. Cerberilla ambonensis Bgh. n. sp. Taf. V, Fig. 6. Taf. XIX, Fig. 32-33.

Auf einem Riff bei Ambon wurde aus einer Tiefe von 36 M. ein Individuum gefangen und lebend abgebildet.

Lebend hatte dasselbe eine Länge von I $5 \mathrm{~mm}$. bei einer Breite von 5; die Fussfuhler und die Tentakel sehr lang. Die Farbe scheint hell bräunlich gewesen zu sein, an der Spitze der Papillen je ein schwarzer Punkt.

Das stark erhärtete und verbogene aufbewahrte Individuum scheint eine Länge von 9 bei einer Breite des Rückens von 5 und einer Höhe von $2 \mathrm{~mm}$. gehabt zu haben; die Länge der Fussfuihler war I,5, der Tentakel 2,5, der Rhinophorien 0,75 und der Rückenpapillen bis $4 \mathrm{~mm}$; die Breite des Fusses 6, die Länge des Schwanzes $2 \mathrm{~mm}$. - Die Farbe war durchgehends hell schmutzig gelblich; die Tentakel gräulich-violet, ebenso das Genick und der vordere Theil des Rückens, jene wie diese weiss punktirt, ferner ebenso die obere Seite der Fussfühler und des vorderen Theils des Fusses; die obere Hälfte der Rhinophorien schwarz; die Spitze der Rückenpapillen grau und unterhalb der Spitze an der Aussenseite (auch bei den kleinen Papillen) ein schwarzbrauner Fleck (Fig. 32), ganz ähnliche Zeichnung kam an der Spitze der Tentakel vor.

Die Körperform war ziemlich kurz. Das Vorderende des Kopfes abgeplattet, $2 \mathrm{~mm}$. breit, mit gelösten Rändern. Die dicht neben einander stehenden Rhinophorien zwischen der ersten Papillenlinie beider Seiten; die Tentakel lang. An beiden Seiten des ziemlich breiten Rückens schwach erhabene Papillenkissen, deren Anzahl I I betrug; an denseiben standen je in einer Querreihe die fest angehefteten Papillen (Epinotidien), in der ersten Reihe 3 , in den zwei folgenden 4 , in den zwei folgenden 6 , in den folgenden vier 7 , dann 6 und in der letzten 4 kleine. Die 2-3 äussersten Papillen der meisten Reihen waren kleiner, die innersten die längsten, und die Papillen bewahrten im Ganzen dieselbe Grösse bis an die letzte Reihe; sie waren fast cylindrisch, oben zugespitzt, liessen den ziemlich ebenen Leberstamm und den

I) Die von Eltot (On some Nudibranchs from East-Africa and Zanzibar. II. Proc. zool. s0c. of London. I903, 1. p. 254) erwähnte Cerb. africana ist wohl nur eine Varietät der Cerb. longicirrha. 
langen Nesselsack durchschimmern. Der nackte Rücken hinten gleichsam verschwindend, wo die Papillenkissen beider Seiten an einander stossen; die Analpapille seitwärts am Rücken vor dem 5. Papillenkissen. Die Körperseiten niedrig. Der kräftige Fuss' vorne mit starker Furche, die Fussfühler ziemlich lang, das Gebräm (1,5 mm.) breit, der Schwanz etwaș zugespitzt.

Das Centralnervensystem wie gewöhnlich, der Durchmesser der Augen 0,07 mm.

Um den Aussenmund ein starkes Drüsenlager. Der Schlundkopf 1,5 mm. lang; die Mandibel gelblich, in der Schlosspartie bräunlich, der Kaurand glatt, 0,025 mm. breit. An der Unterseite der Zunge kamen 4 und sonst in Allem noch 9 Platten vor, die Gesammtzahl derselben somit I3. Die Zahnplatten waren gelb, in der Basalpartie röthlichbraun, die Breite der vordersten betrug 0,12 , der hintersten 0,18 mm.; die Form war wesentlich (Fig. 33) wie bei der typischen Art; in der Mittellinie ein kleiner Dentikel und zu jeder Seite 8 grössere, von welchen die nächstäusserste die grösste; zwischen den Dentikeln kam meistens noch ein ganz kleiner vor.

Die Zwitterdrüse weisslich. Der Penis $2 \mathrm{~mm}$. lang, die Glans unbewaffnet.

Vielleicht ist diese Form von der typischen specifisch verschieden.

\section{Myrrhinidae N. Fam.}

Diese Gruppe zeichnet sich von allen bisher bekannten Aeolidiiden durch ganz ungewöhnliche Beschaffenheit des Nierensystems und der Zwitterdrüse aus. Die Niere zeigt sich mit ihren dünnen, stark verzweigten Röhren durch fast die ganze Körperhöhle verbreitet. Die $\mathrm{Z}$ witterdrüse erinnert im Bau an die gewisser Ascoglossen (Hermaeiden); sie ist von einer Unmenge von kleinen Läppchen gebildet, die fast den grössten Theil der Körperhöhle füllen; die Läppchen bestehen alle aus einem Testiculartheil, an welchem kleine Ovarialfollikel hängen.

Die Familie umfasst bisher nur die Gattung:

\section{Myrrhine Bgh. N. Gen. ").}

Forma corporis sat elongata, non depressa. Tentacula non brevia, rhinophoria simplicia. Notaeum seriebus epinotidiorum (papillarum) sat distantibus transversalibus instructum; papillae magnae applanatae, sat paucae, internae colosseae, sine bursis cnidophoris.

Mandibulae sat breves, margine masticatorio laevi. Radula uniseriata. - Penis inermis.

Die Form der Thiere ist etwas langgestreckt, nicht niedergedruickt, die Rhinophorien sind einfach, die Tentakel nicht kurz. Der Rücken trägt in ziemlich regelmässigen Abständen von einander quergehende, nicht lange Papillenreihen; die Papillen sind nicht zahlreich, abgeplattet, gröss, die innersten von kolossaler Grösse, an die von Phyllodesmizum ${ }^{2}$ ) erinnernd, auch

:) Namen einer weiblichen, in der "Lysistrate" von Aristophanes vorkommenden Person.

2) Vgl. K. BERgh, Anatom. Untersög. af Phyllodesmian hyalinum. Naturh. Foren. vidensk. Meddelelser f. IS6o, P. I-14. Tab. I. 
ohne Nesselsack; die Analpapille dorso-lateral, am inneren Ende der funften Papillenreihe. Der Fuss nicht schmal, mit kurzen vortretenden Fussecken.

Der Schlundkopf ist relativ klein; die Mandibel sind kurz, der Kaufortsatz kurz, der Kaurand eben. Die Zunge hat nur eine Reihe von Zahnplatten; die Zahnplatten mit etwas gespreizten Beinen, der Haken glattrandig.

Der Penis ist unbewaffnet.

Die systematische Stellung der Gattung ist zweifelhaft.

Von der Gattung ist bisher nur die untenstehende neue Art bekannt.

I. Myrrhine longicirra Bgh. n. sp. Taf. IV, Fig. I8. Taf. XX, Fig. 20-29.

Am 26 Oct. wurden auf einem Riff bei Saleyer (St. 213) drei und am ro Dec. bei Elat an der Westküste der Insel Gross-Kei ein Individuum gefangen, und das eine (von Saleyer) lebend und in natürlicher Grösse abgebildet. - Zwei Individuen wurden anatomisch untersucht.

Lebend hatte dasselbe eine Körperlänge von $\mathrm{I}_{3} \mathrm{~cm}$., die Breite scheint $2 \mathrm{~cm}$. betragren zu haben; die Länge der Tentakel 20 mm. der Rhinophorien r $5_{5}$ und der Papillen des Rückens bis $40 \mathrm{~mm}$., die Länge des Schwanzes etwa $30 \mathrm{~mm}$. - Die Farbe des Thieres war gelblich, heller an der Rückenseite, welche überall mehr bräunliche, rundliche Fleckchen zeigte; ähnliche, aber dunklere und am Rande stärkere zierten die Papillen des Rückens.

In Formol bewahrt hatten die Thiere eine Länge des Körpers von 9-I I und I $2 \mathrm{~cm}$. bei einer Höhe von 2,7-I,5 und I,8 und einer Breite von 2,3-I,3 und I,5 cm.; die Länge der Tentakel betrug 6-10, die Höhe der Rhinophorien 5-7 mm.; die Länge der Papillen $2 \mathrm{~mm}$. bis $5,5 \mathrm{~cm}$. bei einer Breite bis $12 \mathrm{~mm}$. und einer Dicke bis 3. Die Breite des Fusses war 1 2-20 mm., die des Fussgebräms 4, die Länge des Fussecken 3-7, die des Schwanzes 7-8 mm. - Die Farbe war durchgehends hell-(schmutzig-)gelblich; am Körper, deutlicher am Rücken als an den Seiten ausgeprägt, fanden sich undeutliche graue Fleckchen; am Fussgebräme waren solche viel stärker (Taf. XX, Fig. 2I); die Papillen waren meistens, und an beiden Seiten, dunkler, wegen der dicht stehenden Leberläppchen (Fig. 20).

Die Form dieser kolossalen Aeolidiide war länglich; der Rücken gewölbt von Seite zu Seite, etwas breiter als der Fuss; die Körperseiten ziemlich hoch; unterhalb der äussersten Rückenpapillen, an der Mitte der Körperlänge noch 12-18 mm. an Höhe messend. Der Kopf ziemlich gross; die Tentakel etwas länger als die unweit von einander stehenden, cylindrischen, glatten (oder schwach geringelten) Rhinophorien. Die Rückenpapillen standen symmetrisch jederseits in 8-9 ziemlich kurzen, wenig gebogenen Querreihen. Die Papillen waren nicht leicht abfallend, das eine Individuum trug sie noch fast alle. Die 2 vordersten Gruppen waren näher an einander gerückt, ebenso die zwei hintersten, sonst waren die Reihen durch ziemlich gleich grosse Abstände geschieden. Der freie Rücken war ziemlich breit, nur hinten ganz schmal, indem die hintersten Reihen beider Seiten fast an einander stiessen. In der ersten Papillengruppe fanden sich 5-8, in der zweiten, dritten und vierten 6 , seltener 5 oder 8 ; in der fünften und sechsten 5-6; in der siebenten und achten 3-6; das eine Individuum zeigte eine neunte Reihe mit 3 Papillen. Die Papillen nahmen in gewöhnlicher Art von aussen nach innen in den 
Reihen an Grösse zu; die äusserste war immer ganz klein, die nächste schon viel grösser; die zwei innersten die grössten, an Länge fast die Hälfte der Körperlänge erreichend, und die Grösse derselben war in den hintersten Reihen kaum wesentlich geringer als in den anderen. Die Papillen waren abgeplattet, fast etwas blattartig, am Grunde eingeengt, oben etwas zugespitzt, die Spitze mitunter etwas ausgezogen; die Innenseite mehr plan oder schwach ausgehöhlt, die Aussenseite schwach gewölbt, beide Flächen durch die, den Contractionszuständen der Papillen nach, mehr oder weniger dichtstehenden Leberläppchen grobknotig; die Seitenränder fast eben; die rundliche oder ovale Anheftungsfacette wie bei anderen Aeolidiiden; an der Papillenspitze kein Nesselsack. Rechts am Rücken, dicht am oberen Ende der fünften Papillenreihe, die Analöffnung, bei dem einen Individuum bildete sie eine fast kugelförmige, im Durchmesser $4 \mathrm{~mm}$. haltende Papille; vorne, am Grunde des Anus die Nierenpore. Die Körperseiten etwas gewölbt, ganz hinten an Höhe stark abnehmend; unten am Grunde der ersten (rechten) Papillenreihe die (zusammengezogene) Genitalöfnung. Der Fuss ziemlich stark; der Vorderrand mit tiefer Furche, die sich bis an die Spitze der ziemlich starken Fussfühler fortsetzt; das etwas vorspringende Fussgebräm wellenförmig (Fig. 21), der Schwanz nicht kurz.

Nur an den Riickenpapillen schimmerten Eingeweide (Leberläppchen) durch. - Die Körperhöhle erstreckte sich bis an die 8. Papillenreihe hinaus.

Das weisse Centralnervensystem klein, an Breite nur 2,5 mm. messend; die obere Commissur kurz, die untere etwas kürzer oder etwas länger als der Querdurchmesser der kurzgestielten pedalen Ganglien; die Nervenzellen einen Durchmesser bis 0, 8 mm. erreichend. Die Augen von 0,09 mm. Durchmesser; die Ohrblasen etwas grösser, mit Otokonien gewöhnlicher Art. Die grauen Flecken des Fussgebräms zeigten sich unter der Loupe durch kleine gelblichgraue Fleckchen (Fig. 2I) gebildet, welche einen Durchmesser bis etwa 0,5 mm. erreichten und aus Driischen bestanden. Von ähnlicher Art waren auch die am Rücken und an den Körperseiten vorkommenden Flecken.

Die Nundröhre kurz. Der kleine, von loser, filziger Bindesubstanz umsponnene Schlund$\mathrm{kopf} 5$ und $7 \mathrm{~mm}$. lang bei einer Höhe von $4,5-5,5$ und einer Breite von 4-5 mm.; die Raspelscheide nur wenig oben am Hinterende vortretend; die Lippenscheibe von starker, gelblicher, radiert gefurchter Cuticula iberzogen. Die blass- und fahlgelben, nur im Vorderende dunkel kastanienbraunen Mandibel (Fig. 22) $6 \mathrm{~mm}$. lang bei einer Höhe von 4,5-5,25, recht hoch, etwas gewölbt; die Schlosspartie nicht stark vorspringend, mit ziemlich starker Crista connectiva; der Kaufortsatz kurz, der Kaurand eben. Der Eingang in die kleine Nebenmundhöhle ziemlich eng (Fig. 22). Die schmale Zunge $2 \mathrm{~mm}$. frei zwischen den Backen vorspringend; an der Spitze und an dem langen Oberrand 9-II, in situ bräunlichgelbe Zahnplatten; in der ziemlich langen Raspelscheide noch I6-18, von welchen die 2 hintersten farblos; die Gesammtzahl der Platten somit 25-29. Dieselben waren von gelber und bräunlichgelber Farbe; ihre Breite betrug (bei dem grössten Individuum) 0,35 mm., die Länge (längs des Rückens) o,65 und die Höhe des Hakens 0,25 mm. Die Form war etwas eigenthümlich (Fig. 23-25); die Flügel des Körpers ziemlich lang und breit; der ziemlich kurze starke Haken glattrandig, mit medianer Furche der Unterseite und Andeutung einer Kluft an der Spitze (Fig. 23, 24).

Die Speicheldrüsen wurden nicht nachgewiesen. Die Speiseröhre nicht ganz kurz, $4 \mathrm{~mm}$. 
lang. Der etwa $15 \mathrm{~mm}$. lange, sackförmige, dünnwandige II agen zeigte an der Innenseite viele Längsfalten, die mit cylindrischen und kegelförmigen Villi von einer Höhe bis wenigstens $0,30 \mathrm{~mm}$. besetzt waren; die Höhle des Magens war leer. Der Darm etwa $2 \mathrm{~cm}$. lang bei einem Durchmesser von I mm., mit feinen Längsfalten der Innenseite; seine Höhle leer.

Der Magen schien wenigstens einen Gallengang von jeder Seite aufzunehmen; hinten verlängerte er sich in den blindsackartigen, ziemlich weiten, diunnwandigen Hauptgallengang, welcher median längs der Rückenseite, gleichsam in der Zwitterdrüse eingebettet, verlief, seine Innenseite zeigte zahlreiche Längsfalten. Den einzelnen Papillenreihen entsprechend, wie es schien, gingen Gallengänge an die Körperwand $a b$, auch mehr oder weniger von der Zwitterdrüse eingehüllt. Diese Gänge hatten an der Körperwand noch ein Lichtung von $3 \mathrm{~mm}$. Durchmesser; längs der Wand verlaufend lieferten sie jeder Papille oder mehreren gemeinschaftlich einen Gang, welcher am Grunde der grösseren Papillen noch eine Lichtung von 0,5 mm. hatte. Die sich axial durch die abgeplatteten Papillen erstreckenden Leberstämme nicht dick, dünnwandig, sie trugen ringsum zahlreiche, den Verhältnissen nach also kürzere und längere, dem Contractionszustande der Papillen nach mehr oder weniger dichtstehende, mehr oder weniger getheilte Äste, deren dickere Scheitel an die Papillenwand angelöthet sind und den Papillen das knotige Aussehen verleihen (Fig. 20); die Knoten zeigten sich aus einer Anzahl von Knötchen zusammengesetzt (Fig. 26); zwischen jenen Ästen kamen kleinere vor, die an die Papillenwand nicht reichten.

Das Pericardium gross; die Herzkammer $6 \mathrm{~mm}$. lang, mit sehr ausgeprägten Aortaklappen. - Die langen und stark verzweigten Nieren röhren (Fig. 27) zeigten sich zwischen den Zwitterdrüsenläppchen eingemischt, hinten bildeten sie ein mehr selbstständiges Gespinnst; in den Rückenpapillen konnten sie nicht nachgewiesen werden.

Die $Z$ witterdrüse füllte mit ihren Körnern-ähnlichen, gelb-weisslichen Läppchen den grössten Theil der Körperhöhle hinter dem Magen, den Hauptgallengang, mit Ausnahme seiner Rückenseite, und zum grossen Theile die Gallengänge einhüllend und nach aussen an die Körperwand angeheftet. Sie bestand aus einer Unmasse von kleinen, durch spinngewebartige Bindesubstanz lose an einander gehefteten Läppchen, deren Ausführungsgang sich, mitunter dichotomisch, mit dem von anderen verband. Jedes Läppchen zeigte eine rundliche oder längliche Testicularpartie, an welche eine variirende Anzahl von runden oder ovalen Ovarialfollikel von einem Durchmesser bis $0,8 \mathrm{~mm}$. befestigt waren (Fig. 28); in jener fanden sich Zoospermienmassen, in diesen grosse Eizellen. - Die ziemlich grosse vordere Genitalmasse I 3 - I $5 \mathrm{~mm}$. lang bei einer Höhe von ro-I I und einer Dicke von etwa $7 \mathrm{~mm}$., gelblichweiss und gelb; der Erhärtungszustand gestattete keine genauere Untersuchung. Die (bei dem einen Individuum in der Genitalöfnung sichtbare) Glans penis unbewaffnet (Fig. 29).

\section{Cratenidae.}

R. BERGH, System. p. IO2I(-IO24).

Corpus subcompressum; rhinophoria simplicia; epinotidia (papillae dorsales) subcylindrica. 
Margo masticatorius (mandibularis) serie vel seriebus denticulorum armatus. Dentes lingvales uniseriati, arcuati vel arcuato-angulares acie grosse denticulati. - Penis inermis.

Die Familie umfasst die Gattungen Cuthona (A. u. H.), Cuthonella (B.), Cratena (B.), Hervia (B.) und Phestilla (B.).

\section{Cratena Bgh.}

R. BERGH, System. 1. c. p. 1022.

Caput non latum; podarium antice leviter arcuatum.

Margo masticatorius singula serie denticulorum minutorum armatus. - Otocysta otoconia continens.

Eine Reihe von Arten, meistens den weniger warmen Meeresgegenden angehörend, ist bekannt oder wenigstens angegeben.

I. Cratena cacullata Bgh. n. sp. Taf. XIX, Fig. 34-36.

Am 28 Aug. wurde auf einem Riff bei der Insel Gisser (St. 172) ein Individuum gefangen.

Dasselbe hatte in der Formol-Lösung eine Länge von $15 \mathrm{~mm}$. bei einer Breite des Körpers von 3,5 und einer Höhe von 3; die Breite des Fusses war vorne 4, sonst meistens $3,5 \mathrm{~mm}$; die Länge des Schwanzes 1,75 ; die Länge der Papillen betrug bis 5,5 mm. - Das Genick war schwarz eingefasst, und diese Einfassung setzte sich in ein schwarzes breites Längsband des Rückens fort (Fig. 34); die Tentakel so wie die Rhinophorien trugen einen schwarzen Ring, die Papillen waren schwarz; sonst war das Thier von grünlicher Farbe.

Der Form war länglich; die Tentakel und die glatten Rhinophorien ziemlich kurz. An den Seiten des Rückens zeigten sich (nach Abflückung der Epinotidien der einen Seite) diese Papillen jederseits in $S$ Gruppen vertheilt, deren Grundfläche sehr schräge der Länge nach verlief, die 4 vordersten enthielten etwa $8,7,6$ und 6 Papillen, die übrigen stiessen fast an einander und trugen 4-3 Papillen; die 4 vordersten Gruppen der beiden Seiten waren durch den nackten Rücken von einander geschieden. Die nicht leicht abfallenden Papillen waren fast cylindrisch, oben ein wenig verschmälert. Die Körperseiten niedrig. Die Analpapille am hinteren Ende der zweiten Papillengruppe. Der gerade vordere Fussrand mit starker Furche, das Fussgebräm nicht schmal, der kurze Schwanz zugespitzt.

Das Centralnervensystem wie gewöhnlich, Die Augen von einem Durchmesser von o, I 4 mm.

Der Schlundk opf von gewöhnlichen Formverhältnissen, 2,5 mm. lang bei einer Höhe von 2 und einer Breite von I,25 mm. Die Mandibel röthlich braungelb, der Kaufortsatz mit einer Reihe von (etwa 90) ziemlich plumpen Dentikeln (Fig. 35), die eine Höhe bis 0,0I5 mm. erreichten. Die Zunge am Unterrande mit Spuren von 6 Zahnplatten, am oberen mit 8 Platten; in der Scheide 9, von welchen die zwei hintersten unreif, die Gesammtzahl der Platten somit 17. Die gelben Zahnplatten (Fig. 36) zwischen den Beinen 0,28 mm. messend, die Länge ihrer Dentikel bis 0,08. Die langbeinigen Platten mit starkem medianem Haken und jederseits 7 langen und spitzen Dentikeln. - Der Gaumen hinten und der Pharynx schwarz. 
Die Speiseröhre kurz. Der Magen $2 \mathrm{~mm}$. lang; der Magenblindsack (Hauptlebergang) an der linken Seite und unter der Zwitterdrüse liegend. - Die ganz ebenen Papillen von den auch fast ganz ebenen Leberlappen fast vollständig ausgefuillt; die Cnidae der Nesselsäcke länglich und kugelig, von einer Länge bis $0,04 \mathrm{~mm}$.

Die $Z$ witterdrüse von vielen, mehr oder weniger rundlichen, gräulichen Lappen von einem Durchmesser bis $0,75 \mathrm{~mm}$. gebildet; in den Läppchen reife Geschlechtselemente. - Die längliche graue vordere Genitalmasse $3,5 \mathrm{~mm}$. lang.

Diese Form bildet eine neue Art der Gattung Cratena, die im Philippinischen Meere schon durch ein Paar Arten (Cr. bylgia B., Cr. longibursa B. und Cr.? lugubris B.) repräsentirt ist.

\section{Hervia Bgh.}

R. Bergh, System. 1. c. p. IO23.

? Riszolia Trinchese.

Tentacula elongata; podarium antice angulis tentaculatim productis.

Margo masticatorius serie denticulorum unica.

Von der Gattung sind kaum mehr als zwei Arten bekannt.

I. Hervia Sibogae Bgh. n. sp. Taf. II, Fig. I 7. Taf. XX, Fig. I-3.

An der Westküste der Insel Kangeang in der Ketapang-Bai (St. 3I 8 ) wurde mit dem Trawl ein Individuum gefischt, nach dem Leben abgebildet und in Formol bewahrt.

Das lebende Thier hatte eine Länge von etwa $16 \mathrm{~mm}$. bei einer Körperbreite (wenn ausgestreckt) von $\mathrm{I}, 5$; die Rhinophorien scheinen länger als die Papillen (Epinotidien) und doppelt so lang wie die Tentakel gewesen zu sein. Die Farbe scheint roth.violet gewesen zu sein, die Papillen theilweise, wenigstens ihre Spitze, citrongelb.

Die Länge des a ufbewahrten Individuums war I $2 \mathrm{~mm}$. bei einer Rückenbreite von 2,25 und einer Körperhöhe von 2,5; die Rhinophorien $3 \mathrm{~mm}$. lang, die Länge der Epinotidien bis 4,5; der Fuss meistens $2,5 \mathrm{~mm}$. breit, der Schwanz $2 \mathrm{~mm}$. lang. Die Farbe war durchgehends schmutzig gelblich.

Die Körperform die 'gewöhnliche langgestreckte. Die glatten Rhinophorien länger als die dünneren Tentakel. Der Rücken gerundet in die Körperseiten übergehend, an seinen Seitentheilen Io Papillengruppen, die durch ziemlich gleiche Zwischenräume geschieden sind, nur die hintersten sind nahe an einander gerückt. In den Gruppen kamen meistens 5-6 Papillen vor, in der nächsthintersten nur 2 und in der hintersten eine. Die Papillen waren fast cylindrisch, oben zugespitzt, nicht abfallend. Der Anus fand sich im Aussenende der fünften (rechten) Papillengruppe. Die Genitalöffnung unter der zweiten Gruppe. Der Fuss mit tentakelartigen Fussecken, fast so lang wie die Tentakel, das Fussgebräm nicht schmal, der Schwanz kurz.

Das Centralnervensystem wie gewöhnlich. Die Augen von fast $0,08 \mathrm{~mm}$. Durchmesser, mit stark gelber Linse. 
Der Schlundkopf I,5 mm. lang, von gewöhnlicher Form; die hellgelben Mandibel mit nicht langem Kaufortsatz, und einer Reihe von (26) bis 0,0 I3 mm. hohen Dentikel (Fig. I). Die lange schmale Zunge enthielt an dem unteren Rande 36 , an dem oberen und in der Scheide 34 entwickelte und 2 jüngere Zahnplatten, die Gesammtzahl derselben war somit 72. Die ältesten Platten maassen an Breite 0,06 , die jüngsten $0,12 \mathrm{~mm}$, die Höhe der Platten stieg bis $0,06 \mathrm{~mm}$; die Platten waren hell gelblich. Die Platten trugen einen kleinen medianen Dentikel und an jeder Seite desselben 5-6 gröbere (Fig. 2, 3).

Die Nesselsäcke gross, bis o,5 mm. lang, mit meistens ganz kleinen Cnidae.

Der Penis unbewaffnet.

Diese Form scheint zunächst der Gattung Hervia an zu gehören, kann aber kaum die H. rosca des Meeres um Amboina sein.

\section{Phestilla Bgh.}

R. BERGir, Neue Nacktschnecken der Südsee. II. Journ. d. Mus. Godeffroy. Heft VI. I874, p. $9 \mathrm{I}(-95$. Taf. II, Fig. I-I 4 ).

Corpus nonnihil depressum. Caput supra limbatum, limbus lateribus quasi alatus, alae podario affixae; tentacula breviora, rhinophoria simplicia. Papillae (epinotidia) non caducae singula serie pedamentis compressis obliquis impositae, sine cnidocystis. Podarium antice rotundatum.

Margo masticatorius mandibularum brevis, quasi laevigatus. Radula uniseriata, dentes denticulis elongatis.

Von den anderen Crateniden unterscheidet sich diese Gattung hauptsächlich durch die besondere Form des Kopfes, die Insertion der fest anhängenden Epinotidien auf erhabenen Kissen und den nicht denticulirten Kaurand der Mandibel.

Von der Gattung war bisher nur eine Art, Ph. melanobrachia, aus dem Philippinischen Meere bekannt, jetzt kommt eine neue hinzu.

I. Phestilla Sibogae Bgh. n. sp. Taf. XX, Fig. 4-r2.

Am ersten Febr. wurden in der Pepela-Bai an der Ostküste der Insel Rotti (St. 30I) zwei Individuen gefangen, die beide anatomisch untersucht wurden.

In Formol bewahrt ähnelten sie ganz einander, das kleinere war $2 \mathrm{I}$, das grössere $24 \mathrm{~mm}$. lang; auf das letztere beziehen sich die folgenden Maasse. Die Höhe des Körpers war 6, seine Breite $8 \mathrm{~mm}$; die Breite des Fusses auch 8, die Länge des Schwanzes $4 \mathrm{~mm}$; die Höhe der gestreckt-kegelförmigen Rhinophorien $2 \mathrm{~mm}$, die Länge der Papillen stieg bis $6 \mathrm{~mm}$. - Die Farbe des Körpers mit den Tentakeln und Rhinophorien war hell milchweiss, die der Papillen schmutzig-braungrau mit weisser Spitze.

Die Körperform (Fig. 4, 5) war länglich. Der Rücken ging gerundet in die niedrigen Körperseiten über, seine breite Mitte war bis an den Schwanz nackt; die Seitentheile trugen die in 9 gegen hinten in sehr schrägen Bogen geordneten Epinotidien (Papillen); die Papillen 
standen meistens in einer einzelnen Reihe, 6-i 2 in der Reihe. Sie (Fig. 10) waren je kegelförmig, aber fast alle stark knotig (wegen der Formol-Lösung), oft in einander geschlungen, wodurch die Feststellung ihrer Ordnung etwas schwer und etwas unsicher wurde. Der Anus dicht hinter dem obersten Ende des fünften Bogens stehend. Der ziemlich breite Fuss vorne gerundet und mit starker Randfurche, das Fussgebräm nicht schmal, der Schwanz zugespitzt.

Das Centralnervensystem wie gewöhnlich. Die Augen von o,ro mm. Durchmesser; die Ohrblasen maassen 0,05, enthielten einem runden Otolithen von 0,035 mm. Diameter.

Der Schlundkopf $3 \mathrm{~mm}$. lang, die Raspelscheide hinten wenig vorspringend. Die Mandibel ziemlich blass-gelb; die Schlosspartie nicht stark; der Kaufortsatz kurz, etwas gebogen; der Kaurand von Längslinien durchzogen. Die schmale Zunge hatte an dem Unterrande I 2-I3, am Oberrande 4-5 Zahnplatten; in der ziemlich langen Raspelscheide 24-26 Platten, von denen die zwei hintersten unreif, die Gesammtzahl der Zahnplatten somit 40-44 (Fig. 6). Die hellgelben Zahnplatten (Fig. 7-9) waren von einer Länge (von der Spitz des Hakens bis an das Hinterende) von 0,20 mm., die Breite zwischen den Schenkeln 0, 10, die Höhe 0,16 mm.; der Kaurand zeigte zu jeder Seite des ziemlich starken glattrandigen Hakens $6(-7)$ lange, spitze, ein wenig gebogene Dentikel. - An der Zunge klebten Massen von Cnidae (Fig. I I).

Die Speiseröhre kurz. Der Magen 4 mm. lang, mit Längsfalten, die sich in den Darm hinein fortsetzen; sein reichlicher Inhalt aus thierischer Masse, mit einer Unzahl von länglichen Nesselzellen vermischt, bestehend. Die dunkeln Leberlappen die Höhle der Papillen ganz ausfüllend; eine Nesselsack konnte nicht nachgewiesen werden.

Die grosse, gräuliche Zwitterdrüse aus einer Menge von an einander hängenden Lappen gebildet, die aus eiförmigen oder sackartigen Ovarialfollikeln (mit grossen Eizellen), meistens von einem Diameter von $0,25 \mathrm{~mm}$., an einer centralen Scheibe (ohne entwickelte Zoospermien) befestigt, zusammengesetzt waren (Fig. I2). - Die weissliche vordere Genitalmasse $3 \mathrm{~mm}$. lang, wegen der zusammengedrückten Schleimdrüse $4 \mathrm{~mm}$. hoch. Der gestreckt-birnförmige Penissack I,25 mm. lang, die kegelförmige Glans sich durch Dreiviertel der Höhle erstreckend.

Diese Form ist von der früher beschriebenen Art verschieden.

\section{Taf. XX, Figs. +, 5, 9, 1 I.}

Dieser Art gehörten sicherlich noch drei Individuen an, zwei kleinere und ein grösseres, die am Riffe der Nalahia-Bai, Insel Nusa-Laut (St. 234), gefangen wurden; sie ähnelten sonst einander.

Das grössere hatte eine Körperlänge von $14 \mathrm{~mm}$. bei einer Breite von 6 und Höhe von 4; die Höhe der Tentakel betrug I, die der Rhinophorien 2 mm., die Länge der Papillen (Epinotidien) bis 6. Die Farbe des eigentlichen Körpers war weisslich, die der Epinotidien grau.

Der Rücken war von den in einander verwickelten Papillen ganz gedeckt, und die Tentakel und Rhinophorien wurden erst nach Entfernung der Papillen sichtbar. Die cylindrischen, am Grunde des oberen Kopfrandes stehenden Tentakel so wie die Rhinophorien (Fig. 4) ganz glatt. Die Epinotidien langgestreckt, unten dicker, fast alle in.der verschiedensten Weise durch unregelmässige Contraction knotig und oben fast immer gleichsam mit einem Knopf endigend 
(Fig. 10); sie hingen fest und standen (meistens zu IO-I2) in je einer einzelnen Reihe aut etwa 10-12 schrägen Leisten, von denen die 6 vordersten fast als zusammengedrückte Fussstiicke hervortraten. Der Anus oben im Zwischenraume zwischen 5. und 6. Papillenkissen.

Der Schlundkopf 3,5 mm. lang. Die Schlosspartie der gelben Mandibel braungelb, der kurze Kaurand schwach quergerunzelt. Die ganz schmale Zunge trug am Unterrande 9, am Ende 4, am oberen Rande 6 und in der Scheide 21 Zahnplatten, die ganze Anzahl war somit 40. Die hellgelben Zahnplatten wie oben, mit $6-7$ Dentikeln jederseits, welche ein wenig länger als bei den früher untersuchten Individuen waren (Fig. 9); die Länge der ältesten war 0,20 , der jüngeren $0,25 \mathrm{~mm}$.

Der Magen wie oben. Die Leberlappen die Höhle der Epinotidien ganz ausfüllend, unten stark knotig, sonst mehr eben, bis an die Spitze reichend. Diese letztere enthielt keinen Nesselsack, war von einer Hülle von Schleimzellen bekleidet, die eine Höhe bis $0,0 S \mathrm{~mm}$. erreichten.

Die weissliche, grosse Zwitterdrüse und die vordere Genitalmasse wie oben.

\section{Tergipedinae.}

R. BERGH, System. 1.c. p. 1024(-1027).

Corpus subcompressum; rhinophoria simplicia; anus latero-dorsalis; epinotidia claviformia, serie unica vel paucis seriebus disposita; podarium antice rotundatum.

Margo masticatorius ut plurimum serie denticulorum unica praeditus. Dentes lingvales ut plurimum uniseriati. - Otocysta cum otolitho singulo.

Die Familie umfasst die Gattungen Tergipes (Cuv.), Capellinia (Trinchese), Forestia (Tr.), Embletonia (A. et H.), Amphorina (Q.), Galoina (A. et H.), Ennoia (B.) und vielleicht Myja (B.).

\section{Ennoia Bgh.}

R. Bergit, Eolidiens d'Amboina. Revue suisse de zool. IV, 2. IS96, p. 392-394. Pl. XVI, Fig. 14-I5.

Caput sat latum processibus lateralibus rotundatis; rhinophoria sicut tentacula simplicia. Nargo masticatorius laevigatus. - Penis inermis.

Diese generische Gruppe scheint in der Nähe der Embletonien zu stehen, von welchen sie sich durch das Dasein von Tentakeln besonders unterscheidet.

Bisher war nur eine Art, ebenfalls aus dem Indischen Meere, die E. briarens (1. c.) bekannt.

I. Ennoia longicirrha Bgh. n. sp. Taf. XX, Fig. I3-I4.

Am Ankerplatz bei Pulu Jedan an der Ostküiste von den Aru-Inseln (St. 273) wurde ein Individuum gefangen. 
Dasselbe hatte eine Länge von $20 \mathrm{~mm}$. bei einer Breite von 3 und Höhe von 4; die Tentakeln waren 4, die Rhinophorien $2,5 \mathrm{~mm}$. lang, die Länge der Papillen betrug bis I I mm.; die Länge der Fussecken 0,5 , die des Schwanzes $3 \mathrm{~mm}$. - Die Farbe war durchgehends schmutzig-gelblichgrau.

Der Rücken etwas gerundet, ohne Grenze in die Körperseiten ïbergehend. Dás Vorderende des Kopfes etwas abgeplattet, ziemlich breit; die Tentakel länger als die stark geringelten (zusammengezogenen) Rhinophorien. Der Rücken trug jederseits 9 Papillengruppen; die erste enthielt 3 Papillen, von welchen die äusserste ganz klein; die zweite enthielt 4 Papillen, diese und die vorige bildeten zusammen gleichsam einen Bogen, was auch mit der nach einem Zwischenraum folgenden 3. und 4., so wie mit der 5. und 6. der Fall war; die dritte Gruppe zeigte 5, und die vierte 6 Papillen; die fünfte 5: und die sechste 4 Papillen; in den drei letzten Gruppen kamen nur 2 Papillen vor. Die Papillen waren cylindrisch und dünn, zeigten den fast ebenen Leberlappen bis an ihre Spitze hinaufsteigend; die äussersten, besonders die äusserste waren klein, die 2 innersten immer sehr lang, und eine solche lange Papille kam noch in der siebenten Gruppe vor. Die Analpapille zwischen der dritten und vierten Gruppe stehend. Die Furche des vorderen Fussrandes bis an die Spitze der Fussecken verlängert, dass Fussgebräm ziemlich dünn und breit; der Schwanz zugespitzt.

Das Centralnervensystem wie gewöhnlich. Die Otocysten von o,o $8 \mathrm{~mm}$. Durchmesser, der stark gelbe kugelförmige Otolith im Diameter 0,05 mm. haltend.

Der gedrungene Schlundkopf fast I mm. lang; die gelben Mandibel mit grob gezähneltem Kaurand (Fig. I3), die Zähnchen bis $0,02 \mathrm{~mm}$. hoch. An der Zunge kamen 8, in der Scheide Io Zahnplatten vor. Die gelblichen Zahnplatten (Fig. I 4) 0,20 mm. lang bei einer Höhe von $\mathrm{O}, \mathrm{IO}$; mit langen, fein gezähnelten Scheiderändern des Hakens.

An der Spitze des Leberlappens der ziemlich grosse Nesselsack mit runden und ovalen Cnidae.

Die kugeligen Lappen der langen Zwitterdrüse mit reifen Geschlechtselementen.

$\mathrm{Ob}$ diese Form der Gattung Ennoia gehört, ist, besonders wegen der Beschaffenheit der Mandibel, sehr zweifelhaft; in ihre Nachbarschaft gehört sie wohl jedenfa.lls.

\section{Flabelinidae.}

R. Bergh, System d. nudibr. Gasteropoden. I892, p. IO33-IO34.

Corpus elongatum, gracile, processibus brachioformibus continuatum, qui ut pedamenta epinotidiis vix caducis inserviunt. Rhinophoria perfoliata vel simplicia, tentacula elongata. Podarium antice angulis tentaculatim productis.

Margo masticatorius mandibularis seriebus denticulorum instructus. Radula uni-vel triseriata. - Penis stylo armatus vel inermis.

Die Familie umfasst die Gattungen Flabellina Cuv. (mit drei Zahnplattenreihen und 
bewaffnetem Penis), Pteracolidia Bgh. (s. unten), Calma Ald. et Hanc. (mit einfachen Rhinophorien und bewaffnetem Penis) und Samla (mit drei Zahnplattenreihen und unbewaffnetem Penis ${ }^{1}$ )).

\section{Pteraeolidia Bgh.}

R. Bergh, Beitr. zur Kenntn. der Aeolidiaden. III. 1. c. XXV. IS76, p. 652 .

Rhinophoria perfoliata Margo anterior podarii inflatus. Radula uniseriata. Penis inermis.

Die Gattung ist besonders durch die einreihige Raspel von den anderen der Familie unterschieden. Sie hat durchblätterte Rhinophorien und das Vorderende des Fusses ist eigenthümlich stark entwickelt. Der Penis ist unbewaffnet.

Bisher ist nur die untenstehende, dem Indischen Meere gehörende Art bekannt.

I. Pteracolidia Semperi Bgh. Taf. I, Fig. I6. Taf. XX, Fig. 15-17.

Flabellina Semperi Bgh. Malacolog. Unters. I (Heft I). I870, p. I8-30. Tab. II; Tab. III, Fig. I-I 5 .

Pteracolidia Semperi Bgh. 1.c. II. I876, p. 652.

Pteraeolidia Semperi Bgh. Eliot, 1. c. II, 1903, p. 255.

Auf einem Riff bei Ambon wurde ein Individuum gefangen und lebend abgebildet.

Das lebende Thier scheint eine Länge von etwa $4 \mathrm{~cm}$. gehabt zu haben bei einer Körperbreite von beiläufig $2 \mathrm{~mm}$. Die Grundfarbe scheint gelblich gewesen zu sein; längs der Seiten des Rückens verlief ein an den Papillenstielen unterbrochenes, rothbraunes Längsband; die Tentakel so wie die Rhinophorien roth geringelt; die Papillen rothbraun (mit dunklerer Spitze). - Das a ufbewahrte Individuum hatte eine Länge von 28 bei einer Körperbreite vorne von 2,25 mm, und einer Höhe von 2; die Länge der Tentakel betrug $\tau$, die der Rhinophorien 2,5 und die der Papillen bis $5 \mathrm{~mm}$; die Breite des Fusses war fast durchgehends 2 mm., vorne wegen der ( $1 \mathrm{~mm}$. langen) Fussfühler etwas breiter, der Schwanz I,5 mm. lang. Die Farbe war durchgehends hell gelblichweiss, die des Fussgebräms und der Papillen heller. Die Eingeweide schimmerten nirgends durch.

Die Form war langgestreckt und sehr schmal; die Tentakel doppelt so lang wie die aufrechten, durchblätterten Rhinophorien. Der ganz ebene, schmale Rücken vorne ein wenig breiter, nach hinten allmählig ein wenig verschmälert; von beiden Seitenrändern erheben sich in Abständen, die nach hinten kürzer werden, symmetrisch I4 (bis I,20 mm. hohen) Papillentragende Arme, von welchen die drei hintersten kleiner waren; diese Arme, Papillenfussstücke, waren etwas zusammengedrückt, oben breiter. Das erste Fussgestell ausserhalb der Rhinophorien, dicht an der Genitalpapille stehend, oben etwas getheilt und an den Enden etwas hornartig vortretend, in, wie es schien, zwei unter einander verschobenen Reihen gegen 30 Papillen tragend. Das zweite Gestell auch etwas ausgekerbt und hinten hornartig ausgezogen, etwa 20 Papillen tragend; das dritte so wie die folgenden Gestelle kaum ausgekerbt oder nach hinten vortretend, mit etwa 20 Papillen. An den folgenden (4. bis 8.) kamen beiläufig I5, 
dann (9.-IO.) г 2, dann 8, 6 und 4 Papillen vor. Die Papillen in den Gruppen wie gewöhnlich von ungleicher Länge, im Ganzen aber nur in den hintersten von geringerer Grösse; sie waren nicht leicht abfallend, cylindrisch, lang, duinn, am Ende zugespitzt. Die kleine Analpapille am Grunde des zweiten Fussgestelles. Vorne an der (rechten) Körperseite die starke Genitalpapille mit zwei Öfnungen. Das Vorderende des Fusses mit tiefer Randfurche, die sich bis an das Ende der Fussfuhler fortsetzt; die obere Lippe des Vorderrandes gleichsam aufgeblasen, in der Mitte gekliiftet; der Fuss schmal mit schmalem Gebräm; der kurze, abgeplattete Schwanz zugespitzt.

Das Centralnervensystem wie gewöhnlich. Die Augen von einem Durchmesser von 0,075 mm. die Ohrblasen maassen $0,09 \mathrm{~mm}$. Die Keule der schönen Rhinophorien mit 22-25 Blättern.

Die Mundröhre vorne von einem starken Drüsenlager eingefasst. Der Schlundkopf r,6 mm. lang, sonst wie früher beschrieben. Die gelblichen Mandibel auch wie gewöhnlich; der Kaurand 0,06 mm. breit, mit mehreren Reihen von spitzen Höckern (Fig. I5) von einer Höhe bis 0,007 mm. An der Zunge kamen 6 Zahnplatten vor, in der Scheide 9, von welchen die zwei noch unreif, die Gesammtzahl derselben somit I 5. Die gelben Zahnplatten (Fig. I6, I 7) bis $0,16 \mathrm{~mm}$. breit bei einer Höhe bis 0,07; von der früher beschriebenen Form, an dem spitzen Haken $\mathrm{I}-2$ feine Dentikel und ausserhalb derselben noch etwa 9 stärkere.

Die weisslichen Speicheldrüsen, jederseits neben den pedalen Ganglien, eine kleine Masse, kaum grösser als die Fussknoten, bildend.

Die Speiseröhre und der kleine Magen wie fruher beschrieben; der Hauptgallengang (Magenblindsack) hauptsächlich links an der Unterseite der Zwitterdrüse verlaufend. - Die Leberlappen die Höhle der Papillen zum grossen Theile ausfullend, feinhöckerig. Der birnförmige Nesselsack zeigte fast nur ovale oder eiförmige Cnidae, meistens von einer Länge von $0,020-0,025 \mathrm{~mm}$.

Die lange $\mathrm{Z}$ witterdrüse ganz wie früher beschrieben; in den Läppchen reife Geschlechtselemente. Die vordere Genitalmasse von rundlichem Umrisse, von einem Durchmesser von I,5 mm.

Ein später am Riffe von Haingsisi gefangenes Individuum hatte eine Länge von $25 \mathrm{~mm}$. und nur i3. Armpaare.

Trotz möglicher Verschiedenheiten in der Farbenzeichnung liegt hier unzweifelhaft die Pter. Semperi vor.

Flabellina Cuv.

R. BERGH, System. 1. c. p. IO33.

Rhinophoria perfoliata.

Radula triseriata, dentes laterales lati interno margine denticulati. - Penis stylo armatus.

Eine Art ist aus dem Mittelmeere und einige aus dem Indischen und Stillen Meere bekannt.

1. Flabellina? macassarana Bgh. n. sp. Taf. V, Fig. 5. Taf. XX, Fig. I8-ig.

Aus einer Tiefe von $27-32$ M. wurde bei ,Makassar' ein Individuum gefangen und jebend abgebildet. 
Das lebende Thier hatte eine Länge des Körpers von $4,5 \mathrm{~cm}$. bei einer Breite bis $3 \mathrm{~mm}$., die Länge der Papillen scheint bis $7 \mathrm{~mm}$. betragen zu haben. Die Farbe des Rückens scheint röthlichgelb gewesen zu sein, ebenso die der Rhinophorien; die Tentakel und Fussfühler (nur oben) wie die Papillen und der Schwanz karminroth.

Das a ufbewa hrte, stark zusammengezogene und erhärtete Individuum war nur i $8 \mathrm{~mm}$. lang bei einer Breite des Körpers bis 2, die Länge der Papillen bis 4, die Breite des Fusses $2 \mathrm{~mm}$. - Die Farbe war durchgehends röthlichgelb.

Die Form war langgestreckt; die perfoliirten Rhinophorien kürzer als die Tentakel, länger als die Fussfuhhler. Die Papillen deutlich auf 6, nicht dicht hinter einander stehenden niedrigen Fussgestellen vertheilt, auf dem ersten zwei Reihen mit je 6 Papillen, auf den folgenden mit je 3 und auf dem hintersten mit 2. Die innersten zwei Papillen grösser als die anderen; sie waren alle cylindrisch, glatt. Der schmale Fuss mit etwas vortretendem Rande, der Schwanz hinten den Körper überragend.

Die kurzgestielten Augen von 0,10 mm. Durchmesser, mit gelblicher Linse.

Der röthlichgelbe $\mathrm{Schlundkopf}$ ziemlich gedrungen, I,25 mm. lang. Die Mandibel hell röthlichgelb, der Kaurand (Fig. IS), mit wenigen Reihen von am Rande selbst spitzen Dentikeln von einer Höhe bis etwa $0,02 \mathrm{~mm}$. Die Nebenmundhöhle ziemlich gross, der Hinterrand der Öffnung schwarz. Die fast farblose Raspel 7 Zahnplattenreihen enthaltend, in der Scheide kamen deren noch Io vor, die Gesammtzahl der Reihen somit I7. Die Zahnplatten farblos; die Breite der medianen betrug o,o $8 \mathrm{~mm}$., die Länge der lateralen O, I3. Die medianen Platten (Fig. I9) mit 5 spitzen Dentikeln an jeder Seite des ziemlich langen spitzen Hakens; die zweischenkeligen lateralen Platten (Fig. I9) mit $4-5$ spitzen Dentikeln des Innenrandes.

Die etwas knotigen Leberlappen füllten fast die Höhle der Papillen aus; die Nesselsäcke klein mit ganz kleinen, meistens rundlichen Cnidae.

Eine mehr eingehende Untersuchung gestattete der Zustand des Individuums nicht ${ }^{1}$ ).

\section{Glaucidae.}

R. BERGH, System d. nudibr. Gasteropoden. I 892 , p. 1035-1036.

Diese eigenthümliche, mit keiner anderen zu verwechselnde, pelagische Gruppe enthält nur zwei Gattungen: Glaucus F. und Glaucilla B.

\section{Glaucus Forster.}

Der Gattung sind mehrere Arten zugeschrieben worden, die alle vielleicht nur eine einzige circumaequatoriale bilden, den:

I) Der Penis konnte nicht auspräparirt werden. Es wäre somit möglich dass diese Form der Gattung Samla (die keinen Stachel hat) gehörte. Vgl. Ergebn. einer Reise nach dem Pacific (Schauinsland). Zoolog. Jahrb. XIII, 3. 1900, p. 237-239. Taf. 20, Fig. $47-55$. 
I. Glaucus atlantious Forster.

R. BERGH, Malacolog. Unters. II (Heft XVII. ISgo), p. $\$ 76$.

Im Oberflächen-Plankton wurde am 7 Nov. auf St. $224\left(5^{\circ} 34^{\prime} \mathrm{S} . \mathrm{Br} ., 127^{\circ} 4^{\prime}\right.$ Ö.L. $) 2$ kleine Individuen gefangen.

Sie hatten eine Länge von 3 und 3,5 mm., waren fast schwarz und zeigten zwei Paar Papillengruppen mit wenigen Papillen, das hintere Paar war viel kleiner.

\section{Fam. Tethymelibidae.}

R. BERGH, System d. nudibr. Gasteropoden. 1. c. I892, p. I039-I043.

Forma corporis fere ut in Aeolidiidis; papillae dorsales attamen colosseae, caducae sine bursis cnidogenis; caput permagnum cuculliforme; tentacula nulla; clavus rhinophoriorum perfoliatus, vagina colossea retractilis.

Bulbus pharyngeus rudimentarius, lingva et interdum quoque mandibulis destitutus. Penis inermis.

Diese Gruppe mit ihrem colossalen als eine Art Reuse entwickelten kapuzenförmigen Kopf enthält nur die zwei Gattungen Tethys und Melibe.

\section{Melibe Rang.}

R. BERGH, 1. c. p. 1042-I043.

Corpus nonnihil compressum; branchiae nullae; podarium angustius.

Bulbus pharyngeus lingva solum destitutus.

Die Meliben sind sowohl im Äusseren wie im inneren Bau von der Gattung Tethys sehr verschieden. Mehrere Arten sind beschrieben.

1. Melibe australis Angas? Taf. XX, Fig. 30.

ILelibaea australis Angas. Descr. d'espèces nouv. - de Port Jackson. Journ. de conchyl. 3 S. IV, r. I864, p. 62-63. Pl. VI, Fig. 2.

Auf einem Riff bei Saleyer (St. 2 I3) wurde ein Individuum gefangen, das sehr stark verdreht und allgemein oberflächlich sehr abgerieben war.

Dasselbe schien eine Länge von $30 \mathrm{~mm}$. bei einer Körperhöhe von 9 und Breite von 7 gehabt zu haben; die Kapuze mass in der Quere $13 \mathrm{~mm}$. bei einer Höhe von I I; die Höhe der Rhinophorien war etwa 3, die Breite des Fusses etwa $4 \mathrm{~mm}$; der Penis ragte $6 \mathrm{~mm}$. iiber die Körperseite neben der kurz kegelförmigen Vulva (Fig. 30) hervor. - Die Farbe war durchgehends gelblichweiss, um den Hals und am Grunde der Rückenpapillen schwarz.

Die colossale Kapuze mit eingerolltem Rande, der 4-5 Reihen von Cirrhi trug; dieser 
Besatz vielleicht oben median fehlend. Die Aussenseite der Kapuze trug zerstreute kleine weiche Kegel, noch kleinere kamen an der Innenseite gegen den Mund hin vor. Die Rhinophorien sehr beschädigt. Der Rücken trug jederseits 4 starke dicke, ziemlich niedrige Papillen, deren breiterer Scheitel in mehrere Lappen getheilt war, die vielleicht baumartig waren. Der Rücken so wie die Körperseiten zeigten sonst einfache und zusammengesetzte kleine Zotten. Der Fuss wie sonst bei der Melibe.

Die Umgebung des Aussenmundes mit kleinen Kegeln stark besetzt. Die Mundröhre mit den gewöhnlichen starken Längsfalten, hinten röthlichbraun pigmentirt. Die Ma ndibel von gewöhnlicher Form, nicht ganz schmal, $2 \mathrm{~mm}$. lang, hellgelblich, die hintere Hälfte des Kaurandes rundzackig. Der Magen $3 \mathrm{~mm}$. lang, ganz rund, von einem Durchmesser von 4,5, mit 30 gelben, ab und zu in Länge alternirenden Platten gewöhnlicher Art.

Die weissliche vordere Genitalmasse $5 \mathrm{~mm}$. lang bei einer Höhe von 5 und Dicke von 4. Die kugelige gelbe Prostata von $3 \mathrm{~mm}$. Durchmesser; der Penis etwas zusammengedrückt, etwas gebogen (Fig. 30).

Vielleicht liegt hier die von AvGAS in seiner Manier abgebildete und erwähnte Art vor: dass dieselbe eine Doto darstellen sollte, wie von mir früher ${ }^{1}$ ) fraglich angedeutet, ist kaum wahrscheinlich.

2. Melibe papillosa (de Filippi)? Taf. XX, Fig. 31-32.

R. Bergi, Beitr. z. Kenntn. d. Gattung Melibe Rang. Zeitschr. f. wiss. Zool. XII. I884, p. I42-154. Taf. X.

Am Riffe von Pulu-Pasi-Tanette (St. $2 r_{3}$ ) wurde ein Individuum, vielleicht dieser Form angehörig, erbeutet.

Dasselbe, ganz schlaff und schlecht conservirt, hatte eine totale Länge von $\mathrm{r} 7 \mathrm{~mm}$. bei einer Höhe von 5 und einer Dicke von 2; die Kapuze hatte eine Breite von 9 bei einer Länge von $5 \mathrm{~mm}$; die Höhe der Rhinophorien war 2,5, die der Rückenpapillen bis I,75, die Breite der Fusssohle bis $0,75 \mathrm{~mm}$. - Die Farbe hell gelblichweiss mit zerstreuten feinen braunen Punkten. Die Eingeweide schimmerten deutlich durch, so auch der Darm.

Der kapuzenartigen Kopf von gewöhnlicher Grösse, der Rand ringsum ununterbrochen; die Aussenseite eben; der eingerollte Rand trägt eine Doppelreihe von Cirrhi, von welchen die äussersten viel schwächer; die Innenseite eben, nur in der nächsten Umgebung der senkrechten Mundöffnung und an der Rändern derselben kamen ganz feine weiche Knötchen vor. An der Aussenseite der Kapuze seitwärts und gegen den Grund hin die Rhinophorien; die becherförmige Scheide derselben mit lappigem Rande und der hintere Lappen etwas ausgezogen; die Keule mit gegen io Blättern. Überall in der Kapuze mit samt den Cirrhi und den Rhinophorscheiden eine Menge von kleinen Drüsenzellen und überall schimmerte das Netzwerk von Nerven mit ihren Ganglien durch. Am schmalen Rücken so wie an den Körperseiten kamen sparsam zerstreute kleine, weiche Kegel vor; an dem Rückenrand standen jederseits etwa gegen Io Rückenpapillen. Dieselben waren aber mit Ausnahme von den hintersten und

I) Vgl. System d. nudibr. Gasteropoden. 1. c. I\$92, p. 1047. 
kleinsten so schlaff und beschäidigt, dass ihre Form und Grösse sich mit Sicherheit nicht bestimmen liess; die bewahrten waren denen der $\%$. papillosa etwas ahnlich. Im ersten rechten interpapillären Raume die Analpapille. Aus der vordersten der zwei Genitalöfnungen ragte dic glans penis $0,5 \mathrm{~mm}$. hervor. Der Fuss ganz schmal, der Schwanz ganz kurz.

Das Centralnervensystem wie früher beschrieben.

Das fast cylindrische M undrohr mit starken Falten der Innenseite. Am Vorderende des ganz kleinen Schlundkopfs die den Innenmund fast einfassenden, sehr schwach gelblichen, an Länge (Breite) etwa $0,05 \mathrm{~mm}$. messenden Mandibel, deren Vorderrand zackig ist (Fig. 3I). Die kurze Speiseröhre (Fig. 32a) öffnet sich in den fast kugelförmigen MI agen, der einen queren Durchmesser von $1,5 \mathrm{~mm}$. hatte und die Magenzähne deutlich durchschimmern liess (Fig. 32b). Der Zahngürtel desselben war von I5 fast gleich grossen Platten gebildet, zwischen denen oft einfache Falten vorkamen; die Platten waren gelblichgrau, von $0,6 \mathrm{~mm}$. Länge bei einer Höhe bis 0,16 (Fig. 32). Am Grunde des Darmes (Fig. 32) die taschenförmige Erweiterung wie bei der $M$. papillosa. - Die drei Hauptleberstämme schienen sich auch wie bei jener zu verhalten.

Die kugeligen und halbkugeligen Läppchen der $\mathrm{Z}$ witterdrise an der Unterseite des gemeinschaftlichen Leberstammes und zwischen den Läppchen desselben liegend; sie enthielten reife Geschlechtselemente. Die vordere Genitalmasse weisslich; eine Prostata war deutlich, und ein „fächerförmiges Organ" schien nicht zu fehlen; der Penis wie gewöhnlich.

Bei der Unmöglichkeit die Art der Rückenpapillen zu bestimmen, bleibt es zweifelhaft. ob diese Form zu der $M$. papillosa (de Filippi) gestellt werden kann.

\section{Timorella Bgh. N. Gen.}

Corpus limaciforme, laeve, rhinophoriis parvis, tentaculis brevibus digitiformibus, podario sat angusto.

Bulbus pharyngeus proprius nullus.

Armatura genitalis nulla.

Diese ganz eigenthümliche, noch dazu im inneren Bau wenig gekannte Gattung, scheint den Nudibranchien an zu gehören.

Der Körper ist Limaxartig; der gewölbte Rücken ohne kiemenartige Anhänge, glatt; die Rhinophorien klein, ebenso die fingerförmigen Tentakel; der Fuss ziemlich schmal.

1. Timorella perplexa Bgh. n. sp. Taf. XII, Fig. 43-46.

An einem Ankerplatz an der Südküste von Timor $\left(8^{\circ} 25^{\prime} .2\right.$ S.B., $127^{\circ}$ i $8^{\prime} .4$ Ö.L. St. 285$)$ wurden zwei in Grösse ganz übereinstimmende Individuen gedredscht ${ }^{1}$ ).

1) Im Aufbewahrungsglase lagen mit den zwei Thieren zusammen zwei 1,5-2,25 mm. lange Papillen (Taf. XII, Fig. 6), wahrscheinlich einer Doto (D. annuligera: vgl. oben p. 221) angehörend, die dem unbewaffneten Auge vielleicht eine Ahnlichkeit mit jenen vorgegaukelt haben. 
Dieselben hatten eine Länge von 7 bei einer Höhe von 3 und einer Breite von 3 mm.; die Breite der Fusssohle betrug I,5. - Die Farbe war gelb; der Fuss an den Seitenrändern seiner ganzen Länge nach bläulich sammtschwarz, so war auch der Kopfrand so wie der Rand der vortretenden Rhinophorscheiden und der Scheitel der zwei kurzen Cylinder am Hinterende des Rückens des einen Individuums; unten an den Körperseiten kamen $2-5$ runde Flecken ähnlicher Farbe vor; auch der Rand der Genitalöffnungen war schwarz. Die Keule der Rhinophorien weisslich.

Die Form länglich, etwas Limax-artig, der Rücken gerundet in die Seiten übergehend. Median fand sich vor der Mitte der Länge eine feine Papille, vielleicht der Anus; dicht vor dem Ende des Körpers standen bei dem einen Individuum zwei kurze Cylinder mit einem oder zwei schwarzen Flecken am Scheitel (Fig. 43, 45), bei dem anderen fehlte jede Spur von solchen (Fig. 46). Die Keule der Rhinophorien schien schwach perfoliirt; die Tentakel kurz, fingerförmig. Der Fuss schmal, nur gegen den kurzen Schwanz noch ein wenig verschmälert, der Vorderrand mit Furche (Fig. 44).

Die cerebralen Ganglien waren rundlich. Die Augen von einem Durchmesser von $0.075 \mathrm{~mm}$., mit grosser gelber Linse. In der Haut (des Rückens) reichliches schwarzes Pigment so wie stabförmige verkalkte, meistens schwarze Spikel, so auch in den Tentakeln.

Um den Aussenmund ein sehr stark entwickeltes Drüsenlager; keine Spur eines Schlundkopfs wurde gesehen.

Die Leber bis an das Körperende reichend, gelblichweiss, zum grossen Theil von den weissen Lappen der Zwitterdrüse bekleidet; in den Läppchen derselben reife Geschlechtselemente. Die vordere Genitalmasse sehr gross, weiss; der ziemlich lange Samengang so wie der Penis unbewaffnet, ebenso die Vagina.

Der Erhärtungszustand der zwei kleinen Individuen gestattete nur diese ungenügenden und ganz fragmentarischen anatomischen Erläuterungen.

Vielleicht lagen auch zwei verschiedene Arten vor; der obige Name wäre dann für die Form mit den hinteren dorsalen. Cylindern zu reserviren. 


\section{INHALTSVERZIEICHNIS.}

Fig. bezeichnet Abbildung des lebenden Thieres.

\section{TECTIBRANCHIATA.}

\section{ANASPIDEA F.}

Aplysia scripta B.

Aplysia Benedicti Eliot.

Aplysia atromarginata B. . . . . . . . 8

Aplysia Sibogae B. . . . . . . . . . . 9

Aplysia vexans B. . . . . . . . . . . 10

Aplysia velifer B.. . . . . Taf. V, Fig. 2. Iz

Dolabeila Rumphii R. . . . . . . . . I3

Dolabella Rumphii R., var. . Taf. III, Fig. I. IS

Aclesia varicolor B. . . . Taf. III, Fig. 2. 2 I

Aclesia pusilla B. . . . . . . . . . . 22

Aplysiella Pasirana B. . . Taf. V, Fig. I. 24

Aplysiclla viridis B. . . . . Taf. III, Fig. 3. 25

Phyllaplysia inornata B. . . . . . . 27

\section{Cephalaspidea $\mathrm{F}$.}

Philine quadripartita A. . . . . . . . $2 S$

Philine rubra B. . . . . . . . . . 29

Philine elegans B. . . . . . . . . . 31

Gastropteron Sibogae B. . . . . . . 32

Gastropteron Sibogae B., var. nigra. . . . . 34

Phanerophthalmus luteus Q. \& G., var. . . . 3(

Phanerophthalmus pauper B. . . . . . . . 37

Cryptophthalmus olivaceus E. . . . . . 39

C. olivaceus E., var. pallida. . Taf. III, [ig. 4. 4 I

Chelidonura velutina B. . . Taf. JII, Fis. 5, 6. 43

Chelidonura amoena B.. . . Taf. III, Fig. 7. 45

\section{Notaspidea $F$.}

Pleurobranchaea morula B. . . . . . . 45 Oscaniopsis luniceps C. . . Taf. III, Fig 9. 50
Oscanius Weberi B. . . . Taf. II, I:i.r. I. 53 Oscanius Sibogae B. . . . . . . . . 55

Oscanius papuligerus B. . . . . . . 56

Oscaniella albiguttata B. . . Taf. II, Fig. 3. $5 \mathrm{~S}$

Oscaniella lugubris B. . . . . . . . 60

Oscaniella purpurea B. . . . Taf. V, Fig. 4. 61

Oscaniella purpurascens B. . . . . . . 62

Oscaniella dubia B. . . . . . . . . 63

Oscaniclla inermis B. . . . . . . . . (. . . . . .

Oscaniella modesta B. . . . . . . . . . 0 5

Pleurobranchus griseus B. . . Taf. III, Fig. S. Gi,

Pleurobranchus latipes B. . . . . . . . . (i)

Berthella Cuvieri Bgh.?. . . . . . . . is

Berthella borneensis B. . . Taf. I, Fis. 3. (x)

Berthella minor B. . . . . . . . . . -o

Berthella minor B., var. . . . . . . . . ; I

Berthella inoperta B. . . . . . . . . 73

Umbrella picta Adams. . . . . . . . . 73

\section{NUDIBRANCHIATA.}

\section{AscoglossA.}

Phyllobranchus rubicundus $\mathrm{B}$.

Phyllobranchus prasinus B.

Cyerce elegans Semper.

Cyerce sp.

Taf. II, IY... IU. Plakobranchus priapinus B. . Taf. II, Fig. 21. Plakobranchus punctulatus $\mathrm{B}$.

Elysia thysanopoda B.

Elysia ornata B.

Elysia lineolata B

Elysia haingsisiana $\mathrm{B}$.
$-$

$-5$ 
NUDIBR, HOLOHEPATICA.

(Dorididae cryptobranchiatae).

Hexabranchus marginatus (Q. et G.). Taf. I, Fig. 2. 90 Hexabranchus marginatus, var. Taf. I, Fig. I. 91 Hexabranchus marginatus, var. Taf. V, Fig. S. 91 Hexabranchus punctatus B. . . . . . . . 92 Archidoris kurana B. . . . . . . . . . 93

Aporodoris rubra B. . . . . . . . . . 94

Anisodoris Sibogae B... . litf. III, Fig. I I. yf

Anisodoris timorensis B. . . . . . . . . 97

Discodoris boholiensis B. . . Taf. I, Fig. 9. 99

Discodoris concinniformis B. . . . . . 100

Discodoris Ellioti A, et H. . . . . . . 102

Discodoris rubra B. Taf. I, Fig. 7. s. Corrigenda. 104

Discodoris? Sibogae 13. Taf. I, Fig. 8. s. Corrigenda.

Discodoris? liturata B. . . . . . . 106

Discodoris? lutescens B. . . . . . . . 107

Discodoris? versicolor B.. . Taf. IV, Fig. I. IoS

Discodoris? spec. . . . . . . . . . IIO

Carminodoris blandula B. . . . . . . III

Hoplodoris desmoparypha B., var. . . . I I3

Halla indecora 13. . . . . . . . . I16

Nirva Brockii 13. . . . . . . . . . . I I7

Diaulula? gigantea B. . . . . . . . . I I9

Diaulula? rubra B. . . . . Taf. II, Fig. 5. I 20

Thordisa tristis B. . . . . . . . . 121

Thordisa hilaris B. . . . . Taf, V, Fig 9. 122

Thordisa? maculosa B. . . . . . . . . 123

Halgerda elegans B. . . . Taf. II, Fig. 4a. 124

Halgerda elegans B., var. . Taf. II, Fig. $4 b . \quad 126$

Halgerda rubra B. . . . Taf. IV, Fig. 2. I26

Halgerda inornata B. . . . . . . . . I $2 S$

Trippa ornata B. . . . Taf. I, Fig. 6. I29

Trippa affinis B.. . . . . . . . . 131

Peltodoris rubescens B. . . Taf. III, Fig. I2. I34

Platydoris argo L. . . . . . . . . 135

Platydoris cruenta (Q. et G.). Taf. I, Fig. 3. I 36

Platydoris eurychlamys B. . . . . . 137

Platydoris flammulata B. . . Taf. I, Fig. 4. I3S

Platydoris sanguinea B. - . Taf. II, Fig. 9. 139

Asteronotus cespitosus (van H.). Taf. I, Fig. 5. I4 I

Chromodoris quadricolor (Küpp.). Taf. II, Fig. 7. 143

Chromodoris elisabethina B. Taf. IV, Fig. 3. 144

Chromodoris Annae B. . . Taf. IV, Fig. 4. 146

Chromodoris Crossei (Angas). Taf. IV, Fig. 6. 146

Chromodoris Semperi B. . Taf. 1V, Fig. 5. 147

Chromod. lineolata (van H.). Taf. IV, Fig. 7. 148

Chromod. marginata (Pease). Taf. III, Fig. I3. 150

Chromodoris flammulata B. Taf. IT, IVis. y. I; I

Chromodoris marpessa B. . Taf. IV, Fig. IO. 152

Chromodoris venusta 13 .
Chromodoris ophthalmica B. Taf. IV, Fig. 8. 153

Chromodoris nodulosa B. . . . . . . 15t

Chromodoris pantherina B. . . . . . . . 155

Chromodoris papulosa B.. . . . . . . 15il

Chromodoris Sibogae B. . . . . . . . $15 \%$

Chronodoris inopinata B. . Taf. II, Fig. 6. I5;

Chromodoris lactea B.. . . . . . . . . I5y

Chromodoris clitonota B. . Taf. V, Fig. I6. Ifo

Chromodoris bimaensis B. . Taf. V, Fig. II. Ifou

Chromodoris virgata B. . . Taf. IV, Fig. II. Iri

Casella atromarginata (C.). . Taf. II, Fig. 8. I6,

Casella atromarginata (C.), var. pallida.

Taf. IV, Fig. I2. $16^{6} 3$

Casella rubra B. . . . . . . . . . $\mathrm{I}_{3}$

Ceratosoma cornigerum Ad. Taf. IV, Fig. I7

und Tat. I, Iig. I2. I65

Ceratosoma bicorne B. . Taf. IV, Fig. I6. IriT

\section{(POROSTOMATA).}

Doriopsis nigra 13. . . . . . . . . If(ic)

Doriopsis nigra B., var. . . Taf. II, Iig. I 3. If(y)

Doriopsis nigra B., var. luteo-punctata.

Taf. II, I. is. I I I 70

Doriopsis tuberculosa (Q. et G.). . . . . . 172

Doriopsis erubescens B. . . Taf. III, Fig. 15. 1;3

Doriopsis amoena B. . . . . . . . . 17t

Doriopsis flaccida B. . . . . . . . 175

Doriopsis Weberi B. . . . . . . . . 175

Doriopsis WVeberi B., var. . . . . . . 176

Doriopsis sp. . . . . . . . . . . $17 \%$

Doriopsilla? laevis B. . . . . . . . 1,4

Phyllidia varicosa Lam. . . . . . . . IŚo

Phyllidia varicosa Lam., var. quadrilineata. . Iミ゙

Phyllidia loricata B. . . . . . . . . I\&े

Phyllidia coelestis B. . . . Taf. III, Fig. I6. 132

Phyllidiella pustulosa (Cuv.). . . . . . . $1 \$ 3$

Phyllidiella nobilis B. . . . . . . . . Ibt

Phyllidiella nobilis B., var. Taf. III, Fig. I7. 1 St $_{4}$

(Dorididae phanerobranchiatae).

Triopa longicornis B. . . . . . . . 14

Triopa tristis B. . . . . . . . . . . . [isi

Trevelyana inornata B. . . . . . . . ISS

Trevelyana rubra B. . . . . . . . 1i,

Trevelyana rubromaculata B. Taf. III, Fig. I4. 1Si,

Trevelyana rubropapulosa 13. Taf. IV, Fig. I5. IyI

Trevelyana? defensa B. . Taf. II, Fig. I2. 1y2

Nembrotha cristata B.. . . . . . . 104

Nembrotha morosa B. . . . Taf. IV, Fig. 13. 195

Nembrotha nigerrima B. . . . . . . Iy') 
Nembrotha Kubaryana B. . Taf. V, Fig. I3. 197 Nembrotha rubropapulosa B. Taf. V, Fig. 14. I98 Nembrotha lineolata B. . . Taf. II, Fig. IO. I99 Nembrotha lineolata B., var. Taf. II, Fig. II. 200 Nembrotha amitina B. . . . . . 20r Nembrotha? rubroocellata B. Taf. IV, Fig, I4. 20 I

\section{NUDIBR. KLADOHEPATICA.}

Tritonia olivacea B. . . . Taf. II, Fig. I8. 204

Tritonia irrorata B.. . . . . . . . . . 205

Marionia distincta B. . . . Taf. IV, Fig. Ig. 206

Marionia tessellata B. . . . . . . . . . 207

Pleuroleura striata (v. H.). . Taf. IV, Fig. 22. 209

Pl. gonatophora (v. H.). . . Taf. IV, Fig. 21. 210

l'leurolemra pallida l3. ... . . . . . 212

Pleuroleura suluensis B. . . . . . . . . 212

Pleurophyllidia rosea B. . Taf. V, Fig. 7. 213

Pleurophyllidia stenidia B. . Taf. II, Fig. I5. 2 I4

Phyllirese atlantica 13. . . . . . . 2 15

Scyllaea pelagica L. . . . . . . . . 216

Bornella digitata Ad. \& Reeve. Taf. IV, Fig. 20. 2 I7

Bornella excepta B. . . . . . . . . 220

Doto annuligera B. . . . . . . $22 \mathrm{I}$
Acolicliella drusilla 13. . . . . . . . . . 22,

Spurilla orientalis 13. . . . . . . . . 23

Cerberilla ambonensis 13. . Taf, V, Fig. 6. 22.

Myrrhine longicirra 13.. . . Taf. IV, Fig. 18. 22,

Cratena cucullata 13. . . . . . . . . . - $3^{\prime}$

Hervia Sibogae B. . . . . Taf. II, Fig. 17. .31

Phestilla Sibogae 13. . . . . . . . . . 132

Ennoia longicirra B. . . . . . . . . . 34

Pteraeolidia Semperi B. . Taf. II, Fig. I6. 36

Flabellina macassarana B. . Taf. V, Fig. 5. 23T

Glaucus atlanticus Forst. . . . . . . . . . 234

Melibe australis (Angas)?. . . . . . . . 23'1

Melibe papillosa de Filippi . . . . . . 40

Timorella perplexa 13. . . . . . . . . 24

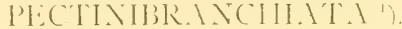

Marsenia perspicua (L.) . . . Taf. III, Fig. L․ Clielyonotus Semperi B. . . . Taf. III, Fig. แ. Scutus unguis (L.). . . . . Taf. III, Fig. 2 21. Amphiperas formosum Ad. \& Reeve. Taf. V, Fig. 2n. Amphiperas ovum L. . . . . Taf. V, Fig. 1.

1) Meine Lntersuchung dieser Pectinibranchier wird in der bald erscheinenden Arbeit ron flerrn M. M. SclrepMLA.: über die Frosolranchier der Siboga-Expedition erscheinen (s, oben p. 2). 


\section{REGISTER.}

Farbige Abbildung des lebenden Thieres.

Aclesia Rang. . . . 20

A. varicolor B. . . . . 21

A. pusilla B. . . . . $\quad 22$

Actinodoris Ehrenberg . 143

A. sponsa E. . . . . 143

Aeolidiidae . . . . . 222

A. propriae. . . . . 222

Aeolidiella B. . . . . 222

A. drusilla B. . . . . 222

Anaspidea . . . . 3-27

Anisodoris B. . . . . 06

"A. Sibogae B. . . . 9)

A. timorensis B. . . . y-

Aplysia L. . . . . 3.12

A. atromarginata B. . . S

A. Benedicti Eliot. . . (,

A. scripta B. . . . . . 4

A. Sibogae B. . . . . 9

A. vexans B. . . . . 10

A. velifer B. . . . . 12

Aplysiclla P. Fischer . . 23

A. viridis $B$. . . $\quad 25$

A. I'aniranil li. . . . 24

Aplysidal . . . . . 3-27

A. propriae. . . . 3-20

Aporodoris B. . . . . . 14

A. rubra B. . . . . 14

Archidorididae . . . . 33

Archidoris 13. . . . . 43

A. Kurana 13. . . . . 13

Artachaea . . . . . 45

Ascoglossa B. (Sacoglossa

Jher.) . . . . 75-87

Asteronotus Ehrenberg. I I 40

A. bertrana B. . . I 41

A. cespitosus (van Hasselt). I4I
Butluclla lianto. . . 68

13. Burnecontis B. . . . 69

13. Cuvieri ls. . . . 6 6s

13. inojerta 13. . . . . 73

13. minor B. . . . 70

B. minor B., var. . . 71, 72

Bornellidae . . . 2I $7-22 \mathrm{I}$

Bornella Gray . . . . $21 /$

B. arborescens Pease. . . 2IT

*B. digitata Ad. et Reeve. 21T

B. digitata A. et R., var. . 2 Iy

13. excepta B. . . . 220

Bullaea Lam. . . . . $2 S$

Bouvicria Vayss. . . . 66

Carminodoris B. . . . . I II

C. blandula B... . . . II I

Cascllar Ad.. . . . . 162

C. atromarsinata (Cuv.). . 162

C. atromarginata (C.), var. pallida. . . . . 162

(․ rubra 13. . . . . . 163

Cephalaspidea . . . 28-93

Ceratosoma Ad. et Reeve. ${ }^{164}$

C. bicorne B. . . . . I $\sigma_{T}$

('. cornigerum Ad. . . . I(i)

C. cornigerum Ad., var. - 166

Cerburilla B. . . . 224

c. ambenencis li. . . . 225

Cheliclomurat Ael. . . . 42

(.) amoenat li. . . . . 45

C. velutina. . . . . . 43

Chromodorididae . I I $42-162$

Chromodoris A. et H. . . I43

C. Annae B. . . I43, I44

C. Innate B.. vir. . . If
Chromodoris bimaensis $B, 160$

C. clitonota B. . . . 160

C. Crossei (Angas) . . I I $4^{6}$

C. elisabethina B. . . . I $4 \hat{3}$

C. elisabethina B., var. . I $4+t$

C. flammulata B. . . . I I I

C. funerea Collingwood. . IfS

C. inopinata B. . . . I5T

C. lactea B. . . . . 154

C. lineolata (van Hass.). . 148

C. marginata Pease . . 150

${ }^{\circ}$ C. marpessa B. . . . I52

C. nodulosa B. . . . 154

C. ophthalmica B. . . . 153

C. pantherina B. . . . 153

C. papulosa B. . . . . 153

C. quadricolor (Rüppell) . 143

C. Sibogae B. . . . . . 157

C. Sumperi B. . . . . It

C. sponsa (Elirenberg) . . I 43

C. striatella B.. . . . I 4 is

C. venustal B. . . . . 153

C. virgata B. . . . . $16 \mathrm{I}$

Cleanthus Leach . . . CS

Cratenidae B. . . . . 220

Cratena B. . . . . . 230

C. cucullata B. . . . 230

Cryptophthalmus Ehrenberg. 39

C. olivaceus E. . . . . 39

C. olivaceus E., var. pallida. $4 \mathrm{I}$

Cyerce B. . . . . . 76

C. elegans (Semper) . . . Tu

C. s1)... . . So

Diaulula B. . . . . I Is

D. gigantea B. . . . I I 9 
"Diaulula rubra B.

Diaululidae. . I I 8 - 121

Dictyodoris 13. . . . 124

Discodorididae. . 98- Is

1)iscolurie B. . . . . . . . . . .

I). Buhulensiv 13. . . y y)

D. concinniformis 13 . . 100

I). Ellinti (.1. ct II.). . . 102

D. Ellioti (A. et H.), var. . $\mathrm{IO}_{3}$

D.? liturata B. . . . 106

D.? liturata B., var. . . 107

D.? lutescens B. . . . . 107

D. rubra B. (s. Corrigenda). I04

D.? Sibogae B. (s. Corrigenda).

1). : Siburac 13., var. . . 107

"D. ? versicolor B. . . . 108

D. sp. . . . . . 110

Dolabella Lam. . . . . $I_{3}$

D. Hasseltii Fér. . . . Is

D. Rumphii Cuv., Rang. - 13

D. Rumpliii C., var. maculosa (Hasseltii) . . . Is

D. Teremidi Rang. . . . IS

Dolabrifera Gray . . . . 23

Dorididae cryptobran-

chiatae. . . S $8-184$

D. phanerobranchiatae. I $85-202$

Doridiiclae . . . . 42-46

Doriopsididae . . I69-ISo

Doriopsilla B. . . . . I 78

D. laevis B. . . . 178

Doriopsis Pease . . . 160

D. amoena B. . . . . I74

D. crubuscens 13. . . . $1-3$

I) flaccida 13. . . . 1,5

D. nigra Stimpson - . 169

D. nigra St. var. . . . I69

D. nigra St., var. luteopunctata . . . . . I7O

D. tuberculosa (Q. et G.) . I72

I). II cberi B. . . . . 1, 15

D. Weberi B., var. nigra . I 76

D. sp........ . 177

D. sp. . . . . . 177

Dotonidae . . . $22 \mathrm{I}-222$

Doto Ok. . . . . $22 \mathrm{I}$

D. annuligera B. . . . $22 \mathrm{I}$

Elysiidae.

$8_{3}$

Elysia Risso. . . . . $\mathrm{S}_{4}$

E. Haingsisiana B. . . . 87

E. lineolata B. . . 85,86

E. ornata (Pease). . . $\$_{4}$
E. thysanopoda B.

Ennoia 13.

E. longicirrha $B$. .

Epinotidia (papillae L.; cerata) .

Flabellinidac

Flabellina Cuv.

F. macassarana $B$.

Gastropteridae.

Gastropteron Kosse .

G. Sibogae B. .

G. Sibogae B. var. nigra. 32

Glaucidae

Glaucus Forster

G. atlanticus F.

Halgerda $B$.

I1. clesurns 13 .

H. elegans 13., var.

$\mathrm{H}$. inornata $\mathrm{B}$.

H. rubra I?.

Ilallar B.

H. indecora B.

Hervia B.

H. Sibogae B. .

Hexabranchidae

Hexabranchus Ehrenberg. .

H. lacer Cuv.

H. marginatus Q. et G.

H. marginatus Q. et $G$., var.

H. marginatus Q. et G., var.

H. punctatus B.

Hirundella Gray

Hoplodoris $B$.

H. desmoparypha B.

Lobaria O. Fr. Miiller .

Marionia Vayss. .

M. distincta B.

M. tessellata B.

Melibe Rang

II. australis (Angas)

II. papillosa (de Filippi)

Myrrhinidae $B$.

Myrrhine B.

M. longicirrha B.

Navarchus Cooper

Neda Ad.

Nembrotha B.
N. amitina 13 .

Nembrotha cristata 13. . . 104

N. Kubaryana B. . . . . 197

N. lineolata B. . . . . 199

N. lineolata 13., var. . . 200

N. morosa B. . . . . I95

N. nigerrima B. . . . . 195

N. rubroocellata B. . . $20 \mathrm{I}$

N. rubropapulosa B. . 198

Nirva B. . . . . . . I I7

N. Brockii B. . . . I I 7

Notarchidae. . . . 20-27

Notaspidea . . . . 47-74

Nudibranchiata. . . $88-24$ I

N. holohepatica . . 8S-202

N. kladohepatica . 203-24I

Ophthalmidae B. . . 35-42

Uscaniella B. . . . . 58

O. albiguttata B. . . . 5

O. dubia B. . . . . . 63

O. inermis B. . . . 64

O. lugubris B. . . . . 60

O. modesta B. . . . . 65

O. purpurascens B. . . . 62

O. purpurea B. . . . 6I

Oscaniopsis B. . . . . 49

O. Amboinei Vayss. . 50

O. luniceps (Cuv.). . . . 50

Oscanius Leach . . . 50

O. papuligerus B. . . 56

O. Perrieri Vayss. . . 54

O. Semonis B.... . 62

O. Sibogae 13. . . . . 55

O. Weberi B. . . . . 53

O. Weberi B., var. . . 54

Peltodoris B. . . . . I 33

$\therefore$ | $\mathrm{P}$. rubescens B. . . . 134

Phanerophthalmus Ad. . $\quad 36$

P. luteus (Q. et G.) . . . $\quad 36$

P. pauper B. . . . . 37

Phestilla B. . . . . . 233

P. Sibogae B. . . . . 232

Philine Ascan... . . . 28

P. elegans B. . . . . 31

P. quadripartita Asc. . . 28

P. quadripartita Asc, var. 29

P. rubra B. . . . . . 29

Philinidae . . . . 28

Phlegmodoris B. . . . . I2S

io Phyllaplysia P. Fischer. . 26

lut P. inornata B. . . . . 27 


\begin{tabular}{|c|c|c|c|c|c|c|c|c|}
\hline a & & 180 & P. sanguinea $B$. & $\begin{array}{l}\text { Seite. } \\
\text { I } 39\end{array}$ & hiata & & & \\
\hline tis $B$. & & $\mathrm{I}_{32}$ & nchaea Leue & 47 & & & & \\
\hline ta B. . . . & & 18 & P. morula B. . . & $4^{8}$ & melibidae. & & & \\
\hline cosa Lam. . & & is & Pleurobranchidae. & $46-73$ & Thimna B. . & & & \\
\hline icosa Lam., var. & & It & Pleurobranchus Cuv. & 66 & Thordisa B.. & 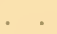 & & \\
\hline cosa Lam., var. & qua- & & P. griseus $B$. . & 6 & ris $\mathrm{B}$. & 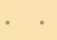 & & \\
\hline .. & & IS I & P. latipes $\mathrm{B}$. & 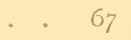 & ulosa $\mathrm{B}$. & . & & \\
\hline B. & & & P. Peronii von Martens. & s. . & B. & . & & \\
\hline$x^{2}$ & & & yss. & . & B. . & • & & \\
\hline var. & & & & $20 S-21$ & sa B. . & . & & \\
\hline Cuv.) & & & $\cdots \cdot$ & . 20 & Kelaar & rt . & & \\
\hline & & $-1 \varepsilon$ & ra (van Has & ass.). 210 & B. . . & . . & & \\
\hline et Les. & & & & $2 \mathrm{I}$ & B. . & . . & & \\
\hline & & 215 & n Hass.) & 209 & .. . . & . . & & \\
\hline ouleyet & & 215 & (1) Hass.), & var. $2 \mathrm{I}$ & lata & B. & & \\
\hline & & & & & osa & B. . & & \\
\hline & & 76 & ia Meckel & . & on. & . & & \\
\hline 1. et I & H. & 7 & 1 & 21 & S. B. . & . & & \\
\hline . & & 77 & & 21 & . . : : & : & & \\
\hline & & 7 & :lla Eliot & 20 & . . & . & & \\
\hline & & $8 c$ & lae. . & $213-21$ & B. & & & \\
\hline an Has & & $\mathrm{S}_{1}$ & 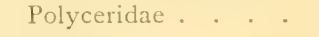 & $185-202$ & B. . & . . & & \\
\hline & . & Si & . . & I $68-$ I 84 & Cuv. . . & . . & & \\
\hline as $\mathrm{B}$. . & . & 82 & $\mathrm{~B}$. & . . 236 & ta B. . & . & & \\
\hline & 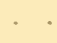 & 82 & P. Semperi B. . & . . 236 & a B. . & . & & \\
\hline . & . & I 35 & & & & & & \\
\hline 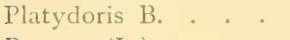 & . & I 35 & & $215-216$ & & & & \\
\hline 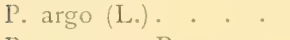 & . & I $3:$ & & & & & & \\
\hline 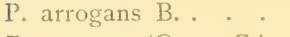 & . & I 36 & L $\mathrm{L}$ & . & & & & \\
\hline G.) & . & I 36 & & 223 & Hlidae. . & & & \\
\hline eurychlamys 13 . & & 1 & $\begin{array}{l}\text { S. orientalis B. } \\
\text { Susania Gr. }\end{array}$ & & & & & \\
\hline fammulata & & & श्रanda Gi. & & & & & \\
\hline
\end{tabular}

\section{CORRIGENDA.}

Seite So statt: Taf. II, Fig. 17, lese man: Fig. 19.

Seite 104 Discodoris? Sibogae Bgh. ist Discodoris rubra Bgh.; zu dieser Art gehört Taf. I,

Fig. 7; Taf. XIV, Fig. I I-I 4 .

Discodoris Sibogae ist nur durch Fig. 8 auf Taf. I bekannt.

Seite 107 statt: Disc. lutesceus, lese man: lutescens.

Seite I66 statt: Taf. IV, Fig. I6, lese man: Fig. I7.

Seite 236 statt: Taf. I, Fig. I6, lese man: Taf. II. 
TAFELN 


\section{TAFEL I.}

Fis. I. Hexabranchus marginatus ((). et G.), var.

Fis. 2. Hexabranchus marginatns (Q. et G.).

Fin. 3. Platydoris cmenta (Q. et G.).

Fis. +. Platydoris flammlata Bgh.

Fig. 5. Asteronotus cespitosus (van Hass.).

Iiv. 6. Trippa ornata Bgh.

Fig. 7. Discodoris rubra Bgh.

Fig. S. Discodoris? Sibogae Bgh.

Fig. 9. Discodoris bolnoliensis Bgh. 


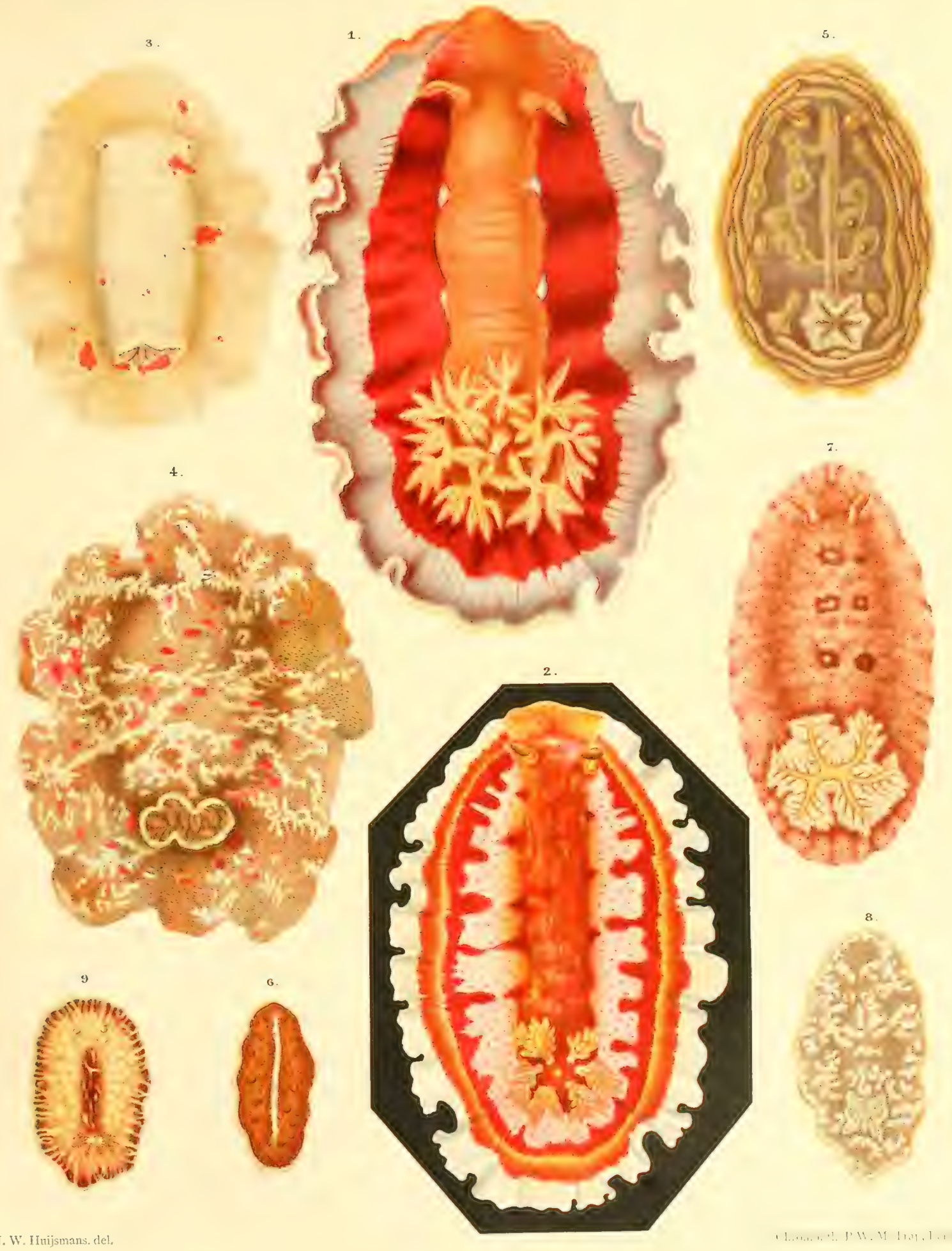






\section{TAFEL II.}

Iis. I. Oscanius Weberi Bgh.

ling. 2. Oscanius sp. 1).

lig. 3. Oscaniella albignttata Bgh.

lis. 4a. Halgerda elegans Bgh.

Iii... 4b. Halgerda elegans Bgh., var.

Iis. 5. Diaulula? Mora Bgh.

liv. 6. Chromodoris inojinata Bgh.

$\mathrm{Iin.}$ 7. Chromodoris elisabetluina Bgh.

Iris. S. Casella atromarginata (Cuv.).

Iis. 9. Platydoris sanguinea Bgh.

I. is. ro. Nembrotha lineolata Bgh.

Iig. II. Nembrotha lineolata Bgh., var.

Iis. I2. Trevelyana? defensa Bgh.

Iis. I3. Doriopsis nigra Stimpson, var. ${ }^{2 / 1}$.

Fin. I4. Doriopsis nigra Stimpson, var. Inteo-punctata.

Fis. I5. Plenrophyllidia stenidia Bgh. ${ }^{2} / 1$.

Fis. I6. Pteraeolidia Semperi Bgh.

Iis. I7. Hervia Sibogat Bgh. ${ }^{2 / 1}$.

IVis. I8. Tritonia olivacea Bgh.

I.ik. I9. Papilla (dorsalis) e Cyerce sp. $3 / 1$.

I i... 20. Ely'sia ornata (Pease), Bgh.

I:is. 2I. Plakobranchus priapinus Bgh.

I) Origiualexemplar so wie Notizen zu dieser Thierform fehlen. 

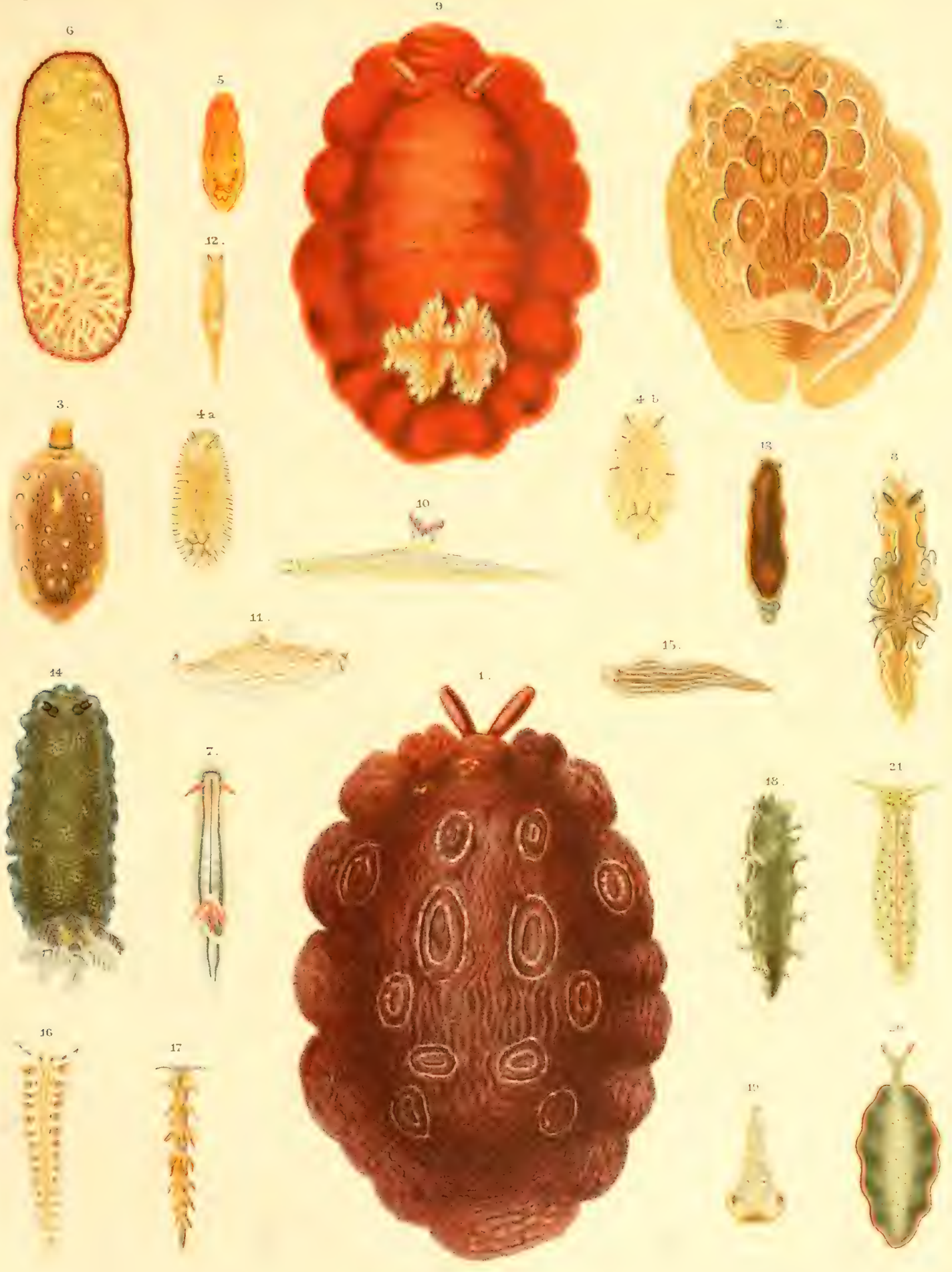




\section{TAFEL III.}

Fig. I. Dolabella Rumphii Cuv., Rang, var. maculosa. '1/.

Fig. 2. Aclesia arricolor B.

Fig. 3. Aplysiclla viridis B.

Fig. 4. Cryptophthalmus olivaceus E., var. pallida.

Fig. 5. Chelidonura velutina B.

Fig. 6. Chelidonura velutina B.

Fig. 7. Chelidonura amoena B.

Fig. S. Pleurobranchus griseus B.

Fig. 9. Oscaniopsis luniceps (Cuv.).

Fig. 10. Elysia? lincolata B. ${ }^{2} / 1$.

I. I I. Anisodoris Sibogae B.

Fin. 12. Peltodoris mbescens B.

Fig. 1 3. Clwomodoris marginata (Pease). "/1.

Fig. 14. Trevelyana rubromaculata B.

Fig. I5. Doriopsis erubescens B. 2/1.

Fig. 16. Playllidia coclestis B.

$\mathrm{Jij}$ 17. Pligllidiella nobilis $\mathrm{B}$.

Fig. IS. Marsenia perspicua (L.).

Fig. 19. Chelyonotus Semperi B.

Fig. 20. Scutus muguis (L.). 

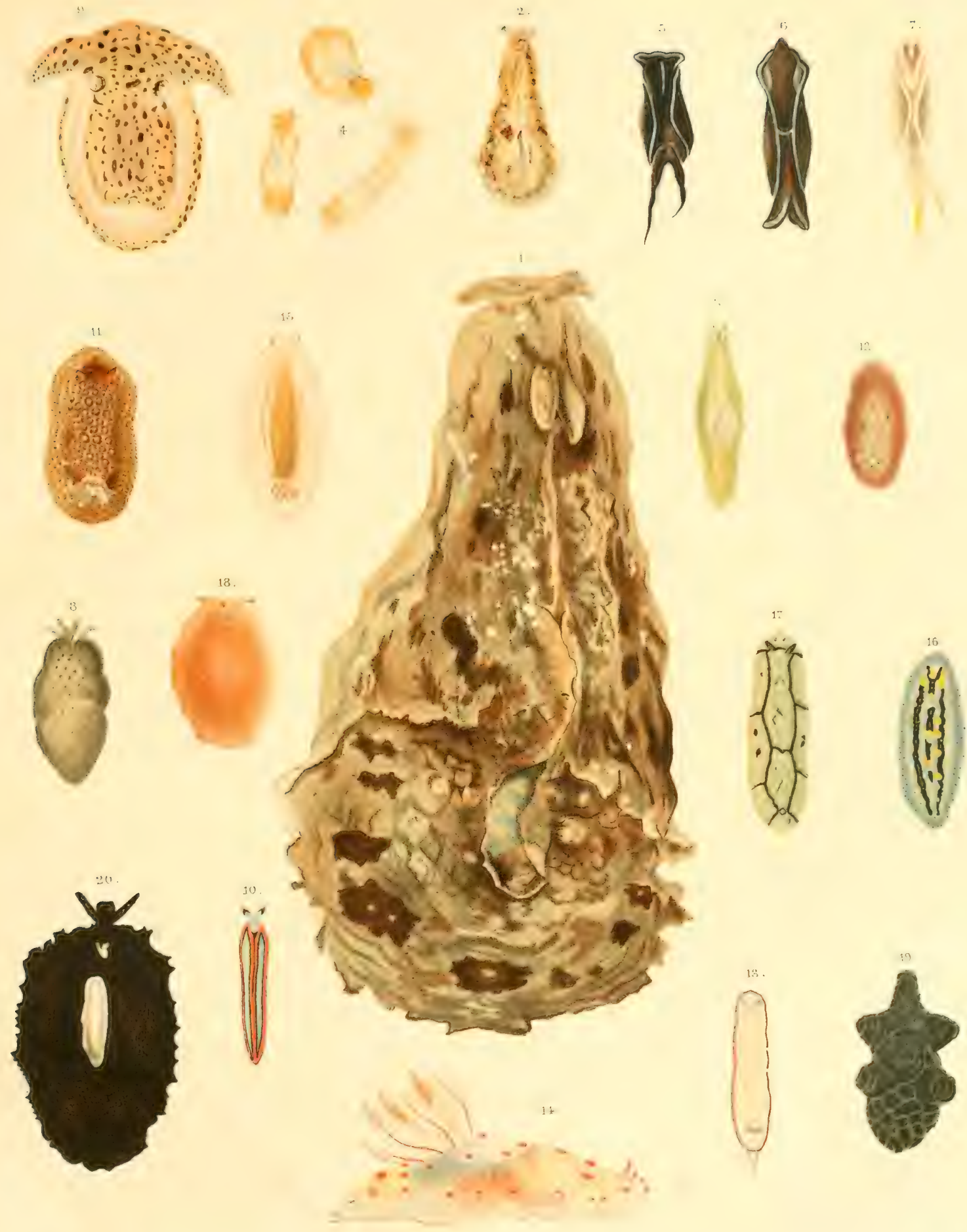

J. W. Huijsmans del. 




\section{'TAFEL IV.}

Fig. I. Discodoris?? a'ersicolor B.

Fig. 2. Halserda rubra B.

Fig. 3. Chromodoris elisahethina B., var. (Clur. Annae B.).

Fig. +. Cleromodoris Annae B.

Fig. 5. Clromodoris Semperi B., var.

Fig. 6. Chromodoris Crossei (Angas). $2 / 1$.

Fig. F. Chromodoris lineolata (van Hass.).

Fig. $\therefore$. Chromodoris ophthalmica B. $2 / 1$.

Fig. 9. Chromodoris flammulata B. ${ }^{2} / 1$.

Fig. 10. Cluromodoris marpessa B. ${ }^{2 / 1}$.

Fig. I I. Chromodoris virgata B. ${ }^{4 / 1}$.

Fig. I2. Casella atromarginata (Cuv.), var. pallida.

Fig. 13. Nembrotha morosa B.

Fig. 14. Nembrotha? mbroocellata B. $3 / 1$.

Fig. 15. Trevelyana mbropapulosa B.

Fig. Ír. Ceratosoma bicorne B.

Fig. 1-. Ceratosoma conigerum Ad, var.

Fig. IS. Myrrline longicirre B. 1/1.

Fig. 19. Marionia distincta B.

Fig. 20. Bornella digitata Ad. et Reeve. ${ }^{2}{ }_{1}$.

1.i.. 21. Plenroleura gonatophora (van Hass.).

Fig. 22. Plenroleura striata (van Hass.). ${ }^{2} / 1$. 

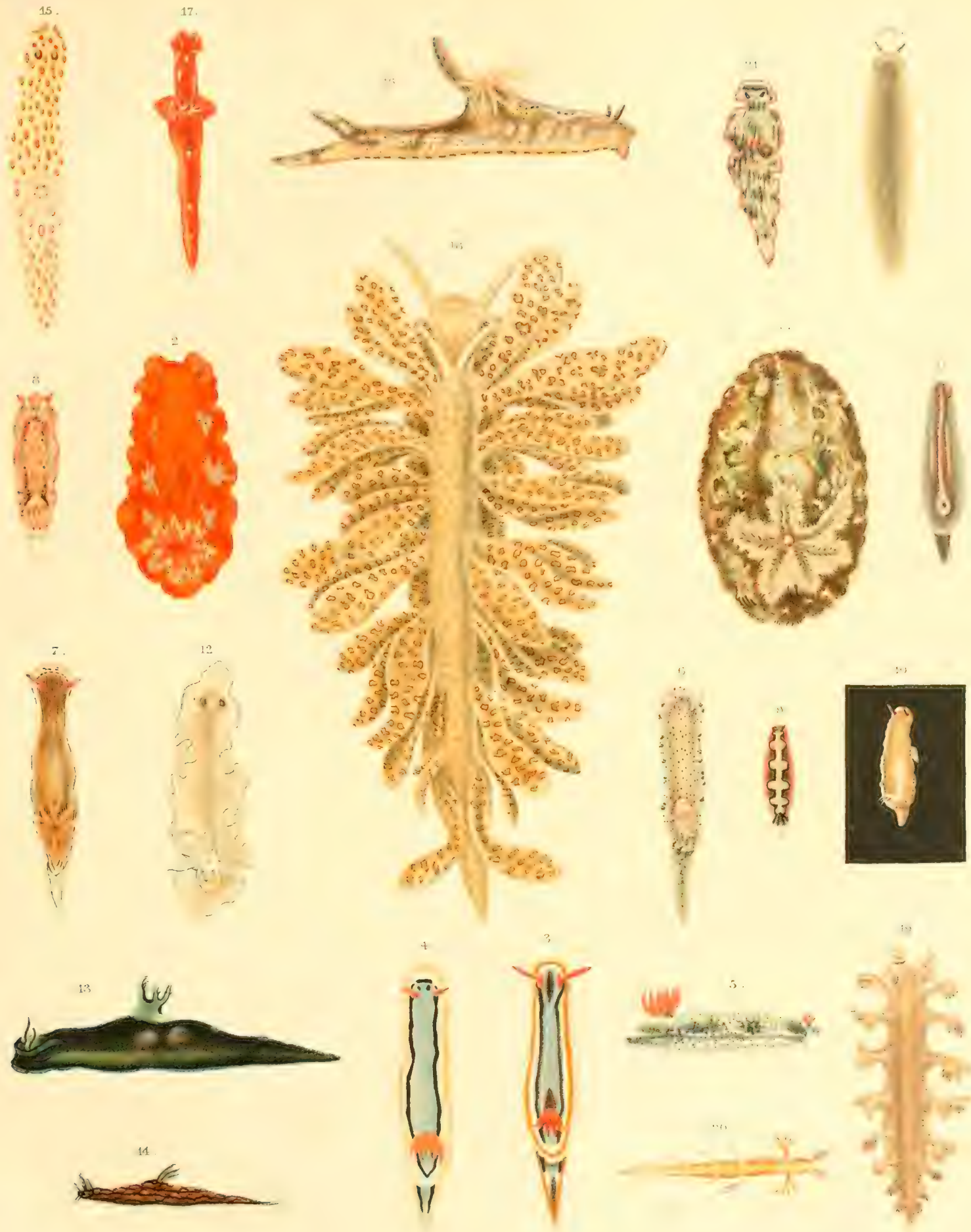

J. IV. Huijsmans, del. 




\section{TAFEL V.}

Iis. I. Aplysiella Pasirana B.

Fis. 2. Aplysia velifer B.

Fin. 3. Berthella borneensis B.

Fin. 4. Oscaniella purpurea B.

Fis. 5. Flabellina macassarana B.

Fir. (). Cerberilla ambonensis B.

Fin. 7. Plenrophyllidia rosea B.

Iiv. \&. Hexabranchus marginatus (Q. et G.), var.

Fis. 9. Thordisa hilaris $\mathrm{B}$.

Fin. I0. Doriopsis?

Fig. I I. Chromodoris bimaensis B. 2

Fiv. I2. Ceratosona cornigemun Ad.

Fig. 13. Nembrotha Kubaryana B.

Fig. I . Nembrotha rubropapulosa B.

Fig. I5. Trevelyana? 2

Fig. I6. Chromadoris clitonota B.?

Fig. 17. Elysia sp.

Fig. Is.

Fig. 19. Doriopsis?

Fig. 20. Ampliperas formosum Ad. et Reeve. 2 .

Fig. 21. Ampluiperas oonm L. jun. 2. 

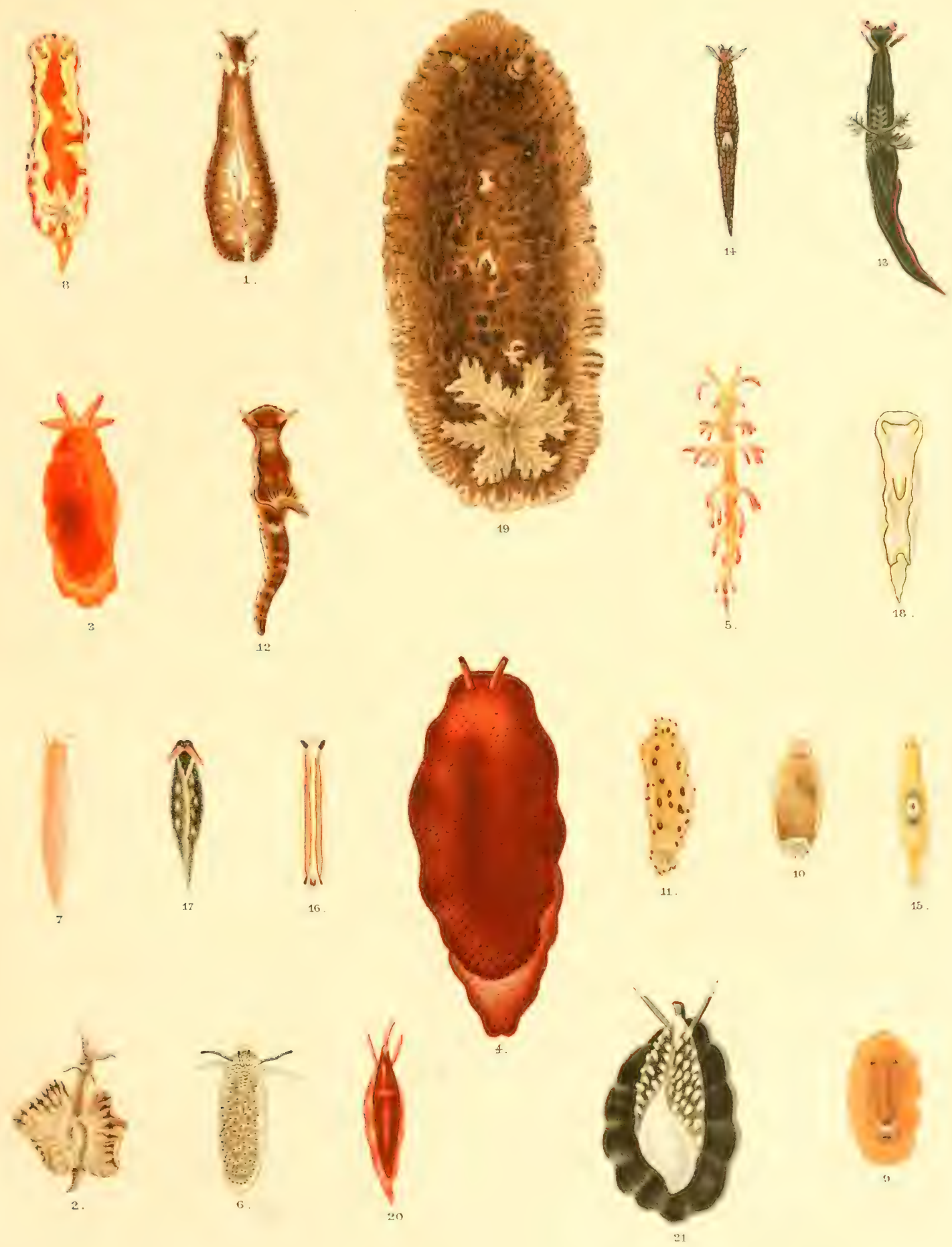




\section{TAFEL TI.}

Dic mikroskopische Zeichnungen dieser und aller folgenden Tafeln sind mit einem SMITI BECKBECK'schen Instrumente bei angegebenen Vergrösserungen gemacht.

$$
\text { Aplysia scrifte } \mathrm{B} \text {. }
$$

Ii.s. I. Zeichnung der Rückenseite.

Fis. 2. Mantelschild, $a$ Sipho.

Fin. 3. Schale, von oben. $1 / 1$.

Iii.. 4. Hinterende derselben, von unten.

Fis. 5. Elemente der Mandibelplatten. 350 .

liv. 6. Mediane Platte.

I.i.. 7. Thnliche eines anderen Individuums.

IVis. S. Zweite Seitenzahnplatte zweier Reihen, von oben.

lis. 9. Ähnliche von der Seite.

Iis. IO. Eine der grössten Seitenplatten.

Iis. II. Aussenende einer Zahnplattenreihe, $a$ äusserste Platte.

Fig. 6-II mit Cam. gezeichnet. 200 .

Fig. 12. a Speiseröhre, b Vormagen, c Kaumagen, d Hintermagen.

I.is. I3. Kleine Platten an der Cardia des Kaumagens.

1:i.. I4. Grundfläche zweier Kauzähne.

I is. [5. Viscerale Ganglien, a Connective. 55.

I\%i... I6. Penis, a Retractoren.

\section{Aplysia Benedicti Eliot.}

Iis. IT. Die Schale, von der Unterseite. $2 / 1$.

I.j. IS. Stiick des Gaumens.

I.... I.. Elemente der Mandibelplatten.

Fig. 2i. Mediane Platte.

$\mathrm{Ii}_{\text {. }}$ 2I. Erste Seitenzahnplatte.

Fig. 22. Seitenzahnplatte, vom Hinterende.

I is. 23. Seitenzahmplatten, von der Seite.

$\mathrm{Fi}$. 24. Aussenende einer Zahnplattenreihe, $a$ äusserste Platte.

Iivg. I $8-24$ mit Cam. gezeichnet. 350
Fig. 25. Kauplatten des Magens.

Fig. 26. Andere.

Aplysia Bencdicti E., var.

Fig. 27. Mediane Platte.

Fig. 28. Stuick des Gaumens.

Fig. 29. Von der Mandibelplatte.

Fig. 27-29 mit Cam. gezeichnet. $350 \times$.

Aplysia atromarginata $\mathrm{B}$.

Fis. 30. Die Schale, von der oberen Seite. $3 / 1$.

Fis. 31. Nuclealpartie, von der Seite.

Fis. 32. Elemente der Mandibelplatte.

Fis. 33. Mediane und erste Seitenzahnplatte.

Iig. 34. Aussenende einer Zahnplattenreihe, $a$ äusserste Platte:

Fig. $32-34$ mit Cam. Iuc. gezeichnet. $350 \times$. Fig. 35. Penis.

\section{Aplysia Sibogac B.}

I.i... 36. Die Schale, von oben. 1/1.

Fis. 37. Hinterende der Schale, von unten.

I. ig. 3S. Mandibelplatte.

Iis. 39. Elemente derselben.

Iig. 40. Mediane Zahnplatte, von der Zunge.

Fig. 39-40 mit Cam. gezeichnet. 350 .

Iis. 4I. Stuck der rhachidialen Partie der Raspel mit der innersten Seitenzahnplatte.

Fig. 42. Zwölfte und dreizehnte Seitenzahnplatte, von der Seite.

Fig. 4I-42 mit Cam. gezeichnet. $200 \times$. 

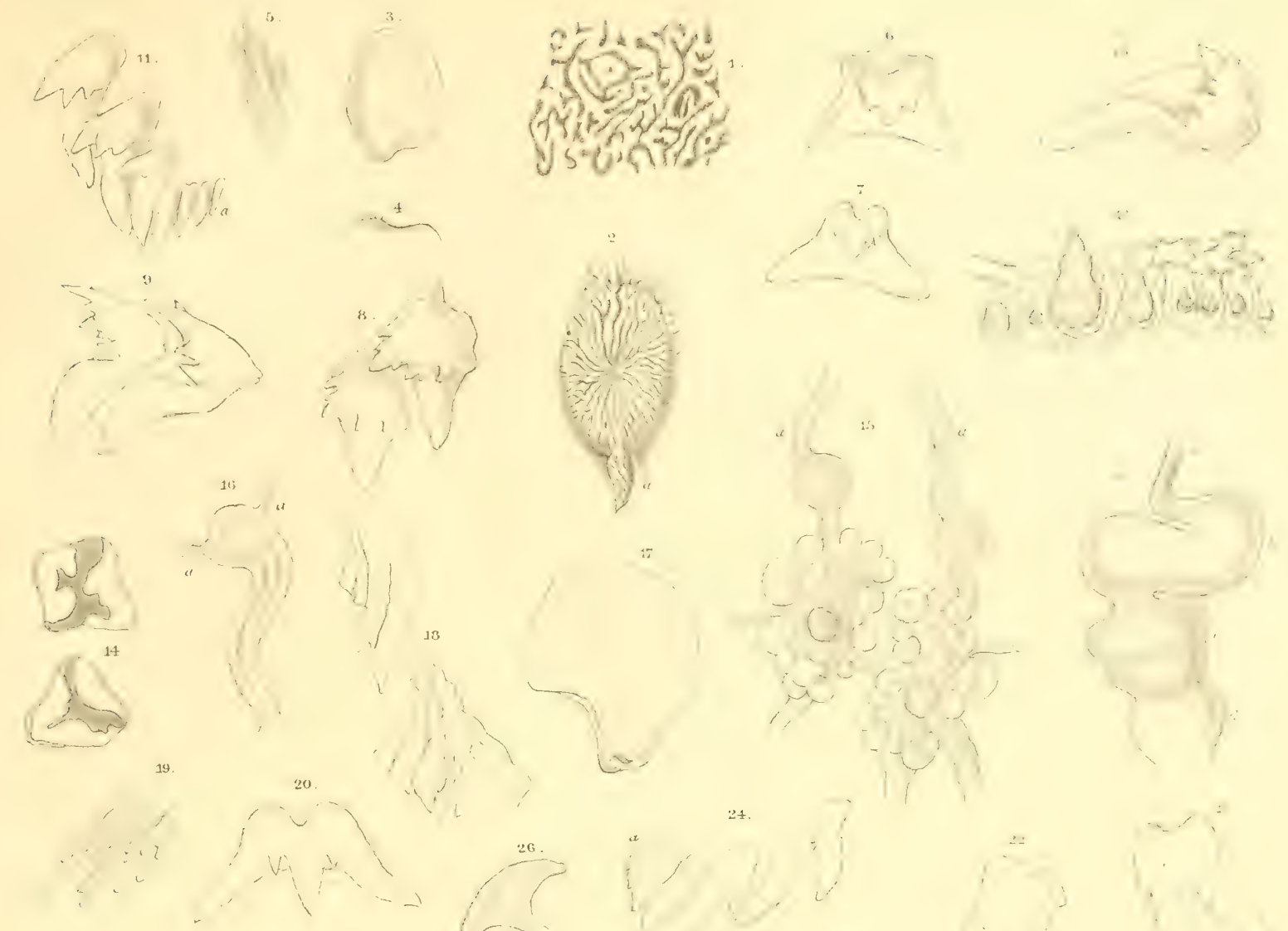

25
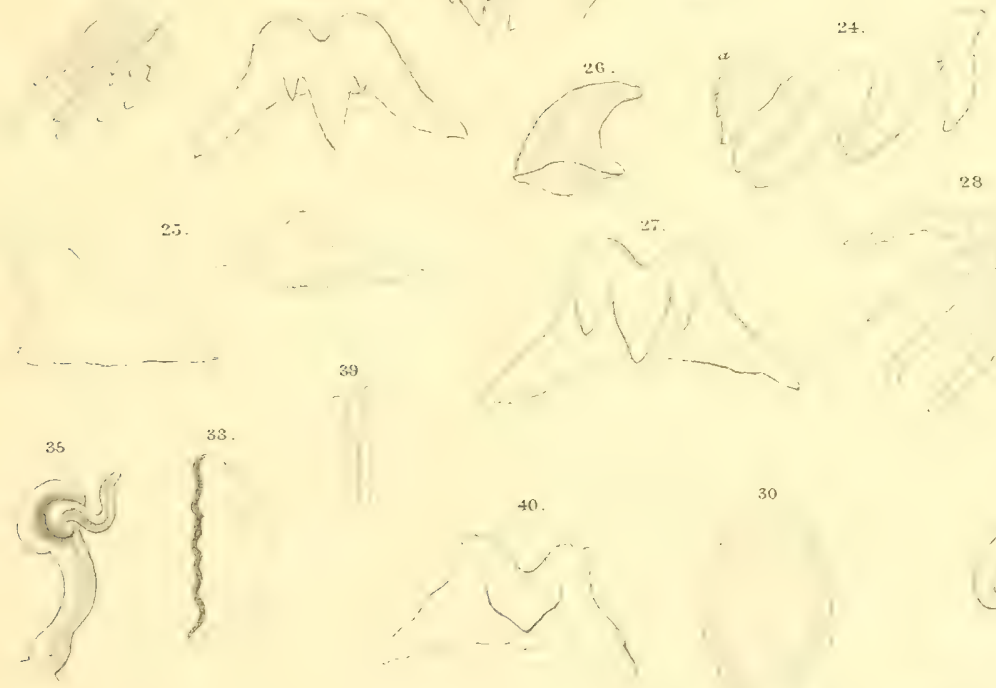

39
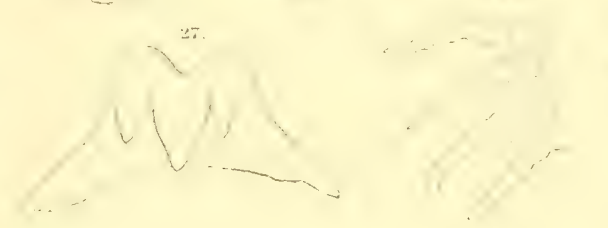




\section{TAFEL VII.}

\section{Aplysia Sibogac B.}

I:ig. I. Mediane Zahnplatte.

[iin. 2. Aussenende einer Zahmplattenreihe, $a$ äusserste Platte.

Fig. I-2 mit Cam. gezeiclnet. $350 \%$.

Fis. 3. Zahnplatte aus der Mitte einer Reihe, von der Seite.

Fin. 4. Die grosse (vordere) Genitalmasse, $a$ Samenleiter, b Schleim-Eiweissdrüse, c Spermoviduct, $d$ Samenblase.

Iis. 5. Penissack, a Retractor.

Fin. 6. Glans penis.

\section{Aplysia vexans $\mathrm{B}$.}

Fin. 7. Die Schale von oben.

live S. Mandibel.

Ii $\because$ 9. Elemente derselben. $350 \times$.

Iin. Io. Mediane Zahnplatte.

Iis. I I. Aus der Mitte der Reihe.

Iis. I2. Aussenende einer Zahnplattenreihe, $a$ ausserste Platte.

Fig. IO-I 2 mit Cam. gezeichnet. $200 \%$

Iis. 13. Gallenblase.

\section{Aply'sia velifer $\mathrm{B}$.}

I.... I4. Von der Rückenhaut.

IFin. I5. Mantel mit Loch und Sipho.

Iin. I6. Die Schale von oben. ${ }^{4} / 1$.

Fis. I7. Elemente der Mandibel.

Iis. IS. Gaumendornen.

I'ï. 19. Mediane Zahnplatte.
Fig. 20. Aus der rhachidialen Partie der Raspel. 200

Fig. 2I. Aussenende einer Zahnplattenreihe, $a$ äusserste Platte.

Fig. 17-21 mit Cam. gezeichnet. $350 \times$.

\section{Dolabella Rumplizi Cuv.}

Fig. 22. Spiclen aus der Hülle des Centralnervensystems. 200

Fig. 23. Mandibel. ${ }^{ \pm} / 1$.

Fig. 24. Ahnliche eines Individuums von Ceylon.

Fig. 25. Elemente der Mandibel. 350 .

Fig. 26. Gaumenplatten. 2/1.

Fig. 27. Gaumendorn.

Fig. 28. Zahnplatte vom ersten Drittel der Reihe.

Fig. 29. Ahnliche vom äusseren Drittel der Reihe.

Fig. 30. Spitze dreier Zahnplatten, von hinten gesehen.

Fig. 27-30 mit Cam. gezeichnet. 350 .

Fig. 31. Von der Wand der Speiseröhre. 55 .

Fig. 32. Zwei Magenplatten. $\% / 1$.

Fig. 33. Von der IVand des Hintermagens.

Fig. 34. Das Genitalsystem, von der rechten Seite. $a$ Zwitterdruse, $b$ Zwitterdrüsengang, c Schleim-Eiweissdruse, Blindsach derselben, $d$ Spermoviduct, $c$ Samenblase.

Fig. 35. Die Schleim-Eiweissdrüe, von der linken Seite; $c, d$ wie oben, ebenso * die Fortsetzung des Schleim-Eiweissdrüse.

Fig. 36. Querschnitt des Spermoviducts.

Fig. 37. Ähnlicher.

Fig. 38. Penissack, a Retractor, $b$ Protractor.

Fig. 39. Glans.

Fig. 40. Andere. 

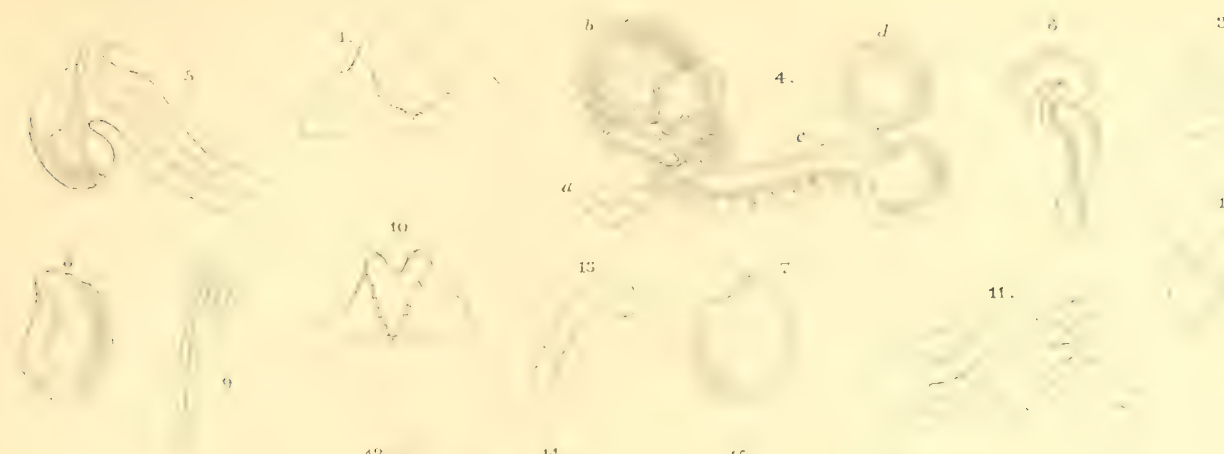

12

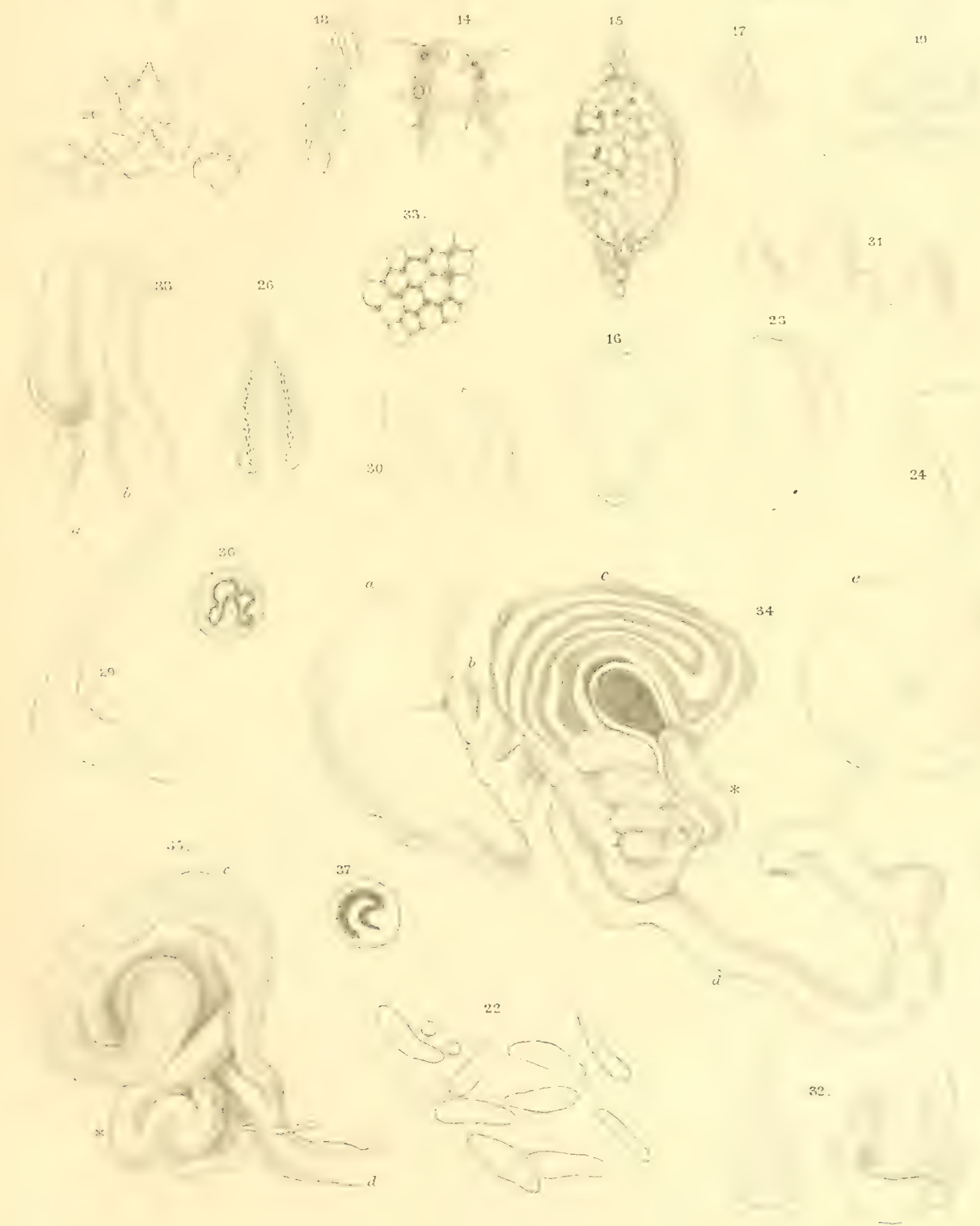

R. Bergh, del.
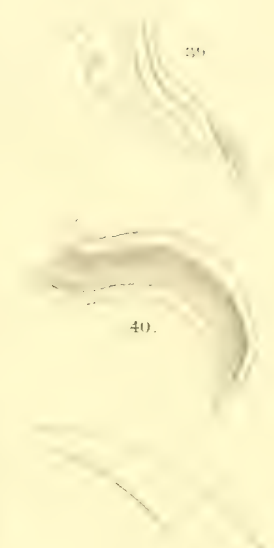

28 




\section{TAFEL VIII.}

Dolabella Kumpliii Cuv, Rang.

Iis. I. Mantel mit Sipho und Anus, schräge von der. Seite.

I i... 2. Nervensystem, a cerebrale Ganglien, bb pleuro-pedale, $c$ buccale, $d$ viscerale.

lï.. 3. Stück der rhachidialen Partie der Raspel. 200

Ii.: 4. Mediane Platte.

Ii.r. - Ausserste Platten, von hinten gesehen. lïig. 4-5 mit Cam. gezeichnet. 350 .

Fin. 6. a Hintermagen, b Darm, c Gallenblase.

lis. 7 a Stuck der Leber mit dem freien Theil der Gallenblase, $b$ Darmschlinge.

\section{Rumplizi, var. maculosa.}

Fis. S. Mandibel.

Fis. 9. Mediane Zahnplatte. 350 .

Aclesia varicolor. $\mathrm{B}$.

Fis. IO. Stück der Gaumenplatte.

Iiv. I 1. Von der Rhachispartie der Raspel, mediane und erste Seitenplatte.

Iis. I2. Ähnliche Partie.

Iis. I3. Seitenplatte.

Fis. 14. Ausserste Seitenplatte.

Fis. 15. Dornartige Kegel der glans penis.

Fis. 10-I 5 mit Cam. gezeichnet. $350 \%$.

\section{Aclesia pusilla $\mathrm{B}$.}

I.i.. I6. Das Thier, von der Rückenseite.

[i. I7. Nervensystem. $a$ cerebrale Ganglien, $b$ pleurale, zwischen denselben die visceralen, $c$ pedale Ganglien. Ioo

Fis. Is. Stück der Nandibelplatte.

1i.i. 19. Gaumendornen.

I.ig. 20. Mediane Zahnplatten.

lig. 2r. Mediane und erste Seitenplatte.
Fir.s. 22. Seitemplatte aus der Mitte einer Reihe.

Fis. 23. Ännliche, in anderer Stellung.

Fis. 24. Vom äusseren Theil einer Reihe.

Iiv. 25. Aussenende einer Zahnplattenreihe.

Fig. I $8-25$ mit Cam. gezeichnet. 350

Fis. 26. Ausserste Platte bei stärkerer Vergrösserung.

Fis. 27. Penis mit durchschimmernder Glans, I00 X.

$$
\text { Aplysiella viridis } \mathrm{B} \text {. }
$$

Fì. 28. Bäumchen des Rückens.

Fis. 29. Elemente der Mandibel.

Fig. 30. Mediane und erste Seitenplatte.

Fig. 31. Innere Seitenplatten, von hinten.

Fis. 32. Zahnplatten, vom äusseren Drittel der Reihe.

Fig. 33. Ähnliche.

Fig. 34. Aussenende einer Zahnplattenreihe, $a$ äus serste Platte.

Fig. 29-34 mit Cam. gezeichnet. 350 .

Fis. 35. Aussenplatte stärker vergrössert.

Fig. 36, 37. Haken abnormer Seitenplatten.

$$
\text { Aplysiella Pasirana B. }
$$

Fis. 38 . Schale, von oben. $4 / 1$.

Fig. 39. Hinterende derselben, von der Unterseite. Fig. 40. Nervensystem. $a$ cerebrale Ganglien, $b b$ pleurale, zwischen denselben die visceralen, cc pedale Ganglien.

Fis. 4I. Gaumendornen.

Fi... 42. Aus den Mandibelplatten.

Iig. 43. Stuick der Rhachispartie mit medianen und ersten Seitenplatten.

I. in. 44. Eine der inneren Seitenplatten.

I.ig. 45. Eine der grössten Seitenplatten, von der Hinterseite.

Iig. 46. Aussenende einer Zahnplattenreihe, $a$ äusserste Platte.

I.ig. 47. Dornen der Glans penis.

Fig. 41-47 mit Cam, gezeichnet. 350 . 


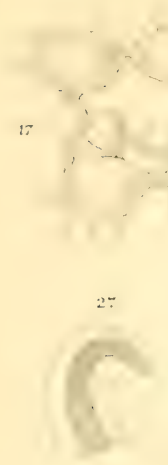

24
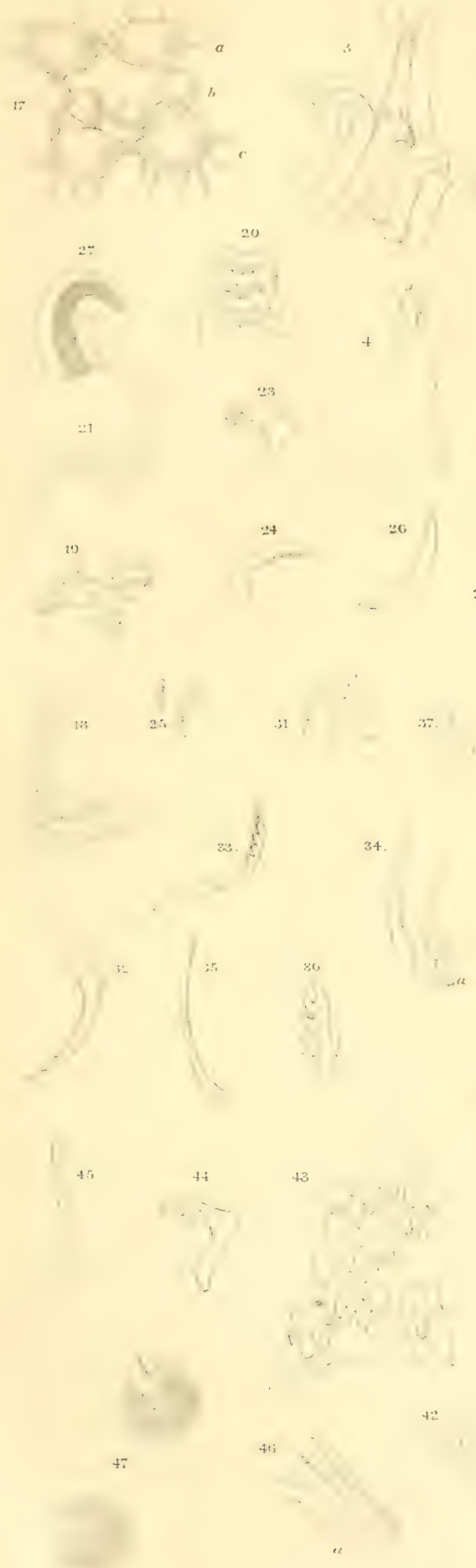

23<smiles>[CH]CC</smiles>

26<smiles>CCCCC</smiles>

l
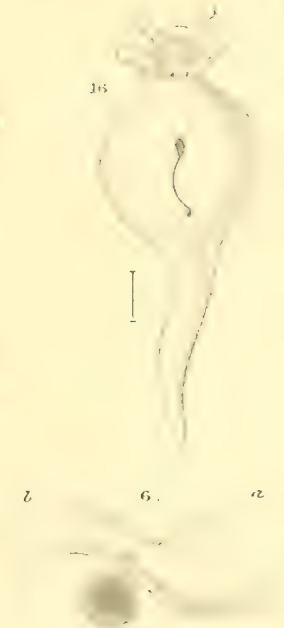

(3)

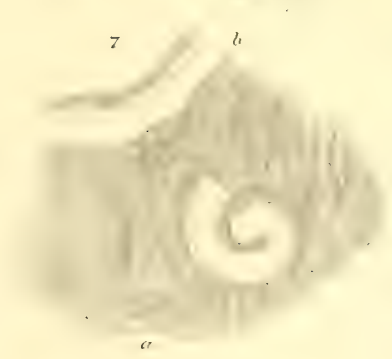

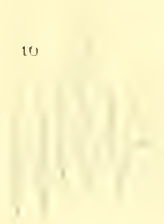

2: 13

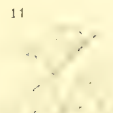

i.

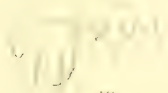

if

29

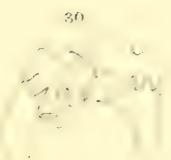

40

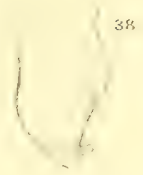

34

$i^{2}$

R. Bergh, del 




\section{TAFEL IX.}

Dolabclla Rumphii (Cuv.), Rang, var. maculosa.

$1 \because \ldots$ r. Eine der grössten Seitenzahnplatten.

$\mathrm{I}_{\sim}$. 2. Aussenende einer Zalunplattenreihe, $a$ äusserste Platte.

Fi.. 3. Achte Platte von aussen ab.

Fig. I -3 mit Cam. gezeichnet. 350 .

Cryptophthalmus olivaceus E., var. pallida.

Fig. 4. Thiere, in verschiedenen Schwimmstellungen. Originalzeichnungen des Kommandanten TrDEMAX.

Plitine quadripartita Asc. var.

1.is. 5. Nagenplatte.

Plitine rubra B.

[i., 6. Zahnplatten. 350

$\mathrm{F} i \mathrm{i}$ - . Magenplatte, von der Innenseite. ${ }^{\top} / 1$.

Fin. S. a Penissack, b Prostata, c Drüse, $d$ MI. retractor.

\section{Philine elegans B.}

Fig. 9. Nucleuspartie der Schale.

Fig. I0. Zahmplatten. 350 .

Fig. II. Die Magenplatten; a rechte, blinke, $c$ untere.

Fig. 12. Stück des Saumes der Magenplatten.

Fig. 13. Ahnliches. 55
Gastropteron Sibogae B.

I: I4. Seitenansicht des Vorderendes des Thieres. a Vorderrand des Fussflügels, $b$ Hinterkörper.

Fis. I 5. Seitenplatten.

Fig. 16. Ahnliche in anderer Stellung.

Fis. 17. Zwei äusserste.

Fig. I $5-17$ mit Cam. gezeichnet. I00 $\times$.

Gastr. Sibogae B., var. nigra.

Fis. I8. Hälfte des Centralnervensystems, $a$ cerebrales, $b$ pedales, $c$ pleurales, $d$ viscerales Ganglion.

[Fig. I9. Mandibelplatten. 100

Fig. 20. Seitenplatte, von hinten. $200 \times$.

Phanerophthalmus lutens (Q. et G.), var.

Fig. 21. Knotchen an der Rhachis der Kieme. 55

Fis. 22. Stück der Mandibelplatte.

Fis. 23. Elemente der Mandibelplatte.

Fis. 24. Rhachispartie der Raspel mit $a$ medianen und innersten Seitenplatten.

Fis. 25. Grösste Seitenplatte.

Fis. 26. Aussenende einer 'Zahnplattenreihe, $a$ äusserste Platte.

Fïg. 22-26 mit Cam. gezeichnet. $350 \%$

Fis. 27. Mediane Platte, mit Cam. gez. $750 \times$.

Fig. 2S. Penis.

Phanerophthalmus pauper B.

Fig. 29. Mantelschild und a Kieme. 
Siboga-Expeditie. L. R. BerGH. Opisthobranchia.
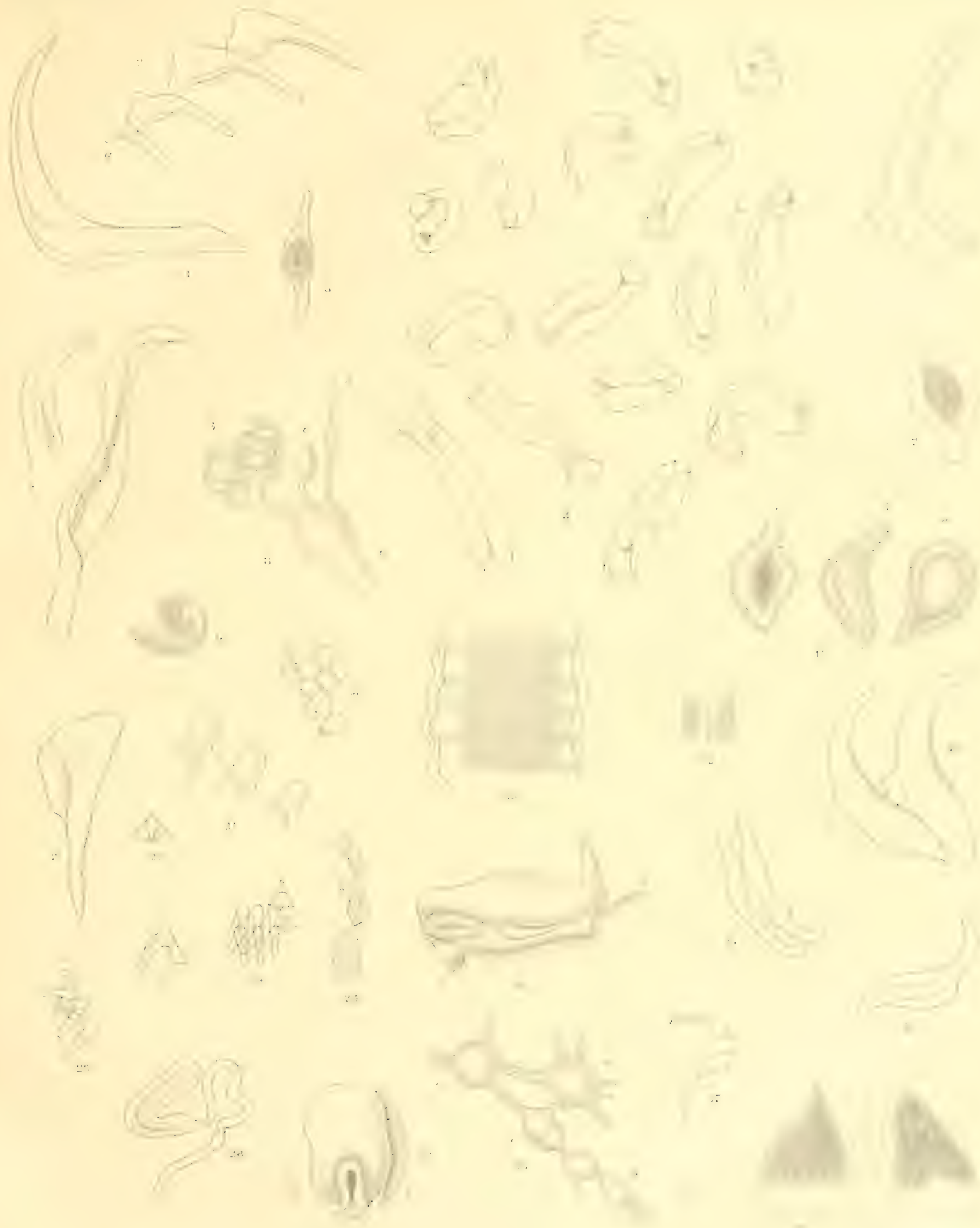

R. Bergh, del.

P. W. M. Trap in 




\section{TAFEL X.}

\section{Phancrophthatmus panter 13 .}

Iis. I. Mandibelplatte.

Vis. 2. Elemente derselben.

Iis. 3. Von der Rhachispartie der Zunge, mediane und erste Seitenplatten.

I i . 4. Eine der grössten Seitenplatten.

1Fi.. 5. Stückchen der Schale.

Fig. 2-5 mit Cam. gezeichnet. $350>$.

Fis. 6. Magenplatte.

1 i... 7. Von der Kielpartie ihres Rückens. $100 x$.

li... S. P'enis mit a P'rostata.

Cryptophthalmus olivacens Ehrenberg.

His. 9. Iandibelplattc. Ioo

I.i. 10. Stück der Mandibelplatte.

Fi... Ir. Elemente derselben.

lis... I2. Mediane Platten.

F... 13. Grösste Seitenplatte.

Fig. 10-13 mit Cam. gezeichnet. 350 x.

Cryptopluthalmus olizaceus E., var. pallida.

1... I4. Das Thier, von der Rückenseite.

Fi. 1. Mantelschild.

I1.. I6. Schale.

$1 \div, 1, a, b$ unregelmässige Seitenplatten, $c$ regelmäsige. 350 : .

\section{Chelidonura velutina $\mathrm{B}$.}

Fig. I8. Vorderende des Thieres, von oben.

liis. I9. Schale.

lig. 20. Fiihlerorgane des Stirnrandes. $350 x$.

liig. 2I. Vordere Genitalmasse; a Spermatotheke, b Spermatocyste.

I.j. 22. $a$ Gang der Spermatotheke, $b$ Spermatocyste. Fig. 23. $a$ Penis, $b$ Prostata.

I. 24. 24. Senkrechter Durchschnitt der Prostata.

\section{Pleurobranclaca morula $\mathrm{B}$.}

lis. 25. Vorderende des Thieres, von oben.

Fic. 26. Stuick der Mandibelplatte.

lig. 27. Zahnplatte.

1.ig. 28. Ahnliche in anderer Stellung.

Fig. 27, 28 mit Cam. gezeichnet. $200 \mathrm{x}$.

Fig. 29. Ausserste Zahnplatte einer Reihe.

Fig. 26, 29 mit Cam. gezeichnet. $350 \times$.

Oscaniopsis lunicops (Cuv.).

Fig. 30. Fuhlerorgane des Stirnsegels (Zotten). $55 x$.

IVi.. 31. Hinterende des Rückens.

Fi... 32. Vorderende des Schlundkopfes.

Fis. 33, 34. Zahnplatten. 350 .

Fi... 35. $c$ Glans penis, $b$ vas deferens.

I. $i_{-}$36. Stück der lekleidung der Glans. $55 \times$.

$\mathrm{Fi}_{-}$. 37. Einer der Kegel derselben. I00 $\times$. 

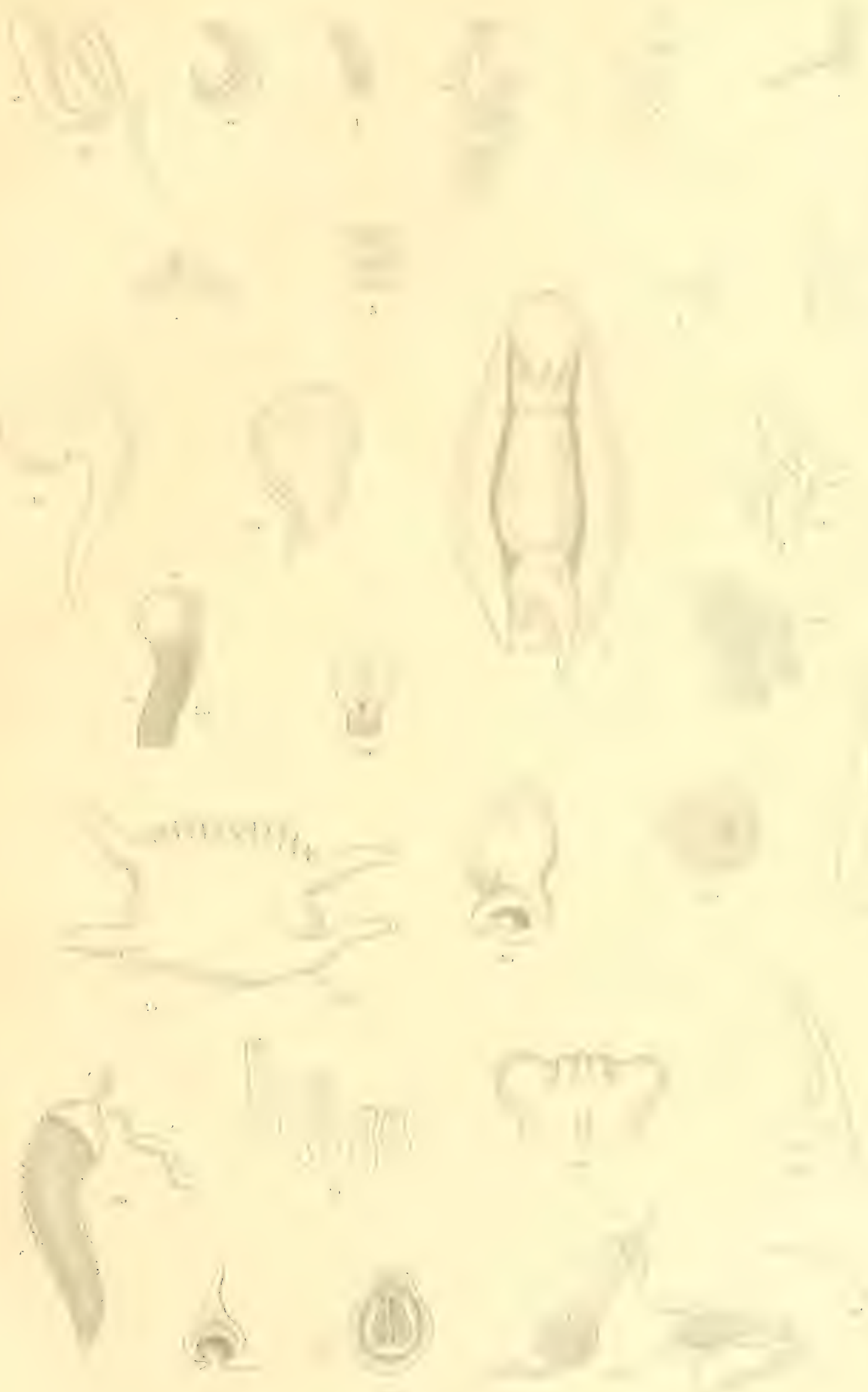

R. Bergh, del

P. W. M. Trap impr. 




\section{TAFEL XI.}

\section{Oscanius Treberi $\mathbf{1 3 .}$}

Fig. I. Schale, von der Rückenseite.

Fig. 2. Thnliche einer Varietät der Art.

Fi.r. Element der Mandibelplatte. $200 \times$.

Fig. 4. Stuck der Rhachispartie der Raspel.

Fi... 5. Grösste Zahnplatten.

Fig. 6. Aussenende zweier Zahnplattenreihen, $a a$ äusserste Platten.

Fig. 5-6 mit Cam. gezeichnet. 350 .

\section{Oscanius Sibogae B.}

Fin. Elemente der Mandibelplatte,

Fig. S. Aus der Mitte einer Zahnplattenreihe.

Fig. 7-8 mit Cam. gezeichnet. 350 >

Fig. 9. Der praebranchiale Sack.

\section{Oscaniella albiguttata $\mathrm{B}$.}

Fig. IO. 1)ic tichale. .

Iis. 11. Schlangenartige Fäden der Rückenhaut.

IVis. I : Element der Mandibelplatte, von der Fläche.

Fig. I3. Ähnliches, von der Seite.

Fig. I4. Zahnplatte vom innersten Theil der Raspel. Fis. I 5. Zahnplatten.

Fig. I6. Aussenende zweier Zahnplattenreihen, $a$ äusserste Platte.

Fig. 12-16 mit Cam. gezeichnet. 350 .

Fig. 17. Praebranchialer Sack.

\section{Oscaniclla lugubris $\mathrm{B}$.}

Fig. I8. Schale. ${ }^{3 / 1}$.

Fig. I 9 . Element der Mandibelplatte.

Fig. 20. Innere Zahnplatte.

Fig. 21. Grösste Zahnplatten.

Fig. 22. Eine der äusseren Zahnplatten.

Fig. 19-22 mit Cam. gezeichnet. $350 \times$.

\section{Oscaniella dubia $\mathrm{B}$.}

Fig. 23. Zahnplatten. $350 \%$.

Oscaniella purpurca $\mathrm{B}$.

Fig. 24. Knötchen des Rückens.

Fig. 25. Elemente der Mandibelplatte.
Iis. 26. Innerste Zahnplatte.

İi.. 27. Eine der grössten Platten.

I ig. 2S. Aussenende zweier Reihen, $a$ äusserste Platte.

Fig. 25-28 mit Cam. gezeichnet. $350 \times$.

$$
\text { Oscaniella purpurascens } \mathrm{B} \text {. }
$$

Fic. 29. Fleckchen des Rückens.

Iis. 30. Schale, von oben. ${ }^{6} / 1$.

Fis. 3I. Schlangenartige Elemente der Rückenhaut.

[i.s. 32. Elemente der Mandibelplatte.

Fig. 33. Innerste Zahnplatten zweier Reihen, aa innerste.

[Vig. 34. Zahnplatten.

lijg. 35. Grösste Zahnplatten.

Fig. 36. Zahnplatten vom äusseren Drittel einer Reihe.

Iis. 37. Aussenende einer Zahnplattenreihe, $a$ äusserste Platte.

Fig. 32-37 mit Cam. gezeichnet. $350 \%$

Plewrobranchus grisens B.

Fir. 38 . Elemente der Mandibelplatten.

Fig. 39. Zahnplatten.

Fig. 40. Eine der grössten Zahnplatten.

Fig. 38-40 mit Cam. luc. gezeichnet. $350 \times$.

\section{Pleurobranclus latipes $\mathrm{B}$.}

Fig. 4I. Stück der Mandibelplatte.

Iig. 42. Zahnplatte.

\section{Berthella Cuvieri B.}

Fig. 43. Elemente der Mandibelplatte.

Fig. 44. Zahnplatte.

Fig. 38-44 mit Cam. gezeichnet. $350 \times$.

\section{Berthella Borneensis B.}

Figr. 45. Schale, von oben. $3 / 1$.

Fig. 46. Stuick der Mandibelplatte.

Fis. 47. Zahnplatte.

Fig. 46-47 mit Cam. gezeichnet. 350

$$
\text { Berthella minor B., var. }
$$

Fis. 48. Abnorme Kieme. 

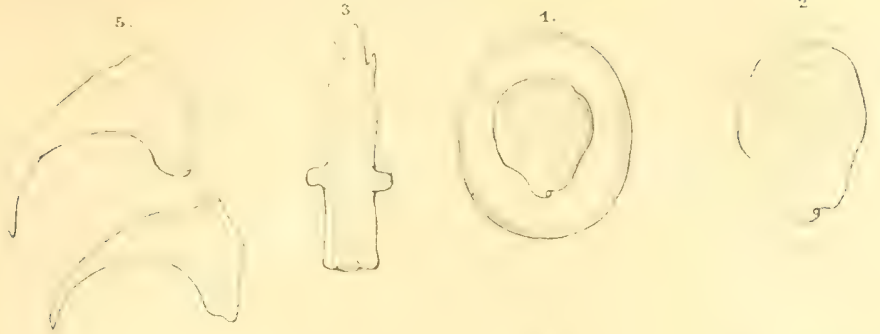

ling
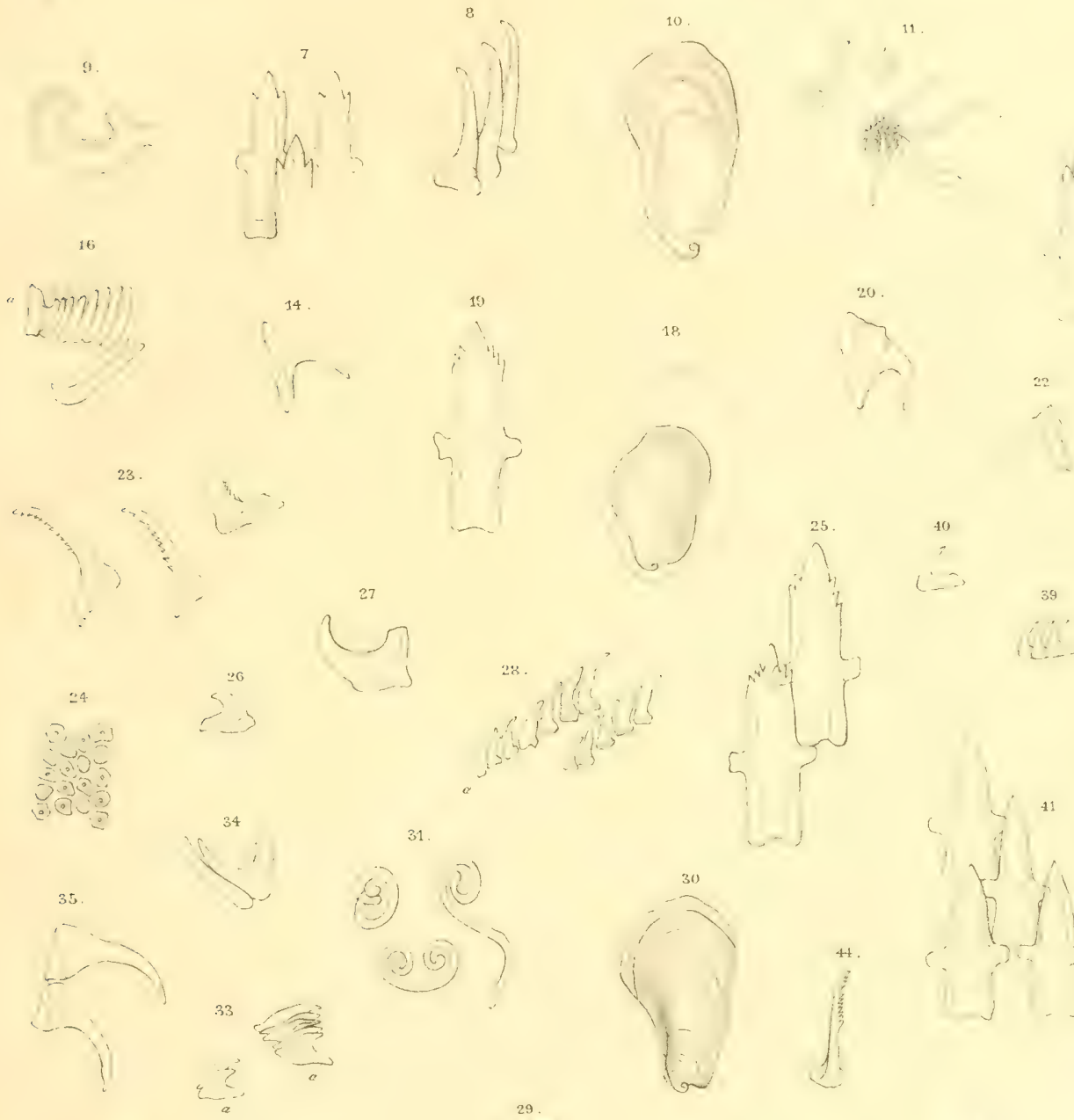

\section{1:

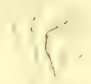

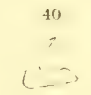
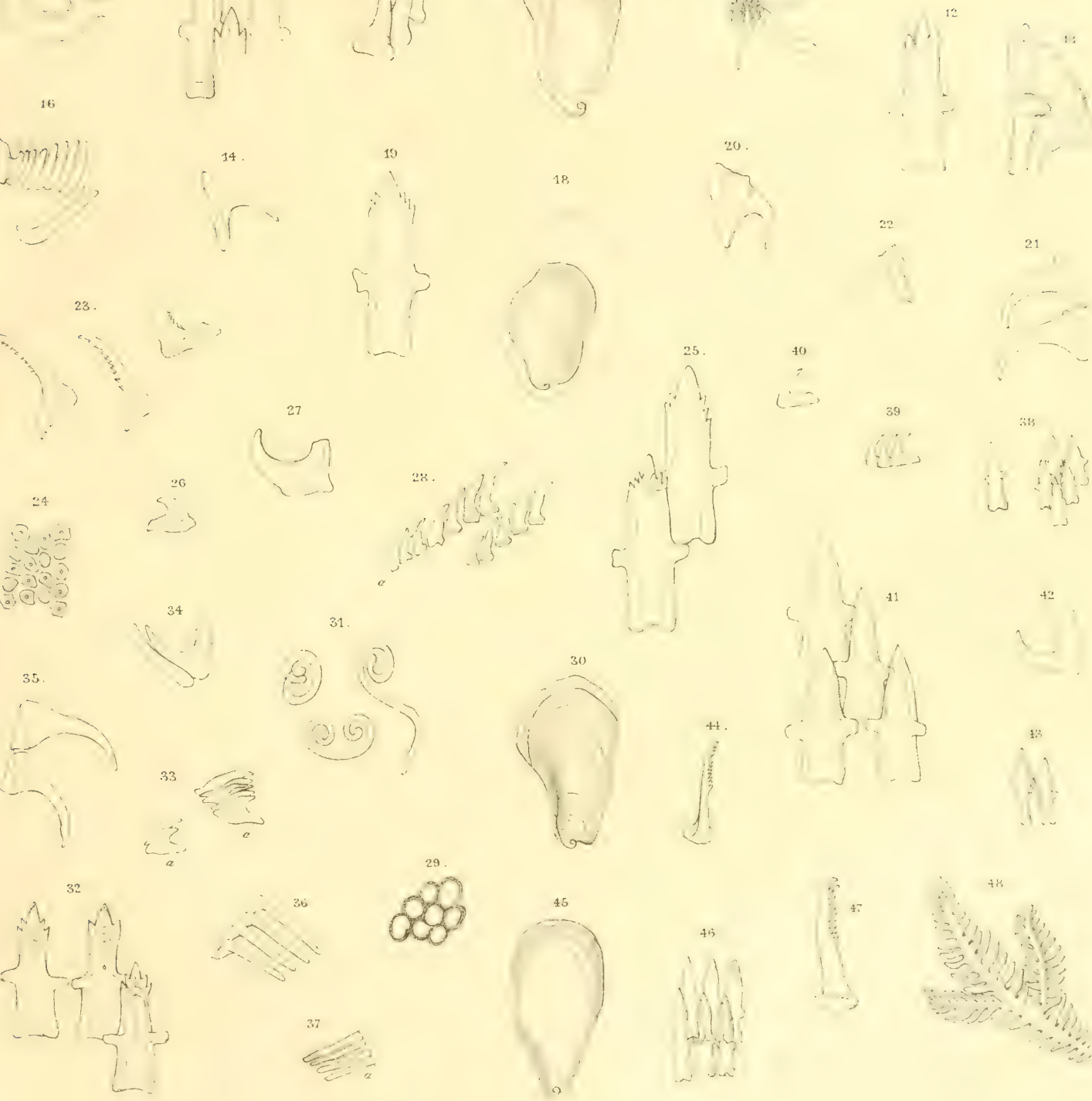

R. Bergh, del
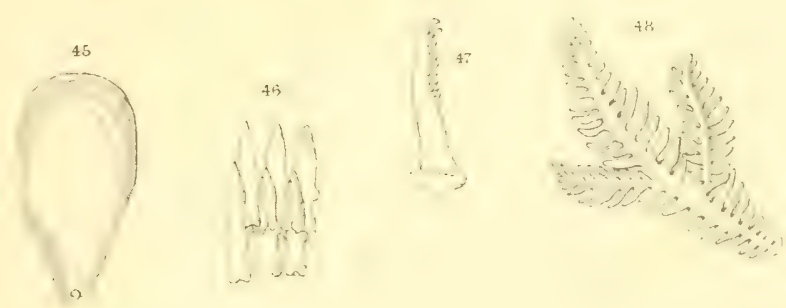

P. W. M. Trap impr. 



\section{TAFEL XII.}

\section{.1Telibe papillosa (Philippi)?}

I.i.. I. Rüichen-Papille, a Stiel.

$1 \%$. 2. Stuick des Plattengütels des Magens. $55 \times$.

Doto anmigera $\mathrm{B}$.

1.i.s. 3. Das Thier, von der Ruickenseite.

I:is. \&. Erste Papille.

I.is. 5. Zweite Papille, a Stiel.

I: i. Bei einer Timarclla perplexa lose liegende Papille (vgl. p. 24I).

\section{Phyllaply'sia inornata B.}

Iij. 7 . Das Thier, von der Ruckenseite. $5 / 1$.

Fis. Die Schale.

Iivg. o. Elemente der Miandibelplatte.

Iiv. IO. Stiick der Rhachis mit medianen Platten und innersten lateralen.

1. i.. I 1, I2. Laterale Platten.

Fi... I 3. Stachel aus der Cardia-Gegend.

Fis. 14. Eine der grössten Magenplatten.

Fig. 10-I4 mit Cam. gezeichnet. 350 .

Aplysiella I'asirana $\mathrm{B}$.

Fis. I 5. Grosse Magenplatten. 55

Oscaniella inermis $\mathrm{B}$.

I.i.s. If. Schlangenartige Fäden der Rückenhaut.

1.is. 17. Element der Nandibelplatte.

l.ig. I. Abgeriebene Elemente vom Vorderende der Mandibel.

Fi... 19. Element, von der Seite.

I i. 20. Eine der inneren Zahmplatten.

I. 21. Eine der grösten Zahnplatten.

Iiis. 22. Aussenende einer Zahnplattenreihe, $a$ äusserste Platte.

Fis. 17-22 mit Cam. gezeichnet. 350>.

\section{Oscaniclla modesta B.}

Fig. 23. Stiick der Ruickenhaut.

Fig. 24. Schale, von der Ruckenseite. $5 / 1$.

Fig. 25. Element der Mandibelplatte.

Fig. 26. Ahnliches von der Seite.

Fig. 27. Zahnplatte.

Fig. 25-27 mit Cam. gezeichnet. 350
Architoris Kurana 13.

Fig. 28. Vom mittleren Theile des Rückens.

Fig. 29. Grösste Zahnplatten. $350 \times$.

$$
\text { Platydoris argo (L.)?? }
$$

Fig. 30. Kopf mit Tentakeln und Vorderende des fiusses.

Fig. 31. Stück der Rückenhaut.

Fig. 32, 32a. Grosste Zahnplatten.

Anisodoris Timorensis B.

Fig. 33. Innerste Zahnplatten.

Fig. 34. Grösste Zahmplatten.

Fig. 35. Aussenende einer Zahnplattenreihe, $a$ äusserste Platte.

$$
\text { Halgerda elegans B., var. }
$$

Fig. 36. Innerste Zahnplatten.

Fig. 37. Eine der inneren Zahnplatten.

Fig. 38. Eine der grössten, von der Seite.

Fig. 39. Ähnliche, von vorne.

Fig. 40. Aussenende zweier Zahnplattenreihen, a äusserste Platte.

Fig. 32-40 mit Cam. gezeichnet. $350 \times$.

Plyyllidia varicosa Lam., var. quadrilineata.

Fig. 4I. Das Thier, von der Ruckenseite. ${ }^{4} / 1$. Fig. 42. Vorgestrecktes Ende des Samenleiters, $a$ Genitalpapille.

\section{Timorella perplexa B.}

Fig. 43. Das Thier, von der rechten Seite. $\% / 1$. Fig. 44. Das Vorderende, von der Unterseite. Fig. 45. Ende eines der zwei hinteren Cylinder. Fig. 46. Hinterende des anderen Individuums.

Pleuroleura pallida $\mathbf{B}$.

Fig. 47. Das Thier, von der Rückenseite. "/1.

Fig. 48. Das Vorderende, von der Unterseite.

Fig. 49. Mediane und erste Seitenplatte.

Fig. 50. Laterale Platten.

Fig. 49-50 mit Cam. gezeichnet. 350 .

Fig. 51. Mediane und erste Seitenplatte.

Fig. 52. Laterale Platte.

Fig. 51-52 mit Cam. gezeichnet. $750 \times$. 

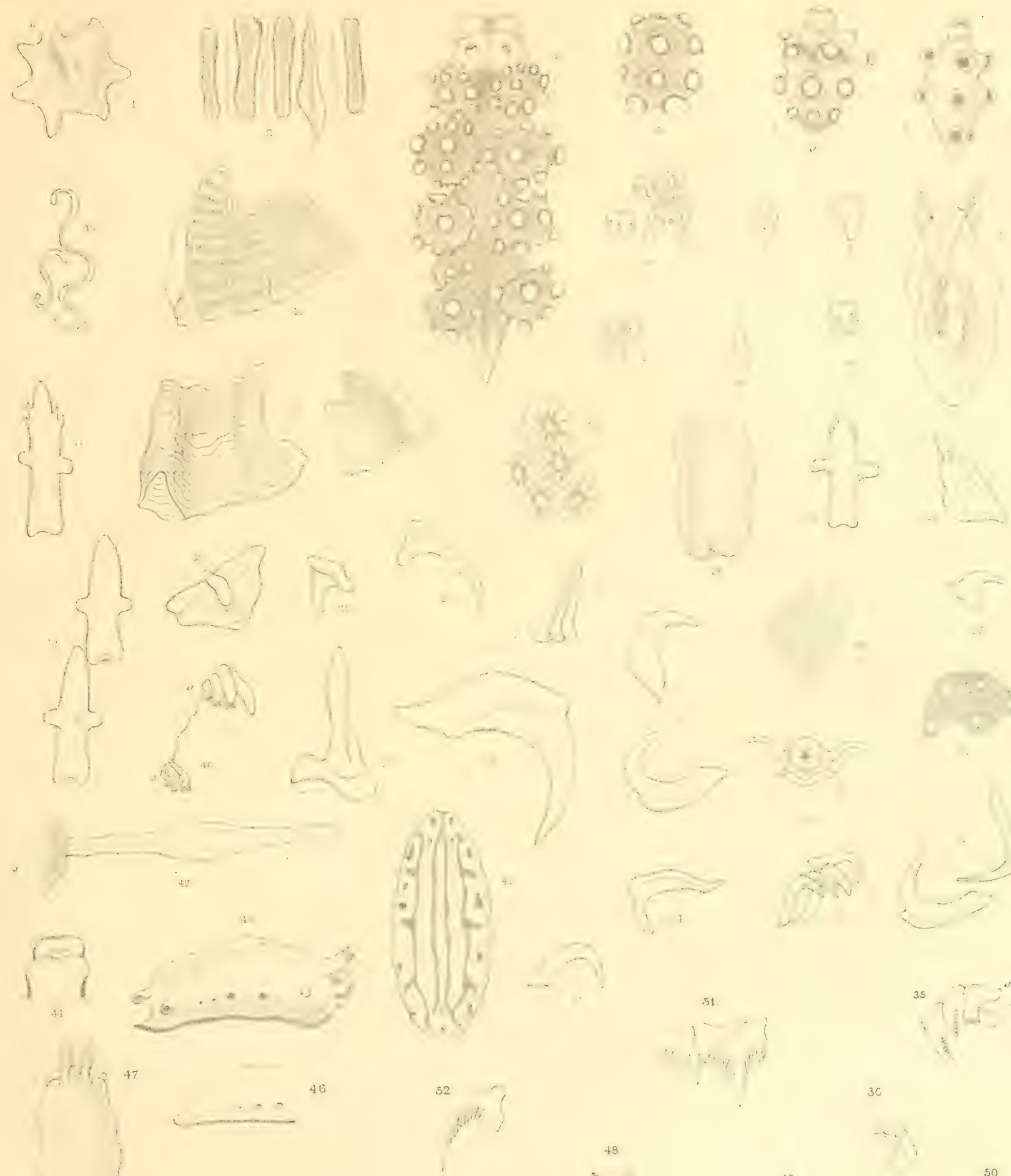




\section{TAFEL XIII.}

Bertlella minor $\mathrm{B}$.

Fig. I. Die Schale, von oben. $5 / 1$.

Fis. 2. Stück der Mandibelplatte.

Fis. 3. Zahnplatten.

Berthella minor B., var.

Fis. 4. Stück der Mandibelplatte.

Iis. 5. Zahnplatten.

Fig. 2-5 mit Cam. gezeichnet. 350>

Fis. 6. Die Schale, von oben. ${ }^{4} / 1$.

\section{Berthella inoperta B.}

Fis. 7. Stück der Mandibelplatte. 350 x.

Fis. 8. Ein Element derselben. 750 >.

Fir. 9. Zahnplatten.

lin... IO. Eine der grössten Zahnplatten.

I'mbrella picta (Ad.).

Fis. II. Zahnplatten.

Fig. 9-I I mit Cam. gezeichnet. 350>

Phyllobranchus rubicundus B.

Fis. 12. Papille (Epinotidium) des Rückens.

$$
\text { Cyerce elegans (Semper), Bgh. }
$$

Fig. I3. Papille.

I: ig. I4. Haken einer Zahnplatte. 350.

I.ig. I5. Penis-Haken.

Iis. I6. Parasitische Copepode. 55 .

Iis. 17. Ende eines der vorderen Beine derselben. $350>$.

\section{Plakobranchus priapinus $\mathrm{B}$.}

Fig. 18. Ende des Penis mit Stachel, I00 $>$.

lig. I9. Öffinung des Stachels. 350
Elysia thysanopoda B.

Fir. 20. Schlundkopf, von der Seite (ein wenig abgeplattet). $100 \times$.

Fis. 21. Zahnplatten. $350 \times$.

$$
\text { Ely'sia ornata (Pease). }
$$

Fig. 22. Raspelscheide, Zunge und Raspelsack.

Fis. 23. Zahnplatte. 350 .

\section{Elysia Haingsisiana $\mathrm{B}$.}

Iig. 24. Rhinophor.

\section{Ely'sia? lineolata B.}

Fig. 25. Das Thicr, von der Unterseite. ${ }^{5 / 1}$.

Fis. 26. Zahnplatte. $350 \times$.

Hexabranchus punctatus $\mathrm{B}$.

Fig. 2\%. Zahnplatte.

Aporodoris? rubra $\mathrm{B}$.

Fig. 2S. Hauthöckerchen.

Fìg. 29. Grösste Zahnplatten.

Fis. 3v. Aussenende einer Zahnplattenreihe, $a$ äusserste Platte.

Anisodoris Sibogae $\mathrm{B}$.

Fis. 31. Vom inneren Theil einer Zahnplattenreihe, $a$ erste Platte.

Figs. 32. Eine der grössten Platten.

Fis. 33. Aussenende einer Zahnplattenreihe, $a$ äusserste Platte.

Fig. 28-33 mit Cam. gezeiclinet. $350 \times$.

Discodoris Boholiensis B.

Fiss. 34. Die Papel der Rückenhaut.

Fig. 35. Grösste Zahnplatte. $350 \times$. 

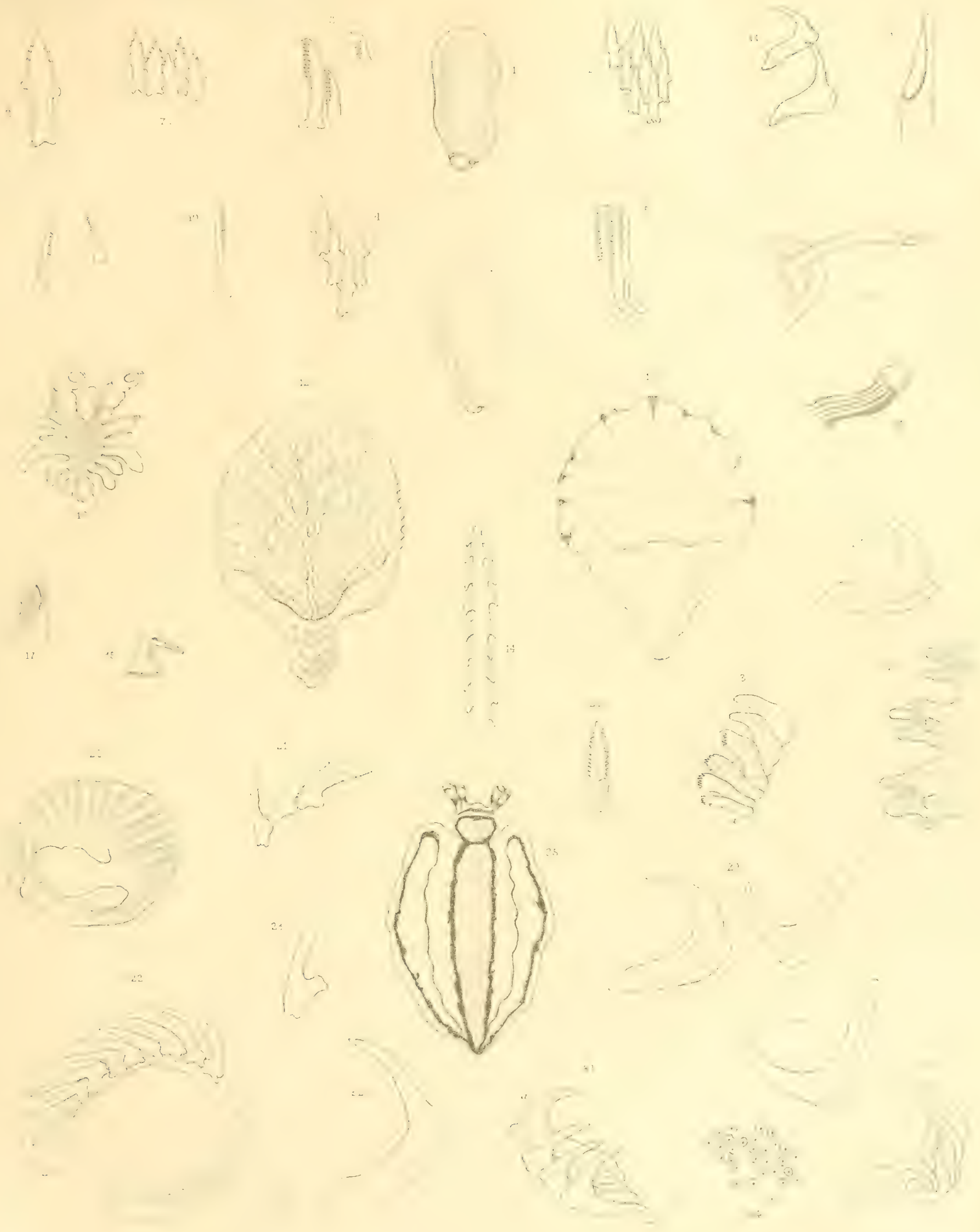




\section{TAFEL XIV.}

\section{Discodor is Boholiensis B.}

IVir. I. Elemente der Lippenplatte.

IVi... 2. Aussenende einer Zahnplattenreihe, $a$ äusserste Platte.

\section{Discodoris concinniformis $\mathrm{B}$.}

IYis. 3. Elemente der Lippenplatte.

I.i.. 4. Grösste Zahnplatten.

Fis. 5. Aussenende einer Zahnplattenreihe, $a$ äusserste Platte.

\section{Discodoris Ellioti (A. et H.).}

Fig. 6. Stück der Lippenplatte.

Fig. 7. Eine der grössten Zahnplatten.

Fig. 8. Aussenende einer Zahnplattenreihe, $a$ äusserste Platte.

Discodoris Ellioti (A. et H.), var.

Fiig. 9. Zahnplatten.

Fig. I-9 mit Cam. gezeichnet. $350 \times$.

liig. IO. Lippenplatten.

\section{Discodoris? nibra $\mathrm{B}$.}

IVin. Ir. Partie des Rüickens.

Fig. 12. Helle Flecken des Riickens.

Fin. I3. Eine der grössten Zahnplatten.

Fi... I4. Aussenende einer Zahnplattenreihe, $a$ äusserste Platte.

\section{Discodoris? liturata $\mathrm{B}$.}

Fig. 15. Das Thier, von der Rückenseite. ${ }^{3} / 1$.

IVig. I6. Elemente der Lippenplatten.

Fis. I7. Innerste Zahnplatte.

I'ig. I8. Eine der grössten Zahnplatten.

1.i. I9. Eine andere.

Fis. 20. Aussenende zweier Zahnplattenreihen, a äusserste Platte.

Fig. 16-20 mit Cam. gezeichnet. 350 : .

\section{Discodoris? liturata B., var.}

Fig. 21. Von der Haut des Rückens.

$$
\text { Discodoris? lutescens } \mathrm{B} \text {. }
$$

Fig. 22. Elemente der Lippenplatten.

Fig. 23. Eine der innersten Zahnplatten.

Fir. 2.4. Von der Mitte einer Zahnplattenreihe.

Fig. 25. Spitze einer dieser Platten.

Fig. 25. Eine mehr nach aussen liegende.

Fig. 27. Eine noch mehr nach aussen liegende.

Fig. 2S. Eine der äussersten Platten.

Discodoris ?? versicolor $\mathrm{B}$.

Fig. 29. Elemente der Lippenplatten.

Fig. 30. Eine der grössten Zahnplatten.

Fig. 31. Aussenende zweier Zahnplattenreihen, $a$ äusserste Platte.

\section{Discodoris sp.}

Fig. 32. Stück der Lippenplatten.

Fig. 33. Innerste Zahnplatten.

Fig. 34, 35. Zwei der grössten Zahnplatten.

Fig. 36. Aussenende einer Zahnplattenreihe, $a$ äusserste Platte.

\section{Carminodoris blandula $\mathrm{B}$.}

Fis. 3-. Elemente der Lippenplatte.

Fig. 3S. Zwei innerste Zahiplatten.

Fin. 39. Zahnplatte.

Fig. 40. Penis-Kegel.

\section{Hoplodoris desmoparypha $\mathrm{B}$.}

Fig. + r. Eine der grössten Zahnplatten.

$\mathrm{F}_{\mathrm{i}}$. +2. Aussenende einer Zahnplattenreihe, $a$ äusserste Platte.

Fig. +3. Elemente der Lippenplatte.

lig. 22-43 mit Cam. gezeichnet. 350 .

lis. H. Lippenplatten.

Fig. 45. Stuick der Bekleidung der Glans penis. 55 . Fig. 46. Stark vergrösserte Dornen derselben. $200 \times$. 
Sibera-Expeditie. L. R. Bergir. Opisthobranchia.

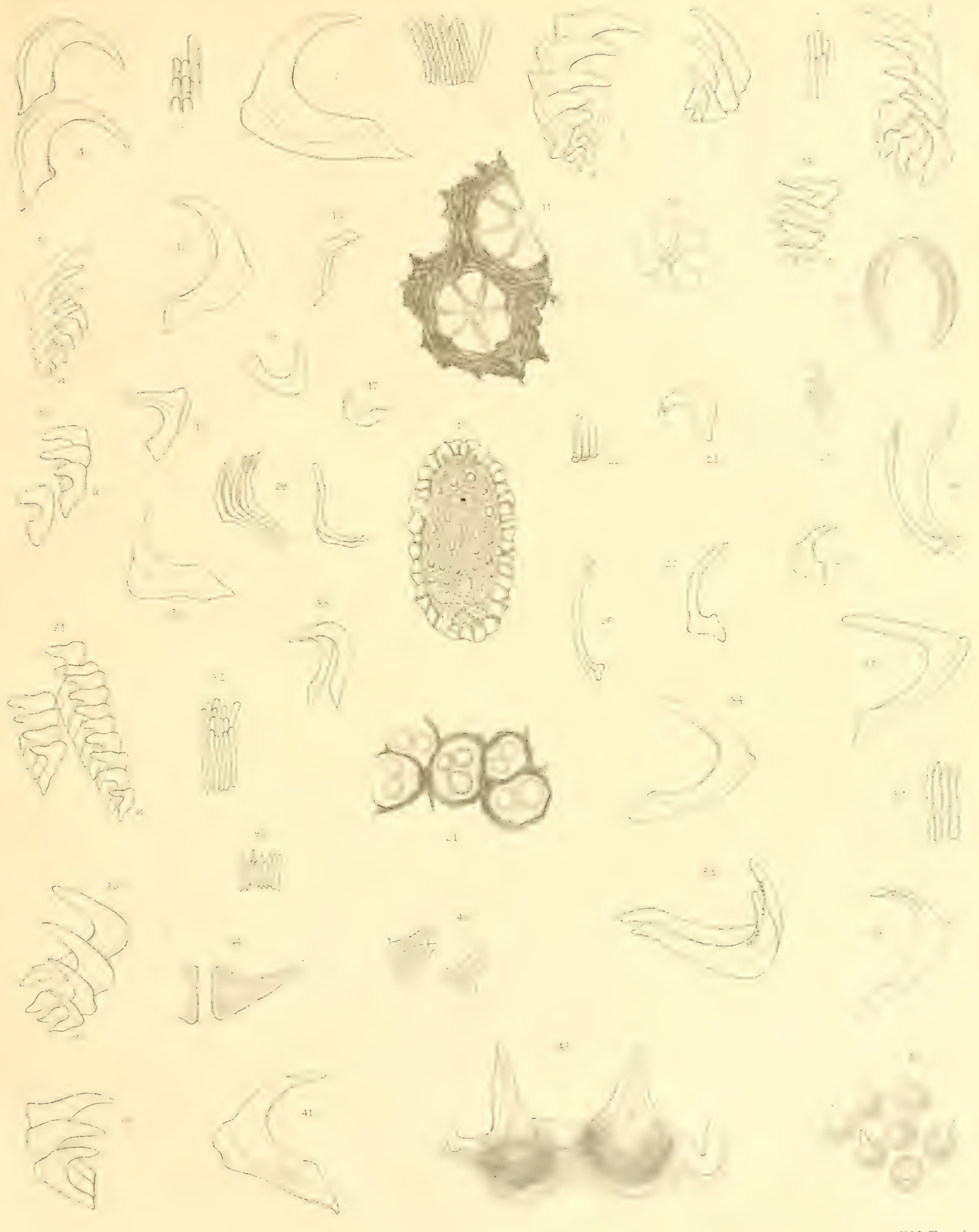

R. Bergh. del. 



\section{TAFEL XV.}

Hoplodoris desmoparypha 13.

Iin. I. Tentakel.

Fin. 2. Stachel.

Halla indecora $\mathrm{B}$.

Fi... 3. Elemente der Lippenplatte.

1.i... 4. $a$ Seitenplatten von der Hinterseite, $b$ erste Aussenplatte.

1.in. 5. Seitenplatten.

Iis. 6. Vom ausseren Theile einer Zahnplattenreihe.

Nirva Brockii 13.

Iiis. 7. Von der Lippenplatte.

Iis. 8. Innerste Zahnplatten, $a$ erste.

lik. 9. Eine der grossten Zahnplatten.

Diaulula? rubra B.

Fig. Io. Aussenende einer Zahnplattenreihe, $a$ äusserste Platte.

\section{Diaulula? gigantea B.}

Fis. I I. Ausserste Platte einer Reihe.

Fig. 4-II mit Cam. gezeichnet. $350 \times$.

Iin. I2. Zwei der grössten Platten.

Ii is. I3. Aussenende einer Zahnplattenreihe, $a$ äusserste Platte.

Fig. 12-I3 mit Cam. gezeichnet. 200

Iis. I4. a Prostata, $b$ Samengang, c Penis.

Fis. I5. Glans penis.

Iii_. I6. a Spermatotheke, b vaginaler Ausfuhrungsgang, $c$ Spermatocyste.

\section{Thordisa tristis B.}

Ii... I7. Nöppchen des Rückens.

Fis. IS. Zahnplatte. 200

Fis. I9. Eine der grössten Zahnplatten.

I.'. 20. Aussere Zahnplatten.

I:... 2I. Zwei äusserste Zahnplatten.

\section{Thordisa hilaris 13.}

F... 22. Eine der grössten Zahnplatten.

$\mathrm{Ii.}$. 23. Aussenende einer Zahnplattenreihe, $a$ äusserste Platte.
Fivs. 24. Sechste Platte von aussen ab.

Fig. 19-24 mit Cam. luc. gez. $350 \%$

Fig. 25. Nöppchen des Rückens.

\section{Thordisa maculosa B.}

Fis. 26. Innerste Zahnplatte.

I:is. 27. Eine der grössten Zahnplatten.

I ig. 28. Aussenende zweier Zahnplattenreihen, $a a$ äusserste Platte.

\section{Halgerda elegans B.}

Fig. 29. Innenende zweier Zahnplattenreihen.

Fig. 30. Eine der grössten Platten.

Fis. 3I. Aussenende einer Zahnplattenreihe, $a$ äusserste Platte.

\section{Halgerda inornata B.}

Fig. 32. Zwei der grössten Zahnplatten.

Fiss. 33. Aussenende einer Zahnplattenreihe, a äusserste Platte.

$$
\text { Halgerda rubra B. }
$$

Fig. 34. Innerste Platte.

Fis. 35. Eine der grössten Platten.

Fiss. 36. Aussenende einer Zahnplattenreihe, $a$ äusserste Platte.

\section{Trippa ornata B.}

Fig. 37. Grösste Zahnplatten.

Fig. 26-37 mit Cam. gezeichnet. $350 \%$

Trippa affinis $\mathrm{B}$.

Fig. 38. Innenende einer Zahnplattenreihe, $a$ innerste Platte.

Fis. 39. Aussenende einer Zahnplattenreihe, $a$ äusserste Platte.

Fig. $38-39$ mit Cam. gezeichnet. 200

Fis. 40. Eine der grössten Platten. 100 $\times$.

Fig. 4I. Vom inneren Theil der Zahnplattenreihe eines anderen Individuums, an innerste Hatte, $b$ sechste.

Iis. 42. Aussenende einer Zahnplattenreihe desselben Individuums, $a$ äusserste Platte.

Fig. $41-42$ mit Cam. gezeichnet. 350 


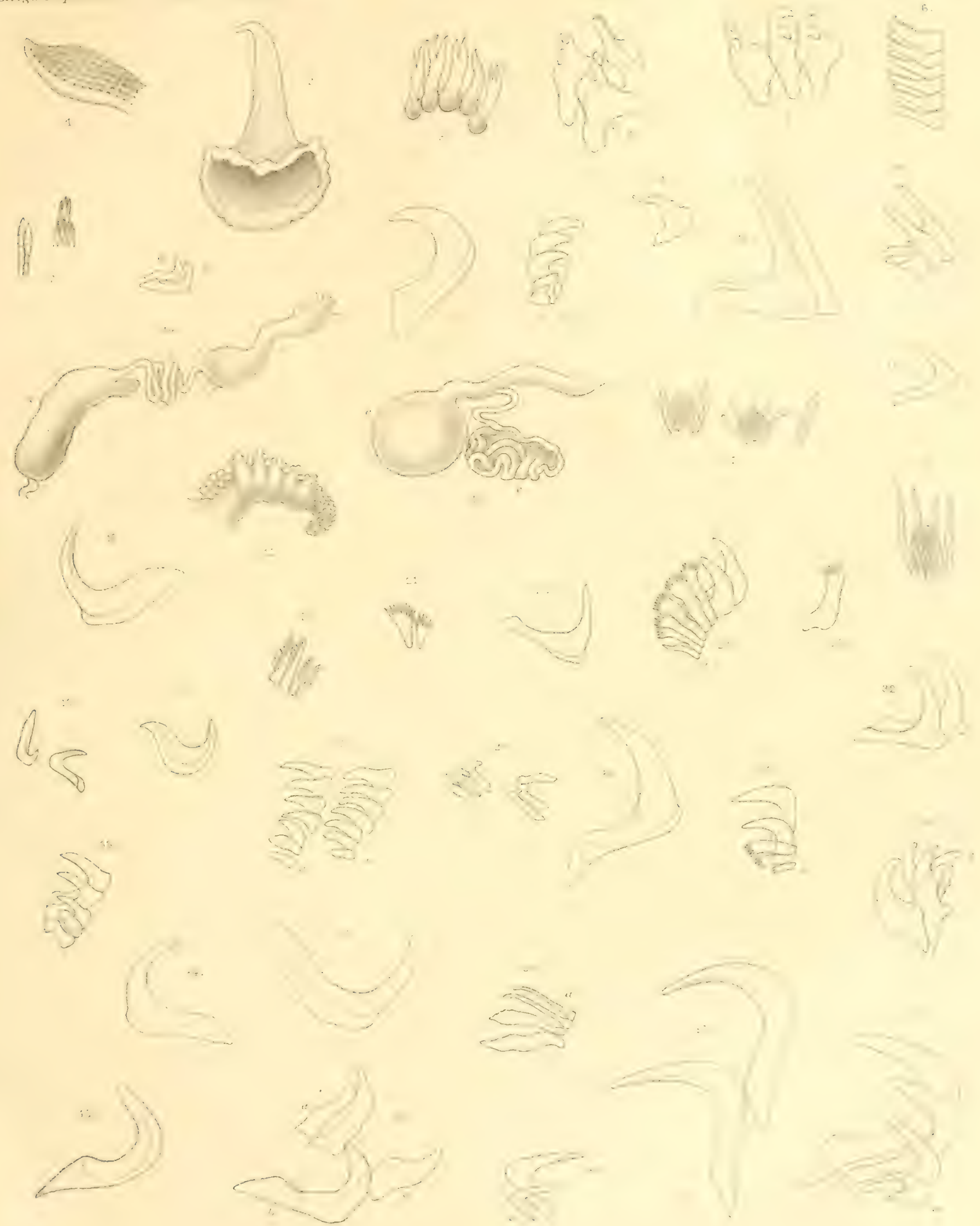

P. W. M, Trap, inpr R. Bergh. del. 




\section{TAFEL XVI.}

Peltodoris mbescens $\mathrm{B}$.

Fig. I. Eine der grössten Zahnplatten.

Fig. 2. Aussenende einer Zahmplattenreihe, $a$ äusserste Platte.

\section{Platydoris flammulata $\mathrm{B}$.}

Fig. 3. Aussenende zweier Zahnplattenreihen, aa äusserste Platte.

\section{Platydoris sanguinea $\mathrm{B}$.}

Fig. 4. Zwei der grössten Zahnplatten.

Fig. 5. Aussenende einer Zahnplattenreihe, $a$ äusserste Platte.

Cluromodoris elisabetizina B., var.

Fig. 6. Aussenende einer Zahnplattenreihe, $a$ äusserste Platte.

Cluromodoris Crossei Angas.

Fig. 7. Elemente der Lippenplatte, von oben, von der Seite und von unten.

I iss. \$. Zahnplatte.

\section{Cluromodoris Semperi B.}

Fig. 9. Elemente der Lippenplatte, von oben und von der Seite.

Fig. Io. Zahnplatten.

Chrom. lineolata (van Hass.) (Chr. funerea Coll.).

Fig. II. Elemente der Lippenplatte.

Fig. 12. Zahnplatte.

\section{Chromodoris marginata (Pease).}

1.is. I 3. Elemente der Lippenplatte.

Fig. 14. Eine der grössten Zahnplatten.

Fig. 15. Eine der äussersten Zahnplatten.

\section{Chromodoris fammulata $\mathrm{B}$.}

Fig. 16. Elemente der Lippenplatte.

Fig. 17. Von der Rhachis-Partie.

Fig. I8. Eine der grössten Platten.

Fig. 19. Ausserste Platte.

\section{Chromodoris marpessa $\mathrm{B}$.}

Fig. 20. Elemente der Lippenplatte.

Fis. 21. Zahnplatten von der Mitte der Reihe.

Cleromodoris venusta 13 .

Fig. 22. Elemente der Lippenplatte.

Fig. 23. Aus der Rhachis-Partie, a mediane falsche Platten.

Fig. 24. Grösste Zahnplatten.

Fig. 25. Aussenende einer Zalnnplattenreihe, $a$ äusserste Platte.
Chromodoris oplithalmica $\mathrm{B}$.

IFig. 26. Elemente der Lippenplatte.

ligs. 27. Zahnplatten.

Chromodoris nodulosa $\mathrm{B}$.

Fig. 28. Elemente der Lippenplatte.

Fig. 29. Innerste Zahnplatten.

Fis. 30. Eine der grössten Zahnplatten.

liig. 31. Aussenende einer Zahnplattenreihe, $a$ äusserste Platte.

Chromodoris pantherina $\mathrm{B}$.

I. ig. 32. Elemente der Lippenplatte.

Iis. 33. Innerste Zahnplatte.

Iig. 34. Grösste Zahnplatten.

\section{Chromodoris papulosa $\mathrm{B}$.}

Fig. 35. Elemente der Lippenplatte.

Fig. 36. Eine der grössten Zahnplatten.

lig. 37. Äusserste Platten.

Chronodoris Sibogae B.

Fig. 3 S. Elemente der Lippenplatte.

Fig. 39. Zahnplatte.

\section{Chromodor is lactea $\mathrm{B}$.}

Figr. 40. Rhachispartie der Raspel, a mediane falsche Platten.

Fig. 4I. Eine der Pseudo-rhachidialen Platten. 750

I.ig. 42. Eine Zahnplatte. 750 .

Fig. 43. Eine der äusseren Platten. $750 \times$.

Chromodoris Bimaensis $\mathrm{B}$.

Iij. 44. Elemente der Lippenplatte.

Fig. 45. Eine der grössten Zahnplatten.

Fig. 46. Aussenende einer Zahnplattenreihe, $a$ äusserste Platte.

Chromodoris? virgata B.

Fig. 47. Zahnplatten.

Chromodoris inopinata B.

Fig. 48. Elemente der Lippenplatte.

Iis. 49. Innerste Zahnplatte.

Fis.s. 50. Zahnplatten.

Fig. 51. Ausserste Zahnplatte.

Fig. I- 5 I mit Cam. gezeichnet. $350 \times$.

I.ig. 52. Stück der Kieme.

Casella mubra B.

Fis. 53. Elemente der Lippenplatte.

Fig. 54. Von der Rhachispartie der Raspel, a mediane falsche Platten.

Fig. 55. Zahnplatten.

Ceratosona comigerum Ad.

Fis. 56. Zahnplatte.

Fig. 53-56 mit Cam. gezeichnet. $350 \times$. 
Sibosa-Fipeditic. I. R, BerGir. Opisthobranchia.

He $11 \%$
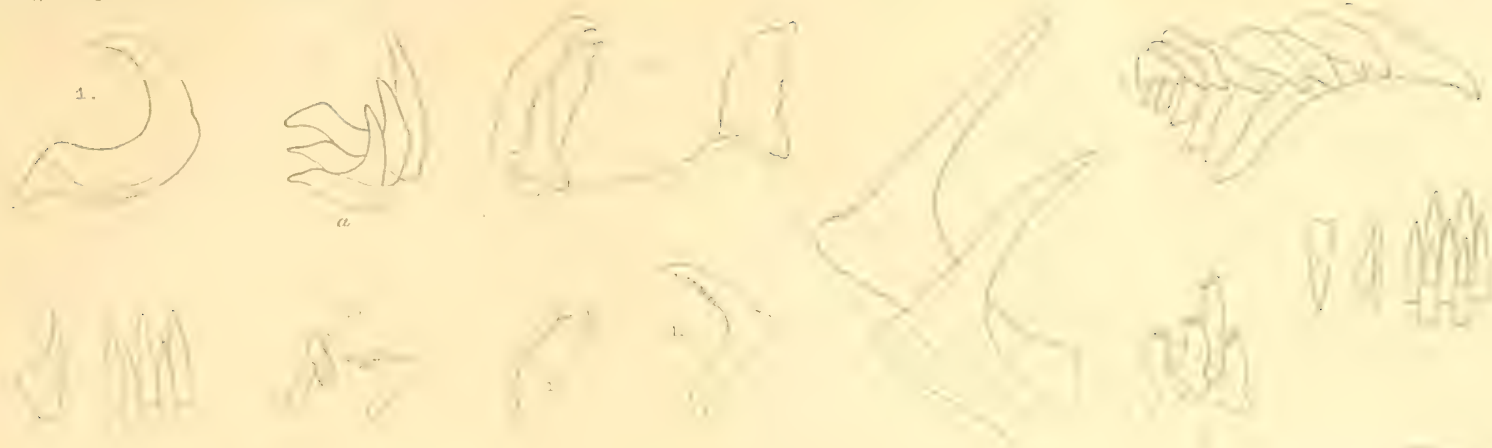

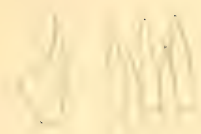
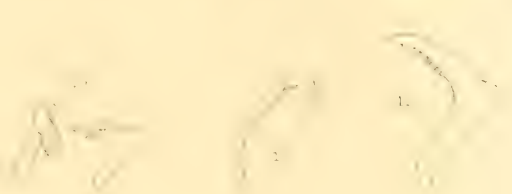

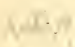
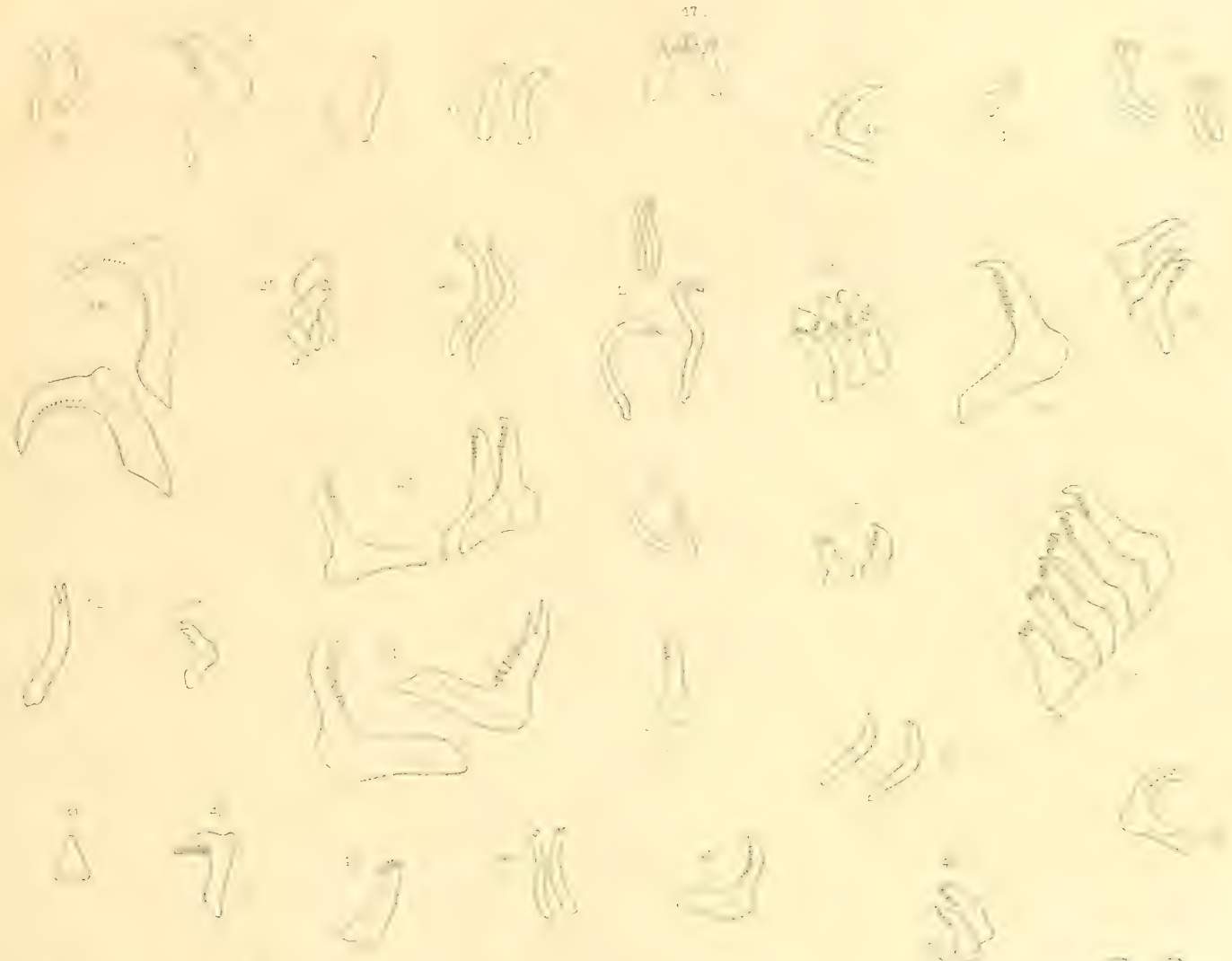

$\therefore \begin{array}{r}31 \\ \because-1\end{array}$

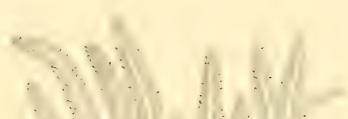

(i)
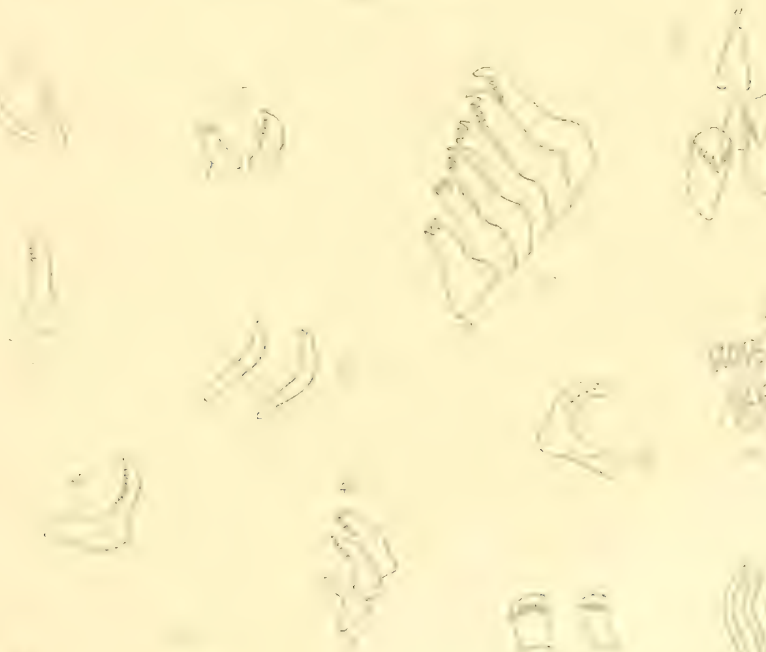

abis
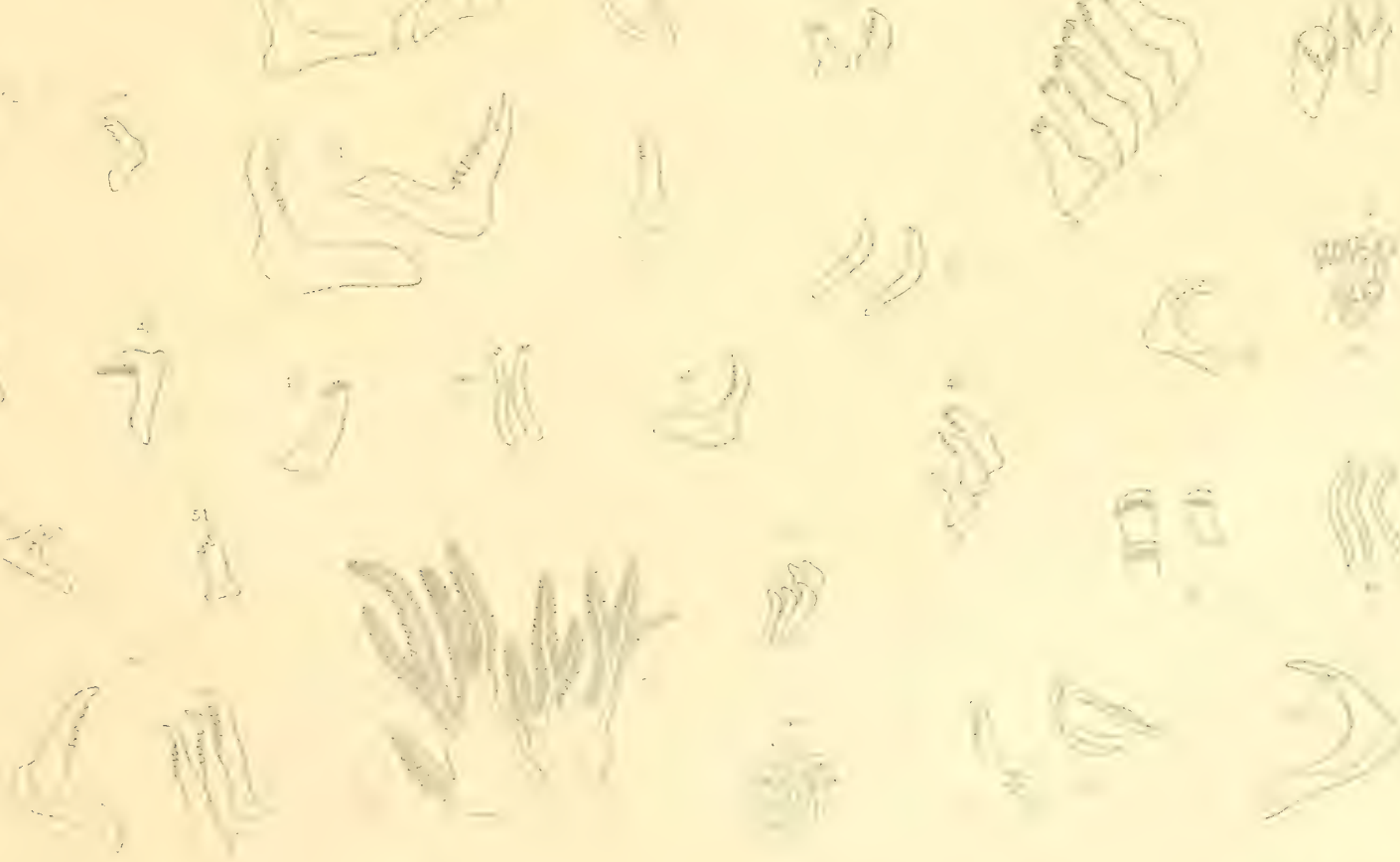

R. litroli, ilel.

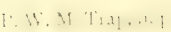






\section{TAFEL XVII.}

\section{Ceratosoma comigerum Ad.}

Fig. I. Abnormes Thier, von der Rückenseite (ohne den hinteren Rückenfortsatz).

\section{Ceratosoma bicorne B.}

1.is. 2. Element der Lippenplatte.

Fin. 3. Zahnplatte.

Fig. 2-3 mit Cam. gezeichnet. 350 .

\section{Doriopsis tuberculosa (Q. et G.).}

Fig. 4. Unterseite der hinteren Eingeweidemasse (Leber, Zwitterdrüse). $1 / 1$.

Fig. 5. Prostata. "//.

\section{Doriopsis amoena B.}

Fiss. 6. Das Thier, von der Rückenseite. $5 / 1$.

\section{Doriopsilla laevis $\mathbf{B}$.}

Fig. 7. Von der Rückenhaut, $a$ Spitze eines Spikels, b flaschenförmige Drüsen. 350 .

Plyyllidia varicosa Lam., var.

Fig. 8. Das Thicr, von der Rückenseite. $5 / 1$.

\section{Pliyllidia loricata B.}

Iiss. 9. Das Thier, von der Rückenseite. ${ }^{15} / 1$. Fig. ro. Von der Bewaffnung des Penis.

\section{Triopa longicornis B.}

I*is. II. Spitze eines Rückenanhanges. $55 \cdots$

Iis. I2. Zahnplattenreihe. 200.

Fis. 13. Stück der Lippenplatte.

Iivg. I4. Von der Bewaffnung des Penis.

lig. I3-I4 mit Cam. gezeichnet. 350 .
Triopa? tristis $\mathrm{B}$.

Fis. 15. Zahnplattenreihe, $a$ äusserste Platte.

Trevelyana inornata $\mathrm{B}$.

Iig. I6. Innerste Zahmplatten, a Falte der Rhachis. lïg. 17. Eine der grössten Platten.

liig. IS. Ausserste Platten zweier Reihen, a äusserste.

Iig. 19. Ende des Samenleiters mit seinen Dornen. Trevelyana rubra $\mathrm{B}$.

Fig. 20. Zahnplatte.

Trevelyana mbromuculata B.

Fig. 2r. Innerster Theil zweier Zahnplattenreihen, $a$ innerste Platte.

Fig. 22. Aussenende einer Zahnplattenreihe, $a$ äusserste Platte.

Fig. 23. Stück der Penis-Bewaffnung.

$$
\text { Trevelyaina? defensa B. }
$$

Fig. 24. Innerer Theil zweier Zahnplattenreihen, a $a$ innerste Platten.

Fig. 25. Aussenende zweier Zahnplattenreihen, aa äusserste Platte.

Fig. 15-25 mit Cam. gezeichnet. $350 \times$.

Fig. 26. Hintere Hälfte des Thieres, von der Seite. Trevelyana mbropapulosa $\mathrm{B}$.

Fig. 27. Innenende einer Zahnplattenreihe, $a$ Seitenplatte, $b$ erste Aussenplatte.

Fig. 28. Grösste Aussenplatte.

Fig. 29. Aussenende zweier Zahnplattenreihen, $a a$ äusserste Platte.

Fig. 30. Dornen des Penis.

Fig. 27-30 mit Cam. gezeichnet. 350 .

Figs. 3I. a Speiseröhre, b Magen mit Leberlappen, c Darm. 
Siboga-Expcditie. L. R. Brrer. Opisthobranchia.

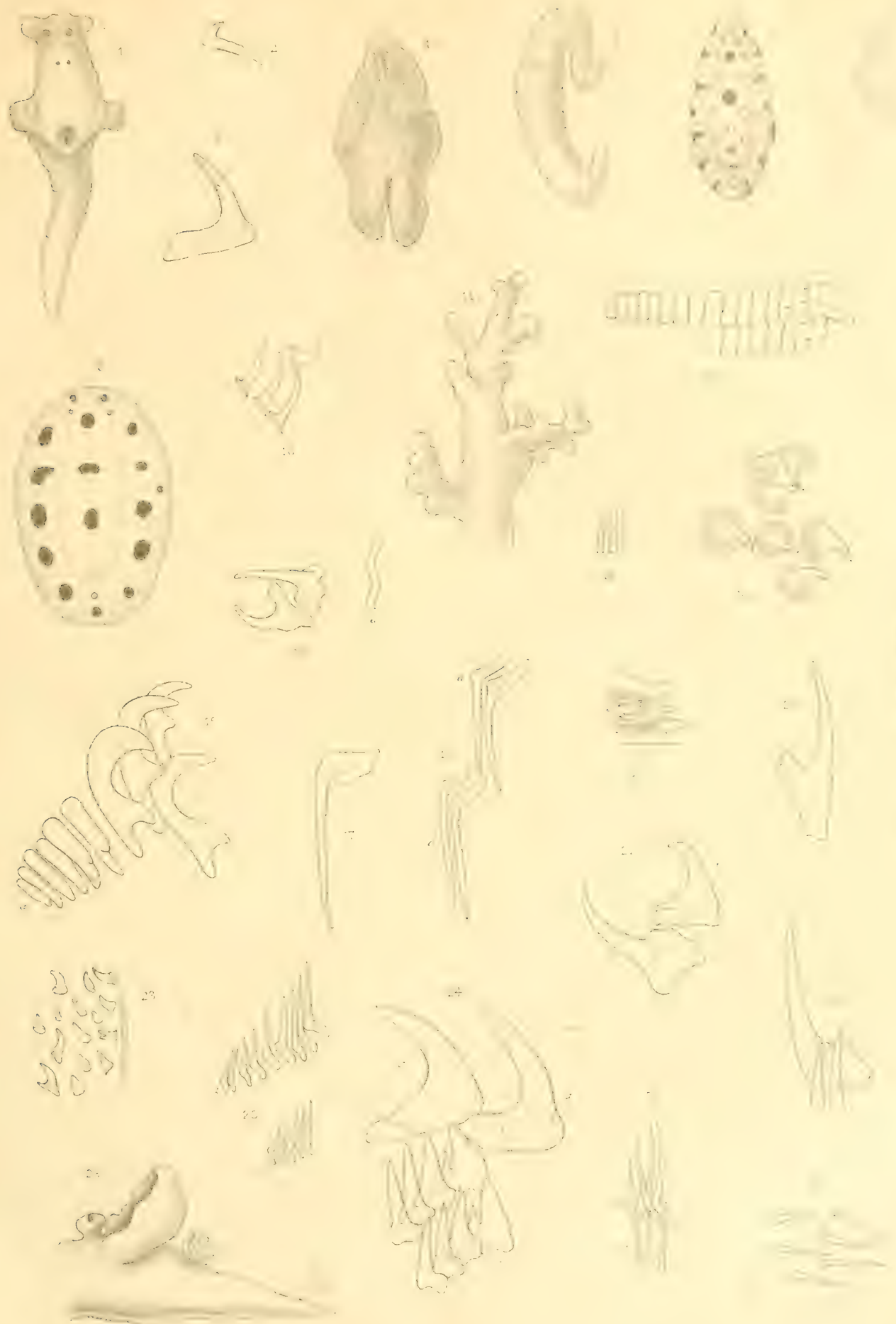

R. Bergh, del. 




\section{TAFEL XVIII.}

\section{Trevelyana mubropapulosa $\mathrm{B}$.}

Fis. I. Nierenröhre.

Fis. 2. Stiick einer solchen. 200 .

Firg. 3. Zwitterdrüse.

\section{Nembrotha cristata $\mathrm{B}$.}

I.ig. 4. Mediane Zahnplatten.

Fig. 5. Seitenplatte und die Aussenplatten.

Fig. 4- 5 mit Cam. gezeichnet. $200 \times$.

Fig. 6. $a$ Vas deferens, $b$ Penis, $c$ Vagina.

Fig. 7. Grundtheil der Glans penis.

Fig. 8. Ende derselben.

\section{Nembrotha morosa B.}

Fis. 9. Mediane und Seitenplatte.

Fig. I0. $a$ Seitenplatte und Aussenplatten, $b$ erste.

Fig. 9-10 mit Cam. gezeichnet. $200 \times$.

Jig. II. Dornen des Penis. 350 .

Fig. 12. Ähnliche. $750>$.

\section{Nembrotha nigerrina B.}

Fig. I3. Mediane Zahnplatte.

Fig. 14. Seitenplatte und erste Aussenplatte.

Nembrotha lineolata B.

I'ig. I5. Stück der Lippenplatte.

Fig. 16. Mediane Zahnplatten.

Fig. $17 . a$ Seitenplatten und $b$ erste Aussenplatte.

Fig. I $3-17$ mit Cam. gezeichnet. $350 \times$.

Fig. IS. Tentakel.

\section{Nembrotha rnbropapulosa B.}

Fir. I9. Mediane Platten.
Fig. 20. Seitenplatten.

Fig. 2I. Stück der Raspel, $a \alpha$ Seitenplatten, $b b$ Aussenplatten.

Fig. 19-2I mit Cam. gezeichnet. $350 \times$.

Fig. 22. Penis-Dornen.

\section{Nembrotha anitina B.}

Fig. 23. Stück der Raspel. a letzte Aussenplatte. IOO $\times$.

Fig. 24. Mediane Platte.

Fig. 25. Seitenplatte.

Fig. 26. Aussenplatten, $a$ äusserste.

Fig. 24-26 mit Cam. gezeichnet. $350 \%$.

Fig. 27. Stück der Bewaffnung des Penis. $350 \times$.

Fig. 28. Dornen derselben. $750 \times$.

\section{Tritonia irrorata $\mathrm{B}$.}

Fig. 29. Stück des Kaurandes.

Fig. 30. Vom Kaufortsatze.

Fig. 29-30 mit Cam. gezeichnet. $350 \times$.

Fig. 3r. Mediane und erste laterale Platte.

Fig. 32. Laterale Platten.

Fig. 3I-32 mit Cam. gezeichnet. $200 \times$.

Marionia distincta $\mathrm{B}$.

Fig. 33. Mediane Platte.

Fig. 34. Laterale Platte.

Marionia tessellata $\mathrm{B}$.

Fig. 35. Mediane Platte mit den zwei innersten Seitenplatten.

Fig. 36. Zwei Seitenplatten.

Fig. 33-36 mit Cam. gezeichnet. $350 \times$. 


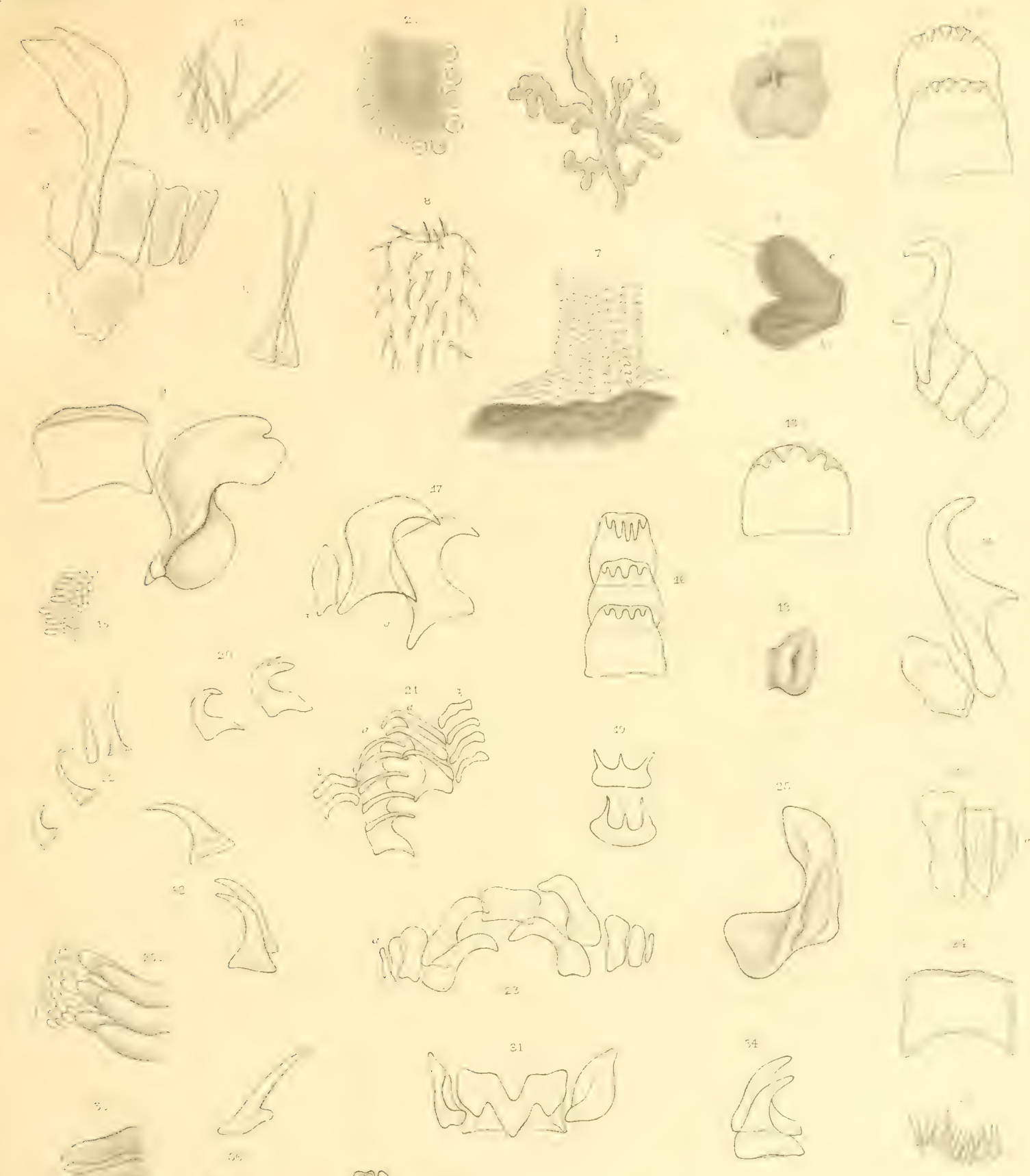






\section{TAFEL XIX.}

\section{Warionia distincta $\mathrm{B}$.}

Firig. I. Stück des Kaurandes $200 \times$.

Fis. 2. Magenplatten. 55

Marionia tessellata $\mathrm{B}$.

Fis. 3. Haut vom mittleren und linken Theil des Rückens.

Fig. +. Schläuchchen von den Feldern des Rückens.

Iris. 5. Stück des Kaurandes. 350 .

Fig. 6. Magenplatten. $55 \times$.

Pleuroleura striata (van Hass.).

1.ig. 7. Nesselelemente.

Fig. S. Kaurand.

Fig. 7-8 mit Cam. gezeichnet. $350 \times$.

Figr. 9. $a$ Mediane, so wie $b$ erste und $c$ zweite laterale Platte. 750 : .

Pleuroleura gonatophora (van Hass.).

Figr. 10. Mediane, erste und zweite Seitenplatte, von oben.

Fig. I I. Mediane Platte von der Seite.

Fig. 12. Eine der inneren Seitenplatten.

Fig. I3. Ausserste Seitenplatten, $a$ äusserste.

Fig. 10-13 mit Cam. gezeichnet. $350 \times$.

Plenroleura Suluensis B.

Fìr. 14. Rückenrand mit Nesselsäckchen. $55 \times$.

\section{Plcuroplyyllidia rosea $\mathrm{B}$.}

Figr. 15. Stück des Kaurandes.

Fig. I6. Mediane Platte, von oben.

Fig. I7. $a$ mediane, $b$ erste und $c$ zweite laterale Platte, von der Seite.

Fig. I8. Laterale Platten.

\section{Plenrophyllidia stenidia B.}

Fis. I9. Ilediane Platte.

Fig. 20. Laterale Platten.
Scyllaea pelagica $\mathrm{L}$.

Fig. 2I. Stück des Kaurandes der Mandibel.

Fig. 22. Zahnplatten.

Fig. I5-22 mit Cam. gezeichnet. $350 \%$

Bornella digitata Ad. et Reeve.

Fig. 23. Hakenring des Penis. $200 \times$.

Fig. 24. Stück desselben. $350 \times$.

Bornella excepta B.

Fig. 25. Rhinophorscheide und die mit derselben verschmolzene Rückenpapille.

Fig. 26. Erste gesonderte Rückenpapille, hinter derselben $a$ Anus.

Fig. 27. Penis-Stachel. $350 \%$

$$
\text { Aeolidiella drusilla } \mathrm{B} \text {, }
$$

Fig. 28. Zahnplatte von der Seite.

\section{Spurilla orientalis $\mathrm{B}$.}

Fig. 29. Kaurand.

Fig. 30. Älteste Zahnplatten.

Fig. 28-30 mit Cam. gezeichnet. $350 \%$.

Fig. 31. Eine der jüngsten Zahnplatten. $200 \times$.

\section{Cerberilla Ambonensis B.}

Fig. 32. Papillen (Epinotidien).

Fig. 33. Zahnplatte.

Cratcna cucullata B.

Fig. 34. Vorderende des Thieres.

Fig. 35. Stuick des Kaurandes.

Fig. 36. Zahnplatte.

Fig. 34- 36 mit Cam. gezeichnet. 350 . 

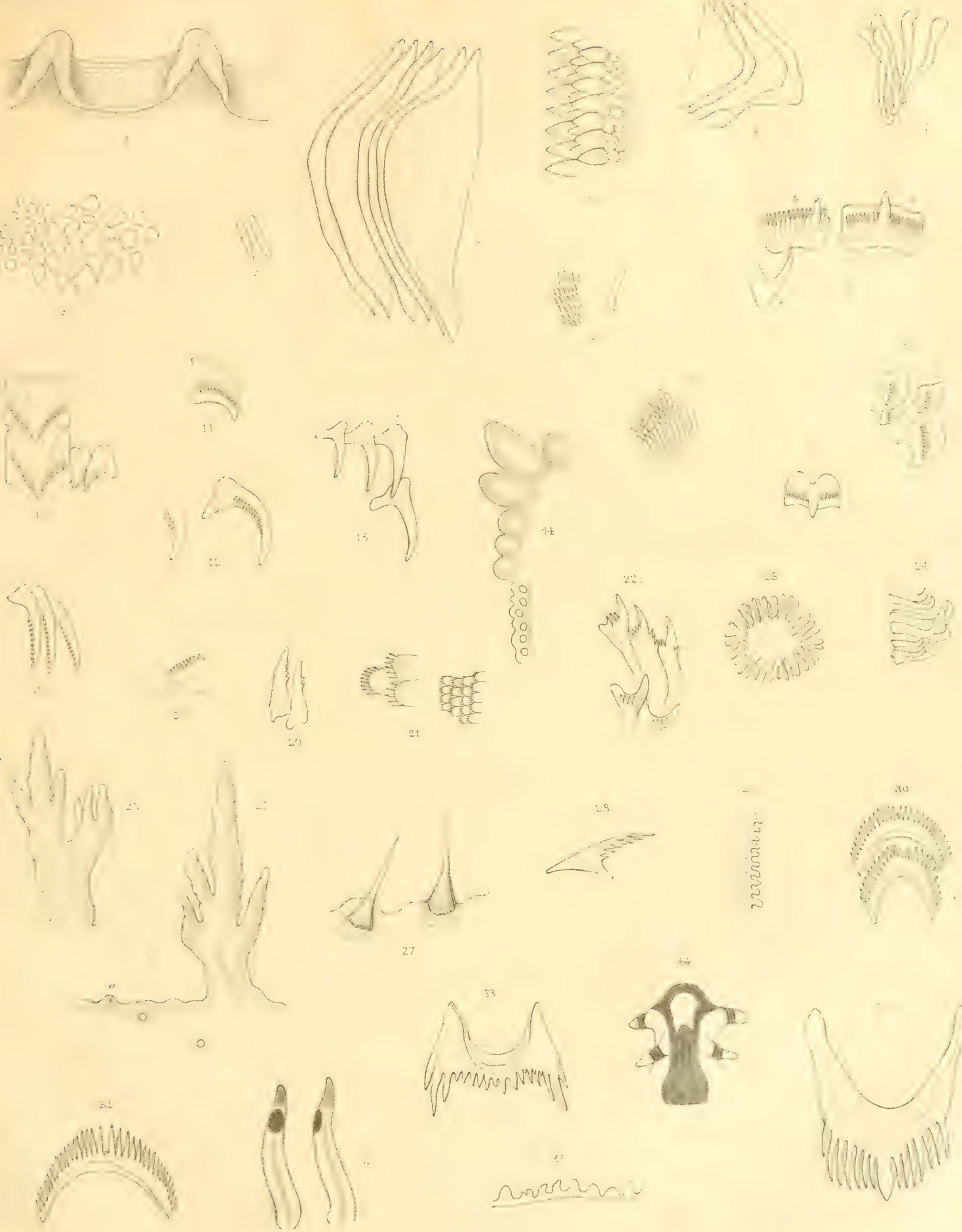

R. Bergh del. 




\section{TAFEL XX.}

Hervin Sibogae $\mathrm{B}$.

Iig. I. Stück des Kaurandes.

Fin. 2. Zahrplatten, von oben.

Iis. 3. Ahnliche von der Seite.

Fig. I-3 mit Cam. gezeichnet. $350>$.

Phestilla Sibogae B.

Fig. 4. Vorderende des Thieres, von oben.

Fis. 5. Ähnliches, von unten.

Fis. 6. Zunge mit Raspel und Raspelscheide, $a$ Raspeldach.

Fig. 7. Zahnplatte, von oben.

Fig. S. Ahnliche, schief von der Seite.

Fig. 9. Ähnliche von der Seite.

Fig. 7-9 mit Cam. gezeichnet. 350

Iigr. 10. Rücken-Papille (Epinotidium).

Fiss. II. Cnidae.

Iig. 12. Läppchen der Zwitterdrüse. 55 .

\section{Ennoia? longicimrlia $\mathrm{B}$.}

Fig. I3. Stück des Kaurandes. 200 .

Fig. 14. Zahnplatten.

\section{Pteraeolidia Semperi B.}

Fis.s. I5. Stück des Kaurandes.

Fig. I6. Zahnplatte, von oben.

I.ig. 17. Ähnliche, von der Seite.

\section{Flabellina macassarana B.}

Fig. I8. Stiick des Kaurandes.

Fig. I9. Theil der Raspel.

Fig. 14-19 mit Cam. gezeichnet. $350 \times$.

$$
\text { Myrrline longicirrla } \mathrm{B} \text {. }
$$

Fig. 20. Rücken-Papille (Epinotidium).

Fig. 2 I. Stück des fleckigen Fussrandes.

Fig. 22. Mandibel, mit Eingang in die Nebenmundhiohle. "'.

Fig. 23. Zahnplatten, von oben.

Fig. 24. Stück der Raspel, von der Seite.

Fig. 25. Zwei jüngste unreife Platten.

Fig. 23-25 mit Cam. gezeichnet. $100 \times$.

Fig. 26. Leberläppchen an der WVand des Epinotidiums, $a$ Gallengänge.

Fis. 27. Nierenröhre. 55 .

Fig. 2S. Läppchen der Zivitterdrüse. $55 \times$.

Fig. 29. Hervorgestülpte Glans penis, von der Unterseite. $350 \cdots$

\section{Mclibe australis (Angas).?}

Fig. 30. Penis, a hervorragende Vulva.

Melibe papillosa (Philippi)?

Fig. 31. Die Mandibel.

Fig. 32. a Speiseröhre, b Magen mit durchschimmerndem Plattengürtel, c Darm. 

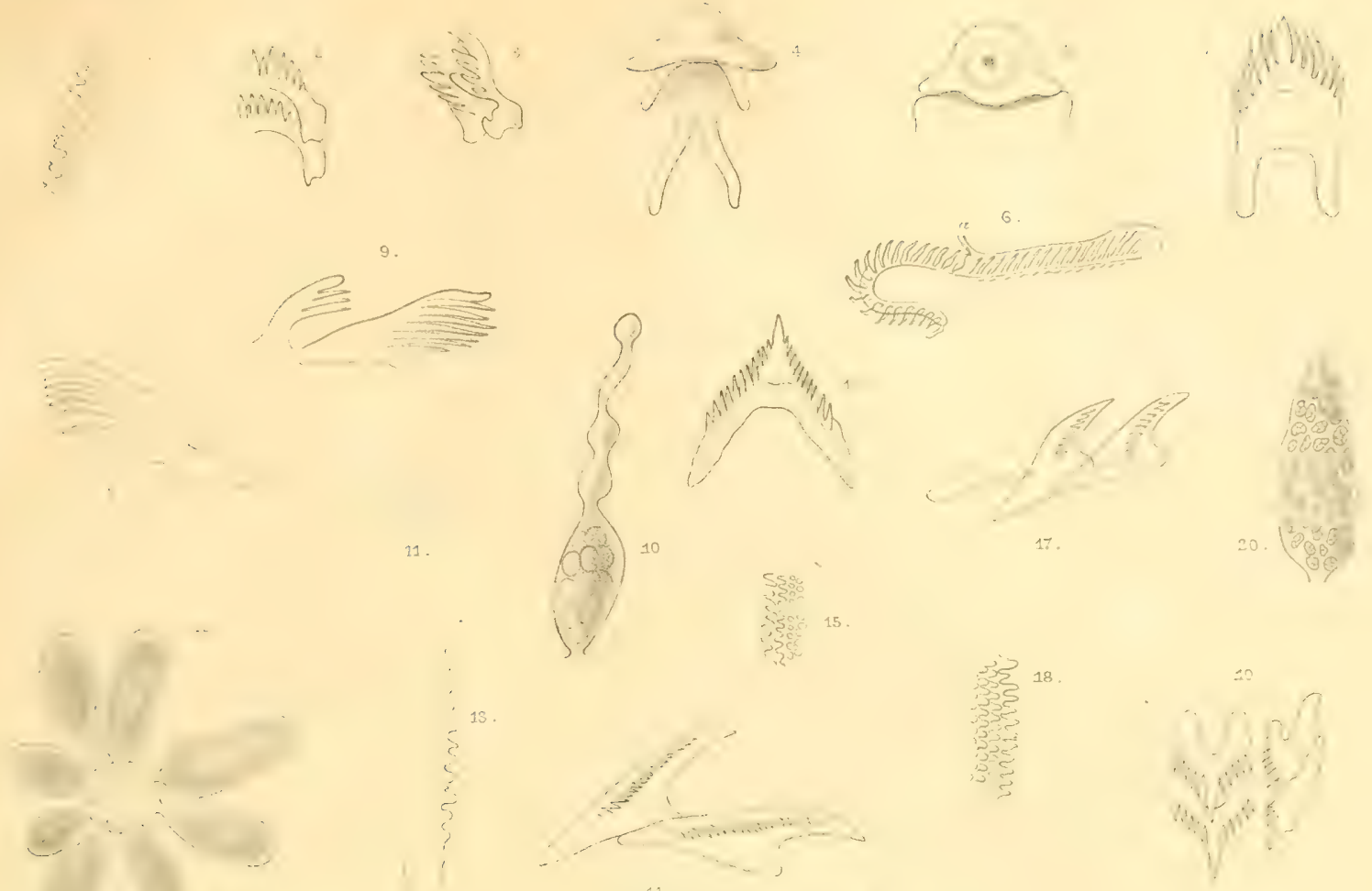

it.
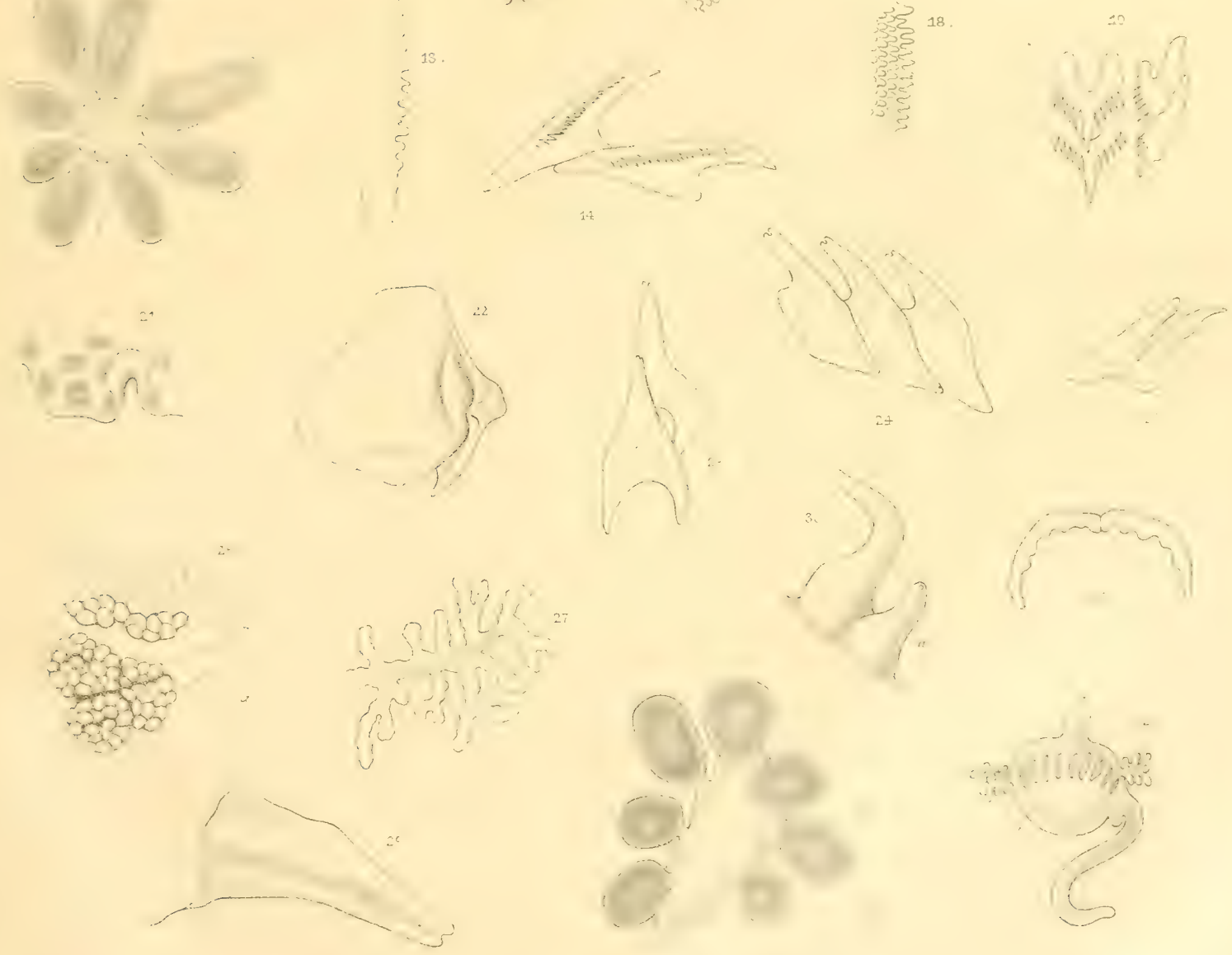
$1 "$

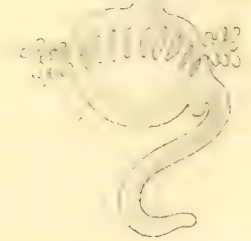

R. Liersht. del. 



\section{CONDITIONS GÉNÉRALES DE VENTE.}

$I^{2}$. L'ouvrage du „Siboga" se composera d'une série de monographies.

$2^{\circ}$. Ces monographies paraîtront au fur et à mesure qu'elles seront prêtes.

$3^{\circ}$. Le prix de chaque monographie sera différent, mais nous avons adopté comme base générale du prix de vente: pour une feuille d'impression sans fig. flor. O.I5; pour une feuille avec fig. flor. 0.20 à 0.25 ; pour une planche noire flor. 0.25 ; pour une planche coloriée flor. 0.40 ; pour une photogravure flor. 0.60 .

$4^{\circ}$ : Il y aura deux modes de souscription:

a. La souscription à l'ouvrage complet.

b. La souscription à des monographies séparées en nombre restreint.

Dans ce dernier cas, le prix des monographies sera majoré de $25 \%$.

$5^{\circ}$. L'ouvrage sera réuni en volumes avec titres et index. Les souscripteurs à l'ouvrage complet recevront ces titres et index, au fur et à mesure que chaque volume sera complet. 


\section{Déjà paru:}

Prix:

Souscription Monographies al'ouvrage complet séparées

15 Livr. (Monogr. XLIV) C. Ph. Sluiter. Die Holothurien der Siboga-Expedition. Mit ro Tafeln.

20 Livr. (Monogr. LX) E. S. Barton. The genus Halimeda. With 4 plates.

$f$ 6. $-f 7.50$

$3^{c}$ Livr. (Monogr. I) Max Weber. Introduction et description de l'expédition. Avec Liste des Stations et 2 cartes.

+ Livr. (Annogr. II) G. F. Tydeman. Description of the ship and appliances used for scientific cxploration. With 3 plates and illustrations.

$5^{c}$ Livr. (Monogr. XLVII) H. F. Nierstrasz. The Solenogastres of the Siboga-Exp. With 6 plates.

6e Liv. (Monogr. XIII) J. Versluys. Die Gorgoniden der Siboga-Expedition.

I. Die Chrysogorgiidae. Mit I70 Figuren im Text.

$7^{c}$ Livr. (Monogr. XVIa) A. Alcock. Report on the Decp-Sea Madreporaria of the SibogaExpedition. With 5 plates. . . . . . . . . . . . . . . . . . . . .

Se Livr. (Monogr. XXV) C. Ph. Sluiter. Die Sipunculiden und Fchiuriden der Siboga-Exp. Mit 4 Tafeln und 3 Figuren im Text.

9e Livr. (Monogr. VIa) G. C. J. Vosmaer and J. H. Vernhout. The Porifera of the SibogaExpedition. I. The genus Placospongia. With 5 plates. . . . . . . . . . . . .

Ioc Lirr. (Monogr. XI) Otto Maas. Die Scyphomedusen der Siboga-Expedition. Mit I2 Tafeln. I le Livr. (Monogr. XII) Fanny Moser. Die Ctenophoren der Siboga-Expedition. Mit 4 Tafeln. I 2e Livr. (Monogr. XXXIV) P. Mayer. Die Caprellidae der Siboga-Expedition. Mit ro Tafeln. I 3e Livr. (MIonogr. III) G. F. Tydeman. Hydrographic results of the Siboga-Expedition. With 24 charts and plans and 3 charts of clepths

I f“ Livr. (MIonogr. XLIII) J. C. H. de Meijere. Die Echinoidea der Siboga-Exp. Mit 23 Tafeln. I5 Livr. (Monorr. ILV'a) René Koehler. Ophiures de l'Expédition du Siboga.

Ie Partie. Ophiures de Mer profonde. Avec 36 Planches.

I (r. Livr. (Mlonogr. LII) J. J. Tesch. The Thecosomata and Gymnosomata of the SibogaExpedition. WVith 6 plates.

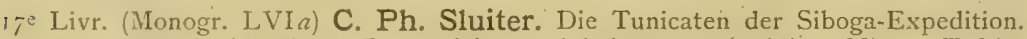

I. Abteilung. Die socialen und holosomen Ascidien. Mit 15 Tafeln

ISe Livr. (Mnnogr. LXi) A. Weber-van Bosse and M. Foslie. The Corallinaccae of the SibogaExpedition. With 16 plates and 34 textfigures

I ge Livr. (Mlonorr. VIII) Sydney J. Hickson and Helen M. England. The Stylasterina of the Siboga Expedition. With 3 plates. . . . . . . . . . . . . . . . . . .

$20^{\circ}$ Liv. (Monogr. XLVIH) H. F. Nierstrasz. Die Chitonen der Siboga-Exp. Mit 8 Tafeln. 2 le Livr. (Monogr. XLVb) René Koehler. Ophiures de l'Expédition du Siboga.

2 Partie. Ophiures littorales. Avec is Planches.

$n \cdot 1.80 \cdots 2.40$

$\pi 6.75,9$.

$72 .-\quad 2.50$

$\pi .3 .90 \pi \cdot 4.90$

"3.

4.60 . 5.75

$3 .-73.75$

\2.40, $3 .-$

7.50 " 9.50

$2.80 \gg 3.50$

, 7:80, 9.75

$\because 9 .-\quad 711.25$

, $15 .-\pi 18.75$

$, 16.50,20.50$

$3.75 \leadsto 4.70$

$6.75 \times 9 .-$

, 12.50 \ 15.50

" $1.50 \% 1.90$

, 5.- $₫ 6.25$

$10.25,12.75$

$6.75,9$. with an account of other species. With 14 plates and 2 text-figures. . . . . .

$23^{c}$ Livr. (MInogr. XXXVI) W. T. Calman. The Cumacea of the Siboga Expedition. With 2 plates and 4 text-figures

$24^{c}$ Livr. (Monogr. LVIa) C. Ph. Sluiter. Die Tunicaten der Siboga-Expedition.

Supplement zu der I. Abteilung. Die socialen und holosomen Ascidien. Mit. I. Tafel.

25" Livr. (Monogr. L) Rud. Bergh. Die Opisthobranchiata der Siboga-Exped. Mit 20 Tafeln.
I.SO, 2.40

$n-75$ n $1 .-$

, $11.25,14.10$ 



Oerried

$6 \cdot 0$ 



$\left.\begin{array}{lll} \\ 3\end{array}\right)$

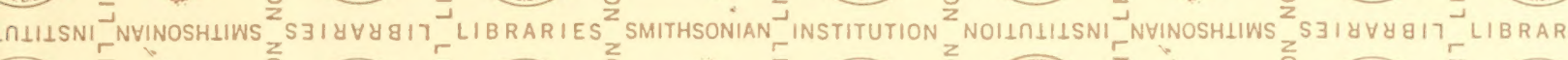

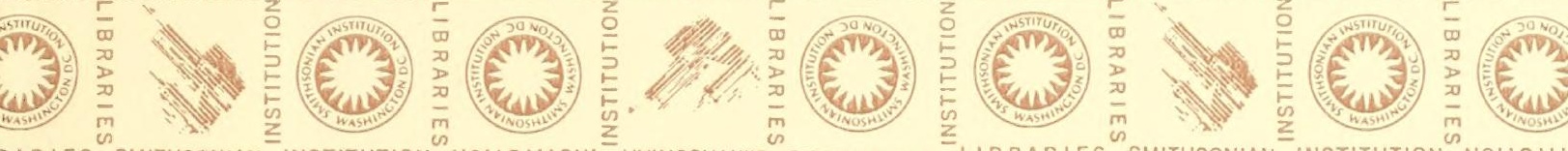

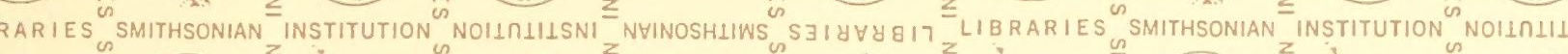 (i)
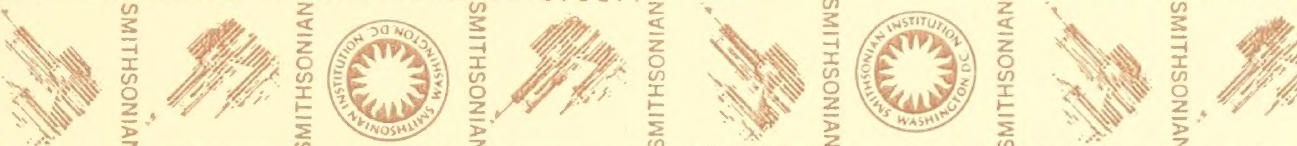

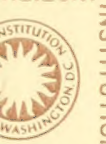
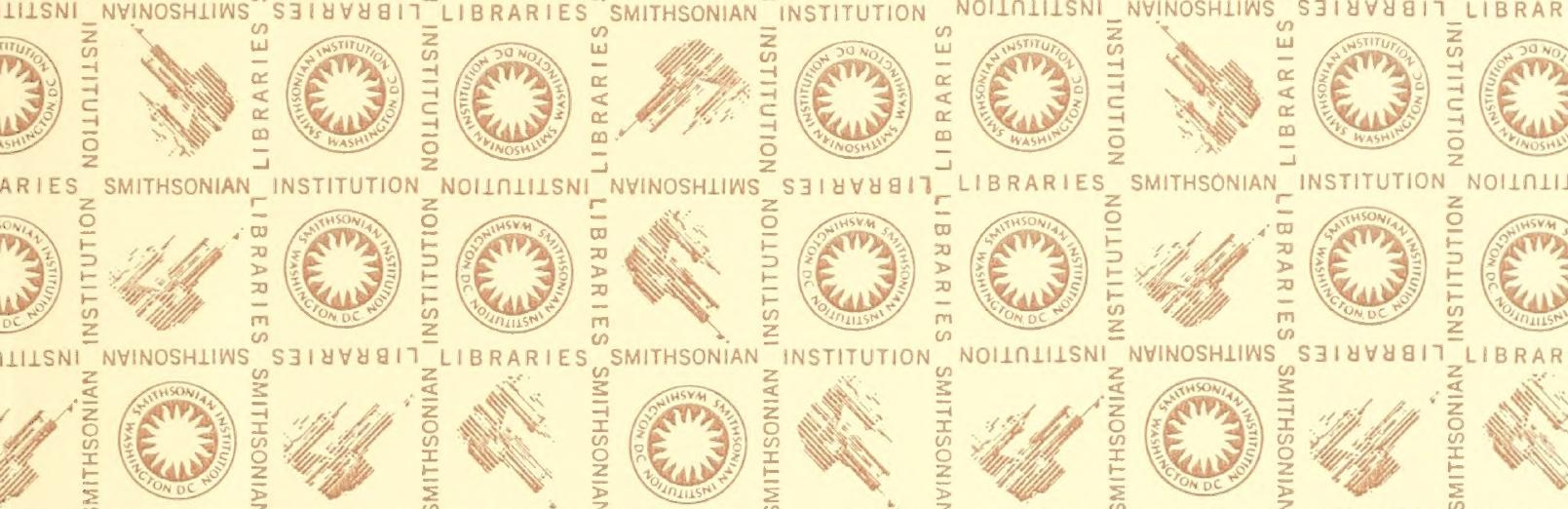

RARIES " SMITHSONIAN
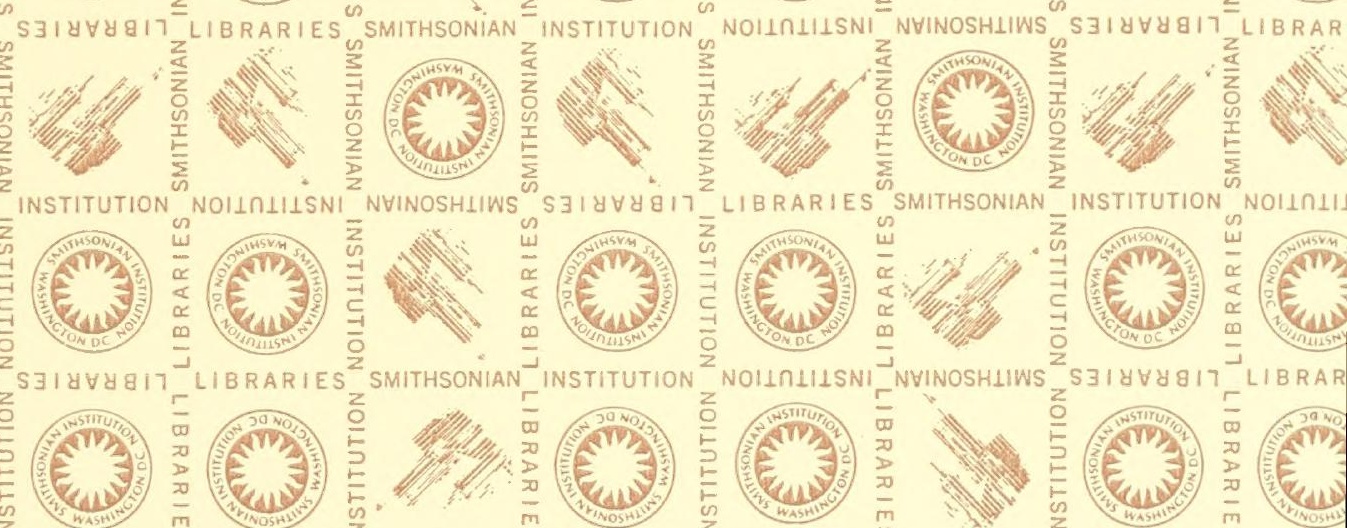

SMITHSONIAN
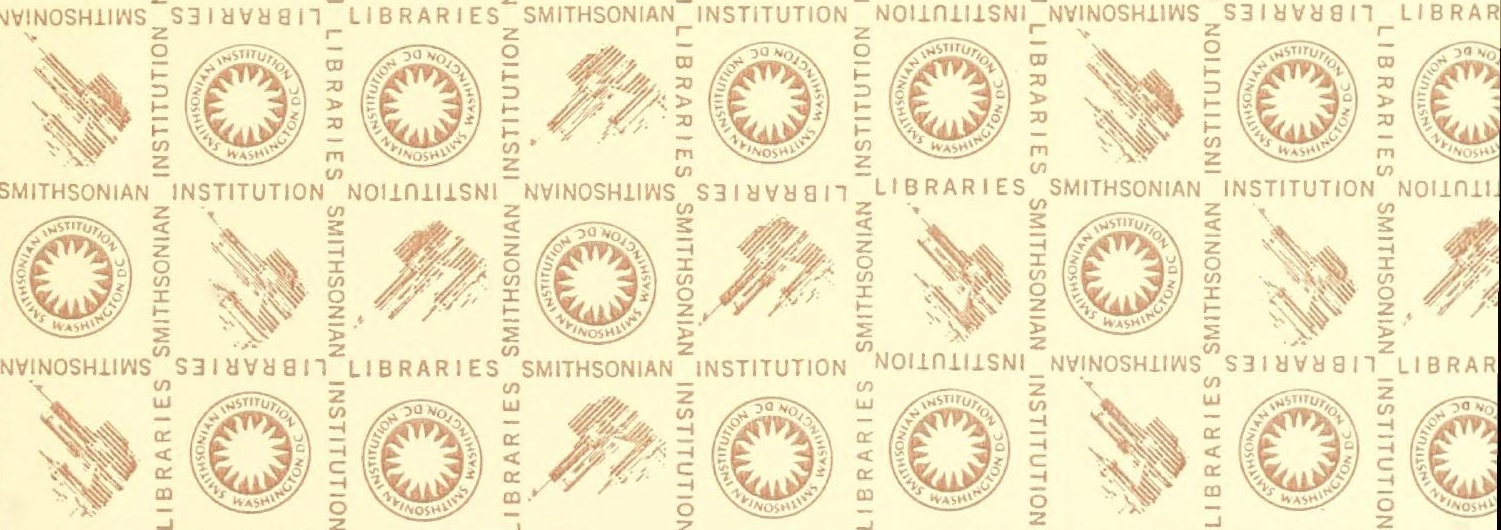

in
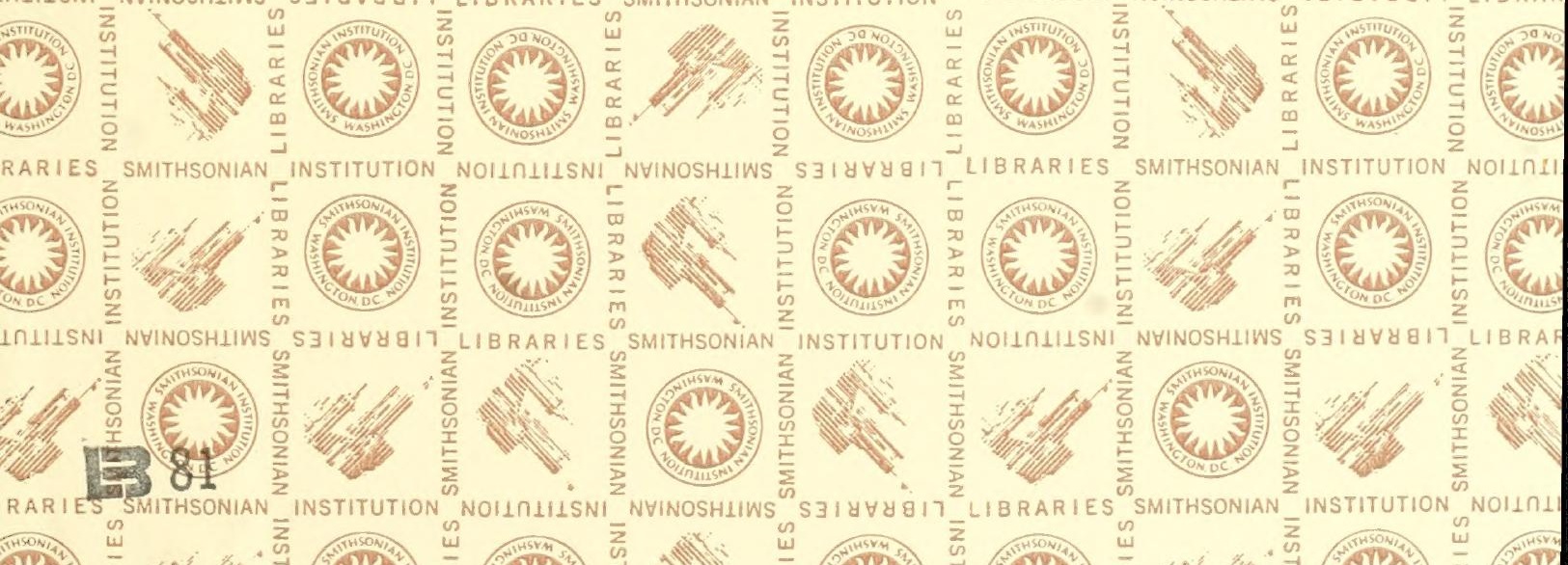

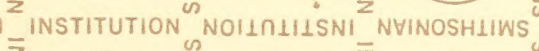

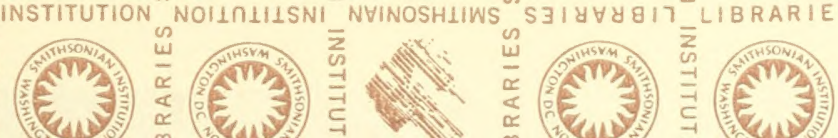


